This report was prepared account of work sponsored by the United States Government. Neither the United States nor the United States Atomic Energy Cominission, nor any of their employees, nor any of their contractors, subcontractors, or their employees, makes any warranty, express or implied, or assumes any makes any warranty, express or implied, or assumes any legal liability or responsibility for the accuracy, completeness or usefulness of any information, apparatus,

product or process disclosed, or represents that its use

would not infringe privately owned rights.

\title{
ABSTRACT \\ SIMPLE EXCITATIONS OF DOUBLY CLOSED SHELL NUCLEI
}

By

Richard Trilling

The problem of describing low lying excitations in doubly closed shell nuclei by simple one particle-one hole excitations has long been of theoretical interest. Without including either core correlation or core polarization contributions in the matrix elements the agreement between experiment and theory of previous calculations has been marginal. The previous calculations have failed to produce enough separation between the $\mathrm{T}=0,1$ states of $\mathrm{N}=\mathrm{Z}$ nuclei and therefore have produced too much isospin mixing in these light nuclei. Another failure of the previous calculations was that the binding energy of the states $(T=0,1)$ was too small. The error in the binding of the $\mathrm{T}=0$ states ( $N=\mathrm{Z}$ nuclei) was much greater than the error in the binding of the $\mathrm{T}=1$ states.

The present calculation replaces the monopole term of the multipole expansion of the interaction by a one parameter isospin dependent spherical potential. The parameter is evaluated from the symmetry energy between $\mathrm{Ca}^{49}$ and $\mathrm{Sc}^{49}$. The reason for the replacement is to take into account the difference between the single particle energies of the 


\section{DISCLAIMER}

This report was prepared as an account of work sponsored by an agency of the United States Government. Neither the United States Government nor any agency Thereof, nor any of their employees, makes any warranty, express or implied, or assumes any legal liability or responsibility for the accuracy, completeness, or usefulness of any information, apparatus, product, or process disclosed, or represents that its use would not infringe privately owned rights. Reference herein to any specific commercial product, process, or service by trade name, trademark, manufacturer, or otherwise does not necessarily constitute or imply its endorsement, recommendation, or favoring by the United States Government or any agency thereof. The views and opinions of authors expressed herein do not necessarily state or reflect those of the United States Government or any agency thereof. 


\section{DISCLAIMER}

Portions of this document may be illegible in electronic image products. Images are produced from the best available original document. 
A 1 mass nuclei used in the calculation and those of the A mass system in which the excited particle moves.

Two different interactions, the Kallio-Kolltveit and the Sussex, were used in two different approximations, the TDA and the RPA. The results obtained with the two different interactions are quite similar and aside from the lowest $3^{-}$state the results obtained from the TDA and the RPA were almost identical.

Using the monopole shift the results for $\mathrm{O}^{16}$ are greatly improved. The $T=0,1$ separation energies increase, along with their binding energies, to where they are in close agreement with experiment. The isospin mixing of the new vectors is such that most of the calculated B(EI)'s are now in good agreement. with experiment.

The transition data for $\mathrm{Ca}^{40}$ includes only the $3^{-}$, $5^{-} \mathrm{T}=0$ levels. The monopole shift does not effect these transitions but gives a net improvement of the position of the levels arising from the three lowest multiplets. The resultant placement of the levels is also in good agreement with the deformed basis calculation of $\mathrm{Ca}^{40}$ by Gerace and Greene. The giant dipole state is however about $1 \mathrm{MeV}$. too low when the shift is used.

In $\mathrm{Ca}^{48}$ and $\mathrm{Sr}^{88}$ only the $\mathrm{T}_{<}$states were calculated. The monopole shift leads to a definite improvement in the level positions of both nuclei. for both the negative parity and the positive parity states. 
In all nuclei the RPA over binds the lowest $3^{-}$ state; a reduction of the interaction strength to $65 \%$, in order to simulate screening, for all the nuclei leads to a fair agreement between experiment and theory.

It should be noted that the calculations for $\mathrm{Sr}^{88}$ predict a strong. low lying $5^{-}$state which up to now has not been seen. 
SIMPLE EXCITATIONS OF DOUBLY CLOSED SHELL NUCLEI

By

Richard Trilling

\author{
A THESIS \\ Submitted to \\ Michigan State University \\ in partial fulfillment of the requirements \\ for the degree of \\ DOCTOR OF PHILOSOPHY \\ Department of Physics
}

1972 


\section{ACKNOWLEDGEMENTS}

I would like to thank Professor Hugh McManus for suggesting this problem and for his guidance and support during the time this work was performed.

Thanks are also due to Dr. Richard Schaeffer for his assistance in the final stages of this work and to Dr. Fred Petrovich for his assistance many times during the course of this work.

Mrs. Julie Perkins is also thanked for the typing of this manuscript. 


\section{TABLE OF CONTENTS}

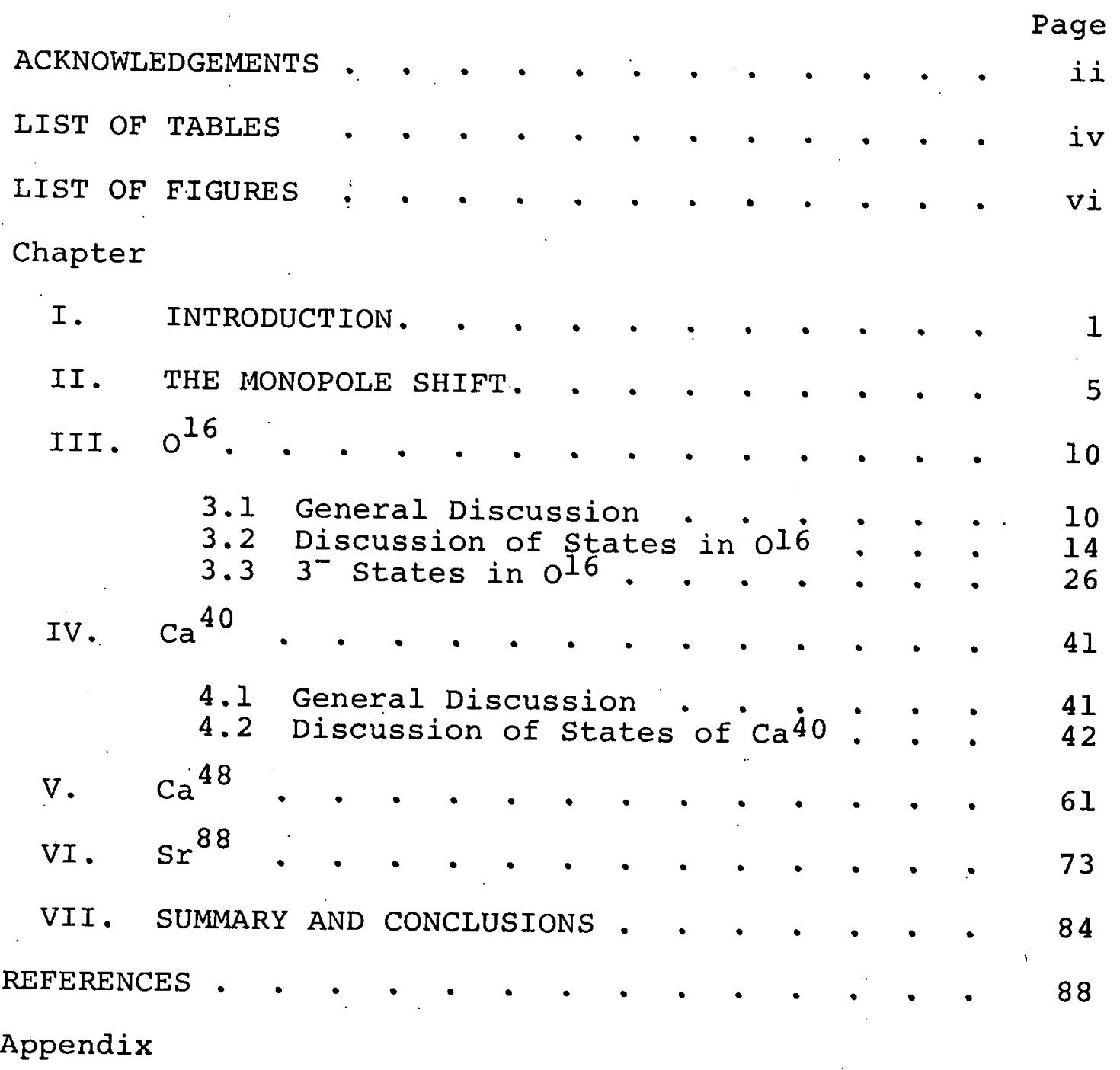

A. RPA PHASE CONVENTIONS AND TRAISITION FORMULAS • • • • • • • • . . • . 91

B. MONOPOLE SHIFT • • • • • • • • • • 94

C. SINGLE PARTICLE IDENTIFICATION CODE • • • 100

D. ENERGY AND TRANSITION SUMMARY • • • • • 102

E. VECTOR AMPLITUDES • • • • • • • • • 161 
Table

Page

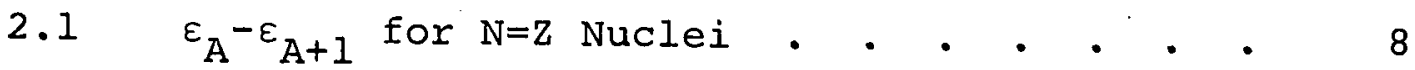

2.2 $\varepsilon_{A}-\varepsilon_{A+1}$ for $N \neq Z$ Nuclei. Overall $\mathrm{T}$ equals that of the g.s. $\mathrm{T}_{0} \cdot$. . . . . . . 8

$3.10^{16}$ Single Particle Energies . . . . . 14

$3.20^{16} \cdot 1^{\text {st }}, 1^{-} \mathrm{T}=0$ vector components . . . 16

3.3 Sussex Matrix Elements for $\left(1 s_{1 / 2}-0 p_{1 / 2}\right)^{00}$

$3.41^{-}, 2^{-} \mathrm{T}=0$ Splitting . . . . . . . 29

3.5 Partial Summary of $\mathrm{O}^{16}$ for Explanation of Maj. Comp. see Appendix C. . . . . 32

3.6 $0^{16}$ Centroid Energies, Energy Dispersions and Sum Rules for Representative Configurations of the $\mathrm{K}-\mathrm{K}$ Interaction with the Monopole Shift (For Formulas See Appendix

A) . . . . . . . . . • • 35

4.I $\mathrm{Ca}^{40}$ Single Particle Levels. . . . . . 45

4.2 Relative strengths of the $3^{-}, \mathrm{T}=0$ states in $\mathrm{Ca}^{40}$. . . . . . . . . . . .

4.3 Partial Summary of $\mathrm{Ca}^{40}$ for Explanation of (Maj. Comp.) See Appendix C. . . .

4.4. Ca ${ }^{40}$ Centroid Energies, Energy Dispersions and Sum Rules for Representative Configuration of the KK Interaction with the Monopole Shift (For Formulas See Appendix A)

$5.1 \mathrm{Ca}^{48}$ Single Particle Levels... . . . . . 61 
5.2 Zero Point Energies of the 3 Low Lying

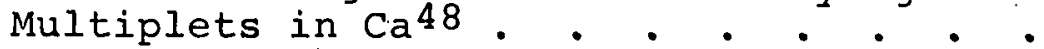

5.3 Partial Summary of $\mathrm{Ca}^{48}$ for Explanation of (Maj Comp. See Appendices $C$ and D). .

$5.4 \mathrm{Ca}^{48}$ Centroid Energies, Energy Dispersions and Sum Rules for Representative $T$ Configurations of the $\mathrm{K}-\mathrm{K}$ Interaction with the Monopole Shift (For Formulas See Appendix A) • • . . . . • . .

$6.1 \operatorname{sr}^{88}$ Single Particle Levels. . . . . 75

6.2 Partial Summary of $\mathrm{Sr}^{88}$ for Explanation of (Maj. Comp. See Appendices C and D) . .

$6.3 \cdot \mathrm{Sr}^{88}$ Centroid Energies, Energy Dispersions and Sum Rules for Representative $T_{<}$ Configurations of the $\mathrm{K}-\mathrm{K}$ Interaction with Monopole Shift (For Formulas See Appendix A) 


\section{LIST OF FIGURES}

Figure

Page

1. $\mathrm{O}^{16}$ Monopole Shifts . . . . . . . 36

2. $\mathrm{O}^{16} \mathrm{~K}-\mathrm{K}$ Energy Levels. . . . . . . . 37

3. $0^{16}$ Sussex Energy Levels. . . . . . . 39

4. $\mathrm{Ca}^{40}\left(\mathrm{Of}_{7 / 2}-0 \mathrm{~d}_{3 / 2}^{-1}\right)$ Multiplet . . . . . 57

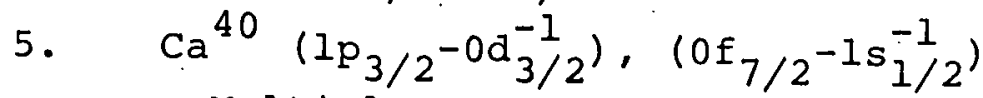

Multiplets. •. . . . . . . . 59

6. $\mathrm{Ca}^{48}$ Monopole Shifts . . . . . . . 70

7. $\mathrm{Ca}^{48}$ Energy Levels. . . . . . . . 71

8. $\mathrm{Sr}^{88}$ Energy Levels. . . . . . . . . 82 


\section{CHAPTER I}

\section{INTRODUCTION}

There are several factors which motivated the present series of calculations. A systematic study of the doubly closed shell nuclei $\mathrm{O}^{16}, \mathrm{Ca}^{40}, \mathrm{Ca}^{48}$, and $\mathrm{Sr}^{88}$ would be useful in order to compare their various properties, particularly the distribution of the multipole strengths. All the above nuclei possess a low lying collective $3^{-}$state which exhausts an appreciable part of the octopole transition strength. Another common phenomena is the existence of low lying positive parity states such as a $0^{+}$which cannot be explained on a $1 \mathrm{p}-1 \mathrm{~h}$ basis.

A common failure of previous lp-lh calculations was that they failed to provide enough separation between the $\mathrm{T}=0$ states and the $\mathrm{T}=1$ states in $\mathrm{N}=\mathrm{Z}$ nuclei such as $\mathrm{O}^{16}$ and $\mathrm{Ca}^{40}$. This leads to too large estimates of coulomb mixing. Very often also the $T=0$ levels were found to be too high in energy. This has been avoided in the present set of calculations by adding an empirical monopole shift. Additional data have also become available on some of the higher. lying $\mathrm{T}=1$ states in $0^{16}$ through inelastic 
electron scattering ( $\mathrm{S} 169)$ and also $\mathrm{T}=1$ states in $\mathrm{Ca}^{40}$ through the charge exchange reaction $\mathrm{Ca}^{40}\left(\mathrm{He}^{3}, t\right) \mathrm{Sc}^{40}$ (Sc7la). There also exists new data on $\mathrm{Sr}^{88}$ through the two particle transfer reaction $\mathrm{Sr}^{86}(t, p) \mathrm{Sr}^{88}$ (Ra70).

The particle-hole matrix elements were calculated for two different interactions, the Kallio-Kolltveit (K-K) interaction and the sussex interaction. The $\mathrm{K}-\mathrm{K}$ interaction has a hard core potential and an exponential radial dependence (Ka64). It fits the nucleon-nucleon $S$-wave phase shifts up to $300 \mathrm{MeV}$. The matrix elements are evaluated by the Scott-Moszkowski separation method (Mo60), i.e. a separation distance is chosen such that within that distance the repulsion due to the hard core is cancelled by the attractive part of the potential. This matrix element is the first term in the expansion of the reaction matrix acting in states of even angular momentum. The best description of the reaction matrix is perhaps given by M. Macfarlane (Ma69) .

The Sussex interaction is derived from the experimental nucleon-nucleon phase shifts by deducing matrix elements of the nucleon-nucleon interaction in a harmonic oscillator basis of the interparticle distance (Er68):

The particle-hole states were calculated within the frame work of both the Tamm-Dancoff Approximation (TDA) and the Random-Phase Approximation (RPA), (La64). The TDA assumes that the ground state of the nucleus is a 
particle-hole vacuum and that the excited states are obtained by acting on the ground state with a particle-hole creation operator. The RPA does not assume that the ground state is a particle-hole vacuum, but that it contains correlations, i.e. the ground state has components of $0 p-0 h, 2 p-2 h, 4 p-4 h$, etc. There then are two ways of creating excited states, by either creating or destroying a particle-hole pair. There is a slight violation of the Pauli principal in the RPA, i.e. denoting particle levels by ' $m$ ' and hole levels by ' $i$ ', the particle-hole creation operatior is then $b_{m i}^{+}=a_{m}^{+} a_{i}$ from which it follows

$$
<0\left|b_{m i} b_{m i}^{+}\right| 0>=1-<0\left|a_{i} a_{i}^{+}\right| 0>-<0\left|a_{m}^{+} a_{m}\right| 0>
$$

where $|O\rangle$ is the correlated ground state. If the number of levels is large compared to the number of holes or particles then $\left\langle 0\left|\mathrm{a}_{i} \mathrm{a}_{i}^{+}\right| 0\right\rangle$ and $\left\langle 0\left|\mathrm{a}_{\mathrm{m}}^{+} \mathrm{a}_{\mathrm{m}}\right| 0\right\rangle$ are approximately zero and then

$$
<0\left|b_{m i} \quad b_{m i}^{+}\right| a>\sim 1
$$

which is the basic assumption of RPA and is called the quasi-boson approximation. (For a description of the RPA. vectors and phases see Appendix A). 
The basis states for the calculation were chosen following the prescription by Ripka (Ra68). For an $N=\mathrm{Z}$ nucleus there are two types of excitations $\mathrm{T}=0,1$. When $\mathrm{N} \neq \mathrm{Z}$ four types of excitations are considered, protonprotion hole, neutron-neutron hole, $\mathrm{T}=0$ and $\mathrm{T}=1$.

The realistic forces used do not give a good account of the centroids, so it is necessary to supplement these interactions by a monopole shift discussed in chapter II.

Each succeeding chapter discusses a single nucleus and treats in detail the basic configurations of the low lying states and the comparison with such experimental information as is available. The energy level information is summarized in level diagrams. Also a table at the end of each chapter summarizes this information on the levels and transition rates. Another table gives the calculated sum rule strengths and widths for various multipole transitions. A corresponding appendix D lists the energy levels and transition rates for all the levels calculated for the particular nucleus and in addition lists the principle componant of the vector along with the transition rate due to it alone. Appendix E gives a list of representative state vectors. Overall conclusions are presented in Chapter VII.

The algebra and labeling for single particle levels are summarized in Appendices A through $C$. 
In a particle-hole calculation the Hamiltonian $\mathrm{H}=\mathrm{H}_{0}+\mathrm{V}$ is diagonalized in the basis $\left|\mathrm{ph}^{-1}, \mathrm{~J}\right\rangle$. The diagonal term

$$
\left\langle\mathrm{ph}^{-1}, \mathrm{~J}|\mathrm{H}| \mathrm{ph}^{-1}, \mathrm{~J}\right\rangle=\varepsilon_{\mathrm{p}}-\varepsilon_{\mathrm{h}}+\mathrm{V}_{\mathrm{C}}+\mathrm{V}_{\mathrm{ph}}^{\mathrm{J}}
$$

where $\varepsilon_{p}$ ! $\varepsilon_{h}$ are the single particle energies obtained from the $A \pm l$ nuclei, where $V_{C}$ contains all the core contributions and where $\mathrm{V}_{\mathrm{ph}}^{\mathrm{J}}$ is the diagonal particle-hole matrix element.

The centroid of a given $\mathrm{p}-\mathrm{h}$ multiplet is not at $\varepsilon_{\mathrm{p}}-\varepsilon_{\mathrm{n}}+\mathrm{V}_{\mathrm{c}}$ but is shifted away. from this value by the average value of $\mathrm{v}_{\mathrm{ph}}^{\mathrm{J}}$ for a given $\mathrm{p}$-h multiple.t.

$$
\text { i.e. } \begin{aligned}
\alpha_{\mathrm{ph}}^{\mathrm{O}} & =\sum_{\mathrm{J}}(2 \mathrm{~J}+1) \mathrm{v}_{\mathrm{ph}}^{\mathrm{J}} \sum_{\mathrm{J}}(2 \mathrm{~J}+1) \\
& =\frac{1}{(2 \mathrm{p}+1)(2 \mathrm{~h}+1)} \sum_{\mathrm{J}}(2 \mathrm{~J}+\mathrm{I})\langle\mathrm{ph}, \mathrm{J}|\mathrm{V}| \mathrm{ph}, \mathrm{J}\rangle
\end{aligned}
$$

This is also equal to the monopole term in the multipole expansion 


$$
\text { i.e. }\left\langle\mathrm{ph}^{-1}, J|v| \mathrm{ph}^{-1}, J\right\rangle=\sum_{K} \alpha_{\mathrm{ph}}^{\mathrm{K}}(-1)^{\mathrm{p}+\mathrm{h}+\mathrm{K}} \hat{\mathrm{p} h \hat{K} W(\mathrm{phph} ; J K)}
$$

of the interaction. The centroid for a given $\mathrm{p}-\mathrm{h}$ multiplet is therefore located at $\varepsilon_{p}-\varepsilon_{h}+v_{c}+\alpha_{p h}^{\circ}$

An explanation for the presence of $\alpha_{p h}^{\circ}$ is that since the single particle levels from the A mass nucleus were not used, the centroid for the $\mathrm{p}-\mathrm{h}$ multiplet as determined by the $A \pm 1$ mass nuclei single particle levels must be corrected. This correction arises because the system does not contain A 1 particles and the single excited particle sees a core of only A-l particles. The correction is provided by the $\mathrm{J}$ independent part of the interaction, the monopole term.

The centroid shift as determined by the interaction does not provide good agreement between observation and theory. An attempt will be made to correct this by removing the monopole term from the diagonal matrix element and by substituting in its place another term. This procedure is due to R. Schaeffer (Sc71).

It can be shown (Appendix B.1) that the monopole term of a diagonal particle hole matrix element coupled to a good $\mathrm{J}$ is equivalent to a single particle matrix element where the particle moves in a spherical potential; i.e. a single particle energy term.

The monopole term will therefore be replaced by a term which takes into account this difference in single particle energies. 
The spherical potential chosen to evaluate this difference will contain both an iso-scalar part, $v_{0}$, and an iso-vector part, $v_{1}$, both of which are assumed to be slowly varying functions of $A$.

The potential corresponding to $A+l$ nucleus will be written as

$$
V_{0}(r)+\frac{4}{A+1} V_{I}(r) \vec{t}_{p} \cdot \vec{T}_{A}
$$

while for the A mass nucleus it is

$$
v_{0}(r)+\frac{4}{A} V_{I}(r) \vec{t}_{p} \vec{T}_{A-I}
$$

The single particle contributions to the single particle energies from this potential are

$$
\varepsilon_{A}=\varepsilon_{O}+\frac{4}{A} \varepsilon_{1}\left\langle A\left|\vec{t}_{p} \cdot \vec{T}_{A-1}\right| A\right\rangle
$$

and

$$
\varepsilon_{A+1} \sim \varepsilon_{O}+\frac{4}{A} \varepsilon_{l}\left\langle A+1\left|\vec{t}_{p} \cdot \vec{T}_{A}\right| A\right\rangle
$$

The corrections to the diagonal elements become $c_{A}-\varepsilon_{A+1}-\alpha_{p h}^{O}$. The values of $\varepsilon_{A}-\varepsilon_{A+1}$ are for the various occuring cases, (Appendix B.2), are in the tables 2.1 and 2.2 
8

TABLE 2.1.- $-\varepsilon_{A}-\varepsilon_{A+1}$ for $N=Z$ Nuclei.

$$
\begin{array}{lc}
\left|\mathrm{pp}^{-1}\right\rangle & -\varepsilon_{1 / \mathrm{A}} \\
\left|\mathrm{nn}^{-1}\right\rangle & -\varepsilon_{1 / \mathrm{A}} \\
\left|\mathrm{ph}^{-1}, \mathrm{~J} ; \mathrm{T}=0\right\rangle & -3 \varepsilon_{1 / \mathrm{A}} \\
\left|\mathrm{ph}^{-1}, \mathrm{~J} ; \mathrm{T}=1\right\rangle & \varepsilon_{1 / \mathrm{A}}
\end{array}
$$

TABLE 2.2. $--\varepsilon_{A}-\varepsilon_{A+1}$ for $N \neq Z$ Nuclei. Overall $T$ equals that of the gas. $\mathrm{T}_{\dot{0}}$.

$$
\begin{array}{ll}
\left|\mathrm{pp}^{-1}\right\rangle & -\varepsilon_{1 / A} \\
\left|\mathrm{nn}^{-1}\right\rangle & -\varepsilon_{1 / A} \\
\left|\mathrm{ph}^{-1}, \mathrm{~J} ; \mathrm{T}=0\right\rangle & -3 \varepsilon_{1 / \mathrm{A}} \\
\left|\mathrm{ph}^{-1}, \mathrm{~J} ; \mathrm{T}=1\right\rangle & -\varepsilon_{1 / \mathrm{A}} .
\end{array}
$$

For $\mathrm{N} \neq \mathrm{Z}$ and where the $\mathrm{T}$ of the state equals $\mathrm{T}_{0}+1$

$$
\mid \mathrm{ph}^{-1}, \mathrm{~J} ; \mathrm{T}=1>\quad\left(2 \mathrm{~T}_{0}+1\right) / \mathrm{A}
$$

The value of $\varepsilon_{1}$ can be obtained from the symmetry energy of a particle in the $2 \mathrm{p}_{3 / 2}$ orbital of $\mathrm{Ca} .48$

$$
E_{s}=\varepsilon_{n}+\Delta-\varepsilon_{p}=\frac{4 T_{0}}{A} \varepsilon_{I}=\frac{1}{3} \varepsilon_{l}
$$


where $\Delta$ is the coulomb difference between $\mathrm{Ca}^{49}$ and $\mathrm{Sc}^{49}$. The value of $\varepsilon_{1} \sim 20 \mathrm{MeV}$. This value will be used for all nuclei.

It is somewhat doubtful whether or not the monopole shift should be used with the RPA due to the multiparticle-multihole nature of the RPA ground state. 
CHAPTER III

$$
\mathrm{o}^{16}
$$

\subsection{General Discussion}

From looking at the energy spectrum of $0^{16}$ (Fig.

$2,3)$ the most immediate observations that can be made are the following:

A. The Sussex interaction produces levels which are less bound then those levels which result from the $\mathrm{K}-\mathrm{K}$ interaction. This can best be explained by looking at Fig. I where the average centroid shifts are illustrated. For the $\mathrm{K}-\mathrm{K}$ interaction there is a shift downward of approximately . $6 \mathrm{MeV}$ for the $\mathrm{T}=0$ levels while the $T=I$ levels are shifted upwards approximately $2.3 \mathrm{MeV}$. For the case of the Sussex interaction there is virtually no downward shift of the $T=0$ leveis while the $T=1$ levels are shifted upwards about $2.3 \mathrm{MeV}$. The net result is that not only are the Sussex interaction $\mathrm{T}=0$ levels less bound then the, $\mathrm{T}=0$ levels from the $\mathrm{K}-\mathrm{K}$ interaction but also the 
$\mathrm{T}=0, \mathrm{~T}=1$ separation is less with a Sussex interaction then with a $\mathrm{K}-\mathrm{K}$ interaction.

B. For a given interaction and shift configuration the major effect of the RPA compared with the TDA is to lower the energy of the lowest $3^{-}$, $\mathrm{T}=0$ state by approximately 1.5 to $3 \mathrm{MeV}$. The effect of the RPA on the next highest level namely the lowest $1^{-}, T=0$ level is considerably smaller and is only about $.5 \mathrm{MeV}$. On the other states the effect of the RPA is even less. It is known (B169) (Sc7la) that screening contributions should be added to the interaction in the RPA; this is simulated by a calculation where the strength of the $\mathrm{K}-\mathrm{K}$ interaction has been reduced to $65 \%$ of full strength (Sc7la). The $\alpha_{\mathrm{ph}}^{0}$ term of the monopole shift was also reduced by the same amount. The main effect of this reduction of the strength is to decrease the binding of the lowest $3^{-}$, $\mathrm{T}=0$ state. All the other states were much less sensitive to the strength of the interaction.

C. The main effect of the monopole shift for a given configuration is to separate the $T=0$ and $\mathrm{T}=1$ levels by shifting them both downwards, (Fig. $1,2,3$ ) but while the $T=1$ levels are shifted 
downward by about . $8 \mathrm{MeV}$ the $\mathrm{T}=0$ levels are shifted downwards by approximately $3.4 \mathrm{MeV}$. This tends to increase the isotopic purity of the vectors. Since the contribution of the $T=1$ component to a $\mathrm{B}(\mathrm{MJ})$ is approximately 25 times larger than the $\mathrm{T}=0$ component one would expect the change in isospin mixture to affect the magnetic transitions which come from primarily $\mathrm{T}=0$ states. Similarly since $\mathrm{B}(\mathrm{EI})=0$ for $\mathrm{a}$ $\mathrm{T}=0$ state, due to the center of mass correction to the effective charge, one would also expect the monopole shift to affect the B(EI)'s, for the $\mathrm{T}=0$ states. The final placement of both the $\mathrm{T}=0$ and $\mathrm{T}=1$ levels for both interactions is approximately the same.

The low lying positive parity states of $0^{16}$ cannot be described as simple lp-lh states. Brown and Green (Br66) have calculated these states using a $2 \mathrm{p}-2 \mathrm{~h}$ and $4 p-4 h$ deformed basis created by exciting particles out of the core. The present calculations are therefore confined to the negative parity states.

For the $\mathrm{o}^{16}$ calculations the oscillator energy, $\hbar \omega=13.3 \mathrm{MeV}$ was chosen from electron scattering and corresponds to an oscillator length, $b=1.77 \mathrm{fm}$. The sussex matrix elements were linearly interpolated from the tables for $b=1.7$ and $b=1.8$. 
Previous calculations using the RPA with $0^{16}$ have been done by V. Gillet and N. Vinh Mau (Gr64). They used a fitted interaction with 4 parameters with a gaussian radial dependence along with harmonic oscillator wave functions. A least squares fitting of the interaction was done within the framework of the RPA. Their results are quite similar to the present ones.

In the present calculations the single particle energies used were obtained from the neighboring nuclei, $\mathrm{O}^{15}, \mathrm{~N}^{15}, \mathrm{~F}^{17}, \mathrm{O}^{17}$ and the particle-hole gap was derived from binding energies obtained from mass tables (Wa65). These can be seen in Table 3.1 .

The single particle energies given are with respect to the well edge of $0^{16}$. This was done by evaluating

$$
\begin{aligned}
& \varepsilon_{\mathrm{p}_{1 / 2}}^{\mathrm{p}}=\mathrm{O}^{16}-\mathrm{N}^{15}-\mathrm{p}=-12.126 \\
& \varepsilon_{\mathrm{p}_{1 / 2}^{\mathrm{n}}}^{\mathrm{n}}=\mathrm{O}^{16}-\mathrm{O}^{15}-\mathrm{n}=-15.668 \\
& \varepsilon_{\mathrm{d}_{5 / 2}^{\mathrm{p}}}^{\mathrm{p}}=\mathrm{F}^{17}-\mathrm{O}^{16}-\mathrm{p}=-0.601 \\
& \varepsilon_{\mathrm{d}_{5 / 2}}^{\mathrm{n}}=\mathrm{O}^{17}-\mathrm{O}^{16}-\mathrm{n}=-4.143
\end{aligned}
$$

The single particle energies are then 
TABLE 3.1.--0 16 Single Particle Energies.

\begin{tabular}{lcccccc}
\hline \hline & $\mathrm{O}_{\mathrm{s}_{1 / 2}}$ & $\mathrm{O}_{\mathrm{p}_{3 / 2}}$ & $\mathrm{o}_{\mathrm{p}_{1 / 2}}$ & $\mathrm{O}_{\mathrm{d}_{5 / 2}}$ & $\mathrm{O}_{\mathrm{s}_{1 / 2}}$ & $\mathrm{O}_{\mathrm{d}_{3 / 2}}$ \\
\hline $\mathrm{P}$ & -42.126 & -18.454 & -12.126 & -0.601 & -0.101 & 4.500 \\
$\mathrm{~N}$ & -45.668 & -21.828 & -15.668 & -4.143 & -3.272 & 0.937 \\
\hline
\end{tabular}

These energies compare quite closely to those used by Gillet (Gi64) .

It might be useful for the reader while reading this section to refer to Table 3.5 at the end of this section which briefly summarizes the findings for a number of the levels discussed in this section. Table 3.5 is organized in a manner such that the lower levels are separated from the higher lying levels and the latter are organized into complexes as found experimentally. For a complete summary of the $0^{16}$ calculation the reader is refered to Appendix D.1, and Appendix E.1.

3.2 Discussion of States in $\mathrm{O}^{16}$

A $1^{-}, T=0$ state is seen at $7.12 \mathrm{MeV}$ with reported $B(E 1)$ 's of $1.24 \times 10^{-4} e^{2} f^{2}$ and $1.64 \times 10^{-4} e^{2} f^{2}$ (Aj7I). A spectroscopic factor of .41 is observed (Bo69) from the reaction ${ }^{15} \mathrm{~N}\left({ }^{3} \mathrm{He}, \mathrm{d}\right){ }^{16} \mathrm{O}$ for this level which indicates a fair amount of $1 \mathrm{p}-\mathrm{ln}$ structure. From the ${ }^{15} \mathrm{~N}(\mathrm{~d}, \mathrm{n}){ }^{16} \mathrm{O}$ 
reaction an $\ell=0$ transfer was seen (Fu67, Mu70), this would indicate that a large component of the $1^{-}, T=0$ state is $1 s_{1 / 2}-0 p_{1 / 2}^{-1}$. Without using the monopole shift the calculated energy of this state is about $3.5 \mathrm{MeV}$. too high irrespective of the interaction used. Using the monopole shift the energy is brought to within $0.5 \mathrm{MeV}$ of the observed level. For the $\mathrm{K}-\mathrm{K}$ interaction in the TDA with the shift the calculated energy is $7.42 \mathrm{MeV}$ and the Sussex interaction gives an energy of $6.69 \mathrm{MeV}$. The transition rates, $B(E l)$ 's for the various cases calculated are all approximately $2 \times 10^{-4} \mathrm{e}^{2} \mathrm{f}^{2}$ (Appendix D.I). Theoretically the only contribution to a $\mathrm{B}(\mathrm{El})$ from a $1^{-}, T=0$ comes from the isospin mixed $\mathrm{T}=1$ component of the vector. This is because the $T=0$ component of the vector has an effective charge $e^{\prime}=e\left(1-2 \frac{Z}{A}\right)$ arising from the center of mass motion of the nucleus. The $T=1$ admixture arises from the difference in the neutron and proton single particle energies. The major component of this $1^{-}$vector is in fact a $\mathrm{T}=0,1 \mathrm{~s}_{1 / 2}-0 \mathrm{p}_{1 / 2}^{-1}$. excitation with an amplitude about .85. There is however a significant amount of mixing among the $\mathrm{T}=0$ components. For the $\mathrm{K}-\mathrm{K}$ interaction in the TDA with shift the amplitudes are 
TABLE 3.2.--O $\mathrm{O}^{16} \cdot \mathrm{l}^{\mathrm{st}}, \mathrm{1}^{-}, \mathrm{T}=0$ vector components.

\begin{tabular}{|c|c|c|}
\hline $0 d_{5 / 2}-0 p_{3 / 2}^{-1}$ & ${ }^{1 s_{1 / 2}}-0 p_{3 / 2}^{-1}$ & $0 \mathrm{~d}_{3 / 2}-0 \bar{p}_{1 / 2}^{-1}$ \\
\hline-.308 & .334 & -.231 \\
\hline
\end{tabular}

The results from the sussex interaction are similar to those of the $K-K$ except the level energies are slightly lower. The major component of the lowest $1^{-}, T=0$ state is $1 \mathrm{~s}_{1 / 2}-0 \mathrm{p}_{1 / 2}^{-1}$ with zero point energy $6.33 \mathrm{MeV}$ so the $\mathrm{K}-\mathrm{K}$ interaction pushes the level further away from the zero point energy than does the Sussex. This behavior is expected since the $\mathrm{K}-\mathrm{K}$ interaction is stronger than the Sussex. The monopole shift decreases the transition rate by increasing the $T=0, T=1$ splitting, $i . e$. for the $K-K$ interaction without the monopole shift $B(E I)=3.5 \times 10^{-4} \mathrm{e}^{2} \mathrm{f}^{2}$, with the shift $B(E I)=1.1 \times 10^{-4} e^{2} f^{2}$. The monopole shift thus is essential for the energy and improves the transition rate for this lowest $1^{-}, T=0$ state.

The $1^{-}, \mathrm{T}=0$ state seen at $9.60 \mathrm{MeV}$ has a small

spectroscopic factor of .017 for the $\mathrm{N}^{15}(\mathrm{~d}, \mathrm{n}) \mathrm{O}^{16}$ reaction and is probably a multiparticle-multihole state. It would not then be described within the framework of this calculation. 
The next reported $1^{-}, T=0$ state $(A j 71)$ is at 12.44 $\mathrm{MeV}$ with a spectroscopic factor of .75 (Bo69) and a mixed ' $\mathrm{l}$ ' transfer of $0,2(F u 67, M u 70)$ is seen in the $N^{15}(d, n) 0^{16}$ reaction. This implies that the proton is either an $s_{1 / 2}$ or $d_{3 / 2}$ coupled to a $p_{1 / 2}$ hole or if correlations exist in the core (and these are needed to explain the $6.05 \mathrm{MeV} 0^{+}$state) then the proton can be a $d_{5 / 2}$ coupled to a $p_{3 / 2}$ hole. Using TDA and the $K-K$ interaction one must again use the monopole shift in order to obtain decent results. Without the shift the energy of the state is at $16.77 \mathrm{MeV}$ and with the shift the energy of the state decreases to $13.60 \mathrm{MeV}$. The RPA results with either the $\mathrm{K}-\mathrm{K}$ or Sussex interaction are essentially identical for this level and for all the other levels. Unless the RPA is specifically discussed it can be assumed that it yields the same results for a given interaction and shift configuration. The major configuration for this $I^{-}, T=0$ level is $1 s_{1 / 2}-0 p_{3 / 2}^{-1}$ which is consistant with the ' $\ell$ ' transfer. The monopole shift increases the $B(E 1)$ from $1.7 \times 10^{-4} e^{2} f^{2}$ to $4.5 \times 10^{-3} e^{2} f^{2}$, the experimental values (Aj71) cited are $3.5 \times 10^{-3} e^{2} f^{2}$ and $6.5 \times 10^{-3} e^{2} f^{2}$ so the monopole shift again seems to improve the transition rate. The increase in the transition rate arises from the change in the $1 s_{1 / 2}-0 p_{1 / 2}^{-1}$, $\mathrm{T}=1$ part of the vector. With the addition of the monopole 
shift this component increases from .051 to .350. What has happened is that with the addition of the shift the $1^{-} \mathrm{T}=0$ at $16.77 \mathrm{MeV}$ is moved down to $13.60 \mathrm{MeV}$ where it is mixed somewhat strongly with the $13.17 \mathrm{MeV} T=1$ state. The Sussex interaction starts off with this $I^{-} T=0$ state higher (18.87 MeV) so after the shift has been added in, the state only comes down to $15.03 \mathrm{MeV}$ which is not as close to the $I^{-}, T=1$ at $13.2 \mathrm{MeV}$ as with the $\mathrm{K}-\mathrm{K}$ interaction. The $B(E 1)$ after the shift is therefore smaller $\left(4.7 \times 10^{-4} \mathrm{e}^{2} \mathrm{f}^{2}\right)$ than with the $\mathrm{K}-\mathrm{K}$ interaction. A $2^{-}, T=0$ at $8.87 \mathrm{MeV}$ is observed along with a $0^{-}, \mathrm{T}=0$ at 10.95. The ' $\ell$ ' transfer and spectroscopic factors from the $\mathrm{N}^{15}\left(\mathrm{He}^{3}, \mathrm{~d}\right) \mathrm{O}^{16}$ reaction (Bo69) indicate that these levels have a large $l p-l h$ component. The ' $l$ ' transfer and spectroscopic factor for the $2^{-}$state are $\ell=2, S=.87$ while for the $0^{-}$state they are $\ell=0, s=1.77$. The major component would seem to be for the $2^{-}, 0 d_{5 / 2}-0 p_{1 / 2}^{-1}$ since it is lower in energy then the $0 d_{3 / 2}-p_{1 / 2}^{-1}$ and for the $0^{-}$. it would be the $1 \mathrm{~s}_{1 / 2}-0 \mathrm{p}_{1 / 2}^{-1}$. The $\mathrm{K}-\mathrm{K}$ interaction without the shift has $E\left(2^{-}\right)=12.25$ and $E\left(0^{-}\right)=12.93$, with the shift $E\left(2^{-}\right)=8.87$ and $E\left(0^{-}\right)=9.78$. The major component for the $2^{-}$is in fact $0 d_{5 / 2}-0 p_{1 / 2}^{-1}$. Again the monopole shift brings the energy into much better agreement with experiment. The experimental $B(M 2)=5.44 \times 10^{-3} e^{2} f^{4}$ for the $2^{-}$state. The calculated B(M2)'s are too large without the shift, 
$4.2 \times 10^{-2} \mathrm{e}^{2} \mathrm{f}^{4}$ and also too large with the shift, $2.2 \times 10^{-2} \mathrm{e}^{2} \mathrm{f}^{4}$. The change in the $\mathrm{B}(\mathrm{M} 2)$ is however in the right direction. The reason for the decrease in the $B$ (M2) with the shift is that the shift reduces the mixing of the $0 \mathrm{~d}_{5 / 2}-0 \mathrm{p}_{1 / 2}^{-1}, \mathrm{~T}=1$ amplitude of the state from .144 to .041 . This mixture arises from the lst $2^{-}, \mathrm{T}=1$ level near $13 \mathrm{MeV}$. When the $\mathrm{T}=1$ component is completely eliminated the $B(M 2)=1.4 \times 10^{-2} e^{2} \mathrm{f}^{4}$.

Most of the contribution to the $B(M 2)$ is from the $\mathrm{T}=1$ componant as it is in general for a $\mathrm{B}(\mathrm{MJ})$. For $\mathrm{T}=0$ states the magnetic moment contribution to the transition matrix element is $u_{p}+u_{u}=.88$ while for $T=1$ states the contribution is $u_{p}-u_{n}=4.71$. The ratio of the 2 parts of the $B(M J)$ are approximately

$$
\operatorname{BMJ}(1) / \operatorname{BMJ}(0) \approx(4.71)^{2} /(.88)^{2}=28.6
$$

The Sussex interaction reverses the ordering of the $2^{-}, 0^{-}$states placing them at $\mathrm{E}\left(2^{-}\right)=12.12 \mathrm{MeV}$ and $\mathrm{E}\left(0^{-}\right)=10.66$ $\mathrm{MeV}$ without the shift while with the shift they are at $\mathrm{E}\left(2^{-}\right)=7.96 \mathrm{MeV}$ and $\mathrm{E}\left(0^{-}\right)=10.38 \mathrm{MeV}$. The $\mathrm{B}(\mathrm{M} 2)^{\prime} \mathrm{s}$ are weaker as expected. The reason for the reversal is that

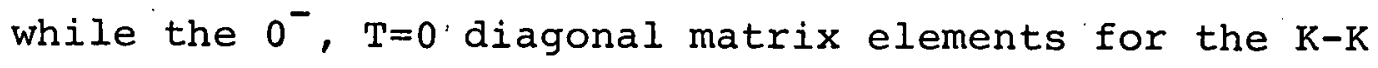
interaction are repulsive, they become attractive for the Sussex interaction. The $K-K$ interaction is restricted to s-waves only. The major component of the $0^{-}, \mathrm{T}=0$ state is $\left(1 \mathrm{~s}_{1 / 2}-0 \mathrm{p}_{1 / 2}^{-1}\right)^{00}$. With the sussex interaction restricted to s-waves only, the above matrix element is also repulsive but the $\mathrm{p}$ and $\mathrm{d}$ wave contributions make the matrix element attractive. 
TABLE 3.3.--Sussex Matrix Elements for $\left(1 s_{1 / 2}-0 p_{1 / 2}\right)^{00}$ state in $0^{16}$.

$\begin{array}{rr}\text { s-wave contribution } & 1.18 \\ \text { s,p-wave contribution } & -0.70 \\ \text { s, p, d-wave contribution } & -1.17\end{array}$

A quartet of $\mathrm{T}=1$ states $\left(0^{-}, 1^{-}, 2^{-}, 3^{-}\right)$is seen at $13 \mathrm{MeV}$. For both interactions without using the monopole shift the quartet comes slightly high in energy. With the monopole shift the energy of the quartet is lowered slightly and is in better agreement with experiment. The $\mathrm{T}=0,1$ splitting is also improved. The $\mathrm{T}=1$ quartet comes from two different particle-hole configurations.

$$
\begin{aligned}
& 0^{-}, 1^{-}: \quad \operatorname{ls}_{1 / 2}-0 \mathrm{p}_{1 / 2}^{-1} \\
& 2^{-}, 3^{-}: \quad 0 d_{5 / 2}-0 \mathrm{p}_{1 / 2}^{-1}
\end{aligned}
$$

There is virtually no I-spin mixing in any of the $\mathrm{T}=1$ states except for the $0^{-}$which has a significant ls $1 / 2^{-0 \mathrm{p}_{1 / 2}^{-1}}, \mathrm{~T}=0$ amplitude for the $\mathrm{K}-\mathrm{K}$ interaction. The shift decreases the I-spin mixing of $T=0$ component of this amplitude for the $\mathrm{K}-\mathrm{K}$ interaction from .4 to . 1 . The $1^{-}, T=1$ member of the quartet is mainly ls $_{1 / 2}-0 \mathrm{p}_{3 / 2}^{-1}$ and has its admixture with the $\mathrm{T}=0$ component increased when the monopole shift is used. Without the 
shift the $1 s_{1 / 2}-0 p_{3 / 2}^{-1}, T=0$ amplitude is .08 and with the shift the amplitude becomes .33. What happens is that the $1^{-}, \mathrm{T}=1$ level is mixing with a higher $1^{-} \mathrm{T}=0$ level which has been brought down by the shift to $13.60 \mathrm{MeV}$ from $16.77 \mathrm{MeV}$. (Experimentally the level is seen at $12.44 \mathrm{MeV}$ ). The $B(E 1)$ for the $1^{-}, T=1$ has been measured $(A j 7 I)$ as both $.021 e^{2} f^{2}$ and $.013 e^{2} f^{2}$. The calculated value of the $B(E I)$ from the $K-K$ interaction is $.032 \mathrm{e}^{2} \mathrm{f}^{2}$ without the shift and with the shift $B(E 1)=.027 e^{2} f^{2}$ so the $T=0$ admixture is necessary to decrease the $B(E I)$ and move it towards the experimental value. This can be checked by turning off the coulomb mixing so the state becomes pure $\mathrm{T}=1$ and then the $B(E I)=.032 e^{2} f^{2}$. The single configuration has a $B(E l)=.083 e^{2} f^{2}$ so the $0 d_{5 / 2}-0 p_{3 / 2}^{-1} T=1$ component of the vector is contributing incoherently.

The $2^{-}, \mathrm{T}=1$ part of the quartet at $12.97 \mathrm{MeV}$ has reported $B(M 2)$ 's of $.24 e^{2} f^{2}$ and $.26 e^{2} f^{4}$ (Aj71). The calculated $\mathrm{B}(\mathrm{M} 2)$ 's for the $\mathrm{K}-\mathrm{K}$ interaction are too large and the shift increases the value from $.36 \mathrm{e}^{2} \mathrm{f}^{4}$ to $.38 \mathrm{e}^{2} \mathrm{f}^{4}$ : this is reduced from the single particle value of $1.26 \mathrm{e}^{2} \mathrm{f}^{4}$. What appears to happen as the $\mathrm{T}=0$ admixture of the state decreases, the $\mathrm{B}(\mathrm{M} 2)$ increases. With the $\mathrm{K}-\mathrm{K}$ interaction and the RPA with no shift the $B(M 2)=.30 \mathrm{e}^{3} \mathrm{f}^{4}$ which is slightly less then the TDA value, the reason being that the $X$ and $Y$ amplitudes for the major component, $0 d_{5 / 2}-0 p_{3 / 2}^{-1}$ subtract and the $B(M 2)$ is sensitive to the $T=1$ components. The 
B(M2) for the sussex interaction is larger, approximately $.5-.6 \mathrm{e}^{2} \mathrm{f}^{4}$ as the interferring $0 \mathrm{~d}_{5 / 2}-0 \mathrm{p}_{1 / 2}^{-1}, \mathrm{~T}=1$ component has been reduced by 508 .

Bernstein (Be71) reports seeing two strong isospin admixed levels at $17.63 \mathrm{MeV}$ and $18.10 \mathrm{MeV}$. Calculations for the $\mathrm{K}-\mathrm{K}$ interaction without the shift yield a $1^{-}, \mathrm{T}=0$ state at $17.99 \mathrm{MeV}$ which is very strongly admixed with a $1^{-}, \mathrm{T}=1$ level at $18.18 \mathrm{MeV}$. With the use of the monopole shift both levels become isotopically pure, the $1^{-}, \mathrm{T}=0$ at $17.99 \mathrm{MeV}$ goes to $15.13 \mathrm{MeV}$ while the $18.18 \mathrm{MeV}$ state becomes an almost pure $\mathrm{T}=1$ state at $17.16 \mathrm{MeV}$. The net result is that no strongly admixed isospin states are predicted near $18 \mathrm{MeV}$.

In nuclei with $\mathrm{T}=0$ ground states the $\mathrm{T}=1$ states can be preferentially excited by $e, e^{\prime}$ at large scattering angles and high momentum transfer. The $o^{16}\left(e, e^{\prime}\right) 0^{16}$ experiment has been performed (Si69) and a number of $\mathrm{T}=1$ complexes have been seen. The complex around $13.5 \mathrm{MeV}$ has already been discussed. Another complex is seen at $17 \mathrm{MeV}$. An unresolved $\mathrm{T}=1$ doublet is seen at $17.20 \mathrm{MeV}$ (St70), one component of which is a $1^{-}$. Another level which has been given a tentative assignment as a $2^{-}$is seen at $17.60 \mathrm{MeV}$. Calculation yields for the KK-TDA with the monopole shift a $1^{-}, \mathrm{T}=1$ at $17.16 \mathrm{MeV}$ and $\mathrm{a} 2^{-}, \mathrm{T}=1$ at $17,03 \mathrm{MeV}$. Without using the shift the energies are 
$1^{-}(19.18), 2^{-}(17.99)$, about one MeV too high. The Sussex interaction yields energies for these two states which are too high, even with the monopole shift, namely $1^{-}(17.84)$, $2^{-}(16.88)$.

I. Sick, et al. (Si69) used a Serber-Yukawa interaction to calculate the $\mathrm{T}=1$ complexes and obtained energies almost $1.5 \mathrm{MeV}$ too high. The experimental B(El) for the $17.20 \mathrm{MeV} \mathrm{1}^{-}, \mathrm{T}=1$ level is $.012^{2} \mathrm{e}^{2} \mathrm{f}^{2}$. The calculated value from the KK-TDA with monopole shift is $.023 \mathrm{e}^{2} \mathrm{f}^{2}$. The major component of the vector is $0 d_{3 / 2}-0 p_{1 / 2}^{-1}$ (amp. 90) which by itself would give a $B(E I)=.41 e^{2} f^{2}$, i.e. 20 times larger. The $B(E I)$ is reduced because the state has sizable components which add incoherently to the main component.

For the $2^{-}, T=1$ state corresponding to the state at $17.03 \mathrm{MeV}$ the experimental $B(M 2)=.051 \mathrm{e}^{2} \mathrm{f}^{4}$. The $\mathrm{B}(\mathrm{M} 2)=.054 \mathrm{e}^{2} \mathrm{f}^{4}$ for the KK-TDA with the monopole shift is approximately twice the single configuration value of $.02 \mathrm{e}^{2} \mathrm{f}^{4}$. The $\mathrm{T}=0$ part of the $B(M 2)$ is adding coherently, since for a pure $\mathrm{T}=1$ vector the $\mathrm{B}(\mathrm{M} 2)=.048 \mathrm{e}^{2} \underline{\mathrm{f}}^{4}$.

Other $\mathrm{T}=1$ states with KK-TDA and monopole shift fall into three groups, $18 \mathrm{MeV}, 20 \mathrm{MeV}$ and $22 \mathrm{MeV}-26 \mathrm{MeV}$. The $18 \mathrm{MeV}$ complex contains 3 levels, a $2^{-}(18.64)$, a $4^{-}(18.77)$ and a $3^{-}(17.89)$. Stroetzel $\left(\right.$ St70) reports seeing a $2^{-}$at 18.5 MeV via $\left(e, e^{\prime}\right)$, but he does not report any parity or decay assignments. The calculated $\mathrm{B}(\mathrm{M} 2)=.086 \mathrm{e}^{2} \mathrm{f}^{4}$ for the state compared with the single configuration $B(M 2)=.61 \mathrm{e}^{2} \mathrm{f}^{4}$. 
The two major components $0 \mathrm{~d}_{5 / 2}-0 \mathrm{p}_{3 / 2}^{-1}(.662)$ and $1 \mathrm{~s}_{1 / 2^{-0}} \mathrm{p}_{3 / 2}^{-1}$ $(-.696)$ of the state have opposite signs for the amplitudes and they contribute incoherently to the transition rate. The strength which is lost goes into the $2^{-}, \mathrm{T}=1$ (20.13) where the 2 major amplitudes have the same sign.

Nobody has reported seeing a $3^{-}, \mathrm{T}=1$ state near $18 \mathrm{MeV}$ or a $4^{-}, \mathrm{T}=1$ state around $18.5 \mathrm{MeV}$. The $4^{-}, \mathrm{T}=1$ state has the largest transition strength in that neighborhood, $B(M 4)=830 \mathrm{e}^{2} \mathrm{f}^{8}$ with the monopole shift. There is however a tentative assignment of a $\left(1^{-}, 5^{-}\right)$to a state at $18.6 \mathrm{MeV}$, obtained from $\mathrm{C}^{12}\left(\alpha, \alpha^{\prime}\right) \mathrm{C}^{12}$ (Ca64).

The $2^{-}$(20.13) $\mathrm{T}=1$ (Si69) carries most of the $2^{-}$, $\mathrm{T}=1$ transition strength, $\mathrm{B}(\mathrm{M} 2)=2.24 \mathrm{e}^{2} \mathrm{f}^{4}$ which is twice the single configuration value and $1.5-2$ orders of magnitude greater than any of the other B(M2)'s. In this case it is interesting to note that the $\mathrm{KK}-\mathrm{RPA}$ value is smaller, $B(M 2)=1.99 e^{2} f^{4}$, because the $X$ and $Y$ components of the wavefunction subtract in calculating the transition rate. This is the magnetic quadrupole state seen at $20.32 \mathrm{MeV}$ by $\left(e, e^{\prime}\right)$ with an experimental $B(M 2)=1.04 e^{2} f^{4}$. The state is quite collective as seen by looking at the amplitudes (Appendix E.1). Without the monopole shift the calculated energy $2^{-}, \mathrm{T}=1$ is $20.94 \mathrm{MeV}$ about $.5 \mathrm{MeV}$ too high. 
The $\mathrm{I}^{-}$state from the $20 \mathrm{MeV}$ complex calculated from the KK-TDA with the monopole shift is at $19.55 \mathrm{MeV}$. $\mathrm{A} 1^{-}$state is seen at $19.5 \mathrm{MeV}$ with a $\mathrm{B}(\mathrm{El})=5.2 \times 10^{-3} \mathrm{e}^{2} \mathrm{f}^{2}$. The shift in this case brings the energy down from $20.21 \mathrm{MeV}$ to $19.55 \mathrm{MeV}$ but also decreases the $B(E 1)$ from $1.5 \times 10^{-2} \mathrm{e}^{2} \mathrm{f}^{2}$ to $8.3 \times 10^{-3} \mathrm{e}^{2} \mathrm{f}^{2}$, so the $\mathrm{B}(\mathrm{El})$ agrees much better with experiment.

The 22-26 MeV complex contain a number of $1^{-}$states, they are seen at $22.80 \mathrm{MeV}$ and $22.5 \mathrm{MeV}$ (Aj71). The KK-TDA with shift yields states at $22.62 \mathrm{MeV}, B(E I)=1.12 \mathrm{e}^{2} \mathrm{E}^{2}$, which is probably the giant dipole state, and a state at $25.46 \mathrm{MeV}, \mathrm{B}(\mathrm{El})=.31 \mathrm{e}^{2} \mathrm{E}^{2}$ whose transition strength is about $1 / 3$ the giant dipole strength. The $22.26 \mathrm{MeV}$ does not have a $B(E I)$ reported, however from (Da65) the photo nuclear cross section has a large peak between 22 and $22.5 \mathrm{MeV}$. At about $24.5 \mathrm{MeV}$ the photo nuclear cross section shows another peak about $1 / 2$ the height of the 22. $2 \mathrm{MeV}$ peak. This would probably correspond to the $25.46 \mathrm{MeV}$ calculated level.

A $2^{-}, \mathrm{T}=1$ state at $23.7 \mathrm{MeV}$ has been tentatively identified. This could correspond to the state at 23.14 calculated with the $\mathrm{K}-\mathrm{K}$ interaction using the monopole shift. The calculation also yields the following other $\mathrm{T}=1$ státes $\mathrm{a} 3^{-}\left(24.19, \mathrm{~B}(\mathrm{E3})=45 \mathrm{e}^{2} \mathrm{f}^{6}\right)$, and $\mathrm{a} 0^{-}$(26.25). None of these states has of yet been identified, however there are lots of unidentified states in the region. 
$3.3 \quad 3^{-}$States in $0^{16}$

The first negative parity state in $\mathrm{O}^{16}$ is a $3^{-} \mathrm{T}=\mathrm{C}$ observed at $6.13 \mathrm{MeV}$ with reported $B(E 3)$ 's to the ground state of $188,214,209 \mathrm{e}^{2} \mathrm{f}^{6}$ (Aj71). Calculation with the bare $\mathrm{K}-\mathrm{K}$ interaction yields an energy for the state of $8.46 \mathrm{MeV}$ and $\mathrm{a} B(\mathrm{E} 3)$ of $71.3 \mathrm{e}^{2} \mathrm{f}^{6}$. The monopole shift while decreasing the energy of the state to $5.08 \mathrm{MeV}$ has very little effect on the $B(E 3)$, decreasing it to $69.7 \mathrm{e}^{2} \mathrm{f}^{6}$. The state vector for the bare $\mathrm{K}-\mathrm{K}$ interaction without the shift is mainly $0 \mathrm{~d}_{5 / 2}-0 \mathrm{p}_{1 / 2}^{-1}, \mathrm{~T}=0$ (amp. = .92) but contains other significant $\mathrm{T}=0$ components, $0 \mathrm{~d}_{5 / 2}-0 \mathrm{p}_{3 / 2}^{-1}$ (amp. $=.30$ ) and $0 \mathrm{~d}_{3 / 2}-0 \mathrm{p}_{3 / 2}^{-1}$ (amp. $\left.=-.26\right)$. The largest $\mathrm{T}=1$ component is the $0 d_{5 / 2}-0 p_{1 / 2}^{-1}$ (amp. $=.028$ ) which arises from Coulomb mixing. Including the monopole shift in the calculation decrease the $T=0,1$ mixing, because of the increased separation of $T=0$ and $T=1$ levels. The $0 d_{5 / 2}-0 p_{1 / 2}^{-1}, T=1$ amplitude then becomes .019. Since the $B(E 3)$ has been decreased slightly, the $T=1$ part of the vector seems to contribute constructively to the transition rate. To verify this a further calculation was done with the $\mathrm{K}-\mathrm{K}$ interaction with the coulomb mixing turned off such that there could be no $T=0,1$ mixing. Another slight decrease was then observed in the $B(E 3)$ down to $67.9 \mathrm{e}^{2} \mathrm{f}^{6}$. The results obtained with the bare Sussex interaction are similar to those with the $\mathrm{K}-\mathrm{K}$. Since it is a weaker interaction 
then the $\mathrm{K}-\mathrm{K}$ interaction, the energy of the lowest $3^{-}, \mathrm{T}=0$ state of the sussex interaction $(9.59 \mathrm{MeV})$ is displaced less from the centroid energy at $11.5 \mathrm{MeV}$ and is therefore found higher in energy than the $3^{-}, \mathrm{T}=0(8.46 \mathrm{MeV})$ calculated from the $\mathrm{K}-\mathrm{K}$ interaction.

The $B(E 3)$ is also slightly larger, $72.8 \mathrm{e}^{2} \mathrm{f}^{6}$ and is accompanied by a slightly larger admixture of the $\mathrm{T}=1$ component of the vector, $0 \mathrm{~d}_{5 / 2}-0 \mathrm{p}_{1 / 2}^{-1}(.036)$. The relative strengths of the weaker $T=0$ components have switched as compared to the $\mathrm{K}-\mathrm{K}$ interaction, $0 \mathrm{~d}_{5 / 2}-0 \mathrm{p}_{3 / 2}^{-1}(\mathrm{amp} \cdot=.26)$ and $0 d_{3 / 2}-0 p_{3 / 2}^{-1}(a m p .=-.31)$. Adding the monopole shift to the sussex interaction lowers the energy of the $3^{-}, T=0$ state to $5.34 \mathrm{MeV}$ and the $\mathrm{B}(\mathrm{E} 3)$ is decreased to $69.5 \mathrm{e}^{2} \mathrm{f}^{6}$. As before with the $K-K$ interaction the $T=1$ part of the vector has decreased. The net effect of the shift for both interactions is to bring the $3^{-}$level into better agreement with experiment. However, the effect of the shift on the transition rate is negligible. Looking at other $3^{-}, \mathrm{T}=0$ levels in the TDA one observes that all the transition strength is in the lowest $3^{-}, T=0$ state. The ratios of the transition strength to the single particle transition strengths for the $3^{-}, \mathrm{T}=0$ states are 


$$
\mathrm{R}_{1}=2.25, \mathrm{R}_{2}=.68, \mathrm{R}_{3}=.32
$$

One expects the RPA to have a large effect on the lowest $3^{-}$ $\mathrm{T}=0$ state. For the $\mathrm{K}-\mathrm{K}$ interaction the energy of the state is. lowered to $7.05 \mathrm{MeV}$ (8.46 for TDA) and the $\mathrm{B}(\mathrm{E} 3)=147 \mathrm{e}^{2} \mathrm{f}^{6}$. The large increase in the $B(E 3)$ is due to the large $Y$ components of the vector which add coherently to the $\mathrm{x}$ components. It should be pointed out that since normalization requires $\mathrm{X}^{2}-\mathrm{Y}^{2}=1$, large $\mathrm{Y}^{\prime}$ 's imply large $\mathrm{X}^{\prime} \mathrm{s}$. Results with the Sussex interaction are similar except that the $3^{-}, \mathrm{T}=0$ is at $8.80 \mathrm{MeV}$ and the $\mathrm{B}(\mathrm{E} 3)=117 \mathrm{e}^{2} \mathrm{f}^{6}$. The RPA moves both the transitions and the energies in the correct direction. In the case of the $\mathrm{K}-\mathrm{K}$ interaction the RPA already over binds the lowest $3^{-}, \mathrm{T}=0$ state without increasing the $B(E 3)$ enough. Similiar effects are observed for $\mathrm{Ca}^{40}$. This point will be discussed further in the next section. Using the monopole shift in RPA, the $3^{-} \mathrm{T}=0$ is extremely over bound for both interactions, the $\mathrm{K}-\mathrm{K}$ interaction places it at $2.12 \mathrm{MeV}$ while the sussex interaction places it $3.86 \mathrm{MeV}$. This is accompanied by a large increase in the transition rate, $367 \mathrm{e}^{2} \mathrm{f}^{6}$ for the $\mathrm{K}-\mathrm{K}$ and $180 \mathrm{e}^{2} \mathrm{f}^{6}$ for the sussex interaction. The large increase for the $\mathrm{K}-\mathrm{K}$ interaction is due to the large diagonal matrix 
elements in the B matrix, approximately $2 \mathrm{MeV}$ coupled with the large reduction of the diagonal elements in the A-matrix, approximately $3 \mathrm{MeV}$. This results in producing $\mathrm{Y}$ components in the vector of the order of .6 which in turn leads to large $\mathrm{x}$ components of the order of 1 . Since the sussex interaction is weaker the results are similar but smaller. second order diagrams, such as core polarization have not been used and since the major effect of these diagrams is to screen the interaction, one should not be surprised at the over binding. To simulate the screening the overall strengths of the interaction were reduced to $65 \%$ along with the potential contribution, $\alpha_{\mathrm{ph}}^{0}$, to the monopole shift. This reduced the binding of the $3^{-}, \mathrm{T}=0$ to $5.68 \mathrm{MeV}$ and decreased the $\mathrm{B}(\mathrm{E} 3)$ to $104 \mathrm{e}^{2} \mathrm{f}^{6}$. Aside from charging the position of the $3^{-}$, $\mathrm{T}=0$ state the interaction reduction decreased the $1^{-}, \mathrm{T}=0$ and $2^{-}, \mathrm{T}=0$ splitting such that it was too small (Table 3.4 ).

TABLE 3.4.--1- $1^{-} 2^{-} \mathrm{T}=0$ Splitting.

\begin{tabular}{llccc}
\hline \hline & Exp. & $\begin{array}{c}\text { K-K-TDA } \\
\text { MS }\end{array}$ & $\begin{array}{c}\text { K-K-TDA } \\
\text { MS }\end{array}$ & $\begin{array}{c}\text { KK (65)-RPA } \\
\text { MS }\end{array}$ \\
\hline $2^{-}$ & 8.87 & 8.87 & 8.82 & 8.48 \\
$1^{-}$ & 7.12 & 7.42 & 7.11 & 7.98 \\
$\operatorname{dif}$ & 1.75 & 1.45 & 1.71 & .51 \\
\hline
\end{tabular}


Within the RPA it is found that in order to reproduce correctly the energy of the $3^{*}, T=0$ state the transition rate becomes too small and in order to obtain the correct transition rate for the state the energy becomes too small: Similar problems have been found in $\mathrm{Ca}^{40}$ (B169).

The $3^{-}, T=0$ state is extremely sensitive to the shift and it is perhaps not a good idea to use this state as a criteria for the validity of the monopole shift.

Another approach to the $0^{16}$ problem that avoids the use of the monopole shift is to use a $\mathrm{C}^{12}$ core and consider 4-particle excitations where the single particle levels are obtained from $\mathrm{C}^{13}$. Such a calculation was done by zuker, et al. (zu68). The particle levels outside the $c^{12}$ core were limited to $0 p_{1 / 2}, 0 d_{5 / 2}, 1 s_{1 / 2}$. With such a model space the positive parity levels can also easily be calculated. For the low-lying states (i.e. up to $8 \mathrm{MeV}$ ) zuker et al. obtained very good agreement with experiment and quite reasonable agreement with experiment up through the low-lying $T=1$ quartet. The binding energies of $\mathrm{O}^{15}$, $0^{17}$ also came out quite well.

In summary the present calculation with "realistic" interactions and a monopole shift gives results for the $\mathrm{O}^{16} \mathrm{p}$-h spectrum which are quite comparable to calculations like that of Gillet where the force is treated as a parameter. There is a correspondingly good identification with 
many of the experimentally observed states. There are some significant differences from previous calculations, particularly in the estimates of isospin mixing, which is in general less in the present calculation and more in agreement with experiment as measured by transition rates. The position of the giant electric dipole (22-25 MeV) and magnetic quadrupole $(\sim 20 \mathrm{MeV})$ excitations is given quite well, i.e. from Table $3.6 \overline{\mathrm{E}}\left(1^{-}, \mathrm{T}=1\right)=22.93 \mathrm{MeV}$ and $\overline{\mathrm{E}}\left(2^{-}, \mathrm{T}=1\right)=19.79 \mathrm{MeV}$ but their strength is overestimated by 50-1008, a feature common to all p-h excitation calculations. 
TABLE 3.5.--Partial Summary of $0^{16}$ for Explanation of Maj. Comp. see Appendix C.

\begin{tabular}{|c|c|c|c|c|c|c|c|}
\hline$i^{-}, 0$ & 7.12 & $\begin{array}{l}1.24 \times 10^{-4} \\
1.64 \times 10^{-4}\end{array}$ & $\begin{array}{l}10.62 \\
3.49 \times 1\end{array}$ & $(5 / 3,3)$ & $\begin{array}{l}7.41 \\
1.12 \mathrm{x}\end{array}$ & $(5 / 3,3)$ & \\
\hline $2^{-}, 0$ & 8.87 & .0054 & $\begin{array}{l}12.25 \\
.042\end{array}$ & $(4 / 3,3)$ & $\begin{array}{l}8.87 \\
.022\end{array}$ & $(4 / 3,3)$ & \\
\hline $1^{-}, 0$ & 9.60 & $\begin{array}{l}2.38 \times 10^{-5} \\
1.94 \times 10^{-5}\end{array}$ & & & & & $\begin{array}{l}\text { Probably multiparticle- } \\
\text { multihole state }\end{array}$ \\
\hline $2^{-}, 0$ & 12.53 & .084 & $\begin{array}{l}16.73 \\
.086\end{array}$ & $(6 / 3,3)$ & $\begin{array}{l}13.87 \\
.091\end{array}$ & $(6 / 3,3)$ & \\
\hline $3^{-}, 0$ & 13.13 & & $\begin{array}{l}16 \cdot 37 \\
17\end{array}$ & $(4 / 2,3)$ & $\begin{array}{l}13.26 \\
20\end{array}$ & $(4 / 2,3)$ & \\
\hline
\end{tabular}


TABLE 3.5.--Continued.

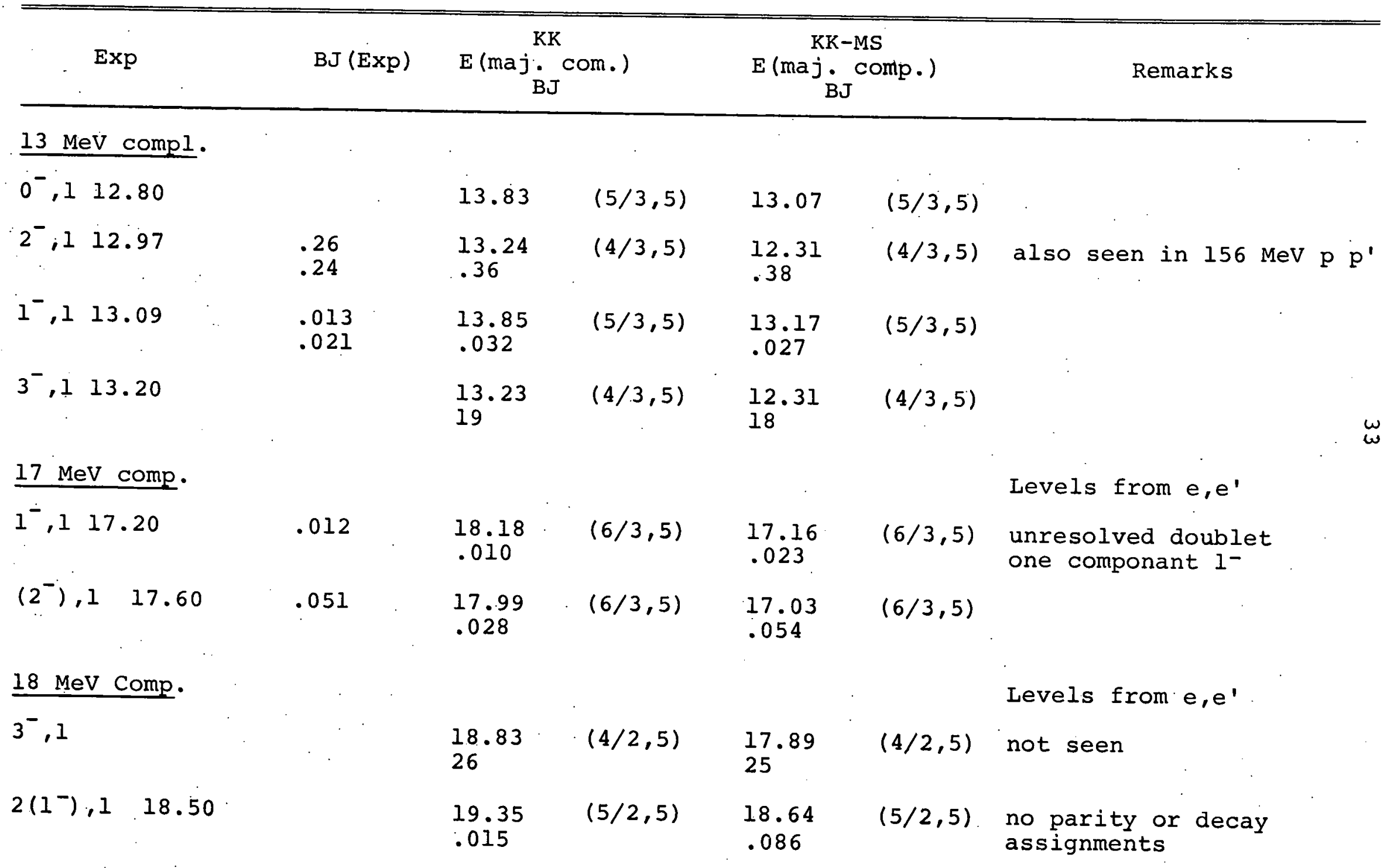


TABLE 3.5.--Continued.

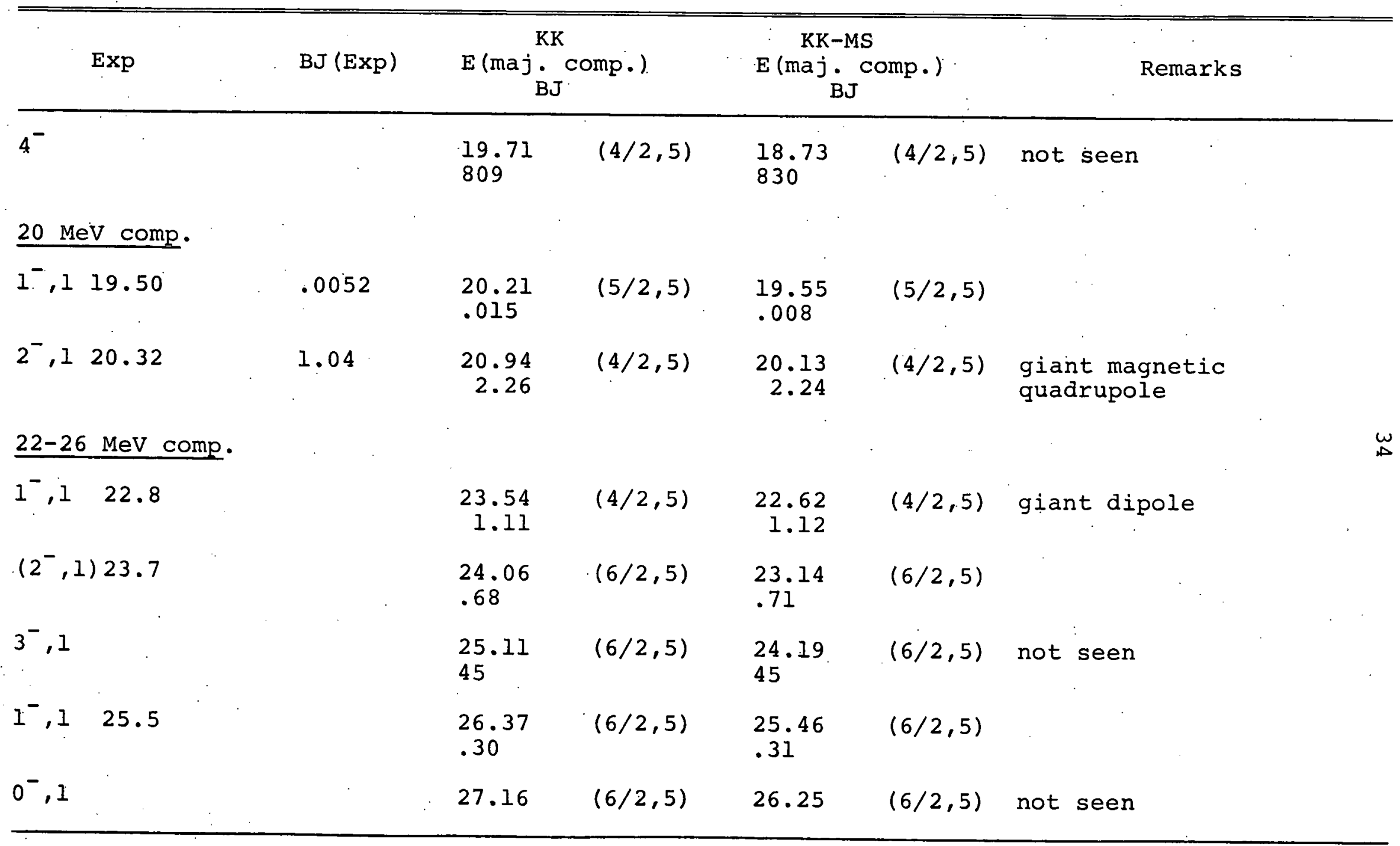


TABLE 3.6.--0 16 Centroid Energies, Energy Dispersions and Sum Rules for Representative Configurations of the K-K Interaction with the Monopole Shift (For Formulas See Appendix A).

\begin{tabular}{lcccccccc}
\hline \hline & $1^{-}, \mathrm{T}=1$ & $2^{-}, \mathrm{T}=1$ & $3^{-} \mathrm{T}=0$ & $\begin{array}{l}3^{-} \mathrm{T}=0 \\
.65 \mathrm{RPA}\end{array}$ & $3^{-\mathrm{T}=1}$ & $4^{-} \mathrm{T}=1$ & $2^{+} \mathrm{T}=0$ & $2^{+} \mathrm{T}=1$ \\
\hline$\overline{\mathrm{E}}$ & 22.93 & 19.79 & 8.29 & 9.03 & 19.95 & 18.77 & 35.34 & 45.52 \\
$\Delta \mathrm{E}$ & 1.92 & 2.95 & 4.99 & 4.87 & 4.73 & 0.0 & 3.58 & 2.50 \\
$\mathrm{~S}$ & 34 & 69 & 840 & 1431 & 1765 & 15581 & 118 & 112 \\
\hline
\end{tabular}

$$
\begin{aligned}
& \text { Observed } 1^{-}, T=1 \\
& \bar{E}=23.5 \\
& S \sim 15
\end{aligned}
$$




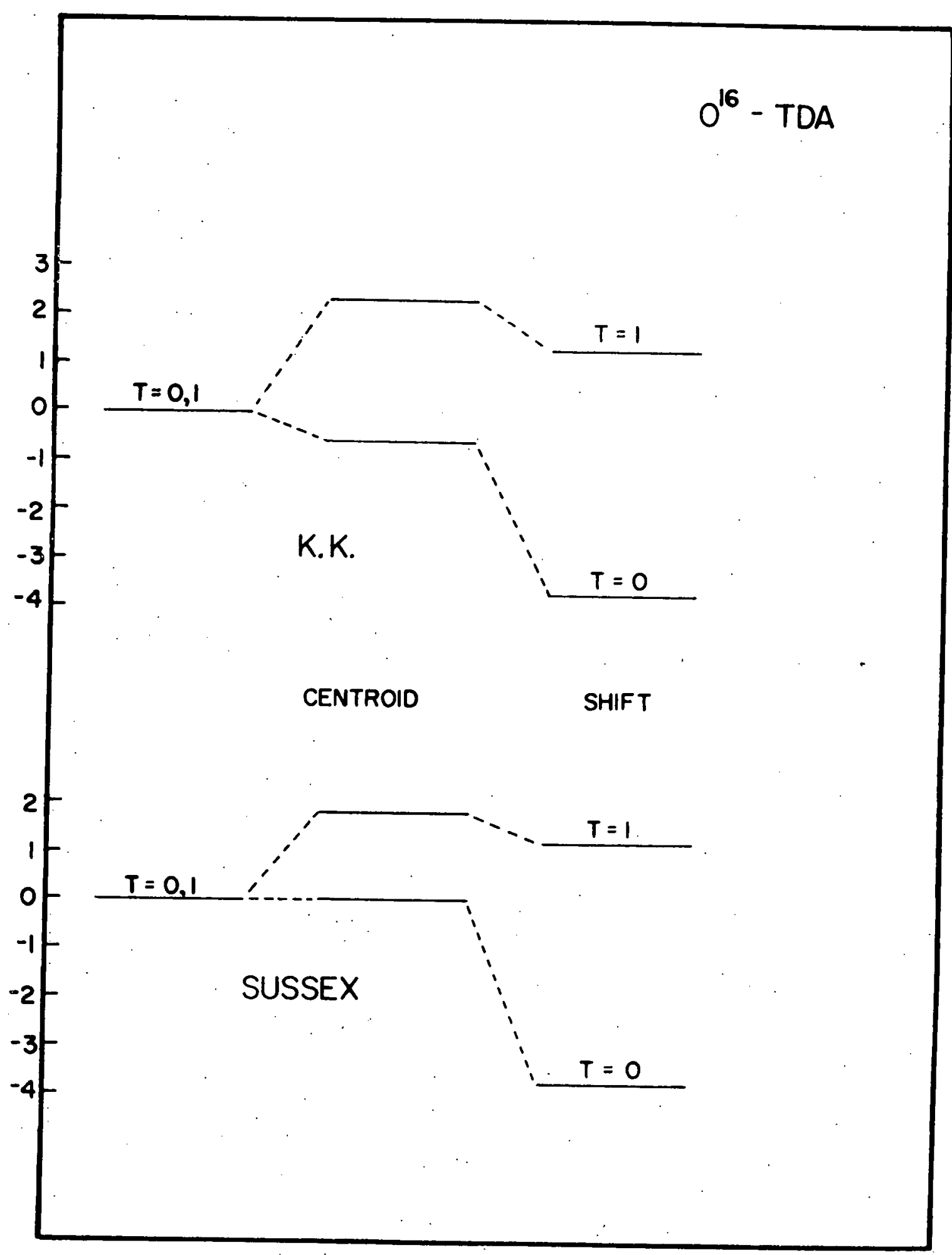

FIGURE $1 .-0^{16}$ Monopole Shifts. 
FIGURE 2.--O $\mathrm{O}^{16} \mathrm{~K}-\mathrm{K}$ Energy Levels.

$$
\begin{aligned}
& A=\exp . \\
& B=K K-T D A \\
& C=K K-M S T D A \\
& D=K K-R P A \\
& E=K K-R P A \text { Shift } \\
& F=K K-R P A \text { Shift } 65 \%
\end{aligned}
$$




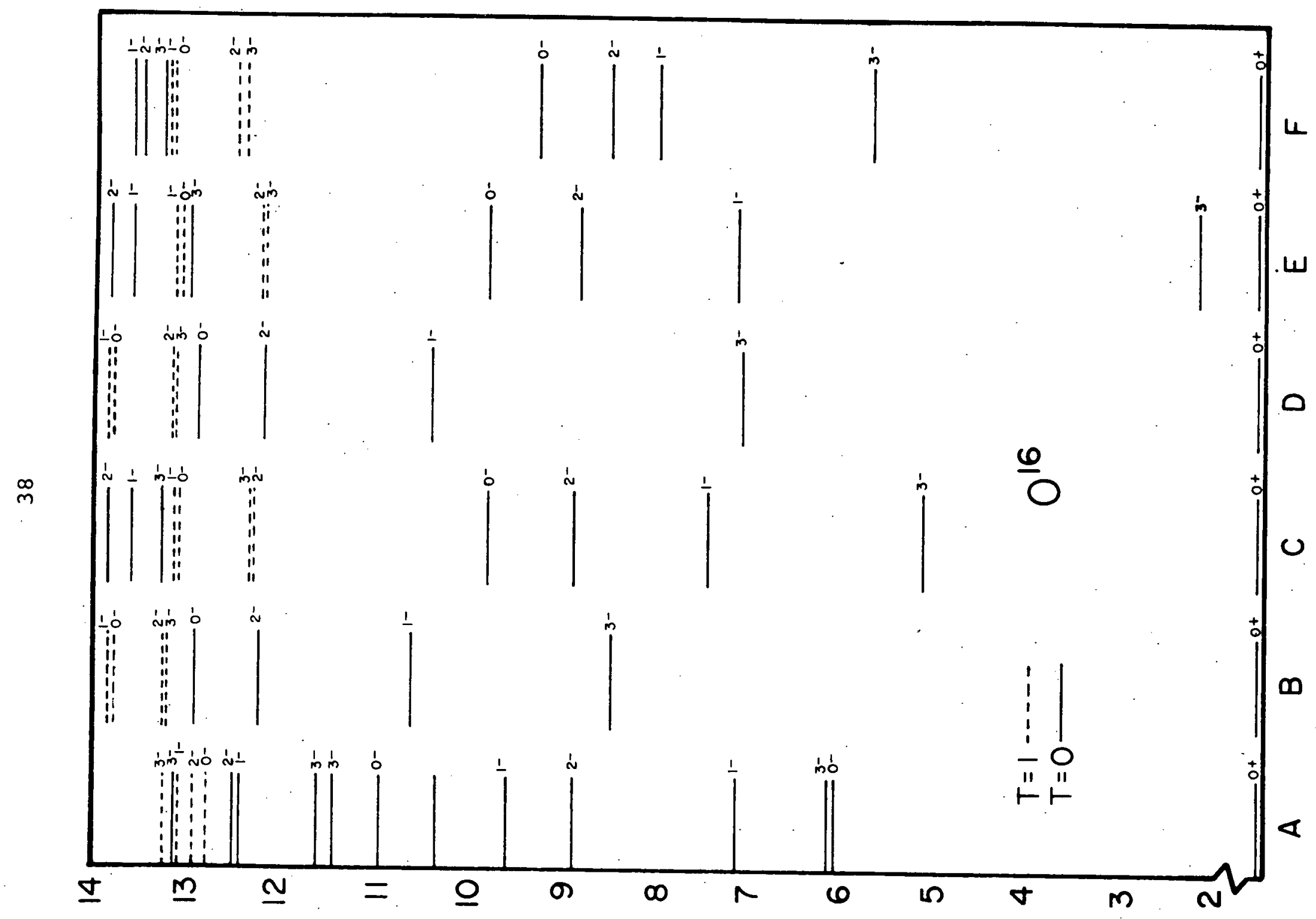


FIGURE 3.--0 $0^{16}$ Sussex Energy Levels.

$$
\begin{aligned}
& A=\exp \\
& G=\text { Sussex-TDA } \\
& H=\text { sussex-Shift TDA } \\
& I=\text { Sussex RPA } \\
& J=\text { Sussex MS - RPA }
\end{aligned}
$$




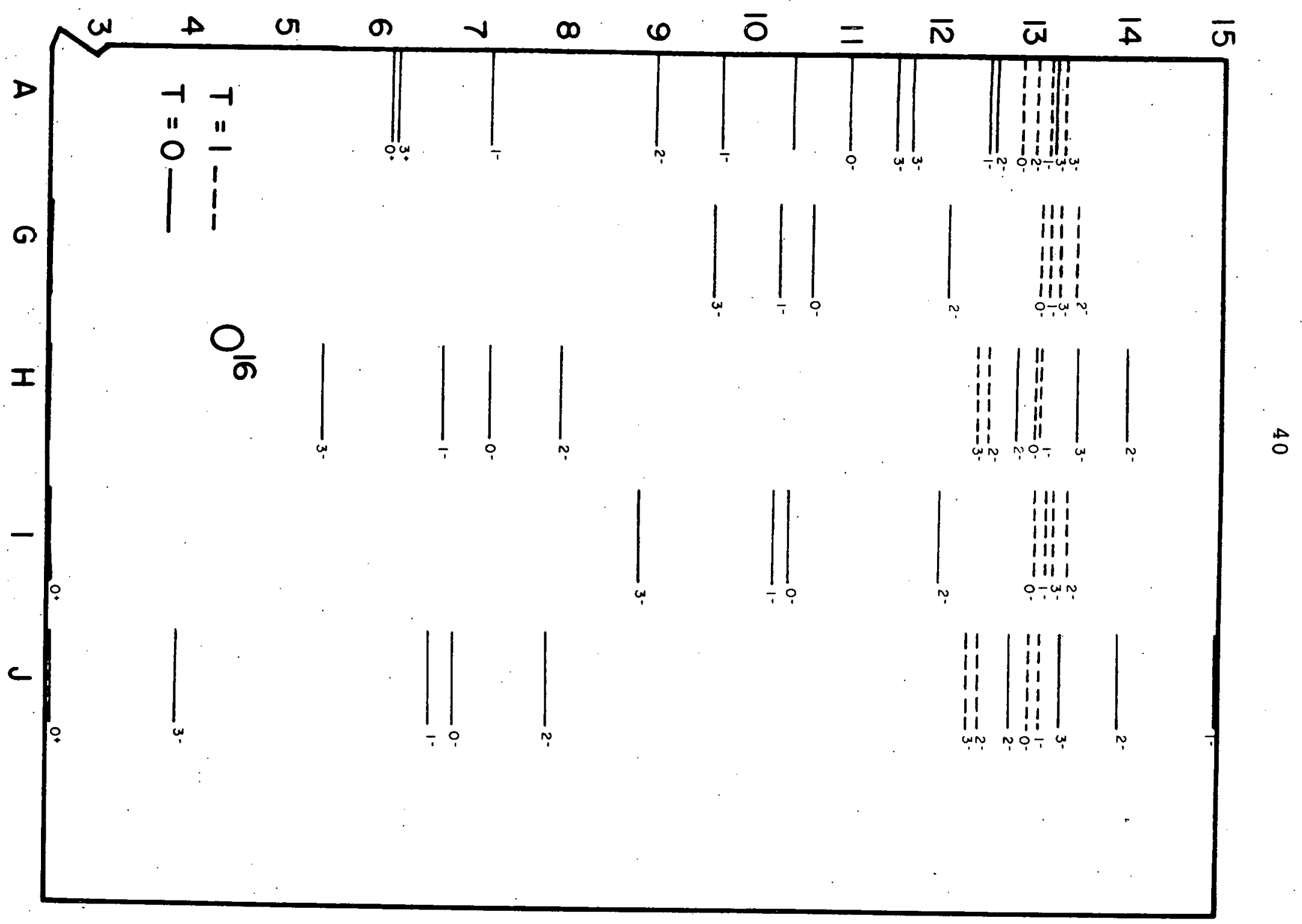


CHAPTER IV

$$
\mathrm{Ca}^{40}
$$

\section{1. $\mathrm{Ca}^{40}$ General Discussion}

A number of studies have been made of $\mathrm{Ca}^{40}$. Gillet and Sanderson (Ge67) calculated the odd parity spectrum of $\mathrm{Ca}^{40}$ within the framework of a $1 \mathrm{p}-1 \mathrm{~h}$ model. They used a parameterized interaction fitted to the lowest $3^{-}, \mathrm{T}=0$ and $5^{-}, \mathrm{T}=0$ levels. Correlations in the ground state were taken into account through the RPA which yielded a ground state wavefunction whose $0 \mathrm{p}-0 \mathrm{~h}$ amplitude was only .6 or about 36 pure shell model. They also found the lowest $3^{-}, T=0$ state to be extremely sensitive to the interaction. This sensitivity for the lowest $3^{-}$state has also been observed in $0^{16}, \mathrm{Ca}^{48}, \mathrm{Sr}^{88}$ and $\mathrm{Pb}^{208}$. Gillet also reported strong $\mathrm{T}=0,1$ admixtures for the higher octopole states. This admixture is contrary to results found by Erskine (Er66) in the $\mathrm{K}^{39}\left(\mathrm{He}^{3}, \mathrm{~d}\right) \mathrm{Ca}^{40}$ reaction. In this reaction Erskine identified the major components of the configurations $\left(0 f_{7 / 2}-0 d_{3 / 2}^{-1}\right)_{T=0},\left(0 f_{7 / 2}-0 d_{3 / 2}^{-1}\right)_{T=1}$ and $\left(1 p_{3 / 2}-0 d_{3 / 2}^{-1}\right)_{T=0}$ through a DWBA analysis of the ' $\ell$ ' transfer. T. Kuo (Ku7I) recently did a $\mathrm{Ca}^{40}\left(\mathrm{p}, \mathrm{p}^{\prime}\right) \mathrm{Ca}^{40}$ experiment and confirmed some of Erskine's tentative level assignments and in 
addition deduced a number of transition rates. Both the $\left(\mathrm{He}^{3}, \mathrm{~d}\right)$ and $\left(\mathrm{p}, \mathrm{p}^{\prime}\right)$ reactions excite both $\mathrm{T}=0$ and $\mathrm{T}=1$ states in $\mathrm{Ca}^{40}$ : In order to locate the $\mathrm{T}=1$ states by themselves one could use a charge transfer reaction $\mathrm{Ca}^{40}\left(\mathrm{He}^{3}, \mathrm{t}\right) \mathrm{Sc}^{40}$ to excite the $\mathrm{T}=1$ states of $\mathrm{Sc}^{40}$. This experiment does not seem to have been done.

The $\mathrm{T}=1$ states from the $\left(0 \mathrm{f}_{7 / 2^{-}}-0 \mathrm{~d}_{3 / 2}^{-1}\right)$ multiplet in $\mathrm{Ca}^{40}$ are the isobaric analog of the $\mathrm{Sc}^{40}$ states. The energy of the analog states can be obtained from the average Coulomb shift. The energy differences Sc ${ }^{40}-\mathrm{Ca} 40$ and $\mathrm{K}^{40}-\mathrm{Ca}^{40}$ are mainly due to the difference in the Coulomb energies of the nuclei. A slightly more accurate description would also include the proton-neutron mass difference. The average coulomb shift is

$$
\dot{v}_{\mathrm{c}}=\frac{\left(\mathrm{Sc}^{40}-\mathrm{Ca}^{40}\right)+\left(\mathrm{K}^{40}-\mathrm{Ca}^{40}\right)}{2}=7.8
$$

The first $T=1$ state seen in $\mathrm{Ca}^{40}$ is the $4^{-}$at 7.69 MeV which is the analog of the $4^{-}$ground state of $K^{40}$ or $\mathrm{Sc}^{40}$

4.2. Discussion of states in $\mathrm{Ca}^{40}$

In order to simplify the discussion, each of the previous three multiplets will be discussed separately. The reader is urged to make use of Table 4.3 found at the end of this section which is organized by multiplet. A 
complete summary of the calculation will be found in Appendices D.2 and E.2.

There exists a large number of low-lying states of both parities in $\mathrm{Ca}^{40}$ which can not be explained from a simple lp-lh shell model calculation. The low-lying positive parity states have been explained microscopically as multiparticle-multihole states calculated on a deformed basis. Gerace and Green (Ge67) constructed these deformed states from $2 p-2 h$ states and $4 p-4 h$ states where they placed the $4 p-4 h$ states below the $2 p-2 h$ states. They found the $0^{+}$vectors to be

$$
\begin{aligned}
& \left|0_{1}^{+}(0.00)>=.90\right| 0 p-0 h>+.41|2 p-2 h>+.11| 4 p-4 h> \\
& \left|0_{2}^{+}(3.55)>=.20\right| 0 p-0 h>-.18|2 p-2 h>-.96| 4 p-4 h>
\end{aligned}
$$

i.e. the ground state is mainly $0 \mathrm{p}-0 \mathrm{~h}$ but contains $16 \%$ $2 \mathrm{p}-2 \mathrm{~h}$ while the second $\mathrm{O}^{+}$is mainly $4 \mathrm{p}-4 \mathrm{~h}$.

Four $3^{-}$states are observed between the ground state and the first $T=1$ state at $7.69 \mathrm{MeV}$, three of these $3^{-}$ states are below $7 \mathrm{MeV}$. The low-lying lp-lh configurations are $\left(0 f_{7 / 2}-0 d_{3 / 2}^{-1}\right),\left(\operatorname{lp}_{3 / 2}-0 d_{3 / 2}^{-1}\right),\left(0 f_{7 / 2^{-1}} s_{1 / 2}^{-1}\right)$, the latter two being almost degenerate, all of which have their centroid energies above $7 \mathrm{MeV}$. Using realistic interactions and the particle-hole gap of $7.2 \mathrm{MeV}$ obtained from the mass table it is difficult to position more than one of the $3^{-}$ states arising from those configurations below $7 \mathrm{MeV}$. The monopole shift however places two levels below $7 \mathrm{MeV}$. Gerace 
and Green (Ge68) described the negative parity states by coupling shell model states on to the deformed states or microscopically as mixtures of $l p-l h$ states and $3 p-3 h$ states. They also used a different value of the particlehole gap by calculating it with shell model state energies and found it to be $5.4 \mathrm{MeV}$.

In the present calculation the particle-hole gap was obtained from the mass tables and the single particle levels used were chosen from neighboring nuclei.

Coulomb mixing was accomplished as in $0^{16}$ by mixing the $\mathrm{T}=0,1$ states through the off diagonal matrix elements $1 / 2\left(\varepsilon_{p}^{p}-\varepsilon_{h}^{p}+\varepsilon_{p}^{n}-\varepsilon_{n}^{n}\right)$ and the proton particle hole gap was reduced by $.3 \mathrm{MeV}$ to simulate the coulomb shift of the single excited proton.

4.2.1. $\left(0 f_{7 / 2}-0 \mathrm{~d}_{3 / 2}^{-1}\right)$ Multiplet

Erskine (Er66) observed $\ell=3$ transfers in the $\mathrm{K}^{39}\left(\mathrm{He}^{3}, \mathrm{~d}\right) \mathrm{Ca}^{40}$ reaction to states at $3.72 \mathrm{MeV}, 4.49 \mathrm{MeV}$, $5.61 \mathrm{MeV}$, a mixed $\ell=1,3$ transfer to the state at $6.03 \mathrm{MeV}$ and $a l=1$ transfer to the state at $6.75 \mathrm{MeV}$. Upon the basis of the $l=3$ transfer Erskine identified the first four levels as belonging to the $\left(0 f_{7 / 2}-0 d_{3 / 2}^{-1}\right)_{T=0}$ multiplet. His identifications were $3^{-}(3.72), 5^{-}(4.49), 4^{-}(5.61), 2^{-}(6.03)$. T. Kuo (Ku7l) agreed with Erskines first three ' $\ell$ ' transfers. However he could not assign an ' $l$ ' transfer to the state at $6.03 \mathrm{MeV}$ but assigned an $\ell=3$ transfer to a state at $6.75 \mathrm{MeV}$. 
TABLE 4.1.--Ca ${ }^{40}$ Single Particle Levels.

\begin{tabular}{llllllllll}
\hline \hline & $0 d_{5 / 2}$ & ${ }_{1 s} s_{1 / 2}$ & $0 d_{3 / 2}$ & $0 f_{7 / 2}$ & $l p_{3 / 2}$ & $l p_{1 / 2}$ & $0 g_{9 / 2}$ & $1 a_{5 / 2}$ & $0 f_{5 / 2}$ \\
\hline$p$ & -14.23 & -11.13 & -9.33 & -1.09 & 0.81 & 3.01 & 4.51 & 4.91 & 5.31 \\
$\mathrm{n}$ & -21.82 & -18.72 & -15.92 & -8.36 & -6.42 & -4.41 & -2.76 & -2.36 & -1.96 \\
\hline
\end{tabular}


Experimentally both the $6.03 \mathrm{MeV}\left(2_{1}^{-}\right)$and the $6.75 \mathrm{MeV} .\left(2^{-}\right)$states have been identified as $2^{-} \mathrm{T}=0$ states, but the two experiments quoted disagree as to which is the state to be assigned to the configuration. The present calculation with the $\mathrm{K}-\mathrm{K}$ interaction and without the monopole shift places the energy of the $\left(0 f_{7 / 2}-0 d_{3 / 2}^{-1}\right)_{T=0}$ multiplet too high, i.e. $3^{-}(5.6), 5^{-}(5.83), 4^{-}(7.15)$, $2^{-}(8.10)$. With the monopole shift the states are at $3^{-}(4.34), 5^{-}(4.48), 4^{-}(5.91), 2^{-}(6.81)$. The monopole shift is needed in order to bring the $5^{-}$and $4^{-}$states into good agreement with experiment. The results with the sussex interaction using the monopole shift for the $5^{-}(6.35)$ and $4^{-}(7.11)$ are also in good agreement with experiment. However, the $\mathrm{K}-\mathrm{K}$ interaction with the monopole shift places the $2^{-}$ at $6.80 \mathrm{MeV}$ which is in better agreement with the $2_{2}^{-}$then the $2^{-}$, on the other hand the sussex interaction with the shift places the $2^{-}$at $6.23 \mathrm{MeV}$ which is in better agreement with the $2^{-}$than the $2^{-} 2^{\circ}$

Gerace and Green have calculated that the $5_{1}^{-}$and $4_{1}^{-}$ states are almost pure shell model while the $2^{-}$level is mostly deformed, being $6783 \mathrm{p}-3 \mathrm{~h}$. They found the $2^{-}$level to be $29 \% 3 p-3 h$. The major shell model componant was of $7 / 2-0 d_{3 / 2}^{-1}$. These admixtures of the $3 p-3 h$ states in the $2^{-}$vectors could explain the ambiguities between Erskine's results and Kuo's results in the ' $l$ ' transfers. Gerace's 
identification of the $2^{-}$being mostly shell model tends to favor the $\mathrm{K}-\mathrm{K}$ calculation with monopole shift over the similar Sussex calculation.

For the $5^{-}$member of the multiplet the experimental $B(E 5)=2.43 \times 10^{5} e^{2} \mathrm{f}^{10}$, the $\mathrm{K}-\mathrm{K}$ interaction without the shift has $B(E 5)=1.75 \times 10^{5} e^{2} \mathrm{f}^{10}$ while with the monopole shift $B(E 5)=1.69 \times 10^{5} e^{2} f^{10}$, a slight decrease.

For the $4^{-}, T=0$ level of the multiplet the values of $B(E 4)$ for the $K-K$ potential with and without the shift are $92 \mathrm{e}^{2} \mathrm{f}^{8}$ and $35 \mathrm{e}^{2} \mathrm{f}^{8}$ respectively. The decrease in the $\mathrm{B}(\dot{\mathrm{M}} 4)$ with the monopole shift is due to the decrease in the $T=I$ admixture. The Gillet vector for this state is very similar to the $\mathrm{K}-\mathrm{K}$ interaction vector when the monopole shift is used, i.e. about $10 \%$ of the vector is $\mathrm{T}=1$.

The screened RPA (65\% K-K with the monopole shift) places the $5^{-}(4.80)$ and the $4^{-}(5.84)$ states close to the right values, the $B(E 5)=2.12 \times 10^{5} \mathrm{e}^{2} \mathrm{f}^{10}$ which is a slight improvement over the TDA results while $B(E 4)=31 e^{2} f^{8}$.

The $3^{-}, \mathrm{T}=0$ state of the $\left(0 \mathrm{f}_{7 / 2}-0 \mathrm{~d}_{3 / 2}^{-1}\right)$ multiplet is quite collective, its largest component, as expected is $\left(0 f_{7 / 2}-0 d_{3 / 2}^{-1}\right)$ but it represents less than $40 \%$ of the vector, the $\left(0 f_{7 / 2}-1 s_{1 / 2}^{-1}\right)$ configuration contains about $18 \%$ while the $\left(1 p_{3 / 2}-0 d_{3 / 2}^{-1}\right)$ and the $\left(0 f_{7 / 2}-0 d_{5 / 2}^{-1}\right)$ each contain about $10 \%$ of the vector. This structure for the vector along with a negligible $\mathrm{T}=1$ admixture is independent of whether or not the monopole shift is used. The calculated $B(E 3)=869 e^{2} f^{6}$ 
for the KK-TDA no shift, this is an order of magnitude higher than the single configuration value of $66 \mathrm{e}^{2} \mathrm{f}^{6}$ and is a factor of 3 . smaller than the experimental value of $2410 \mathrm{e}^{2} \mathrm{f}^{6}$. The KK-RPA without: the monopole shift gives a $B(E 3)=3190 \mathrm{e}^{2} \mathrm{f}^{6}$. These results are quite similar to the results obtained by J. Blomqvist and T. T. S. Kuo (Be69) with the bare G-matrix. The $\mathrm{K}-\mathrm{K}$ interaction in the RPA with monopole shift drives the $3^{-}$level imaginary. The screened RPA has $B(E 3)=1120 \mathrm{e}^{2} \mathrm{f}^{6}(6.62 \mathrm{MeV})$. A slightly smaller value for the screening, say $70 \%$ of full strength for the matrix elements might have given an almost perfect fit to the energies of the $0 f_{7 / 2}-0 d_{3 / 2}^{-1}$ quartet. The problem of fitting the $3^{-}$energies and the $B(E 3)$ 's has been discussed by J. Blomqvist (B169). They used various combinations of second order graphs in the RPA to try and fit both the energy of the $3^{-}$state and the relative transition strengths. Their best fit to the relative transition rates resulted in the $3^{-}$energy being too low, $1.33 \mathrm{MeV}$, while their best fit to the energy (using a different combination of graphs than with the relative transition rates) resulted in all the $3^{-}$strength being put into the lowest state whereas experimentalily the $3^{-}$has about .28 the strength of the $3^{-}$ 
TABLE 4.2.--Relative Strengths of the $3^{-}, \mathrm{T}=0$ states in $\mathrm{Ca}^{40}$.

\begin{tabular}{ccccc}
\hline Exp. & & Blomqvist & K-K & KK-Shift \\
\hline $3_{1}^{-}$ & 1.00 & 1.00 & 1.00 & 1.00 \\
$3^{-} 2_{2}^{--28}$ & .16 & .12 & .03 & .19 \\
3 & .15 & .17 & .06 \\
\hline
\end{tabular}

The same problem exists in the bootstrap theory (Go70). Attempts to find self consistant solutions of the equations for $\mathrm{Ca}^{40}$ resulted in the phonon energy of the $3^{-}$state being driven to zero if an attempt was made to stabilize the transition rate near the experimental value. A first order solution to the bootstrap equations confirmed Gerace and Green's choice of $5.4 \mathrm{MeV}$ for the particle-hole gap. If one inputs a $5.4 \mathrm{MeV}$ particle-hole gap in the Hartree-Fock levels into the bootstrap equations then the first order solution to the observed particle-hole splitting is $7.2 \mathrm{MeV}$ in agreement with the value obtained from the mass table. The $\left(0 f_{7 / 2}-0 d_{3 / 2}^{-1}\right), T=1$ levels were also identified by Erskine through $l=3$. transfers in the $\mathrm{K}^{39}\left(\mathrm{He}^{3}, \mathrm{~d}\right) \mathrm{Ca} \mathrm{a}^{40}$ reaction. He found them at, $4^{-}(7.66), 3^{-}(7.70), 2^{-}(8.47)$ and $5^{-}(8.55)$. They were however mainly identified through their position in relationship to their being analogs of the $\left(0 f_{7 / 2}-0 d_{7 / 2}^{-1}\right)$ multiplet in $\mathrm{Sc}^{40}$ and $\mathrm{K}^{40}$. The $\mathrm{K}-\mathrm{K}$ interaction without the shift places the levels slightly high, at $4^{-}(7.82), 3^{-}(7.75)$, $5^{-}(8.43), 2^{-}(8.99)$ while with the monopole shift they are 
found slightly low, at $4^{-}(7.15), 3^{-}(7.47), 5^{-}(7.87)$, $2^{-}(8.42)$. In both cases it should be noted that the $2^{-}, 5^{-}$splitting has been reversed by the $\mathrm{K}-\mathrm{K}$ interaction. The results for the sussex interaction are similar except that the levels come a little lower and closer 'together.

The monopole shift also provides the correct separation between the $T=0,1$ parts of the multiplet. Without the shift the two sets of levels intermix (Fig. 4).

R. Schaeffer (Sc7la) calculated the position of the $\left(0 \mathrm{f}_{7 / 2}-0 \mathrm{~d}_{3 / 2}^{-1}\right) \mathrm{T}=1$ configuration states in $\mathrm{Ca}$. 40 from the experimental levels of $\mathrm{K}^{40}$ and $\mathrm{sc}^{40}$ by taking into account the coulomb shifts. The results of this calculation agree much better with the results obtained from the $K-K$ interaction with the shift than they do with experiment.

\begin{tabular}{|c|c|}
\hline & 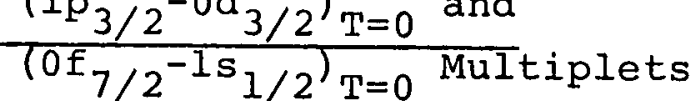 \\
\hline
\end{tabular}

Erskine also observed a number of $\ell=l$ transfers along with the $l=3$ transfers. The lowest lp-lh configuration which would exhibit an $\ell=1$ transfer in the $\mathrm{K}^{39}\left(\mathrm{He}^{3}, \mathrm{~d}\right) \mathrm{Ca}^{40}$ reaction is the $\left(1 p_{3 / 2}-0 d_{3 / 2}^{-1}\right)$. The allowed values of $J$ for this multiplet are $\mathrm{J}=0^{-}, 1^{-}, 2^{-}, 3^{-}$. The $\left(1 \mathrm{p}_{3 / 2^{-}} 0 \mathrm{~d}_{3 / 2}^{-1}\right)$ is almost degenerate with the $\left(0 f_{7 / 2^{-1}}^{-1} s_{1 / 2}\right)$ whose allowed $\mathrm{J}$ values are $\mathrm{J}=3^{-}, 4^{-}$. (Fig. 5). Since the two configurations are almost degenerate one should expect a lot of configuration mixing for the $3^{-}$states. 
The $1^{-}, T=0$ state from the $\left(1 p_{3 / 2}-0 d_{3 / 2}^{-1}\right)$ multiplet for the $K-K$ interaction with the monopole shift is at $7.19 \mathrm{MeV}$ (8.45 without the shift). There are two observed $1^{-}, \mathrm{T}=0$ states at $5.90 \mathrm{MeV}\left(1_{1}^{-}\right)$and at $6.94 \mathrm{MeV}\left(1_{2}^{-}\right)$. Gerace and Green find that the $1^{-} I$ is mostly deformed and has a $3 p-3 h$ amplitude of .98. On the other hand they assign the $1^{-}$to be practically pure shell mode (4\% deformed) with the major componant the $\left(1 \mathrm{p}_{3 / 2}-0 \mathrm{~d}_{3 / 2}^{-1}\right)$. This is in good agreement with the present calculation.

Nobody has yet reported seeing the $0^{-}$level or the $2^{-}$level from this multiplet.

The $3^{-}$state from the $\left(\operatorname{lp}_{3 / 2}-0 d_{3 / 2}^{-1}\right)$ multiplet mixes quite strongly with the $3^{-}$state from the $\left(0 f_{7 / 2^{-1}} s_{1 / 2}^{-1}\right)$ multiplet as expected. The $K-K$ interaction with the monopole shift predicts two $3^{-}, T=0$ states with major components,

$$
\begin{aligned}
& \left|.3_{2}^{-}(6.56)>=.65\right| \operatorname{lp}_{3 / 2}-0 \mathrm{~d}_{3 / 2}^{-1}>-.60 \mid 0 \mathrm{f}_{7 / 2} \mathrm{2}^{-1 \mathrm{~s}_{1 / 2}^{-1}>} \\
& \left|3^{-}(7.75)>=-.51\right| 1 p_{3 / 2}-0 d_{3 / 2}^{-1}>+.64\left|0 f_{7 / 2}-1 s_{1 / 2}^{-1}\right\rangle
\end{aligned}
$$

the $3^{-}$state has a significant $\mathrm{T}=1$ component from

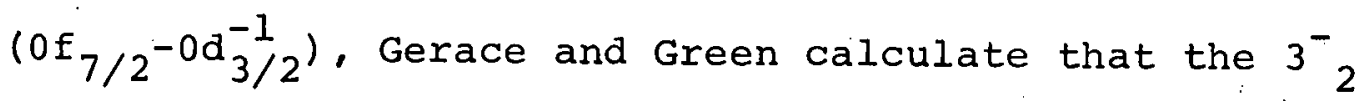
state is about 50 o deformed with major shell model configurations of $\left(\operatorname{lp}_{3 / 2}-0 d_{3 / 2}^{-1}\right)$ and $\left(0 f_{7 / 2^{-1}} s_{1 / 2}^{-1}\right)$ while the $3_{3}^{-}$is pure shell model with major configuration of $\left(0 f_{7 / 2^{-1}}^{-1} s_{1 / 2}^{-1}\right)$. Experimentally there are two $3^{-}, \mathrm{T}=0$ states near $3^{-}$, at $6.28 \mathrm{MeV}$ and $6.58 \mathrm{MeV}$. Erskine found a $\ell=1$ 
transfer to both the states. It doesn't seem that one can make a firm identification for the theoretical $3_{2}^{-}(6.56)$ with either the $6.28 \mathrm{MeV}$ or $6.58 \mathrm{MeV}$ level, but that the strength is split between both levels.

A third $3^{-}, \mathrm{T}=0$ level is seen at $7.53 \mathrm{MeV}$. Erskine assigned it to the $\left(1 \mathrm{p}_{3 / 2}-0 \mathrm{~d}_{3 / 2}^{-1}\right)$ multiplet on the basis of an $\ell=1$ transfer. Gerace and Green calculate a $3^{-}, \mathrm{T}=0$ level at $8.05 \mathrm{MeV}$ which is $36 \%$ deformed and whose major shell model configuration is a $\left(1 p_{3 / 2}-0 d_{3 / 2}^{-1}\right)$. Part of the $3^{-} 3^{-7.75)}$ strength may be contained in this level. There appears to be seen exerimentally much more $3^{-}$strength then can be accounted for in a lp-lh calculation. Most of the $3^{-}$levels in the $7 \mathrm{MeV}$ region are probably mixtures of $3 p-3 h$ states and the above two multiplets. The effect of the monopole shift is to decrease the $T=0,1$ mixing for some of the levels but to increase the mixing for other levels. This is due to the large size (18x18) of the $3^{-} \operatorname{matrix}$ (i.e. accidental degeneracies occur). The $4^{-}, T=0$ state from the $\left(0 f_{7 / 2}-i s_{1 / 2}^{-1}\right)$ multiplet is found at $9.08 \mathrm{MeV}$ with the $\mathrm{K}-\mathrm{K}$ interaction and the monopole shift. The effect of the monopole shift on the state is to remove the $\mathrm{T}=1$ componants, greatly reducing the theoretical transition rate. No $4^{-}, \mathrm{T}=0$ state has yet been identified in that region. There is however a $4^{-}, \mathrm{T}=0$ level seen at $7.11 \mathrm{MeV}$. Gerace and Green have calculated a total of three $4^{-}$states, $4_{2}^{-}(7.27)$ which is 838 deformed and $4_{3}^{-}(9.70)$ which is 
mainly $\left(0 f_{7 / 2}-1 s_{1 / 2}^{-1}\right)$. The state seen is probably the deformed state and not the shell model state.

As in the case of $0^{16}$ one notices that the sussex interaction is much more attractive for the $0^{-}$level then $\mathrm{K}-\mathrm{K}$ interaction.

The giant dipole resonance is found through the photo nuclear reactions $(\gamma, p),(\gamma, n)$ and is centered about $19 \mathrm{MeV}$. The $\mathrm{K}-\mathrm{K}$ interaction with the monopole shift predicts it to be at $18.0 \mathrm{MeV}$ and without the shift at $18.5 \mathrm{MeV}$ (see Table 4.4). 
TABLE 4.3.--Partial Summary of $\mathrm{Ca}^{40}$ for Explanation of (Maj. Comp.) See Appendix C.

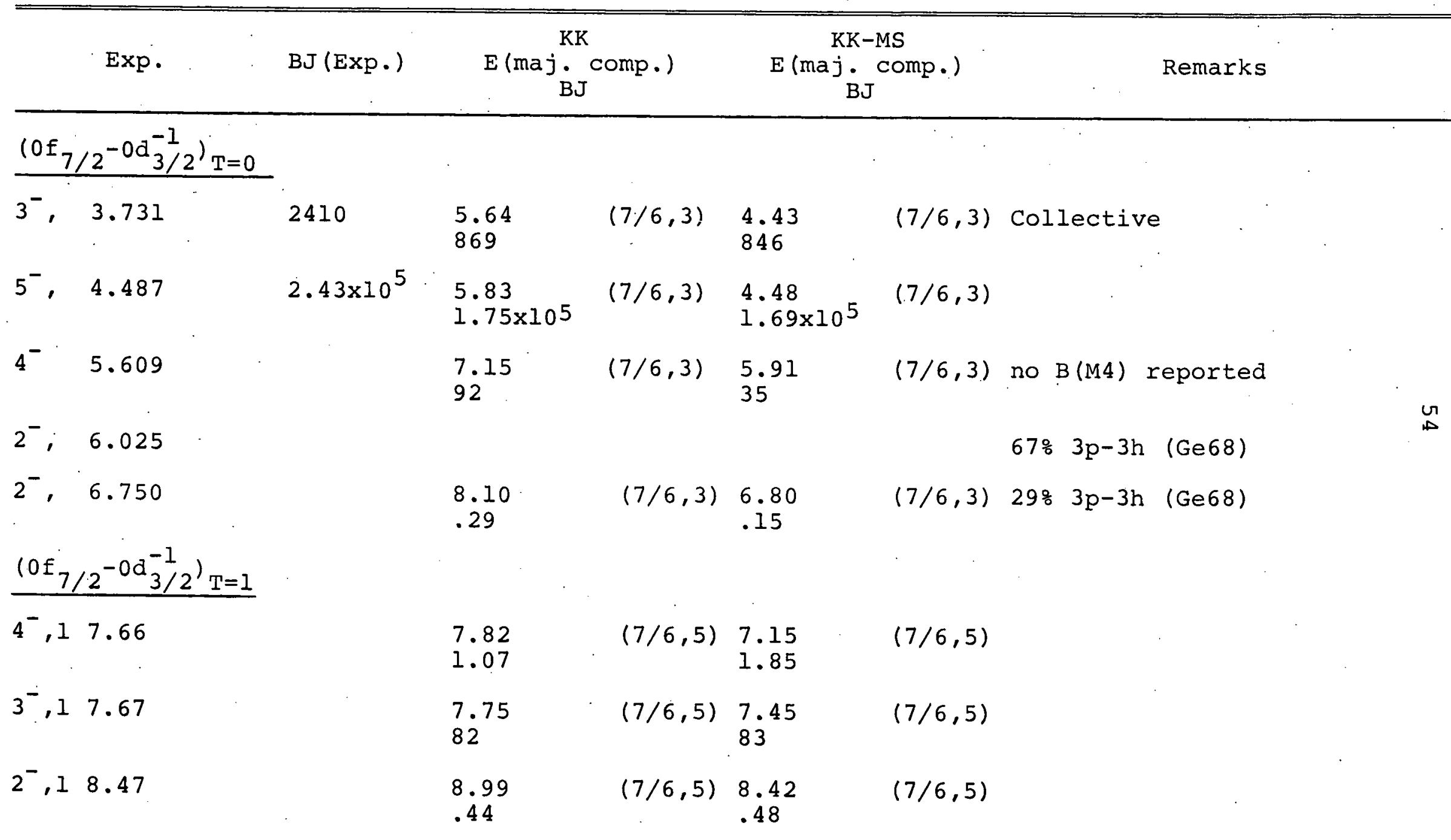


TABLE 4.3.--Continued.

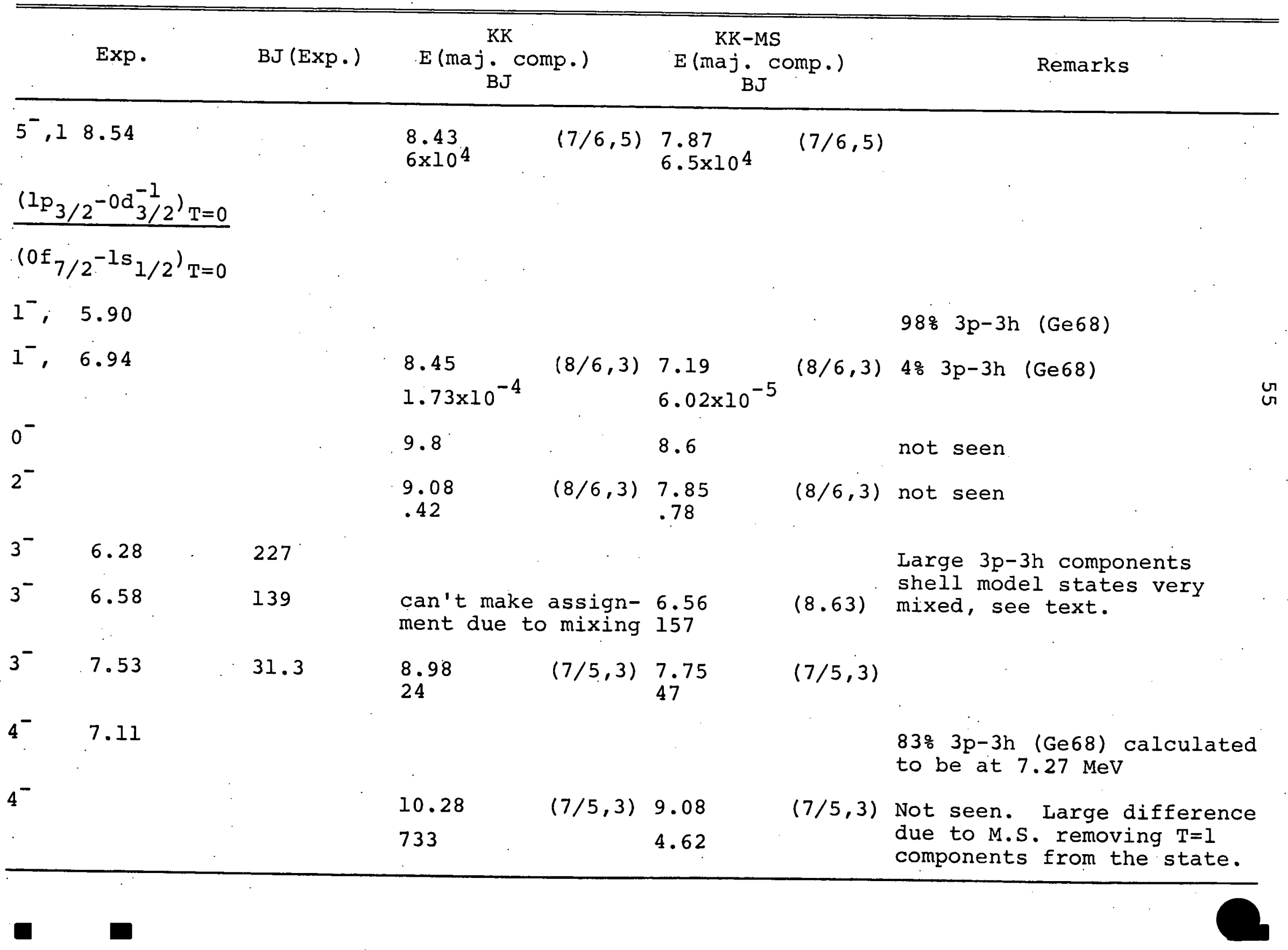


TABLE 4.4.--Ca 40 Centroid Energies, Energy Dispersions and Sum Rules for Representative Configuration of the KK Interaction with the Monopole Shift (for formulas see Appendix A).

\begin{tabular}{lccccccccc}
\hline & $1^{-} \mathrm{T}=1$ & $\begin{array}{l}1^{-}{ }_{\mathrm{T}=1} \\
.65 \mathrm{RPA}\end{array}$ & $2^{-} \mathrm{T}=1$ & $3^{-\mathrm{T}=0}$ & $\begin{array}{l}3^{-} \mathrm{T}=0 \\
.65 \mathrm{RPA}\end{array}$ & $3^{-\mathrm{T}=1}$ & $4^{-} \mathrm{T}=1$ & $2^{+} \mathrm{T}=0$ & $2^{+} \mathrm{T}=1$ \\
\hline$\overline{\mathrm{E}}$ & 18.00 & 16.47 & 14.89 & 6.80 & 7.23 & 15.15 & 13.34 & 13.98 & 20.26 \\
$\Delta \mathrm{E}$ & 1.65 & 1.40 & 3.00 & 4.48 & 3.97 & 3.46 & 2.70 & 1.17 & 1.76 \\
$\mathrm{~S}$ & 85 & 61 & 255 & 8643 & 14270 & 15868 & $1.96 \times 10^{5}$ & 583 & 701 \\
\hline
\end{tabular}

Observed $I^{-}, T=1$
$\bar{E}=19.8$
$S=44$


FIGURE $4 .--C a^{40}\left(0 f_{7 / 2}-0 d_{3 / 2}^{-1}\right)$ Multiplet.

$$
\begin{aligned}
& A=\exp . \\
& B=K K \\
& C=\text { KK-MS } \\
& D=\text { sussex } \\
& E=\text { Sussex-MS } \\
& F=.65 \text { KK-RPA MS }
\end{aligned}
$$




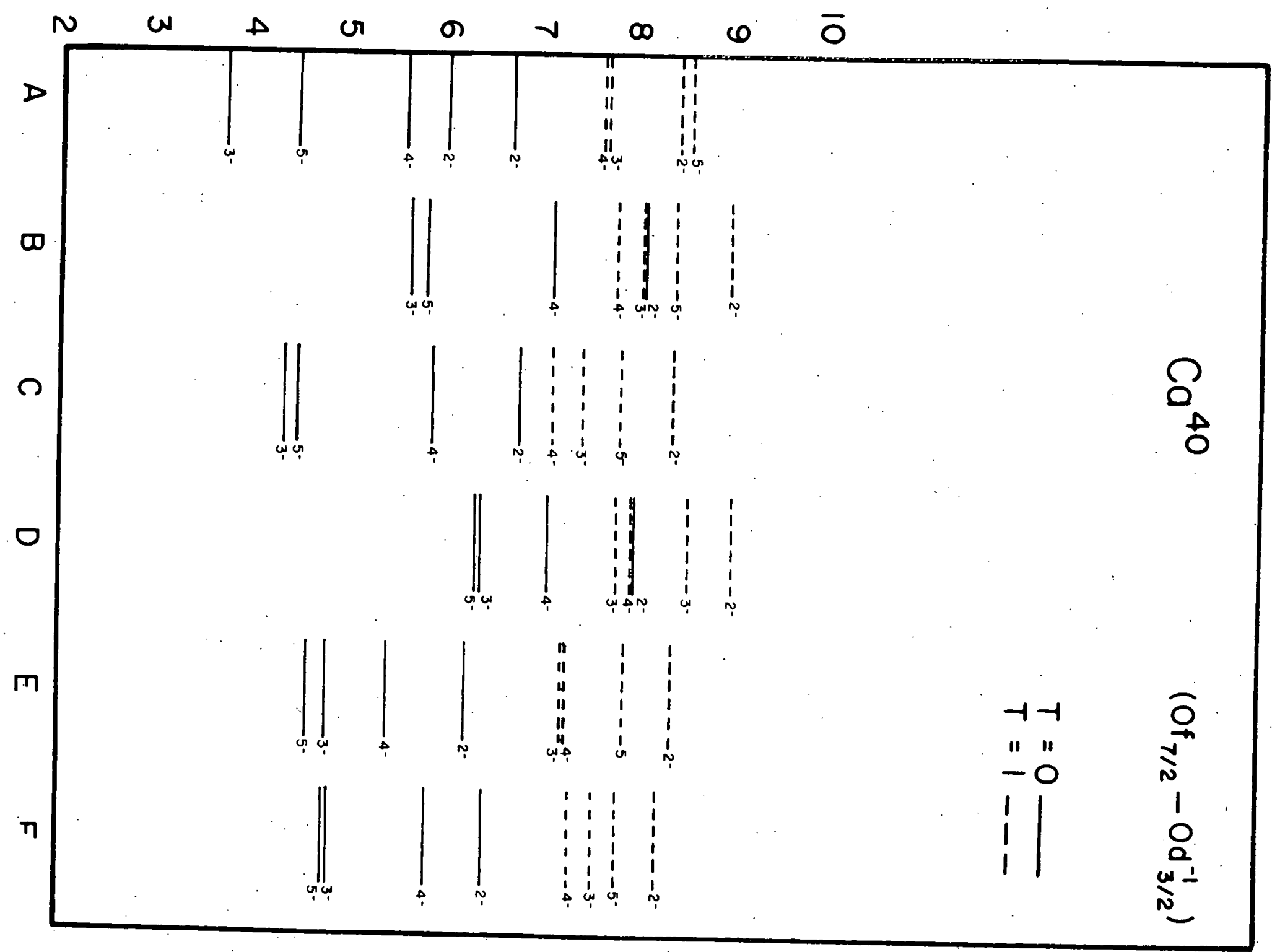


FIGURE 5.--Ca ${ }^{40}\left(1 p_{3 / 2}-0 d_{3 / 2}^{-1}\right),\left(0 f_{7 / 2}-1 s_{1 / 2}^{-1}\right)$ Multiplets.

$$
\begin{aligned}
& A=\exp . \\
& B=K K \\
& C=K K-M S \\
& D=\text { Sussex } \\
& E=\text { Sussex-MS } \\
& F=.65 \mathrm{KK}-\mathrm{RPA} . \mathrm{MS}
\end{aligned}
$$




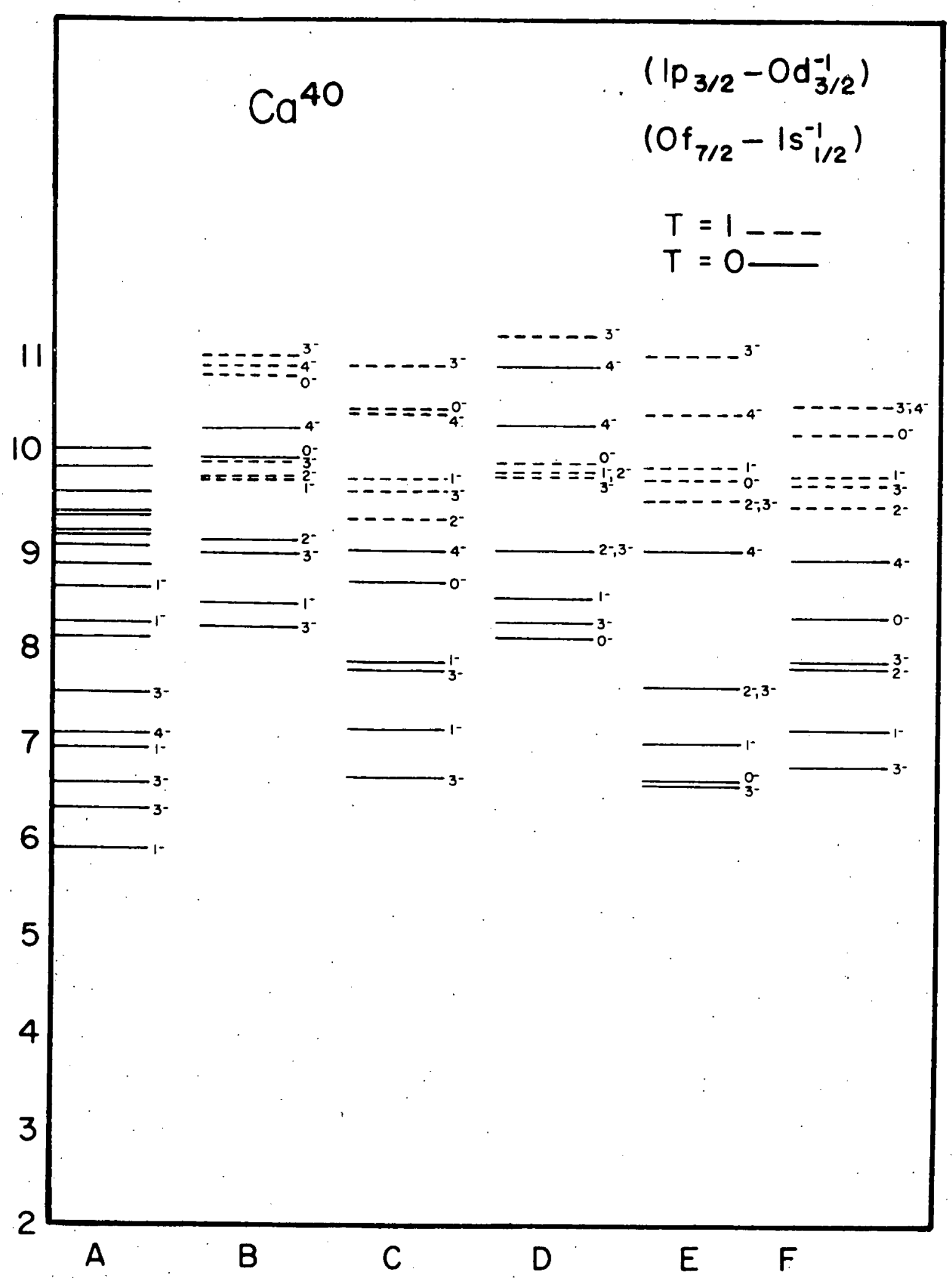




\section{CHAPTER V}

$$
\mathrm{Ca}^{48}
$$

The reader is urged to make use of Table 5.3 at the end of this section which briefly summarizes the levels of $\mathrm{Ca}^{48}$. For a more complete summary of the $\mathrm{Ca}^{48}$ calculation the reader is referred to Appendices D. 3 and E. 3 .

$\mathrm{Ca}^{48}$ differs from the previous two nuclei in that $\mathrm{N}$ is greater than $\mathrm{Z}$ and that the isospin of the ground state is no longer zero but $\mathrm{T}=4$. The experimental levels (Fig. 7) were obtained from various experiments ( $\left.p, p^{\prime}\right)$ (Pe65, Le67) and transition rates for the $2^{+}(3.830)$ $B(E 2)=45.7 \mathrm{e}^{2} \mathrm{f}^{4}, 3^{-}(4.50) \quad B(E 3)=1.05 \times 10^{3} \mathrm{e}^{2} \mathrm{f}^{6}$ and the $5^{-}(4.49) \quad \mathrm{B}(\mathrm{E} 5)=7.77 \times 10^{5} \mathrm{e}^{2} \mathrm{f}^{10}$ were obtained from C. Gruhn (Gr72). The single particle levels used were obtained from the neighboring nuclei.

TABLE 5.1.--Ca ${ }^{48}$ Single Particle Levels.

\begin{tabular}{lllllllll}
\hline \hline $\mathrm{od}_{5 / 2}$ & $\mathrm{Is}_{I / 2}$ & $\mathrm{od}_{3 / 2}$ & $0 \mathrm{f}_{7 / 2}$ & $\mathrm{lp}_{3 / 2}$ & $0 \mathrm{f}_{5 / 2}$ & $\mathrm{lp}_{1 / 2}$ & $0 g_{9 / 2}$ \\
\hline $\mathrm{P}$ & -18.73 & -15.32 & -14.95 & -9.62 & -5.20 & -3.74 & -2.75 & 0.00 \\
$\mathrm{~N}$ & -16.63 & -13.64 & -13.63 & -9.94 & -5.14 & -1.18 & -3.12 & -1.12 \\
\hline
\end{tabular}


The zero point energies of the $T=0,1$ excitations are no longer equal for $\mathrm{N} \neq \mathrm{Z}$ nuclei due to the admixture of the $2 \mathrm{p}-2 \mathrm{~h}$ configurations to the $\mathrm{T}=1$ excitations which are necessary in order to form states of good total T. Coulomb mixing was obtained in the usual way by adding off diagonal matrix elements between the $\mathrm{T}=0$ and the $\mathrm{T}=1$ matrix elements. The proton particle-hole gap was also reduced by $.3 \mathrm{MeV}$ to take into account the coulomb shift. It should be emphasized that despite the references to $\mathrm{T}=0$ and $\mathrm{T}=1$ excitations the isospin of the states calculated is equal to the ground state isospin of the nucleus, $\mathrm{T}_{0}=4, \mathrm{i} . \mathrm{e}$. only $\mathrm{T}=4$ states are calculated.

From Fig. 6 one can see that the main effect of the monopole shift is to move all the centroids down by roughly the same amount. For $\mathrm{Ca}^{48}, \frac{\varepsilon_{1}}{\mathrm{~A}}=5 / 12$.

In $\mathrm{O}^{16}$ and $\mathrm{Ca}^{40}$ the way to obtain low lying positive parity states was to use a deformed basis consiting of multiparticle-multihole states. This is not necessary in $\mathrm{Ca}^{48}$ since lowest $\mathrm{nn}^{-1}$ configuration is $\left(1 \mathrm{p}_{3 / 2}-0 \mathrm{f}_{7 / 2}^{-1}\right)$ which can yield a low lying $2^{+}$state. There is however a low lying $0^{+}$at $4.28 \mathrm{MeV}$ which can not be accounted for by $1 \mathrm{p}-1 \mathrm{~h}$ shell model excitations. As in $\mathrm{O}^{16}$ or $\mathrm{Ca}^{40}$ this is probably a $2 \mathrm{p}-2 \mathrm{~h}$ state on a deformed basis. Since this state has been excited through $\left(p, p^{\prime}\right)$ it implies that the ground state contains multiparticle-multihole excitations which could also contaminate the $2^{+}$state. 
The three low lying configurations in $\mathrm{Ca}^{48}$ have as their zero point energies lenergy before the switching on of the interaction).

TABLE 5.2.--Zero Point Energies of the 3 Low Lying Multiplets in $\mathrm{Ca}^{48}$.
$\mathrm{pp}^{-1}$
$\mathrm{pp}^{-1}$
$\left(0 f_{7 / 2}-0 d_{3 / 2}^{-1}\right)$
$5.33 \mathrm{MeV}$
$\mathrm{nn}^{-1}$
$\left(0 f_{7 / 2^{-1 s}}^{-1}{ }_{1 / 2}\right)$
$5.70 \mathrm{MeV}$
$\left(\mathrm{lp}_{7 / 2}-0 \mathrm{f}_{7 / 2}^{-1}\right)$
4. $80 \mathrm{MeV}$

Since the two $\mathrm{pp}^{-1}$ configurations are less than $.4 \mathrm{MeV}$ apart one expects a lot of mixing of the $3^{-}$and $4^{-}$ states originating from these configurations. This is in fact the case and the lowest calculated $3^{-}$state comes from the higher of the two $\mathrm{pp}^{-1}$ configurations.

The lowest excited state in $\mathrm{Ca}^{48}$ is a $2^{+}$at $3.830 \mathrm{MeV}$ with a $B(E 2)=45.7 \mathrm{e}^{2} \mathrm{f}^{4}$. The $\mathrm{nn}^{-1} \cdot\left(1 \mathrm{p}_{3 / 2}-0 \mathrm{f}_{7 / 2}^{-1}\right)$ configuration with the $\mathrm{K}-\mathrm{K}$ interaction and no monopole shift places the $2^{+}$energy at 4.52 with a $B(E 2)=.34 \mathrm{e}^{2} \mathrm{f}^{4}$ the same interaction with the monopole shift lowers the $2^{+}$energy to $3.88 \mathrm{MeV}$ however the $\mathrm{B}(\mathrm{E} 2)=.37$. Energies calculated from the sussex interaction are slightly higher and the transition rates are about one third the size. The large discrepancy between theory and experiment for the $B(E 2)$ is due to the fact that the vector is more than $99 \% \mathrm{nn}^{-1}$ which does not contribute to a B(EJ). An effective charge of I would give 
a $B(E 2)=30 e^{2} E^{4}$. More serious is what the other members of the $n n^{-1}\left(1 p_{3 / 2}-0 f_{7 / 2}^{-1}\right)$ multiplet have not been seen in the region of 4-5 MeV with the possible exception of the $4^{+}$state. Gruhn (Gr72) has reported a possible $4^{+}$at $4.62 \mathrm{MeV}$. Two other $4^{+}$states have been seen (Pe65) but at a higher energies, $6.35 \mathrm{MeV}$ and $6.65 \mathrm{MeV}$. The $3^{+}$and $5^{+}$members of the multiplet have not been reported. The sussex interaction without the monopole shift places a $4^{+}$ state with the above configuration at $4.91 \mathrm{MeV}$. The $\mathrm{K}-\mathrm{K}$ interaction places the level at $4.69 \mathrm{MeV}$ without the shift and at $4.06 \mathrm{MeV}$ with the shift.

One notes that in $\mathrm{Ca}^{40}$ there is a possibility of a $0^{+}, 2^{+}$and $4^{+}$rotational band, where there is no such candidate in $\mathrm{Ca}^{48}$ at present. Multishell calculations predict large numbers of positive parity states (MC70) which do not form a rotational band. Again very few of these states have been identified in the experimental spectrum.

One should be able to account for low lying negative parity states by mostly the $\left(0 f_{7 / 2}-0 d_{3 / 2}^{-1}\right)$ and $\left(0 f_{7 / 2}-1 s_{1 / 2}^{-1}\right)$ proton configurations which are almost degenerate. The lowest observed negative parity state is the $3^{-}$at $4.50 \mathrm{MeV}$ with an observed $B(E 3)=1.05 \times 10^{3} e^{2} f^{6}$. The calculated TDA levels with or without the monopole shift using the $K-K$ interaction are too low. For the TDA with the sussex interaction the $3^{-}$level is almost correct with no monopole shift 
and is too low with the monopole shift. All the TDA B(E3)'s are the same, $B(E 3)=1.27 \times 10^{3} \mathrm{e}^{2} \mathrm{f}^{6}$ which is slightly higher than the experimental value of $1.05 \times 10^{3} e^{2} f^{6}$. The RPA with the $K-K$ interaction and the monopole shift gives an imaginary $3^{-}$state. Reducing the $\mathrm{K}-\mathrm{K}$ interaction and monopole shift to $65 \%$ still places the $3^{-}$too low by about $.8 \mathrm{MeV}$ but at the same time it doubles the transition rate, $B(E 3)=2.16 \times 10^{3} e^{2} f^{6}$. As can be seen from Appendix D.3, most of the $3^{-}$transition strength is placed into 2 levels, the lowest $3^{-}$state which is mainly $\mathrm{pp}^{-1}$ and the highest $3^{-}$ state near $15 \mathrm{MeV}$ which is mainly a $\mathrm{T}=1$ excitation.

Due to the near degeneracy of the low $\mathrm{pp}^{-1}$ configurations the lowest $3^{-}(3.14 \mathrm{MeV})$ vector does not have as its main componant the lowest energy particle-hole configuration, $\left(0 \dot{f}_{7 / 2}-0 \mathrm{~d}_{3 / 2}^{-1}\right)$ but instead its main componant (50\%) is the

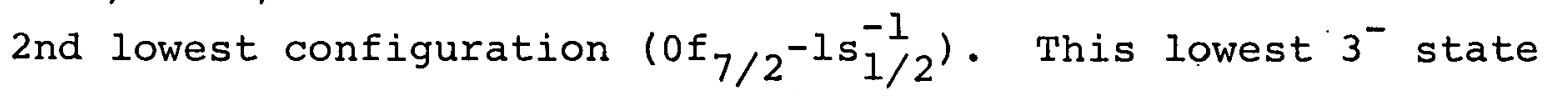
vector also has significant $\mathrm{nn}^{-1}$ (14\%) and $\mathrm{T}=0$ (23\%) excitations:

Three other $3^{-}$excitations have been observed below $8 \mathrm{MeV}$ at $5.15 \mathrm{MeV}, 5.37 \mathrm{MeV}$ and at $7.65 \mathrm{MeV}$. The $\mathrm{K}-\mathrm{K}$ interaction with the monopole shift predicts three such $3^{-}$states (Fig. 7) below $8 \mathrm{MeV}$ at. $4.79 \mathrm{MeV}$ (mainly $\mathrm{pp}^{-1}$ ), at $6.61 \mathrm{MeV}$ (significant $\mathrm{pp}^{-1}, \mathrm{nn}^{-1}, \mathrm{~T}=0$ ) and at $7.39 \mathrm{MeV}$ (significant $\left.\mathrm{pp}^{-1}, \mathrm{nn}^{-1}, \mathrm{~T}=0\right)$. All three states have $\mathrm{B}(\mathrm{E} 3)^{\prime}$ 's less than the single configuration values. 
At the present there is insufficient information (such as $\ell$ transfer), on the experimental levels to be able to match the theoretical states with the experimental states. As in $\mathrm{Ca}^{40}$ there are probably deformed contributions to the negative parity states.

The other state namely the $4^{-}$, from the $\left(0 f_{7 / 2^{-1 s_{1 / 2}}}{ }^{-1}\right)$ configuration has not been seen. This is predicted at $5.49 \mathrm{MeV}$ with the $\mathrm{K}-\mathrm{K}$ and no shift and at 4.62 with the $\mathrm{K}-\mathrm{K}$ and the monopole shift. There is however a possible candidate at $5.26 \mathrm{MeV}$.

The $5^{-}$state seen at $5.723 \mathrm{MeV}$ has a theoretical $B(E 5)=2.9 \times 10^{5} e^{2} f^{10}$ which is approximately four times bigger than the reported experimental value of $7.74 \times 10^{4} \mathrm{e}^{2} \mathrm{f}^{10}$. The calculated $5^{-}$level even without the shift is too low. One possible reason for the large calculated $B(E 5)$ is that the wavefunction is most $\mathrm{pp}^{-1},\left(0 \mathrm{f}_{7 / 2}-0 \mathrm{p}_{3 / 2}^{-1}\right)$ if however the level was slightly higher it would mix more with the $\mathrm{nn}^{-1}$ excitation and the $\mathrm{pp}^{-1}$ strength would then be weakened. In summary there are not too many conclusions one can draw about $\mathrm{Ca}^{48}$. The predicted multiplets are not observed experimentally. The theoretical results are very similar to those of Ripka who used a force fitted to the $3^{-}$and $5^{-}$states. The monopole shift has virtually no effect on transition rates or on the composition of state vectors (Appendices D.3, E.3). While there is not too much experimental evidence, there is a definite discrepancy between 
experiment and this and other simple theoretical calculations. The discrepency is that experimentally a $2^{+}$level is the lowest state with the $3^{-}$state above it. The $3^{-}$state is. also less collective then the $3^{-}$state in $\mathrm{Ca}^{40}$. The theory predicts both the $3^{-}$and $5^{-}$states too low in energy and too collective, with the $3^{-}$below the $2^{+}$. The $2^{+}$state is predicted to be too high and almost degenerate with the $4^{+}$, where experimentally the $2^{+}$and $4^{+}$are well separated, the tentative assignment for the $4^{+}$being accepted. Though there is no experimental evidence it seems unlikely that the dipole excitation lies at the predicted value of $14 \mathrm{MeV}$, below that observed in the strontium region (16.5 MeV) and far below that observed in $\mathrm{Ca}^{40}$ (19 MeV). 

TABLE 5.3.--Partial Summary of $\mathrm{Ca}^{48}$ for Explanation of (Maj Comp See Appendices

\begin{tabular}{|c|c|c|c|c|c|c|c|}
\hline Exp & & $B J(E x p)$ & $E$ (maj $_{B}$ & $\begin{array}{l}\text { comp) } \\
J J\end{array}$ & $\begin{array}{l}\mathrm{KK}-\mathrm{MS} \\
\mathrm{(Maj} \\
\quad \mathrm{BJ}\end{array}$ & comp) & Remarks \\
\hline $2^{+}$ & 3.83 & 45.7 & 4.51 & $(8 / 7,2)$ & 3.88 & $(8 / 7,2)$ & $\begin{array}{l}90 \% \text { neutron configuration. } \\
\text { Effective charge of } 1 \text { gives } \\
\text { BE } 2 \sim 30 \text {. }\end{array}$ \\
\hline $0^{+}$ & 4.28 & & & & & & deformed, not seen \\
\hline $3^{-}$ & 4.50 & 1050 & $\begin{array}{l}3.94 \\
1270\end{array}$ & $(7 / 5,1)$ & $\begin{array}{l}3.141 \\
1280\end{array}$ & $(7 / 5,1)$ & collective \\
\hline$\left(4^{+}\right)$ & 4.62 & & 4.69 & & 4.09 & & $\begin{array}{l}\text { spin-parity identification } \\
\text { not found }\end{array}$ \\
\hline $3^{-}$ & 5.15 & & 5.62 & $(7 / 6,1)$ & 4.79 & $(7 / 6,1)$ & no information to be able \\
\hline $3^{-}$ & 5.37 & . & .23 & & 3.2 & & to make identification. \\
\hline $\begin{array}{l}\left(4^{-}\right) \\
0^{+}\end{array}$ & $\begin{array}{l}5.26 \\
5.46\end{array}$ & & 5.49 & & 4.62 & & $\begin{array}{l}\text { spin-parity identification } \\
\text { not found } \\
\text { probably deformed, not seen }\end{array}$ \\
\hline $5^{-}$ & 5.72. & $7.7 \times 10^{4}$ & $\begin{array}{l}5.04 \\
2.91 \times 10^{5}\end{array}$ & $(7 / 6,1)$ & $\begin{array}{l}4.16 \\
2.92 \times 10^{5}\end{array}$ & $(7 / 6,1)$ & \\
\hline$\left(2^{+}\right)$ & 6.10 & & & & & & probably deformed, not seen \\
\hline $3^{-}$ & 7.65 & & $\begin{array}{l}.836 \\
.096\end{array}$ & $(8 / 6,3)$ & $\begin{array}{l}7.39 \\
9.05\end{array}$ & $(8 / 6,3)$ & $\mathrm{T}=0$ excitation \\
\hline
\end{tabular}


TABLE 5.4.--Ca ${ }^{48}$ Centroid Energies, Energy Dispersions and Sum Rules for Representative $T_{<}$Configurations of the $\mathrm{K}-\mathrm{K}$ Interaction with the Monopole Shift (for Formulas See Appendix A).

\begin{tabular}{lccccccccc}
\hline & $1^{-}$ & $2^{-}$ & $3^{-}$ & $\begin{array}{c}3^{-} \\
.65 \mathrm{RPA}\end{array}$ & $4^{-}$ & $2^{+}$ & $4^{+}$ & $6^{+}$ \\
\hline$\overline{\mathrm{E}}$ & 14.08 & 10.62 & 7.10 & 6.40 & 9.74 & 16.81 & 14.86 & 14.49 \\
$\Delta \mathrm{E}$ & 1.53 & 2.59 & 4.68 & 3.87 & 2.54 & 2.95 & 2.50 & 2.15 \\
$\mathrm{~S}$ & 67 & 155 & $1.7 \times 10^{4}$ & $2.2 \times 10^{4}$ & $9.5 \times 10^{4}$ & 886 & $3.9 \times 10^{5}$ & $1.6 \times 10^{8}$ \\
\hline
\end{tabular}

Observed $1^{-}$ 


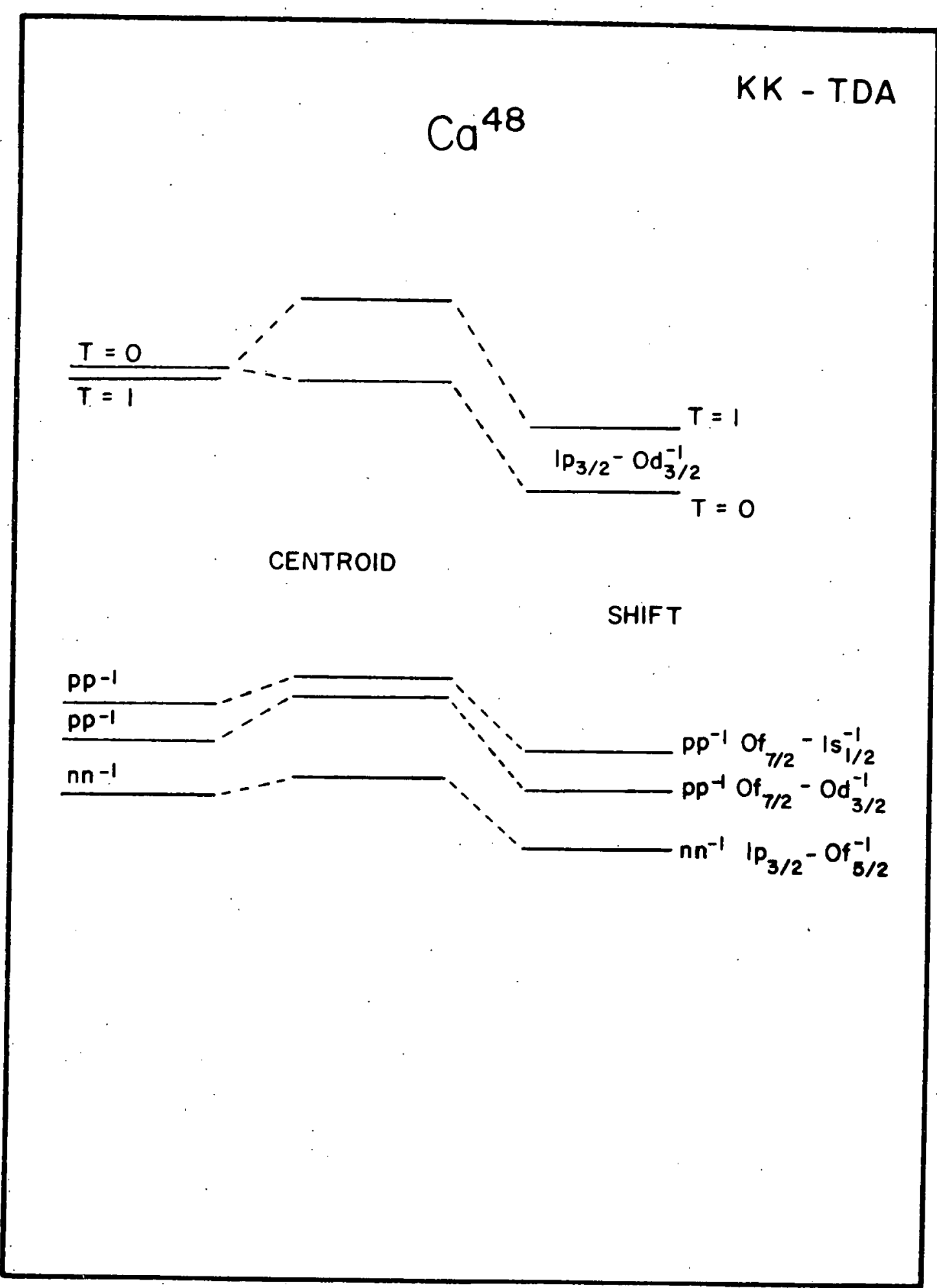

FIGURE 6.--Ca ${ }^{48}$ Monopole Shifts. 
FIGURE 7.--Ca ${ }^{48}$ Energy Levels.

$$
\begin{aligned}
& A=\exp . \\
& B=K K \\
& C=K K-M S \\
& D=\text { Sussex } \\
& E=\text { Sussex-MS } \\
& F=65 \% \mathrm{KK}-\mathrm{MS} \quad \mathrm{RPA}
\end{aligned}
$$




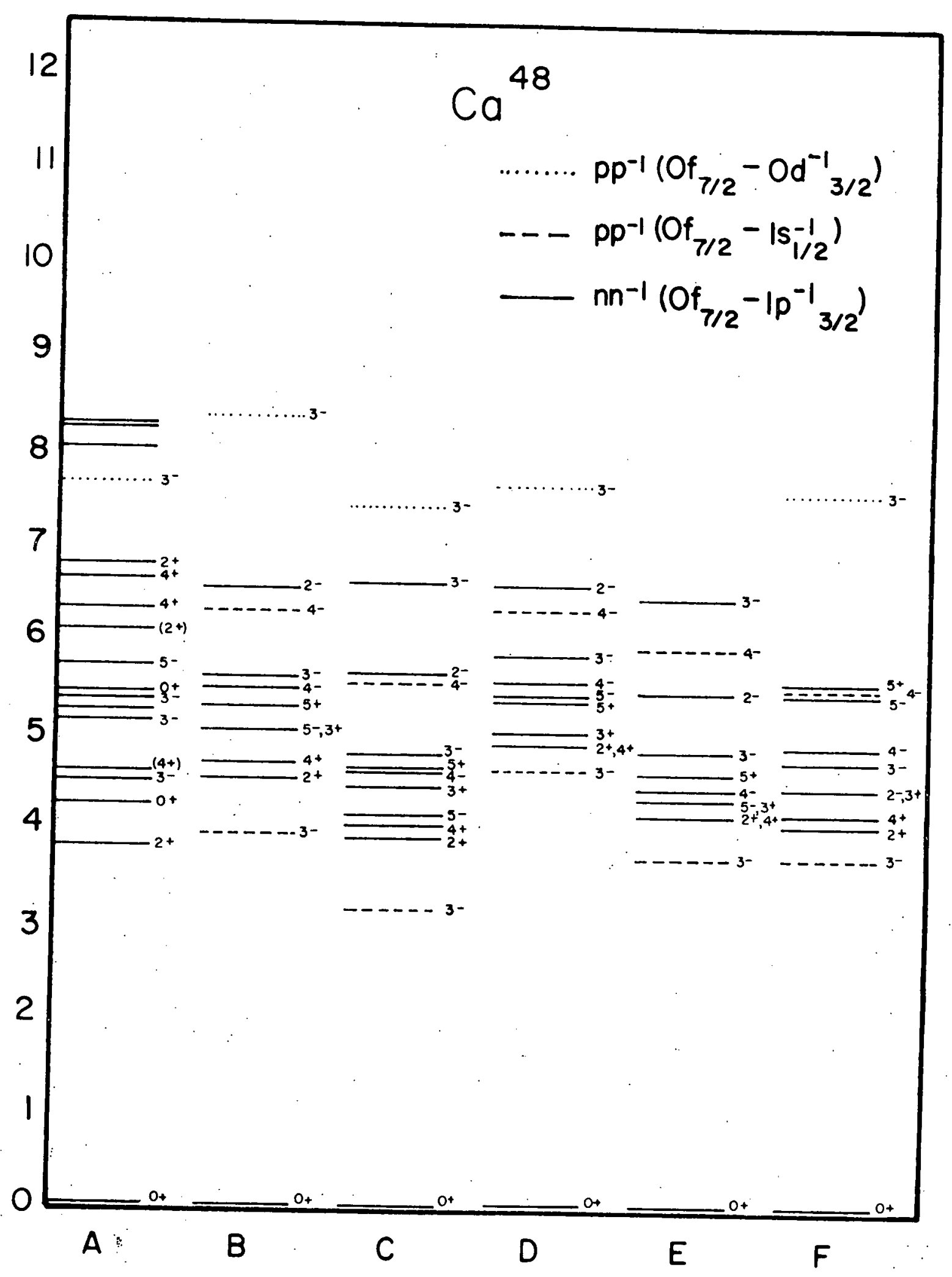




\section{CHAPTER VI}

$$
\mathrm{Sr}^{88}
$$

$$
\mathrm{Sr}^{88} \text { is similar to } \mathrm{Ca}^{48} \text { in that there is a neutron }
$$

excess. In this case both the $0 g_{9 / 2}$ and $l p_{1 / 2}$ levels are filled for neutrons and empty for protons. Several experiments (Go70a) have been performed to study the levels of $\mathrm{Sr}^{88}$. Proton $\mathrm{lp}-\mathrm{lh}$ states incorporating a $1 \mathrm{p}_{1 / 2}$ proton have been observed in the $\mathrm{Y}^{89}\left(\mathrm{He}^{3}, \mathrm{~d}\right) \mathrm{Sr}^{88}$ reaction and the $Y^{89}(t, \alpha) s^{88}$ reaction. Neutron $l p-l h$ states based on a $09_{9 / 2}$ hole have been studied by the $\mathrm{sr}^{87}(\mathrm{~d}, \mathrm{p}) \mathrm{Sr}^{88}$ reaction. The neutron $2 \mathrm{p}-2 \mathrm{~h}$ and $1 \mathrm{p}-1 \mathrm{~h}$ components of the levels have been studied by the $\operatorname{sr}^{86}(t, p) s^{88}$ reaction. Since the $\mathrm{sr}^{86}$ target is largely a mixture of the neutron components $\left.\log _{9 / 2}\right)^{-2} \cdot\left(\operatorname{lp}_{3 / 2}\right)^{-2}$, etc. the $t, p$ reaction populates states which have neutron components $\left(\operatorname{ld}_{5 / 2}\right)^{2}\left(\lg _{9 / 2}\right)^{-2}$, etc. The collective properties of some of the levels have been investigated by inelastic scattering of protons, deuterons, alphas and electrons. The experimentaliy observed levels along with the present calculation are in Fig. 8 . The results from the $\mathrm{Y}^{89}\left(\mathrm{He}^{3}, \mathrm{~d}\right) \mathrm{Sr}^{88}$ reaction and the $\mathrm{Y}^{89}(t, \alpha) \mathrm{Sr}^{88}$ reaction have shown that the low lying 
states are mostly proton-proton hole. The single particle energies used were again obtained from neighboring nuclei. The neutron particle-hole gap is seen to be $4.71 \mathrm{MeV}$ while the proton particle-hole gap after deducting the $.3 \mathrm{MeV}$ due to the coulomb shift is $3.22 \mathrm{MeV}$. This leads one to expect, as has been confirmed experimentally, that the low lying levels in $\mathrm{Sr}^{88}$ would have mainly proton-proton hole components. The value of the oscillator parameter used was $\hbar \omega=9.0 \mathrm{MeV}$.

The size parameter for the monopole shift $\varepsilon_{1 / A}=.23$. As in the other closed shell nuclei a low lying $0^{+}$level is observed. Again there is no explanation for this state in terms of $1 p-1 h$ excitations and one must go to multiparticlemultihole states for the explanation. These multiparticlemultihole states can also contaminate the other positive parity states.

The lowest observed state in $\mathrm{Sr}^{88}$ is the $2^{+}$at $1.84 \mathrm{MeV}$ with a $\mathrm{B}(\mathrm{E} 2)=199 \mathrm{e}^{2} \mathrm{f}^{4}$. The calculated $2_{1}^{+}$is too high in energy for the $\mathrm{K}-\mathrm{K}$ interaction. In the TDA the monopole shift lowers the energy from $2.76 \mathrm{MeV}$ to $2.26 \mathrm{MeV}$. The transition rate changes very little, $B(E 2)=62 e^{2} f^{4}$ and is about twice the single configuration value. The $\mathrm{RPA}$ increases the transition rate to $\mathrm{B}(\mathrm{E} 2)=83 \mathrm{e}^{2} \mathrm{f}^{4}$. A calculation of $\mathrm{Sr}^{88}$ by. T. A. Hughes (Hu69) using a two proton hole basis (i.e. the core would be $\mathrm{zr}^{90}$ ) places the $2_{1}^{+}$close to the right energy, with a $B(E 2)=66 e^{2} f^{4}$. So while the two hole basis does slightly better for the 
TABLE 6.1.---Sr ${ }^{88}$ Single Particle Levels.

\begin{tabular}{lllllllllll}
\hline \hline & $0 f_{7 / 2}$ & $0 f_{5 / 2}$ & ${ } \mathrm{lp}_{3 / 2}$ & $\mathrm{lp}_{1 / 2}$ & $0 \mathrm{~g}_{9 / 2}$ & $1 \mathrm{~d}_{5 / 2}$ & $\mathrm{ls}_{1 / 2}$ & $1 \mathrm{~d}_{3 / 2}$ & $0 \mathrm{~g}_{7 / 2}$ & $0 \mathrm{~h}_{11 / 2}$ \\
\hline $\mathrm{P}$ & -13.25 & -11.00 & -10.59 & -7.07 & -6.17 & -2.69 & -1.65 & -0.67 & 0.01 & 0.34 \\
$\mathrm{~N}$ & -15.75 & -13.48 & -13.12 & -11.69 & -11.10 & -6.39 & -5.36 & -4.39 & -3.72 & -3.39 \\
\hline
\end{tabular}


energy of the state it does not improve the transition rate. The cross section in the $\mathrm{Sr}^{86}(t, \mathrm{p}) \mathrm{Sr}^{88}$ reaction is much smaller for $2_{1}^{+}$then the cross section for the higher lying $2^{+}$states which would indicate a very small $2 \mathrm{p}-2 \mathrm{~h}$ neutron component to the state. From the $\mathrm{Y}^{89}\left(\mathrm{~d}, \mathrm{He}^{3}\right) \mathrm{Sr}^{88}$ reaction Kavalaske (Ka67) et al. concluded that the $\left(I p_{1 / 2}-1 p_{3 / 2}^{-1}\right)$ and $\left(l p_{1 / 2}-0 f_{5 / 2}^{-1}\right)$ proton configuration. made up $80 \%$ of the $2_{1}^{+}$state. The present calculation shows that these two configurations form $83 \%$ of the state when the monopole shift is used and $96 \%$ of the state without the monopole shift. Most of the $B(E 2)$ strength is predicted to be concentrated in the lowest $2^{+}$state $(2.26 \mathrm{MeV})$ and in the highest $2^{+}$state at $14.8 \mathrm{MeV}$. The $2_{2}^{+}$is seen experimentally at $3.22 \mathrm{MeV}$, the $\mathrm{K}-\mathrm{K}$ interaction with and without the shift yields energies of $3.55 \mathrm{MeV}$ and $3.04 \mathrm{MeV}$, so the monopole shift moves the $2_{2}^{+}$state down too far but still closer than before. The $\mathrm{B}(\mathrm{E} 2)=1.0 \mathrm{e}^{2} \mathrm{f}^{4}$ without the monopole shift and $.037 \mathrm{e}^{2} \mathrm{f}^{4}$ with the monopole shift. The experimental $B(E 2)$ obtained from inelastic scattering $\left(\alpha, \alpha^{\prime}\right)$ is $.08 \mathrm{e}^{2} \mathrm{f}^{4}$. The present calculation with the monopole shift indicates that the state is $90 \% \mathrm{pp}^{-1}$. This $2_{2}^{+}$ state is also observed to have a small cross section $(\operatorname{Ra} 70)$ in $\operatorname{Sr}^{86}(t, p) \mathrm{Sr}^{88}$. 
The next calculated $2_{3}^{+}$with the $\mathrm{K}-\mathrm{K}$ interaction and the monopole shift is at $4.55 \mathrm{MeV}$ and is $79 \%$ neutronneutron hole with the main component $\left(1 d_{5 / 2}-0 g_{9 / 2}^{-1}\right)$. The higher $2^{+}$states between $4 \mathrm{MeV}$ and $5 \mathrm{MeV}$ all have significant cross sections in the t,p reaction. Some of these states. are possibly deformed since a simple lp-ih shell model calculation can't generate the number of states required. The two proton hole calculations by Hughes yields one more level but this is still about 6 or 7 levels short.

The $\mathrm{K}-\mathrm{K}$ interaction with the monopole shift yields levels $1_{1}^{+}(3.39), 3_{1}^{+}(3.56), 33_{2}^{-}(3.05)$, and $6_{1}^{+}(4.32)$. These levels seem to correspond to the experimental levels $1^{+}(3.48), 3^{+}(3.64), 3^{-}(3.99), 6^{+}(4.41)$. In addition there is a $4^{+}$doublet seen at $4.23 \mathrm{MeV}$ and $4.30 \mathrm{MeV}$. The $\mathrm{K}-\mathrm{K}$ interaction with shift puts the $4_{1}^{+}$at $4.07 \mathrm{MeV}$ which could be split by coupling to a deformed state.

The lp-lh shell model breaks down in other ways besides not being able to deduce the correct number of $2^{+}$states. The lp-lh. model predicts a low lying $5^{-}$state at $3.36 \mathrm{MeV}$ ( $\mathrm{K}-\mathrm{K}$ interaction with monopole shift) whose major component is a $\left(\log _{9 / 2}-1 p_{3 / 2}^{-1}\right)$ proton-proton hole. This state as of now has not been seen. Since it should be a proton configuration the state should be seen in a $\mathrm{Rb}^{87}\left(\mathrm{He}^{3}, \mathrm{~d}\right) \mathrm{Sr}^{88}$ reaction. This state carries most of the E5 transition strength, its $B(E 5)$ is an order of magnitude greater than the single configuration $B(E 5)$. The Ip-lh 
model also predicts a $5_{2}^{-}(4.00)$ and $7_{1}^{-}(3.84)$ both of which are mainly proton configuration and are not seen: In the lp-lh model the $3^{-}$state comes too low in energy. The $\mathrm{K}-\mathrm{K}$ interaction with monopole shift places it about $.75 \mathrm{MeV}$ too low. The RPA makes it imaginary, by reducing the strength of the $\mathrm{K}-\mathrm{K}$ interaction to $65 \%$ of its strength the RPA with the monopole shift places the state at $2.10 \mathrm{MeV}$. The sussex interaction without the monopole shift in the TDA places the state at the correct energy but no real meaning can be attributed to this. The $3^{-}$state carries most of the $3^{-}$transition rate $B(E 3)(e x p)=8960 e^{2} f^{6}$. $B(E 3)(K-K)=4850 e^{2} f^{6}$ and $B(E 3)=12500 e^{2} f^{6}$ for the $65 \% \mathrm{~K}-K$ interaction in the RPA.

In summary the calculations do predict a collective $3^{-}$ and a fairly collective $2^{+}$state corresponding roughly to experiment along with a set of positive parity levels in the region 3.50 to $5.50 \mathrm{MeV}$. However there are many extra positive parity states observed which are not accounted for by simple particle-hole calculations. The theory also predicts a collective $5^{-}$state which is not seen and as in $\mathrm{Ca}^{48}$ the $2^{+}$and $3^{-}$states are inverted. The dipole centroid is much too low at $12.3 \mathrm{MeV}$ as compared with $16.5 \mathrm{MeV}$ experimentally. 

TABLE 6.2.--Partial summary of $\mathrm{Sr}^{88}$ for Explanation of (Maj. Comp. See Appendices
C and D).

\begin{tabular}{|c|c|c|c|c|c|c|c|}
\hline \multicolumn{2}{|c|}{ Exp. } & \multirow{2}{*}{$\frac{B J(\operatorname{Exp})}{199}$} & \multicolumn{2}{|c|}{$E\left(\mathrm{maj}_{\mathrm{BJ}}^{\mathrm{KK}} \mathrm{comp}\right)$} & \multicolumn{2}{|c|}{$\begin{array}{c}\mathrm{KK}-\mathrm{MS} \\
\mathrm{E}(\mathrm{maj} \cdot \mathrm{comp})\end{array}$} & Remarks \\
\hline $2^{+}$ & 1.836 & & $\begin{array}{l}2.76 \\
62\end{array}$ & $(10 / 9,1)$ & $\begin{array}{l}2.26 \\
63\end{array}$ & $(10 / 8,1)$ & $\begin{array}{l}\text { Too high might be pushed } \\
\text { down by } 2 \mathrm{p}-2 \mathrm{~h} \text { contribu- } \\
\text { tion, see } \mathrm{Ca} 48\end{array}$ \\
\hline $3^{-}$ & 2.73 & 8960 & $\begin{array}{l}2.29 \\
4850\end{array}$ & $\begin{array}{l}(11 / 8,1) \\
4870\end{array}$ & 1.86 & $(11 / 8,1)$ & collective \\
\hline $0^{+}$ & 3.15 & & & & & & probably deformed \\
\hline $2^{+}$ & 3.22 & .08 & $\begin{array}{l}3.55 \\
1.02\end{array}$ & $(10 / 8,1)$ & $\begin{array}{r}3.03 \\
.04\end{array}$ & $(10 / 8,1)$ & \\
\hline $1^{+}$ & 3.49 & & $\begin{array}{l}4.025 \\
.024\end{array}$ & $(10,8,1)$ & $\begin{array}{l}3.39 \\
.024\end{array}$ & $(10 / 8,1)$ & \\
\hline $3^{+}$ & 3.64 & & $\begin{array}{l}3.95 \\
.040\end{array}$ & $(10 / 9,1)$ & $\begin{array}{l}3.55 \\
.040\end{array}$ & $(10 / 9,1)$ & \\
\hline $4^{+}, 3^{-}$ & -3.99 & & $\begin{array}{l}4.51\left(3^{-}\right) \\
4.89\end{array}$ & $(11 / 9,1)$ & $\begin{array}{l}4.047\left(3^{-}\right) \\
1.25\end{array}$ & $(11 / 9,1)$ & \\
\hline $4^{+}$ & 4.23 & & & & & & $\begin{array}{l}\text { can't identify as to parti- } \\
\text { cular } 4^{+} \text {state theory does }\end{array}$ \\
\hline $4^{+}$ & 4.30 & & $\begin{array}{l}4.44 \\
8.13 \times 10^{3}\end{array}$ & $(12 / 11,2)$ & $\begin{array}{l}4.08 \\
9.24 \times 10^{2}\end{array}$ & $(12 / 11,2)$ & $\begin{array}{l}\text { not predict enough } 4^{+} \\
\text {states, possibility of } \\
\text { deformed state }\end{array}$ \\
\hline $2^{+} 6^{+}$ & 4.41 & & $\begin{array}{l}4.67\left(6^{+}\right) \\
1.6 \times 10^{5}\end{array}$ & $(11 / 11,2)$ & $\begin{array}{l}4.316\left(6^{+}\right) \\
1.8 \times 10^{5}\end{array}$ & $(12 / 11,2)$ & \\
\hline
\end{tabular}


TABLE 6.2.--Continued.

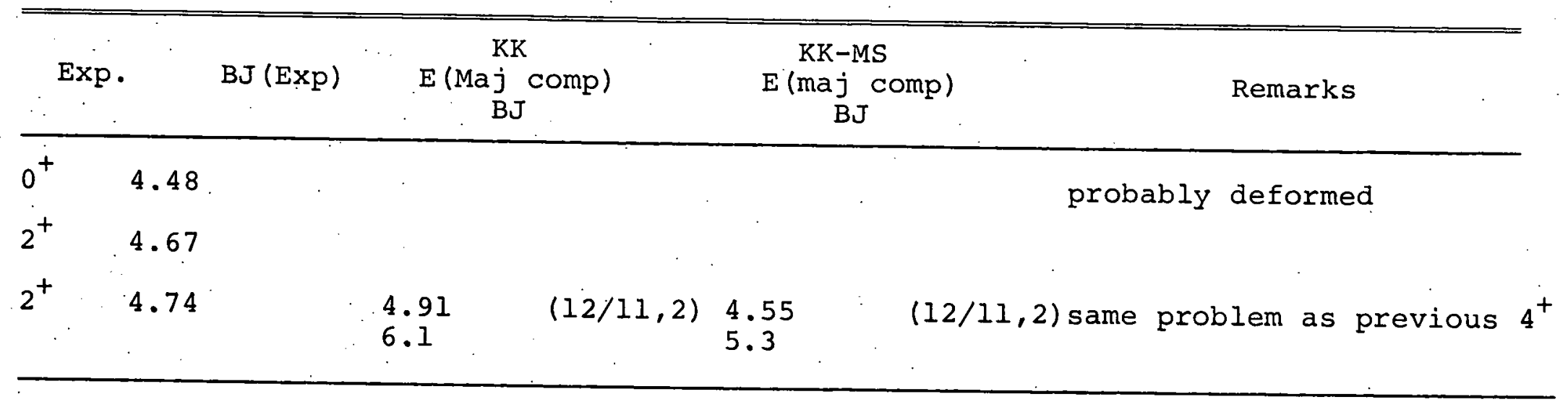


TABLE 6.3.--Sr ${ }^{88}$ Centroid Energies, Energy Dispersions and Sum Rules for Representative $\mathrm{T}_{<}$Configurations of the $\mathrm{K}-\mathrm{K}$ Interaction with Monopole Shift (for Formulas See Appendix A).

\begin{tabular}{lllllll}
\hline & $1^{-}$ & $2^{-}$ & $3^{-}$ & $\begin{array}{c}3^{-} \\
.65 \mathrm{RPA}\end{array}$ & $4^{-}$ & $2^{+}$ \\
\hline$\overline{\mathrm{E}}$ & 12.27 & 9.03 & 5.66 & 8.16 & 8.65 & 9.31 \\
$\Delta \mathrm{E}$ & 1.22 & 2.41 & 4.12 & 3.44 & 2.51 & 5.38 \\
$\mathrm{~S}$ & 122 & 272 & $5.4 \times 10^{4}$ & $5.8 \times 10^{4}$ & $4.0 \times 10^{5}$ & 1834 \\
\hline
\end{tabular}

Observed $1^{-}\left(\right.$in $\left.\mathrm{Zr}^{90}\right)$

$$
\begin{aligned}
& \overline{\mathrm{E}}=16.5 \mathrm{MeV} \\
& \mathrm{S} \approx 100 \mathrm{MeV} \mathrm{f}
\end{aligned}
$$


FIGURE 8.--Sr ${ }^{88}$ Energy Levels.

$$
\begin{aligned}
& A=\exp \\
& B=K K-T D A \\
& C=K K-T P A \quad M S \\
& D=65 \% \text { KK-RPA MS } \\
& E=\text { Sussex-TDA } \\
& F=\text { Hughes } 2 p^{-1} .
\end{aligned}
$$




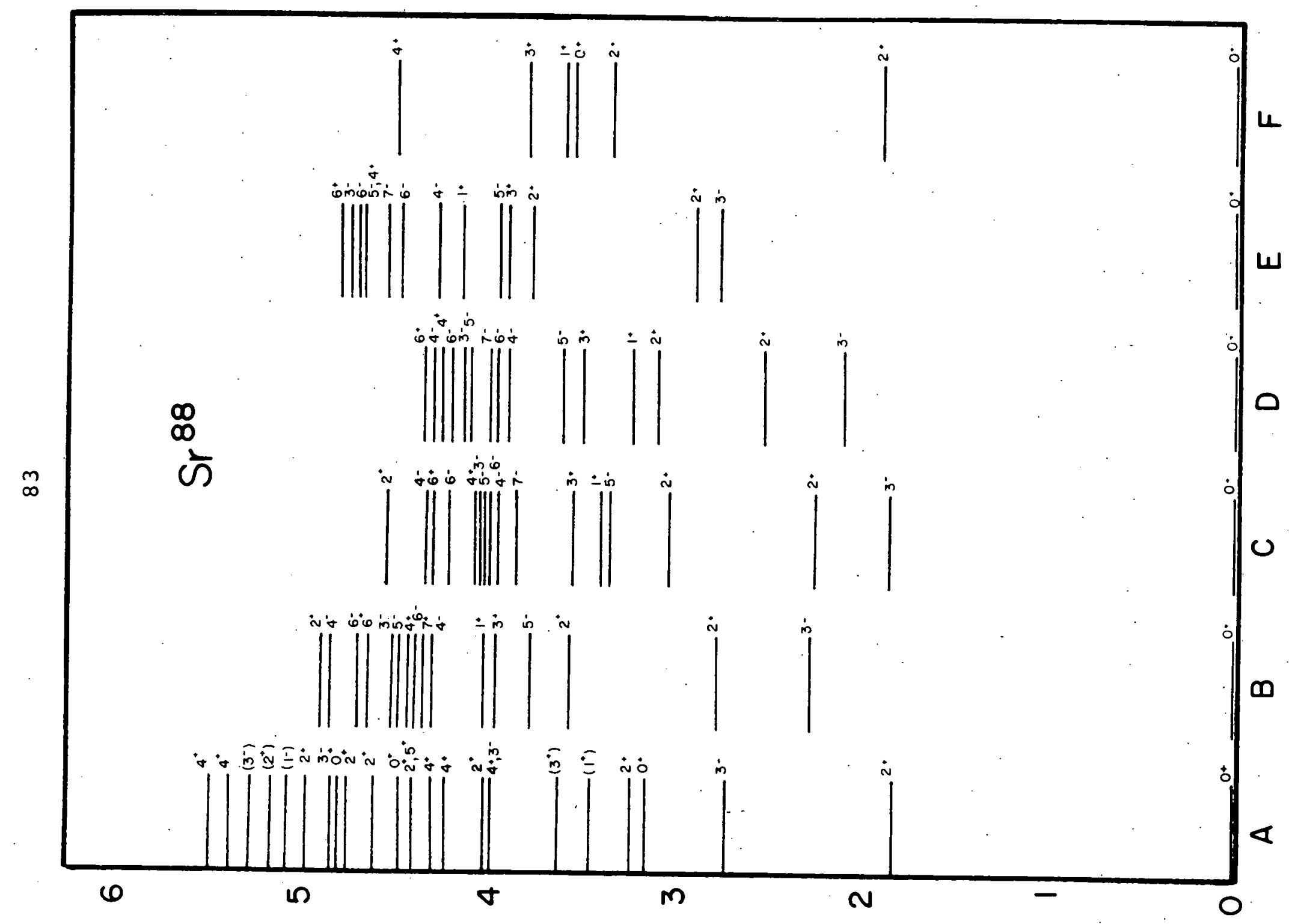


CHAPTER VII

SUMMARY AND CONCLUSIONS

It is felt that the results of this work demonstrate a number of things. First that the corrections provided by the monopole term of the particle-hole interaction are inadequate. This inadequacy is reflected in that the calculated centroid energies of the identified multiplets are too high in energy and that for the two $\mathrm{N}=\mathrm{Z}$ nuclei, $\mathrm{O}^{16}$ and $\mathrm{Ca}^{40}$ the $\mathrm{T}=0,1$ splitting is too small.

The inclusion of the monopole shift in the calculation significantly improves the position of the centroids and of the $\mathrm{T}=0, \mathrm{I}$ splitting for the $\mathrm{N}=\mathrm{Z}$ nuclei. The improvement reflects the $1 / \mathrm{A}$ dependence of the isovector part of the monopole term.

The relative $\mathrm{T}=0,1 \mathrm{mixing}$ of the vectors in $\mathrm{O}^{16}$ has also been improved. The B(EI)'s which are particularly sensitive to the $T=1$ component, since the $T=0$ component does not contribute to the transition rate; are also significantly improved, at times by an order of magnitude. The B(M2) is from all bit the lowest $2^{-}$state are within 
an order of magnitude of the experimental transition rate. In addition both the giant dipole and quadrupole states are correctly predicted in energy when the monopole shift is used.

In $\mathrm{Ca}^{40}$ only the transition rates from the lowest $3^{-}$and $5^{-}$levels are known. There is however a net improvement of both the $T=0,1$ splitting and of the centroid energies for the lowest multiplets. The giant dipole state is however placed about $\mathrm{I} \mathrm{MeV} \mathrm{too} \mathrm{low} \mathrm{by} \mathrm{the} \mathrm{monopole}$ shift. There is a good correspondence between the states calculated with the monopole shift and the shell model states from the deformed basis calculation of Gerace and Green. It should be emphasized that this however is a comparison between mathematical models.

Much less is known about structure of the two $\mathrm{N} \neq \mathrm{Z}$ nuclei $\mathrm{Ca}^{48}$ and $\mathrm{Sr}^{88}$. The only transitions rates reported are the $B(E 3)$ 's from the lowest $3^{-}$state. In both cases the use of the monopole shift does little to improve the agreement between the observed and calculated levels. It also has virtually no effect on either the transition rates or on the composition of the state vectors of these two nuclei. $\mathrm{O}^{16}$ and $\mathrm{Ca}^{40}$ have proved to be a much better test of the monopole shift. 
The two interactions used, the Sussex and the $\mathrm{K}-\mathrm{K}$, are with one exception similar in behavior. The exception is the $0^{-}$states in $\mathrm{O}^{16}$ and $\mathrm{Ca}^{40}$, where the $\mathrm{K}-\mathrm{K}$ and the Sussex matrix elements have opposite sign due to the large attractive nature of the $\mathrm{p}$ and $\mathrm{d}$ wave contributions in the Sussex matrix element. Other than this it is generally observed that the sussex interaction is weaker than the $\mathrm{K}-\mathrm{K}$ interaction and therefore the levels of a given multiplet are closer to the centroid energy when using the Sussex interaction.

The RPA and TDA yield almost identical results except for the lowest $3^{-}$state with the same isospin as that of the ground state. For this state the binding increases such that the level is over bound for $\mathrm{o}^{16}$ and $\mathrm{Ca}^{40}$ and driven imaginary for $\mathrm{Ca}^{48}$ and $\mathrm{Sr}^{88}$. If the strength of the interaction is reduced by $35 \%$ to simulate screening then there is fairly good agreement between the experimental and calculated results when the monopole shift is used for this lowest $3^{-}$state.

For the $\mathrm{N} \neq \mathrm{Z}$ nuclei, $\mathrm{Ca}^{48}$ and $\mathrm{Sr}^{88}$, the theoretical calculation inverts the order of the lowest states, the $2^{+}$and $3^{-}$, and tends to overestimate in the RPA the collectivity of the $3^{-}$state. Also in $\mathrm{Sr}^{88}$ a low lying collective $5^{-}$state is predicted but up to now has not been seen. The dipole centroid is also predicted much too low, though the strength is approximately correct. 
Particle-hole calculations in lead, such as those of Gillet and Sanderson give similar results. They predict a very collective $3^{-}$state below a weakly collective $2^{+}, 4^{+}$, etc. band of states. In lead this happens to agree with the observed spectrum. The prediction for the dipole state, however is 3-4 MeV too low. This points to a persistant failure of the model for $\mathrm{N} \neq \mathrm{Z}$. nuclei, which can not be corrected by a simple monopole shift dependant on the symmetry potential. Some systematic effects of neutron excess are missing from the model. As has been noted (Fi70) the TDA calculation systematically overestimates sum rule strengths.

Only. the electric dipole and quadrupole excitations have a narrow enough width to show a "giant" multipole excitation character. For other excitations, remembering that we have not looked at the monopole, the strength is widely distributed, though in a different fashion for different excitations. 
REFERENCES 


\section{REFERENCES}

Aj71 F. Ajzenberg-Selove, Nucl. Phys. Al66 (1971)

Be71 E. M. Bernstein, et al., Phys. Rev. C3 (1971) 422.

B169 J. Blomqvist and T. T. S. Kuo, Phys. Lett. 29B (1969) 544 .

Bo69 Bohne, et ai., Nucl. Phys. Al28(1969) 537.

Br66 G. E. Brown and A. M. Green, Nucl. Phys. 75(1966) 401 .

Ca64 Carter, Mitchel1, Davis, Phys. Rev. 133(1964)B1421.

El68 J. P. Elliot, A. D. Jackson, H. A. Mavromatis, E. A. Sanderson and B. Singh, Nucl. Phys. Al21 (1968) 241 .

Er66 J. R. Erskine, Phys. Rev. 149(1966) 854 .

Fi70 F. W. Fink, Ann. Rev. Nucl. Sci. 20(1970) 39 .

Fu67 Fuchs, Grabisch, Kraaz, Roschert, Nucl. Phys. Al05 (1967) 590 .

Ge64 V. Gillet and N. Vinh-Mau, Nucl. Phys. 54(1964) 321.

Ge67 W. J. Gerace, A. M. Green, Nucl. Phys. A93(1967) 110.

Ge67 V. Gillet and E. Sanderson, Nucl. Phys. 93(1967) 296.

Ge68 W. J. Gerace, A. M. Green, Nucl. Phys. A113(1968)641.

Go70 A. Goswami, O. Nalcioglu, A. Sherwood, Nucl. Phys. A153(1970) 445 .

Go70a C. D. Goodman, T. A. Hughes, M. W. Johns, K. Way, Nuclear Data Tables A8(1970) 323 .

Gr72 G. R. Gruhn, T. Y. T. Kuo, C. J. Maggiore, B. M. Preedom, Phys. Rev. C.6 (1972) 
Hu69 T. A. Hughes, Phys. Rev. 181 (1969) 1586.

Ka64 A. Kallio and K. Kolltveit, Nucl. Phys. 53.(1964)87.

Ka67 C. D. Kavaloski, J. J. Tilley, D. C. Shreve and N. Stern, Phys. Rev. 161(1967)1107.

Ku71 T. T. Kuo, Thesis Unpublished.

Li67 E. P. Lippincott, A. M. Bernstein, Phys. Rev. 163 (1967) 1170 .

- La64 A. M. Lane, Nuclear Theory (New York: W. A. Benjamin, Inc., 1964).

Ma69 Proc. Inter. School of Physics 40 (1969) 457.

Mc70 J. B. McGrory, B. H. Wildenthal and E. C. Halbert, Phys. Rev. C2 (1970) 186 .

Mu70 Murphy and Ritter, Bull. Am. Phys. Soc. 15 (1970)483.

Mo60 S. Moszkowski and B. Scott, Annals of Phys. 11 (1960) 65.

Pe65 R. J. Peterson, Phys. Rev. 140 (1965) B1479.

Ra70 R. C. Ragaini, J. D. Knight, W. T. Leland, Phys. Rev. 2 (1970)C1020.

Sc71 R. Schaeffer, F. Petrovich, Phys. Rev. Letts. 26 (1971) 1380 .

Sc7la R. Schaeffer, Private communication.

Si69 I. Sick, E. B. Hughes, T. W. Donnelly, J. D. Walecka, G. E. Walker, Phys. Rev. Letters 23(1969)1117.

St70 Stroetzel, Goldmann,

Wa65 Walecka, et al., Nucl. Phys. 67(1965)1.

Zu68 A. P. Zuker, B. Buck, J. B. McGrory, Phys. Rev. Letts. $21(1968) 39$.

Zu68 A. P. Zuker, B. Buck and J. B. MCGrory, Phys. Rev. Letts. 21 (1968) 39 . 


\section{APPENDIX A \\ RPA PHASE CONVENTIONS \\ AND \\ TRANSITION FORMULAS}


Part a) Iso-spin Independent

Part b) with Iso-spin Formalism

1. Particle-Hole Creation. Operator
a) $A^{+}\left(p^{-1}, J M\right)=\sum_{m_{p} m_{h}}<p m_{p} h-m_{h} \mid J M>a_{p m_{p}}^{+} a_{h m_{h}}(-1)^{h-m_{h}}$

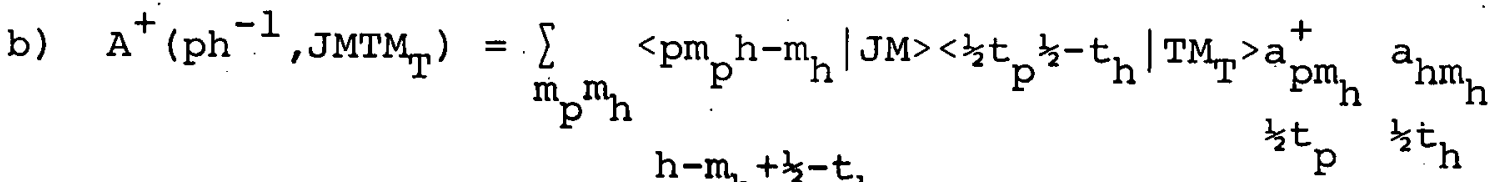 $x(-1)^{h-m_{h}+\frac{1}{2}-t_{h}}$

2. RPA Basis Vector
a) $Q^{+J M}(n)=\sum_{p h}\left[\dot{x}_{J}^{n}(p h) A^{+}\left(p h^{-1}, J M\right)-(-1)^{J-M_{Y}^{n}}(p h) A\left(p h^{-1}, J M\right)\right]$
b) $Q_{T M_{T}}^{+J M}(n)=\sum_{p h}\left[x_{J T}^{n}(p h) A^{+}\left(p h^{-1}, J M T M_{T T}\right)-(-1)^{J+T-M-M_{T}}\right.$

$$
\left.Y_{J T}^{n}(p h) A\left(p h^{-1}, J M T M_{T}\right)\right]
$$

3. RPA Matrices

$$
\begin{aligned}
& \text { a) }\left\langle\mathrm{ph}^{-1}, J|A| \mathrm{p}^{\prime} \mathrm{h}^{\prime-1}, \mathrm{~J}\right\rangle=\left(\varepsilon_{\mathrm{p}}-\varepsilon_{\mathrm{h}}\right) \delta_{\mathrm{pp}}, \delta_{\mathrm{hh},}+\left\langle\mathrm{ph} \mathrm{h}^{-1}, \mathrm{~J}|\mathrm{~V}| \mathrm{p}^{\prime} \mathrm{h}^{\prime-1}, \mathrm{~J}\right\rangle \\
& \left\langle\mathrm{ph}^{-1}, J|B| \mathrm{p}^{\prime} \mathrm{h}^{\prime-1}, \mathrm{~J}\right\rangle=(-1)^{\mathrm{p}+\mathrm{h}+\mathrm{J}+1}\left\langle\mathrm{ph}^{-1}, \mathrm{~J}|\mathrm{~V}| \mathrm{hp} \mathrm{p}^{-1}, \mathrm{~J}\right\rangle \\
& \text { b) }\left\langle\mathrm{ph}^{-1}, \mathrm{JT}|\mathrm{A}| \mathrm{p}^{\prime} \mathrm{h}^{\prime-1}, \mathrm{JT}>=\left(\varepsilon_{\mathrm{p}}-\varepsilon_{\mathrm{h}}\right) \delta_{\mathrm{pp}}, \delta_{\mathrm{hh}},+<\mathrm{ph}^{-1}, \mathrm{JT}|\mathrm{V}|\right. \\
& p^{\prime} h^{\prime-1}, J T>
\end{aligned}
$$




$$
\begin{aligned}
& \left.<\mathrm{ph}^{-1}, J T|B| \mathrm{p}^{\prime} \mathrm{h}^{\prime-1}, \mathrm{JT}\right\rangle=(-1)^{\mathrm{p}+\mathrm{h}+\mathrm{J}+\mathrm{T}+1}<\mathrm{ph}^{-1}, \mathrm{JT}|\mathrm{V}| \\
& \mathrm{h}^{\prime} \mathrm{p}^{\prime-1}, \mathrm{JT}>
\end{aligned}
$$

4. Transitions

The phase relation between the $\mathrm{X}$ and $\mathrm{Y}$ amplitudes is
a) $\mathrm{X}+(-1)^{\mathrm{J}} \mathrm{Y}$
b) $\mathrm{X}+(-1)^{\mathrm{J}+\mathrm{T}} \mathrm{Y}$

5. Single Particle Transition Operators

$$
\begin{aligned}
M(E J, M)= & \sum_{k} e\left(\frac{1}{2}-t_{z}(k)\right) r_{k}^{J} Y_{J M}\left(\Omega_{k}\right) \\
M(M J, M)= & \frac{e \hbar}{2 M C} \sqrt{J(2 J+1)} \sum_{k} r_{k}^{J-1}\left[\left(g_{s}-\frac{2 g_{\ell}}{J+1}\left(Y_{J-1} s\right)\right.\right. \\
& \left.+\frac{2 g_{\ell}}{J+1}\left(Y_{J-1} j\right)\right](J-1,1) J M
\end{aligned}
$$

6. Centroid Energies, Dispersions and Sum Rule Formulas

$$
\begin{aligned}
& \bar{E}=\frac{\sum_{t_{i} E_{i}}}{i t_{i}} \\
& \Delta E=\sqrt{\frac{\sum_{i} t_{i}\left(E_{i}-\bar{E}\right)^{2}}{\sum_{i} t_{i}}} \\
& s=\sum_{i} t_{i} E_{i}
\end{aligned}
$$




\section{APPENDIX B}

MONOPOLE SHIFT 
1. Equivelence between the monopole term and a single particle moving in a spherical potental

$$
\begin{aligned}
\left\langle j_{1} j_{2}{ }^{-1}, J|v| j_{1} j_{2}^{-1}, J\right\rangle= & \sum_{L}\left\langle j_{1} j_{2}^{-1}, J\right| v_{L}\left(r_{1}, r_{2}\right) C_{L}(1) \cdot \\
& C_{L}(2)\left|j_{1} j_{2}^{-1}, J\right\rangle
\end{aligned}
$$

ignoring exchange terms

$=\sum_{L}(-1)^{j_{1}+j_{2}-J} \hat{j}_{1} \hat{j}_{2} W\left(j_{1} j_{2} j_{1} j_{2} ; J L\right) M_{j_{1} j_{1}{ }^{L} M_{j_{2} j_{2}}^{L} I_{1}}$

where

$$
\begin{aligned}
& M_{j_{1} j_{1}}^{L}=\left\langle j_{1}|| C_{L}(I)|| j_{1}\right\rangle \\
& \text { and } I_{L}=\int \phi^{*}\left(j_{1}\right) \phi^{*}\left(j_{2}\right) v_{L}\left(r_{1}, r_{2}\right) \phi\left(j_{1}\right), \phi\left(j_{2}\right) d^{3} r_{1} d^{3} r_{2}
\end{aligned}
$$

therefore

$$
\alpha_{j_{1} j_{2}}^{L}=\frac{1}{\hat{L}} M_{j_{1} j_{1}}^{L} M_{j_{2} j_{2}}^{L}{ }^{I}
$$

the monopole componant is

$\alpha_{j_{1} j_{2}}^{\circ}=M_{j_{1} j_{1}}^{\circ} M_{j_{2} j_{2}}^{\circ} I_{0}=I_{0}=\int \phi^{*}\left(j_{1}\right) U\left(r_{1}\right) \phi\left(j_{1}\right) d^{3} r_{1}$

where $U\left(r_{1}\right)=\int \phi^{*}\left(j_{2}\right) v_{0}\left(r_{1}, r_{2}\right) \phi\left(j_{2}\right) d^{2} r_{2}$ and is spherical. 


\section{Symmetry Energy}

The symmetry energy is the difference between neutron and proton energies where the coulomb energy has been added to the neutron energy.

$$
\begin{aligned}
& \mathrm{E}_{\mathrm{s}}=\varepsilon_{\mathrm{n}}+\Delta-\varepsilon_{\mathrm{p}} \\
& \varepsilon_{h}=\varepsilon_{0}+\frac{4 \varepsilon_{1}}{A}<\square \\
& {\left[\left(T_{0}+1 / 2\right)\left(T_{0}+3 / 2\right)-\frac{3}{4}-T_{0}\left(T_{0}+1\right)\right]} \\
& =\varepsilon_{0}+\frac{2 \varepsilon_{1}}{A} T_{0} \\
& \left.\varepsilon_{p}=\Delta+\varepsilon_{0}+4 \frac{\varepsilon l}{A}<\square\right]\left|\vec{t}_{p} \cdot \vec{T}_{A}\right| \square \square> \\
& =\Delta+\varepsilon_{0}+4 \frac{\varepsilon}{A}\left[\frac{2 T_{0}}{2 T_{0}+1}<\left(\frac{1}{2}, T_{0}\right) T_{0}-\frac{1}{2}, T_{0}-\frac{1}{2}\left|\vec{t}_{p} \cdot \vec{T}_{A}\right|\left(\frac{1}{2}, T_{0}\right) T-\frac{1}{2}, T_{0}-\frac{1}{2}\right\rangle \\
& \left.+\frac{1}{2 T_{0}+1}<\left(\frac{1}{2}, T_{0}\right) T_{0}+\frac{1}{2}, T_{O}-\frac{1}{2}\left|\vec{t}_{p} \cdot \vec{T}_{A}\right|\left(\frac{1}{2} T_{O}\right) T_{O}+\frac{1}{2}, T_{0}-\frac{1}{2}>\right] \\
& \text { upon resolving } \square \text { into state of good } T_{A} \text { i.e. } T_{0}^{ \pm \frac{1}{2}} \\
& =\Delta+\varepsilon_{0}-\frac{2 \varepsilon_{1}}{A} T_{0}
\end{aligned}
$$

The symmetry energy is therefore

$$
E_{s}=E_{h}+\Delta-\varepsilon_{p}=4 \frac{\varepsilon_{l}}{A} T_{0}
$$


97

3. $N=Z$ nucleus $\left(T_{0}=0\right) \quad T=1$ excitation

$$
\begin{aligned}
& \left.\varepsilon_{A}-\varepsilon_{A+1}=\frac{4 \varepsilon_{I}}{A}<A\left|\vec{t}_{p} \cdot \vec{T}_{A-1}\right| A>-<A+1\left|\vec{t}_{p} \cdot \vec{T}_{A}\right| A+I>\right] \\
& \text { where }|\dot{A}\rangle \text { is a } \mathrm{T}=1 \text { state } \\
& \overrightarrow{\mathrm{T}}_{\mathrm{A}}=\overrightarrow{\mathrm{T}}_{\mathrm{O}} \\
& \left|\overrightarrow{\mathrm{T}}+\vec{t}_{\mathrm{p}}\right|=\vec{I} \\
& \varepsilon_{A}-\varepsilon_{A+1}=\frac{4 \varepsilon_{1}}{2 A}(2-3 / 4-3 / 4-3 / 4-3 / 4)=\frac{\varepsilon_{1}}{A}
\end{aligned}
$$

4. $\mathrm{N} \neq \mathrm{Z} \mathrm{pp}^{-1}$ excitation

$$
\begin{aligned}
& \frac{\varepsilon_{A}=\varepsilon_{0}-\frac{2 \varepsilon_{1}}{A}\left(T_{0}+3 / 2\right)}{\varepsilon_{A+1}=\varepsilon_{0}-\frac{2 \varepsilon_{1}}{A}\left(T_{0}+1\right)} \\
& \varepsilon-\varepsilon_{A+1}=-\varepsilon_{1 / A}
\end{aligned}
$$

5. $\mathrm{N} \neq \mathrm{Z}, \mathrm{T}=0$ excitation

$$
\begin{aligned}
& |A\rangle=\frac{1}{\sqrt{2}} \mid \sqrt[x]{0}+\stackrel{x}{[0}> \\
& \varepsilon_{A+1}=\frac{1}{2}\left(\varepsilon_{p}+\varepsilon_{n}\right) \\
& \varepsilon_{n}=\varepsilon_{0}+\frac{4 \varepsilon_{1}}{A}<\square^{x}\left|\vec{t} \cdot \vec{T}_{A}\right| \stackrel{x}{\square^{x}}>\quad \vec{T}_{A+1}=\vec{T}_{0}+\vec{t}_{2} \\
& =\varepsilon_{0}+2 T_{0} \frac{\varepsilon_{1}}{A}
\end{aligned}
$$


98

$$
\left.\varepsilon_{p}=\varepsilon_{0}+\frac{4 \varepsilon_{1}}{A}<\square\left|\vec{t} \cdot \vec{T}_{A}\right| \square\right\rangle
$$

expanding with Clebsch-Gordon coefficients

$$
\begin{aligned}
& \left.\left|\square,=-\sqrt{\frac{2 T_{0}}{2 T_{0}+1}}\right| T_{0}-\frac{1}{2}, T_{0}-\frac{1}{2}\right\rangle+\frac{1}{2 T_{0}+1}\left|T_{0}+\frac{1}{2}, T_{0}-\frac{1}{2}\right\rangle \\
& \varepsilon_{p}=\varepsilon_{0}-2 T_{0} \frac{\varepsilon_{1}}{A}
\end{aligned}
$$

Therefore $\varepsilon_{A+1}=\varepsilon_{0}$

$\varepsilon_{\mathrm{A}}$ evaluation

$$
\left|\left[\Gamma_{0}\right\rangle=-\sqrt{\frac{2 \mathrm{~T}_{0}}{2 \mathrm{~T}_{\mathrm{O}}+1}}\right| \mathrm{T}_{0}-\frac{1}{2}, \mathrm{~T}_{0}-\frac{1}{2}>+\sqrt{\frac{1}{2 \mathrm{~T}_{\mathrm{O}}+1}}\left|\mathrm{~T}_{\mathrm{O}}+\frac{1}{2}, \mathrm{~T}_{\mathrm{O}}-\frac{1}{2}\right\rangle
$$

The expansion of $|A\rangle$ in terms of states of good $T$ is therefore

$$
\begin{aligned}
|A\rangle=\frac{1}{\sqrt{2}} \mid\left(\frac{1}{2}, T_{0}+p\right) T_{0}>- & \frac{1}{\sqrt{2}} \sqrt{\frac{2 T_{0}}{2 T_{0}+1} \mid\left(\frac{1}{2}, T_{0}-\frac{1}{2}\right) T_{0}>} \\
& +\frac{1}{\sqrt{2}} \sqrt{\frac{1}{2 T_{0}+1}} \mid\left(\frac{1}{2}, T_{0}+\frac{1}{2}\right) T_{0}>
\end{aligned}
$$

then

$$
\varepsilon_{\mathrm{A}}=\varepsilon_{\mathrm{O}}-\frac{3 \varepsilon_{1}}{\mathrm{~A}}
$$

and

$$
\varepsilon_{A}-\varepsilon_{A+1}=-\frac{3 \varepsilon_{1}}{A}
$$


6. $\quad N \neq Z$ nucleus

$T=1$ excitation coupled to $T_{0}$ to form a state of $\mathrm{T}_{0}$, i.e. $\left(1 \mathrm{~T}_{\mathrm{O}}\right)^{\mathrm{T}_{\mathrm{O}}}$. Expand $|\mathrm{A}\rangle$ by using $6-\mathrm{J}$ symbols in $\mathrm{a}$ basis of $|A-1\rangle$ states coupled to a good $\mathrm{T}$.

i.e.

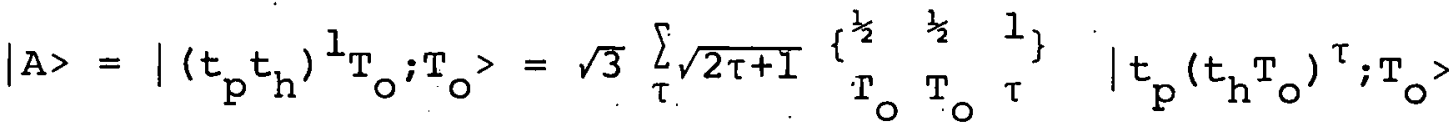

$$
\begin{aligned}
& \text { where } \vec{\tau}=\vec{T}_{A-1}
\end{aligned}
$$

therefore

$$
\begin{aligned}
& \varepsilon_{A}=\varepsilon_{0}+\frac{4 \varepsilon_{1}}{A}\left\langle A\left|\vec{t}_{p} \cdot \vec{T}_{A-1}\right| A\right\rangle
\end{aligned}
$$

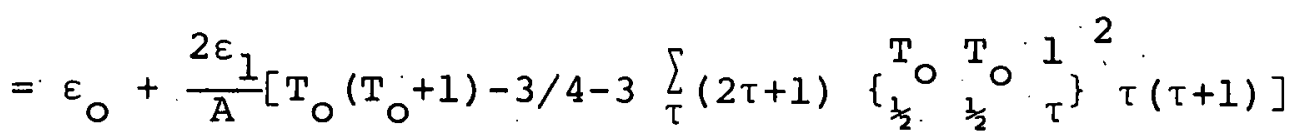

$$
\begin{aligned}
& \text { for } \tau=T_{0}-\frac{1}{2}, 6-J=\frac{T_{0}+1}{6 T_{0}\left(2 T_{0}+1\right)} \\
& \tau=\mathrm{T}_{0}+\frac{1}{2} \cdot 6-\mathrm{J}=\frac{\mathrm{T}_{0}}{6\left(\mathrm{~T}_{0}+1\right)\left(2 \mathrm{~T}_{0}+1\right)}
\end{aligned}
$$

and

$$
\begin{aligned}
& \varepsilon_{A}=\varepsilon_{0}-\frac{\varepsilon_{1}}{A} \\
& \varepsilon_{A+1}=\varepsilon_{0} \text { see } \mathrm{N} \neq \mathrm{Z}, \mathrm{T}=0 \text { excitation }
\end{aligned}
$$

therefore

$$
\varepsilon_{A}-\varepsilon_{\dot{A}+1}=-\frac{\varepsilon_{1}}{\cdot A}
$$


APPENDIX C

SINGLE PARTICLE IDENTIFICATION CODE 
TABLE C.1.--Single Particle Identification Code.

\begin{tabular}{|c|c|c|c|}
\hline$i$ & $0 s_{1 / 2}$ & 18 & $\mathrm{Oh}_{9 / 2}$ \\
\hline 2 & $0 p_{3 / 2}$ & 19 & $0 i_{13 / 2}$ \\
\hline 3 & $o p_{1 / 2}$ & 20 & $2 p_{3 / 2}$ \\
\hline 4 & $0 d_{5 / 2}$ & 21 & $1 f_{5 / 2}$ \\
\hline 5 & $1 s_{1 / 2}$ & 22 & $2 p_{1 / 2}$ \\
\hline 6 & $\mathrm{od}_{3 / 2}$ & 23 & $\lg _{9 / 2}$ \\
\hline 7 & $0 f_{7 / 2}$ & 24 & $0 i_{11 / 2}$ \\
\hline 8 & $1 p_{3 / 2}$ & 25 & $0 j_{15 / 2}$ \\
\hline 9 & $0 f_{5 / 2}$ & 26 & $2 d_{5 / 2}$ \\
\hline 10 & ${ }^{1} p_{1 / 2}$ & 27 & $\lg _{7 / 2}$ \\
\hline 11 & $\log _{9 / 2}$ & 28 & $3 s_{1 / 2}$ \\
\hline 12 & $1 d_{5 / 2}$ & 29 & $2 \mathrm{~d}_{3 / 2}$ \\
\hline 13 & $\log _{7 / 2}$ & 30 & $\ln _{11 / 2}$ \\
\hline 14 & $2 s_{1 / 2}$ & 31 & $0 \mathrm{k}_{17 / 2}$ \\
\hline 15 & $1 d_{3 / 2}$ & 32 & $0 j_{13 / 2}$ \\
\hline 16 & $\mathrm{Oh}_{11 / 2}$ & 33 & $2 f_{7 / 2}$ \\
\hline \multirow[t]{2}{*}{17} & $1 f_{7 / 2}$ & 34 & $\operatorname{lh}_{9 / 2}$ \\
\hline & & 35 & $0 \ell_{19 / 2}$ \\
\hline
\end{tabular}


APPENDIX D

ENERGY AND TRANSITION SUMMARY

102 
This appendix consists of four sections, summarizing the theoretical calculations.

1. Summary of $\mathrm{O}^{16}$

2. Summary of $\mathrm{Ca}^{40}$

3. Summary of $\mathrm{Ca}^{48}$

4. Summary of $\mathrm{Sr}^{88}$

Each section consists of several columns, where each column represents a specific interaction and approximation, the headings of which are found before each of the sections of Appendix D.

Each entry in a column consists of four lines:

Iine 1 -- Transition rate of that state to the ground state.

line 2 -- Transition rate of that state to the ground state where the state consists soley of its major configuration.

line 3 -- Major $\mathrm{p}-\mathrm{h}$ configuration of that state (see Appendix C). If last number after comma is

$$
\begin{array}{llll}
1 & \mathrm{pp}^{-1} & \text { excitation } & \\
2 & \mathrm{nn}^{-1} & \text { excitation } & \\
3 & \mathrm{~T}=0 & \text { excitation } & \\
4 & \mathrm{~T}=1 & \text { excitation } & \mathrm{N} \neq \mathrm{Z} \\
5 & \mathrm{~T}=1 & \text { excitation } \mathrm{N}=\mathrm{Z}
\end{array}
$$

line 4 -- Energy of that state. 


\begin{tabular}{|c|c|c|c|c|}
\hline \multicolumn{5}{|c|}{ Column } \\
\hline$a$ & $0^{16}-\mathrm{TDA}$ & $K-K$ & & \\
\hline $\mathrm{b}$ & $\mathrm{o}^{16}-\mathrm{TDA}$ & $\mathrm{K}-\mathrm{K}$ & M.S. & \\
\hline C & $\mathrm{O}^{16}-\mathrm{TDA}$ & $K-K$ & $\mathrm{M} . \mathrm{S}$. & E.M. Off. \\
\hline$d$ & $\mathrm{o}^{16}-\mathrm{RPA}$ & $\mathrm{K}-\mathrm{K}$ & & \\
\hline e & $0^{16}-\mathrm{RPA}$ & $\mathrm{K}-\mathrm{K}$ & M.S. & \\
\hline $\mathrm{f}$ & $0^{16}-R P A$ & $\mathrm{~K}-\mathrm{K}$ & M.S. & 65\% Strength \\
\hline $\mathrm{g}$ & $\mathrm{O}^{16}-\mathrm{TDA}$ & Sussex & & \\
\hline $\mathrm{h}$ & $\mathrm{O}^{16}-\mathrm{TDA}$ & Sussex & $\mathrm{M} . \mathrm{S}$ & \\
\hline$i$ & $\mathrm{O}^{16}-\mathrm{RPA}$ & Sussex & & \\
\hline j & $\mathrm{O}^{16}-\mathrm{RPA}$ & Sussex & M.S. & \\
\hline
\end{tabular}




\begin{tabular}{|c|c|c|c|c|c|c|c|c|c|c|}
\hline & a & $b$ & $\dot{C}$ & $d$ & e & $\mathbf{f}$ & 9 & h & $i$ & $j$ \\
\hline$\overline{\overline{1 \bullet}}$ & $\begin{array}{c}3.49 E-C 4 \\
8.27 E-C 2 \\
51313 \\
10.624\end{array}$ & $\begin{array}{r}1 \cdot 12 E=04 \\
8.275-02 \\
5 / 3.3 \\
7.416\end{array}$ & $\begin{array}{c}. C O E-50 \\
8.27 E-C 2 \\
51,3,3 \\
7.431 \\
\end{array}$ & $\begin{array}{c}4 \cdot 16 E-04 \\
8.27 E-02 \\
513 \cdot 3 \\
10.413\end{array}$ & $\begin{array}{c}2 \cdot 00 E-C 4 \\
8.27 E-62 \\
5 \prime 3.3 \\
7.112\end{array}$ & $\begin{array}{r}2 \cdot 3 \text { FE }=04 \\
3.27 E \cdot C 2 \\
513.3 \\
7.37=\end{array}$ & $\begin{array}{r}3 \cdot 1 G E-54 \\
8 . ? 7 E-2 ? \\
b 13,2 \\
10 \cdot 13\end{array}$ & $\begin{array}{r}7.45 E=05 \\
8.27 E-0 ? \\
513.3 \\
6.694\end{array}$ & $\begin{array}{r}4 \cdot 915: 04 \\
8 \cdot 27=02 \\
513,3 \\
10 \cdot 2.2\end{array}$ & $\begin{array}{r}\cdot 97 E-04 \\
8.275-02 \\
51,3.3 \\
6.539 \\
\end{array}$ \\
\hline 1. & $\begin{array}{c}1.67 E \cdot C 4 \\
1.65 E \cdot C 1 \\
5 / 2,3 \\
16.268\end{array}$ & $\begin{array}{r}4.54 E-03 \\
1.65 E-C 1 \\
5 / 2,3 \\
13.597\end{array}$ & $\begin{array}{r}\text { COE } 20 \\
1.65 E \cdot 01 \\
512,3 \\
13.552\end{array}$ & $\begin{array}{c}1.31 E-04 \\
1.65 E=01 \\
512.3 \\
16.750\end{array}$ & $\begin{array}{r}4 \cdot 87 E-C 3 \\
1,6,5 E-31 \\
512.3 \\
13.379\end{array}$ & $\begin{array}{c}4.04 E-03 \\
1.65 E-01 \\
5,2.3 \\
13.522\end{array}$ & $\begin{array}{r}1.53 E=05 \\
1.55 E-: 1 \\
512 \cdot 3 \\
15 \cdot 573\end{array}$ & $\begin{array}{c}4.6 \circ F=04 \\
1.655-0 . \\
512.3 \\
15.032\end{array}$ & $\begin{array}{c}1 \cdot 1 j E-c 6 \\
10 E=C E-c i \\
5 / 2,3 \\
18.793\end{array}$ & $\begin{array}{r}3 \cdot 1=5-04 \\
:-65 E-01 \\
512,3 \\
14 \cdot 352\end{array}$ \\
\hline 1. & $\begin{array}{r}1.12 E-c 2 \\
4.14 E-c 1 \\
613,3 \\
17.987\end{array}$ & $\begin{array}{c}2.0 O E-C 4 \\
4.14 E-C 1 \\
613.3 \\
15 \cdot 131\end{array}$ & $\begin{array}{r}. C E E \text { OO } \\
4014 E \cdot .01 \\
6 / 3,3 \\
15 \cdot 137\end{array}$ & $\begin{array}{c}1.07 E-32 \\
4.14 E-01 \\
6 / 3.3 \\
17.945\end{array}$ & $\begin{array}{c}1.97 \varepsilon-C 4 \\
4.14 E-C .1 \\
\epsilon / 3.3 \\
15.896\end{array}$ & $\begin{array}{c}2.94 E-04 \\
4.1+E-01 \\
E / 3.3 \\
14.518\end{array}$ & $\begin{array}{c}4, .4 E-.24 \\
4,14 E-21 \\
4,13,3 \\
20.751\end{array}$ & $\begin{array}{c}2,7 \in E-C 4 \\
4,14 E-5: \\
613,3 \\
17 \cdot 11:\end{array}$ & $\begin{array}{r}9 \cdot 90 E-54 \\
1 \cdot 6=E-01 \\
512 \cdot 3 \\
20 \cdot 661\end{array}$ & $\begin{array}{r}2.05=04 \\
4,14 E=-24 \\
613,3 \\
16,903\end{array}$ \\
\hline 1. & $\begin{array}{r}1.90 E-C 3 \\
8.27 E-C 2 \\
6 / 2.3 \\
24.422\end{array}$ & $\begin{array}{c}7.60 E-C_{5} \\
8.27 E-C 2 \\
612.3 \\
21.09^{2}\end{array}$ & $\begin{array}{c}2.28 E-C 2 \\
4.14 E-C 1 \\
613,3 \\
17.149\end{array}$ & $\begin{array}{c}1.17 E-C 3 \\
8.27 E=0 ? \\
612.3 \\
24.359\end{array}$ & $\begin{array}{r}1.65 E-C 4 \\
8.27 E-C \bar{c} \\
6 / 2,3 \\
2.1 .019\end{array}$ & $\begin{array}{c}2.27 E-04 \\
8.27 E-02 \\
612,3 \\
20.183\end{array}$ & $\begin{array}{r}1 \cdot 24 E \cdot C 4 \\
8 \cdot 27 E=.02 \\
5 / 2 ? 3 \\
27 \cdot 123\end{array}$ & $\begin{array}{r}3.75 E-04 \\
8.27 E-C 2 \\
612.3 \\
23.437\end{array}$ & $\begin{array}{r}7.6 S E-C 5 \\
8.27 E-02 \\
6 / 2,3 \\
27.100\end{array}$ & $\begin{array}{c}5 \cdot 12 E-34 \\
8.27 E-02 \\
6 / ? .3 \\
23.409\end{array}$ \\
\hline 1. & $\begin{array}{c}3.22 E-C 2 \\
8.27 E-C 2 \\
5 / 3.5 \\
13.846\end{array}$ & $\begin{array}{c}2.69 E-c 2 \\
8.275-c ? \\
5,3.5 \\
13.169\end{array}$ & $\begin{array}{c}.00 E \text { OC } \\
8.27 E-C 2 \\
612,3 \\
21.093\end{array}$ & $\begin{array}{c}3.01 E-02 \\
8.27 E-02 \\
513,5 \\
13.326\end{array}$ & $\begin{array}{c}2.46 E-C 2 \\
8.27 E-c 2 \\
5 / 3.5 \\
13 \cdot 141\end{array}$ & $\begin{array}{c}3.52 E-02 \\
9.27 E-02 \\
5 / 3.5 \\
13 \cdot 245\end{array}$ & $\begin{array}{c}2.52 E \cdot 02 \\
8, \hat{c} 7 E-C 2 \\
5 / 3.5 \\
13.133\end{array}$ & $\begin{array}{r}2 . ? 3 E-02 \\
8 \cdot ? 7 E-02 \\
5 / 3,5 \\
13 \cdot 117\end{array}$ & $\begin{array}{c}2 \cdot 34 E-c^{2} \\
8.27 E-c^{2} \\
513,5 \\
13 \cdot 145\end{array}$ & $\begin{array}{c}2.11 E-02 \\
3.27 E-02 \\
5 / 3.5 \\
13.076\end{array}$ \\
\hline 1. & $\begin{array}{r}1.03 E-02 \\
4.14 E-C 1 \\
6 / 3,5 \\
18.179\end{array}$ & $\begin{array}{c}2.30 E-C 2 \\
4 \cdot 1+E=C 1 \\
6,3,5 \\
17 \cdot 156\end{array}$ & $\begin{array}{r}3.15 E--22 \\
8.27 E-c^{2} \\
513.5 \\
13 \cdot 20^{8}\end{array}$ & $\begin{array}{r}8.59 E-C 3 \\
4 \cdot 14 E-01 \\
613.5 \\
18.142\end{array}$ & $\begin{array}{r}2.05 E-02 \\
4.14 E-01 \\
6,3.5 \\
17.107\end{array}$ & $\begin{array}{c}4.20 E-02 \\
4.14 E-01 \\
6,3,5 \\
17.473\end{array}$ & $\begin{array}{c}4,50 E=02 \\
4,14 E=01 \\
51,3.5 \\
17.236\end{array}$ & $\begin{array}{c}2,68 E-C 2 \\
4.145-01 \\
67.3 .5 \\
17.844\end{array}$ & $\begin{array}{c}3 \cdot 82 E-02 \\
4 \cdot 14 E-01 \\
6>3,5 \\
17.7 c^{4}\end{array}$ & $\begin{array}{r}2.245-02 \\
4.126-01 \\
6,3.5 \\
: 7.74=\end{array}$ \\
\hline 1. & $\begin{array}{c}1,48 E-C 2 \\
1.65 E \cdot 01 \\
5 / 2,5 \\
20.211\end{array}$ & $\begin{array}{c}8.33 E-C 3 \\
1.65 E-01 \\
512.5 \\
19.554\end{array}$ & $\begin{array}{c}8.45 E-=3 \\
1,65 E-0: \\
5 / 2,5 \\
19.545\end{array}$ & $\begin{array}{c}1.30 E-02 \\
1.65 E-01 \\
5 / 2,5 \\
20.187\end{array}$ & $\begin{array}{c}6.37 \varepsilon-03 \\
1.65 \varepsilon \cdot 01 \\
5 / 2.5 \\
19.5 ? 7\end{array}$ & $\begin{array}{c}2.55 E-03 \\
1.65 E \cdot 01 \\
5 / 2.5 \\
19.547 .\end{array}$ & $\begin{array}{c}5.02 E=04 \\
1.65 E=01 \\
3 / 2,5 \\
20.444\end{array}$ & $\begin{array}{c}8.02 E=05 \\
1.65 E=01 \\
5 / 2,5 \\
20.131\end{array}$ & $\begin{array}{c}6 \cdot 8^{6 E-c 5} \\
1.5 E E-01 \\
512.5 \\
20 \cdot 364\end{array}$ & $\begin{array}{c}8.4 ! E-C 4 \\
1.6=5-5 ! \\
5,2,5 \\
20 \cdot c^{8} 3\end{array}$ \\
\hline 10 & $\begin{array}{r}1.11 E 00 \\
7.44 E \cdot C 1 \\
4,2.5 \\
23.537\end{array}$ & $\begin{array}{r}1.12 E 00 \\
7.44 E-C 1 \\
412.5 \\
22.623\end{array}$ & $\begin{array}{r}1.12 E .00 \\
7.44 E \cdot .1 \\
412.5 \\
22.622\end{array}$ & $\begin{array}{r}9.55 E=01 \\
7.44 E=01 \\
412,5 \\
23 \cdot 161\end{array}$ & $\begin{array}{r}9.52 E-C 1 \\
7.44 E-01 \\
4,2,5 \\
22.235\end{array}$ & $\begin{array}{r}1.06 E 00 \\
7.44 E-01 \\
412.5 \\
21.122\end{array}$ & $\begin{array}{r}1.35 E=0 \\
7.44 E \cdot 01 \\
412.5 \\
22.451\end{array}$ & $\begin{array}{r}1,36 E 00 \\
7,44 E-01 \\
412,5 \\
22.091\end{array}$ & $\begin{array}{r}1.19 E \quad 00 \\
7.44 E-01 \\
4,2.5 \\
22.276\end{array}$ & $\begin{array}{r}1.20 E=0 \\
7.44 E-01 \\
4,2.5 \\
21.915\end{array}$ \\
\hline 1. & $\begin{array}{c}3 . C 3 E=01 \\
8.27 E=c 2 \\
6 / 2,5 \\
26.368\end{array}$ & $\begin{array}{r}3.06 E-C 1 \\
8.27 E-02 \\
612,5 \\
25.458 .\end{array}$ & $\begin{array}{r}3 \cdot C_{6} E-01 \\
8 \cdot 27 E-02 \\
6 / 2,5 \\
25.457\end{array}$ & $\begin{array}{c}2.20 E-01 \\
8.27 E-02 \\
612.5 \\
26.156\end{array}$ & $\begin{array}{c}2,21 E \cdot 01 \\
3,27 E \cdot 02 \\
6 / 2.5 \\
25 \cdot 239\end{array}$ & $\begin{array}{r}1.58 E-C 1 \\
8.27 E-C 2 \\
612,5 \\
24.687\end{array}$ & $\begin{array}{c}6 \cdot 71 E \cdot .22 \\
8 \cdot 27 E \cdot .2 \\
612.5 \\
26 \cdot 1.05\end{array}$ & $\begin{array}{c}7.39 E-02 \\
8.27 E-02 \\
6 / 2.5 \\
25.496\end{array}$ & $\begin{array}{c}7 \cdot 23 E-02 \\
8.27 E-02 \\
612,5 \\
25.694\end{array}$ & $\begin{array}{r}7 \cdot 9 F E=02 \\
8.27 E=0 ? \\
6 / 2,5 \\
25 \cdot 069\end{array}$ \\
\hline
\end{tabular}




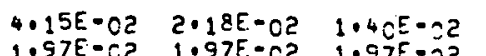

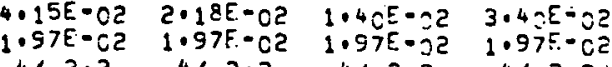

$12 \cdot 250$

$3 \cdot 3$
$8 \cdot 569$

3,3
2.875

1.975 .02
413.3

$1 \cdot 46 E \cdot C 2$

$5.505 E-05$

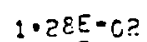

$3 \cdot 38 E \cdot-25 \quad 6 \cdot 07 E-03$

$12 \cdot 211$

413,3
8.021

3,3
8,48

$4,3,3$

$4 / 3,3$

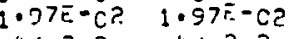

$\begin{array}{rr}3.3 & 4 / 3,3 \\ i 2.000 \quad 7.794\end{array}$

2.

$8.63 E-02 \quad 9.12 E-C 2 \quad 9.24 E-02 \quad 8.71 E-02$

$9.24 E-02 \cdot 6.34 E-02 \quad 1.13 E-01$

$1.04 E-01 \quad 1.23 E-C 1 \quad 1.21 E-01$

$3.44 E-03 \quad 3.44 E-C 3 \quad 3.44 E-03$

$6 / 3,33$

$6 / 3,3 \quad 6 / 3,3$

$.44 E-0.3 \quad 3.44 E-C 3$

$16 \cdot 705$

$6,3 \cdot 3$
$13 \cdot 033$

$6 / 3,3$

$6 / 3,3$

$\begin{array}{lll}4 / 2: 3 & 6 / 3,3 & 4 / 2,3 \\ 12.861 & 16.367 & 12.76 ?\end{array}$

$1.23 E-C 1 \quad 1.21 E-01$

2

$\begin{array}{llll}1 \cdot C 6 E-01 & 6.9 J E-C 2 & 7.95 E-C 2 & 100 \\ 1.33 E-01 & 1.38 E-C 1 & 1.38 E-01 & 103\end{array}$

$4,2,3$

$6.96 E=-2 \quad 1.24 E-0$

18.563

$15 \cdot 505$

$15 \cdot 515$

412,3

$1,38 E \cdot 01$

$\begin{array}{lll}2,3 & 412,3 & 412,3 \\ 15.474 & 14.893 & 17.534\end{array}$

$1.35 E-O$
$.52 E-0$

$6 \cdot 11 E=52$

$2.4 \mathrm{CE} \cdot 02$

$16 \cdot 367$

$12 \cdot 76 ?$

$2 \cdot$

$\begin{array}{cccc}1.94 E-01 & 1.00 E-01 & 7.09 E-C 2 & 1 \\ 2.12 E-02 & 2.12 E-02 & 2.12 E-02 & 2\end{array}$

$.97 E-01$

. 44 E. -0

$5 \cdot 43 E=02 \quad 1.08 E-03$ $\begin{array}{rrr}5 / 2.3 & 5 / 2,3 & 5 / 2.3 \\ 19.698 & 16.449 & 16.463\end{array}$

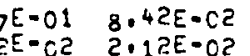

14.893

$17 \cdot 5.34$

$14 \cdot 015$

7.551

$13 \cdot 929$

-

$1.995-02 \quad 2.60 E-C 2$

$1059=04$ l.5EE-C. $1 \cdot 5.9 E=04$

23.276 $19 ? \div 35$ 6/9.536

$19 \cdot 659$

5.69E-OE 2.93E-C1

7.67E-02 2.63E-01 6.04E-02

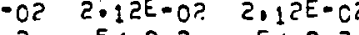

$\begin{array}{lll}07 E-02 & 2.63 E=01 & 0.04 E-02\end{array}$

$\begin{array}{rrr}5,2.3 & 512,3 & 5,2,3 \\ 16.320 & 20.514 & 10 \cdot 264\end{array}$

$3.55 E-C 1 \quad 3.82 E-C 1 \quad 3.84 E-01$

$\begin{array}{ccc}1.26 E \text { CO } & 1.26 E, 00 & 1,26 E \text { OO } \\ 4 / 3,5 & 4 / 3,5 & 4,3,5\end{array}$

$\begin{array}{rr}15.677 & 50.559\end{array}$

13.236

3,5
$12 \cdot 312$

$4,3,5$
$12 \cdot 30^{6}$

(1)

$1 \cdot 3 \varepsilon E-0, \quad 9.22 E-C 4$

-

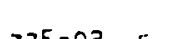

$7=01 \quad 3.175-01$

$6 / 2,3$

$6,2,3$

$6 / 2: 3$
$19 \cdot 58 ?$

$6 / 2 \cdot 3$

$6 / 2,3$
19.428 $5 . C 1 E-05$ $6,3,5$
17.988

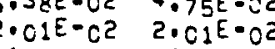

6/3,5

- 26E OC

$3 \cdot 17 E-01 \quad 4.86 E-01$

$5.86 E-01$
$1.26 E$ C0

$13.162 \quad 4,3.5$

$1.26 E$ OO

$.80 E-015.02$

. $2 E E$ OO $1.26 E$ CO $1.2 E E$ CO

$\begin{aligned} & 3,5 \\ & 3,5\end{aligned}, 3,5$

$17.033 \quad 17.026 \quad 17.936$.

2.

$1.51 E=02$
$6.08 E-01$
$5 / 2.5$

$8 \cdot 6^{3} E-C 2$
$6 \cdot 08 E-01$

$8.16 E-02$

$2.03 E .02$

13.479

12.533

13.37

12.422

$19 \cdot 351$

2,5
$18: 642$

$5, C 8 E-01$
$5,2,5$

$3.4 \div . E-25$

$7.14 E-03$ 3. $10 E-05 \quad 5.71$ $\begin{array}{rll}0.31 E-05 & 5.01 E-C 5 & 5.01 E-03\end{array}$ $6,3,5 \quad 6,3,5$, $13,3,5$

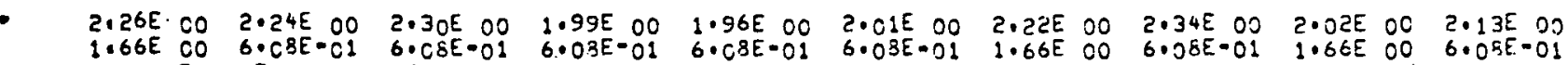
$\begin{array}{cccccccccc}1.66 E & 60 \\ 4 / 2,5 & 5 / 2,5 & 5 / 2,5 & 5 / 2,5 & 5 / 2,5 & 5 / 2,5 & 4,2,5 & 5 / 2,5 & 4 / 2,5 & 5 / 2,3\end{array}$

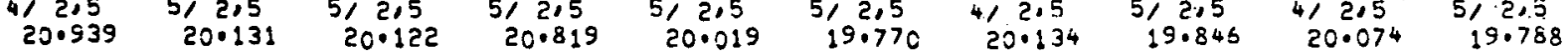


$5 \cdot 32 E-01$ $151 E-01$

$5 \cdot 46 \ddot{E}-\hat{v}$

$3 \cdot 4=E-O:$

$4.03 E-C 1$

$4,15-0: \quad 3 \cdot 15 E-C 1 \quad 3 \cdot 27-0$ : $23 \cdot 985$

$+12,5$
$23 \cdot c 68$

2,5

$1,2,5$

$6,2,5$

i. 2.5 का 2,5

3.

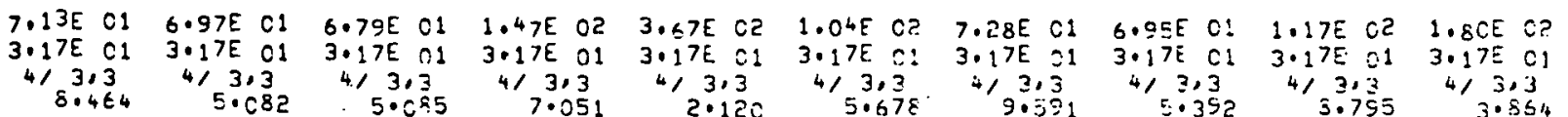

3.

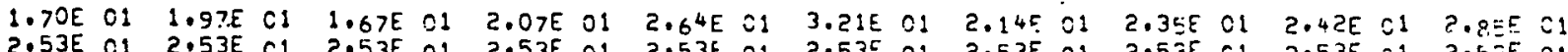

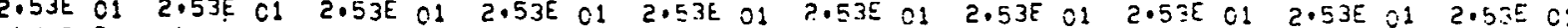

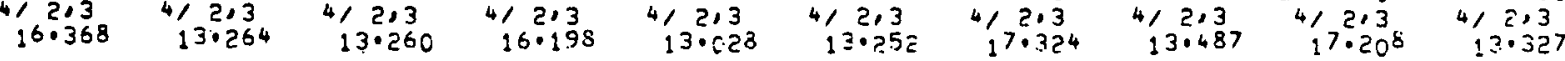

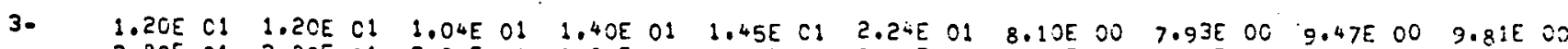

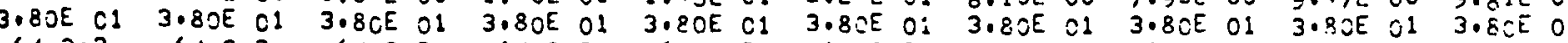

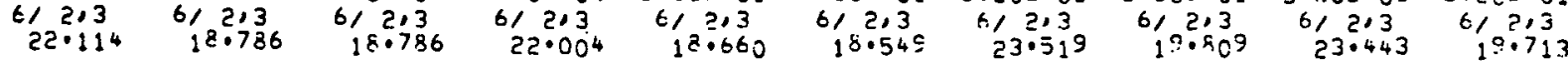

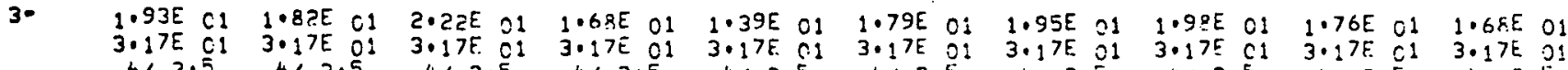

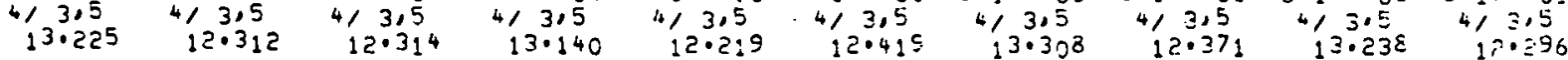

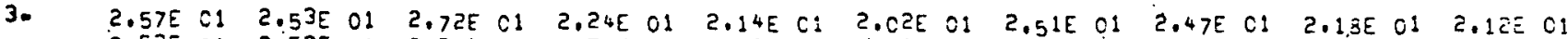

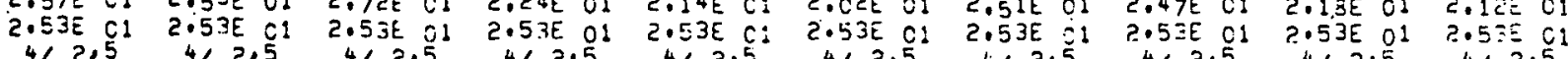

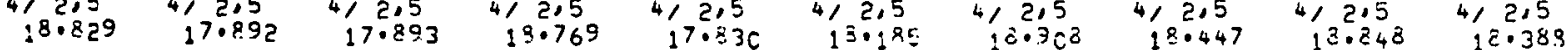

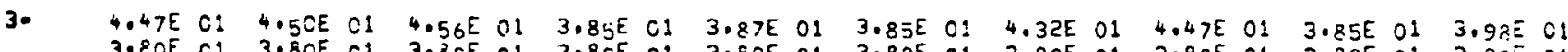
3.RCE CI 3.8OE OI 3.8CE 01 3.8OE O1 3.8CE O1 3.8OE O1 3.8CE OL 3.8

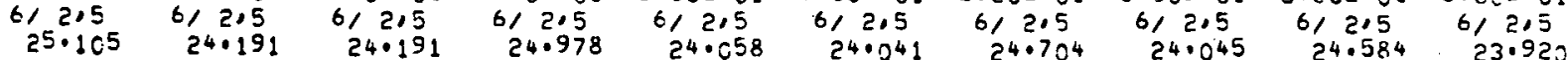

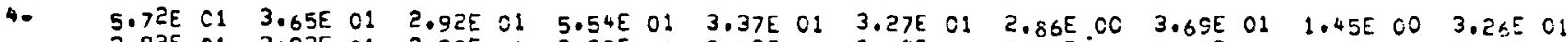

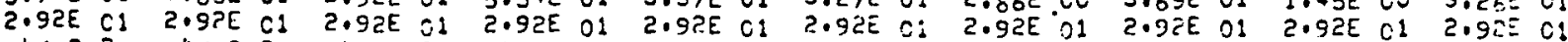

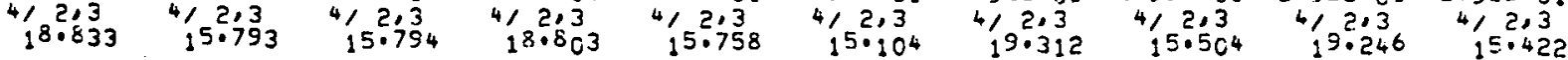

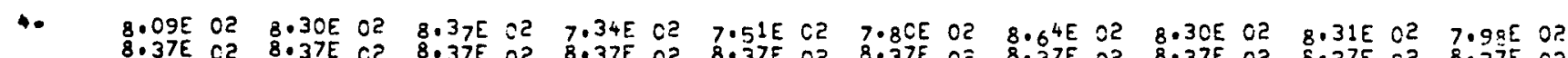
8.37E C2 8.37E C2 8.37E O2 8.37E O2. 8.37E O2 8.37E OE 8.37E O2 8.37E O2 8.37E C2 8.37E O2

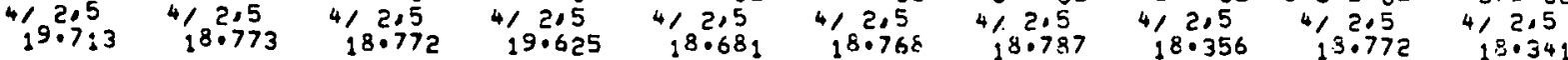


$1+$

$1 \cdot 18 E-15$ $2 \cdot 37 E-15$ $5 / 1: 3$

$1 \cdot 1$ PE - 15 $5737-15$

$4.53 E-16$ $1 \cdot 13 E-15$
$2.37 E-15$ 512.3 $\therefore O 5$ CO i. उTE-IS 41.452

- COE OC 2.37E-:5 $2,37 E \cdot 15$ $5 / 1,3 \quad 311,3$

$1 \cdot 1$ SEE- 15 $2 \cdot 37 E-15$ $40 \cdot 277$ -OCE CO $1 \cdot 15 E-15$ DOOE OD DOCE CO

$2+$

$.00 \varepsilon 00$

- OCE CO . COE OC

$6 / 113 \quad 6 / 1,3$

- COE OO

- CCE OO

$6 / 113$

$.00 E 00$

. ONE OO

$6 / 1: 39$

. OCE CO

- COE 00

43.

6
$44 \cdot 454$

$.00 E$

$7.40 E-17$

OC OCDE DO

$6 / 113 \quad 6 / 11,3$

$6.66 E-16$

. OCE OO

$44: 015$

$5 / 1,3$

to

$\begin{array}{rr}1.18 E-15 & 2.96 E-14 \\ .0 O E \text { CO } & .00 E \text { OO }\end{array}$

- OOE CO

$4.26 E-14$

$1.13 E-15$

- OOE OC

$4.74 E-15$

$1.90 E-12 \quad 1.13 E-15$

COOE CO

$5 / 115$

.OOE CO

-OOE CL OOUE CO

- CCE CO

- OOE CO 5.3UE-14

DOCE CO

42.738

$5 / 1,5$
44.438

- OCE 00

.ODE OO

611,5
48.410

- CCE CO

$6 / 1.5$
47.5 ?

$\begin{array}{lll}\text {.OJE OC: } & 1.18 E-15 \\ .0 O E & 0: 1 & \text {. COE } 00\end{array}$

6) 1.5 की

- OOF OO

$6 / 1,5$
$47 \cdot 869$

$4 \cdot 74 E-15$
$.00 E 00$

D) 000

$61: 5$
48.213

- ONE Jo 61
48.421

$2+$

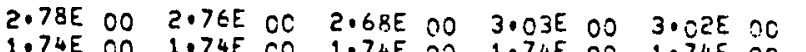

ग 1 प

$36.505 \quad 41 \% 1 \% 3$

$43: 703$

$41,1: 3$

$4,1,3$

$2.75 E$ OIV $2.95 E$

$41,3,4 / 1,3$

$1.74 E$ OJ

$4,1,3$
$33 \cdot 70^{4}$

$3 \cdot 11 E$ OO

1.745 .

$3.14 E-C 1 \quad 5.78$

$3.14 E-C 1 \quad 5 \cdot 78 E-C 1 \quad 2.2 C E-01 \quad 3.25 E-01$

6) 1,3 o, $1,1,3$

$5 \cdot 71 E-C 1$

$i, \in>E-0$

$37.72 C$

$4 / 1,3$

$33 \cdot 635$

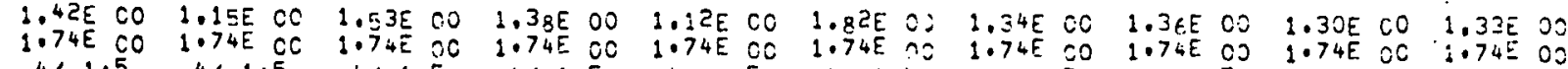

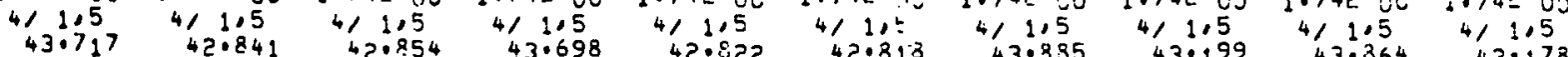

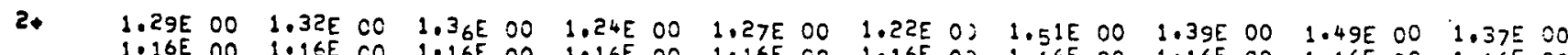

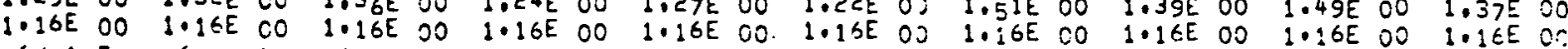

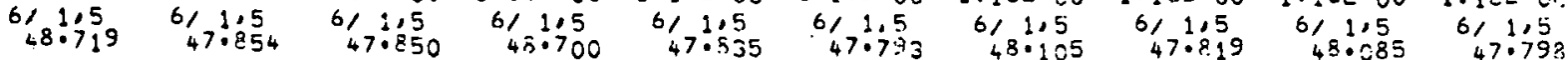

$3+$

2.12E CO $8.29 E-01 \quad 5.21 E-01 \quad 2.12 E$ OO $3.27 E-01 \quad 7.74 E-01 \quad 9.70 E$ OC $\quad 7.74 E-01$

$5.21 E-01$ 5.21E-Cl 5.21E-01 $5.21 E=01$ 5.21E-01 $5.21 E-01$ 5.21E-01 5.21E-01 .00E 00 7.75E-01

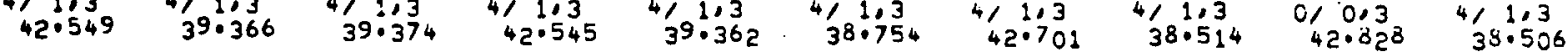




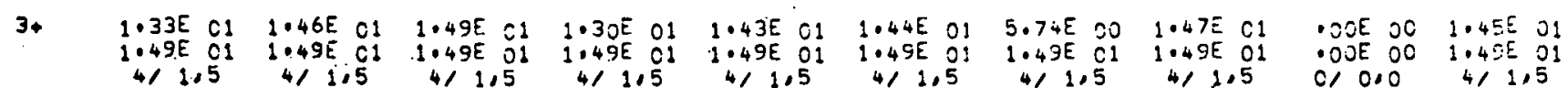

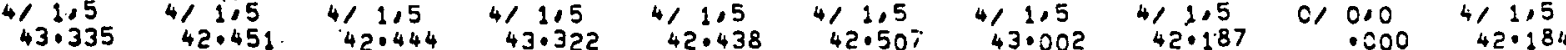
-5TOP. 0 
TABLE D.2.--

\begin{tabular}{|c|c|c|c|c|c|}
\hline Column & & & & & \\
\hline$a$ & $\mathrm{Ca}^{40}-\mathrm{TDA}$ & $\mathrm{K}-\mathrm{K}$ & & & \\
\hline $\mathrm{b}$ & $\mathrm{Ca}^{40}-\mathrm{TDA}$ & $\mathrm{K}-\mathrm{K}$ & M.S. & & \\
\hline C & $\mathrm{Ca}^{40}-\mathrm{RPA}$ & $K-K$ & & & \\
\hline $\mathrm{d}$ & $\mathrm{Ca}^{40}-\mathrm{RPA}$ & $\mathrm{K}-\mathrm{K}$ & M.S. & & \\
\hline$e$ & $\mathrm{Ca}^{40}-\mathrm{RPA}$ & $\mathrm{K}-\mathrm{K}$ & M.S. & $65 \%$ & strength \\
\hline $\mathrm{f}$ & $\mathrm{Ca}^{40}-\mathrm{TDA}$ & Sussex & & & \\
\hline 9 & $\mathrm{Ca}^{40}-\mathrm{TDA}$ & Sussex & M.S. & & \\
\hline $\mathrm{h}$ & $\mathrm{Ca}^{40}-\mathrm{RPA}$ & Sussex & & & \\
\hline$i$ & $\mathrm{Ca}^{40}-\mathrm{RPA}$ & Sussex & M.S. & & \\
\hline
\end{tabular}




\begin{tabular}{|c|c|c|c|c|c|c|c|c|c|}
\hline & $a$ & $b$ & C & $\mathrm{d}$ & e & $f$ & 9 & $\mathrm{~h}$ & $i$ \\
\hline 10 & $\begin{array}{r}1 \cdot 73 E \cdot 04 \\
4.19 E \cdot C 2 \\
8 / 6,3 \\
8.450\end{array}$ & $\begin{array}{c}6.025-65 \\
4.1,05.02 \\
8,6,3 \\
7.190 \\
\end{array}$ & $\begin{array}{r}4.51 E-0^{4} \\
4.195-02 \\
8,6.3 \\
8.217\end{array}$ & $\begin{array}{r}2.95 E-C^{4} \\
4 \cdot 1: 2 E-C ? \\
8 / 6.3 \\
6.017\end{array}$ & $\begin{array}{r}1.49 E \cdot 24 \\
4190-C E \\
876.3 \\
7.645\end{array}$ & $\begin{array}{r}1 \cdot 9.35-04 \\
4.195-.02 \\
816.3 \\
8.500\end{array}$ & $\begin{array}{r}5 \cdot 61 E-05 \\
4 \cdot 19 E-02 \\
\because 7,6 \\
7 \cdot 056\end{array}$ & $\begin{array}{c}5.835-C 4 \\
4.105-c ? \\
3,4.3 \\
2.410\end{array}$ & $\begin{array}{r}3 \cdot 69 E-C^{4} \\
4 \cdot 19 E-02 \\
6,3 \\
6.394\end{array}$ \\
\hline 30 & $\begin{array}{r}8 \cdot 3 C E-C 4 \\
5 \cdot 24 E-21 \\
815.3 \\
10.073\end{array}$ & $\begin{array}{r}3.88 E=05 \\
2.1 C E-01 \\
10 / 6.3 \\
8.677\end{array}$ & $\begin{array}{c}8.67 E-34 \\
5 . \hat{c} 4 E-01 \\
8 / 5,3 \\
9.970\end{array}$ & $\begin{array}{r}1,13 F-C 3 \\
4.19 E-C 2 \\
8 / 6,3 \\
\pi .641\end{array}$ & 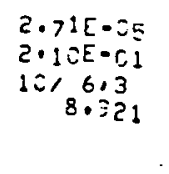 & $\begin{array}{c}5 \cdot 8=6-04 \\
5 \cdot 24 \varepsilon \cdot 0 ! \\
815.3 \\
1:-349\end{array}$ & $\begin{array}{r}0.465-37 \\
5,24 E=21 \\
5,5,3 \\
8,7=2\end{array}$ & $\begin{array}{r}7.1 \geqslant 5-04 \\
5.24 E-01 \\
81503 \\
10 \cdot 294\end{array}$ & $\begin{array}{r}3.22 E-C 5 \\
5.24 E-31 \\
8 / 5.3 \\
8.641\end{array}$ \\
\hline !. & $\begin{array}{c}6.38 E-03 \\
2.62 E-01 \\
1015.3 \\
13.978\end{array}$ & $\begin{array}{c}3.5^{4} E-C i \\
5.24 E-C 1 \\
8 / 5,3 \\
8.957\end{array}$ & $\begin{array}{r}6 . C 1 E-03 \\
2.62 E=-1 \\
1015.3 \\
13.969\end{array}$ & $\begin{array}{r}7.04 E-04 \\
5.24 E=0: \\
3 / 5,3 \\
8.025\end{array}$ & $\begin{array}{r}5 \cdot 32 E-04 \\
5 \cdot 24 E=-21 \\
5 / 5 \cdot 3 \\
9.551\end{array}$ & $\begin{array}{r}3.20 E-04 \\
2.12 E-01 \\
10 / 4,3 \\
10.323\end{array}$ & $\begin{array}{r}6.52 E-34 \\
2.10 E \cdot-21 \\
1016.3 \\
9.3 .02\end{array}$ & $\begin{array}{c}3.74 E-04 \\
4.19 E-02 \\
8,6.3 \\
10.309\end{array}$ & $\begin{array}{r}7.95 E-64 \\
2 \cdot 10 E-C 1 \\
1 C / 6.3 \\
9.249\end{array}$ \\
\hline 10 & $\begin{array}{r}1.22 E=03 \\
3.77 E-C 1 \\
814,3 \\
14.060\end{array}$ & $\begin{array}{c}1.56 E-C 3 \\
3.77 E-01 \\
81,4,3 \\
12.844\end{array}$ & $\begin{array}{c}1.91 E=03 \\
3.77 E=01 \\
8 / 4,3 \\
14.026\end{array}$ & $\begin{array}{c}1.6,3 E=03 \\
3.7>E=C 1 \\
8 / 4,3 \\
12.8 \mathrm{C}^{8}\end{array}$ & 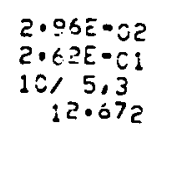 & $\begin{array}{c}3.05 E=04 \\
3.775=01 \\
814,3 \\
15.058\end{array}$ & $\begin{array}{r}5.01 E-33 \\
3.77 E \cdot=1 \\
214,3 \\
13.561\end{array}$ & $\begin{array}{c}4.20 E-04 \\
3.77 E-01 \\
5 / 4,3 \\
15.038\end{array}$ & $\begin{array}{r}5.89 E=03 \\
3.77 E-21 \\
8 / 4,3 \\
13.513\end{array}$ \\
\hline 10 & $\begin{array}{c}4,235-02 \\
9.43 E-02 \\
914.3 \\
20.801\end{array}$ & $\begin{array}{r}1,27 E=02 \\
2.62 E=01 \\
10 / 5,3 \\
12.910\end{array}$ & $\begin{array}{c}3.18 E-03 \\
2,62 E-01 \\
10 / 5,3 \\
14.631\end{array}$ & $\begin{array}{c}1.29 E-02 \\
2.62 E-01 \\
10 / 5,3 \\
12.904\end{array}$ & $\begin{array}{c}1.46 E-03 \\
3.77 E=C 1 \\
8 / 4,3 \\
12.8 C 1\end{array}$ & $\begin{array}{r}1.88 E-02 \\
2.62 E-01 \\
10 / 5,3 \\
15.762\end{array}$ & $\begin{array}{r}4.49 E=24 \\
20: 2 E=-01 \\
1015,3 \\
14 \cdot 3: 8\end{array}$ & $\begin{array}{l}1.32 E-02 \\
2.62 E=01 \\
10 / 5,3 \\
15.730\end{array}$ & $\begin{array}{r}3.39 E=03 \\
2.62 E=01 \\
10 / 5,3 \\
14.256\end{array}$ \\
\hline 10 & $\begin{array}{r}1 \cdot 21 E-C 3 \\
4 \cdot 19 E-C^{2} \\
8,6,5 \\
9.710\end{array}$ & $\begin{array}{c}9.90 E-C^{5} \\
1.32 E \text { CO } \\
9,6,3 \\
13.651\end{array}$ & $\begin{array}{r}3.41 E=-22 \\
9.43 E-32 \\
914.3 \\
20.746\end{array}$ & $\begin{array}{r}1 \cdot C 2 E-04 \\
2.62 E-01 \\
10 / 5,3 \\
13.517\end{array}$ & $\begin{array}{r}6 \cdot 075=04 \\
2 \cdot 62 E-01 \\
10 / 5.3 \\
13 \cdot 137\end{array}$ & $\begin{array}{c}1.96 E \cdot 01 \\
1 \cdot 32 E \text { OC } \\
S / 6,3 \\
16.754\end{array}$ & $\begin{array}{c}1.65 E-03 \\
1.32 E \text { CO } \\
96,6 \\
15.357\end{array}$ & $\begin{array}{c}2 \cdot 26 E-01 \\
3.775-01 \\
3 / 4.3 \\
16.663\end{array}$ & $\begin{array}{c}4.63 E=03 \\
1.325,00 \\
9,6,3 \\
15.234\end{array}$ \\
\hline 10 & $\begin{array}{c}1 \cdot c^{8}=-03 \\
4 \cdot 19 E-c 2 \\
816.5 \\
10.262\end{array}$ & $\begin{array}{c}3.77 E=02 \\
9.43 E-C 2 \\
9 / 4.3 \\
19.688\end{array}$ & $\begin{array}{c}1 \cdot 13 E-03 \\
4 \cdot 19 E-02 \\
8 / 6,5 \\
9 \cdot 680\end{array}$ & $\begin{array}{c}2.60 F^{-C} C 2 \\
9.43 E-O 2 \\
914.3 \\
19.434\end{array}$ & $\begin{array}{c}1.16 \mathrm{E}=02 \\
9.43 \mathrm{E}-02 \\
914.3 \\
18.680\end{array}$ & $\begin{array}{c}1 \cdot 11 E-02 \\
9.43 E-0 ? \\
914.3 \\
22 \cdot 399\end{array}$ & $\begin{array}{c}4 \cdot 57 E \cdot C 2 \\
9.43 E \cdot 02 \\
9 \prime 4,3 \\
21 \cdot 175\end{array}$ & $\begin{array}{c}6.205-03 \\
9.43 E-02 \\
914.3 \\
22.961\end{array}$ & $\begin{array}{c}7.00 E=C 2 \\
9,43 E-02 \\
914.3 \\
21.024\end{array}$ \\
\hline 10 & $\begin{array}{r}3 \cdot 89 E-C 2 \\
2 \cdot 10 E-C 1 \\
1016.5 \\
12 \cdot 326\end{array}$ & $\begin{array}{c}2 \cdot 54 E-C 3 \\
4 \cdot 19 E-C 2 \\
8,6: 5 \\
9.737\end{array}$ & $\begin{array}{c}1.46 E-03 \\
4019 E=02 \\
3 / 6,5 \\
10 . \sigma^{4} 1\end{array}$ & $\begin{array}{c}2 \cdot 5 \text { RE }=03 \\
4 \cdot 13 E=02 \\
8 / 6.5 \\
3.724\end{array}$ & $\begin{array}{c}6.7 C E-C 3 \\
4.19 E-C 2 \\
8,6.5 \\
9.776\end{array}$ & $\begin{array}{c}2 \cdot 20 E-03 \\
4 \cdot 19 E=02 \\
8 / 6,5 \\
9.794\end{array}$ & $\begin{array}{r}2.44 E-03 \\
4.19 E-02 \\
2,6.5 \\
9.346\end{array}$ & $\begin{array}{c}2 \cdot 19 E-C 3 \\
4 \cdot 19 E-0 ? \\
8,6.5 \\
9.759\end{array}$ & $\begin{array}{r}2 \cdot 77 E-C 3 \\
4.19 E-C^{2} \\
8 / 6.5 \\
9.827\end{array}$ \\
\hline 20 & $\begin{array}{c}7.45 E-c 2 \\
5.24 E-01 \\
8 / 5.5 \\
13.163\end{array}$ & $\begin{array}{r}1.14 E=02 \\
2.10 E=0.1 \\
2016.5 \\
11.996\end{array}$ & $\begin{array}{c}3,5, E-22 \\
2.10 E=01 \\
10,6,5 \\
12.296\end{array}$ & $\begin{array}{c}9.17 E-03 \\
2.10 E-01 \\
1016.5 \\
11.957\end{array}$ & $\begin{array}{c}3.0^{5 E-C 2} \\
2.10 E-01 \\
10,6.5 \\
11.919\end{array}$ & $\begin{array}{r}3.43 E-C ? \\
2.10 E-C .1 \\
10,6,5 \\
12.020\end{array}$ & $\begin{array}{r}2,8.8 E=C 2 \\
2,10 E-01 \\
10,6,5 \\
12 \cdot 937\end{array}$ & $\begin{array}{c}3.2 P E-C 2 \\
2,10 E-01 \\
10,6,5 \\
11,985\end{array}$ & $\begin{array}{c}2 \cdot \in 7 E-02 \\
2,10 E-C 1 \\
10 / 6,5 \\
11.901\end{array}$ \\
\hline
\end{tabular}




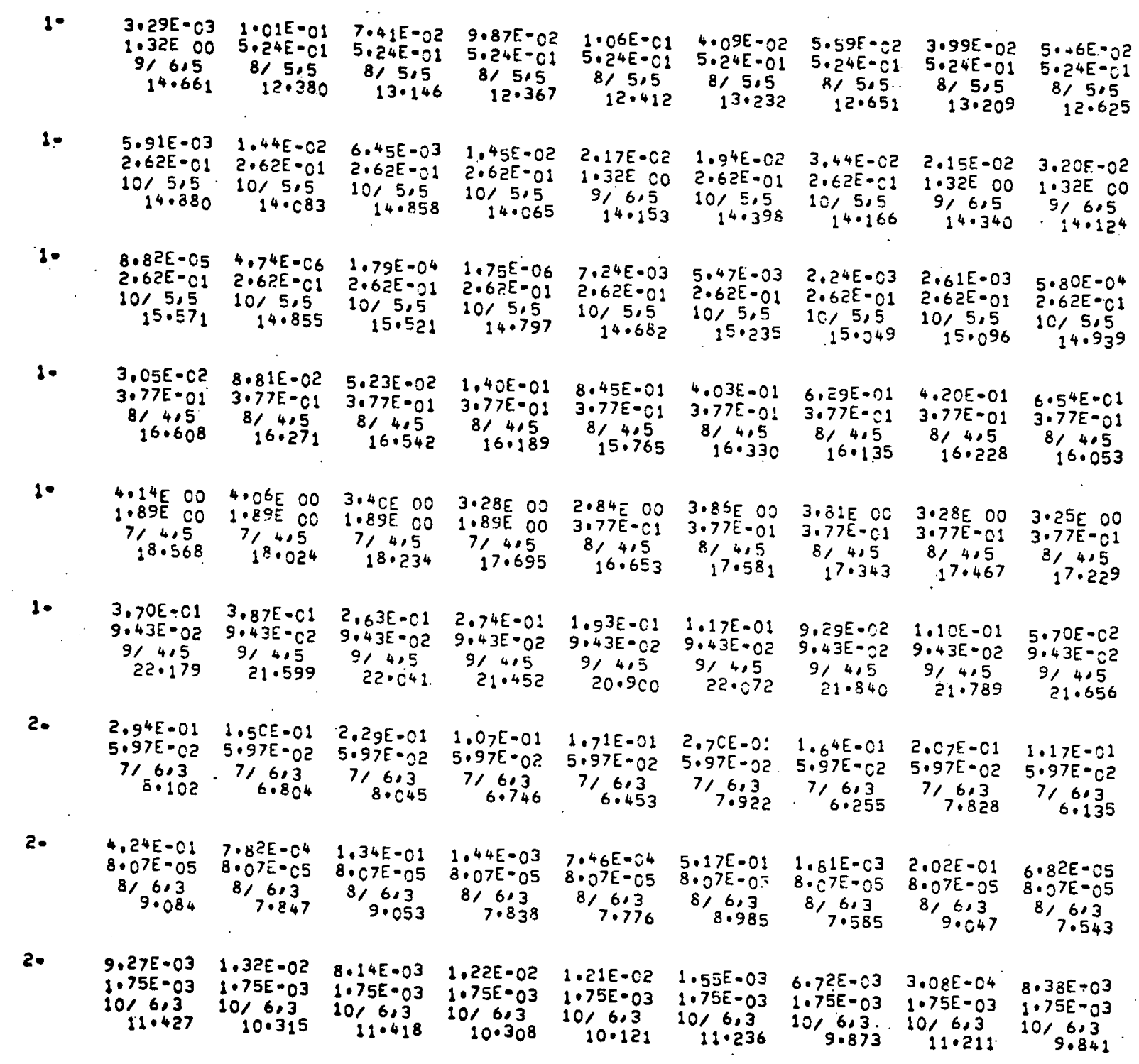




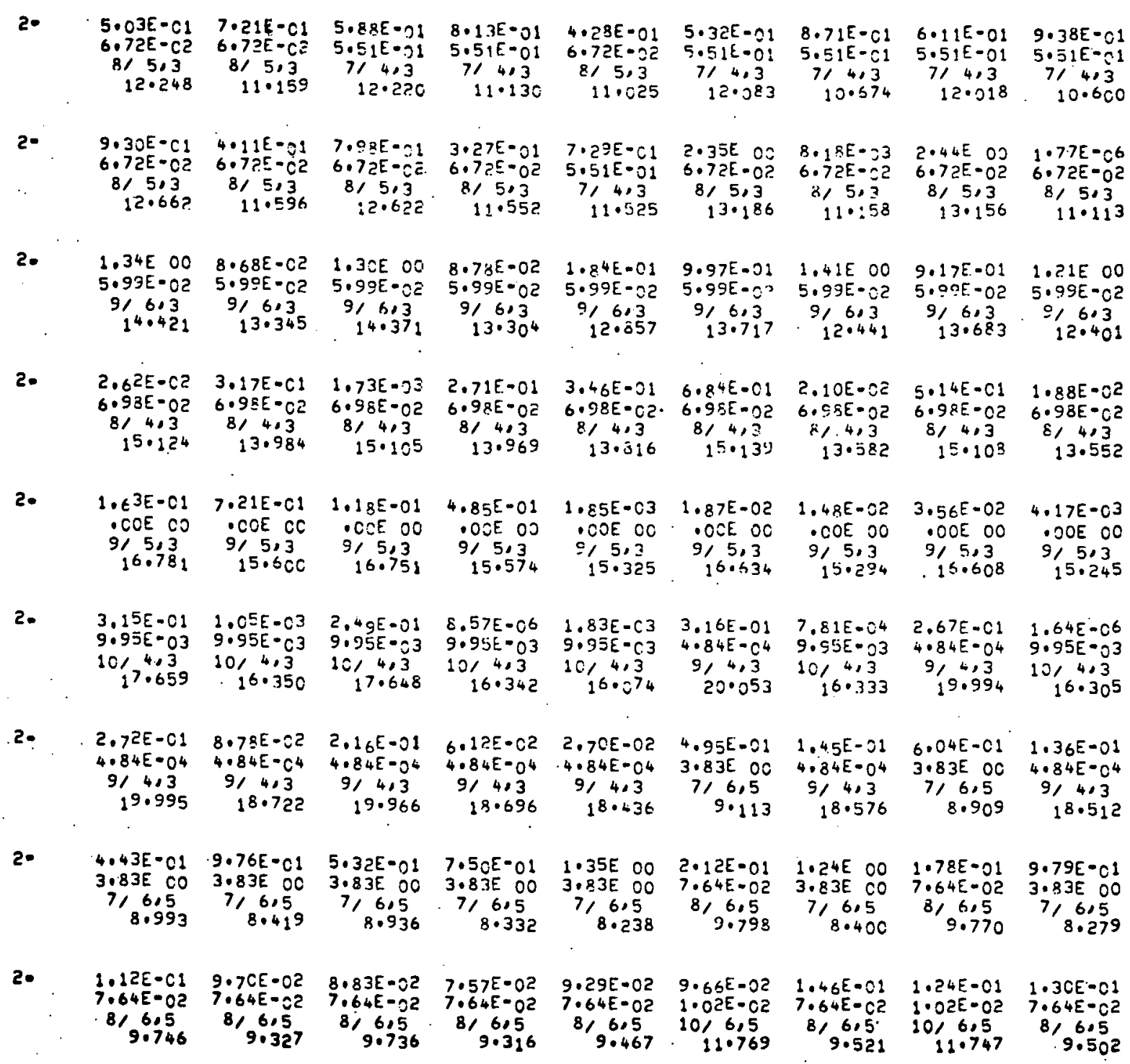


4. $45 E-03 \quad 3.9 .9 E-C 3$ 1.C2E-02 $1.02 E-C 2$ 1016,5
11.989 $10 / 6,5$
11.639 $4 \cdot 8 C E-33$
$1 \cdot C 2 E=-25$ $1 . C 2 E-)^{2}$
$10 / 6.5$ $5.83 E-C 6 \quad 9.13 E-C 4$ $100 ? E-05$ 1. $.52 \mathrm{e}-\mathrm{cs}$

2.33E 00 $11 \cdot 627$ 11.096

$1.92 E$
$8,5,5$

$5.062=21$ $2 \cdot 0$ RE CO $10 / 6,5 \quad 8 / 5,5$

$2 \cdot 40 E-01$

110696

$3.51 E$ OO $4.23 E$ OC $3.45 E$ CO $8 / 5,5 \quad 8 / 5,5 \quad 8,5,5$

6.5?E-0: 4.09500 $13.189 \quad 12.330$

$13 \cdot 175$ $8 / 5,5$ $1.92 E$ CO
$8,5,5$ $9,6,5$

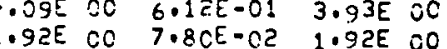

$.53 E-C 1 \quad 1.67 E$ CO

$7.57 E-01$
$7.80 E=05$

$7.80 E-C 2 \quad 7.80 E-C 2$

14.302

1, 5,50 T)

$1.92 E$ CO

916.5
14.234

$9,6.5$
$14 \cdot ? .13$

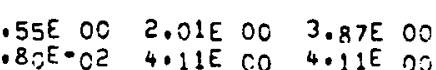
B., $4 \cdot 11 E$ CO

$12 \cdot .00$

$14 \cdot 286$

12.176

$2 \cdot$

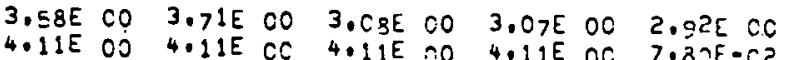
$1.8 \mathrm{CE} \cdot \mathrm{C} 2$
4,2

$3.21 E 00$

$8 \cdot 75 E \cdot 01$ 3.649

$13.747 \quad 714,5$
14.700

$9,6,5$

$7,4,5$

$7.80 E-02$ $\geqslant 4,5$

$11 E$ CC

.11E OC

$\begin{array}{rl}7.02 E & C C \\ 3.30 E-C z\end{array}$

$2.13 E 20$

4.10500

2.

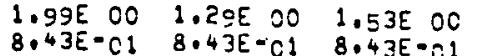

1.43E-CI $8.43 E-01 \quad 1.32 E$ CO

$\begin{array}{ll}4.5 & 8 / 4,5 \\ 15.948 & 15.547\end{array}$

$8 / 4.5$

$8 / 4,5$ 8/ 4,5 .

$8 \cdot 43 E-0$

$3.12 E 00$ $15 \cdot 924$

$8 / 4,5$
$15 \cdot 586$

$6.35 E-03$

- OOE OO $8.43 \mathrm{E}-01$

$8.43 E-C 1 \quad 4.11 E 00$

$.56 E-01$

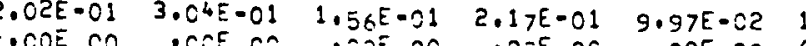

-COE CO DCOE OC DEAE OC DOEE OO OCOE CC 6.3EE-OA

17.494 9/5.5 9/5.5 9/5.5 9/5.5 12/4,5

B. 425 OCE $00 \quad 8.43 E=01$

$170494 \quad 17.092$

$: 7.452 \quad 17.042$

$\begin{array}{rr}17.000 & 10 / 4,5 \\ 17.366\end{array}$

$7.27 E-03 \quad 1.00 E 00$

$\begin{array}{lll}5,5 & 10 / 4,5 & 91,5,5\end{array}$

2.

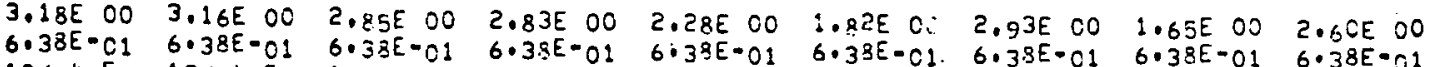

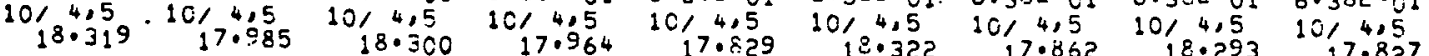

2.

$1.49 E$ CO $1.71 E$ OO $1.17 E$ EO $1.35 E$ OO $9.70 E-01 \quad 1.15 E$ OO $1.36 E$ CO $8.12 E-01 \quad 9.75 E-C 1$

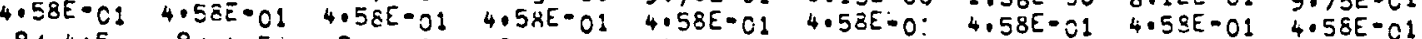

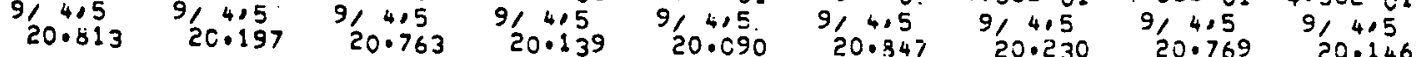

\section{$8.69 E$ O2 $8.46 E$ O2 $3.19 E \quad 3$} $6.62 E$ OI $6.62 E$ OI $6.62 E$ OI $\begin{array}{rrr}716,3 & 71.6,3 & 716.3 \\ 5.640 & 4.340 & 3.309\end{array}$

- OOE $00 \quad 1.12 E$ O3 $3.38 E$ O2 $7.83 E$ C2 $1.97 E$ 03 $2.87 E$. 33 .OCE OO 6.62E J1 6.62E O1 6.62E O1 6.62E O1 6.62E C1 $\begin{array}{rrrrrr}0 / 0 & 7 \% 6,3 & 716.3 & 716,3.3 & 716,3 & 716,3 \\ .000 & 4.838 & 6.416 & 4.785 & 5.173 & 2.975\end{array}$ 
2.46E C1 1.57E C2 $1.55 E$ O1 $1.25 E$ O2

.21E C2 1.54 C2 $1.55 E$ OI $1.25 E$ O2 4 . 10 E 02

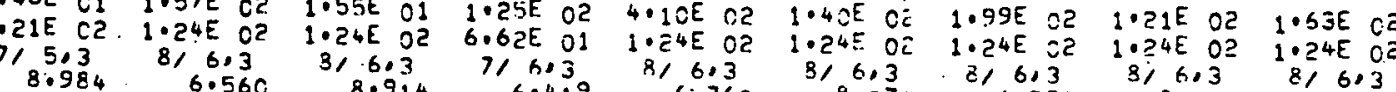

$8.914 \quad 6.419 \quad 6.760 \quad 8.271 \quad 6.583 \quad 8.212 \quad 8 / 6.3$

3. $1.44 E$ C2 $4.70 E$ OI $1.51 E$ C2 3.74E O1 $1.08 E$ CE $5.89 E 01 \quad 7.04 E 21 \quad 4.95 E$ C1 $7.00 E$ O1

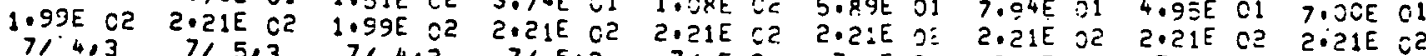

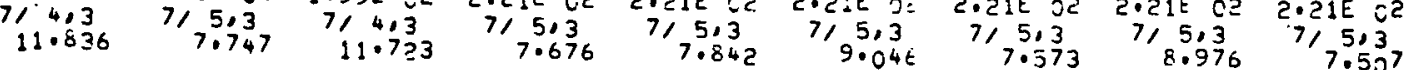

3. $\quad 5.38 E-01 \quad 4.61 E-C 2 \quad 4.83 E-01 \quad 2.67 E$ OO $4.06 E$ CO $2.15 E$ OC $1.58 E .01$ 2.25E 02 2.98E 01

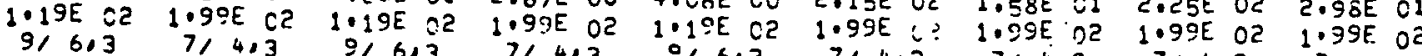

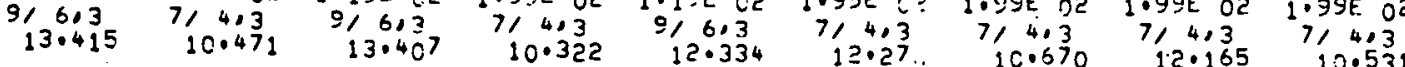

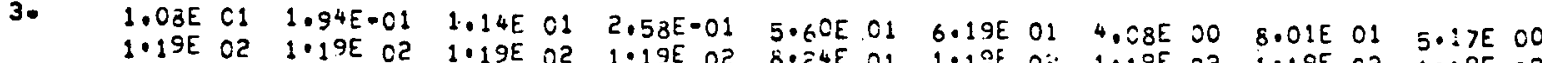

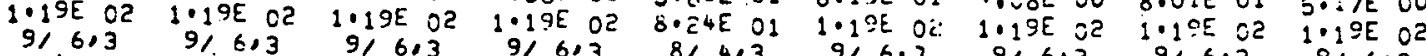

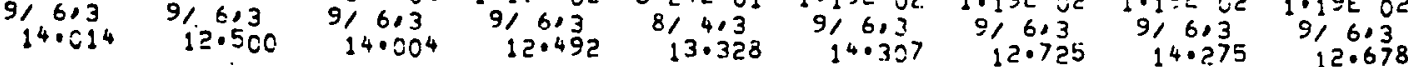

3. $\quad 1.85 E$ CO $2.6 C E$ C1 $1.36 E-01 \quad 3.61 E$ O1 $1.05 E$ O2 $1.38 E$ C2 $5.21 E 01 \quad 1.2 E E$ C2 $5.3 ! E$ OI B.24E C1 8.24E C1 8.24E O1 $8.24 E$ O1 $1.65 E$ O2 $9.24 E$ OI $8.24 E$ C1 $8.24 E$ CI $8.24 E$ CI

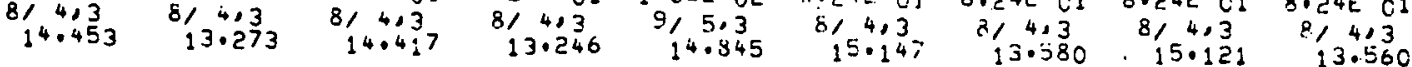

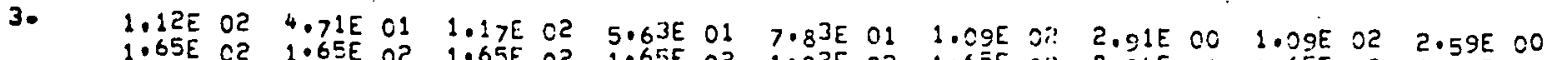

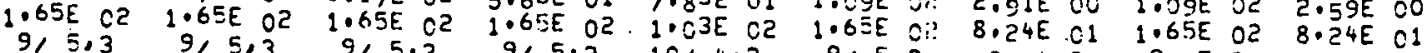

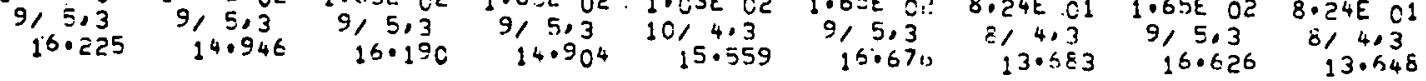

3. $2.40 E$ C1 $5.95 E$ CI $2.38 E$ O1 $5.74 \mathrm{~F}$ O1 $9.16 E$ O1 $7.77 E$ C: $1.13 E$ C1 $7.67 E$ C1 $2.02 E 01$

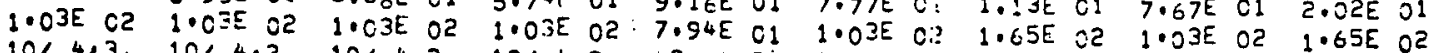
$\begin{array}{rrrrrrrrr}10 / 4,3 & 10 / 4,3 & 10 / 4.3 & 10 / 4,3 & 9 / 4,3 & 10 / 4,3 & 9 / 5,3 & 10 / 4,3 & 9 / 5,3 \\ 16.882 & 15.583 & 16.865 & 15.570 & 18.119 & 17.67 .5 & 15.156 & 17.652 & 15.103\end{array}$

3. $8.01 E$ OI $8.74 E$ ol $8.14 E$ OI $8.76 E$ OI $9.39 E$ 00 1.45E $0 ?$ ? $1.03 E$ O1 $1.40 E$ O2 $1.26 E$ O1

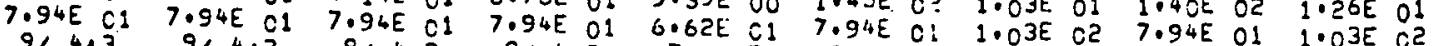

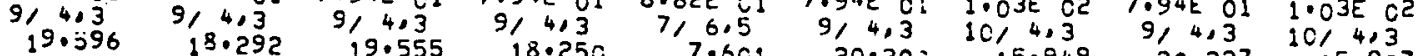

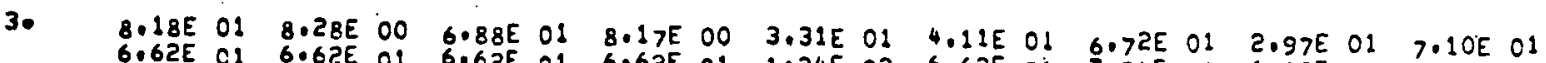

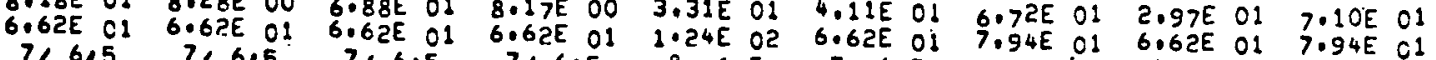

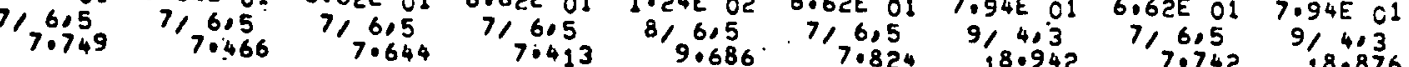


3•

9.63E C1 2.CEE CI 8.19E O1 $6.62 E .01$ 8.199

$\begin{array}{rr}8,5 & 7,6.5 \\ 9.617 & 8.15\end{array}$

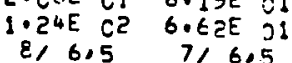

$\begin{array}{lll}2 \cdot 05 E & 01 \\ 1.24 E & 0\end{array}$

$1.24 E 02$
$8 / 6.5$

$4.50 E \cdot 01$ 2.21102

$2.36 E$ O1 $1.79 E 00$

$8,6,5$

$6.622,31$
716,5

$2 \cdot 35 E$ C1 $2 \cdot 30 \hat{E} 00$

$10 \cdot 506$

9.744

7.257

(1) $24 \mathrm{E}$ C2

9.734

$6.62 E$ Cl

$7 / 6,5$

3.

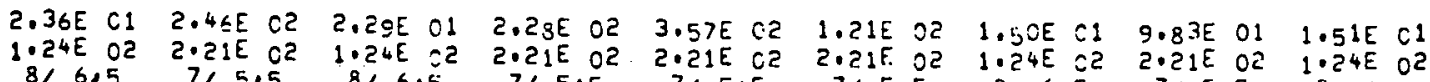

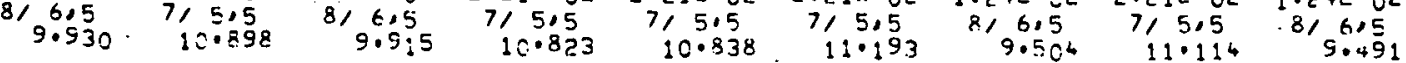

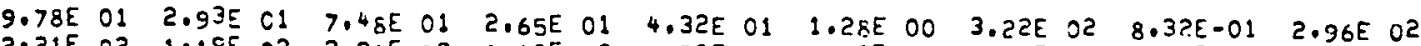

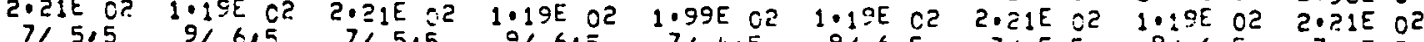
$10.990 \quad 13.310 \quad 7 / 5,5$ 9/6,5 $1 / 4,5 \quad 9 / 6,5 \quad 7 / 5,5$

3. 2.97E C2 2.5CE O2 2.67E $02 \quad 2.07 E$ C2 $1.88 E$ CE 1.59502 2.63E C2 $1.06 E$ 02 2.?.4E 02

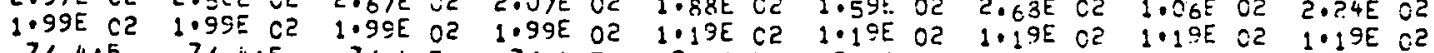
$714,57 \% 4,57 / 4,5$ 7/4,5 $9 / 6,5$ 9, 6,5 9, 6,5 9/6,5 $9,6,5$

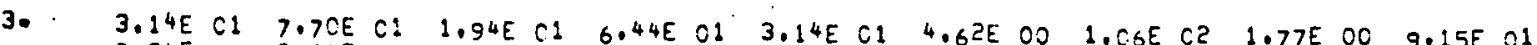

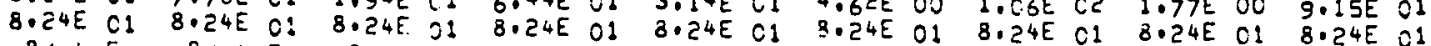

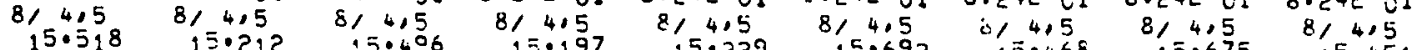

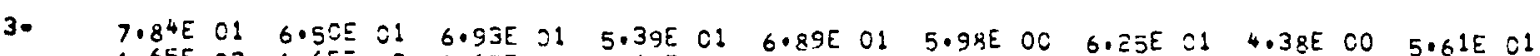

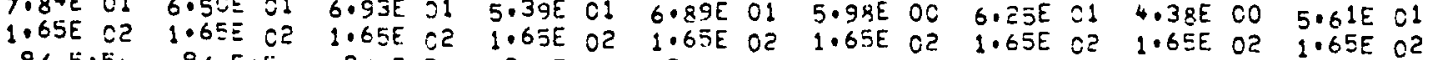

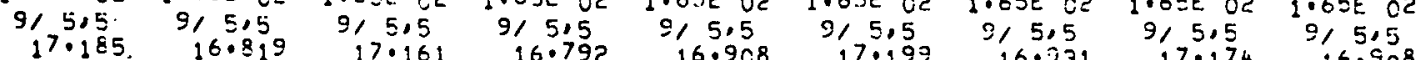

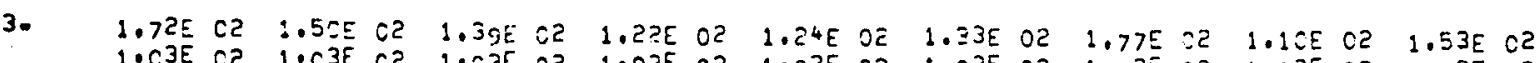

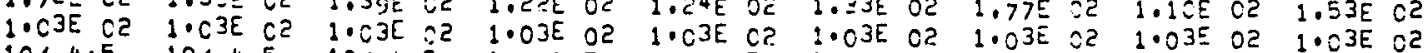
$\begin{array}{rrrrrrrrr}10 / 4,5 & 10 / 4,5 & 10 / 4,5 & 10 / 4,5 & 10 / 4,5 & 10 / 4,5 & 10 / 4,5 & 10 / 4,5 & 10 / 4,5 \\ 18.091 & 17.787 & 18.054 & 17.753 & 17.733 & 18.216 & 17.334 & 18.183 & 17.850\end{array}$

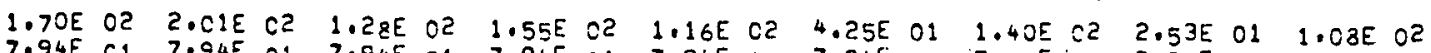
$7.94 E$ C1 7.94E. C1 7.94E O1 7.94E O1 7.94E C1 7.24E 01 7.94E C1 7.94E $01 \quad 7.94 E$ OL

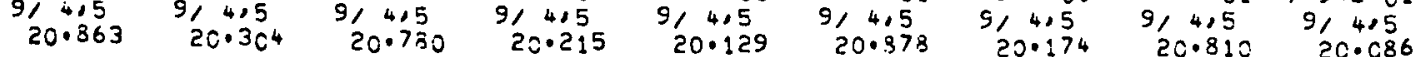

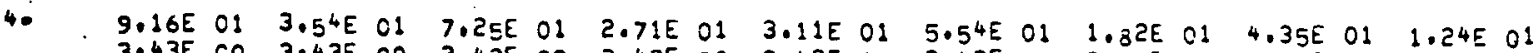

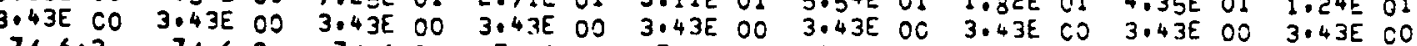

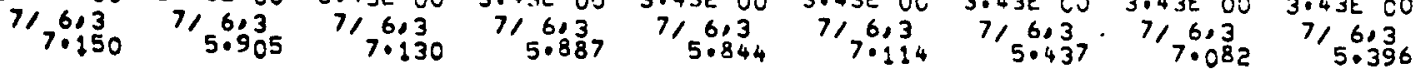




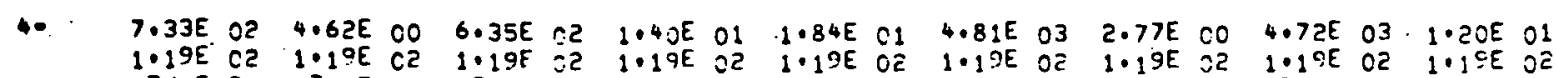

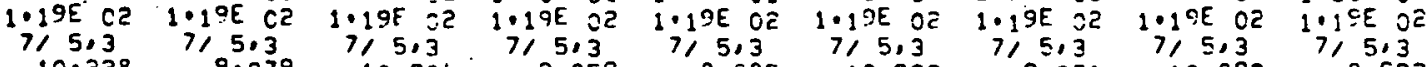

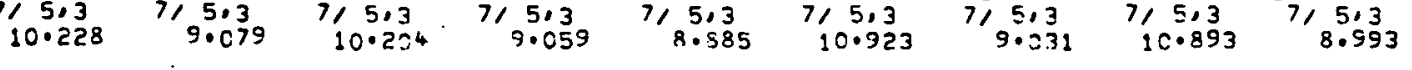

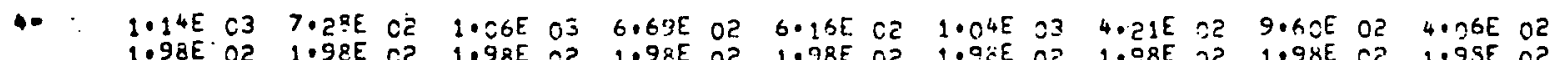

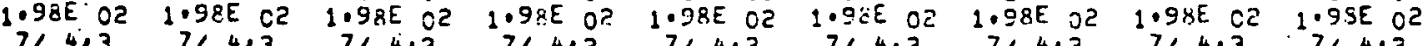

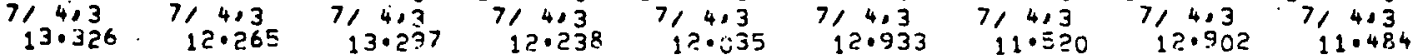

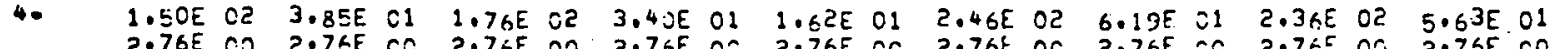

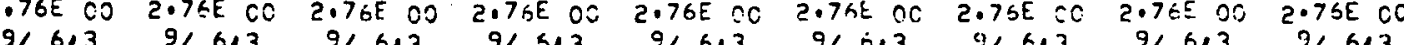

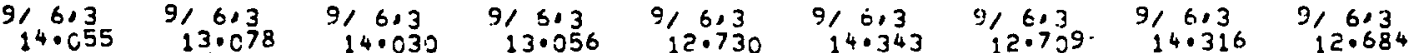

4. $\quad 1.81 E$ C3. $6.06 E$ C2 $1.60 E$ O3 $4.09 E$ C2 $2.62 E$ CE $1.41 E$ O3 $4.19 E$ C? $1.35 E 03 \quad 3.73 E 02$ $9.51 E$ C1 $9.51 E$ C1 $9.51 E$ C1 $9.51 E$ C1 $9.51 E$ O1 $9.51 E$ C1 $9.51 E$ C1 $9.51 E$ O1 $9.51 E$ O1

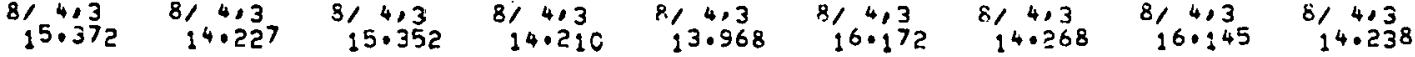

4- $\quad 1.39 E$ C2 $2.58 E$ O1 $1.11 E$ C.2 $1.81 E \quad 01 \quad 7.17 E$ CC $\quad 3.94 E \quad 01 \quad 8.36 E \quad 00 \quad 2.6 C E \quad 01 \quad 4.45 E \quad 00$ $\begin{array}{llllllllll}2.55 E-C 1 & 2.55 E-01 & 2.55 E-01 & 2.55 E-01 & 2.55 E-C 1 & 2.55 E-01 & 2.55 E-01 & 2.55 E-01 & 2.55 E-01\end{array}$

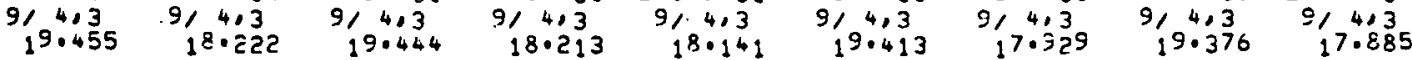

4. $\quad 1.07 E$ O2 $1.85 E \quad 02 \quad 8.29 E$ O1 $\quad 1.44 E \quad 02 \quad 2.54 E \quad 02 \quad 2.27 E$ 02 $3.10 E$ C2 $2.05 E$ O2 $2.72 E \quad 02$

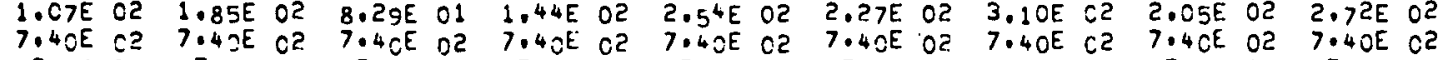

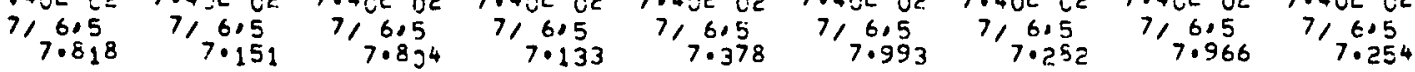

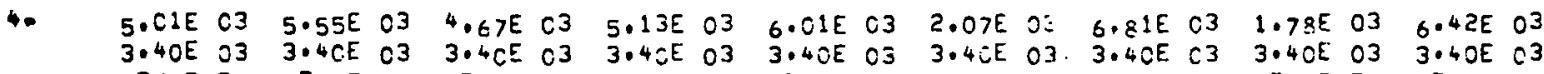

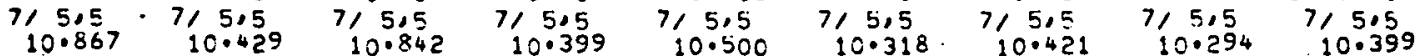

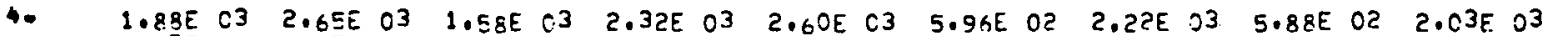

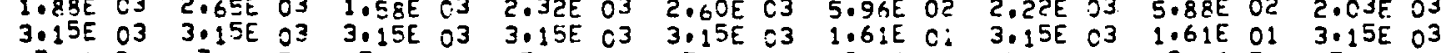

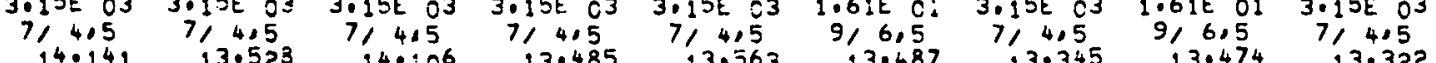

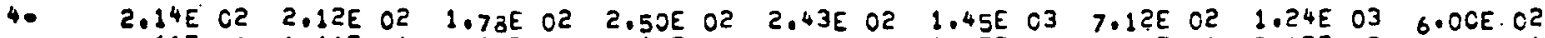

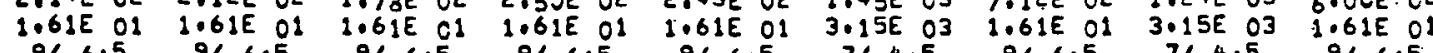

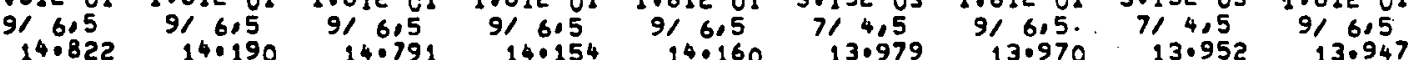


$\because \quad 4.41 E \quad 03 \quad 5.54 E \quad 03 \quad 3.8 \mathrm{IE} \quad 03 \quad 4.85 E \quad 03 \quad 4.44 E \quad 03 \quad 3.79 E \quad 03 \quad 4.72 E \quad 03 \quad 3.51 E \quad 03 \quad 4.46 E \quad 03$

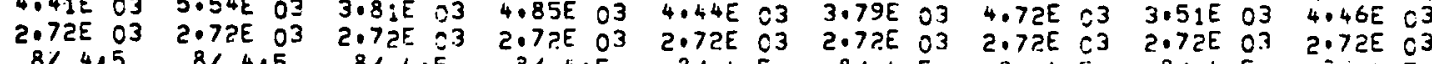

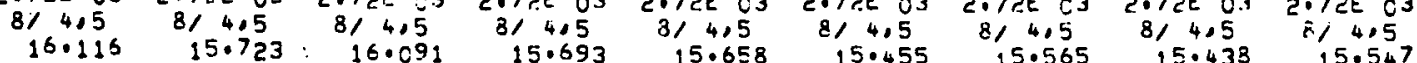

4. $\quad 4.42 E$ C? $5.62 E$ C2 $3.71 E$ O2 $4.63 E \quad 02 \quad 3.04 E$ C2 $4.07 E 02 \quad 4.45 E \quad 22 \quad 3.53 E \quad 02 \quad 3.80 E \quad 02$ $2.41 E$ O2 $2.41 E$ C2 $2.41 E$ O2 $2.41 E$ O2 $2.41 E$ D2 $2.41 E$ O2 $2.41 E$ O2 $2.41 E$ O2 $2.41 E$ OL

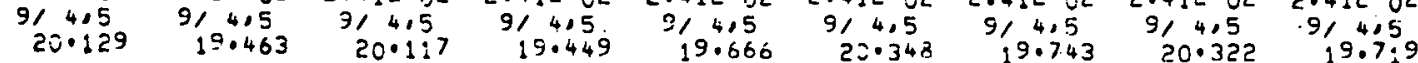

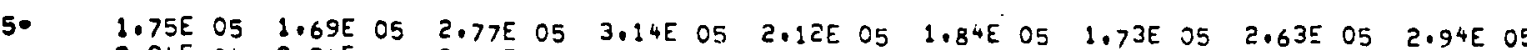

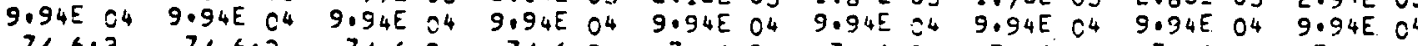

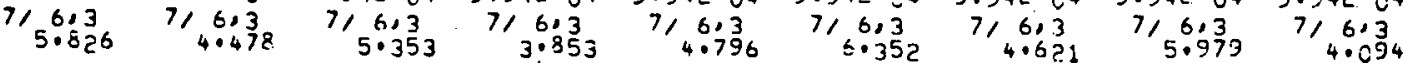

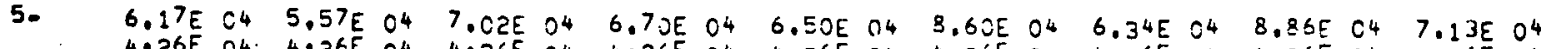

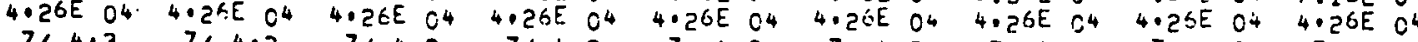

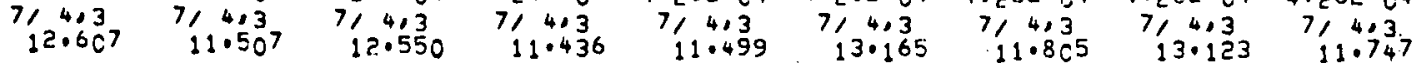

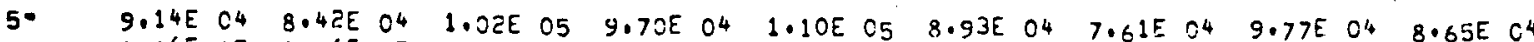

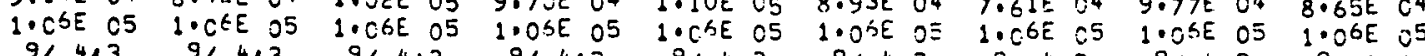

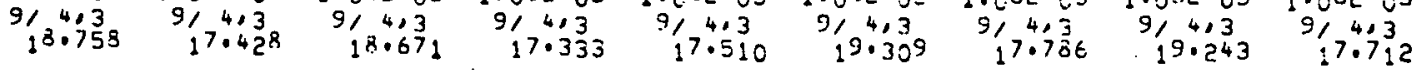

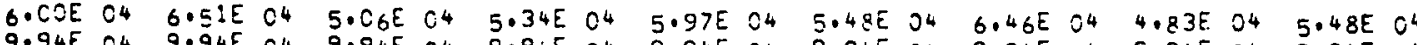

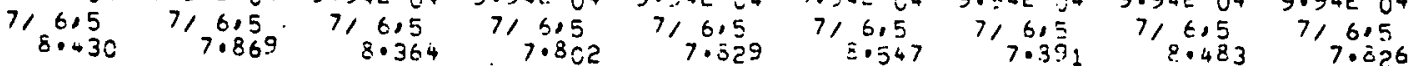

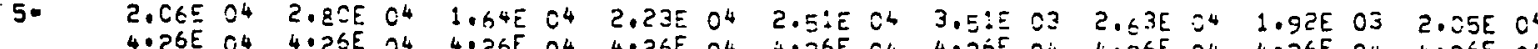
4.2EE O4 $4.26 E C^{4}$

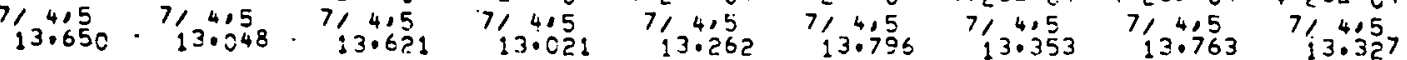

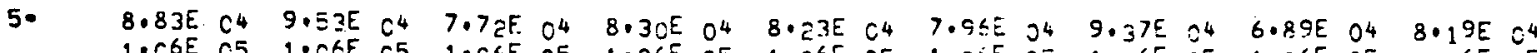

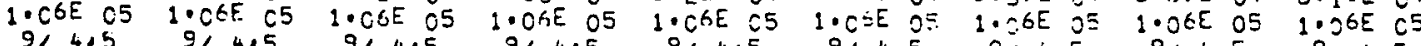

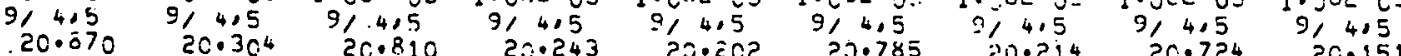

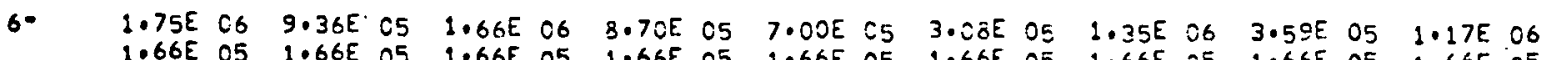
$1.66 E$ O5 $1.66 E$ O5 $1.66 E$ O5 $1.66 E$ O5 $1.66 E$ O5 $1.66 E$ O5 $1.66 E$ OS $1.66 E$ OS $1.66 E$ O5

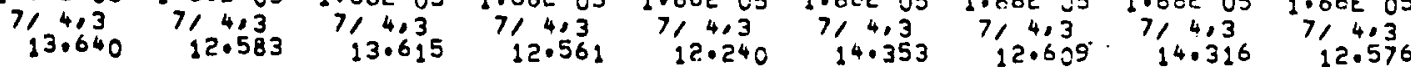




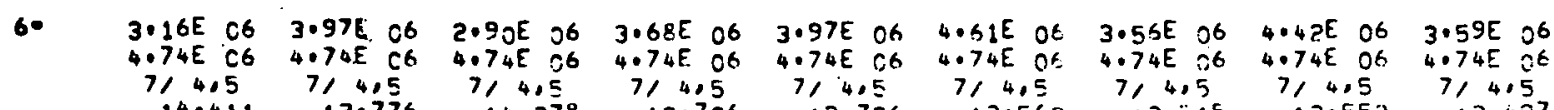

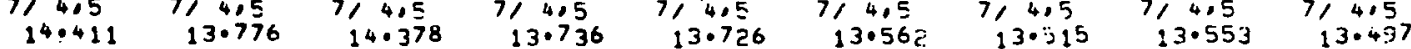

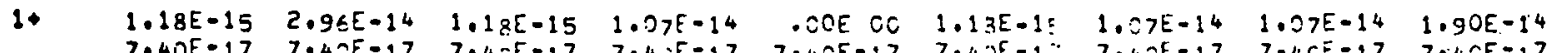

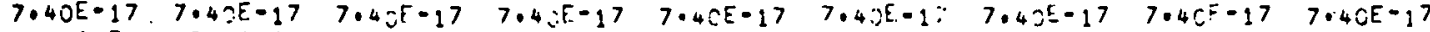

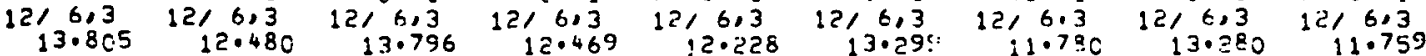

1. $\quad 4.27 E-13 \quad 2.32 E-13 \quad 9.59 E-14 \quad 2.00 E-13 \quad 1.18 E-13 \quad 4.26 E-11 . \quad 5.50 E-14 \quad 7.58 E-14 \quad 2.00 E-13$ 7.11E-15 7.11E-15 7.11E-15 7.11E-15 7.11E-15 7.11E-1=7.11E-15 7.1:E-15 7.11E-15

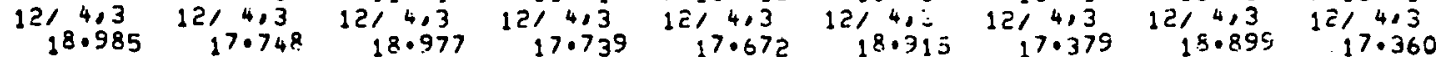

14 $\quad 2.00 E-13 \quad 9.59 E-14 \quad 2 . C C E-13 \quad 4.26 E-14 \quad 2.32 E-13 \quad 7.58 E-1 \times \quad 1.18 E-13 \quad 2.06 E-14 \quad 3.42 E-13$ $4 \cdot 74 E-15 \quad 4 \cdot 74 E-15 \quad 4 \cdot 74 E \cdot 15 \quad 4 \cdot 74 E-15 \quad 4 \cdot 74 E-15 \quad 4 \cdot 74 E-1 ; \quad 4 \cdot 74 E \cdot 15 \quad 4 \cdot 74 E-15 \quad 4 \cdot 74 E-15$ $\begin{array}{rrrrrrrrr}12 / 6,5 & 12 / 6,5 & 12 / 6,5 & 12 / 6,5 & 12 / 6,5 & 12 / 6,5 & 12 / 6,5 & 12 / 6,5 & 12 / 6,5 \\ 14.661 & 14.413 & 14.643 & 14.395 & 14.209 & 14.557 & 140.389 & 14.547 & 14.379\end{array}$

1. .OOE CO $3.03 E-13 \quad 3.03 E-13 \quad 3.03 E-13 \quad 3.03 E-13 \quad 3.03 E-13 \quad$.OCE DO .0OE OO 00 .0OE CO $2 \cdot 84 E-14 \quad 2.84 E-14 \quad 2 \cdot 84 E-14 \quad 2.84 E-14 \quad 2.84 E \cdot 14 \quad 2.84 E-14 \quad 2.84 E-14 \quad 2 \cdot 84 E-14 \quad 2.84 E-14$ $1214,5 \quad 12,4,5 \quad 12,4,5 \quad 12,4,5 \quad 12,4,5 \quad 12,4,5 \quad 12,4,5 \quad 12,4,5 \quad 12,4,5$

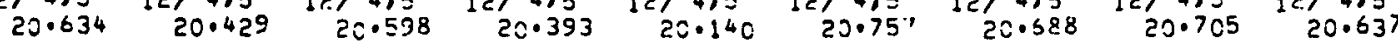

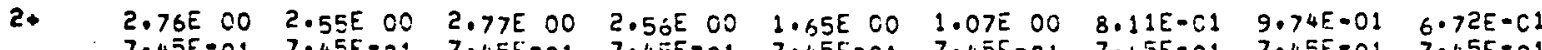
$7.45 E-01 \quad 7.45 E-01 \quad 7.45 E-01 \quad 7.45 E-01 \quad 7.45 E-01 \quad 7.45 E-C 1 \quad 7.45 E-01 \quad 7.45 E-01 \quad 7.45 E-C 1$

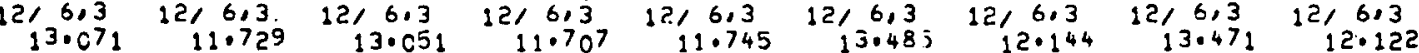

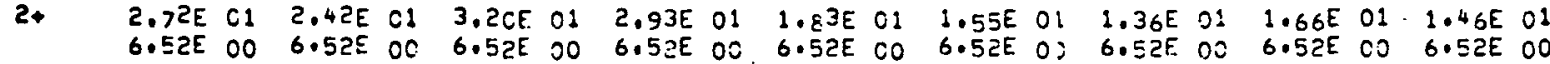

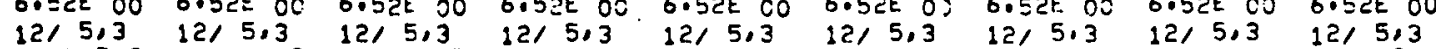
$\begin{array}{rrrrrrrrr}12 / 4.738 & 1215,3 & 1215,3 & 12 / 5,3 & 12 / 5,3 & 12 / 5,3 & 12 / 5.3 & 12 / 5,3 & 12 / 5,3 \\ 14.728 & 13.419 & 1.4057 & 13.343 & 13.913 & 15.667 & 13.912 & 15.655 & 13.900\end{array}$

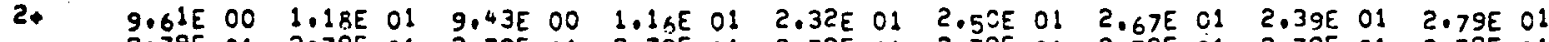

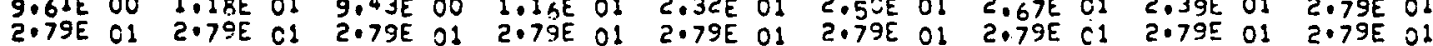

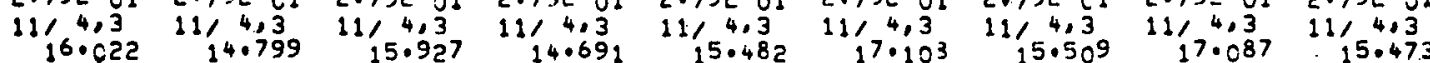

2. 2.78E $00 \quad 3.18 E$ OO $2.94 \mathrm{E} 00 \quad 3.38 E$ OO $3.25 E$ CO $2.51 E$ OO $2.31 E$ CO $2.63 E$ OO $2.45 E$ OO $2.98 E$ CO $2.98 E$ OO $2.98 E$ OO. 2.98E 00 2.98E 00 2.9BE 00 2.98E 00 2.98E 00 2.98E 00

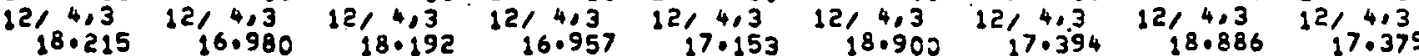


$2+$ $12,6,5$

$14 \cdot 022$

$2+$

$4.08 E$ CO $2.57 E$ OC $6.52 E$

215,5

$$
16 \cdot 3 \mathrm{C}
$$

$2.21 E 00 \quad 2.50 E$ CC $2.16 E$ OC 1214,5 20.5 OO $2.53 E$ CO

19.998

$9.93 E-C^{2}$ 1216,5

$94 E \div 0$
$6.91 E-02$ $7.45 E-01 \quad 7.45 E-5 ?$ 1216,5 13.799

$3.66 E-C 1$ $7.45 E-C$ 13.793

$5 \cdot 75 E-54$ $7.45 E \cdot C$ $14 \cdot 074$

$1.87 E=-22$ I.

$\cos (x)$

$2.43 E$
6.520
1.25

3.795 C0

$13 \cdot 724$

$12, t, 5$ ic/ 6,5

$2.76 E$ CI $2.81 E$ C1

$11 / 4,5$

$11,4,5$ $2 \cdot 79 E$ O 1

127.50
$15 \cdot 50$

6.5?.E OC

4.02500

5.30500

6.165 OO $2.95 E$ OO

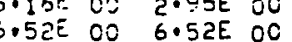

$\begin{array}{rr}12,5.5 & 12,5,5 \\ 16.523 & 16.322\end{array}$

$\begin{array}{ll}6.71 E \cdot 01 & 7.34 E-04 \\ 4.42 E-C 3 & 4.42 E=03\end{array}$

$12,6,3$

$12,6,3$

$11 \cdot 850$

$12,6,3$

$2,4,6 E 00$

16.617

16.935

$16 \cdot 325$

g一E 00 2.58E 00

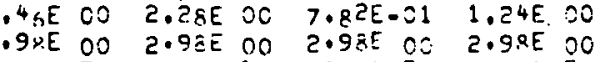

$19 \cdot 788 \quad 12,4,5$

$7.23 E-01 \quad 1.12 E \quad 00$ $.9-\mathrm{E}$ OO $2.98 \mathrm{OE}$ OC

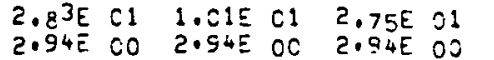

$\begin{array}{rrr}11 \% 6,3 & 11 / 6.3 & 11 / 6,3 \\ 13.480 & 12.154 & 13.470\end{array}$

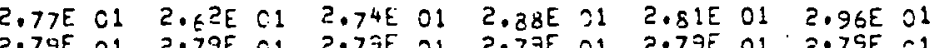

19.754

19.940

4,5
$19 \cdot 341$.

19.935

$12>4,5$

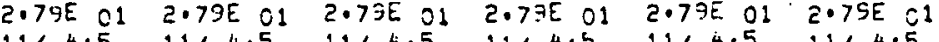

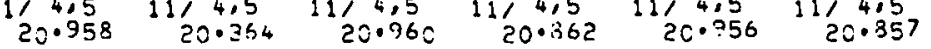

$1.40 E \quad 01 \quad 2.81 E \quad 00 \quad 1.43 E \quad 01 \quad 2.49 E \quad 00 \quad 3.76 E$ OO $3.43 E$ O1 $2.49 E$ CO $3.44 E \quad 01 \quad 2.14 E \quad 00$

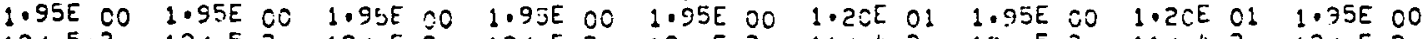

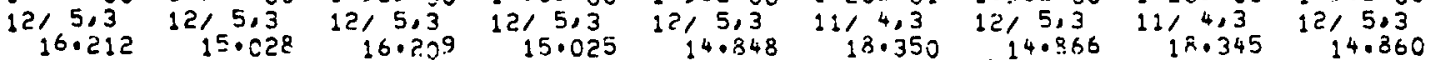

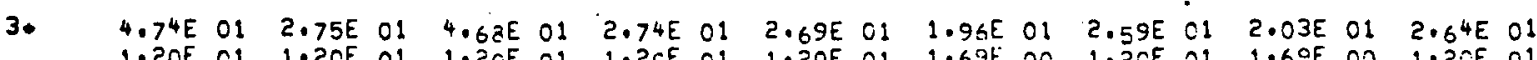
$1.20 E$ O1 1.2CE OI $1.2 C E$ OI $1.2 C E$ OI 1 . 2OE O1 $1.69 E$ OC $1.20 E$ O1 $1.60 E$ OO $1.20 E$ O

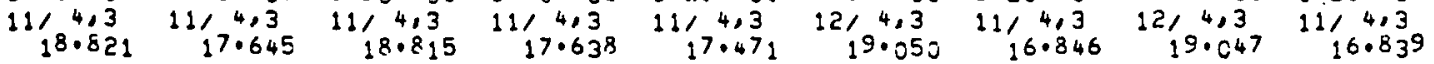

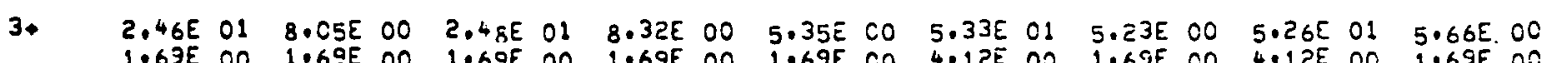
$1.69 E$ OO $1.60 E$ OO $1.69 E$ OO $1.69 E$ OO $1.69 E$ CO $4.12 E$ OO $1.69 E$ CO $4.12 E$ OO $1.69 E$ OO $\begin{array}{rrrrrrrrr}12 / 4,3 & 121.4,3 & 12 / 4,3 & 12 / 4,3 & 12 / 4,3 & 12 / 6,5 & 12 / 4,3 & 12 / 6,5 & 12 / 4,3 \\ 19.208 & 18.058 & 19.205 & 18.055 & 17.893 & 13.658 & 17.591 & 13.645 & 17.586\end{array}$ 
$3+$

$2.50 E$ CO 3.67E CO $\begin{array}{rl}1.12 E \text { OO } & 4.12 E \text { OO } \\ 1216,50 & 12,6,5 \\ 13.749 & 13.424\end{array}$
$1.38 E$
$4.12 \mathrm{OC}$ $4,12 E$
12,60

13.744

$3.46 E$
$4.12 E$ $\begin{array}{ll}3.12 E & 00 \\ 1215,5 & 0\end{array}$

$13 \cdot 419$

$4.64 E 0.0$
$4.12 E 00$ $1=16,5$

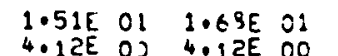
$4.12 E$ OJ $4.12 E$ OO

1.29501 $4.12 E$ DO $\begin{array}{ll}1.77 E & 01 \\ 4.12 E & 00\end{array}$

$5.69 E$ C1 $7.45 E$ CI 1.47E C2 $1.47 E$ CI

5.198 .01 13.333 13.62 :

13.930 13.616

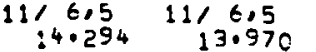
1,47502

$6.83 E \quad 01$

9.C7E 01

$4.1110^{01}$

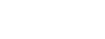

1.0. $: 4 \cdot 294 \quad 13.970$

6,5
$14 \cdot 272$

$1 / 6,5$
$13 \cdot 946$

$11 / 6,5$
13.792

$147 E$ O? $1.47 E$ O? $1.47 E$ O?

$7.42 E \quad 01$ $14 \cdot 356$

6,5
13.839

$1 / 6,5$ 11/ $t, 5$

$3+$

$1.72 E$ O2 1.81E C2 1.5RE O2 $1.72 \mathrm{E}$ 02 $1.83 \mathrm{E}$ C2 7.34

$5.59 E$ C1 5.59 C1 5.598

$\begin{array}{lr}1216,560 & 121,5,5 \\ 16.556\end{array}$

$2,5,5 \quad 12,5,5$

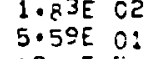

$7.34 E 01$

$1.79 . \mathrm{Cl}^{2}$

$14 \cdot 337$

13.818

3.

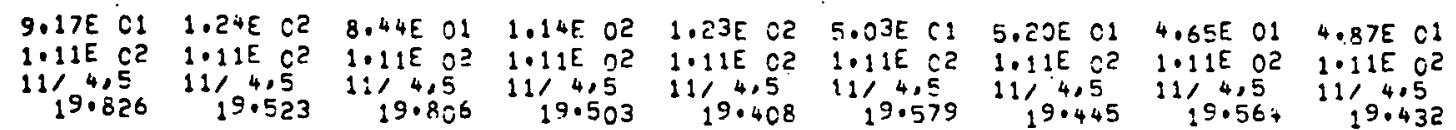

3.

6.44E C1 7.02E O1 6.15E 01 6.96E $01 \quad 3.05 E$ C1 $1.00 E$ C2 $1.24 E$ C2 $9.52 E \quad 01 \quad 1.18 E 02$ $2.41 E$ O1 $2.41 E$ C1 $2.41 E$ O1 $2.41 E$ O1 $2.41 E$ O1 $2.41 E$ Cl $2.41 E$ OI $2.41 E$ O1 $2.41 E \quad 01$

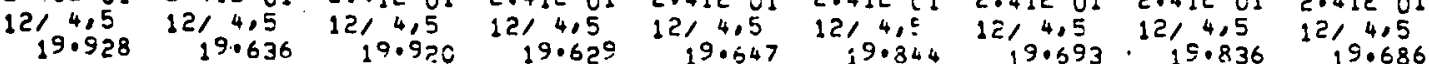

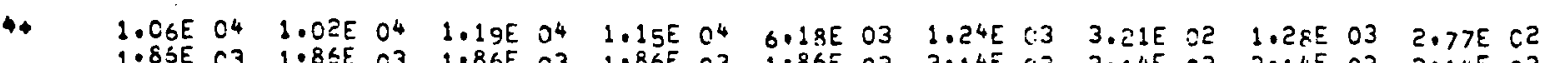
$1.85 E$ C3 1.8SE O3 $1.86 E$ O3 $1.8 \mathrm{KE}$ O3 $1.96 \mathrm{E}$ C3 $3.14 \mathrm{E}$ O3

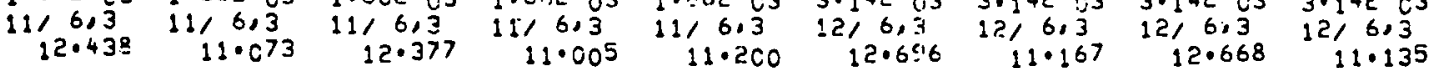

44 $\quad 6.30 E$ C2 $2.21 E$ C2 $9.92 E$ O2 $5.79 E$ O2 $3.36 E$ C3 $6.33 E$ I3 $6.94 E \quad 03 \quad 7.17 E \quad 03 \quad 7.94 E \quad C 3$ $\begin{array}{llllllllllllllllll}3.14 E & 03 & 3.14 E & 03 & 3.14 E & 03 & 3.14 E & 03 & 3.14 E & 03 & 1.86 E & \text { I3 } & 1.86 E & 03 & 1.86 E & 03 & 1.86 E & 03\end{array}$ $\begin{array}{rrrrrrrrr}12 / 6,3 & 12 / 6,3 & 12 / 6,3 & 12 / 6,3 & 12 / 6,3 & 11 / 6,3 & 11 / 6,3 & 1116,3 & 111 / 6,3 \\ 12.553 & 11.187 & 12.518 & 11.147 & 11.351 & 12.5 \% & 11.375 & 12.944 & 11.337\end{array}$

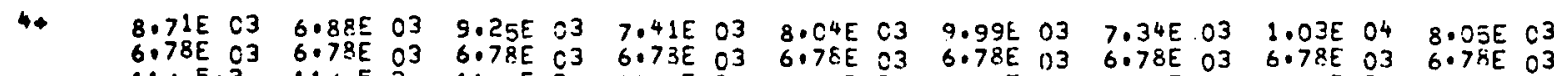

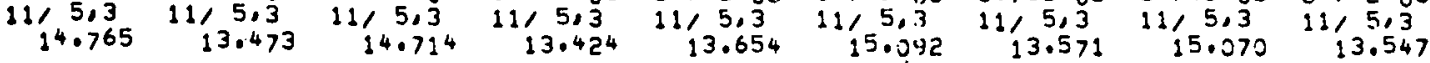

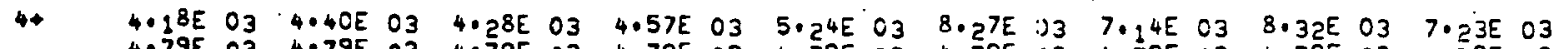
$\begin{array}{lllllllllllllllll}4.79 E & C 3 & 4.79 E & 03 & 4.79 E & C 3 & 4.79 E & 03 & 4.79 E & 03 & 4.79 E & 03 & 4.79 E .03 & 4.79 E & 03 & 4.79 E & 03\end{array}$

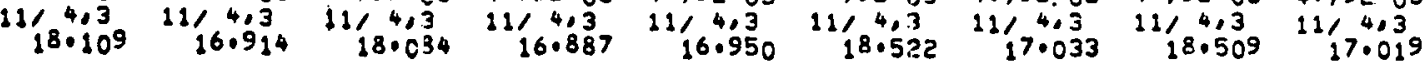


4.

$2 \cdot C 4 E \quad C 3 \quad 1.49 E \quad C^{4}$

$1214,3 \quad 1214,3$

17.564

214,3

1.57503

$1.63 E 03$

4,3

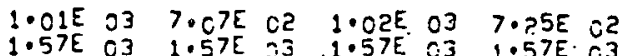

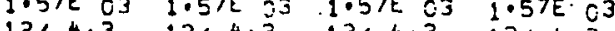

4.

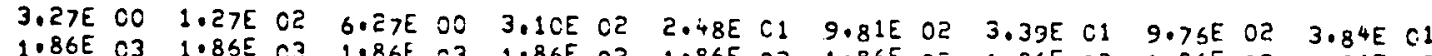

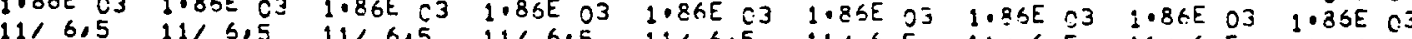

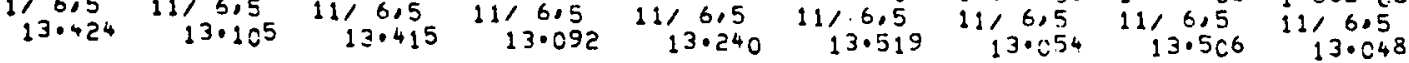

4. $\quad 8.92 E \quad C 2 \quad 2.54 E \quad 03 \quad 8.69 E \quad 02 \quad 2.45 E \quad 03 \quad 3.45 E \quad 03 \quad 4.77 E \quad 02 \quad 3.02 E \quad 03 \quad 4.77 E \quad C 2 \quad 2.73 E \quad 03$ $3.14 E \quad 03 \quad 3.14 E$ C $3 \quad 3.14 E$ O3 $3.14 E$ O3 $3.14 E$ O3 $3.14 E$ O3 $3.14 E$ C3 3.1 HE 03 $3.14 E$ E

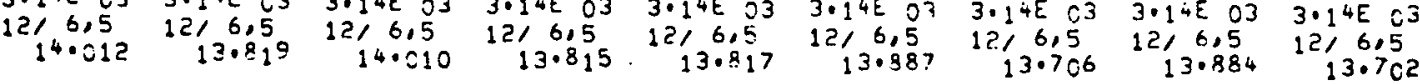

4. 3.C5E $03 \quad 2.96 E \quad C 3 \quad 2.58 E \quad 03 \quad 2.82 E \quad 03 \quad 3.48 E \quad 03 \quad 3.21 E \quad 03 \quad 3.65 E$ O3 $3.26 E$ C3 $3.73 E$ C3

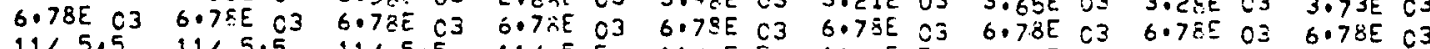

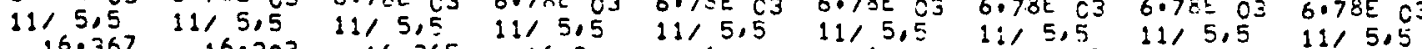

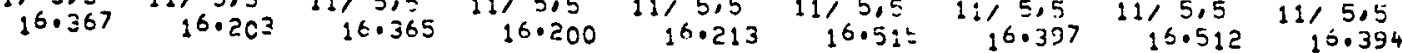

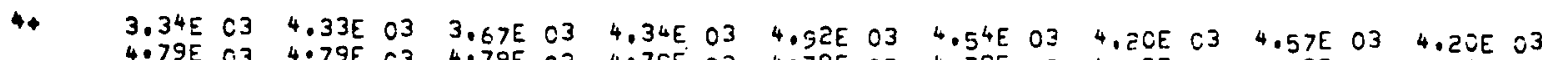
4.79E O3 4.79E C3 4.79E O3 4.79E O3 4.79E C3 $4.79 E$ O 3 4.79E 33 4.79E O3 $4.79 E$ O3

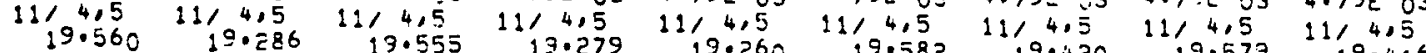

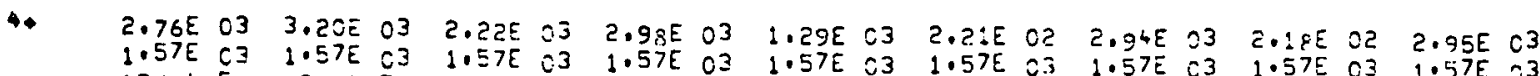

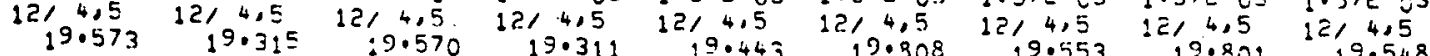

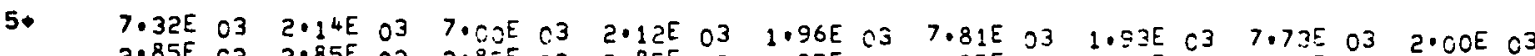

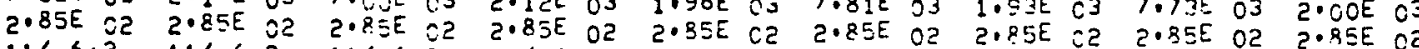
$\begin{array}{rrrrrrrrr}11 / 6,3 & 11 / 6,3 & 11 / 6,3 & 11 / 6,3 & 11 / 6,3 & 11 / 6,3 & 11 / 6,3 & 11 / 6,3 & 11 / 6,3 \\ 12.705 & 11.450 & 12.700 & 11.445 & 11.405 & 12.773 & 11.134 & 12.768 & 11,6\end{array}$

5. $\quad 4.70 E$ C $4.5 .51 E$ C2 $4.73 E$ O4 $2.33 E$ O2 $7.48 E$ C2 $2.23 E$ O5 $1.01 E$ C2 $2.18 E$ 05 $2.41 E$ C1

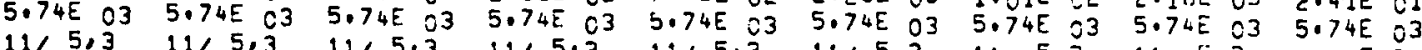

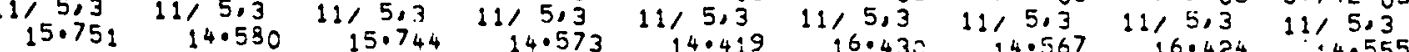

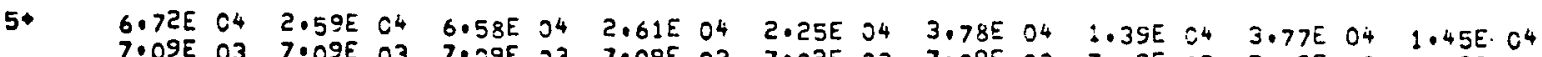

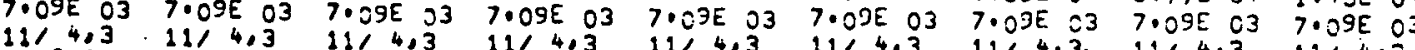

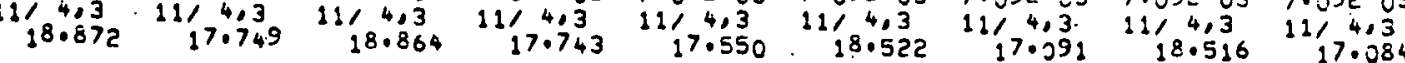


$5+$

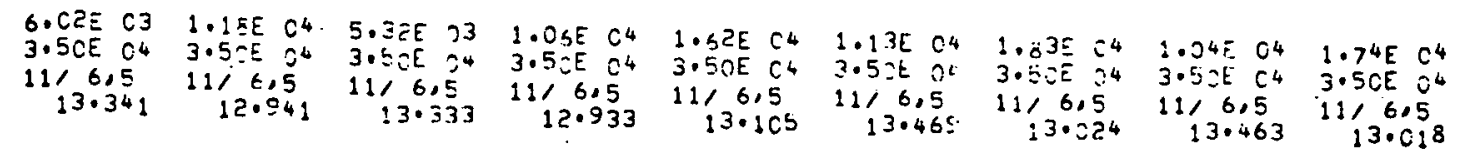

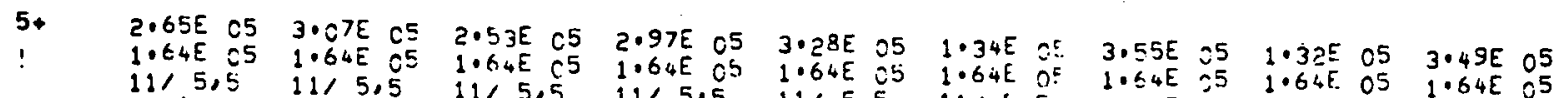

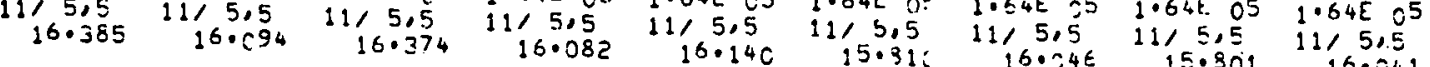

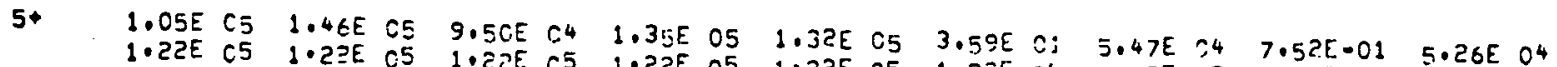

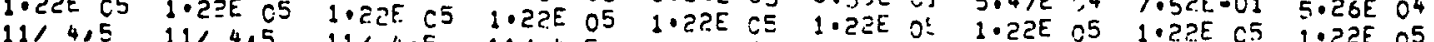

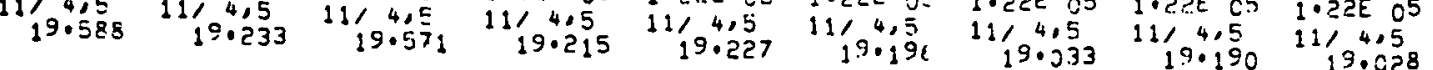

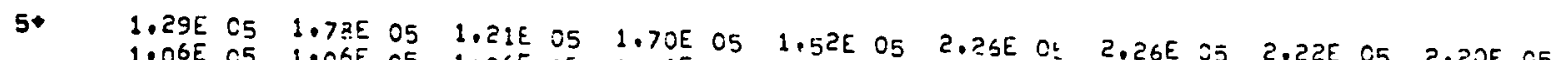
$1.06 E$ C5 1.CGE C5 1.CKE O5 $1.06 E$ O5 $1.06 E$ C5 $1.06 E$ CE $1.26 E$ S5 $2.22 E$ C5 $2.20 E$ OS

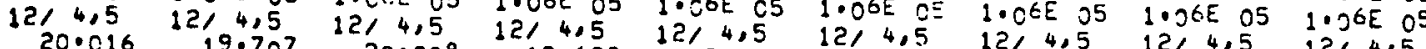

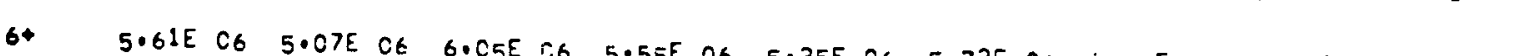

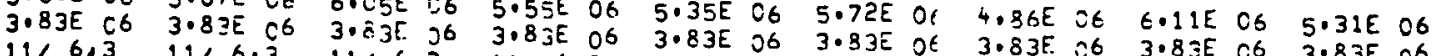
$11 / 6,3 \quad 11 / 6,3 \quad 11,6,3$ 11,6,3 3.83E 06 3.33E OE $3.83 E$ O6 $3.83 E$ C6 $3.83 E$ O6 $\begin{array}{rrrrrrrrr}12.014 & 11 / 6.3 & 11 / 6,3 & 11 / 6,3 & 11 / 6,3 & 11 / 6,3 & 11,6,3 & 1115,3 & 1116,3 \\ & 10.623 & 11.954 & 10.557 & 10.85 \mathrm{C} & 12.596 & 10.358 & 12.535 & 10.794\end{array}$

6+. $\quad 2.26 E$ O6 $1.68 E$ O6 $2.31 E$ O6 $1.74 E$ O6 $1.80 E$ C6 $3.13 E$ CE $1.96 E$ O6 $3.12 E$ O6 $1.95 E$ O6

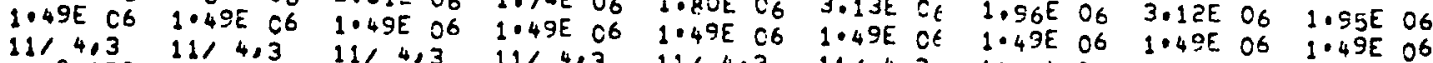

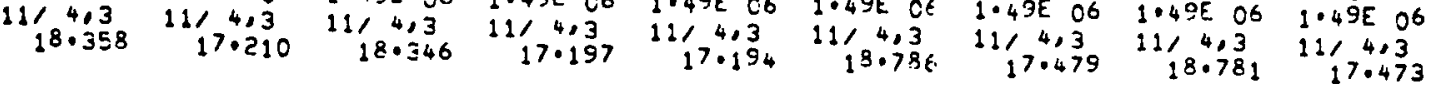

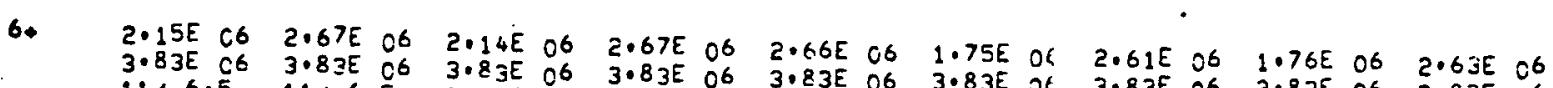
$11 / 6,5$ 11, 6.5 $11 / 6,5$ 3.83E 06 $3.83 E$ O6 $3.83 E$ Of $3.83 E$ O6 $3.83 E$ O6 $3.83 E$ O6

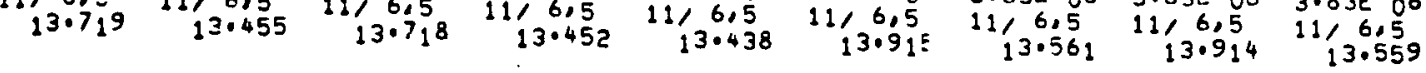

6. $\quad \begin{array}{llllllllllllllllll}6.01 E & 05 & 1.21 E & 06 & 5.8 C E & \text { C5 } & 1.13 E & 06 & 1.13 E & 06 & 2.37 E & 04 & 1.21 E & 06 & 2.38 E & 04 & 1.20 E & 06\end{array}$

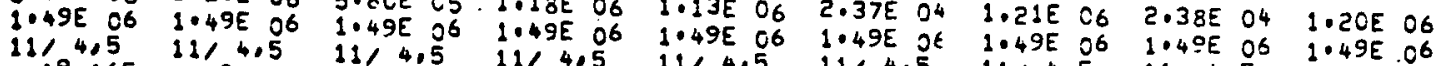

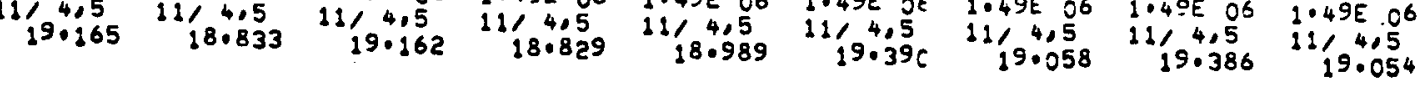




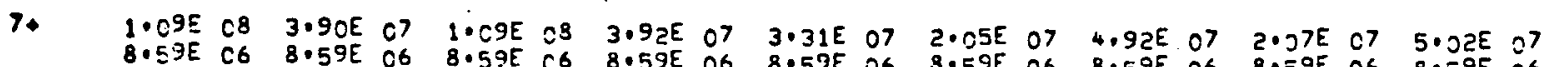

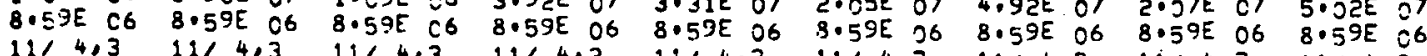

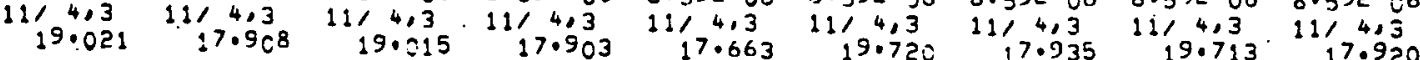
7* $\quad \begin{array}{lllllllllllllllllll}1.45 E & 08 & 2.15 E & 08 & 1.38 E & 08 & 2.07 E & 08 & 2.16 E & 08 & 2.34 E & 08 & 2.05 E & 08 & 2.32 E & 08 & 2.03 E & 08\end{array}$

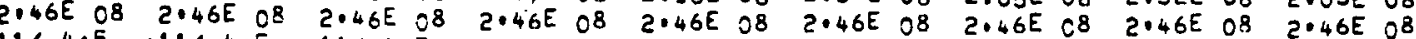

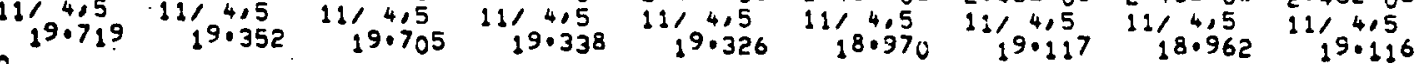
-stap.


TABLE D.3.--

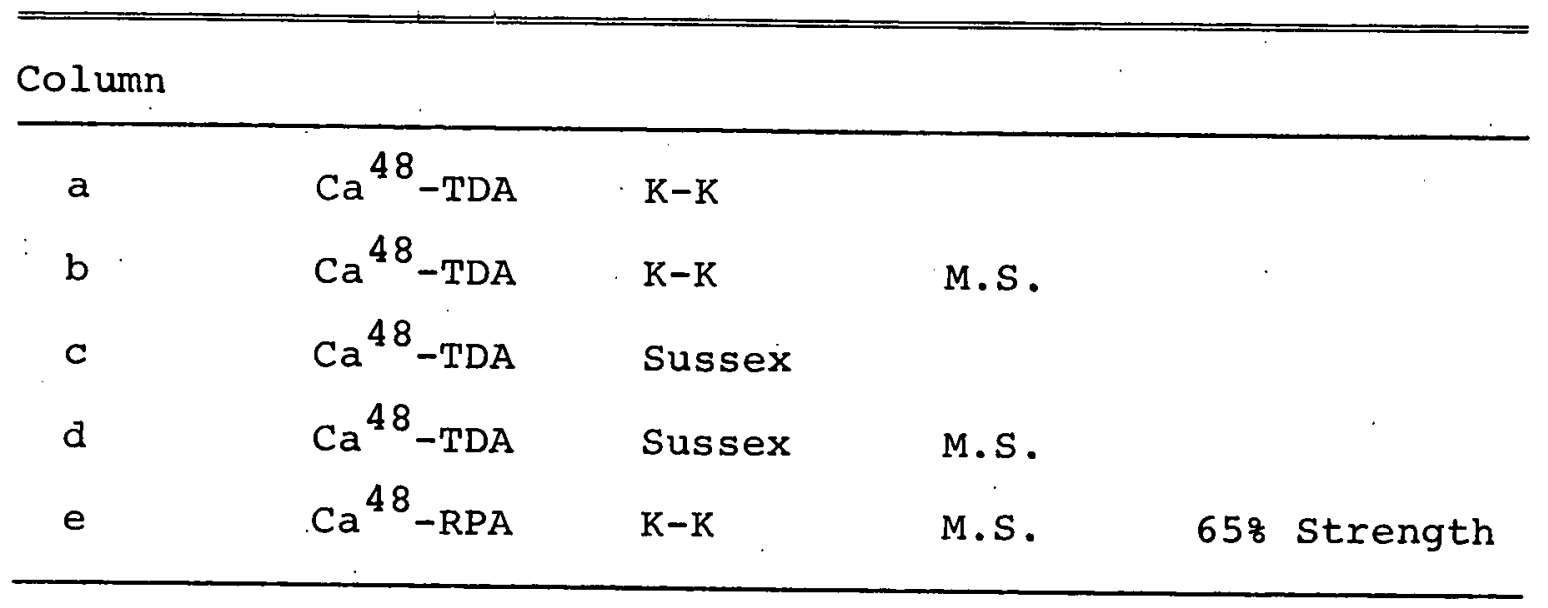




\begin{tabular}{|c|c|c|c|c|c|}
\hline & a & $b$ & C & $d$ & e \\
\hline$\overline{1-}$ & $\begin{array}{r}3.88 E-01 \\
.00 E \text { OO } \\
11 / 7,2 \\
12.180\end{array}$ & $\begin{array}{r}3 \cdot 33 E-01 \\
\cdot 00 E \text { OC } \\
11 / 7,2 \\
11.216\end{array}$ & $\begin{array}{r}6.29 E-01 \\
.00 E \text { 00 } \\
11 / 7.8 \\
12 \cdot 335\end{array}$ & $\begin{array}{r}.59 E-01 \\
.00 E \text { OO } \\
11 / 7.2 \\
11.299\end{array}$ & $\begin{array}{c}5.35 E-01 \\
3.86 E 00 \\
7 / 4.1 \\
10.066\end{array}$ \\
\hline $1-$ & $\begin{array}{r}1.89 E-04 \\
5 \cdot 37 E-C 1 \\
8 / 5,3 \\
7 \cdot 192\end{array}$ & $\begin{array}{c}1 \cdot 93 E-C 3 \\
5 \cdot 37 E-01 \\
8 / 5.3 \\
6 \cdot 298\end{array}$ & $\begin{array}{c}1.93 E-03 \\
5.37 E-01 \\
8 / 5.3 \\
7.183\end{array}$ & $\begin{array}{c}4.36 E-03 \\
5 \cdot 37 E-01 \\
8 / 5.3 \\
5.974\end{array}$ & $\begin{array}{r}4.65 E-01 \\
.0 O E \text { CO } \\
11 / 7,2 \\
10.667\end{array}$ \\
\hline $1=$ & $\begin{array}{c}3.42 E-03 \\
3.86 E-01 \\
8 / 4.3 \\
7.548\end{array}$ & $\begin{array}{r}2.49 E-03 \\
3.86 E-01 \\
8 / 4.3 \\
6.539\end{array}$ & $\begin{array}{c}4.97 E-04 \\
3.86 E=01 \\
8 / 4.3 \\
7.971\end{array}$ & $\begin{array}{r}1.13 E-04 \\
3.86 E-01 \\
8 / 4.3 \\
6.652\end{array}$ & $\begin{array}{r}4.53 E-03 \\
5.37 E-C 1 \\
8 / 5.3 \\
5.327\end{array}$ \\
\hline $1-$ & $\begin{array}{c}2 \cdot 33 E-03 \\
4 \cdot 29 E-02 \\
816 \cdot 3 \\
10 \cdot 341\end{array}$ & $\begin{array}{c}8.99 E=05 \\
4 \cdot 29 E=02 \\
8 / 6.3 \\
9.234\end{array}$ & $\begin{array}{c}8.40 E-1,3 \\
4.29 E=02 \\
8 / 6: 3 \\
10 \cdot 771\end{array}$ & $\begin{array}{r}3.25 E-0 ? \\
4.29 E=02 \\
8 / 6: 3 \\
3 \cdot 525\end{array}$ & $\begin{array}{r}7.78 E-03 \\
4 \cdot 2.9 E-02 \\
8 / 6.3 \\
7.325\end{array}$ \\
\hline $1-$ & $\begin{array}{c}3.27 E-C ? \\
2.68 E-C 1 \\
10 / 5,3 \\
11.171\end{array}$ & $\begin{array}{c}1.69 E-04 \\
1: 35 E=0 \\
9 / 6,3 \\
10.578\end{array}$ & $\begin{array}{c}2.22 E-02 \\
2.65 E-01 \\
10 / 5.3 \\
13 \cdot 376\end{array}$ & $\begin{array}{r}3.0 / E-03 \\
2: 6: E-01 \\
10 / 5.3 \\
12 \cdot 325\end{array}$ & $\begin{array}{r}1.33 E-02 \\
2 \cdot 68 E=01 \\
10 / 5 \cdot 3 \\
3 \cdot .45\end{array}$ \\
\hline $1-$ & $\begin{array}{c}5.07 E-02 \\
1: 35 E 00 \\
9 / 6,3 \\
11.642\end{array}$ & $\begin{array}{c}1.59 E-02 \\
2 \cdot 685-01 \\
10 / 5,3 \\
11.629\end{array}$ & $\begin{array}{c}1.94 E=20 \\
3.86 E=01 \\
3 / 423 \\
14.19 ?\end{array}$ & $\begin{array}{c}1.4 O E-C 2 \\
9.65 E-02 \\
9 / 4.3 \\
17.377\end{array}$ & $\begin{array}{c}1.66 E-02 \\
1 \cdot 35 E 00 \\
9 / 6.3 \\
10 \cdot 358\end{array}$ \\
\hline $1-$ & $\begin{array}{c}3.24 E-0 ? \\
9.66 E-0 ? \\
9 / 413 \\
16.579\end{array}$ & $\begin{array}{c}6.24 E-02 \\
9.6 \leq E-02 \\
9 / 4,3 \\
15.490\end{array}$ & $\begin{array}{c}1.33 E-02 \\
9.66 E-22 \\
9 / 4.3 \\
18 \cdot 639\end{array}$ & $\begin{array}{c}1.33 E=0 ? \\
3.43 E=0 ? \\
8 / 6.4 \\
8 \cdot 248\end{array}$ & $\begin{array}{c}1.29 E-01 \\
9.66 E=02 \\
9 / 4.3 \\
14.802\end{array}$ \\
\hline $1-$ & $\begin{array}{c}5 \cdot 76 E-03 \\
3.43 E-02 \\
8 / 6.4 \\
9.237\end{array}$ & $\begin{array}{c}3.5 .9 E=0.3 \\
3.4 .3 E=02 \\
8 / 6.4 \\
8.108\end{array}$ & $\begin{array}{c}3.04 F=02 \\
3.43 E-02 \\
8 / 6.4 \\
9.334\end{array}$ & $\begin{array}{c}2.32 E-03 \\
4.29 E-01 \\
8 / 5.4 \\
3.847\end{array}$ & $\begin{array}{c}1.05 E-02 \\
3.43 E-02 \\
8 / 6.4 \\
8.297\end{array}$ \\
\hline $1=$ & $\begin{array}{c}1.08 E-02 \\
4.29 E-01 \\
8 / 5,4 \\
10.171\end{array}$ & $\begin{array}{c}5 \cdot 28 E-0.3 \\
4 \cdot 29 E-01 \\
8 / 5.4 \\
8.605\end{array}$ & $\begin{array}{c}7.34 E-02 \\
4.29 E-01 \\
815.4 \\
10 \cdot 111\end{array}$ & $\begin{array}{r}3.53 E-01 \\
1.77 E-01 \\
10 / 6: 4 \\
10.166\end{array}$ & $\begin{array}{c}8.13 E-03 \\
4.29 E-01 \\
815.4 \\
8.720\end{array}$ \\
\hline
\end{tabular}




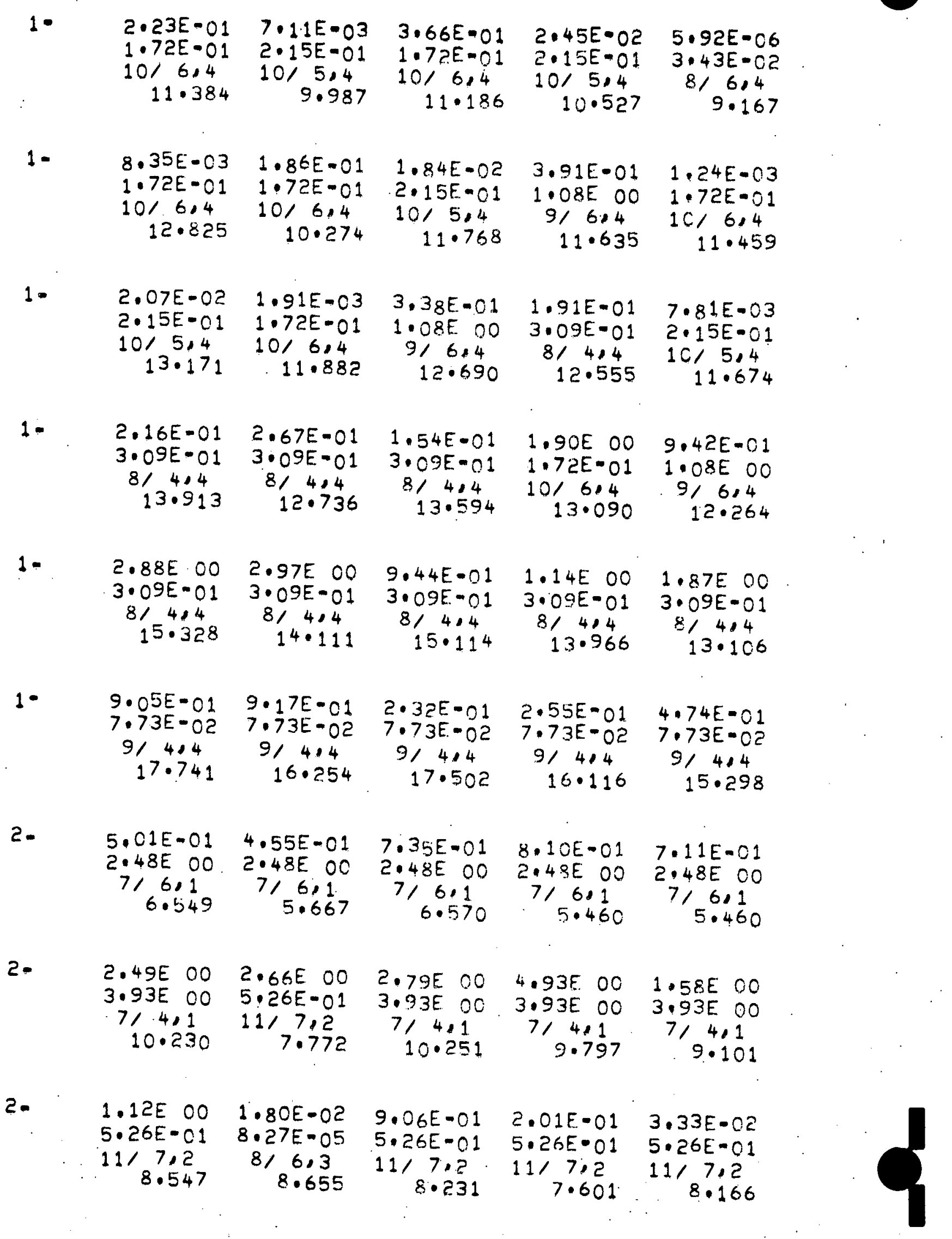


$5 \cdot 50 E-02$ $8 \cdot 27 E-05$

$8 / 6,3$

8.673

2

$1 \cdot 75 E-C 1$ $1 \cdot 79 E-C 3$ $10 / 6,3$

$10 \cdot 900$

2.

1. $30 E-C 1$

7.15E-O?

$8 / 4,3$

$11 \cdot 893$

2.

$$
\begin{gathered}
3.88 E-01 \\
6.14 E-02 \\
9 / 6.3 \\
12.105
\end{gathered}
$$

2.

1.96E-01 . OOE 00

$9 / 5,3$ $12 \cdot 397$

2.

$$
\begin{array}{r}
6.13 E-C 2 \\
. C O E, O O \\
9 / 5,3 \\
12.685
\end{array}
$$

2

$$
\begin{array}{r}
1.47 E C O \\
1.02 E-0 ? \\
10 / 4,3 \\
14.375
\end{array}
$$

$2=$

$$
\begin{array}{r}
2.89 E=01 \\
4 \cdot 96 E=04 \\
914.3 \\
15.985
\end{array}
$$

$2=$
$1.44 E \quad 00$

$6.89 E-02$

$8 / 5,3$

9.378

7.97E- 01

$1 \cdot 79 E-03$

$10 / 6.3$

$11 \cdot 115$

$9 \cdot 35 E-02$ - COE OO

$9 / 5.3$

$11 \cdot 296$

1.87E-C1

$6 \cdot 14 E-02$

$9 / 6.3$

12.229

$7.26 E-01$

$7 \cdot 15 E-0$ ?

$8 / 4,3$

12.707

$1.34 E O C$

1. $C 2 E-02$

$10 / 4,3$

$13 \cdot 215$

1. $49 E-01$

4. $96 E-0^{4}$

$9,4,3$

$14 \cdot 801$

$3.96 E-04$

$6 \cdot 26 E-02$
$8 / 6,4$
7.515

1.82500

$1.58 E$ OO

$8 / 5,4$

$9 \cdot 211$

$9,4,3$

$15 \cdot 60^{8}$

$5.98 E-01$
$1.02 E-02$

$10 / 4,3$

16.753

1. $27 E-0 ?$

$4.96 E-04$

7/ 4,3

$14 \cdot 480$
$3.48 E C O$

$1.58 E$ OO

$8 / 5,4$

7.835

$6 \cdot 70 E-02$

1.79E-03

$16 / 6: 3$

9.809

1. $21 E-01$

$7 \cdot 15 E-C 2$

$8 / 4: 3$

$10 \cdot 739$

$7.15 E-02$

- OOE OC

$9 / 5,3$

11.231

$1.04 E$ OC

1. O2E-Oa

$10 / 4,3$

12.977

$1.77 E-01$

4. $96 E-C 4$

$9 / 4: 3$

14.543

1. $22 E-02$

$6 \cdot \hat{c} 6 \mathrm{E}-02$

$81.6,4$

8.709
$1.25 E 00$ $1.58 E \quad 00$

$8 / 5,4$

9.416
7.59E-01

$1.58 E$ OC

$8 / 5,4$ 8.073
$1 \cdot 325-02$

$6 \cdot 2.6 E-0.2$

$8 / 6,4$ 9.714
$7.14 E-01$ 1. $02 E-02$.

$10 / 4 \cdot 3$

$15 \cdot 394$

$2.48 E 00$ $1.58 E 00$

2) 5.4 7.741

$3.27 E \quad 00$ 1.58E OC

है। 5,4 9.560 
$2-$

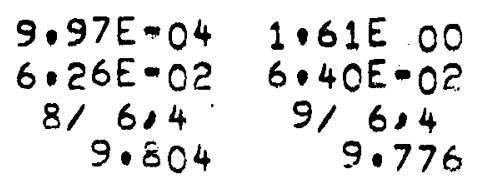

$9.97 E-04$
$6.26 E-02$
$8 / 6.4$
9.804

$2=$

$\begin{array}{ll}2.35 E & C O \\ 1.58 E & 00\end{array}$

$8 / 5,4$

11.002

2

1.31E 00 - OOE OO

$9 / 5,4$

11.526

2

$$
\begin{gathered}
1.57 E-01 \\
6.40 E-02 \\
9 / 6.4 \\
13.375
\end{gathered}
$$

$2-$

$7 \cdot 90 E-01$

$6 \cdot 91 E-01$

$8 / 4,4$

13.824

$2-$

4.18E-01

$3.76 E-01$

$9 / 4,4$

15.558

2

1. 48 E 00

5. $23 E-01$

$10 / 4,4$

16.623

3.

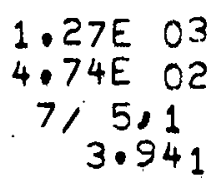

3-
$4 \cdot 77 E-01$
$8.34 E-03$
$10 / 6,4$
9.856

1.57E OC - OOE OC

$9 / 5,4$

$10 \cdot 330$
1.39E-01

$8 \cdot 34 E-03$

$10 / 6,4$

$11 \cdot 627$

8.19E-01

3. $76 E-01$

$9 / 4,4$

$14 \cdot 182$

1. 32E CO

$5 \cdot 23 E-01$.

$10 / 4,4$

15.454

$1.28 E \quad 03$

$4.74 E$ O?

$7 / 5,1$

$3 \cdot 141$

2.27E-01

$3.18 E \quad 00$
$3.34 E=01$

- COE 00

$5 \cdot 93 E-02$

6.91E-O1

$8 / 4,4$

10.763
$9 / 5.4$.

$11 \cdot 674$

3.15E.02

- ODE 00

9) 5,4

$11 \cdot 304$

$7 \cdot 39 E-02$

$8 \cdot 34 E-03$

$10 / 6,4$

$12 \cdot ? 32$

$9.87 E-02$

$6.40 E-02$

$9,6,4$ $12 \cdot 341$.

$3.59 E=01$
$.00 E=00$
915.4
10.546

$4.46 E-02$ - OOE OO

$9 / 5,4$ 10.721

$3 / 6: 4$

$8 \cdot 597$

1. $01 E-01$

$8 \cdot 34 E-03$

$10 / 6,4$

$11 \cdot 138$
4.84E-01

$6.40 E-02$

$9 / 6,4$

$10 \cdot 287$

3.15E-01 - ODE OC 9) 584 10.866

3.19E-04

8. 34E-03

$10 / 6,4$

$11 \cdot 413$

$1 \cdot 95 E-01$

$6.40 E-02$

$9 / 6,4$

$11 \cdot 853$

1. 06E 00

6.91E-D1

$8 / 4,4$

13.875

$1 \cdot 09 E-06$

$6.40 E-02$

$9 / 6,4$

$11 \cdot 229$

6. 20E- 01

6. $91 E-01$

$8 / 4.4$

$12 \cdot 607$

$6 \cdot 52 E-01$

5. $23 E=01$

$1.14 E \quad 00$

4.97E-01

$6.91 E-01$

$3 \cdot 76 E-01$

$8 / 4,4$

$9 / 4,4$

$14 \cdot 384$

12.669

14.076

$1.48 E-01$

1. $52 E 00$

9.16E-01

3. $46 E-01$

15.855

3.76E-01

$9 / 4,4$

5. $23 E-01$

$10 / 4,4$

$14 \cdot 265$

$15 \cdot 212$

1.23E 03

$1.25 E \quad 03$

2.16E O3

$4.74 E$ O2

$4.74 E$ O2

$7 / 5,1$

4.74E O2

7/ 5,1 4.633

$3 \cdot 686$

3.711

$1.42 E$ O2

$7 / 6,1$

$5 \cdot 618$

1.42E O?

$7 / 6,1$

4.787

$7.84 E=0^{4}$

$1.42 E$ O2

$7 / 6,1$

1.37E 01

1.59E 01

$1.42 E$ O2 1.42E.02.

$7 / 6,1$

$7 / 6,1$

$5 \cdot 829$

$4 \cdot 825$

$4 \cdot 871$ 
$3-$

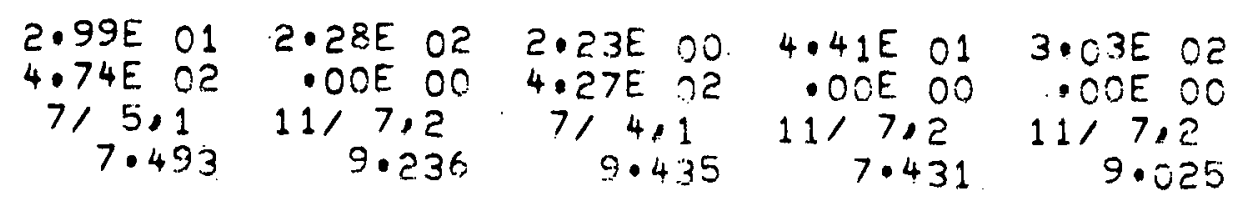

3.

$9 \cdot 64 E-02$
$1 \cdot 33 E$ C?
$8 / 6,3$
$8 \cdot 358$

$2.53 E 01$ $1.33 E \cdot 02$

$8,6.3$

$6 \cdot 613$

$9.51 E 00$ - OCE DO

$11 / 7 ! ?$

$8 \cdot 349$

$3.43 E$ O? .00500

$11 / 7: 2$

$3 \cdot 151$

1.51E CE

$1.33 E \quad 0$ ?

$8 / 6: 3$

6.790

$3-$

5.99E 01

$1.23 E$ O?

$9 / 6,3$

11.013

$9 \cdot 05 E$ OO

$8.54 E \quad 01$

$1.33 \mathrm{E} 0 \mathrm{C}$

$8 / 6,3$

$8 / 6 \cdot 3$

7.631

$6.29 E 01$

1.33E O2

$8 / 6.3$

7.394

6.453

$4 \cdot 71 E \quad 01$

1.33E 02

$3 / 6,3$

7.548

3.

$3.94 \mathrm{E} 01$ 8.85E O1

$8 / 4,3$

11.584

$7.64 E 01$

$8.85 E$ O 1

$8 / 4,3$

10.520

6.31E 00

$1.78 \mathrm{E} C$

$9,5,3$

$11 \cdot 664$

$1.6 .3 E \quad 00$

$1.7 \% E$ O?

$9 / 5,3$

10.466

$2.55 E 01$

$1.78 E$ O2

$3 / 5,3$

$10 \cdot 312$

3-

$1 \cdot 18 \mathrm{E} \mathrm{C1}$

$1.78 E$ O?

$9 / 5.3$

12.272

$1 \cdot 45 E \quad 01$

$1.28 E$ O2

$9 / 6.3$

$11 \cdot 228$

1.2.2E O. 1.84E OC

1.23E O2 1.23E O?

$9 / 6: 3$

$12 \cdot 393$

9) 6.3

$11 \cdot 511$

$5 \cdot 73 E \quad 01$

$8.85 E$ O1

$8,4: 3$

$10 \cdot 514$

3. $\quad 5.60 E$ O1 5.C9E 01

1.11E O2 1.11E O?

$10 / 4,3 \cdot 10 / 4,3$

$13.974 \quad 12.823$

3.15E O1

$8.85 \mathrm{~F} .01$

$8 / 4,3$

$13 \cdot 801$

$3.1 \mathrm{CE}$ OI

$8.8 ' j E$ OI

$8 / 4,3$

12.560

$1.77 E \quad 01$

$1.28 E$ O2

$9 / 6,3$

$11 \cdot 192$

$3-$

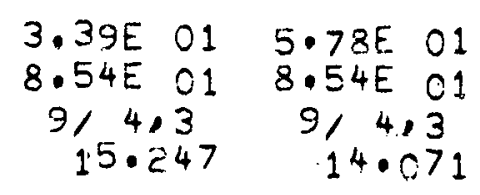

6.8PE 01

$1.11 E 02$

6.61E 01

$1.11 E$ O?

$10 / 4,3$

$14 \cdot 371$

$10 / 4,3$

13.026

$4.29 E \quad 01$

1.11E O2

$10 / 4,3$

12.730

$3-$

$6.13 E 00$ $1.06 \mathrm{E} \mathrm{O2}$

$8 / 6,4$
9.621

$6 \cdot 54 E-01$

$8.54 E \quad 01$

$9.14,3$

8.66E 01

$8.54 E 01$

$8 \cdot 84$ E. 01

$8.54 E \quad 01$

$9 / 4,3$

$9 / 4,3$

$16 \cdot 197$

14.901

$9.80 E$ O1

$8.54 E O 1$

$9 / 4,3$

13.945

3.

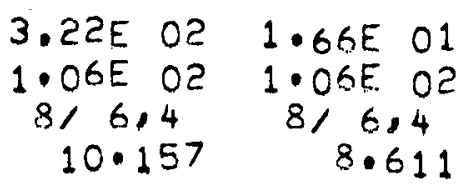

$1.28 E 02$

$1.11 E$ O2

$8.57 E .00$

1.06E 02

$10 / 4,3$

$16 \cdot 604$

8) 6,4

$5.50 E 00$

$1.06 E$ O2

$8 / 6,4$

8.672 


\section{3-}

$$
\begin{array}{r}
4 \cdot 31 E-01 \\
1.42 E 02 \\
9 / 5,4 \\
11.452
\end{array}
$$

3.

$8.94 E \quad 01$
$1.42 E \quad 02$
91514
12.578

$1.03 E \quad 02$

$1.02 E 02$

$9 / 6,4$

9.908

$4.91 E 00$

1.42.E O?

9) 5.4

10.335

$3.74 E \quad 01$

1.02E 02

9/ 6.4

$11 \cdot 247$

816,4

$10 \cdot 024$

2.84E 01

1.02E O2

9/ 6.4

10.208

1.32E 02

1.02E 02

. $3 / 6,4$

9.961

$1.76 E 02$

$7.08 E \quad 01$

$8 / 4,4$

10.964

$5.03 E$ C1

$1.42 E$ O2

9/ 5,4

$11 \cdot 314$

3-

$9 \cdot 35 E .01$
$7.08 E .01$
814.4
13.125

$7.44 E \quad 01$

$1.42 E$ O2

$9 / 5,4$

$11 \cdot 348$

$1.78 E \quad 02$

$7.08 E 01$

3/ 4.4

$12 \cdot 142$

$2.16 E \quad 01$

$1.42 E \quad 02$

$9 / 5.4$

11.272

$9.69 E \quad 01$

$7.08 E \quad 01$

$8 / 4,4$

12.131

3.

$1.72 E-C 1$ $6.83 \mathrm{E} 01$

$9 / 4,4$ 15.715

3.

3.32E O2 $8.85 E \quad 01$ $10 / 4,4$ 16.371

$8.14 E \quad 01$

7.08E 01

$8 / 404$

11.985

$3.96 E \quad 00$

$1.42 E$ O2

$9 / 5,4$

12.592

$3.16 E 02$

$8.85 E$ O1

$10 / 4,4$

$15 \cdot 107$

4-

1.39E CO

4.54E O?

$7 / 6,1$

$5 \cdot 487$

$1.42 E ~ C 1$

4.54E C2

$7,6,1$

$4 \cdot 617$

$6.64 E 01$

$6.83 E .01$

$9 / 4,4$

$15 \cdot 585$

$1.41 E \quad 01$

4.54E O2

$7,6,1$

5.574

$5.83 \mathrm{~F} \quad 01$

$4.54 E \quad 02$

$7 / 6,1$

$4 \cdot 478$

$6.83 E$ O1

9) 4,4

$14 \cdot 170$

$1.23 E 02$

$8.85 E \quad 01$

$10 / 4,4$

$15 \cdot 282$

$6.76 E 00$

$6.83 E \quad 01$

914,4

$14 \cdot 344$

$2.54 E 02$ $8.85 E \quad C 1$ $10 / 4,4$

14.949

$3 \cdot 38 \mathrm{E} \quad 01$

4.54E OZ

$7 / 6,1$

$4 \cdot 730$

$1.84 E \quad 03$

$2.58 \mathrm{E} \quad 03$

$7 / 5,1$

$1.81 E \quad 03$

$2.58 E \quad 03$

$7 / 5,1$

5.557

2.08E 03

$2.58 E \quad 03$

$7,5,1$

$6 \cdot 399$

$2.05 E \quad 03$

$2.58 E \quad 03$

7/ 5 , 1

$5 \cdot 492$

$1.87 E \quad 03$

$2.58 E \quad 03$

$7 / 5,1$

$5 \cdot 458$

$4-$

$3.76 \mathrm{E}^{03}$ $2.65 E$ C3

$7 / 4,1$

9.892

$3.61 E \quad 03$

$2.65 E \quad 03$

$7 / 4,1$.

9.125

$3.83 E \quad 03$

$2.65 E \quad 3$

714,1

9.571

$3.69 E \quad 03$

$2.65 E$ O?

$7 / 4,1$

8.785

$3.23 E \quad 03$

2.65 E C 3

$7 / 4,1$

8.927

4-

$3.61 E$ CI

$7.56 \mathrm{E} 0$ ?

$11 / 7 ; 2$

5.34E OO

$7.56 E$ O?

9.085

$11 / 7,2$

8.410

$7 \cdot 6.3 E-01$

$7.56 E$ O2

$11 / 7,2$

$8 \cdot 678$

$3.04 E \quad 01$

$7.56 E$ O?

$11 / 7.2$

7.957

$5 \cdot 31 E \quad 01$

7.56E O2

$11 / 7,2$

8.425 


\begin{tabular}{|c|c|c|c|c|c|}
\hline $4=$ & $\begin{array}{c}1.37 E \text { O3 } \\
1.02 E \text { O2 } \\
8 / 4,3 \\
12 \cdot 104\end{array}$ & $\begin{array}{c}6.77 E \text { O1 } \\
2.96 E \text { OO } \\
916.3 \\
11.857\end{array}$ & $\begin{array}{c}4.61 E \text { OC } \\
2.96 E, 00 \\
9 / 6.3 \\
12.633\end{array}$ & $\begin{array}{c}3.17 E \text { OC } \\
2.96 E \text { OO } \\
9 / 6.3 \\
11.587\end{array}$ & $\begin{array}{r}1.33 E \text { 03 } \\
1: 02 E \text { 02 } \\
8 / 4.3 \\
10.861\end{array}$ \\
\hline $4-$ & $\begin{array}{c}5.36 E \quad 01 \\
2.74 E-01 \\
9 / 4.3 \\
15.429\end{array}$ & $\begin{array}{c}1.83 E 03 \\
1.02 E 02 \\
8 / 4: 3 \\
12.820\end{array}$ & $\begin{array}{c}1.76 E \text { O3 } \\
1.02 E \text { O2 } \\
8 \% 4.3 \\
13.978\end{array}$ & $\begin{array}{c}2.05 E \text { O3 } \\
1.02 E \text { O2 } \\
814.3 \\
12.720\end{array}$ & $\begin{array}{c}4.66 E \text { O } \\
2.96 E \text { OO } \\
916.3 \\
11.610\end{array}$ \\
\hline 4. & $\begin{array}{c}3.05 E \text { C1 } \\
1.38 E \text { O1 } \\
9 / 6.4 \\
11.781\end{array}$ & $\begin{array}{c}8.52 E=00 \\
2.74 E-01 \\
9 / 4,3 \\
14.289\end{array}$ & $\begin{array}{c}9.76 E \quad 01 \\
2.74 E-01 \\
9 / 4,3 \\
15.094\end{array}$ & 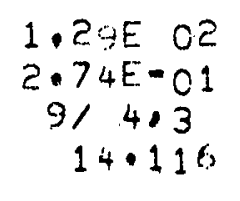 & $\begin{array}{r}4.69 E \quad 01 \\
2.74 E-01 \\
914.3 \\
14.220\end{array}$ \\
\hline $4-$ & $\begin{array}{c}8 \cdot 69 E \text { O } 1 \\
1.38 E \text { O1 } \\
916.4 \\
12.880\end{array}$ & 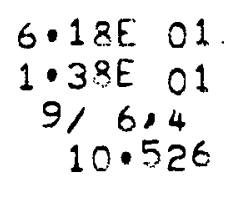 & $\begin{array}{c}1.28 E \text { क } \\
1.38 E \text { C1 } \\
9 / 6.4 \\
11.263\end{array}$ & $\begin{array}{r}1 \cdot 6 O E \text { O2 } \\
1 \cdot 3, E \text { O1 } \\
9 / 6: 4 \\
10 \cdot 238\end{array}$ & $\begin{array}{r}3.40 E \text { O1 } \\
1: 38 E \text { O1 } \\
9 / 6.4 \\
10.443\end{array}$ \\
\hline 4. & 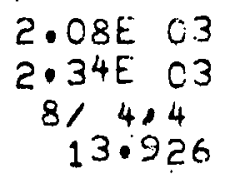 & 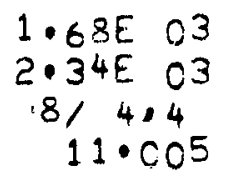 & $\begin{array}{c}1.16 E \\
2.34 E \\
813 \\
11.384\end{array}$ & 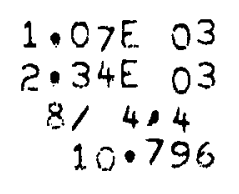 & $\begin{array}{c}2 . \text { COE C.3 } \\
2.34 E \text { O3 } \\
8 / 4.4 \\
12.687\end{array}$ \\
\hline $4-$ & $\begin{array}{c}4.57 E \text { 02 } \\
2 \cdot 0.7 E .02 \\
9 / 4.4 \\
14.940\end{array}$ & $\begin{array}{c}6.36 E \text { C2 } \\
2 \cdot 07 E \text { C2 } \\
9 / 4.4 \\
13.499\end{array}$ & $\begin{array}{c}1.92 E \text { D2 } \\
2.07 E .02 \\
9 / 4.4 \\
15.485\end{array}$ & $\begin{array}{c}1.7+E \text { O? } \\
2.07 E \text { O? } \\
3 / 4.4 \\
13.716\end{array}$ & $\begin{array}{c}3.54 E \text { O2 } \\
2.07 E \text { O2 } \\
914: 4 \\
13.677\end{array}$ \\
\hline $5-$ & 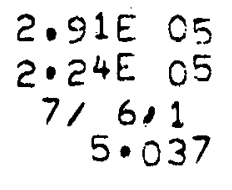 & $\begin{array}{rl}2 \cdot 92 E & 05 \\
2 \cdot 24 E & 05 \\
7,6 & 1 \\
4 \cdot 157\end{array}$ & $\begin{array}{c}2.91 E \text { C5 } \\
2.24 E .05 \\
7 / 6.1 \\
5.429\end{array}$ & $\begin{array}{c}2.92 E \text { O5 } \\
2.24 E \text { O5 } \\
7 / 6.1 \\
4.318\end{array}$ & $\begin{array}{r}3.31 E \text { O5 } \\
2 \cdot 24 E \text { O5 } \\
7 / 6.1 \\
4.409\end{array}$ \\
\hline 5- & $\begin{array}{r}6.70 E \text { C4 } \\
9.61 E \text { C4 } \\
7 / 4.1 \\
9.398\end{array}$ & $\begin{array}{c}6.08 E \quad 0^{4} \\
9.61 E \text { O4 } \\
7 / 4.1 \\
8.677 \\
\end{array}$ & $\begin{array}{c}8.33 E, 04 \\
9.61 E, 04 \\
7 / 4,1 \\
9.472\end{array}$ & 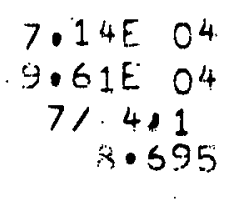 & $\begin{array}{r}6.25 E \quad 04 \\
9.61 E \quad 04 \\
7 / 4.1 \\
8.633\end{array}$ \\
\hline $5-$ & $\begin{array}{r}1.36 E \text { O4 } \\
.00 E \text { OO } \\
11 / 7.2 \\
8.488\end{array}$ & $\begin{array}{c}1.95 E \text { O4 } \\
.00 E .0 O \\
11 / 7.2 \\
7.764\end{array}$ & $\begin{array}{r}9.91 E \text { O3 } \\
.00 E 00 \\
11 / 7 . ? \\
8.985\end{array}$ & 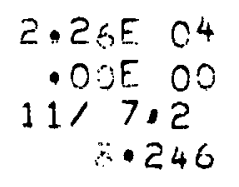 & $\begin{array}{r}3.25 E \text { O4 } \\
. \text { COE OC } \\
11 / 7.2 \\
7.969\end{array}$ \\
\hline
\end{tabular}




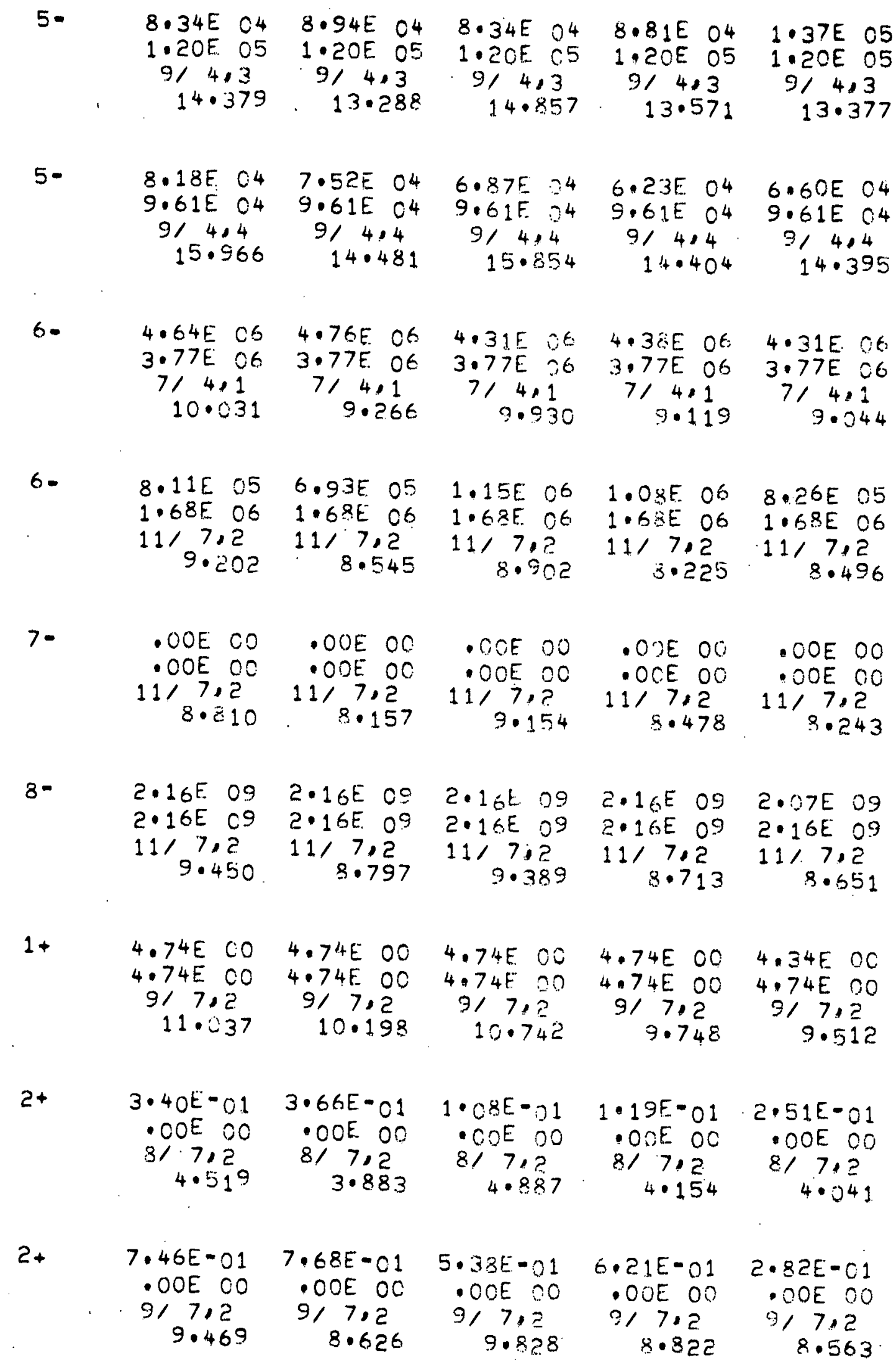
$1 \cdot 08 E-01$
- coE DO
$817 . ?$ - ONE OC
$8 / 7.2$
$4 \cdot 154$
$2 \cdot 51 E-01$
- OOE 00
8/ 7:?
$4 \cdot 041$

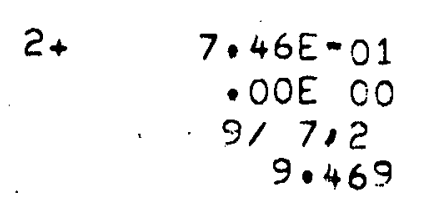
$7.68 E-01$
- OOE OC
$9 / 7.2$
8.626
$5 \cdot 38 E-01$
- OOE 00
$9 / 7,2$
9.828
$6 \cdot 21 E-01$
. OOE OO
I, 7.2
8.822
$2 \cdot 82 E-C 1$
. DOE 00
$9,7,2$
8.563

5
年

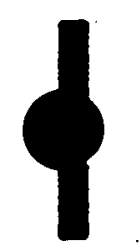




\begin{tabular}{|c|c|c|c|c|c|}
\hline $2+$ & $\begin{array}{c}1.54 E \text { OI } \\
2.93 E \text { O1 } \\
11 / 4.3 \\
13.942\end{array}$ & 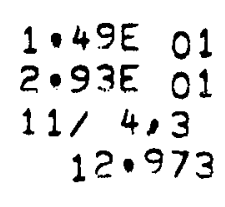 & 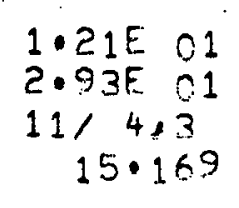 & 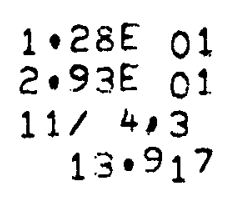 & $\begin{array}{c}1.43 E \\
2.93 E \\
11 / 4,3 \\
13.576\end{array}$ \\
\hline $2+$ & $\begin{array}{c}3.63 E . O 1 \\
2.34 E \text { O1 } \\
11 / 4,4 \\
19.845\end{array}$ & 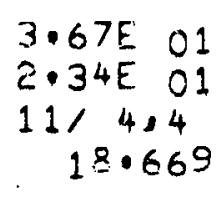 & $\begin{array}{r}4 . O 1 E \text { O1 } \\
2.34 E \text { O1 } \\
11 / 4,4 \\
19.5200\end{array}$ & $\begin{array}{c}3.92 E \text { OI } \\
2.34 E \text { O1 } \\
11 / 4.4 \\
18.584\end{array}$ & $\begin{array}{r}4.08 E \\
2 \cdot 34 E \\
11 / 4.4 \\
18 \cdot 16\end{array}$ \\
\hline $3+$ & 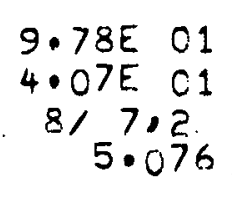 & 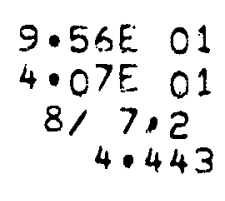 & $\begin{array}{r}1.14 E \text { 02 } \\
4: 07 E \text { O1 } \\
8 / 7.2 \\
5.021\end{array}$ & 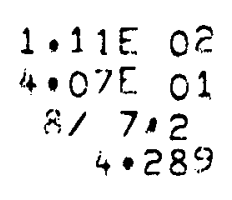 & 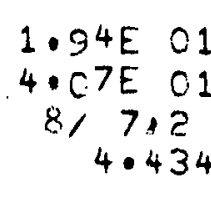 \\
\hline $3+$ & $\begin{array}{r}1.03 E \text { O2 } \\
1.08 E \text { O2 } \\
10 / 7,2 \\
7.350\end{array}$ & $\begin{array}{r}1.02 E \text { O2 } \\
1.08 E \text { O2 } \\
10 / 7.2 \\
6.675\end{array}$ & $\begin{array}{c}1.18 E \text {.2 } \\
1.08 E \text { 02 } \\
10 / 7,2 \\
7.406\end{array}$ & $\begin{array}{r}1.19 E \text { O2 } \\
1.03 E \text { O2 } \\
10 / 7.2 \\
6.609\end{array}$ & 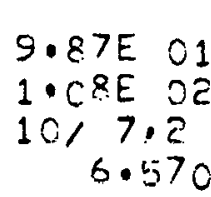 \\
\hline $3+$ & $\begin{array}{r}2.90 E \text { O1 } \\
2.32 E \text { O1 } \\
9 / 7.2 \\
9.268\end{array}$ & 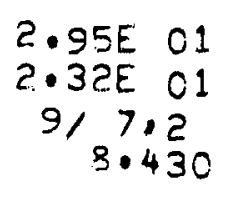 & $\begin{array}{r}1.725 .01 \\
2.32 E .01 \\
9 / 7.2 \\
9.315\end{array}$ & $\begin{array}{cc}1.675 & 01 \\
2.32 E & 01 \\
9 / 7.2 \\
3.315\end{array}$ & $\begin{array}{r}2.31 E 0 \\
2.32 E 0 \\
917.2 \\
8.39\end{array}$ \\
\hline
\end{tabular}

3+ 2.54E O1 2.65E 01 $\begin{array}{cc}3.08 E \text { OO } & 3.08 E \text { CO } \\ 11 / 6,3 & 11 / 6,3 \\ 13.601 & 12.444\end{array}$
4.C.3E O1 3.66E O1 2.69E O1 3.08E OO 3.C.3E OC 3.C8E OD $11 \% 6, ?$ $11 / 6.3$ $11 / 6,3$ $\begin{array}{lll}13.791 \quad 12.411 & 12.231\end{array}$

$3+$

4.32E O1 4.93E O1 $1.26 E$ O1 1.26E 01 $11 / 4,3$ $16 \cdot 327$ $11,4,3$

$6.98 E$ O 1 1.26E 01 1.26E 01 $11 / 4,3$ $15 \cdot 849$ $9 \cdot 95 E-02$
$1 \cdot 26 E \quad 01$
$11 / 4,3$
14.726

3. 30E C1 $1 \cdot 26 E$ OI $11,4,3$ $15 \cdot 013$

$3+$

4.33E C1 4.24E O1 $1.23 E$ O2 $1.23 E$ O2 $11 / 6,4 \quad 11 / 6,4$

9.19E OO B.19E 01 3.08E OO 1.23E O2

6.37E O1 $11 / 6,3 \quad 11 / 6,4$ 1.23E 02 15.851 14.678 $16 \cdot 012$ 14.566 $11 / 6,4$ $14 \cdot 487$

\section{$3+$}

$1.44 E$ O2 1.38E C2 $9.29 E$ O1 $9.20 E$ OI $11 / 4,4 \quad 11 / 4,4$ $19.196 \quad 18.091$

1. $3 O E$ OC 9.295 O1 $11 / 4,4$ 18.873
1. 3อE O? Q. 2OE 01 $11 / 4,4$ 17.766
1. $26 E$ C? 9.2.9E 01 $11 / 4,4$ 17.906 


\begin{tabular}{|c|c|c|c|c|c|}
\hline $4+$ & $\begin{array}{c}8.32 E \text { O1 } \\
.00 E \text { CO } \\
817.22 \\
4.693\end{array}$ & $\begin{array}{r}9.18 E \text { O1 } \\
.00 E \text { OC } \\
817.2 \\
4.059\end{array}$ & $\begin{array}{c}1.45 E \text { O1 } \\
.0 O E \text { OC } \\
817.2 \\
4.913\end{array}$ & 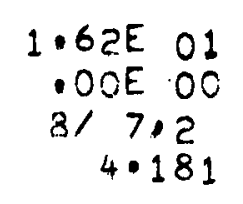 & $\begin{array}{c}1.09 E \text { O2 } \\
.00 E \text { OO } \\
8 / 7.2 \\
4.171\end{array}$ \\
\hline $4+$ & $\begin{array}{r}1.49 E \\
.00 E \\
10 / 7.2 \\
6.809\end{array}$ & $\begin{array}{r}1.70 E \text { O2 } \\
.00 E \text { OC } \\
10 / 7.2 \\
6.133\end{array}$ & $\begin{array}{c}7.38 E \text { O1 } \\
.00 E 00 \\
10 / 7.2 \\
7.023\end{array}$ & $\begin{array}{r}8.79 E \text { O1 } \\
.00 E \text { OO } \\
10 / 7.2 \\
5.221\end{array}$ & $\begin{array}{c}1.64 E \text { O2 } \\
.00 E \text { OO } \\
10 / 7.2 \\
6.226\end{array}$ \\
\hline $4+$ & $\begin{array}{r}5.30 E \text { O2 } \\
.00 E \text { OO } \\
9 / 7,2 \\
8.830\end{array}$ & $\begin{array}{c}5.84 E \text { O? } \\
.00 E \text { CO } \\
917.2 \\
7.979\end{array}$ & $\begin{array}{c}3.55 E \text { C2 } \\
.00 E \text { CO } \\
917.2 \\
9.045\end{array}$ & $\begin{array}{c}4.185 \text { C2 } \\
.00 E \text { OO } \\
917.2 \\
8.033\end{array}$ & $\begin{array}{r}4.43 E \text { OE } \\
.0 O E \text { OO } \\
977.2 \\
8.128\end{array}$ \\
\hline $4+$ & $\begin{array}{r}3.25 E \text {. } 3 \\
7.46 E .03 \\
11 / 5.3 \\
12.332\end{array}$ & $\begin{array}{r}3.24 E \text { O3 } \\
7.46 E \text { O3 } \\
11 / 5.3 \\
11.271\end{array}$ & $\begin{array}{c}1.19 E \text { O3 } \\
7.46 E \text { O3 } \\
11 / 5.3 \\
12.637\end{array}$ & 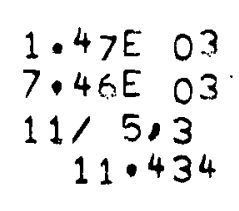 & $\begin{array}{c}3.15 E \text { O3 } \\
7.46 E \text { C. } \\
11 / 5,3 \\
11.385\end{array}$ \\
\hline $4+$ & $\begin{array}{r}5.72 E \text { O2 } \\
2.05 E \text { C.3 } \\
11 / 6,3 \\
12.777\end{array}$ & $\begin{array}{c}4.19 E 02 \\
2.05 E \text { O3 } \\
11 / 6,3 \\
11.622\end{array}$ & 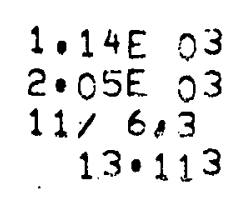 & $\begin{array}{r}1.30 E \text { O3 } \\
2.05 E \text { O3 } \\
11 / 6.3 \\
11.730\end{array}$ & $\begin{array}{r}2.00 E \text { OC } \\
2.05 E \text { O3 } \\
11 / 6.3 \\
11.665\end{array}$ \\
\hline $4+$ & 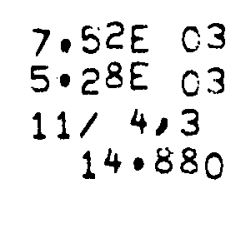 & $\begin{array}{r}4.80 E \\
5 \cdot 28 E \\
11 / 4,3 \\
15.096\end{array}$ & 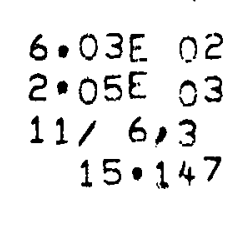 & 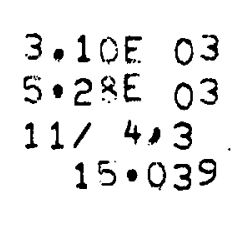 & $\begin{array}{r}4.04 E \text { O3 } \\
5: 2^{8 E}, 03 \\
11 / 4,3 \\
14.391\end{array}$ \\
\hline $4+$ & 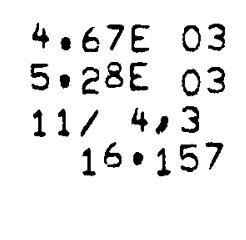 & 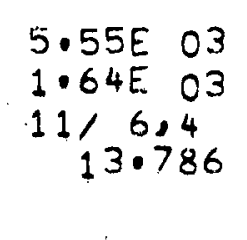 & $\begin{array}{c}3.32 E \text { O3 } \\
5.28 E \text { O3 } \\
11 / 4,3 \\
16 \cdot 235\end{array}$ & 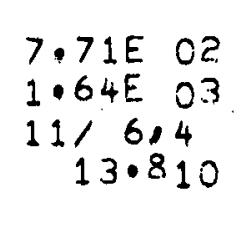 & $\begin{array}{r}3.55 E \text { O3 } \\
1.64 E \text { O3 } \\
11 / 6.4 \\
13.898\end{array}$ \\
\hline $4+$ & $\begin{array}{r}3.38 E \text { O2 } \\
1.64 E \text { C.3 } \\
11 / 6,4 \\
15.009\end{array}$ & 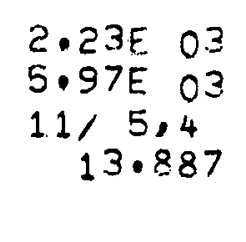 & $\begin{array}{c}9.79 E \text { O3 } \\
5.97 E \text { O3 } \\
11 / 5,4 \\
15.276\end{array}$ & 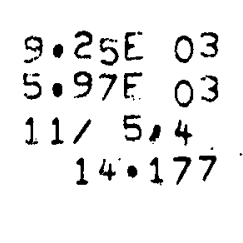 & $\begin{array}{c}7.13 E \text {.03 } \\
5.97 E .03 \\
11 / 5.4 \\
14.021\end{array}$ \\
\hline$+t$ & $\begin{array}{c}9.52 E \quad 03 \\
4.22 E \text { O3 } \\
11 / 4,4 \\
18.681\end{array}$ & 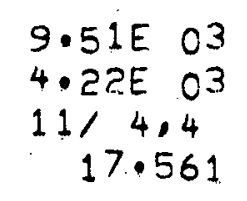 & $\begin{array}{c}1.01 E .04 \\
4.22 E .03 \\
11 / 4,4 \\
18.844\end{array}$ & 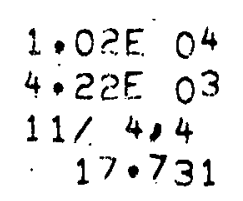 & $\begin{array}{rl}9.26 E & 03 \\
4.22 E & 03 \\
11.4 .44 \\
17.575\end{array}$ \\
\hline
\end{tabular}




\begin{tabular}{|c|c|c|c|c|c|}
\hline $5+$ & 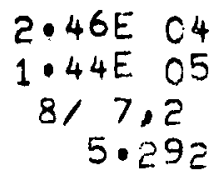 & $\begin{array}{c}2.4 O E \text { O4 } \\
1.44 E \text { O5 } \\
8 / 7.2 \\
4.659\end{array}$ & 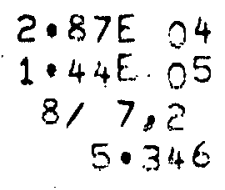 & 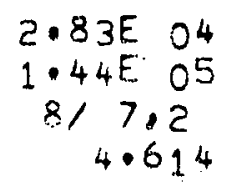 & 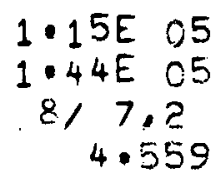 \\
\hline+ & 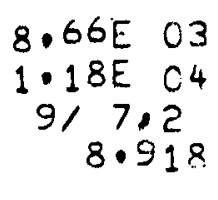 & 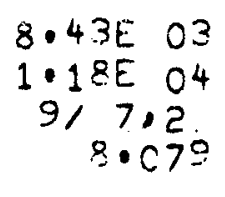 & $\begin{array}{r}6.29 E \text { C3 } \\
1.18 E \text { O4 } \\
9 / 7.6 \\
8.369\end{array}$ & $\begin{array}{rl}6.14 E & 03 \\
1 \cdot 1 . E & 04 \\
9 / 7.2 \\
7.973\end{array}$ & 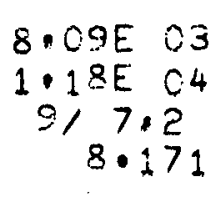 \\
\hline $5+$ & $\begin{array}{cc}2.68 E & 04 \\
3.14 E & 02 \\
11 / 6,3 \\
12.671\end{array}$ & 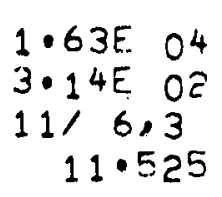 & $\begin{array}{c}3.91 E \\
3.14 E \\
11 / 6,3 \\
12.731\end{array}$ & 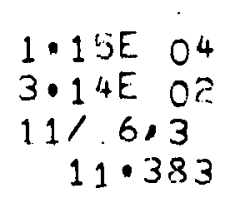 & 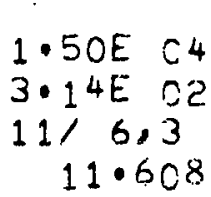 \\
\hline
\end{tabular}

$5+\quad 2 \cdot 00 E$ O5 $6 \cdot 32 E$ C.3 $11 / 5,3$
$13 \cdot 187$

$2 \cdot 10 E$ OS $6 \cdot 32 E \cdot 03$ $11 / 5,3$

$1 \cdot 14 E$ D 5 $6 \cdot 32 E$ O

$2 \cdot 38 E$ O5 $6.32 E$ O.3

$2 \cdot 03 E \quad 05$ $6.32 E$ O3 $12 \cdot 097$ $11 / 5.3$ $11 / 5,3$ $11 / 5,3$ $15 \cdot 6.76 \quad 12.070$ 11.989

$5+$

8.82E $04 \quad 5.86 E \quad 04$ $7.81 E \quad 03$. $11 / 4,3$ $16 \cdot 163$

$6 \cdot 32 \mathrm{E} \quad 03$

1. $27 E \quad 04$

$7.81 E$ O3

$11 / 5,3$

$14 \cdot 534$

$11,4.3$

1.5 .871

$1.21 E \quad 04$

$7.81,03$

$11 / 4,3$

$1, \cdot 684$

$6.89 E \quad 04$

$7.81 E \quad 03$

$11 / 4,3$

14.947

$5+$

$9.73 E$ O2 $1.01 E \quad 05$ $3.08 E \quad 04$

$11 / 6: 4$

$7.81 E$ O3

2.27E 25

$1 \cdot 45 E$ D 5

$4.79 E \quad O 3$

$3 \cdot 0 . S E O^{4}$

$2.46 E .03$

$11 / 4,3$

$11 / 5,4$
$13 \cdot 269$

$11 / 6: 4$

$13 \cdot 667$

$3 \cdot 08 E \quad 04$

$11 / 6.4$

$13 \cdot 856$

$5+$

$6.44 E \quad 04 \quad 1.84 E \quad 03$

$1.45 E$ O5

$11 / 5,4$ 15.620

$3.08 E .04$

$11 / 6,4$

13.757

3.08E 03

$1.23 E$ OS

$1.45 E$ O5

$9.35 E \quad 04$ $1.45 \mathrm{E}$ O5

$11,6,4$

$11 / 5,4$

$11 / 5.4$ $14 \cdot 988$ 14.512

14.472

$5+$

$1.31 E \quad 05$ $1.08 E$ O5

$11 / 4,4$ 19.006

1. 26E C5 1.08E O5 $11 / 4,4$

$1.14 E \quad 05$ $1.08 E$ O5 $11 / 4,4$. 1.20E O5 1. 035 O5

$1.14 E .05$ 1.08E 05 $11 / 4,4$ $11 / 4,4$ 18.598 17.567 17.813

$6+$ $2.59 E$ C5
$.00 E 00$
917.2
8.580

$2.89 E \quad 05$ - OOE 00

$9 / 7,2$
$2.50 E \quad 05$ -OOE 00
$9 / 7,3$ 8.761
3.0OE 05 - OOE 00
917,2 7.734

2.35E C5 - OOE OC $\because 7,2$ 7.955 


\begin{tabular}{|c|c|c|c|c|c|}
\hline $6+$ & $\begin{array}{r}1.05 E \text { O6 } \\
4.42 E \text { O6 } \\
11 / 6,3 \\
12.548\end{array}$ & 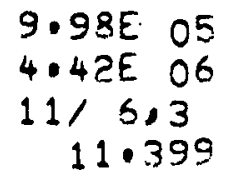 & $\begin{array}{r}5.15 E \text { O5 } \\
4.42 E \text { O6 } \\
11 / 6.3 \\
13.093\end{array}$ & $\begin{array}{c}7.00 E \text { OS } \\
4.42 E \text { O6 } \\
11 / 6.3 \\
11.677\end{array}$ & 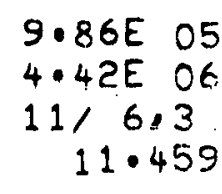 \\
\hline $6+$ & $\begin{array}{r}1.34 E \text { O6 } \\
1.72 E \text { O6 } \\
11 / 4,3 \\
15.819\end{array}$ & $\begin{array}{r}1.2 .3 E \text { O6 } \\
1.72 E \text { O6 } \\
11 / 4,3 \\
14.730\end{array}$ & $\begin{array}{r}1.16 E \text { O6 } \\
1.72 E \text { O6 } \\
11 / 4.3 \\
16.093\end{array}$ & 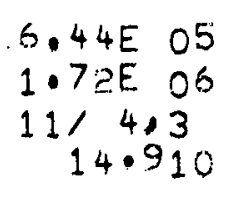 & $\begin{array}{c}5.22 E \text { O5 } \\
1.72 E \text { O6 } \\
11 / 4,3 \\
114.695\end{array}$ \\
\hline $6+$ & $\begin{array}{r}5.45 E \text { OG } \\
3.54 E \text { O6 } \\
11 / 6,4 \\
14.943\end{array}$ & $\begin{array}{r}5.61 E \text { O6 } \\
3.54 E \text { O6 } \\
11 / 6.4 \\
13.792\end{array}$ & $\begin{array}{r}3.39 E \text { C6 } \\
1.72 E \text { O6 } \\
11 / 4.3 \\
18.857\end{array}$ & $\begin{array}{c}6.00 E \text { O6 } \\
3.54 E \text { O6 } \\
11 / 6.4 \\
13.995\end{array}$ & $\begin{array}{c}6.72 E \text { O6 } \\
3.54 E \text { O6 } \\
11 / 6.4 \\
13.391\end{array}$ \\
\hline $6+$ & $\begin{array}{r}2.95 E \text { O6 } \\
1.38 E \text { O6 } \\
11 / 4.4 \\
18.543\end{array}$ & $\begin{array}{r}2.93 E \text { CE } \\
1.38 E \text { OE } \\
11 / 4.4 \\
17.453\end{array}$ & $\begin{array}{c}5.74 E \text { O6 } \\
3.54 E \text { O6 } \\
11 / 6.4 \\
15.276\end{array}$ & $\begin{array}{c}3.41 E \text { O6 } \\
1.38 E \text { O6 } \\
11 / 4.4 \\
17.706\end{array}$ & $\begin{array}{r}2.99 E \text { 06 } \\
1: 38 E 06 \\
11 / 4.4 \\
17.524\end{array}$ \\
\hline $7+$ & 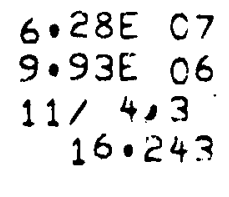 & 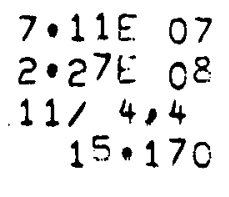 & $\begin{array}{c}1.45 E \text { O8 } \\
9.93 E \text {.6 } \\
11 / 4.3 \\
1 \% .119\end{array}$ & $\begin{array}{r}1.56 E \text { O8 } \\
3.93 E \text { O6 } \\
1114.3 \\
17.947\end{array}$ & $\begin{array}{r}6.01 E \text { O } \\
9.93 E .06 \\
11 / 4.3 \\
15.026\end{array}$ \\
\hline $7+$ & $\begin{array}{cc}1.74 E & 08 \\
2.27 E & 08 \\
11 / 4,4 \\
19.132 \\
0\end{array}$ & $\begin{array}{r}1 \cdot 66 E .08 \\
2 \cdot 27 E \text { C8 } \\
11 / 4,4 \\
18 \cdot 05 C\end{array}$ & $\begin{array}{r}9.29 E \text { O7 } \\
2.27 E \text { O8 } \\
11 / 4.4 \\
16 \cdot 185\end{array}$ & $\begin{array}{rl}8.17 E & 07 \\
2.27 E & 08 \\
11 / 4.14 \\
15.054\end{array}$ & $\begin{array}{c}1.71 E \text { O8 } \\
2 \cdot 27 E \text { 08 } \\
11 / 4,4 \\
17.917\end{array}$ \\
\hline
\end{tabular}


TABLE D.4.--

\begin{tabular}{|c|c|c|c|c|}
\hline Column & & & & \\
\hline$a$ & $\mathrm{Sr}^{88}-\mathrm{TDA}$ & $\mathrm{K}-\mathrm{K}$ & & \\
\hline $\mathrm{b}$ & $\mathrm{Sr}^{88}-\mathrm{TDA}$ & $\mathrm{K}-\mathrm{K}$ & M.S. & \\
\hline C & $S r^{88}-\mathrm{RPA}$ & $\mathrm{K}-\mathrm{K}$ & M.S. & 65\% Strength \\
\hline$d$ & $\mathrm{Sr}^{88}-\mathrm{TDA}$ & Sussex & & \\
\hline e & $\mathrm{Sr}^{88}-\mathrm{TDA}$ & Sussex & M.S. & \\
\hline
\end{tabular}


$\begin{array}{llllll}a & b & c & d & e\end{array}$

\begin{tabular}{|c|c|c|c|c|c|}
\hline $1-$ & $\begin{array}{c}1.74 E-03 \\
.00 E \text { OO } \\
14 / 10.2 \\
7.257\end{array}$ & $\begin{array}{r}1.67 E-03 \\
.00 E 00 \\
14 / 10.2 \\
6.733\end{array}$ & $\begin{array}{r}2 \cdot 29 E-03 \\
.00 E 00 \\
14 / 10,2 \\
6.864\end{array}$ & $\begin{array}{c}3.81 E .05 \\
.00 E 00 \\
14 / 10.2 \\
7.021\end{array}$ & $\begin{array}{r}2.82 E-05 \\
.00 E 00 \\
14 / 10.2 \\
6.477\end{array}$ \\
\hline $1-$ & $\begin{array}{c}2.29 E-02 \\
.00 E, 00 \\
15 / 10.2 \\
8.085\end{array}$ & $\begin{array}{c}2.60 E-03 \\
.00 E \text { OO } \\
15 / 10.2 \\
7.508\end{array}$ & $\begin{array}{c}1.14 E-02 \\
000 E 00 \\
15 / 10.2 \\
7.808\end{array}$ & $\begin{array}{r}3.32 E=03 \\
.00 E \text { OC } \\
15 / 10.2 \\
8.222\end{array}$ & $\begin{array}{r}1.49 E=01 \\
.00 E \text { OO } \\
15 / 10.2 \\
8.388\end{array}$ \\
\hline $1-$ & $\begin{array}{r}2.54 E-02 \\
1.54 E 00 \\
1218.3 \\
5.399\end{array}$ & $\begin{array}{r}1.82 E=04 \\
.00 E \text { OO } \\
15 / 10.2 \\
7.996\end{array}$ & $\begin{array}{r}2.73 E=02 \\
1.54 E 00 \\
1218,3 \\
5.478\end{array}$ & $\begin{array}{c}5.06 E-0 ? \\
100 E 00 \\
15 / 10.2 \\
8.855\end{array}$ & $\begin{array}{r}4.98 E-02 \\
1.54 E 00 \\
1218.3 \\
4.920\end{array}$ \\
\hline $1=$ & $\begin{array}{r}9.25 E-03 \\
6.29 E-01 \\
1217,3 \\
5.782\end{array}$ & $\begin{array}{r}2.73 E-02 \\
1.54 E, 00 \\
12 / 8,3 \\
4.948\end{array}$ & $\begin{array}{r}3.70 E-02 \\
6.29 E-01 \\
1217,3 \\
6.233\end{array}$ & $\begin{array}{r}5.41 E=02 \\
1.54 E 00 \\
1218.3 \\
5.538\end{array}$ & $\begin{array}{r}2.48 E=04 \\
6.29 E=01 \\
1217.3 \\
5.382\end{array}$ \\
\hline $1-$ & $\begin{array}{r}6 \cdot 37 E-03 \\
3.14 E-02 \\
1219,3 \\
7.962\end{array}$ & $\begin{array}{r}7.92 E=03 \\
6.29 E-01 \\
12 / 7,3 \\
5.265\end{array}$ & $\begin{array}{c}1.69 E-02 \\
3,14 E-02 \\
12,9,3 \\
7 \cdot 387\end{array}$ & $\begin{array}{r}4 \cdot 46 E=04 \\
6.29 E=01 \\
1217,3 \\
6.048\end{array}$ & $\begin{array}{r}5 \cdot 24 E-05 \\
3.14 E-02 \\
12 / 9.3 \\
7.624\end{array}$ \\
\hline 1 - & $\begin{array}{r}5.21 E-06 \\
4.89 E-01 \\
1418.3 \\
8.546\end{array}$ & $\begin{array}{c}3.85 E-03 \\
3.14 E=02 \\
1219.3 \\
7.371\end{array}$ & $\begin{array}{r}5.31 E-03 \\
4.89 E-01 \\
14 / 8.3 \\
8.079\end{array}$ & $\begin{array}{r}2.63 E=01 \\
4.89 E=01 \\
14 / 8.3 \\
9.382\end{array}$ & $\begin{array}{r}1.7 O E-01 \\
4.89 E-01 \\
14 / 8.3 \\
8.661\end{array}$ \\
\hline 1- & $\begin{array}{r}2.53 E=03 \\
2.83 E 00 \\
13 / 9.3 \\
8.963\end{array}$ & $\begin{array}{r}1.74 E-04 \\
4.89 E-01 \\
14 / 8.3 \\
8.035\end{array}$ & $\begin{array}{c}9.22 E=03 \\
2.83 E 00 \\
13 / 9.3 \\
8.243\end{array}$ & $\begin{array}{c}5 \cdot 05 E=01 \\
2.83 E 00 \\
13 / 9,3 \\
10.105\end{array}$ & $\begin{array}{r}4.81 E-01 \\
2.83 E 00 \\
13 / 9.3 \\
9.498\end{array}$ \\
\hline $1-$ & $\begin{array}{c}1.93 E-04 \\
1.71 E-01 \\
1518.3 \\
\quad 10.053\end{array}$ & $\begin{array}{r}3.97 E-04 \\
2.83 E 00 \\
13 \% 9,3 \\
8.503\end{array}$ & $\begin{array}{r}1.33 E=03 \\
1.71 E=01 \\
15 / 8,3 \\
9.288\end{array}$ & $\begin{array}{c}5.97 E=03 \\
6.29 E=01 \\
1217.3 \\
12.052\end{array}$ & $\begin{array}{r}1.41 E=02 \\
1.71 E=01 \\
15 / 8,3 \\
10.716\end{array}$ \\
\hline $1-$ & $\begin{array}{c}2.64 E-04 \\
4.40 E-01 \\
15 / 9,3 \\
10.395\end{array}$ & $\begin{array}{r}1.15 E-03 \\
1.71 E-01 \\
15 / 8.3 \\
9.442\end{array}$ & $\begin{array}{r}2.39 E-06 \\
4.40 E=01 \\
15 / 9.3 \\
9.645\end{array}$ & $\begin{array}{r}9.19 E=02 \\
1.05 E=01 \\
13 / 7.3 \\
14.560\end{array}$ & $\begin{array}{r}1.37 E-02 \\
6: 29 E=01 \\
1217.3 \\
11.399\end{array}$ \\
\hline
\end{tabular}




\begin{tabular}{|c|c|c|c|c|}
\hline $\begin{array}{r}2 \cdot 25 E=03 \\
1 \cdot 05 E=01 \\
13 / 7,3 \\
12 \cdot 177\end{array}$ & $\begin{array}{r}4.89 E=C 3 \\
4.4 C E-01 \\
15 / 9.3 \\
9.881\end{array}$ & $\begin{array}{r}9.37 E-02 \\
1.05 E-01 \\
13 / 7.3 \\
10.922\end{array}$ & $\begin{array}{c}1.83 E-01 \\
1.32 E 00 \\
1218.4 \\
8.070\end{array}$ & $\begin{array}{r}6: 87 E=02 \\
1: 05 E-01 \\
13 / 7.3 \\
13.803\end{array}$ \\
\hline
\end{tabular}

1.

$4.11 E-02 \quad 6.45 E-04$ $1.32 E$ OO $1.05 E-01$ $12 / 8,4 \quad 13 / 7,3$

$2.35 E-04 \quad 1.32 E-01$

$1.32 E$ OO $2.69 E-02$

$12,8,4 \quad 12 / 9,4$

$8.46 E-02$

$1 \cdot 32 . E$ OO

11.581

7.465

9.020

$12 / 8,4$

$\begin{array}{rrrrr}1.22 E-02 & 1.22 E-02 & 4.10 E-02 & 4.41 E-01 & 6.62 E-02 \\ 2.69 E-02 & 2.69 E-02 & 2.69 E-02 & 2.43 E-00 & 2.69 E-02 \\ 1219.4 & 12 / 9.4 & 12 / 9.4 & 13 / 9.4 & 1219.4 \\ 8.936 & 8.282 & 8.209 & 9.592 & 8.296\end{array}$

1. $\quad 7.20 E-01 \quad 5 \cdot 10 E-01$

$2.43 E$ OO $2.43 E$ OO

1. CGE CO

1. 32E 00

$1 \cdot 63 E-01$

4.19E-01

$13 / 9.4$

$13 / 9.4$

$12 / 8.4$

$14 / 8,4$

10.529

4. $71 E-01$

$2.43 E 00$

$13 / 9,4$

8.955

$1-$

$1 \cdot 16 E=03$
$4 \cdot 19 E=01$

$1 \cdot 63 E-03$

$1.19 E-02$

4. $19 E-01$

1.57E-03

4. $19 E-01$

$14 / 8,4$
$10 \cdot 480$

$14 / 8.4$

$14 / 8,4$

$4 \cdot 19 E-01$.

$3.03 E-02$

$14 / 8,4$

10.814

4. $19 E-01$

$14 / 8,4$

$9 \cdot 543$

9.802

1. $\quad 1.38 E=019.27 E-02$

$1.47 E-01$

$15 / 8,4$

$1.47 E=01$

$2.63 E$.0

$2.43 E$ OO

1.93E OC

$5 \cdot 39 E-01$

$13 / 9,4$

$12 / 7.4$

11.228 .

10.407

$10 \cdot 128$

$11 \cdot 005$

$6.87 E-02$

$1 \cdot 47 E-01$

$15 / 8,4$

$10 \cdot 082$

1. $\quad 6.42 E-01 \quad 1 \cdot 41 E$ CO

$5 \cdot 39 E-015 \cdot 39 E-01$

$4.84 E-0.1$

$1 \cdot 47 E-01$

$3 \cdot 45 E-01$

1.86E 00

$12 / 7,4$

11.576

$12,7,4$

10.896

$15 / 8,4$

$10 \cdot 430$

$3.77 E-01$

$15 / 9,4$

$11 \cdot 218$

$5 \cdot 39 E-01$

$12 / 7,4$

$10 \cdot 398$

1.

$8 \cdot 70 \mathrm{E}-01$

3.87E-01

$1.80 E .0$

$2.22 E-03$

1.11E OO

$3.77 E-013.77 E-01$

$15 ; 9,4$

$15 / 9,4$

$5 \cdot 39 E=01$

$1.47 E-01$

$3 \cdot 77 E-01$

$12 / 7,4$.5/ 8,4

$15,9,4$

$11 \cdot 644$

$10 \cdot 948$

$10 \cdot 753$

$11 \cdot 438$

10.608

1. $\quad 5.01 E 00.4 .78 E 00$

3.77E-01 3.77E-01

$3.43 E$.O

$5.24 E \quad 00$

$5 \cdot 21 E 00$

$15 / 9,4$

$15,9,4$

$13 \cdot 127$

12.439

$3.77 E-01$

$3.77 E-01$

$3.77 E-01$

$15 / 9,4$

$15 / 9.4$

$15,9,4$

$11 \cdot 511$

$12 \cdot 606$

12.025 


\begin{tabular}{|c|c|c|c|c|c|}
\hline- & $\begin{array}{c}2.74 E 00 \\
8.98 E-02 \\
13 / 7.4 \\
14.262\end{array}$ & $\begin{array}{r}3.01 E 00 \\
8.98 E-02 \\
13 / 7.4 \\
13.405\end{array}$ & $\begin{array}{c}1.45 E-00 \\
8.98 E-02 \\
1317.4 \\
12.373\end{array}$ & $\begin{array}{r}3.43 E=01 \\
8.98 E=02 \\
1317.4 \\
13.865\end{array}$ & $\begin{array}{c}4.03 E-01 \\
8.98 E-02 \\
13 / 7.4 \\
13.091\end{array}$ \\
\hline $2-$ & $\begin{array}{c}1.21 E-01 \\
5.05 E 00 \\
11 / 9.1 \\
5.414\end{array}$ & $\begin{array}{r}8.66 E-02 \\
5.05 E \text { OD } \\
11 / 9.1 \\
4.920\end{array}$ & $\begin{array}{r}3.75 E-01 \\
5.05 E \text { CO } \\
11 / 9.1 \\
4.828\end{array}$ & $\begin{array}{c}2.98 E=02 \\
5.05 E 00 \\
1119,1 \\
5.462\end{array}$ & $\begin{array}{r}7.04 E=02 \\
5.05 E 00 \\
11 / 9,1 \\
4.825\end{array}$ \\
\hline $2-$ & $\begin{array}{c}4,00 E \text { CO } \\
8.78 E \text { OO } \\
11 / 7,1 \\
6.571\end{array}$ & $\begin{array}{r}3.86 E O O \\
8.78 E O O \\
1117.1 \\
6.235\end{array}$ & $\begin{array}{c}4.29 E 00 \\
8.78 E 00 \\
11 / 7.11 \\
6.369\end{array}$ & $\begin{array}{r}4.06 E \text { OC } \\
8.78 E \text { OO } \\
11 / 7.1 \\
6.400\end{array}$ & $\begin{array}{r}3.80 E 00 \\
8.78 E 00 \\
11 / 7.1 \\
5.891\end{array}$ \\
\hline $2-$ & $\begin{array}{c}2.62 E \text { OO } \\
1.55 E \text { OO } \\
12 / 10,2 \\
5.763\end{array}$ & 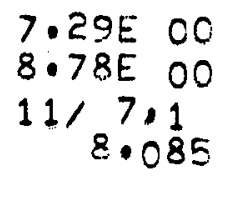 & $\begin{array}{c}3.14 E \text { OO } \\
1.55 E \text { OO } \\
12 / 10,22 \\
5.178\end{array}$ & $\begin{array}{c}3,11 E 00 \\
1.55 E 00 \\
12 / 10,2 \\
5.764\end{array}$ & $\begin{array}{r}3.25 E 00 \\
1.55 E 00 \\
12 / 10.2 \\
5.059\end{array}$ \\
\hline $2-$ & $\begin{array}{c}6 \cdot 78 E=03 \\
9 \cdot 70 E=02 \\
15 / 10.2 \\
8 \cdot 264\end{array}$ & $\begin{array}{r}2.60 E \text { OO } \\
1.55 E \text { OO } \\
12 / 10.2 \\
5.243\end{array}$ & $\begin{array}{c}1.37 E-01 \\
9.70 E=02 \\
15 / 10,2 \\
7.794\end{array}$ & $\begin{array}{r}6 \cdot 38 E-05 \\
9.70 E=02 \\
15 / 10.2 \\
7.912\end{array}$ & $\begin{array}{r}9.90 E-01 \\
9.70 E-02 \\
15 / 10.2 \\
7.872\end{array}$ \\
\hline $2-$ & $\begin{array}{r}1.49 E-01 \\
2.85 E-01 \\
12 / 8.3 \\
7.200\end{array}$ & $\begin{array}{c}7.15 E-02 \\
9.70 E=02 \\
15 / 10.2 \\
7.824\end{array}$ & $\begin{array}{r}6.94 E-01 \\
2.85 E=01 \\
1218.3 \\
6.567\end{array}$ & $\begin{array}{r}7.12 E=01 \\
9.70 E-02 \\
15 / 10.2 \\
8.123\end{array}$ & $\begin{array}{r}3.73 E 00 \\
5.00 E=01 \\
16 / 11.2 \\
8.225\end{array}$ \\
\hline $2-$ & $\begin{array}{r}5.21 E=03 \\
1.61 E=04 \\
12 / 9,3 \\
7.487\end{array}$ & $\begin{array}{r}4.33 E-01 \\
2.85 E=01 \\
1218.3 \\
6.678\end{array}$ & $\begin{array}{r}2.47 E-03 \\
1.61 E-04 \\
1219: 3 \\
6 \cdot 821\end{array}$ & $\begin{array}{r}5.45 E \text { OO } \\
5.00 E=01 \\
16 / 11.2 \\
8.787\end{array}$ & $\begin{array}{r}3.15 E-01 \\
2.85 E-01 \\
12.8 .3 \\
6.1 .95\end{array}$ \\
\hline - & $\begin{array}{r}1.55 E-0.3 \\
: 00 E \text { OO } \\
13 / 8,3 \\
8.312\end{array}$ & $\begin{array}{r}4.59 E-03 \\
1.61 E=04 \\
1.219 .3 \\
6.865\end{array}$ & $\begin{array}{r}1.76 E-02 \\
.00 E 00 \\
13 / 8,3 \\
7.619\end{array}$ & $\begin{array}{r}1.37 E-01 \\
2.85 E=01 \\
12,8.3 \\
6.911\end{array}$ & $\begin{array}{r}1.32 E=01 \\
1 \cdot 61 E=04 \\
12 / 9,3 \\
6.699\end{array}$ \\
\hline 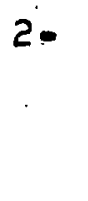 & $\begin{array}{r}3.98 E-02 \\
3.14 E-01 \\
13 / 9,3 \\
9.150\end{array}$ & $\begin{array}{r}3.99 E-02 \\
.00 E \text { OO } \\
1318.3 \\
7.723\end{array}$ & $\begin{array}{r}4 \cdot 33 E=01 \\
3,14 E=01 \\
13 / 9,3 \\
8 \cdot 353\end{array}$ & $\begin{array}{r}6.17 E-02 \\
1.61 E-04 \\
1219.3 \\
7.404\end{array}$ & $\begin{array}{r}9.23 E-02 \\
.00 E .00 \\
13 / 8,3 \\
7.548\end{array}$ \\
\hline
\end{tabular}




\begin{tabular}{|c|c|c|c|c|c|}
\hline $2-$ & $\begin{array}{r}1.42 E \quad 00 \\
1.84 E-01 \\
12 / 7.3 \\
9.387\end{array}$ & $\begin{array}{c}5.16 E-02 \\
6.27 E-02 \\
14 / 8.3 \\
8.614\end{array}$ & $\begin{array}{r}2.23 E \quad 00 \\
6.27 E-02 \\
14 / 8.3 \\
8.670\end{array}$ & $\begin{array}{c}7.65 E-01 \\
3.14 E-01 \\
1.3 / 9.3 \\
8.422\end{array}$ & $\begin{array}{r}1: 24 E \text { OO } \\
3: 14 E \cdot 01 \\
13 / 9,3 \\
7.762\end{array}$ \\
\hline $2-$ & $\begin{array}{r}2.06 E-01 \\
.00 E 00 \\
141.9 .3 \\
9.513\end{array}$ & $\begin{array}{r}1.29 E \text { OO } \\
1.84 E-01 \\
12 / 7,3 \\
8.860\end{array}$ & $\begin{array}{r}6.95 E-03 \\
.00 E .00 \\
14,9.3 \\
8.862\end{array}$ & $\begin{array}{r}1.10 E \text { OO } \\
1.84 E-01 \\
12 / 7.3 \\
9.2 .14\end{array}$ & $\begin{array}{r}1.82 E 00 \\
1.84 E-01 \\
1217,3 \\
8.528\end{array}$ \\
\hline $2-$ & $\begin{array}{c}1.61 E-01 \\
1.84 E-01 \\
12 / 7,3 \\
9.562\end{array}$ & $\begin{array}{r}4.18 E-01 \\
.0 O E \text { OO } \\
14 / 9,3 \\
8.946\end{array}$ & $\begin{array}{r}7.75 E-03 \\
1.84 E-01 \\
1217.3 \\
8.996\end{array}$ & $\begin{array}{r}1.51 E .00 \\
6.27 E-02 \\
14 / 8.3 \\
9.552\end{array}$ & $\begin{array}{r}3.34 E-03 \\
.0 O E \text { OO } \\
14 / 9.3 \\
8.940\end{array}$ \\
\hline $2-$ & $\begin{array}{c}3 \cdot 52 E-01 \\
3.30 E-04 \\
15 / 3.3 \\
9.818\end{array}$ & $\begin{array}{r}5.58 E-01 \\
1.84 E-01 \\
121.7 .3 \\
9.012\end{array}$ & $\begin{array}{c}3.18 E-01 \\
3.30 E=04 \\
15 / 8.3 \\
9.129\end{array}$ & $\begin{array}{c}9.7 \text { E-O? } \\
.00 E \text { OO } \\
1419,3 \\
9.611\end{array}$ & $\begin{array}{c}2.38 E-01 \\
3,30 E-04 \\
15 / 8,3 \\
9 \cdot 183\end{array}$ \\
\hline $2=$ & $\begin{array}{c}6.47 E-02 \\
2.00 E-02 \\
15 / 9,3 \\
10.433\end{array}$ & $\begin{array}{r}6 \cdot 98 E=01 \\
3 \cdot 30 E=04 \\
15 \% 8 \cdot 3 \\
9 \cdot 195\end{array}$ & $\begin{array}{r}1.81 E \text { ก0 } \\
2 \cdot 0, E-02 \\
15 / 9.3 \\
9.6 .97\end{array}$ & $\begin{array}{r}3.05 E-01 \\
3.30 E-.04 \\
15 / 8.3 \\
9.850\end{array}$ & $\begin{array}{r}1.68 E \text { OO } \\
2.00 E-02 \\
15 / 9.3 \\
9.764\end{array}$ \\
\hline $2=$ & $\begin{array}{c}2.00 E-01 \\
1.01 E=03 \\
13 / 7,3 \\
11.280\end{array}$ & $\begin{array}{c}2.94 E-01 \\
1.01 E=03 \\
13 / 7.3 \\
10.640\end{array}$ & $\begin{array}{r}4.07 E-01 \\
1.01 E-03 \\
13 / 7,3 \\
10.390\end{array}$ & $\begin{array}{r}3.32 E-04 \\
2 \cdot 0.0 E-02 \\
15,9.3 \\
10 \cdot 355\end{array}$ & $\begin{array}{c}1.08 E=02 \\
1: 01 E-03 \\
1: 3 / 7.3 \\
10.358\end{array}$ \\
\hline $2-$ & $\begin{array}{r}3.24 E-01 \\
1.99 E-02 \\
15 / 7.3 \\
12.931\end{array}$ & $\begin{array}{r}2 \cdot 88 E-01 \\
1 \cdot 99 E-02 \\
15,7,3 \\
12 \cdot 305\end{array}$ & $\begin{array}{c}1 \cdot 88 E-01 \\
1.99 E-32 \\
15 / 7.3 \\
12 \cdot 045\end{array}$ & $\begin{array}{r}4 \cdot 18 E=01 \\
1 \cdot 01 E=03 \\
13 / 7: 3 \\
11 \cdot 127\end{array}$ & $\begin{array}{r}4.82 E-01 \\
1.99 E-02 \\
15 / 7.3 \\
12.318\end{array}$ \\
\hline $2=$ & $\begin{array}{r}7.37 E-C 1 \\
2.95 E \text { OO } \\
12 / 8.4 \\
8.053\end{array}$ & $\begin{array}{c}5.67 E-03 \\
2.95 E 00 \\
12 / 8.4 \\
7.413\end{array}$ & $\begin{array}{c}1.88 E-03 \\
2.35 E 00 \\
12 / 8.4 \\
7.403\end{array}$ & $\begin{array}{c}6.14 E-01 \\
1.99 E-02 \\
15 / 7.3 \\
13 \cdot 111\end{array}$ & $\begin{array}{r}1.08 E-01 \\
2.95 E \text { C. } \\
12,8.4 \\
7.349\end{array}$ \\
\hline - & $\begin{array}{r}2,63 E-01 \\
1,31 E-01 \\
12 / 9,4 \\
8.585\end{array}$ & $\begin{array}{c}2.08 E-01 \\
1.31 E-01 \\
12 / 9.4 \\
7.935\end{array}$ & $\begin{array}{r}6.37 E \text { OO } \\
2.35 E \\
12,80 \\
7.829\end{array}$ & $\begin{array}{c}1.59 E-01 \\
1.31 E=01 \\
12,3.4 \\
8.323\end{array}$ & $\begin{array}{r}1,05 E-01 \\
1.31 E-01 \\
12 / 9.4 \\
8.029\end{array}$ \\
\hline
\end{tabular}




\begin{tabular}{|c|c|c|c|c|c|}
\hline $2-$ & $\begin{array}{r}7.55 E \text { O0 } \\
2.95 E \text {.00 } \\
12 / 8.4 \\
8.748\end{array}$ & $\begin{array}{r}3.60 E-01 \\
.0 O E \text { OO } \\
13 / 8.4 \\
8.728\end{array}$ & $\begin{array}{c}3.98 E-01 \\
1.31 E-01 \\
12 / 9.4 \\
7.979\end{array}$ & $\begin{array}{c}8.06 E-01 \\
1.31 E-01 \\
12 / 9.4 \\
8.694\end{array}$ & $\begin{array}{r}1.45 E \text { OO } \\
100 E \text { OO } \\
13 / 8,4 \\
8.669\end{array}$ \\
\hline $2=$ & $\begin{array}{c}2.31 E-01 \\
.00 E 00 \\
13 / 8,4 \\
9.406\end{array}$ & $\begin{array}{c}4.53 E=02 \\
1.54 E 00 \\
14 / 8.4 \\
9.543\end{array}$ & $\begin{array}{c}9.48 E-02 \\
.00 E \text { DO } \\
13 / 8.4 \\
8.726\end{array}$ & $\begin{array}{r}5.17 E-O 1 \\
.00 E 00 \\
13 / 8,4 \\
9.390\end{array}$ & $\begin{array}{r}1.07 E \text { CO } \\
.00 E \text { CO } \\
13 / 8,4 \\
8.807\end{array}$ \\
\hline $2-$ & $\begin{array}{c}3.54 E-02 \\
8.42 E-02 \\
13 / 9,4 \\
10 \cdot 3.35\end{array}$ & $\begin{array}{c}1.26 E \text { OO } \\
1.54 E 00 \\
14 / 8.4 \\
9.761\end{array}$ & $\begin{array}{r}7.85 E=02 \\
8.42 E=02 \\
13 / 9.4 \\
9.360\end{array}$ & $\begin{array}{r}8.65 E-02 \\
8.42 E-02 \\
13 / 9.4 \\
9.947\end{array}$ & $\begin{array}{r}5 \cdot 10 E \cdot 02 \\
8.42 E-02 \\
13 / 9.4 \\
9.300\end{array}$ \\
\hline 2- & $\begin{array}{r}5.79 E-01 \\
.00 E \text { OO } \\
1419,4 \\
10.582\end{array}$ & $\begin{array}{r}5.02 E-01 \\
.00 E \text { OO } \\
14 / 9.4 \\
9.910\end{array}$ & $\begin{array}{r}6.42 E-01 \\
1.54 E 00 \\
14 / 8.4 \\
9.645\end{array}$ & 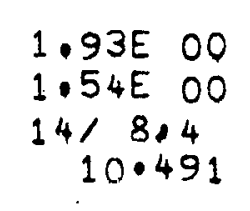 & $\begin{array}{c}8.72 E-01 \\
1.54 E 00 \\
14 / 8.4 \\
9.612\end{array}$ \\
\hline $2-$ & $\begin{array}{c}1.19 E \quad C 0 \\
8.42 E-0 ? \\
13 / 9.4 \\
10.621\end{array}$ & $\begin{array}{c}6.33 E-01 \\
.00 E \text { OO } \\
14 / 9.4 \\
10.010\end{array}$ & $\begin{array}{c}2.63 E-03 \\
100 E \text { OO } \\
14 / 9.4 \\
10.005\end{array}$ & $\begin{array}{r}3.67 E-01 \\
.00 E 00 \\
14 / 9.4 \\
10.610\end{array}$ & $\begin{array}{r}1.92 . E-01 \\
.00 E 00 \\
14 / 9.4 \\
9.998\end{array}$ \\
\hline $2-$ & $\begin{array}{c}3.98 E=04 \\
2.67 E-01 \\
15 / 8.4 \\
10.868\end{array}$ & $\begin{array}{r}1.16 E-01 \\
2.67 E-01 \\
15 / 8.4 \\
10.092\end{array}$ & $\begin{array}{c}2.53 E-01 \\
2.67 E-01 \\
15 / 8.4 \\
10 \cdot 144\end{array}$ & $\begin{array}{c}1.01 E-01 \\
2.67 E-01 \\
15 / 814 \\
10.978\end{array}$ & $\begin{array}{c}8.03 E-02 \\
2.67 E-01 \\
15 / 8.4 \\
10.209\end{array}$ \\
\hline $2-$ & $\begin{array}{c}3.11 E 00 \\
1.17 E 00 \\
1217,4 \\
11.022\end{array}$ & $\begin{array}{c}2.48 E 00 \\
1.17 E 00 \\
1217.4 \\
10.328\end{array}$ & $\begin{array}{c}1.72 . E \text { OO } \\
1.17 E \text { oO } \\
1217,4 \\
10.3 ? 2\end{array}$ & $\begin{array}{c}1.44 E \text { 00 } \\
1.17 E 00 \\
1217,4 \\
11.063\end{array}$ & $\begin{array}{c}1.96 E \text { OO } \\
1.17 E \text { CO } \\
1217.4 \\
10.474\end{array}$ \\
\hline 2. & $\begin{array}{c}1.70 E \text { OO } \\
2.23 E-02 \\
15 / 9,4 \\
11.679\end{array}$ & $\begin{array}{c}1.52 E \text { OO } \\
2.23 E-02 \\
15 / 9,4 \\
11.025\end{array}$ & $\begin{array}{c}6.32 E-01 \\
2.23 E-02 \\
15 / 9.4 \\
10.833\end{array}$ & $\begin{array}{c}2.13 E \text { OO } \\
2.23 E-02 \\
1519.4 \\
11.447\end{array}$ & $\begin{array}{c}2.04 E \text { OO } \\
2,23 E-02 \\
15 / 9.4 \\
10.844\end{array}$ \\
\hline - & $\begin{array}{r}1.58 E 00 \\
8.18 E-01 \\
13 / 7.4 \\
12.578\end{array}$ & $\begin{array}{r}1.69 E \text { O0 } \\
8 \cdot 18 E-01 \\
13 / 7.4 \\
11.750\end{array}$ & $\begin{array}{c}1.33 E \text { OO } \\
8.18 E=01 \\
13 / 7.4 \\
11.541\end{array}$ & $\begin{array}{c}2.06 E \text { O0 } \\
3.18 E-01 \\
13 / 7.4 \\
12.607\end{array}$ & $\begin{array}{c}2.06 E \text { OO } \\
8.18 E-01 \\
13 / 7,4 \\
11.758\end{array}$ \\
\hline
\end{tabular}




\begin{tabular}{|c|c|c|c|c|c|}
\hline 2- & 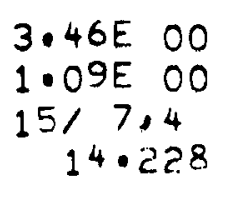 & $\begin{array}{c}3.34 E \text { OC } \\
1.09 E \text { OO } \\
15 / 7.4 \\
13.566\end{array}$ & $\begin{array}{c}2.21 E \text { OO } \\
1.09 E \text { 00 } \\
15 / 7: 4 \\
13.304\end{array}$ & $\begin{array}{rl}2.17 E & 00 \\
1.09 E & 00 \\
15 / 7.4 \\
14.102\end{array}$ & $\begin{array}{c}2.30 E \text { OO } \\
1.09 E \text { OO } \\
1517.4 \\
13.388\end{array}$ \\
\hline & 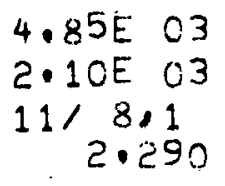 & $\begin{array}{rr}4.87 E & 03 \\
2.1 O E & 03 \\
11 / 8.1 \\
1.863\end{array}$ & $\begin{array}{r}1.25 E \text { O4 } \\
2.10 E \text { O3 } \\
11 ! 8.1 \\
2.098\end{array}$ & 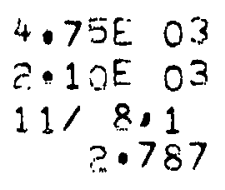 & 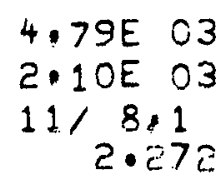 \\
\hline
\end{tabular}

3-

4.89E CO 1.25E 00 $2.75 E$ O2 $2.75 E$ O?

7.79E. 01 $2.75 E$ กิ

$2.70 E$ OL $2 \cdot 75 F \quad 0 ?$ 11/ 9,11 $11 / 9 ! 1$ $11 / 9,1$ $11 / 9,1$

$3.98 E$ OO $2.75 E$ 0? $11 / 9,1$ $4 \cdot 140$ $4 \cdot 711$ $4 \cdot 133$

$3-$

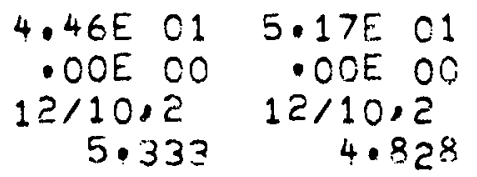

$1 \cdot 34 E-r 1$ - ODE OO $12 / 10,2$ $4 \cdot 820$

2.71E O2 $1.65 E$ O3 $11 / 7,1$ $6 \cdot 11 ?$

$3.56 E$ OE $1 \cdot 65 E \quad 03$ $11 / 7,1$ 5.537

$3=$

$9.55 E \quad 01$ . OOE OO $12 / 10,2$ 5.362
$1.11 E .02$ - OOE OC $12 / 1 \mathrm{C}, 2$ 5.406

4.836 .22 - COE OO $12 / 10,2$ $5 \cdot 431$
$1.77 E$ OI - OOE. 00 $12 / 10.2$ 5.496

3.67E O1 . OOE OO $12 / 10,2$ $4 \cdot 814$

3. $\begin{array}{rr}2.16 E \text { O2 } & 1.22 E \text { O? } \\ .00 E \text { OO } & .00 E \text { OC } \\ 13 / 10.2 & 13 / 10.2 \\ 6.542 & 6.108\end{array}$

$1.81 E$ OC - OOE 00

$13 / 10 \cdot 2$ $6 \cdot 136$

3.2SE O2 - ODE OO $13 / 10 \cdot 2$ $6 \cdot 635$

$1.47 E$ OE - DOE OO $13 / 10 \cdot 2$ 6.160

3.

$$
\begin{array}{r}
8.61 E 02 \\
.00 E \text { OO } \\
16 / 11,2 \\
8.502
\end{array}
$$

$6 \cdot 30 E$ O2 -OOE OC $16 / 11,2$

7.950

1.23E O? 3.95E OC

$1 \hat{c}, 8,3$ $6 \cdot 373$

2.70E 01 . OOE OO $16 / 1112$

7.787

$7.68 E \quad 01$ - ODE 00 $13 / 10:$ ? $6 \cdot 2 \leqslant 6$

$3-$

4.16E.00 2.76E O1 3.95E O2 $12 / 8,3$ 6.802 $3.95 E$ O2 $12 / 8,3$

$5.36 \mathrm{~F} O 1$ 1. $44 E ?$ $12,9,3$

$7.38 E$ O2 - OCE 00 $16 / 1112$ $6 \cdot 326$ 6.608 8.439

$8.27 E 02$ - DOE DO $16 / 11.2$

8.33E O1 $1.44 E \quad O 2$ $12 / 9,3$ 7.069
1.11E C? $1.44 E$ OZ $12 / 9,3$ $6 \cdot 481$
$2 \cdot 21 F \quad 01$ 2. 10E 02 $13 / 8,3$ $7 \cdot 439$
1.0.5E OI 3. $95 E$ OC $12 / 8,3$ 6.870
$8.89 E \quad 01$ 1. $44 E$ O2 $12 / 9,3$ 6.548 
3-
$3.83 E-03 \cdot 9.06 E=01$
2.10E O2 2.10E O2
$6.90 E$ DO
$5 \cdot 14 E 01$
$6.06 E$ D2 $1.44 E$ O2
6.92E O1
$13 / 8,3$
8.087
$13 / 8,3$
$13 / 9,3$
$12 / 9,3$
$2 \cdot 10 E$ O2
$13 / 8.3$
7.260
7.599

3-
$4.84 E \quad 1$ $6.06 E$ C2 $13 / 9,3$ 8.333
$8.64 E 01$ $6.06 E$ O2 $13 / 9,3$
7.876
$1.42 \mathrm{gE} \quad 02$ 2.10E O2 $14 / 9,3$
$4 \cdot 80 E=01$
$2 \cdot 10 E .02$
1318.3
8.270
$1.58 E$ O? $8 \cdot 288$ $6.06 E 02$ $13 / 9.3$ 8.071

3. $2.98 E \quad 01$ $5.92 E$ O2 $15 / 8,3$

$1.00 E$ O2
$5.92 E$ O2
$15 / 8.3$
8.873

2.25E d2 $5.92 E$ D2 $15 / 8,3$

9.452 $8 \cdot 867$

$2.54 E \quad 02$ $6.06 E 02$ $13 / 9,3$

7.2ิ7E 01 $2 \cdot 10 E \quad 02$ $14 / 9,3$ 8.667 $8 \cdot 394$

$3 \cdot$

1.23E $02 \quad 2.57 E$ O2 $1.8 C E$ O2 $5.92 E$ O2 $2.10 E$ O2 $3.60 E$ OL $15 / 8,3$ $14,9,3$ $12,7,3$ $\begin{array}{ll}6.00 E & 01 \\ 2.10 E & 02\end{array}$ $8 \cdot 910$ $\begin{array}{rl}14 / 9 & 9.3 \\ 9 \cdot 052\end{array}$

$1.86 E \quad 02$ $3.60 E$ O2 $12.77,3$ 8.993

$3-$

5.79E 01 $2.16 E$ O2 $15 / 9,3$

$2 \cdot 31 E \quad 01$ $5 \cdot 16 E$ OS 9.943 $15,9,3$

2.32E 01 2.16E 02 $15 / 9.3$ $9 \cdot 377$

$1.05 E \quad 02$ $5.92 E$ O? $15 / 8,3$ 9.713

$1 \cdot 72 E$ O2 $5.92 E \quad 02$ $15,8,3$ 0.396

3.

$\begin{array}{lllllll}1.12 E & 02 & 8.37 E & 01\end{array}$ $1.65 E$ O2 $13 / 7,3$ $1 \cdot 65 E$ O2 $13 / 7,3$ $10 \cdot 928$ 10.468

$\begin{array}{ll}1 \cdot 18 \mathrm{E} & 02 \\ 1.65 E & 02\end{array}$ $13 / 7,3$ $10 \cdot 145$

$8.86 E \quad 01$ $5.92 E$ O2 $15 / 8,3$ $9 \cdot 988$

$2.63 \mathrm{E} \mathrm{O1}$ $2.16 \mathrm{E} 02$ $15 / 9,3$
9.534

3 -

3.17E O2 2.08E 02 $2.80 E \quad 02$ $14 / 7,3$ 11.615 $2 \cdot 80 E$ O2 $14 / 7,3$ 11.010

6.55E 01 2.80502 $14 / 7,3$ $10 \cdot 937$

$2.44 \mathrm{E} O 1$ $2.16 E$ O2 $15 / 9,3$ $10 \cdot 172$

$7.21 E 01$ 1.65E 02 $13 / 7.3$ 10.757

3.

$1.14 E \quad C 2$ $1.20 E$ O2 $15,7,3$ 12.358

$2.21 E 01$ $1.20 E$ O2 $15,7,3$ 11.761
$2,13 E-01$ $1,200^{2}$ त2 $15,7,3$ $11 \cdot 703$
$7.24 E 01$ $1.65 E$ Da $13 / 7,3$ $11 \cdot 513$
2.37E 02 2.80E C2 $14,7,3$ $11 \cdot 195$

3.

$1.31 E 00$ 3. $38 E$ E2 $12 / 8,4$ 7.833
$8.91 E 01$ 3. 38E O2 $12 / 8,4$ 7.152
$9.10 E$ O1 3.38E 02 $12 / 8.4$
7.211
$1.95 E 02$ $2.80 E$ O2 $14,7,3$ 11.930
$1.21 E 01$ $3.38 \mathrm{E} 02$ $12 / 8,4$ 


\begin{tabular}{|c|c|c|c|c|c|}
\hline 3- & $\begin{array}{r}7.53 E-C 1 \\
1.24 E=02 \\
12 / 9.4 \\
8.245\end{array}$ & $\begin{array}{c}1.89 E=01 \\
1.24 E \text { O2 } \\
12 / 9,4 \\
7.615\end{array}$ & $\begin{array}{l}1.63 E \text { O2 } \\
3.38 E \text { O2 } \\
12 / 8.4\end{array}$ & $\begin{array}{l}1.60 E \text { O2 } \\
3.3,5 \text { O2 } \\
12 / 8.4 \\
\text { \&.292 }\end{array}$ & $\begin{array}{c}4.28 E \text { O1 } \\
3.38 E \text { 02 } \\
12 / 8.4 \\
7.559\end{array}$ \\
\hline
\end{tabular}

$3=$

1.22E 01 1.24E O2 $12 / 9,4$ 8.799

$8 \cdot 15 E-01$ 1. $24 E$ O? $12 / 9,4$ 8.190

$5.73 E$ O2 $1.24 E$ ? ?

$12 / 9,4$

4.31E OO 1.80E OC

$13 / 8.4$

5.4OE OO 1. $80 E$ Oद $13 / 8,4$ $.8 \cdot 637$
3.

1.01E 01 $1.80 E$ O2 $13 / 8,4$

9.231
$1.52 E$ OC
$1.80 E$ C2

$13 / 8,4$

8.564

3.

4.04E 02.

5.19E O?

$13 / 9,4$

9.907
3.11E 02

$5.13 E \quad 02$

$13 / 9,4$

9.149
$2.24 E \quad 01$

1.80E D2

$13 / 8.4$

$8 \cdot 602$

$3.67 E$ OC

5.19E DZ

$13 / 9,4$

$9 \cdot 085$
$3.34 E \quad 0 ?$

5.19E O2

$13 / 2,4$

9.648
1. $40 E$ O2

5.19E O2 $13 / 9,4$

9.346

3.

$6.12 E$ C1

$1.80 E$ O2

$14 / 9,4$

$10 \cdot 608$

4.94E 01

$1.80 E$ O?

$14 / 9,4$

10.005

$9.57 E$ O1

1. $80 \mathrm{OE}$.2

$14 / 9,4$

$10 \cdot \cos 2$

$1.55 E \quad 0 ?$

1.73E O2

$1.8 \mathrm{SE}$ O?

$14 / 9,4$

$1 \mathrm{c} \cdot 595$

$1.80 E$ O2

$14 / 9,4$

10.001

\section{3.}

$1.35 E$ D2

3.09E D2

$12 / 7,4$

10.841

3.2.7E C1

5. O8E OE

2.13E Qอ

3. C9E त?

$15 / 8,4$

$12 / 7,4$

$10 \cdot 166$

$10 \cdot 216$

$2.095-01$

$3.09 E \quad 02$

$12 / 7,4$

12.907

$5.80 E$ O1

5. J8E O?

$15,8,4$

$10 \cdot 200$

3. $\quad 2 \cdot 8^{4 E} 01$

1. $85 E \quad 02$

$15 / 9,4$

$11 \cdot 182$

$3.81 E \quad 02$

3. 095 O2

$12 / 7,4$

$10 \cdot 236$

$3-$

$9.74 E \quad 02$

$5.08 E \quad 02$

$15 / 8,4$

$11 \cdot 255$
$9.20 E \quad 02$ $1.85 E$ O2 $15 / 9,4$ 10.590
$6.66 E$ O2

$5.08 \mathrm{E}$ O2

$15 \% 8,4$ $1.0 \cdot 371$
$3.14 E \quad 02$

$5.03 E$ O?

$15 / 8.4$ $11 \cdot 100$
4.02E C2 3.09E 02 $12.17,4$ 10.400

3-

3.78E O2 1.42E O2

5.76E 02 1.42E O? $13 / 7,4$ $12 \cdot 484$

$9.49 E \quad 02$ $1.85 E$ O2 $15 / 9,4$ $11 \cdot 239$
7.8.E O己 $1.85 E$ O2 $15,9,4$ 10.653
$6.34 E \quad 02$

$1.85 E$ O2 $15 / 9,4$ $10 \cdot 585$
3.2.6E O2 3.43E C2. $1.42 E$ O? $1.42 E$ C2 $13 / 7,4$ $12 \cdot 487$ $13 / 7,4$ $11 \cdot 645$

$5.49 E$ J2 $1.42 E \supset 2$ $13 / 7,4$ $11 \cdot 447$ $\begin{array}{ll}8.95 E & 01 \\ 1.03 E & 02\end{array}$ $15 / 7,4$ 12.893
1. O2E O1 $1.03 E$ OZ $15,7,4$ $12 \cdot 187$ 
4.64E C2 2. 40 E C? $14 / 7,4$ $12 \cdot 908$
$3.85 E \quad 02$ 2. $40 E$ O2 $14 / 7,4$ $12 \cdot 300$
$3.71 E$ O2 $2.40 F \quad 22$ $14,7,4$ 12.290
$3.45 E$ O2

2.4 E O? $14 / 7,4$ $13 \cdot 082$
$3.48 E$ O2

$2.40 E$ O? $14 / 7,4$ $12 \cdot 407$
$3-$

$4=$

$2.95 E \quad 03$ $6.08 E$ C 3 $11 / 8,1$

$4 \cdot 30.4$
$6.97 E \quad C 2$ $1 \cdot 03 E$ O2 $15 / 7,4$ $13 \cdot 10^{8}$

2.53E 03 6.08E. 03 $11 / 8,1$ $3 \cdot 905$
$4.35 E$ O2 $1.03 E$ D2 $15 / 7,4$ $12 \cdot 998$
$4.54 E \quad 02$ $1.03 E$ O? $15 / 7: 4$ $13 \cdot 827$

5.09E 02 $1.03 E$ DZ $15 / 7,4$ $13 \cdot 108$
1.87E 03 $2.11 E 0^{3}$ $11 / 9,1$
2. 23 E 03 2.11E O3 $11 / 9.17$
$3.04 E \quad .3$

$6.08 \mathrm{E} O 3$

$11 / 811$ $3 \cdot 914$
$4.09 E \quad 03$ $6 \cdot 03 E$ O3

$11 / 8.1$ $4 \cdot 279$
$3.70 E \quad 03$ $6 \cdot 0.8 E$ 03 $11 / 8,1$ 3.833
$1.87 E \quad 03$ $2 \cdot 11 E$ O3 $11 / 9,1$
$1.44 E \quad 03$ $2 \cdot 11 E$ O3 $11 / 9: 1$ 4.363
1.87E 03 $2 \cdot 11 E \quad 03$ $11 / 9,17$
$4-$

4. $82 E \quad 03$ $9.19 E \quad 03$ $11 / 7,1$ $6 \cdot 988$
$4.7^{4} E \quad 03$ $9.19 E \quad 03$ $11 / 7.1$ 6.556
$5.97 E .03$

$9.19 E \quad 0.3$

$11 / 7,1$ $6 \cdot 564$
3.27E $0.3 \quad 2.66 E \quad 03$ $9.19 E$ O3 $9.19 E \quad 0_{3}$ $11 / 7 / 1 \quad 11 / 7.1$ $5 \cdot 746$

4.

1.11E O2 $4.63 E$ O 1 $13 / 10,2$ 6.561

1.3OE C? $4.63 E$ O1 $13 / 10,2$ 6.179

$8.50 E \quad 01$ 4.63E 01 $13 / 10,2$ $6 \cdot 161$

$1.21 E \quad 03$ $4.63 E$ O 1 $13 / 10,2$ 6.459

1.57E 03 $4.63 E$ O1 $13 / 10 \cdot 2$ 6.032

$4 \cdot$

$1.44 E \quad 03$ 1.19E 03 $16 / 11,2$ $7 \cdot 922$

$2 \cdot 23 E \quad 01$ $1: 19 E \quad 03$ $16 / 11 \cdot 2$ 7.547

$1.92 E$.1 $1 \cdot 19 \mathrm{E} \quad 03$ $16 / 11, ?$ 7.505

3.24E 03 1.26E O2 1.19E O3 1.19E C3 $16 / 11 \cdot 2$ 7.819 $16 / 11,2$ $7 \cdot 4.37$

$4-$

$6.99 E 00$ $4.62 E-01$

1.50E 02

$2.76 E$ Q1 $4.56 E$ O2 $12,9,3$

7.331

4.62E-01 $12,9,3$ $12,8,3$ $6 \cdot 650$

$3.84 E \quad 01$ 4.62E-01 1.2/ 9.3

1.00E 02 $4.62 E-01$ $12,9.3$ 6.723 7.170

6.463

4.

$1.55 E-02$ 4. 62E-01 $12 / 9,3$ $7 \cdot 383$

4. 68E O2 $4.56 E$ C? $12 / 8,3$ 6.791
$1.24 E \quad 01$ 4. 62 2E- 21 $12 / 9,3$ $6 \cdot 734$
$1.49 E \quad 0.3$ 4.5口E O2 $12,8.3$
2.39E 03 $4.56 E$ O2 $1 \hat{c} / 8,3$ 6.726 


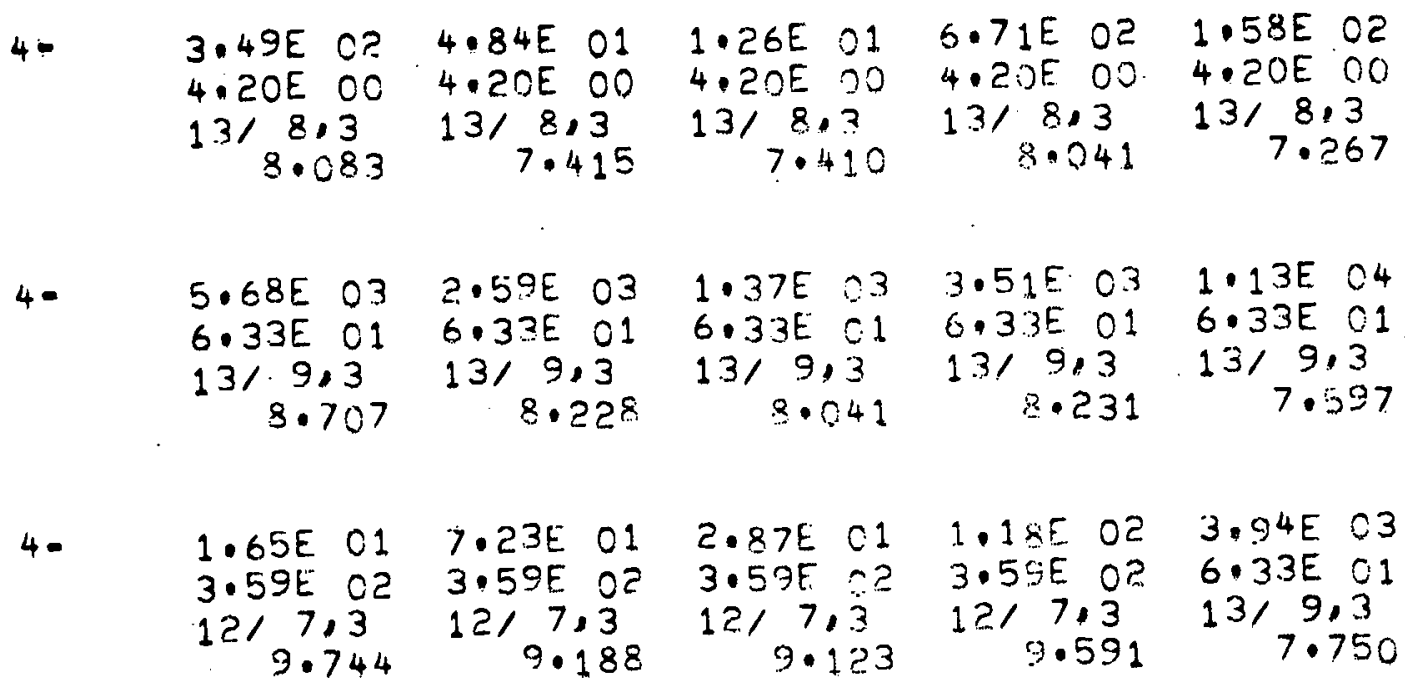

$4-$

9.1OE O1

1.16E O2

$5.00 E$ OO

5. OCE OO

$15 / .9,3$ 10.278

$15 / 9,3$

5.81E OI

$3.60 E$ O?

$1.03 E 01$

$5.00 E$ OC

$5.00 E 00$

$3.59 E$ O2

$15 / 9,3$

$12 / 7,3$

$9 \cdot 615$

$10 \cdot 298$

8.840

$4=$

9.80E C2

1.27E 00

4. OSE OC

$3.87 E 01$

$9.14 E$ OC

3.29E 02

1.27E OC

$1.27 E .00$

$13 / 7,3$

10.834

$13 / 7,3$

10.180

$13 / 7,3$

$1.27 E$ OC

$13 / 7,3$

5. OOE OC

$15 / 9.3$

$10 \cdot 115$

10.757

9.662

4. $\quad 1.02 E \quad 03$

$1.51 E$ C2

$8.70 E$ O2

$8.53 E 02$

$9.43 \mathrm{E} O 2$

$3.93 E$ DI

$1.51 E$ O?

1.51E C2 1.51E.02

1.27E OC

$14 / 7,3$

$14 / 7,3$

$14,7,3$

$14,7: 3$

$13 / 7,3$

11.813

$11 \cdot 222$

$11 \cdot 143$

11.976

$10 \cdot 010$

$4 \cdot$

$3.57 E$ O?

3.82E.02

$2.35 E$ O2

1.1OE 03

1.52E O1

$6.23 E 00$

$6.23 E$ OC

$6.23 E 00$

6.23E OC

$1.51 E$ O2 $15 / 7,3$

$15 / 7,3$

$15 / 7: 3$

$15 / 7,3$

$14,7,3$ $12 \cdot 387$

$11 \cdot 76 \mathrm{C}$

$11 \cdot 711$

$12 \cdot 439$

$11 \cdot 240$

4- 2.11E 02

3.75E 02

$12 / 9,4$

1.68E C3

$1 \cdot 52 E: 4$

Э.37E 03

3.75E 02

$12 / 9,4$

8.416

7.756

$1 \cdot 12 E$ O 4

$1 \cdot 12 E \quad 0^{4}$

$12 / 8,4$

8.81E C2

$12,8,4$

$3 \cdot 394$

$6.23 E$ CO

$15 / 7,3$

$11 \cdot 646$

4- $\quad 1.21 E$ O4 $1.52 E$ O4 $1.55 E$. . $1 \cdot 12 E$ O4 $12 / 8,4$

1. 1 IE $0^{4}$

$3.75 E$ C2

1.79E 03

3.75E D2

$2.20 \mathrm{~F} .03$

$12 / 8,4$

$12,9,4$

$12 / 9.4$
8.548

3.75E Ca

$12 / 9,4$

$8 \cdot 598$

7.860

$7 \cdot 861$

$7 \cdot 913$ 


\begin{tabular}{|c|c|c|c|c|c|}
\hline 40 & 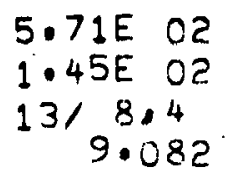 & 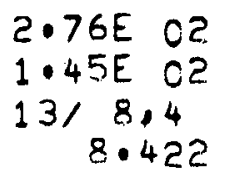 & $\begin{array}{r}2.07 E \text { O2 } \\
1.45 E \text { O2 } \\
13 / 8.4 \\
8.500\end{array}$ & 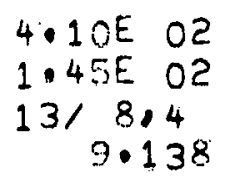 & 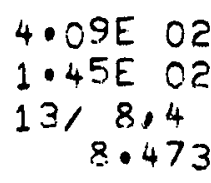 \\
\hline 40 & $\begin{array}{c}3.92 E \text { O2 } \\
1.25 E \text { C2 } \\
13 / 9,4 \\
9.846\end{array}$ & $\begin{array}{r}3.67 E \text { OC } \\
1.25 E \text { O2. } \\
13 / 9.4 \\
9.059\end{array}$ & $\begin{array}{r}1.86 E \text { तc } \\
1.25 E \text { Oz } \\
13 / 9,4 \\
9.630\end{array}$ & $\begin{array}{r}1.95 E \text { OR } \\
1.25 E \text { O2 } \\
13 / 9,4 \\
.2 .481\end{array}$ & $\begin{array}{r}3.29 E \text { O2 } \\
1.25 E \text { O2 } \\
13 / 9.4 \\
8.920\end{array}$ \\
\hline $4-$ & $\begin{array}{r}3.5 O E \text { O3 } \\
4.90 E \text { O3 } \\
12.7 .4 \\
10.351\end{array}$ & 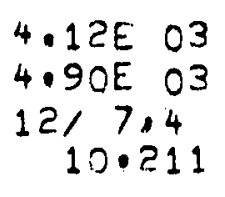 & $\begin{array}{r}4.61 E .33 \\
4.90 E .03 \\
1217.4 \\
10.230\end{array}$ & 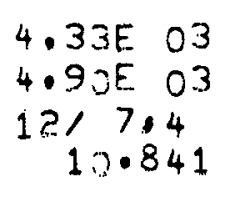 & $\begin{array}{r}5.30 E \text { O3 } \\
4.90 E \text { O3 } \\
1217.4 \\
10.206\end{array}$ \\
\hline $4-$ & $\begin{array}{c}4.15 E \text { C2 } \\
2.50 E \text { O1 } \\
15 / 9.4 \\
11.413\end{array}$ & $\begin{array}{c}4.97 E \text { O? } \\
2.50 E \text { O1 } \\
15 / 9.4 \\
10.771\end{array}$ & $\begin{array}{r}2.33 E \text { O2 } \\
2.50 E \text { O1 } \\
15 / 9.4 \\
10.736\end{array}$ & 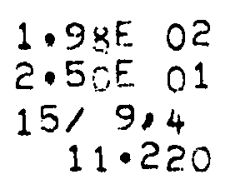 & $\begin{array}{r}2.42 E \text { 0.2 } \\
2.50 E \text { O1 } \\
15 / 9,4 \\
10.518\end{array}$ \\
\hline $4-$ & 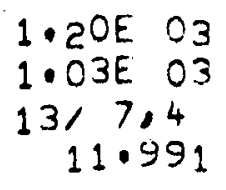 & 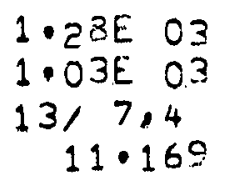 & 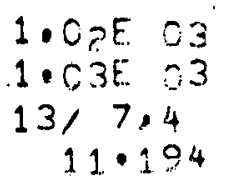 & 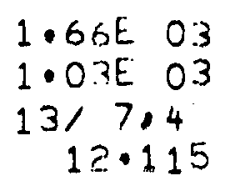 & 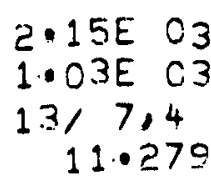 \\
\hline $4-$ & $\begin{array}{c}4.22 E \quad 03 \\
3.71 E \quad 03 \\
14 / 7,4 \\
12.887\end{array}$ & 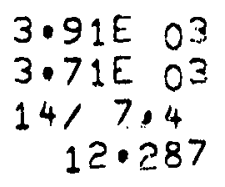 & $\begin{array}{c}4.39 E=3 \\
3.71 E=3 \\
14,7.4 \\
12.291\end{array}$ & 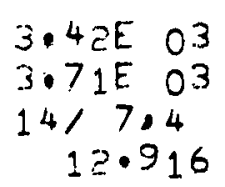 & $\begin{array}{c}3.71 E \text { O3 } \\
3.71 E \text { O3 } \\
14.7 .4 \\
12.28 ?\end{array}$ \\
\hline $4-$ & 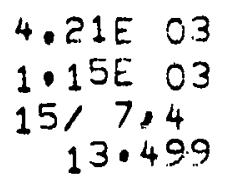 & 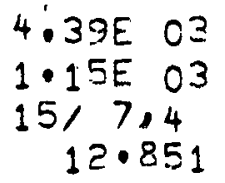 & $\begin{array}{c}2.71503 \\
1.15 E \text { :3 } \\
15 / 7.4 \\
12.862\end{array}$ & $\begin{array}{rr}2.77 E & 0.3 \\
1.15 E & 03 \\
15 / 7.4 \\
1.3 .539\end{array}$ & $\begin{array}{c}3.08 E .03 \\
1.15 E \text {.03 } \\
15 / 7.4 \\
12.832\end{array}$ \\
\hline
\end{tabular}

5. $\quad 2.32 E$ O6 $2.48 E$ OE $2.45 E$ O6 $1.94 E$ OE $2.19 E \quad 06$ $7.64 E$ OS 7.64E C5 7.64E O5 7.64E O5 7.64E OS $\begin{array}{rrrrr}11 / 8,1 & 11 / 8,1 & 11 / 8,1 & 11 / 8,1 & 11 / 8.1 \\ 3.786 & 3.363 & 3.593 & 3.966 & 3.474\end{array}$

5- $\quad 3.77 E$ O5 $2.38 E$ O5 $5.32 E$ O5 $5.32 E$ OE $11 / 9,1,11 / 9,1$

$5 \cdot 38 E \quad 05$ 5.325 O5

$4.4 \%$ O 05 $5.32 E \quad 05$

$2 \cdot 12 E$ O5 उ2E OS $11 / 9,1$ $4.671 \quad 4.049$ 


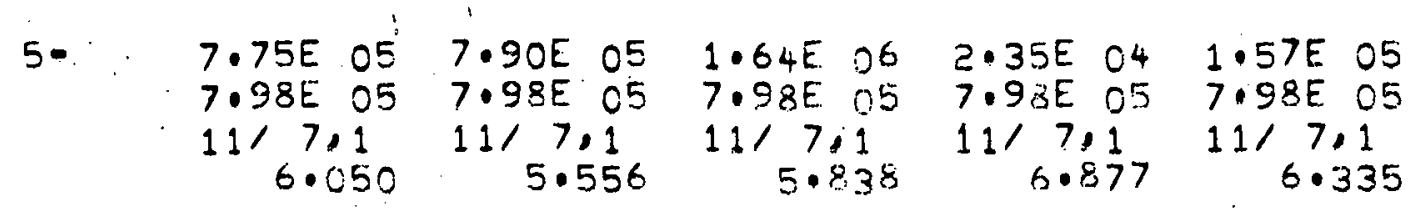

\begin{tabular}{|c|c|c|c|c|}
\hline $\begin{array}{r}6.20 E \text { O3 } \\
.00 E \text { OO } \\
16 / 11.2 \\
7.711\end{array}$ & $\begin{array}{r}1.78 E \text { O4 } \\
.00 E \text { OO } \\
16 / 11.2 \\
7.511\end{array}$ & $\begin{array}{r}2.14 E \text { O4 } \\
. C O E \text { OO } \\
16 / 11.2 \\
7.482\end{array}$ & $\begin{array}{r}2.41 E \text { O? } \\
.00 E \text { OO } \\
16 / 11.2 \\
7.745\end{array}$ & $\begin{array}{r}3.79 E 0 \\
.00 E 0 \\
16 / 11.2 \\
7.48\end{array}$ \\
\hline
\end{tabular}

$5-$

$1.48 E \quad C^{4}$

$5.92 E$ O5

$12 / 9,3$

9.20E OZ

5.92E O5

$12,9,3$

1.95E 03

$5.92 E$ O 5

$12 / 9,3$

1.2.1E 06

$5.92 E$ C5

$12 / 9.3$

1.11E 06

5.92E O5

$12,9.3$

6.934

6.492

5.777

5.

$\begin{array}{ll}5.90 E & 04 \\ 7.64 E & 05\end{array}$

$1.53 E \quad 03$

3.16E 24

$1.94 E^{4}$

$1.39 E \quad 04$

$13 / 8,3$

$7.64 E$ O5

$7.64 E$ O 5

$7.64 E \quad 05$

$7.64 E \quad 05$

8.012

$13 / 8,3$
7.216

$13 / 8.3$

$13 / 8.3$

$13 / 8,3$

$7 \cdot 169$

$8 \cdot 101$

7.229

5

$7.11 E \quad 03$

\section{$9.63 E \quad 03$}

$2.47 E$ O5

1.92E 04

$3.75 E \quad 05$

$2.47 E$ O5

$3.79 E \quad 05$

$2.47 E \quad 05$

$13 / 9,3$

$2.47 E$ O5

$13 / 9,3$

8.282

7.783

$13 / 9,3$

7.769

8.552

$2.47 E$ O5

$13 / 9,3$

8.071

5

1.34E O5

$2.37 E$ O5

1.70E 05

$9.10 E$ O4

1.96E O5

2.37E 05

$12 / 7,3$

$12 / 7,3$

2.37F 05

$12 / 7,3$

$2.37 E$ O5

$12 / 7,3$

2.05E 05

2.37E 05

$12 / 7,3$

$8.970 \quad 9.953$

$9 \cdot 265$

5-

1.68E O5 $2.85 E \quad 05$

2.01E 05

2.85E O5

$13 / 7,3$

$13 / 7,3$

4.2OE 04

$2.85 E$.5

$8.01 E 04$

1. $55 E$ OS

$13 / 7,3$

2.85E O5

$13 / 7 \cdot 3$

2.85E 05

$10 \cdot 628$

$10 \cdot 082$

9.980

11.082

$13 / 7,3$

$10 \cdot 328$

$5-$

$2 \cdot 32 E$ C5

5.83E O2

$2 \cdot 24 E \quad 04$

$2 \cdot 20 E$ O2

1.65E 03

2.85E O5

5.52E O5

5.52E O5

5.52E O5

$13 / 7,3$

$15 / 7,3$

$15 / 7,3$

$15 / 7,3$

$5.52 E \quad 05$

11.513

$11 \cdot 517$

$12 \cdot 651$

$15 / 7,3$

11.849

$5-$

3.10E O5 $5.52 E$ O5 $15 / 7,3$ $12 \cdot 055$
6.8OE O5 5.07E O5 $12 / 9,4$
7.27E O5 5.07E O5 $12,9,4$ 8.051
$6.29 E \quad 05$ $5.07 E$ OS $12 ! 9.4$

$8 \cdot 675$
$5 \cdot 81 E \quad 05$

$5 \cdot 07 E$ O5 $12,9,4$

7.982 


\begin{tabular}{|c|c|c|c|c|c|}
\hline 5. & $\begin{array}{c}7.18 E .05 \\
5.07 E \cdot C 5 \\
12 / 9,4 \\
3.732\end{array}$ & 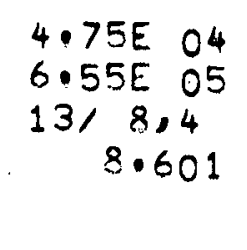 & $\begin{array}{c}3.42 E \text { O5 } \\
6.55 E \text { O5 } \\
13 / 8.4 \\
8.650\end{array}$ & 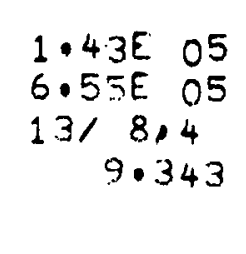 & $\begin{array}{r}2.05 E \text { O5 } \\
6.55 E \text { O5 } \\
13 / 8.4 \\
8.688\end{array}$ \\
\hline $5=$ & $\begin{array}{r}1.78 E \text { O5 } \\
6.55 E \text { 0.5 } \\
13 / 8.4 \\
9.282\end{array}$ & 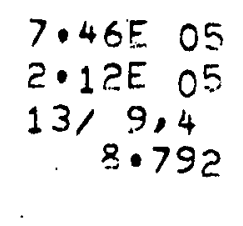 & $\begin{array}{c}7.22 E \text {.5 } \\
2.12 E \text {.5 } \\
13 / 9.4 \\
8.835\end{array}$ & $\begin{array}{r}4.1 \exists E \text { O5 } \\
2.12 E \text { O5 } \\
13 / 9.4 \\
9.511\end{array}$ & $\begin{array}{r}3.1 O E \text { O5 } \\
2 \cdot 12 E \text { O5 } \\
13 / 9.4 \\
8.887\end{array}$ \\
\hline $5-$ & 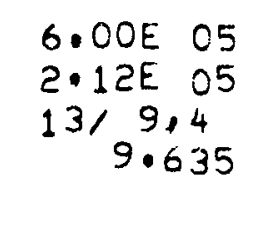 & 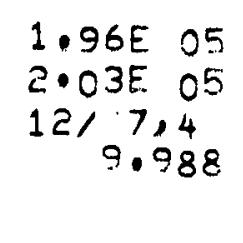 & 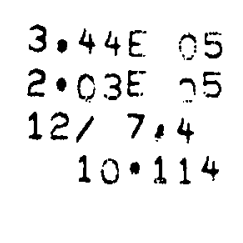 & 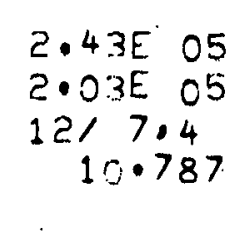 & 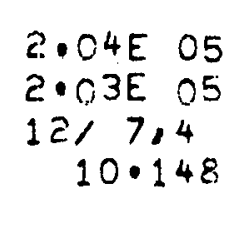 \\
\hline $5-$ & 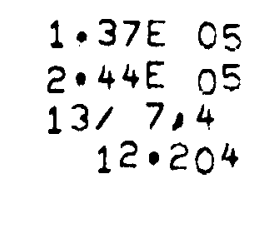 & $\begin{array}{r}4.81 E \text { O5 } \\
2.44 E \text { O5 } \\
13 / 7,4 \\
11.273\end{array}$ & $\begin{array}{r}5.44 E \text { 05 } \\
2.44 E, 05 \\
13 / 7: 4 \\
11.264\end{array}$ & $\begin{array}{r}4.29 E \text { OS } \\
2.44 E \text { O5 } \\
13 / 7,4 \\
12.139\end{array}$ & $\begin{array}{r}4.41 E \text { O5 } \\
2.44 E \text { O5 } \\
13 / 7.4 \\
11.2 .81\end{array}$ \\
\hline $5-$ & $\begin{array}{c}1.02 E \text { OG } \\
4.73 E \text { O5 } \\
15 / 7.4 \\
13.721\end{array}$ & $\begin{array}{r}1.01 E \text { OE. } \\
4.73 E 05 \\
15 / 7.4 \\
13.059\end{array}$ & $\begin{array}{c}9.17 E \text { O5 } \\
4.73 E, 05 \\
15,7.4 \\
13.000\end{array}$ & 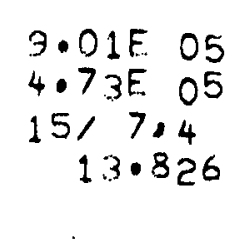 & $\begin{array}{c}8.93 E \text { C5 } \\
4.73 E \text { O5 } \\
15 / 7,4 \\
13.119\end{array}$ \\
\hline $6-$ & $\begin{array}{c}9.96 E .06 \\
2.31 E \text { O7 } \\
11 / 8,1 \\
4.416\end{array}$ & 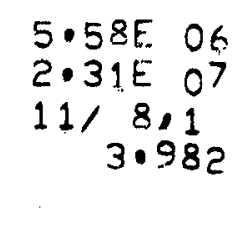 & $\begin{array}{r}1.10 E \text { O7 } \\
2.31 E \text { O7 } \\
11 / 8.11 \\
3 \cdot 379\end{array}$ & 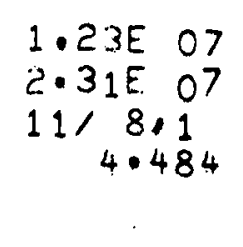 & $\begin{array}{c}1.70 E \text { O6 } \\
1.42 E \text { O6 } \\
11 / 9.1 \\
3.934\end{array}$ \\
\hline $5=$ & 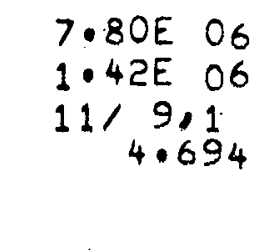 & $\begin{array}{r}1.20 E \text { O7 } \\
1.42 E \text { O6 } \\
11 / 9: 1 \\
4 \cdot 222\end{array}$ & $\begin{array}{r}7.44 E \text { O6 } \\
1.42 E \text { O6 } \\
11 / 9.1 \\
4.210\end{array}$ & $\begin{array}{r}7.35 E \text { O6 } \\
1.42 E \text { OE } \\
11 / 9.1 \\
4.690\end{array}$ & 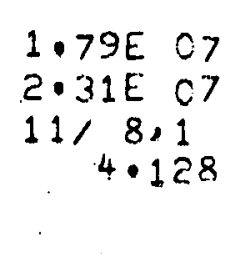 \\
\hline - & 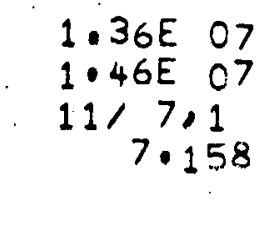 & 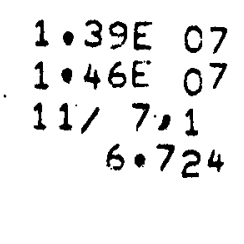 & $\begin{array}{r}1.30 E \text { O7 } \\
1.46 E .07 \\
11 / 7.1 \\
6.653\end{array}$ & $\begin{array}{r}1.22 E \text { O7 } \\
1.46 E 07 \\
11 / 7.1 \\
6.870\end{array}$ & $\begin{array}{r}1.24 E \text { O7 } \\
1: 46 E \text { O7 } \\
11 / 7.1 \\
6.410\end{array}$ \\
\hline $6^{\circ}$ & $\begin{array}{r}1.01 E \text { O. } \\
6.04 E \text { C6 } \\
16 / 11.2 \\
7.956\end{array}$ & $\begin{array}{c}9.38 E \text { OS } \\
6.04 E \text { OS } \\
16 / 1.1 .2 \\
7.571\end{array}$ & $\begin{array}{c}7.85 E \quad 06 \\
6.04 E \text { O6 } \\
16 / 11.2 \\
7.536\end{array}$ & $\begin{array}{r}1.14 E \text { O7 } \\
5.04 E \text { O6 } \\
16 / 11.2 \\
7.752\end{array}$ & $\begin{array}{c}1.09 E \text { 07 } \\
6.04 E \text { 06 } \\
16 / 11.2 \\
7.357\end{array}$ \\
\hline
\end{tabular}




\begin{tabular}{|c|c|c|c|c|c|}
\hline 60 & 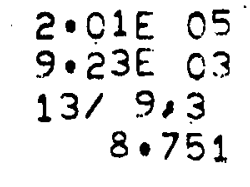 & 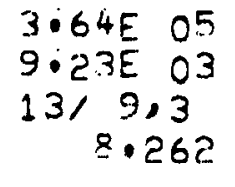 & 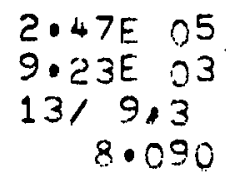 & 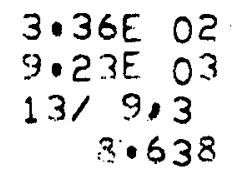 & $\begin{array}{r}2.92 E .01 \\
9.23 E .03 \\
13 / 9.3 \\
8.060\end{array}$ \\
\hline $6=$ & $\begin{array}{r}2.38 E \text { O6 } \\
9.21 E \text { O5 } \\
12 / 7.3 \\
9.904\end{array}$ & 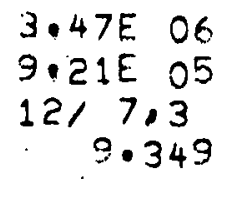 & $\begin{array}{c}2.68 E \text { O6 } \\
9.21 E \text { OS } \\
1217.3 \\
9.2 .17\end{array}$ & 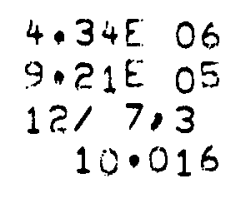 & $\begin{array}{r}3.13 E \text { O6 } \\
9.21 E \text { O5 } \\
12 / 7.3 \\
9.314\end{array}$ \\
\hline $6-$ & $\begin{array}{r}1.93 E \text { OS } \\
1.28 E \text { C3 } \\
1317,3 \\
10.680\end{array}$ & $\begin{array}{c}3.04 E \text { O5 } \\
1.28 E \text { O3 } \\
13 / 7.3 \\
10.016\end{array}$ & 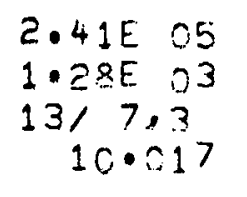 & $\begin{array}{r}6.37 E \text { O6 } \\
1.28 E 03 \\
13 / 7,3 \\
1.619\end{array}$ & $\begin{array}{r}4.40 E \text { O6 } \\
1: 28 E 03 \\
13 / 7,3 \\
9.835\end{array}$ \\
\hline $6-$ & $\begin{array}{c}2.31 E \quad 05 \\
4.61 E \text { C4 } \\
13 / 9.4 \\
9.953\end{array}$ & 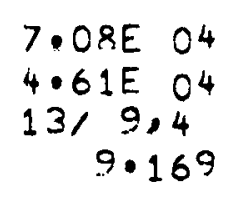 & $\begin{array}{c}6.0 C E \text { O4 } \\
4.61 E \text {. } \\
13 / 9.4 \\
9.106\end{array}$ & $\begin{array}{r}4.21 E \text { O5 } \\
4.61 E \text { O4 } \\
13 / 9.4 \\
9.543\end{array}$ & $\begin{array}{r}4.23 E \text { O5 } \\
4.61 E \text { O4 } \\
13 / 9,4 \\
8.950\end{array}$ \\
\hline $6^{-}$ & $\begin{array}{c}2.71 E \text { O7 } \\
2.26 E \text { O7 } \\
1217,4 \\
11.019\end{array}$ & $\begin{array}{r}2.63 E \text { O7 } \\
2 \cdot 26 E \text { O7 } \\
1217,4 \\
10 \cdot 376\end{array}$ & $\begin{array}{r}2 \cdot 61 E \text { O7 } \\
2 \cdot 26 E \text { o7 } \\
12 / 7.4 \\
10 \cdot 330\end{array}$ & 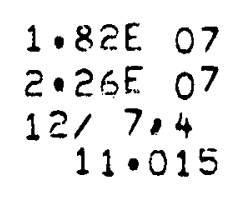 & $\begin{array}{r}2.16 E \text { O7 } \\
2.26 E \text { O } \\
1217.4 \\
10.350\end{array}$ \\
\hline 6. & $\begin{array}{c}2.18 E \text { O6 } \\
1.04 E \text { O6 } \\
1317,4 \\
11.779\end{array}$ & $\begin{array}{c}2 \cdot 36 E \text { OE } \\
1 \cdot 04 E \text { OG } \\
13 / 7.4 \\
10.959\end{array}$ & $\begin{array}{c}1.62 E .06 \\
1.04 E, 06 \\
13 / 7.4 \\
11.063\end{array}$ & $\begin{array}{r}1.36 E .06 \\
1.04 E .05 \\
1317.4 \\
11.955\end{array}$ & $\begin{array}{c}1.31 E 06 \\
1.04 E \text { 06 } \\
13 / 7.4 \\
11.081\end{array}$ \\
\hline $7-$ & $\begin{array}{c}2.12 E \text { O9 } \\
1: 67 E \text { O9 } \\
11 / 9,1 \\
4.361\end{array}$ & 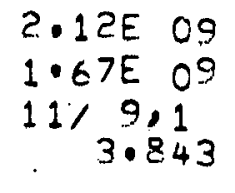 & $\begin{array}{c}2.26 E \text { O9 } \\
1.67 E \text { O9! } \\
11 \% 9.1 \\
4.011\end{array}$ & $\begin{array}{r}2.13 E \text { O9 } \\
1.67 E \text { O9 } \\
11 / 9,1 \\
4.570\end{array}$ & $\begin{array}{r}2.13 E \text { O9 } \\
1.67 E \text { O9 } \\
11 / 9.1 \\
3.897\end{array}$ \\
\hline $7-$ & 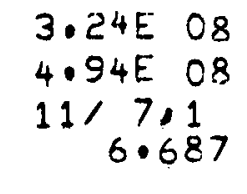 & 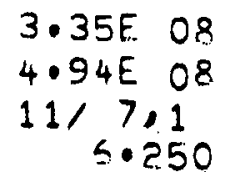 & $\begin{array}{r}4.57 E \text {. } 8 \\
4.94 E \text {. } 8 \\
11 / 7.1 \\
6.359\end{array}$ & $\begin{array}{r}4.40 E \text { O8 } \\
4.94 E \text { O8 } \\
11 / 7.11 \\
6.967\end{array}$ & $\begin{array}{r}4.51 E \text {. } \\
4: 94 E \text { O8 } \\
11 / 7.1 \\
6.503\end{array}$ \\
\hline $7^{-}$ & 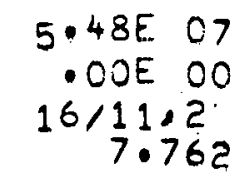 & $\begin{array}{r}4.52 E \text { O7 } \\
.0 O E \text { OO } \\
16 / 11.2 \\
7.377\end{array}$ & $\begin{array}{r}1.02 E \text { O7 } \\
.00 E \text { OO } \\
16 / 11.2 \\
7.390\end{array}$ & 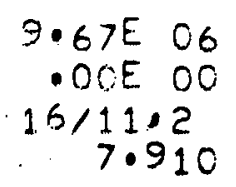 & $\begin{array}{r}5.82 E \text { O6 } \\
.0 O E \text { OO } \\
1 \epsilon / 11 . ? \\
7.512\end{array}$ \\
\hline
\end{tabular}




\begin{tabular}{|c|c|c|c|c|c|}
\hline 7. & $\begin{array}{r}2.31 E \\
8.65 E \\
13 / 7.3 \\
10.196\end{array}$ & $\begin{array}{r}1.98 E \text { O8 } \\
8.65 E \text { C8 } \\
13 / 7.3 \\
9.587\end{array}$ & $\begin{array}{r}3.22 E \text { O8 } \\
8.65 E \text { O8 } \\
13 / 7,3 \\
9.666\end{array}$ & $\begin{array}{l}1.28 E \text { O8 } \\
8.65 E \text { OB } \\
13 / 7.3 \\
10.519\end{array}$ & $\begin{array}{r}1.05 E \text { O8 } \\
8.65 E \text { 08 } \\
13 / 7.3 \\
9.777\end{array}$ \\
\hline $7=$ & 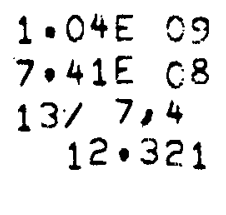 & $\begin{array}{r}1.07 E \text { CO } \\
7.41 E \cdot 08 \\
13 / 7.4 \\
11.450\end{array}$ & $\begin{array}{r}1.20 E \text { 00 } \\
7.41 \mathrm{E}, 8 \\
13 / 7,4 \\
11.378\end{array}$ & $\begin{array}{r}1.06 E \text { OQ } \\
7.41 E \text { O8 } \\
1317.4 \\
12.283\end{array}$ & 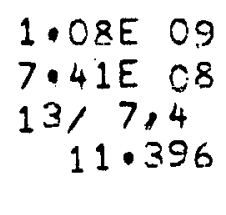 \\
\hline $8-$ & $\begin{array}{r}3.45 E \quad 10 \\
4.56 E \quad 10 \\
11 / 7.1 \\
7.335\end{array}$ & $\begin{array}{r}3.54 E \text { 1C } \\
4.56 E \text { 10 } \\
11 / 7.1 \\
6.902\end{array}$ & $\begin{array}{rr}3.76 E & 10 \\
4.56 E & 10 \\
11 / 7.1 \\
6.775\end{array}$ & 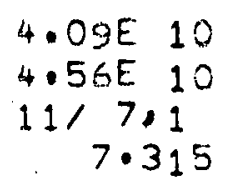 & 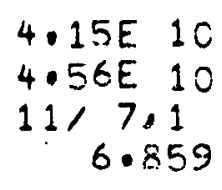 \\
\hline $8=$ & $\begin{array}{c}3.51 E \quad 10 \\
2.40 E \text { 10 } \\
16 / 11.2 \\
7.996\end{array}$ & 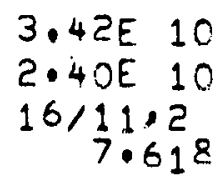 & $\begin{array}{r}2.86,10 \\
2.40 E 10 \\
16 / 11,2 \\
7.563\end{array}$ & $\begin{array}{r}2.87 E \quad 10 \\
2.40 E \text { 10 } \\
16 / 11.2 \\
7.772\end{array}$ & $\begin{array}{c}2.81 E \quad 10 \\
2.40 E \quad 10 \\
16 / 11.2 \\
7.383\end{array}$ \\
\hline $9-$ & $\begin{array}{c}.0 O E \text { OO } \\
.00 E \text { OO } \\
16 / 11.2 \\
7.706\end{array}$ & $\begin{array}{c}\text {.OOE OO } \\
\text {.OOE OO } \\
16 / 11,2 \\
7.329\end{array}$ & $\begin{array}{r}\text { COE OO } \\
. O O E \text { OO } \\
16 / 11.2 \\
7.38 ?\end{array}$ & $\begin{array}{r}.00 E \text { OO } \\
.00 E \text { OO } \\
16 / 11.2 \\
7.935\end{array}$ & $\begin{array}{r}.0 O E \text { OO } \\
.00 E \text { CO } \\
16 / 11.2 \\
7.546\end{array}$ \\
\hline $0-$ & 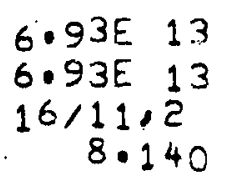 & $\begin{array}{r}6.93 E \quad 13 \\
6.93 E \quad 13 \\
16 / 11,2 \\
7.763\end{array}$ & $\begin{array}{c}6.69 E \quad 13 \\
6.9 .3 E \\
16 / 11 . ? \\
7.660\end{array}$ & $\begin{array}{rl}6.93 E & 13 \\
6.93 E & 13 \\
16 / 11.2 \\
8.110\end{array}$ & 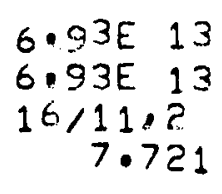 \\
\hline $1+$ & $\begin{array}{c}2.36 E-02 \\
2.47 E-02 \\
10 / 8,1 \\
4 \cdot 025\end{array}$ & $\begin{array}{r}2.37 E-02 \\
2.47 E-02 \\
1018.1 \\
3.391\end{array}$ & $\begin{array}{c}2.11 E-02 \\
2.47 E-02 \\
10 / 8.1 \\
3.229\end{array}$ & $\begin{array}{r}2.35 E-02 \\
2.47 E-02 \\
10 / 8.1 \\
4.167\end{array}$ & $\begin{array}{r}2.36 E-02 \\
2.47 E-02 \\
1 C / 8.1 \\
3.375\end{array}$ \\
\hline $1+$ & $\begin{array}{c}5.81 E-03 \\
4.77 E-03 \\
13 / 11.2 \\
7.645\end{array}$ & $\begin{array}{r}5.76 E-03 \\
4.77 E-03 \\
13 / 11.2 \\
7.149\end{array}$ & $\begin{array}{c}4.72 E-03 \\
4.77 E-03 \\
13 / 11.2 \\
6 \cdot 539\end{array}$ & $\begin{array}{c}5.98 E-03 \\
4.77 E-0.3 \\
13 / 11.2 \\
7.387\end{array}$ & $\begin{array}{r}5.91 E-03 \\
4.77 E-C 3 \\
13 / 11.2 \\
6.778\end{array}$ \\
\hline $2+$ & 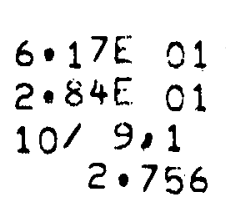 & $\begin{array}{r}6.32 E \text { C1 } \\
2.74 E \text { O1 } \\
10 / 8,1 \\
2.259\end{array}$ & $\begin{array}{c}8.27 E \text {. } \\
2.74 E \text {.1 } \\
10 / 8.1 \\
2.522\end{array}$ & 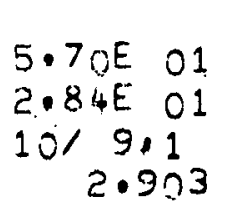 & $\begin{array}{c}5.97 E \text { O1 } \\
2.74 E \text { O1 } \\
10 / 8.1 \\
2.309\end{array}$ \\
\hline
\end{tabular}




\begin{tabular}{|c|c|c|c|c|c|}
\hline $2+$ & $\begin{array}{r}1.02 E \text { OO } \\
2.74 E \text { O1 } \\
10 / 8,1 \\
3.554\end{array}$ & $\begin{array}{c}3.69 E=02 \\
2.84 E \text { O1 } \\
10 / 9.1 \\
3.037 \\
1 \ldots\end{array}$ & 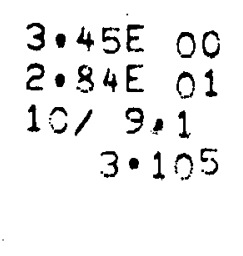 & 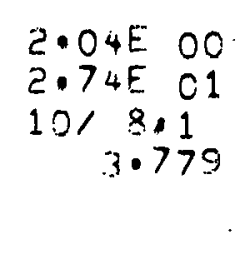 & $\begin{array}{r}2: 36 E \cdot 02 \\
2: 84 E \text { O1 } \\
10 / 9,1 \\
3 \cdot 157\end{array}$ \\
\hline $2+$ & $\begin{array}{r}6.10 E \text { CO } \\
.00 E \text { OO } \\
12 / 11.2 \\
4.513\end{array}$ & $\begin{array}{r}5.32 E \text { OO } \\
.00 E \text { OO } \\
12 / 11.2 \\
4.547\end{array}$ & $\begin{array}{r}2.04 E \text {.0 } \\
.00 E \text { 00 } \\
12 / 11,2 \\
4.451\end{array}$ & $\begin{array}{r}6.69 E \text { OO } \\
.00 E \text { OO } \\
12 / 11.2 \\
5.192\end{array}$ & $\begin{array}{r}5.93 E \text { OO } \\
.00 E \text { OO } \\
12.111 .2 \\
4.773\end{array}$ \\
\hline $2+$ & $\begin{array}{r}6.22 E-04 \\
.00 E 00 \\
13 / 11.2 \\
6.492\end{array}$ & $\begin{array}{r}3.7 O E=04 \\
.0 O E \text { OO } \\
13 / 11,2 \\
5.996\end{array}$ & $\begin{array}{r}1.52 E-01 \\
.0 C E \text { OO } \\
13 / 11.2 \\
5.810\end{array}$ & $\begin{array}{r}6 \cdot 26 E=03 \\
\cdot 00 E=00 \\
13 / 11 \cdot 2 \\
6.839\end{array}$ & $\begin{array}{r}9.67 E-03 \\
.0 O E \text { OO } \\
13 / 11.2 \\
6.232\end{array}$ \\
\hline $2+$ & $\begin{array}{r}4.91 E \text { O1 } \\
7.60 E \text { O1 } \\
16 / 7.3 \\
10.432\end{array}$ & $\begin{array}{r}4.87 E \text { O1 } \\
7.60 E \text { O1 } \\
16 / 7.3 \\
9.948\end{array}$ & $\begin{array}{c}6.23 E \text {. } 21 \\
7.60 E \text { O1 } \\
16 / 7,3 \\
10.516\end{array}$ & 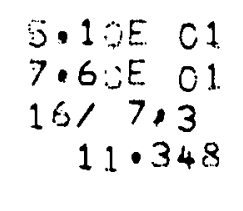 & $\begin{array}{r}5.12 E \text { O1 } \\
7.60 E \text { O1 } \\
1617.3 \\
10.661\end{array}$ \\
\hline 2 & 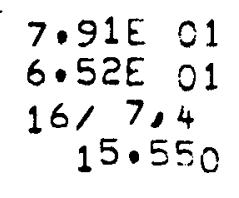 & 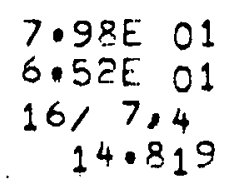 & $\begin{array}{r}8.51 E \text { O1 } \\
6.52 E \text { O1 } \\
16,7,4 \\
14.231\end{array}$ & 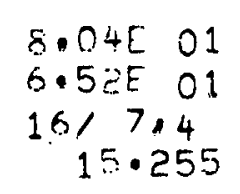 & $\begin{array}{r}8.01 E \text { O1 } \\
6.52 E \text { O1 } \\
16 / 7.4 \\
14.654\end{array}$ \\
\hline
\end{tabular}

$3+$

$$
\begin{array}{rr}
4.02 E-02 & 4.02 E-02 \\
1.41 E-01 & 1.41 E-01 \\
10 / 9,1 & 10 / 9,1 \\
3.953 & 3.559
\end{array}
$$

$3.20 E-02$

$1.41 E \cdot 01$

$5 \cdot 17 E-01$

1. $41 E-01$

$5 \cdot 38 E-01$

$10 / 9,1$

$10 / 9,1$

$3 \cdot 498$

$1.41 E-01$

$10 / 9,1$

3.462

$3+$

$4.52 E$ O1
$6.96 E$ O1
$10 / 7.1$
6.298

4.63E O1

6.96E O1

$10 / 7,1$
5.849

$4.76 E$ O1
$6.96 E$ O1
$10,7.11$
5.772

$4.83 E \quad 01$

5.01E C1 $6.96 E$ O1

6.96E 01

$10 / 7,1$

$10 / 7.1$
$5 \cdot 947$

$3+$

$3.81 E$ CO $3.63 E$ OC 6.02E 01 $12 / 11,2$ 4.894

$6.02 E$ O 1

$12 / 11,2$

4.543
4.23E DO

6.C2E 01

$12 / 11+2$

4.528
$6.32 E \quad 00$ G.02E 0 ? $12 / 11,2$

4.858
6.26E OO 6.02E O1 $12 / 11.2$ 4.451

$3+$

2.33 E OO 6.02E O1 $13 / 11 / 2$ $6 \cdot 152$
4.88E-01 $6.02 E$ O 1 $13 / 11: 2$
$7.08 E-C 4$

6.02E O. 13/11:?
S.1EE OO 6. OZE OI $13 / 11: 2$ 6.043
6.79E DO

$6.02 E$ O 1 $13 / 11 \cdot 2$ 


\begin{tabular}{|c|c|c|c|c|c|}
\hline $3+$ & $\begin{array}{r}2.90 E \text { O1 } \\
1.97 E \text { C.2 } \\
15 / 11.2 \\
7.956\end{array}$ & $\begin{array}{c}2.73 E \text { O1 } \\
1.97 E \text { O2 } \\
15 / 11.2 \\
7.569\end{array}$ & $\begin{array}{r}2.56 E \\
1.97 E\end{array}$ & $\begin{array}{r}2.84 E \text { O1 } \\
1.97 E \text { O? } \\
15 / 11.2 \\
7.912\end{array}$ & $\begin{array}{r}2.81 E \text { OI } \\
1.97 E \text { O2 } \\
15 / 11.2 \\
7.442\end{array}$ \\
\hline $3+$ & $\begin{array}{r}1.64 E 01 \\
8.57 E 00 \\
16 / 9.3 \\
11.076\end{array}$ & $\begin{array}{r}1.85 E \text { OI } \\
8.57 E \text { OO } \\
16 / 9.3 \\
10.447\end{array}$ & $\begin{array}{c}1.84 E \text { O1 } \\
8.57 E \text { OO } \\
16 / 9.3 \\
10.227\end{array}$ & $\begin{array}{r}2.87 E \text { O1 } \\
8.57 E \text { OO } \\
16 / 9,3 \\
11.297\end{array}$ & $\begin{array}{r}2.52 E \text { O1 } \\
8.57 E \text { CO } \\
16 / 9.3 \\
10.464\end{array}$ \\
\hline $3+$ & $\begin{array}{r}1 \cdot 84 E-C 1 \\
4.42 E C 1 \\
16 / 7,3 \\
12 \cdot 863\end{array}$ & $\begin{array}{r}5 \cdot 63 E-01 \\
4 \cdot 4 ? E \text { O } \\
16 / 7,3 \\
1 ? \cdot 346\end{array}$ & $\begin{array}{r}7.78 E-02 \\
4.42 E-11 \\
16 / 7.3 \\
12.158\end{array}$ & 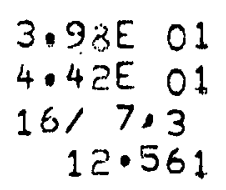 & 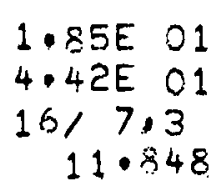 \\
\hline
\end{tabular}

$3+$

\begin{tabular}{|c|c|c|c|c|}
\hline 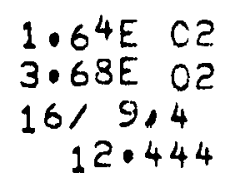 & $\begin{array}{r}1.62 E \text { O2 } \\
3.68 E \text { O2 } \\
16 / 9,4 \\
11.733\end{array}$ & $\begin{array}{r}2.34 E \text { OE } \\
3.68 E \text { O2 } \\
16 / .9,4 \\
11.525\end{array}$ & 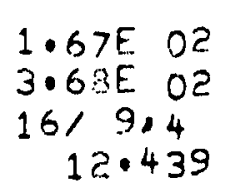 & $\begin{array}{c}2.07 E \text { O2 } \\
3.68 E \text { O2 } \\
16 / 9.4 \\
11.669\end{array}$ \\
\hline
\end{tabular}

3+ $\quad 5.40 E \quad 0 ? \quad 5.43 E$ 0? $2.58 E$ O2 $2.58 E$ O2 $16 / 7,4$ 16/7,4

$4.37 E \quad 22$

$2 \cdot 58 E$ ?2

$14 \cdot 455$

13.744

$16 / 7,4$

4.73E 02

?.5BE 02

$16 / 7,4$

4.59E 02

$2 \cdot 58 E$ O2

$13 \cdot 517 \quad 14 \cdot 260$

$16 / 7,4$

13.644

\section{$4+$}

2.01E 04 $2.03 E 04$ $10 / 7,1$ 5.573

$9.24 E \quad 0.3$ - ODE OC $12 / 11,2$

6.22E 03 - có no

C.26E $0^{4}$ 2.03E $0^{4}$ $12 / 11 \cdot 2$ 4.067

$$
4 \cdot 249
$$

10/7:1

$$
5.909
$$

1.97E 04 2.03E 04 $10 / 7,1$ $5 \cdot 356$

$4+$
$8.13 E \quad 03$ . OOE CO $12 / 11 \cdot 2$ $4 \cdot 435$

1.82E O4 -OOE 00 $13 / 11,2$ $5 \cdot 122$
$2.02 E \quad 0^{4}$ - OOE CO $13 / 11,2$ 11.2
5.267

$2.91 E \quad 03$ - OCE 00 $12 / 11 \cdot 2$

3. 66E C3 - OOE OO $12 / 11,2$

$$
4.674 \quad 4.254
$$

4+ 5.59E O3 - OOE OC

$13 / 11,2$

$6 \cdot 193$
7. O.9E 03 - OOE OO $13 / 11,2$ 5.731
$8.72 E \quad 03$ - OOE DO $13 / 11$, ? 5.679

3.69E 03 - OOE OO $13 / 11,2$ 6.192
6.92E O3 . OOE OO $13 / 11.2$ 5.511

4.37E. 02 - OOE OO $14 / 11,2$

$2.84 E \quad 0.1$ - COF CO $6 \cdot 387$

$14 / 11.2$ $6 \cdot 402$
2.00E 03 . OOE 00 $14 / 11,2$ 6.844
$1.35 E \quad 03$ - OOE OO $14 / 11,2$ $6 \cdot 427$ 


\begin{tabular}{|c|c|c|c|c|c|}
\hline $4+$ & $\begin{array}{r}5.00 E \text { C1 } \\
.00 E \text { CO } \\
15 / 11 . ? \\
7.434\end{array}$ & $\begin{array}{r}1.11 E \text { OC } \\
.0 O E \text { OC } \\
15 / 11,2 \\
7.104\end{array}$ & $\begin{array}{c}2.47 E \text { O2 } \\
.00 E \text { OO } \\
15 / 11: 2 \\
7.113\end{array}$ & 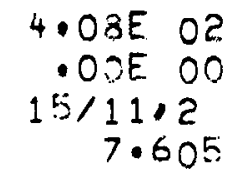 & $\begin{array}{r}5.91 E \text { O2 } \\
.00 E \text { OD } \\
15 / 11.2 \\
7.130\end{array}$ \\
\hline $4+$ & 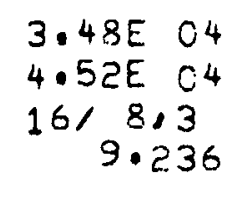 & $\begin{array}{r}3.37 E \quad 04 \\
4.52 E \text { O } \\
16 / 8,3 \\
8.686\end{array}$ & 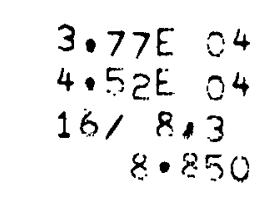 & 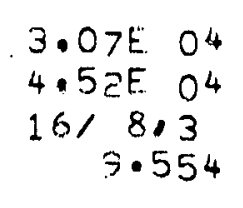 & $\begin{array}{r}3.14 E \quad 04 \\
4.52 E \text { O4 } \\
16 / 8.3 \\
8.272\end{array}$ \\
\hline $4+$ & $\begin{array}{c}3.83 E \text { C3 } \\
5.25 E \text { O3 } \\
16 / 9.3 \\
10.429\end{array}$ & $\begin{array}{r}3.45 E \\
5.25 E \\
16 / 9,3 \\
9.785\end{array}$ & $\begin{array}{r}3.10 E \\
5.25 E \\
16 / 9.3 \\
9.763\end{array}$ & 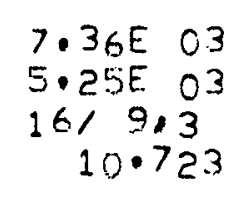 & $\begin{array}{r}4.87 E \text { 03 } \\
5.25 E \text { 03 } \\
1 t: 19.3 \\
9.503\end{array}$ \\
\hline $4+$ & $\begin{array}{c}9.15 E \text { O2 } \\
2 \cdot 62 E \text { C.4 } \\
16 / 7,3 \\
12 \cdot 342\end{array}$ & $\begin{array}{r}2.97 E \\
2.62 E \\
16 / 7,3 \\
11.813\end{array}$ & $\begin{array}{r}4.81 E .22 \\
2.62 E 04 \\
16 / 7,3 \\
11.784\end{array}$ & $\begin{array}{r}1.76 E \text { O2 } \\
2.62 E \text { O4 } \\
16 / 7.3 \\
12.602\end{array}$ & $\begin{array}{r}2 \cdot 62 E \text { Q2 } \\
2 \cdot 62 E \text { Q4 } \\
16 / 7,3 \\
11.904\end{array}$ \\
\hline $4+$ & 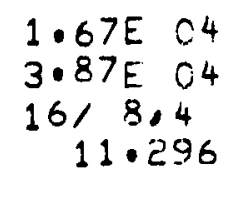 & $\begin{array}{r}1.37 E \text { O } \\
3.87 E \text { O } \\
16 / 8.4 \\
10.65\end{array}$ & $\begin{array}{c}2.53 E .0^{4} \\
3.87 E, 0^{4} \\
16 / 8.4 \\
10.684\end{array}$ & $\begin{array}{c}1.32 E \text { O4 } \\
3.87 E 04 \\
16 / 814 \\
11.421\end{array}$ & $\begin{array}{r}6.68 E 03 \\
3.87 E 04 \\
16 / 8.4 \\
10.730\end{array}$ \\
\hline $4+$ & $\begin{array}{c}2.44 E \text { C4 } \\
4.50 E \text { O3 } \\
16 / 9,4 \\
11.817\end{array}$ & $\begin{array}{r}2.76 E \\
4.50 E \\
16 / 9.4 \\
11.157 \\
\end{array}$ & $\begin{array}{l}3.13 E 04 \\
4.5 O E \text { O.3 } \\
16 / 9.4 \\
11.105\end{array}$ & 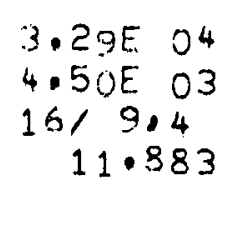 & $\begin{array}{r}4.11 E \text { O4 } \\
3.87 E 04 \\
16 / 8,4 \\
11.193\end{array}$ \\
\hline $4+$ & 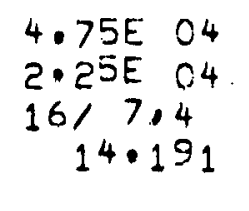 & 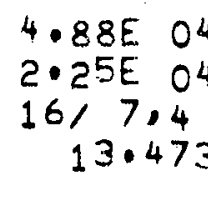 & $\begin{array}{c}4.4 \mathrm{CE} 04 \\
2.25 E 0^{4} \\
16 / 7.4 \\
13.366\end{array}$ & $\begin{array}{rl}4.66 F & 04 \\
2.25 E & 04 \\
1617.14 \\
14.109\end{array}$ & $\begin{array}{r}4.62 E \quad 04 \\
2.25 E \quad 04 \\
1617.4 \\
13.502\end{array}$ \\
\hline $5+$ & 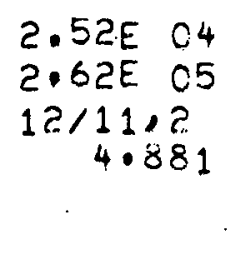 & $\begin{array}{r}2.48 E \text { O4 } \\
2.62 E \text { O5 } \\
12 / 11.2 \\
4.530\end{array}$ & $\begin{array}{r}1.39 E \text { o5 } \\
2.62 E \text { o5 } \\
12 / 11.2 \\
4.518\end{array}$ & 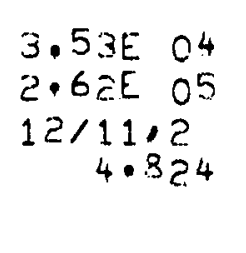 & $\begin{array}{r}3.50 E \text { O4 } \\
2.62 E \text { O5 } \\
12 / 11.2 \\
4.417\end{array}$ \\
\hline $5+$ & 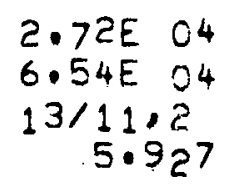 & $\begin{array}{r}2.99 E \text { C4 } \\
6.54 E \text { C4 } \\
13 / 11.2 \\
5.432\end{array}$ & $\begin{array}{rl}3.37 E & 04 \\
6.54 E & 04 \\
13 / 11 & ? \\
5.461\end{array}$ & 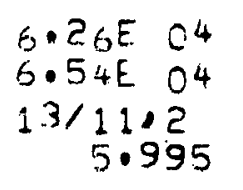 & 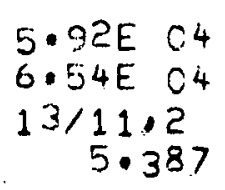 \\
\hline
\end{tabular}


$5+$

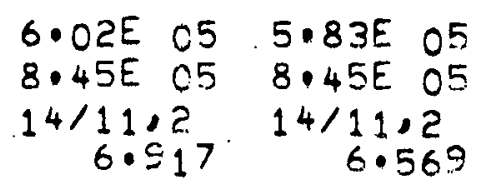

$6.59 E \quad 05$

$8.45 E$ O5

6.15E 05

$14 / 11,2$

8. $45 E$ E 05

5.95E O5

6.544

$14 / 11,2$

$8 \cdot 45 E \cdot 05$

$14 / 11,2$

6.557

$5+$

$2.69 E \quad 05$

$1.61 E$ C5

$15 / 11,2$

7.507

$2.78 E \quad 05$

$1.61 E$ O5

$15 / 11,2$

7.125

2.15E O5

$1 \cdot 61 E \quad 05$

2.50E 05

$1.61 E$ O5

$2.74 E \quad 05$

$15 / 11$ ?

$15 / 11,2$

7.126

7.505

$1.61 E$ O5

$15 / 11,2$

$7.04 \mathrm{C}$

$5+$

5.18E 05

$5.12 E \quad 05$

$16 / 10,2$.

8.578

4.95E 05

$5 \cdot 12 E$ O5

$16 / 10,2$

$8 \cdot 185$

4. $62 E$ OS

$5.12 E$ O5

$16 / 10.2$

$8 \cdot 147$

$5.20 E \quad 05$

$5.12 E$ O5

$16 / 10,2$



$5.12 E \quad 05$

$16 / 10,2$

8.623

$8 \cdot 161$

$5+$

$1.03 E \quad 55$ $2.87 E \quad 04$

$16 / 813$.

$9.81 E 04$ $2.87 E \quad 04$

$16 / 8,3$

9.01E 04

$2 \cdot 87 E \quad 04$

1.28505

2.87E 04

$16 / 8,3$

$9.49 E \quad 04$

$16 / 8.3$

$9.457 \quad .10 \cdot 018$

$2 \cdot 87 E \quad 04$

$16 / 8,3$

$9 \cdot 326$

$5+$

$8.22 E \quad 04$

$1.87 E \quad 03$

$1.07 E \quad 05$

$1.87 E \quad 03$

$6.10 E \quad O^{4}$

$1.15 E \quad 05$

1.87E D3 1.87E O3

$16 / 9,3$
10.554

$16 / 9,3$

$16,9,3$

9.834

$16 / 9.3$

10.630

$1.22 E \quad 05$

$1.87 E \quad 03$

$16 / 9,3$

$5+$

$3.45 E \quad 04$

4.37E O4

$1 \in / 7,3$

12.801

6.6OE $0^{4}$

4.37E O4

$2 \cdot \operatorname{tgF} 04$

$4 \cdot 37 E 04$

$16,7,3$

12.279

$12 \cdot 153$

$3.67 E \quad 05$

$4.24 E$ O5

$16 / 8.4$

$11 \cdot 124$

$1.31 E 0_{4}$

$4 \cdot 37 E \quad 04$

$16,7,3$

$11 \cdot 843$

$5+$

$2.99 E \quad 05$

$4 \cdot 24 E \quad 05$

$16 / 8,4$

$11 \cdot 122$

2.57E 05

$4 \cdot 24 E$ O5

3.53E 05

$4.24 E$ O5

2.485 .05

$3.49 E \quad 05$

1.97 E 05

$4 \cdot 24 E \quad 05$

$16 / 8,4$

$16 / 8,4$

$15 / 9,4$

$16 / 8,4$

10.562

11.734

10.529

5+ $\quad 3.09 E$ C5 1.97E C5 $16 / 9,4$

$11 \cdot 689$

$3 \cdot 34 E \quad 05$ $1 \cdot 97 E 05$ $16 / 9,4$ 10.992

$3.33 E 05$ $1.97 E$ O5 $16 / 9,4$ 10.596

1.50F 04 . 4.37E 04 16/7:3 12.528

3.03E 05 1.97E O5 $16 / 9,4$ 10.950

$5+$

7.37E O5 $4.52 E$ O5 $16 / 7,4$ 14.034

$7.20 E \quad 05$ 4.5? E O5 $16 / 7,4$ $13.34 \mathrm{C}$
5.90E 05 4. 5 $2 E$ O 5 $16,7,4$ $13 \cdot 303$
6.29E 05 4.52E O5 $16 / 7,4$ 13.852
$6 \cdot 32 E$ CE $4.52 E$ C5 $16,7,4$ 13.242 


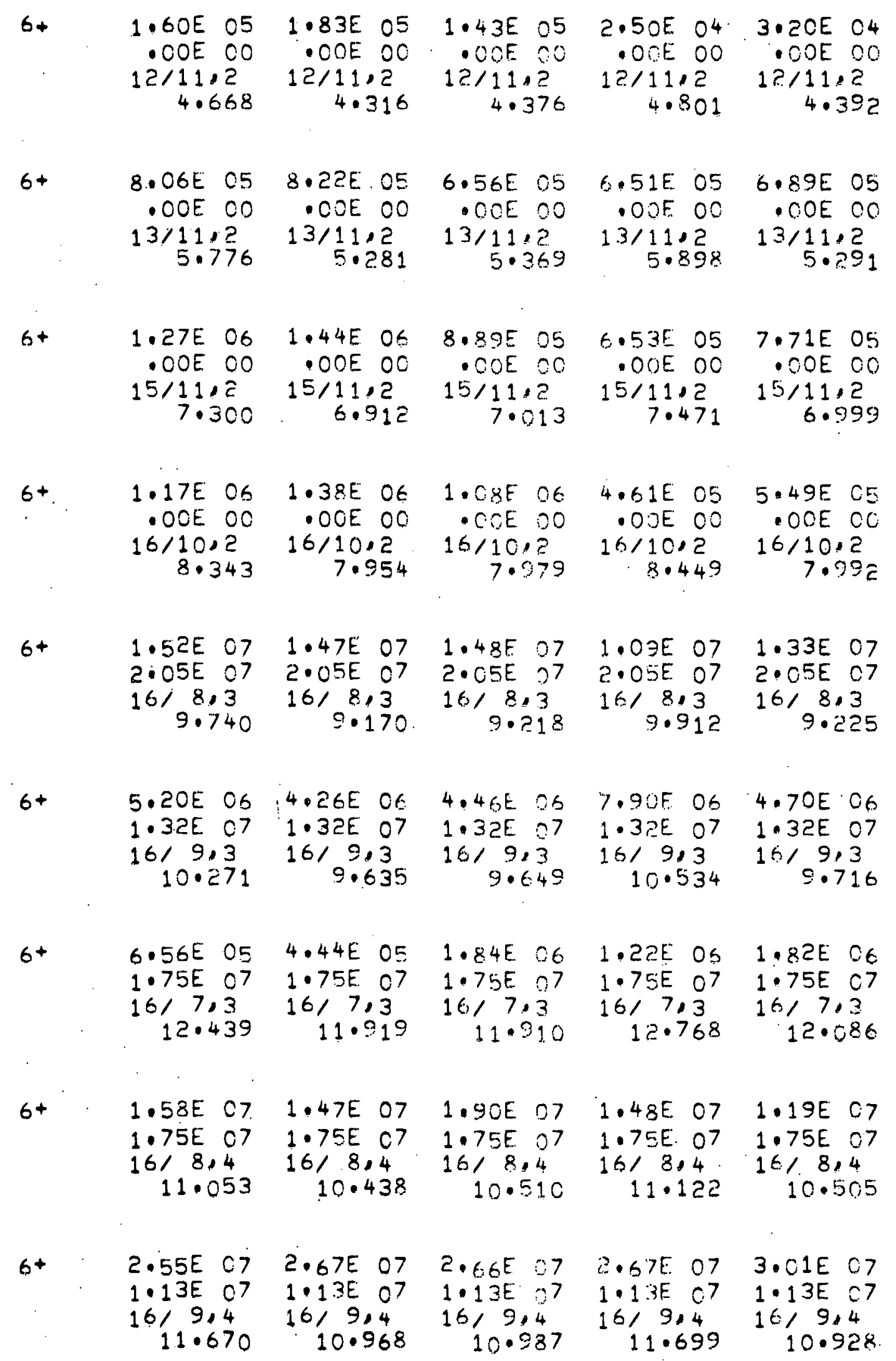


$6+$

$\begin{array}{lllllll}2.92 E & 07 & 3.03 E & 07 & 2.82 E & 07\end{array}$

$1.50 E$ O7 $1.50 E$ C7 $1.50 E$ O7

$16 / 7.4 \quad 16 / 7.4 \quad 16 / 7.4$

$13.844 \quad 13.141$

$13 \cdot 182$

$3 \cdot 18 E$ O7 3.12E 07

$1.50 E$ O7 $1.50 E$ OT

$16 / 7,4 \quad 16 / 7,4$

$13 \cdot 903 \quad 13 \cdot 288$

$7+$

$4.27 E \quad 08$

$1 \cdot 46 E$ O9

4.17E 08

1.60508

$5.12 E$ O8

$5.09 E$ O\&

$12 / \frac{11}{5}, 223$

$1246 E 0$

1. $46 E$ O 9

$1.46 E$ O3

$1.46 E$ O9

$12 / 11 \cdot 2$

$1 ? / 11,2$

4.671

$4 \cdot 605$

4.659

$7+$

$1.03 E \quad 08$

$7.20 E \quad 07$

$1 \cdot 15 E \quad 08$

$8 \cdot 13 E 07$

$7 \cdot 20 E$ O 7

$7.20 E$ D 7

$13 / 11,2$

$13 / 11,2$

$13 / 11,2$

$5 \cdot 066$

4.64E $07 \quad 4.36 E \quad 07$

$7.20 E$ O7 7.20E O7

$13 / 11,2 \quad 13 / 11,2$

$5 \cdot 389 \quad 5.849 \quad 5 \cdot 240$

\section{$7+$}

3.97E O8

$5 \cdot 325$

$8.67 E$ OP

$16 / 8,3$

$10 \cdot 177$

$3.11 E \quad C 8$

4.31E 08

$3.45 E \quad 08$

$7.46 E \quad 07$

$8.67 E$ O?

$8.67 E$ O7

$7.54 \mathrm{E}$ 05

$7.54 E \quad 05$

$16 / 8,3$

$16 / 9,3$

$16,9,3$

9.578

9.530

$10 \cdot 220$

$9 \cdot 433$

$7+$

$2.17 E \quad 08$

$7.54 E$ O5

$3.48 E$ O8

1. $25 \mathrm{~F} \quad 08$

$7.52 E$ OB

$8 \cdot 52 E \cdot 08$

$16 / 9,3$

$10 \cdot 414$

$7.54 E$ C5

$7.54 E \quad 05$

$7.54 E \quad 05$

$8.67 E \quad 07$

$16 / 9,3$

$10 \cdot 487$

$16,8,3$

9.729

9.762

$7+$

$1 \cdot 21 \mathrm{E}$ 08

$6.31 E$ O

$16 / 7,3$

$12 \cdot 836$

$2 \cdot 22 E \quad 0^{8}$

6.31E O7

1.01E. 8

$6 \cdot 31 E O^{7}$

$7.21 E \quad 07$

$5 \cdot 57 E \cdot 07$

$16,7,3$

$16 / 7,3$

$6.31 E$ O 7

$6 \cdot 31 E$ O 7

$16 / 7,3$

$16,7,3$

$12.661 \quad 11.982$

$7+$

1.15E 09

2.13E 09

$16 / 8 ; 4$

$12 \cdot 30^{4}$

$12 \cdot 186$

$11 \cdot 23 ?$

$7.94 E \quad 08$

1.54E O9

$1.36 E \quad 09$

1.02E CS

$2 \cdot 13 E \quad 03$

$2 \cdot 13 E$ O?

$2.13 E$ Oᄋ

2. $13 E$ OS

$16 / 8,4$

$16 / 8,4$

15/ 8,4

$16 / 8,4$

$10 \cdot 645$

$11 \cdot 218$

$10 \cdot 580$

$7+\quad 1.07 E 09$

$1.66 E$ O8

$16 / 9,4$

$1.35 E \quad 09$

$8.82 E$ O8

6. 60 OS

$1.66 E$ O

11.541

$16 ; 9,4$

$16,9,4$

$1.66 E$ O 8

$16 / 914$

1.17E O9

1. $66 \mathrm{E}$.8 $10.867 \quad 10.891$

$11 \cdot 612$

$16 / 9,4$

$10 \cdot 857$

$7+\quad 1.64 E 09$

1.04E 09

$16 / 7,4$

1.57E 09

1.38E O9

$1.33 E$ O9

1.35E 09

$1 \cdot 04 E$ C9

1.04E O?

$1 \cdot 04 E \quad 09$

1.04E OS

$16 / 7,4$

$16 / 7.4$

$16 / 7,4$

$16 / 7.4$

$13 \cdot 986$

$13 \cdot 303$

$13 \cdot 277$

$13 \cdot 766$

13.150 


\begin{tabular}{|c|c|c|c|c|c|}
\hline $8+$ & 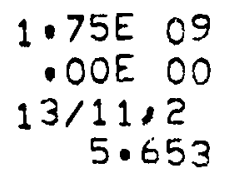 & $\begin{array}{r}1.85 E \text { O? } \\
.00 E \text { OO } \\
13 / 11,2 \\
5.154\end{array}$ & $\begin{array}{r}1.62 E \text { O9 } \\
\text { OOE OO } \\
13 / 11, ? \\
5.280\end{array}$ & $\begin{array}{r}2.31 E \text { O9 } \\
.0 D E \text { OO } \\
13 / 11.2 \\
5.748\end{array}$ & $\begin{array}{r}2.52 E \text { OS } \\
.00 E \text { OC } \\
13 / 11.2 \\
5.130\end{array}$ \\
\hline $8+$ & 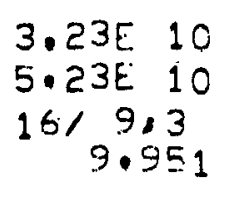 & 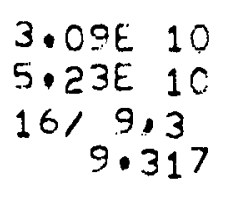 & $\begin{array}{rl}3.06 E & 10 \\
5.23 E & 10 \\
16 / 0.3 \\
9.421\end{array}$ & $\begin{array}{r}2.51 E \\
5.23 E \\
16 / 9.3 \\
10.417\end{array}$ & 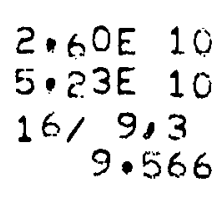 \\
\hline $8+$ & $\begin{array}{r}1.26 E C 7 \\
1.43 E \\
16 / 70 \\
12.551\end{array}$ & $\begin{array}{r}8.95 E \quad 07 \\
1.43 E \quad 10 \\
16 / 7.3 \\
1 ? .017\end{array}$ & $\begin{array}{r}4.52 E 08 \\
1.43 E 10 \\
15 / 7,3 \\
11.933\end{array}$ & $\begin{array}{r}4.23 E \quad 07 \\
1.43 E \quad 10 \\
16 / 7,3 \\
12.870\end{array}$ & $\begin{array}{r}4.29 E \quad 07 \\
1.43 E \quad 10 \\
16 / 7.3 \\
12.196\end{array}$ \\
\hline $8+$ & 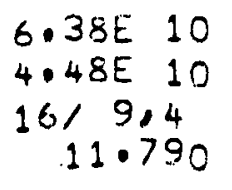 & $\begin{array}{c}6.44 E \quad 10 \\
4.48 E \quad 10 \\
16 / 9,4 \\
11.076\end{array}$ & 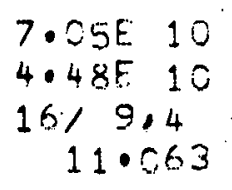 & 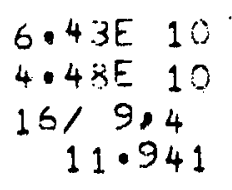 & 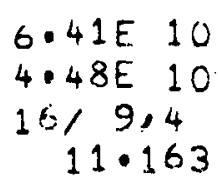 \\
\hline $8+$ & $\begin{array}{r}2.58 E \\
1.22 E \\
16 / 7,40 \\
13.710\end{array}$ & 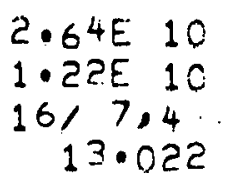 & $\begin{array}{rl}2.4 .35 & 10 \\
1.22 E & 10 \\
16,7,4 \\
13 \cdot 106\end{array}$ & 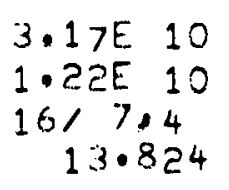 & 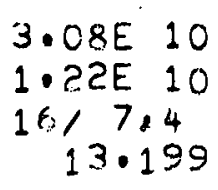 \\
\hline $9+$ & 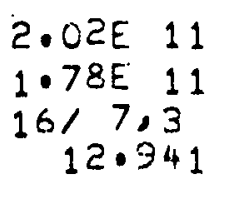 & $\begin{array}{r}4.07 E \text { 11 } \\
1.78 E \text { 11 } \\
16 / 7,3 \\
12.410\end{array}$ & 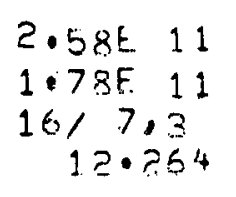 & $\begin{array}{r}1.12 E \quad 12 \\
1.78 E-11 \\
16 / 7.3 \\
13.079\end{array}$ & 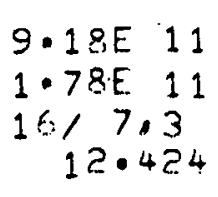 \\
\hline $9+$ & 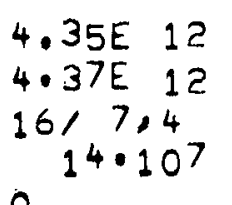 & $\begin{array}{c}4.14 E \quad 12 \\
4.37 E, 12 \\
16 / 7,4 \\
13.422\end{array}$ & $\begin{array}{r}4.19 F \quad 12 \\
4.37 F, 12 \\
16 / 7.4 \\
13.358\end{array}$ & $\begin{array}{r}3.44 E \quad 12 \\
4.37 E, 12 \\
16 / 7.4 \\
13.942\end{array}$ & 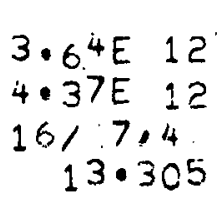 \\
\hline
\end{tabular}


APPENDIX E

VECTOR AMPLITUDES

161 
This appendix consists of four sections as Appendix D.

Summary of important vectors:

$$
\begin{aligned}
& \mathrm{J}=\text { spin, parity of state } \\
& \mathrm{E}=\text { excitation energy of state } \\
& \mathrm{N}=\text { dimension of vector }
\end{aligned}
$$$$
\text { Type - } 1 \mathrm{pp}^{-1} \text { excitation }
$$$$
2 n^{-1} \text { excitation }
$$$$
3 \quad \mathrm{~T}=0 \text { excitation }
$$$$
4 \quad \mathrm{~T}=1 \text { excitation } \mathrm{N} \neq \mathrm{Z}
$$$$
5 \mathrm{~T}=1 \text { excitation } \mathrm{N}=\mathrm{Z}
$$

Configuration: $\mathrm{p} / \mathrm{h}$ see Appendix $\mathrm{C}$.

$$
\begin{aligned}
& X \text { amp. } \\
& Y \text { amp. }
\end{aligned}
$$

BEJ (UP), BEJ (DOWN) units of $e^{2} \mathrm{f}^{2 \mathrm{~J}}$

$B M J(U P), B M J(D O W N)$ units of $e^{2} f^{2 J}$

SINGLE PARTICLE

Transition as of vector was composed solely to major componant and type.

$\mathrm{P}-\mathrm{TO}-\mathrm{H}$

Transition of single particle between orbits $\mathrm{P}, \mathrm{H}$. (PH) $-\mathrm{TO}-(\mathrm{G} . \mathrm{S}$.

Transition of a single particle-hole configuration, $\mathrm{ph}^{-1}$, to ground state.

Ratio of BMJ or BEJ to above can be considered a measure of the enhancement or dehancement due to configuration mixing.

Density Function

to be ignored. 
Q16-TDA K.K.

ISPIN(G.S.) = O ITDRP=0 IA=16 IZ=8 HW=13.30 $I P U=0$ J. 1 . $E=10.624 \quad N=10$

TYPE - 3
$4 / 2$
$5 / 3$
$5 / 2$
$6 / 3$
$6 / 2$

. .294

.859

- 337

. .228

.040

TYPE -5

412

$5 / 3$

$5 / 2$

$6 / 3$

$6 / 2$

.009

.089

.007

.004

. .002

$B E J(U P)=1.047 E-03$

$B E J(D O W N)=3.490 E-04$

MAJOR COMPENENT $P=5 \quad H=3$ TYPE $=3$

SINGLE PARTICLE. BEJ

$P-T B-H=1.241 E-O 1$

$$
(P H)-T \theta-0 .(G \cdot S \cdot)=8 \cdot 27.1 E-02
$$

DENSITY FUNCTION

CSTORE ( 2) $=-1 \cdot 028 E-01$

CSTORE $(4)=5.313 E-02$ 


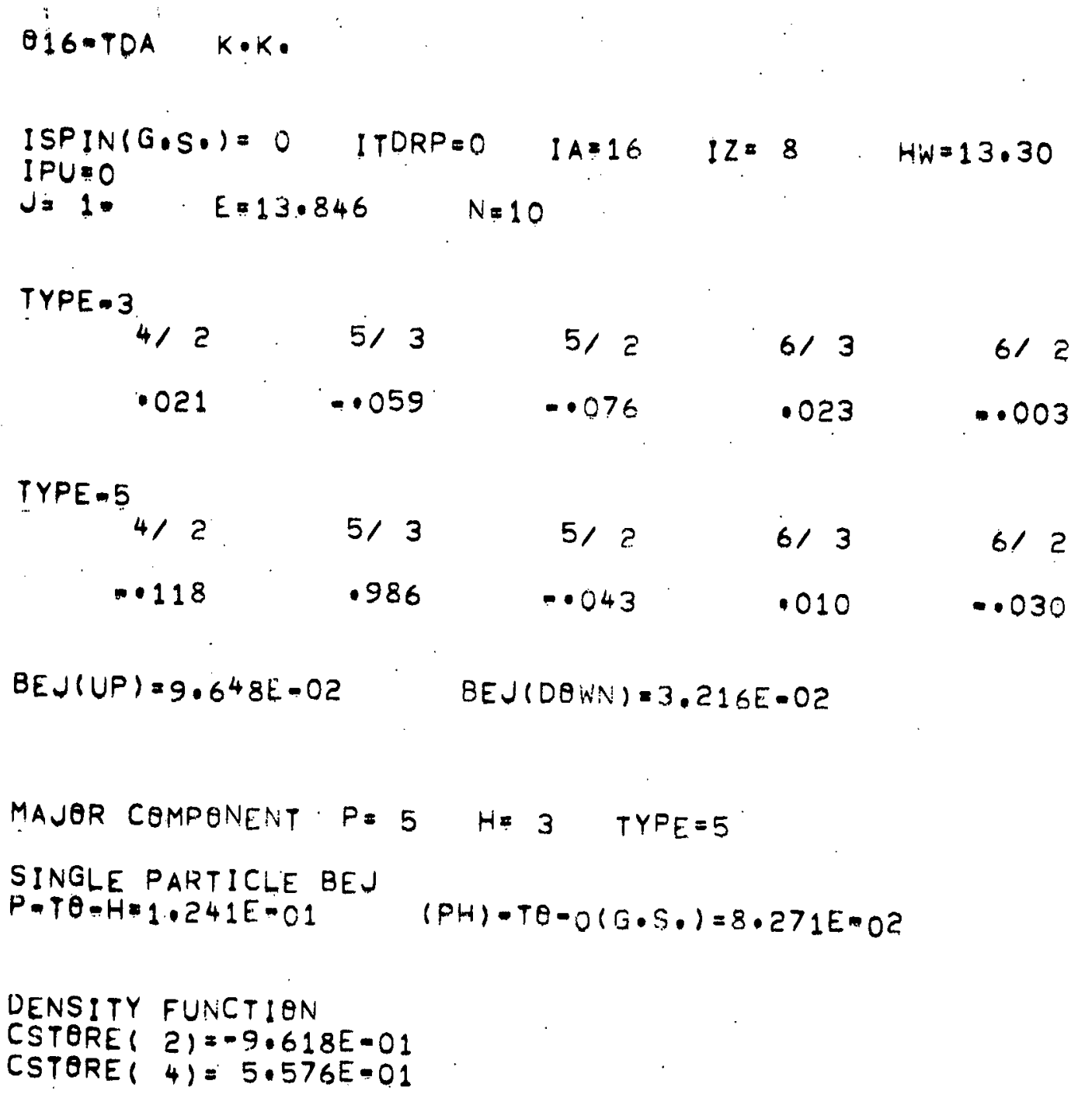




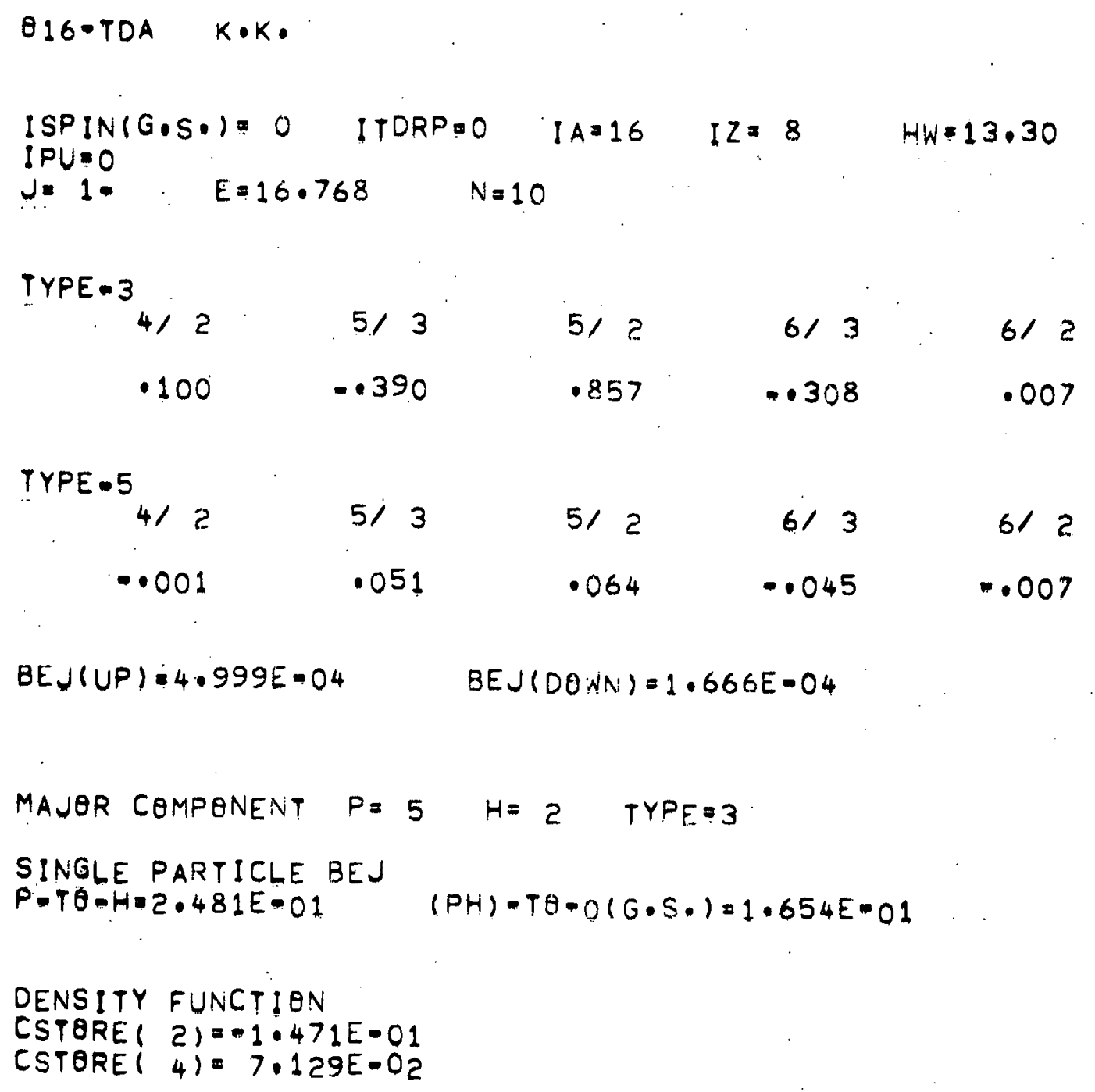




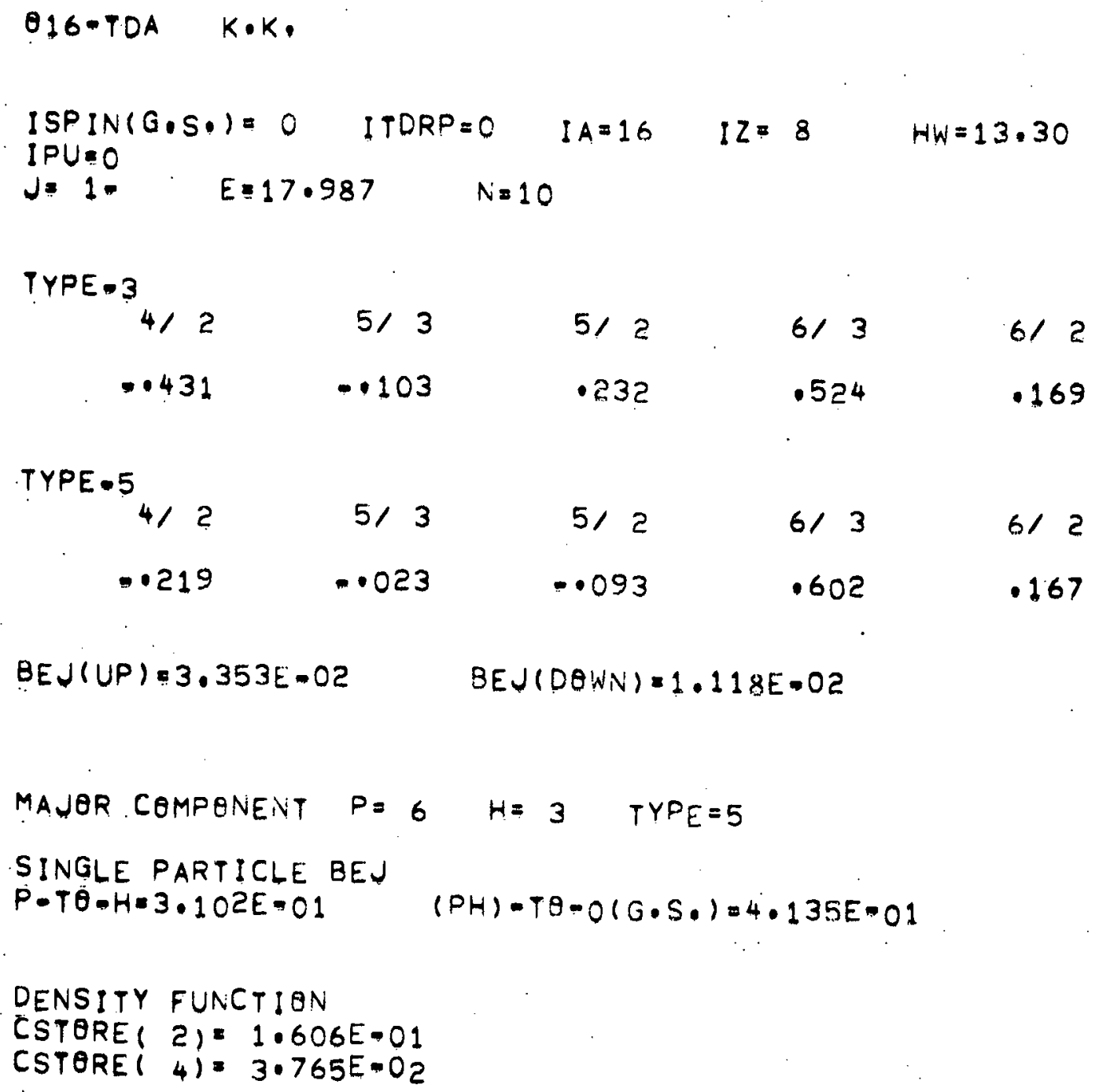




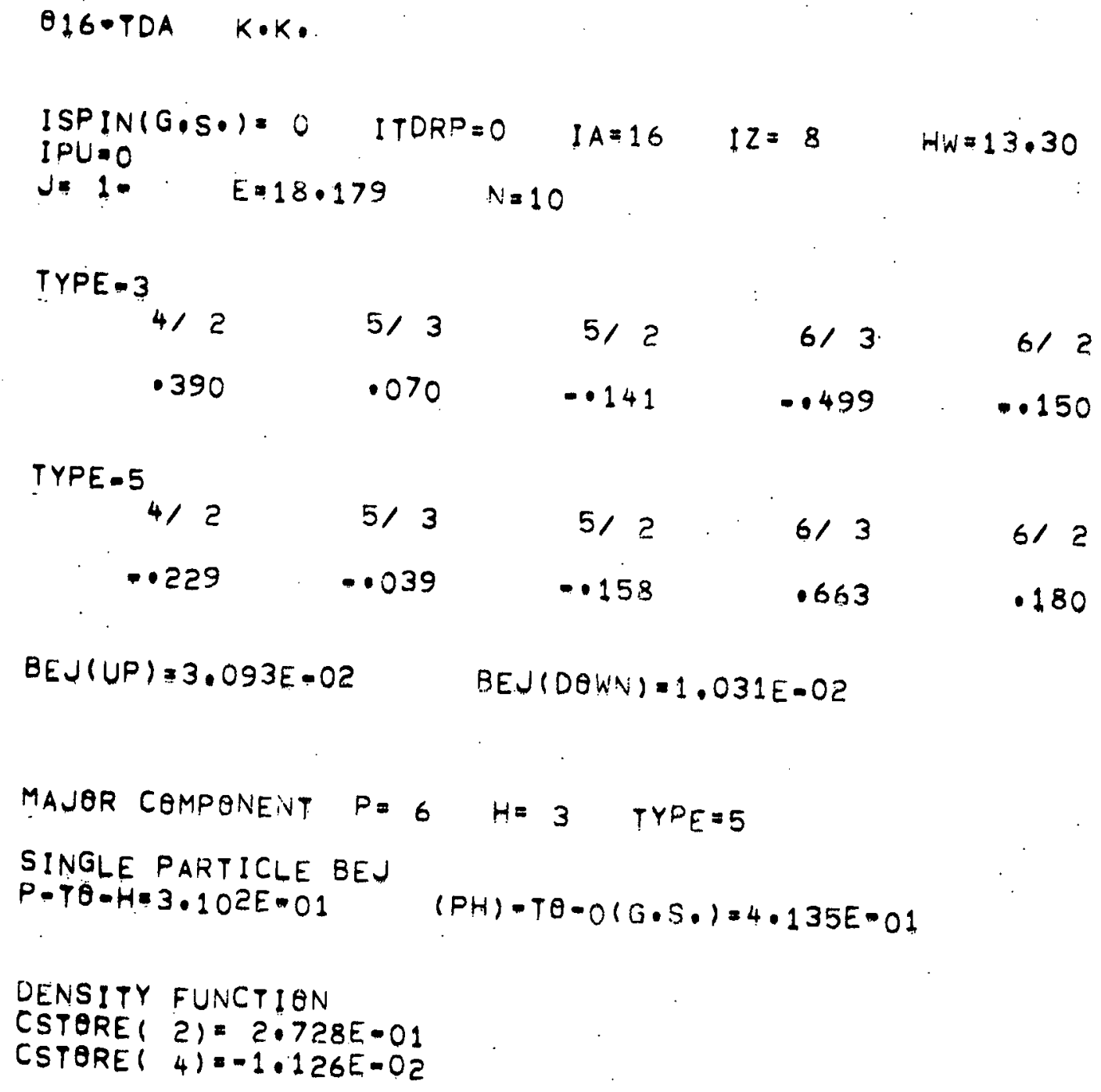


Q16-TDA K.K.

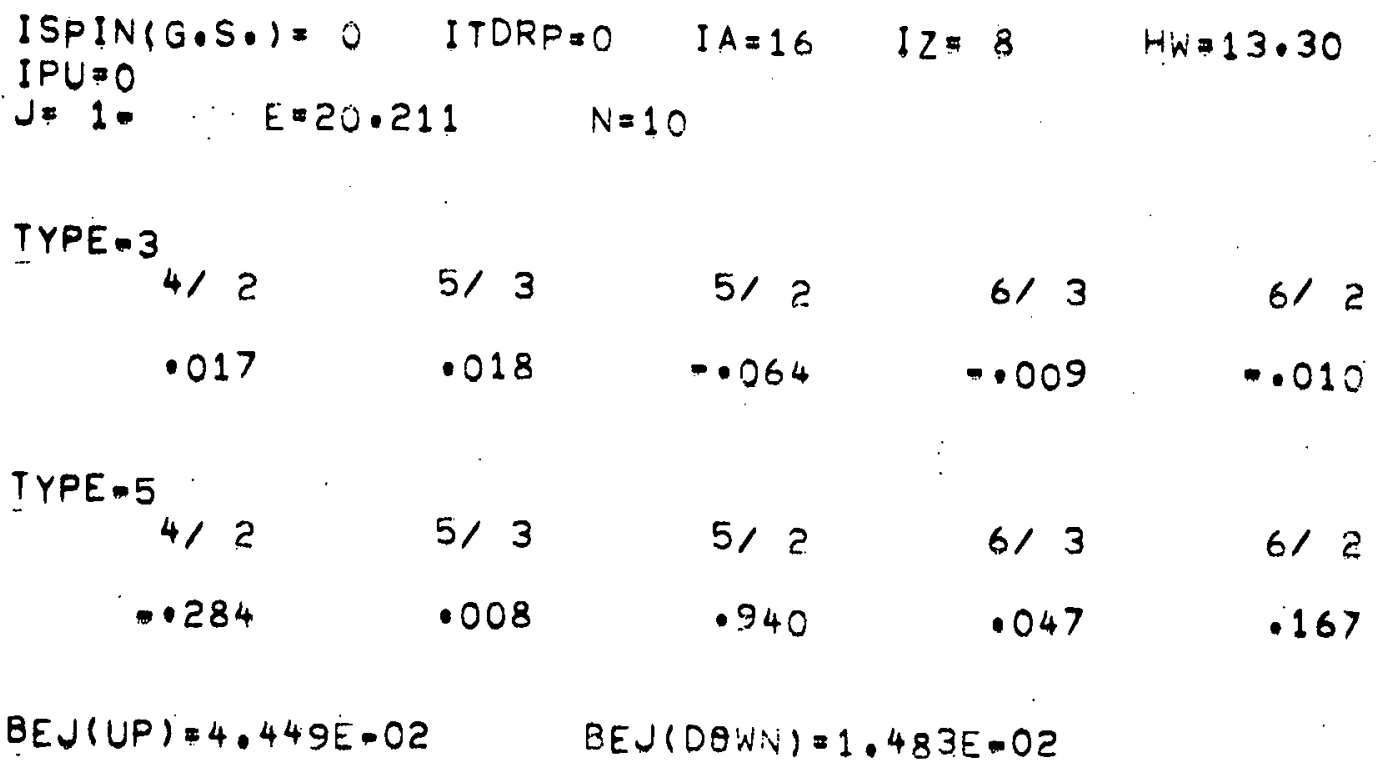

MAJOR COMPONENT $P=5 \quad H=2 \quad$ TYPE $=5$

SINGLE PARTICLE BEJ

$P=T \theta-H=2.481 E-01 \quad(P H)=T Q-O(G . S)=.1.654 E=01$

DENSITY FUNCTION

CSTORE ( 2$)=-1.390 E$ OO

CSTORE $(4)=6.735 E-01$ 


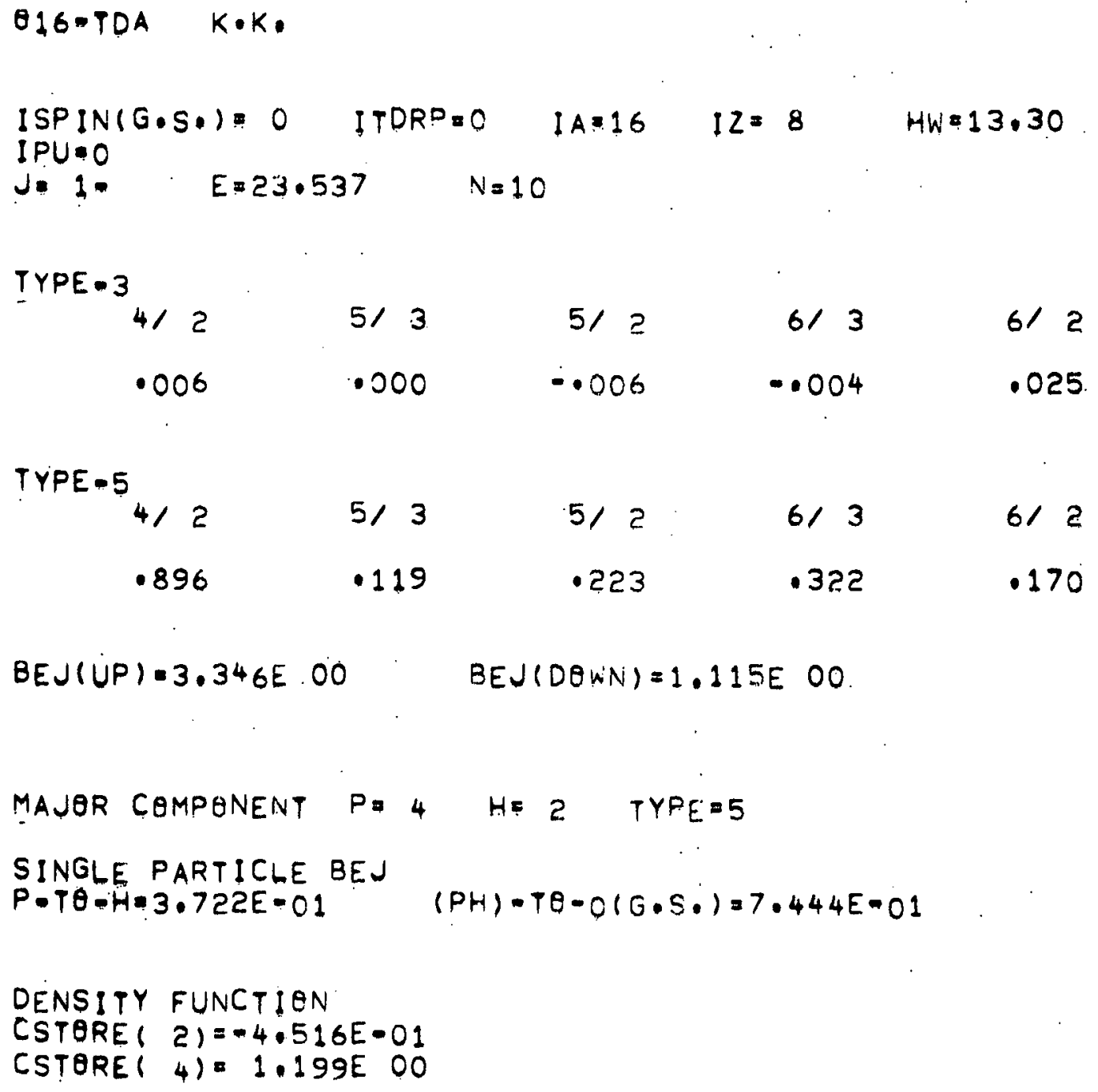




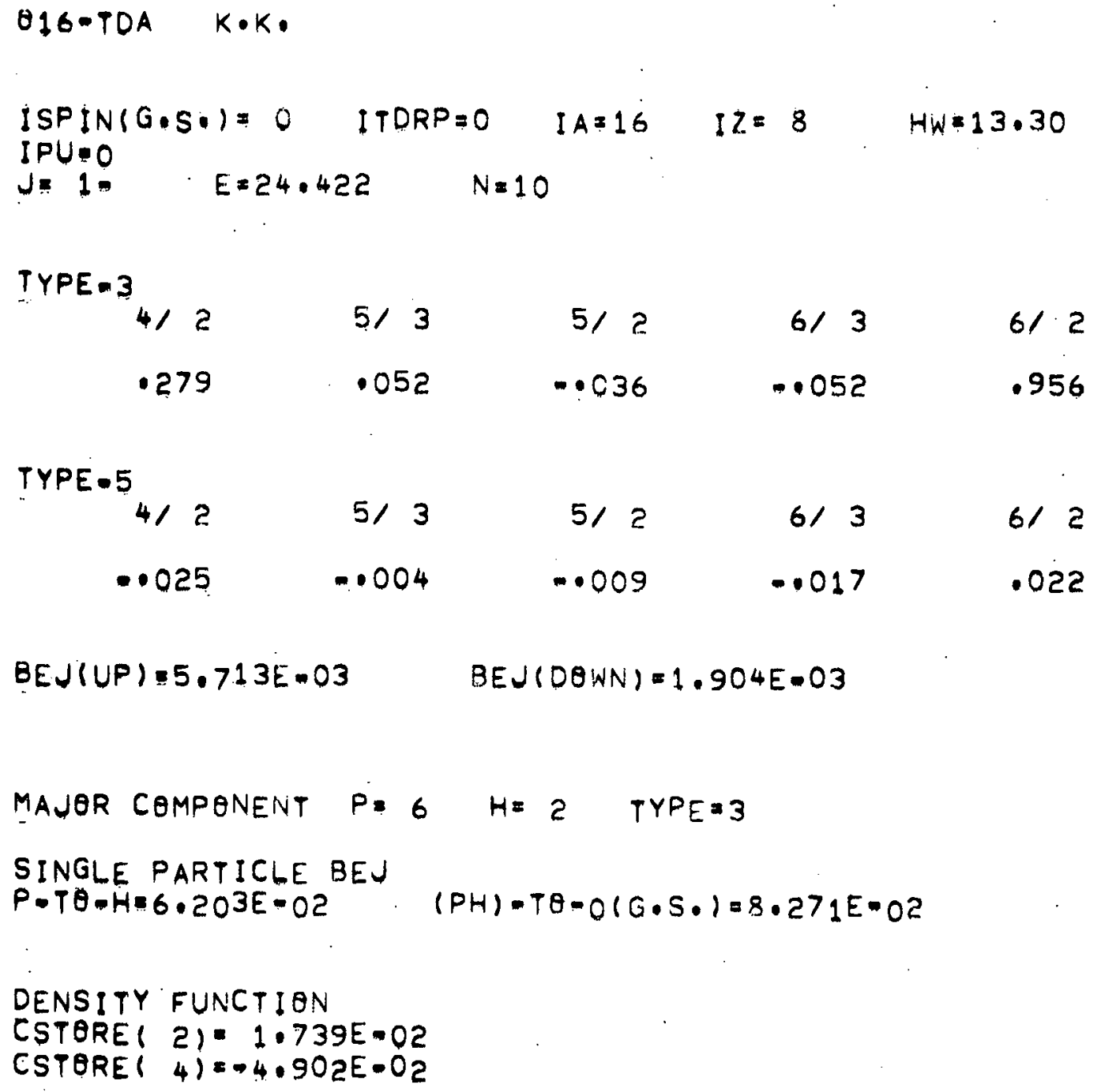




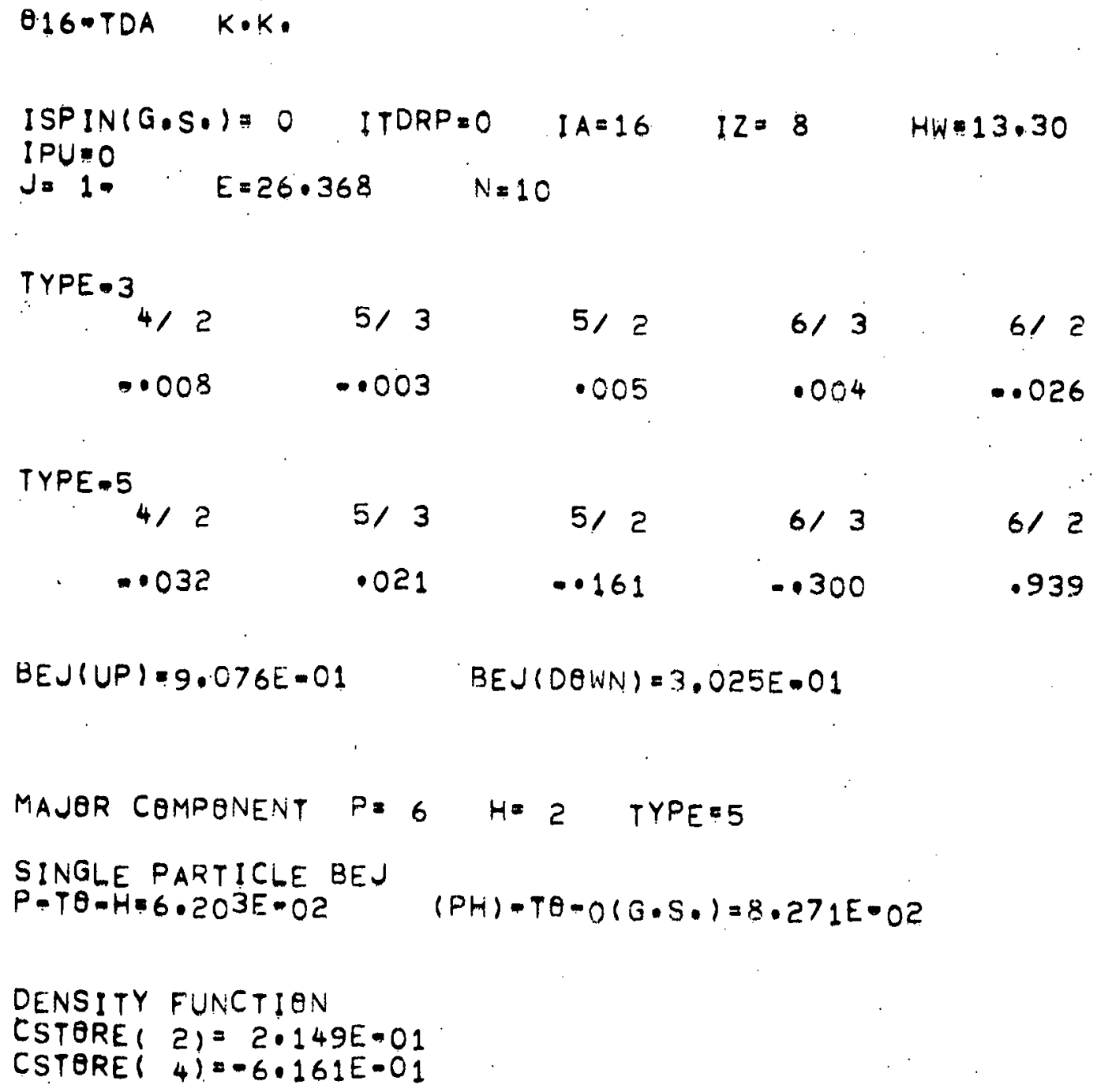




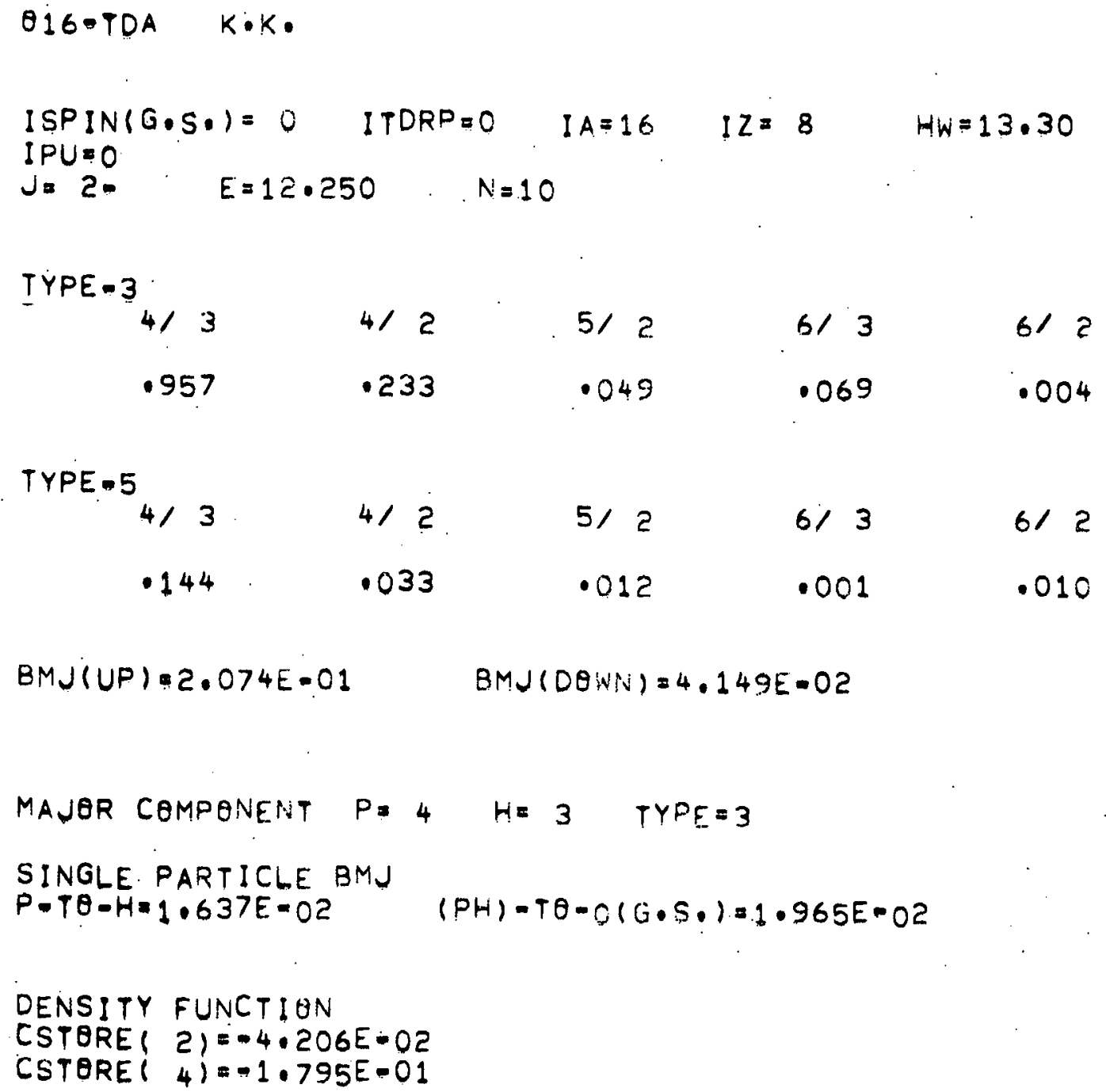




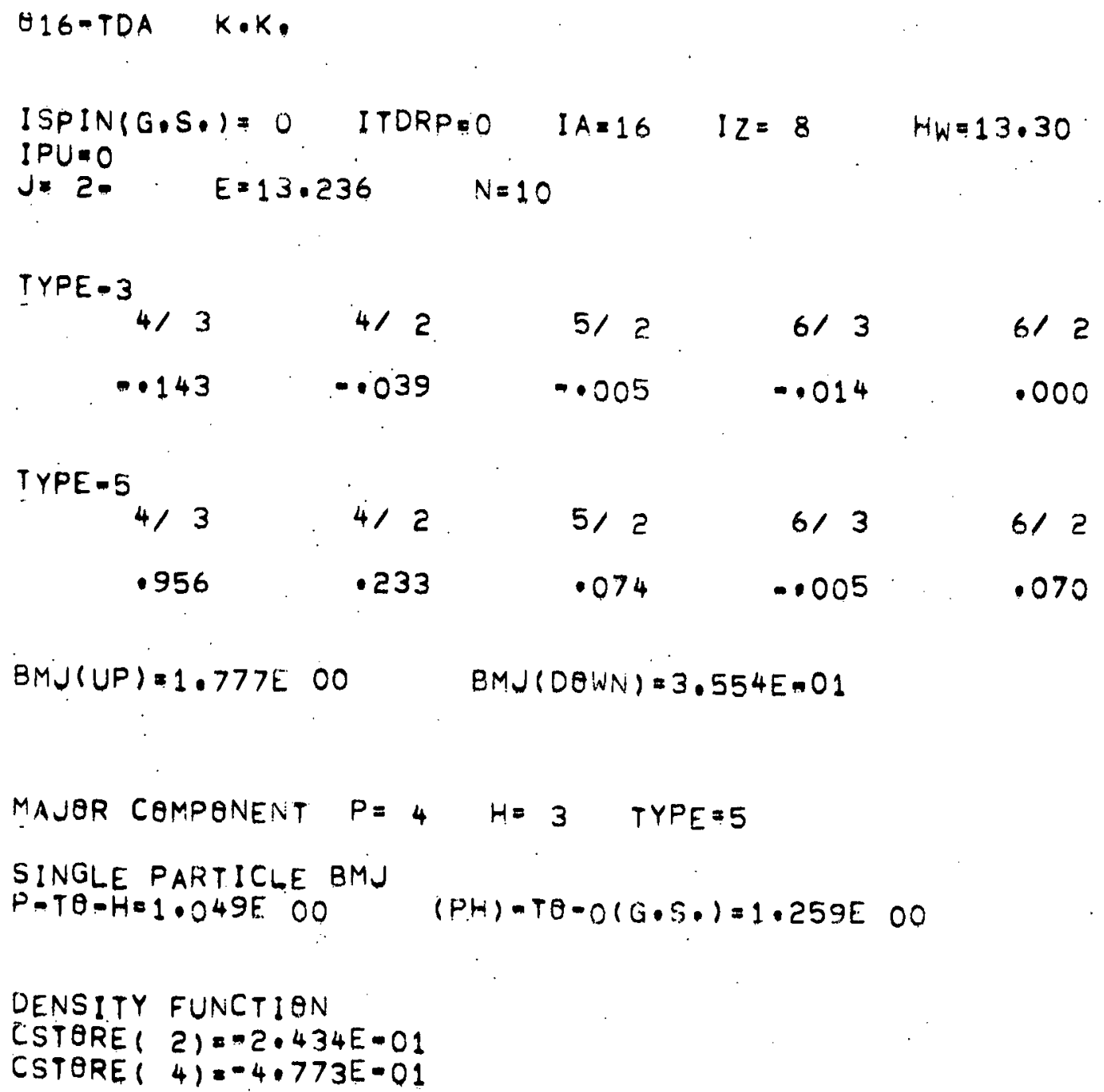




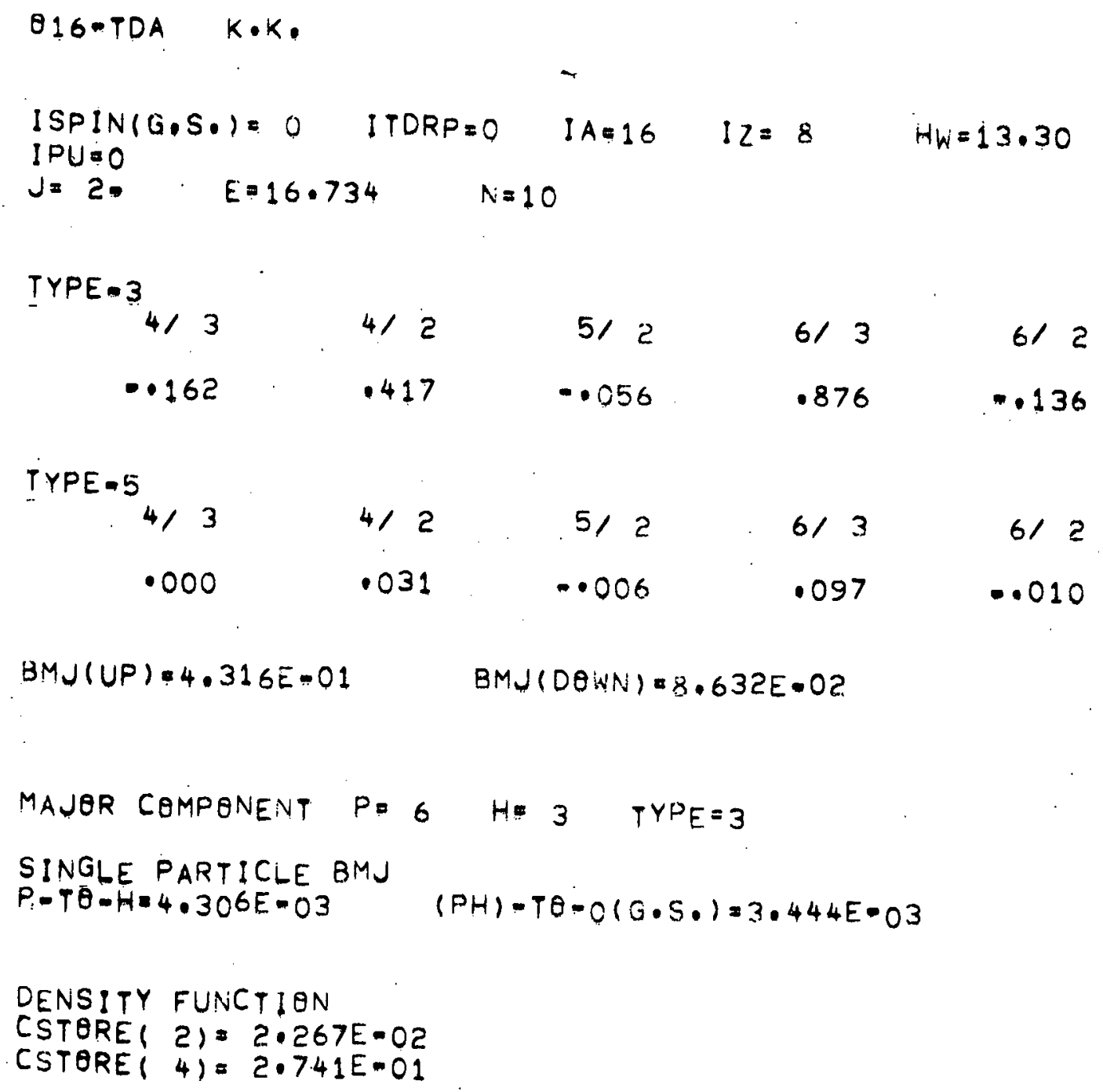




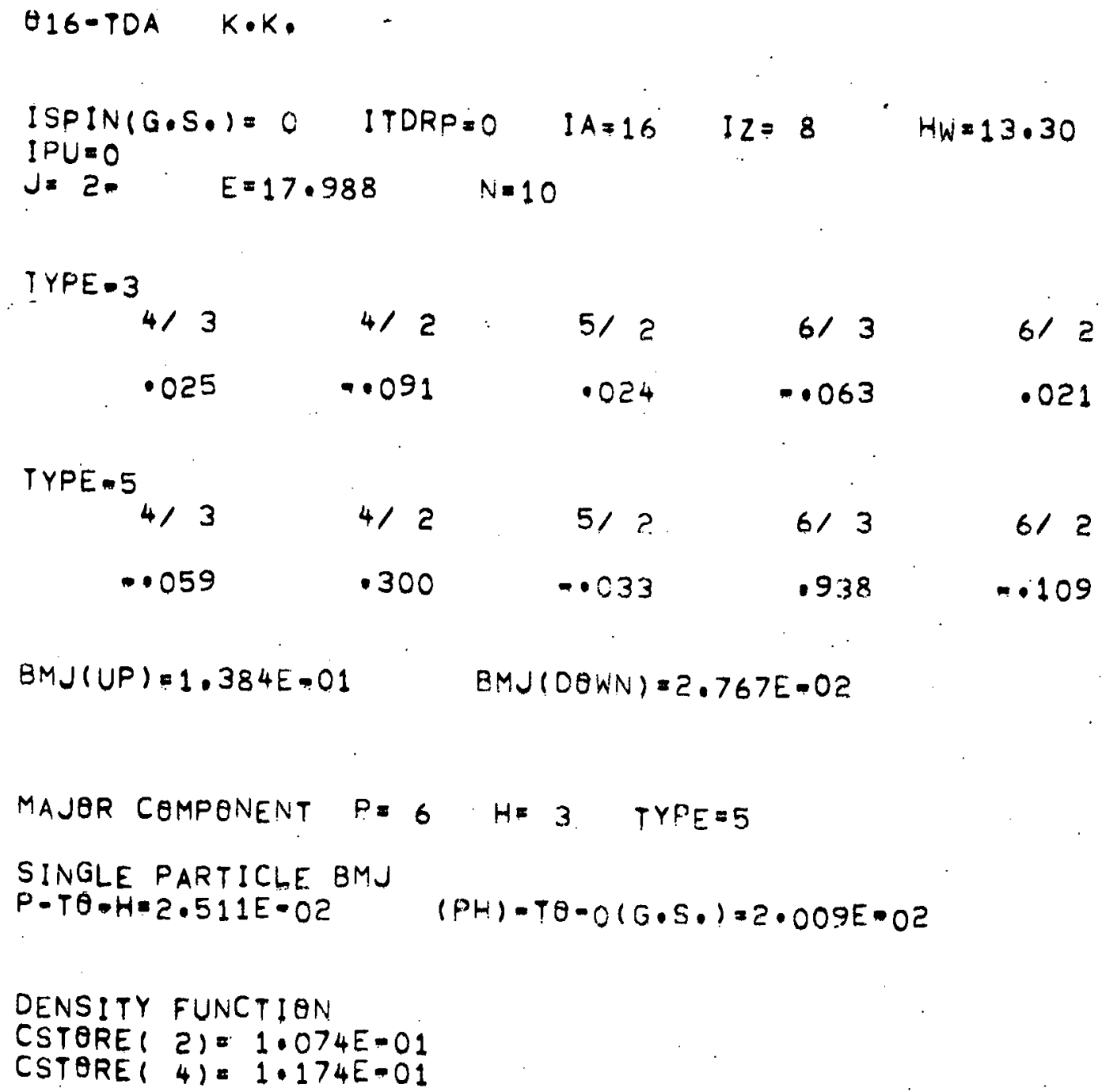

BMJ(UP) $=1.384 E .01$

MAJOR COMPONENT $P=6$ HE 3. TYPE $=5$

SINGLE PARTICLE BMJ

$P-T \theta-H=2.511 E-02$

DENSITY FUNCT!ON

CSTORE ( 2) $1.074 E-01$

CSTORE $(4)=1.174 E-01$ 


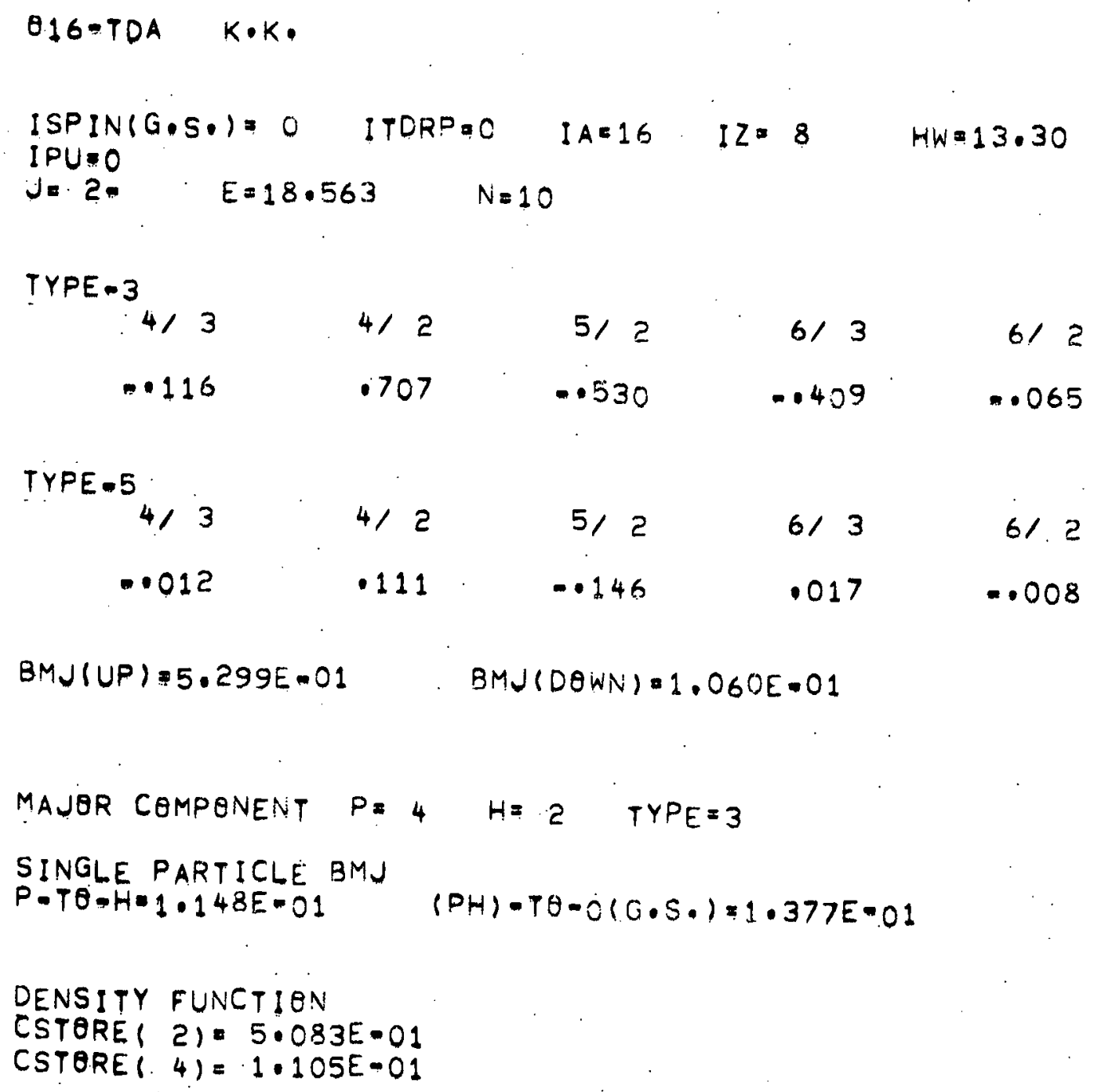




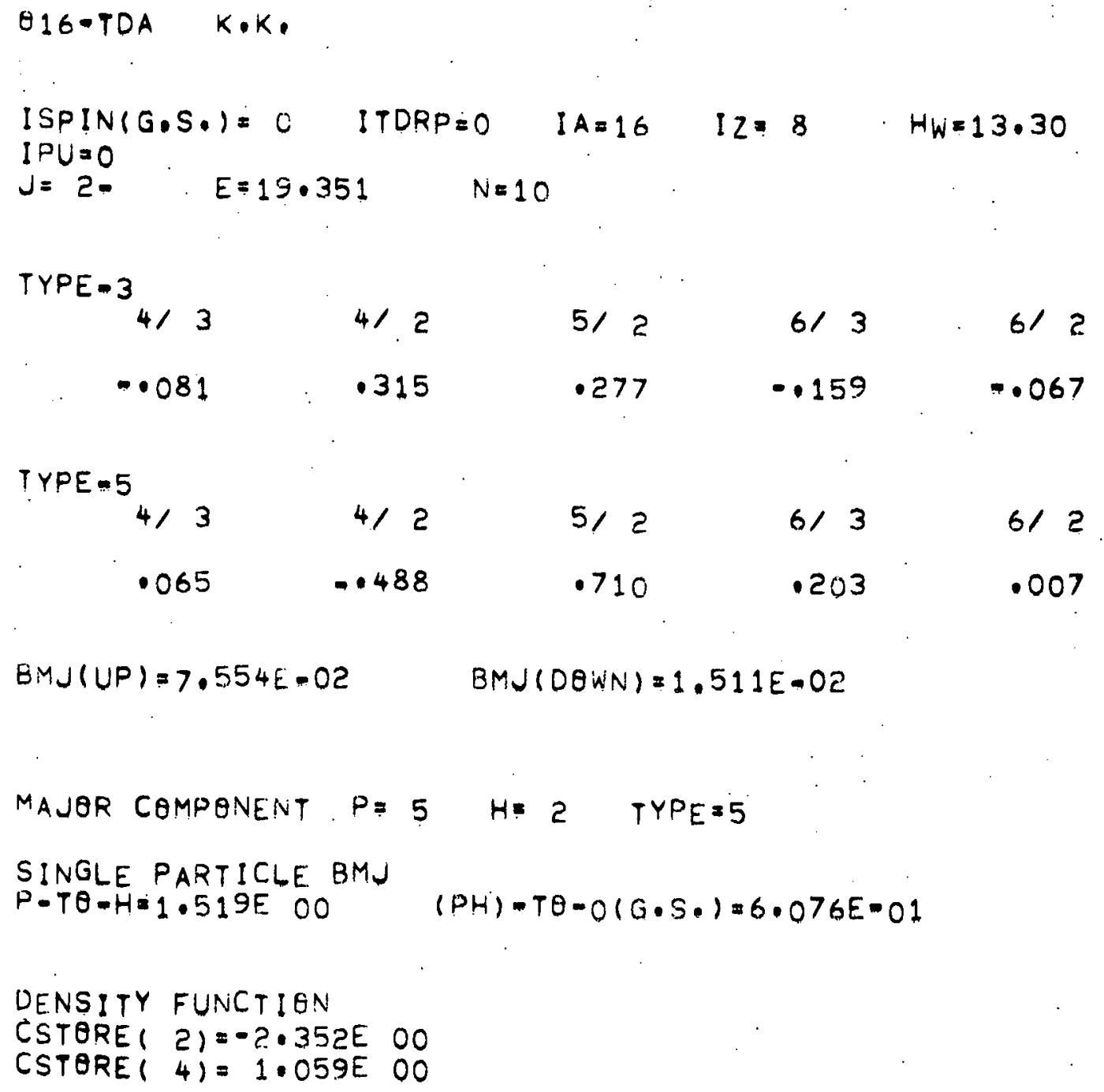




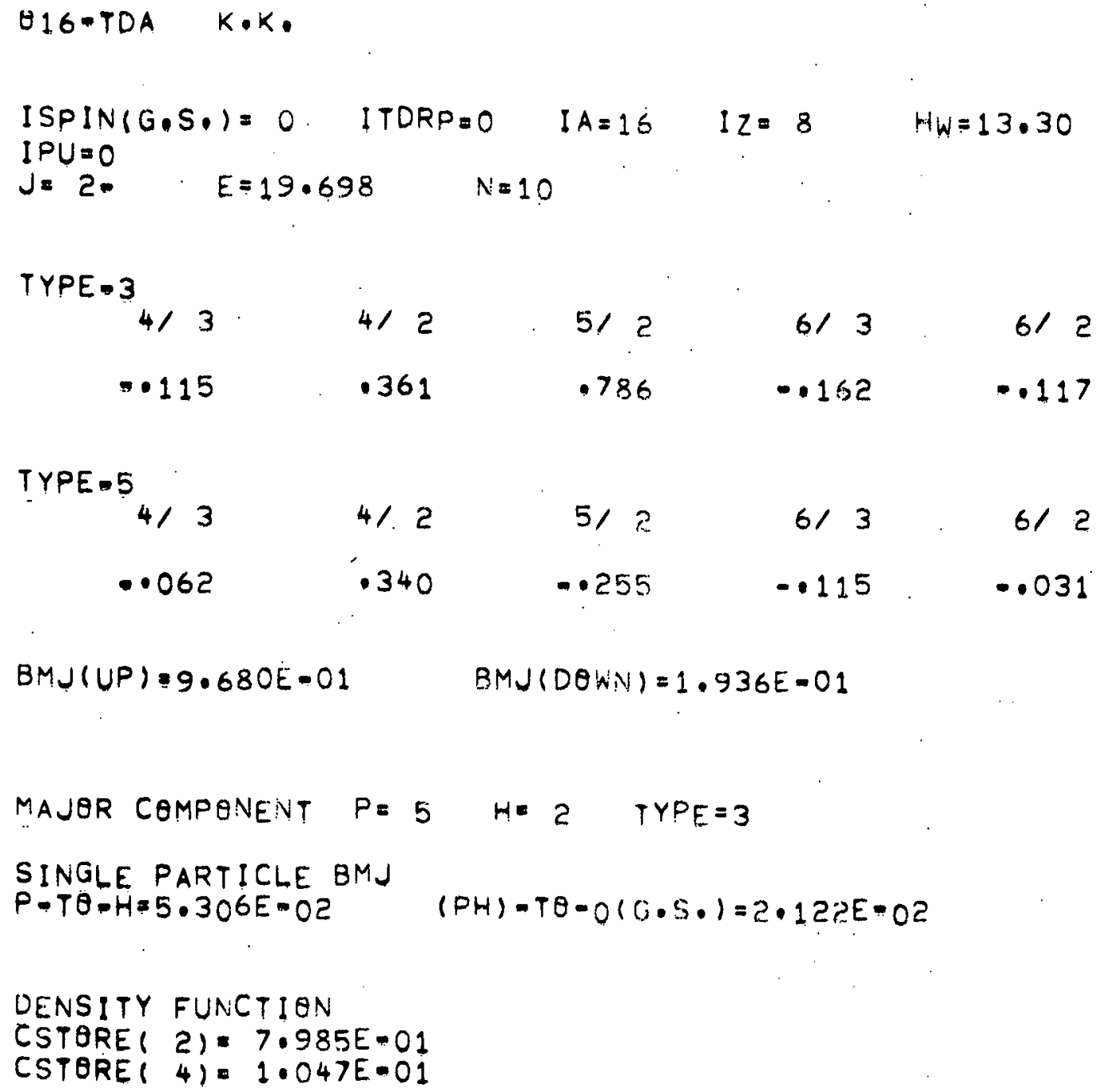




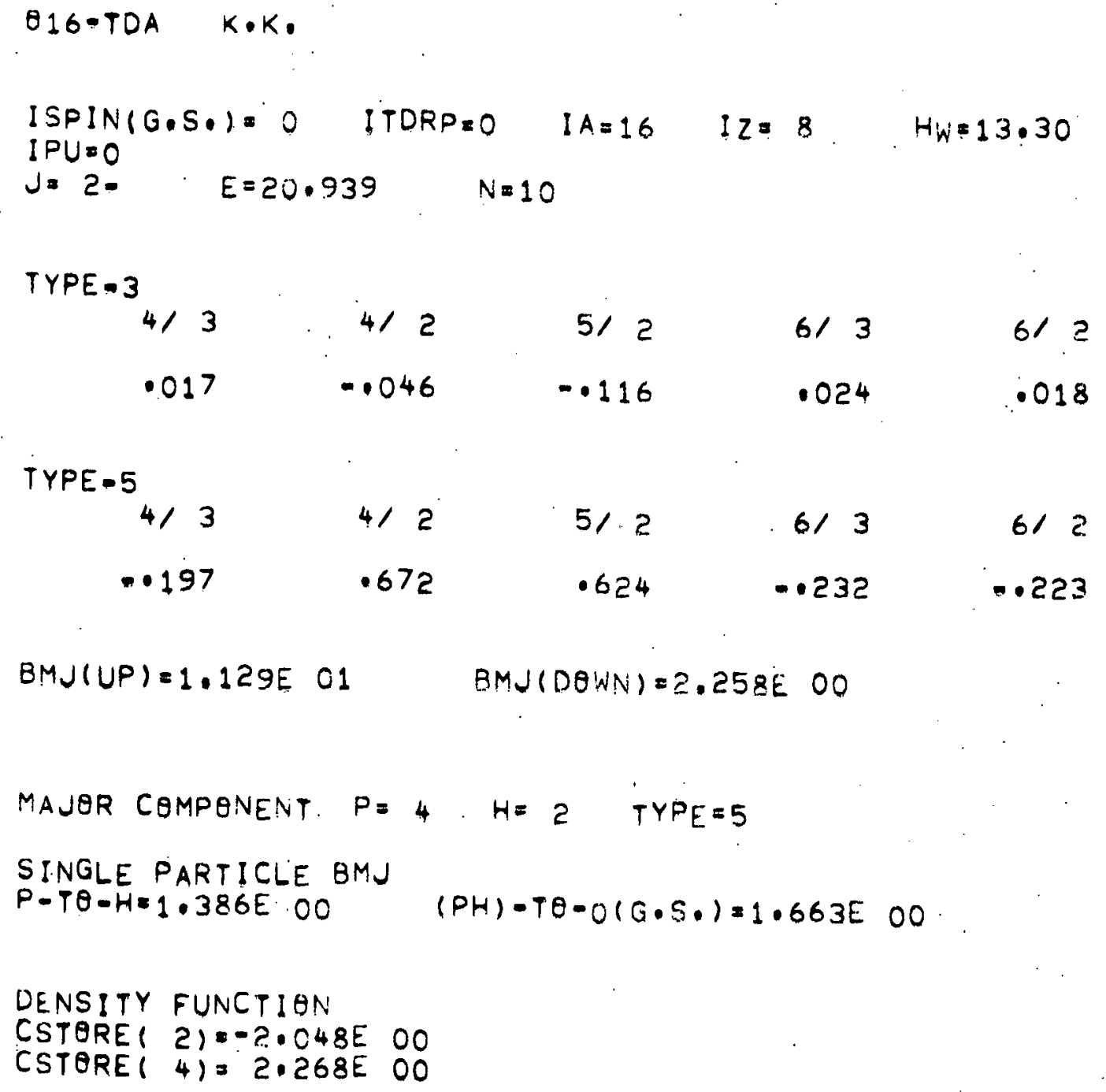


U16-TDA K.K.

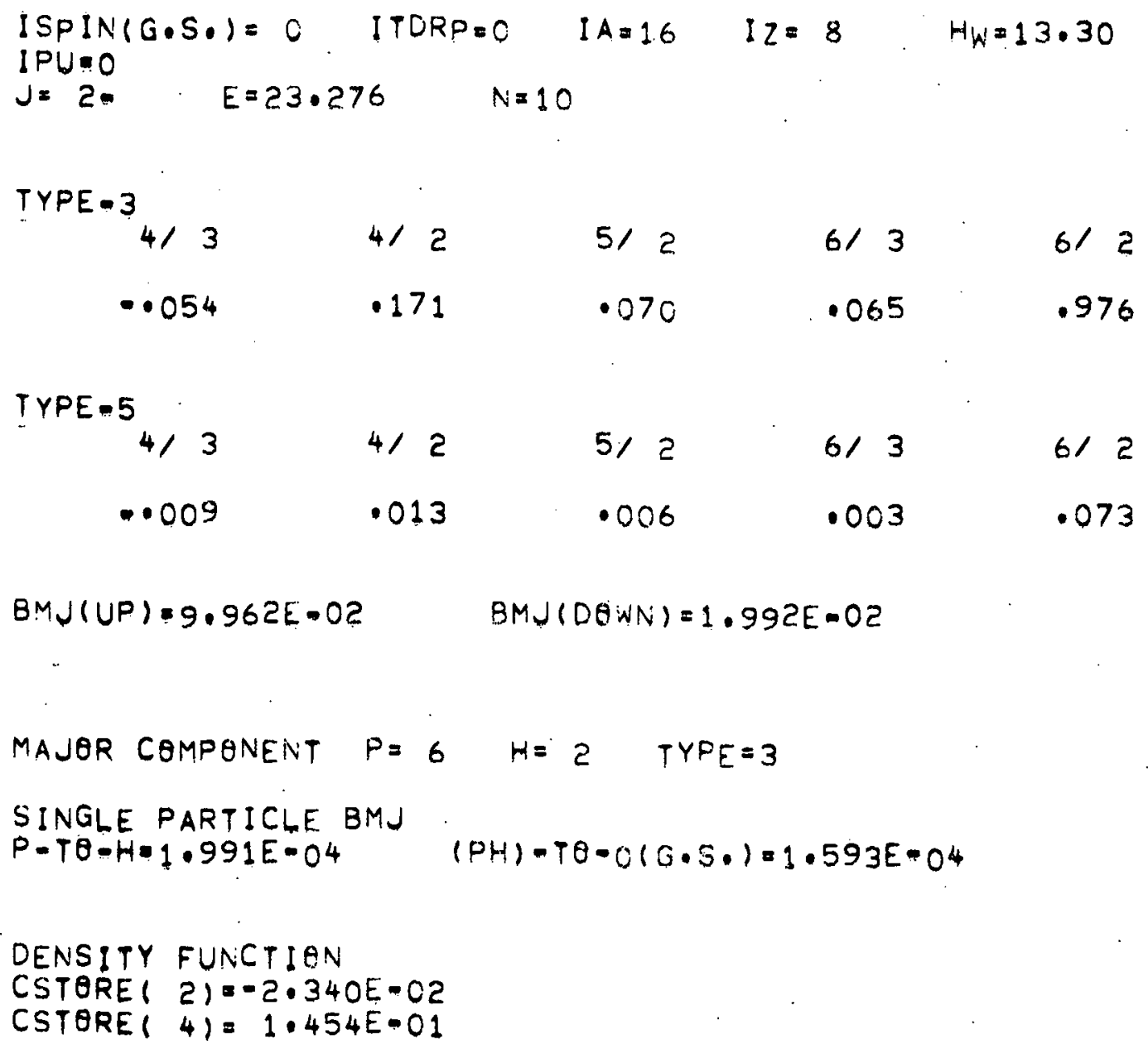




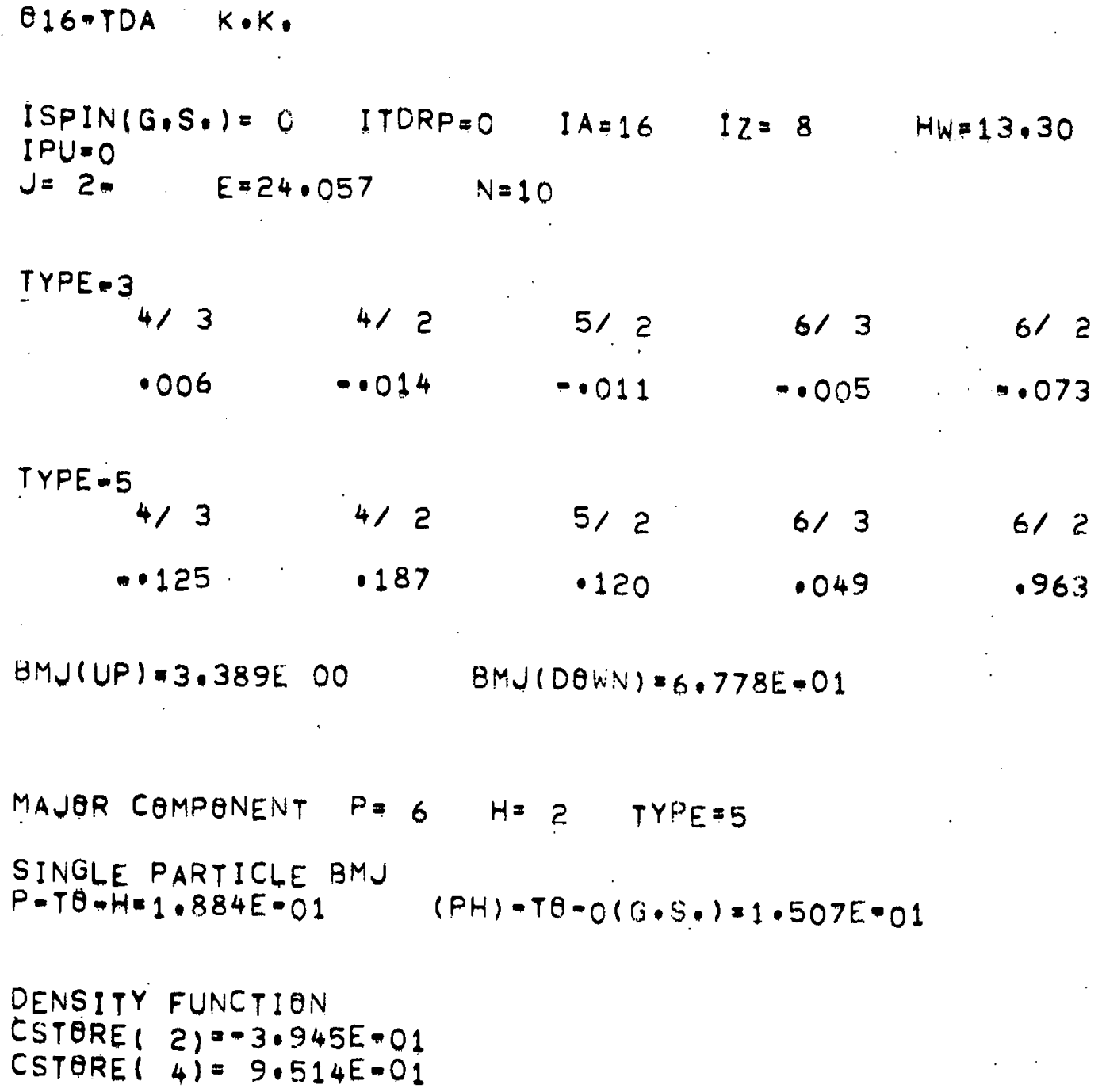

BMJUUP) $=3.389 E 00$

$B M J(D Q W N)=6.778 E-01$

MAJOR COMPONENT $P=6 \quad H=2 \quad$ TYPE $=5$

SINGLE PARTICLE BMJ

$P=T \theta-H=1.884 E=01$

$$
(P H)-T \theta-O(G \cdot S \cdot)=1 \cdot 507 E-01
$$

DENSITY FUNCTION

CSTORE ( 2) $=-3.945 E-01$

CSTERE $(4)=9.514 E-01$ 


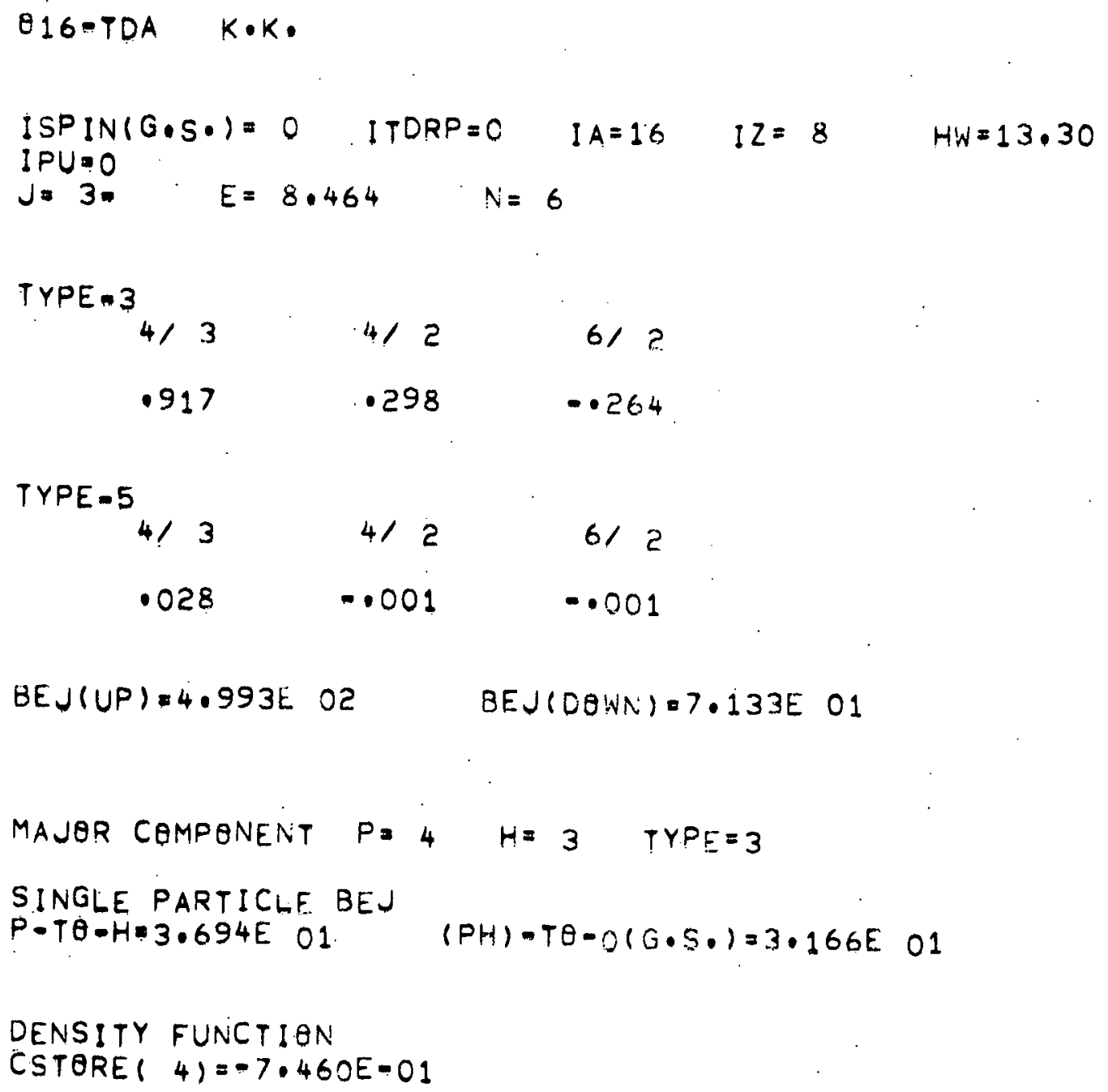




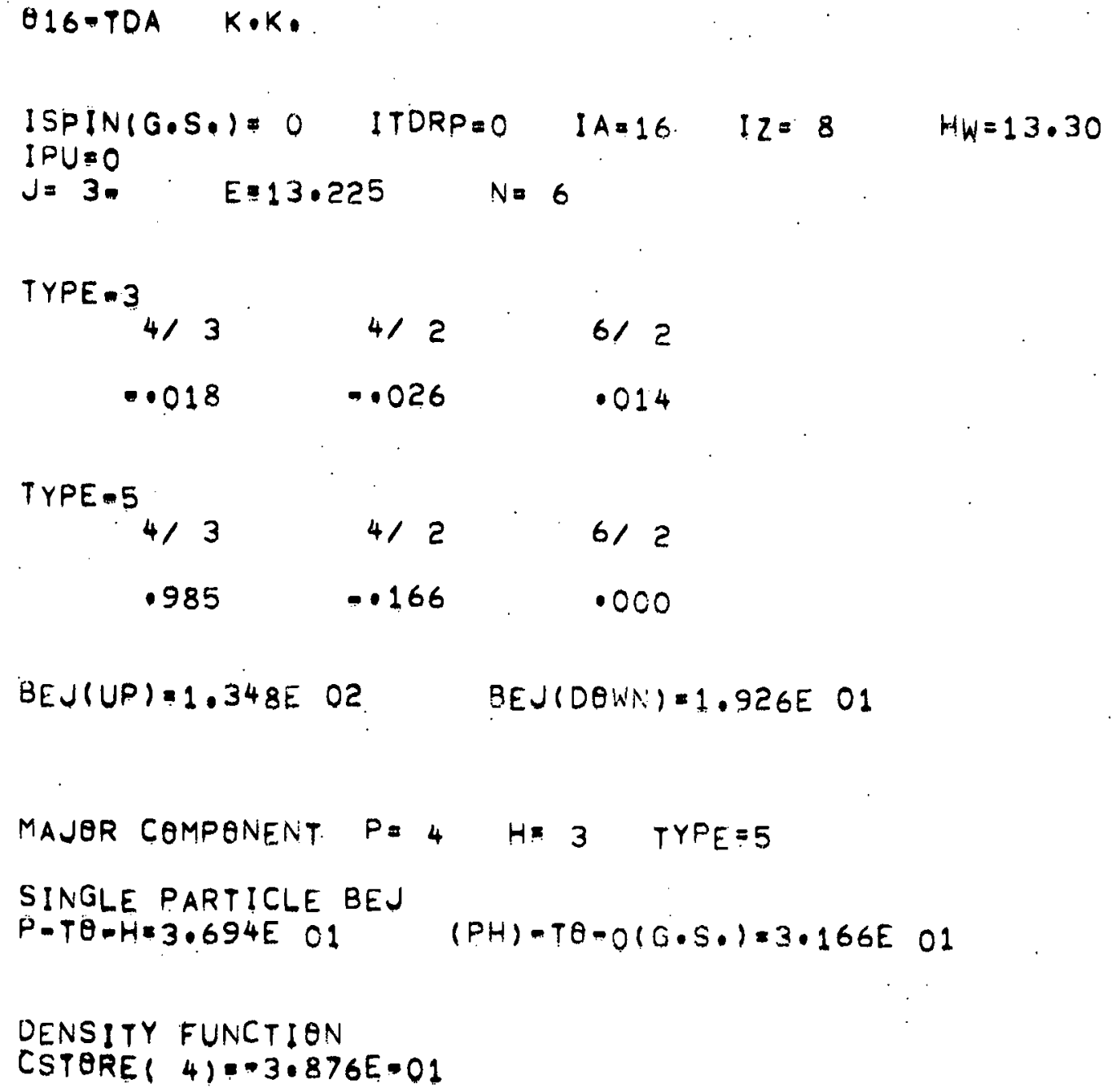




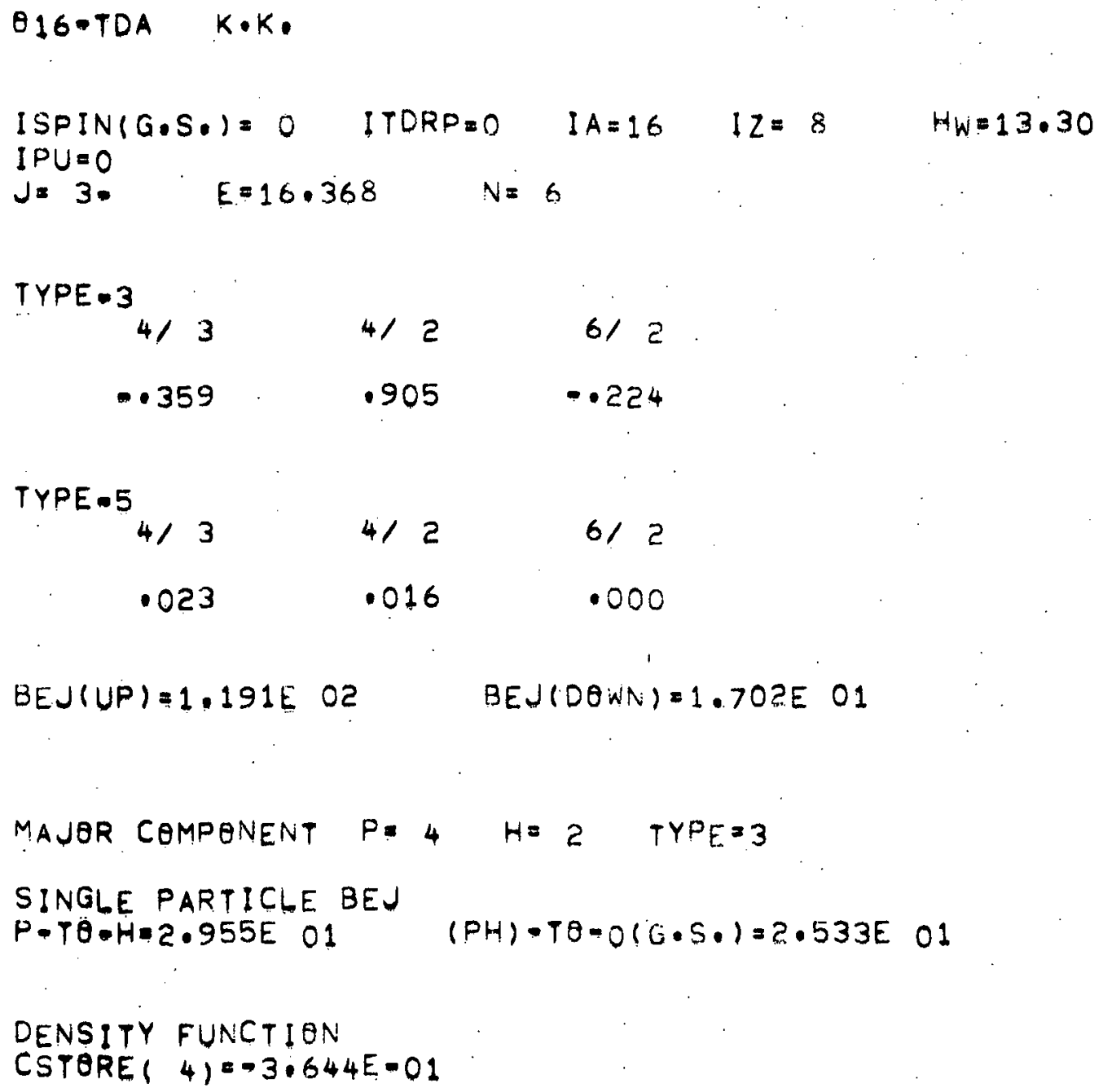




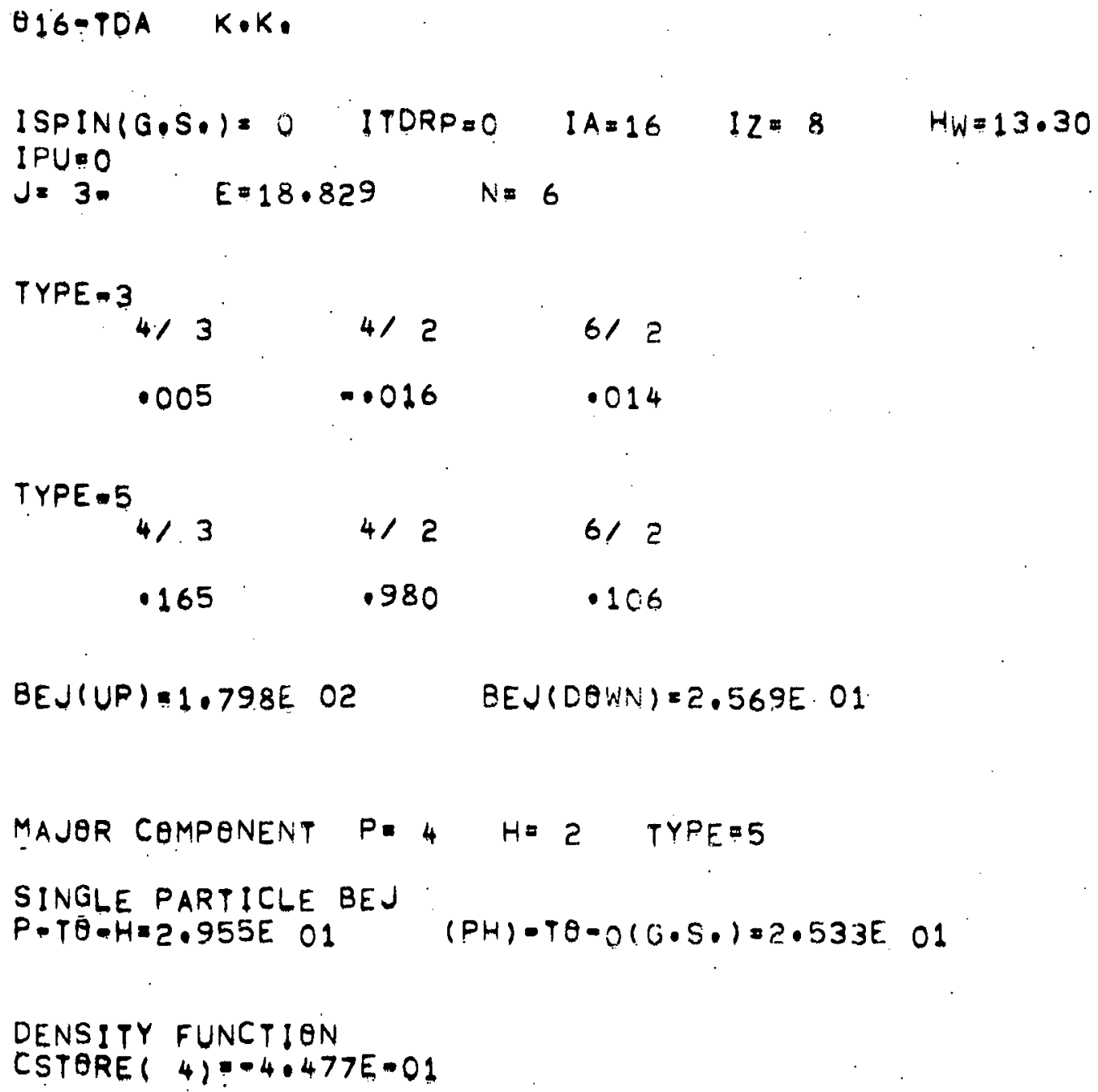




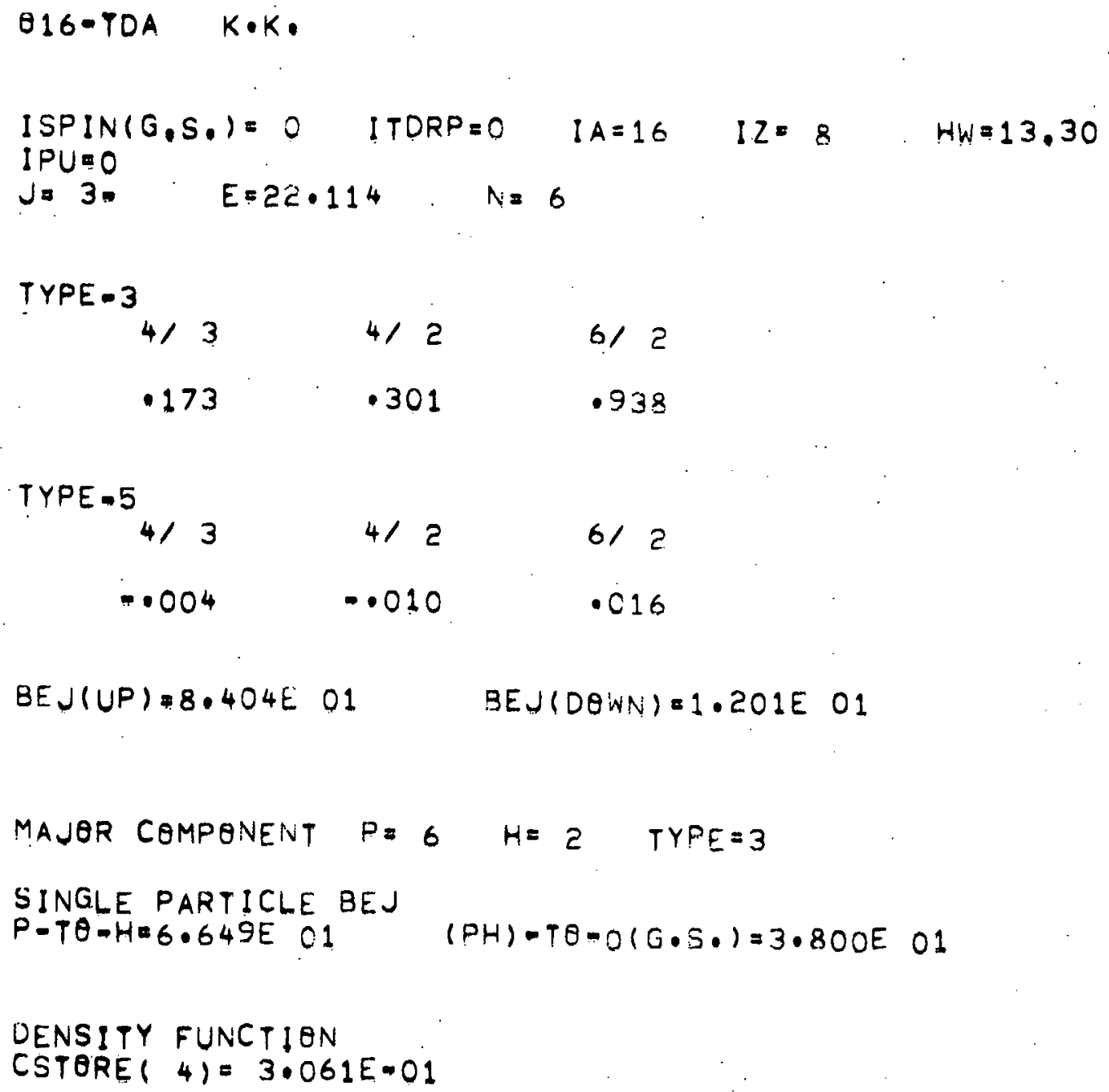




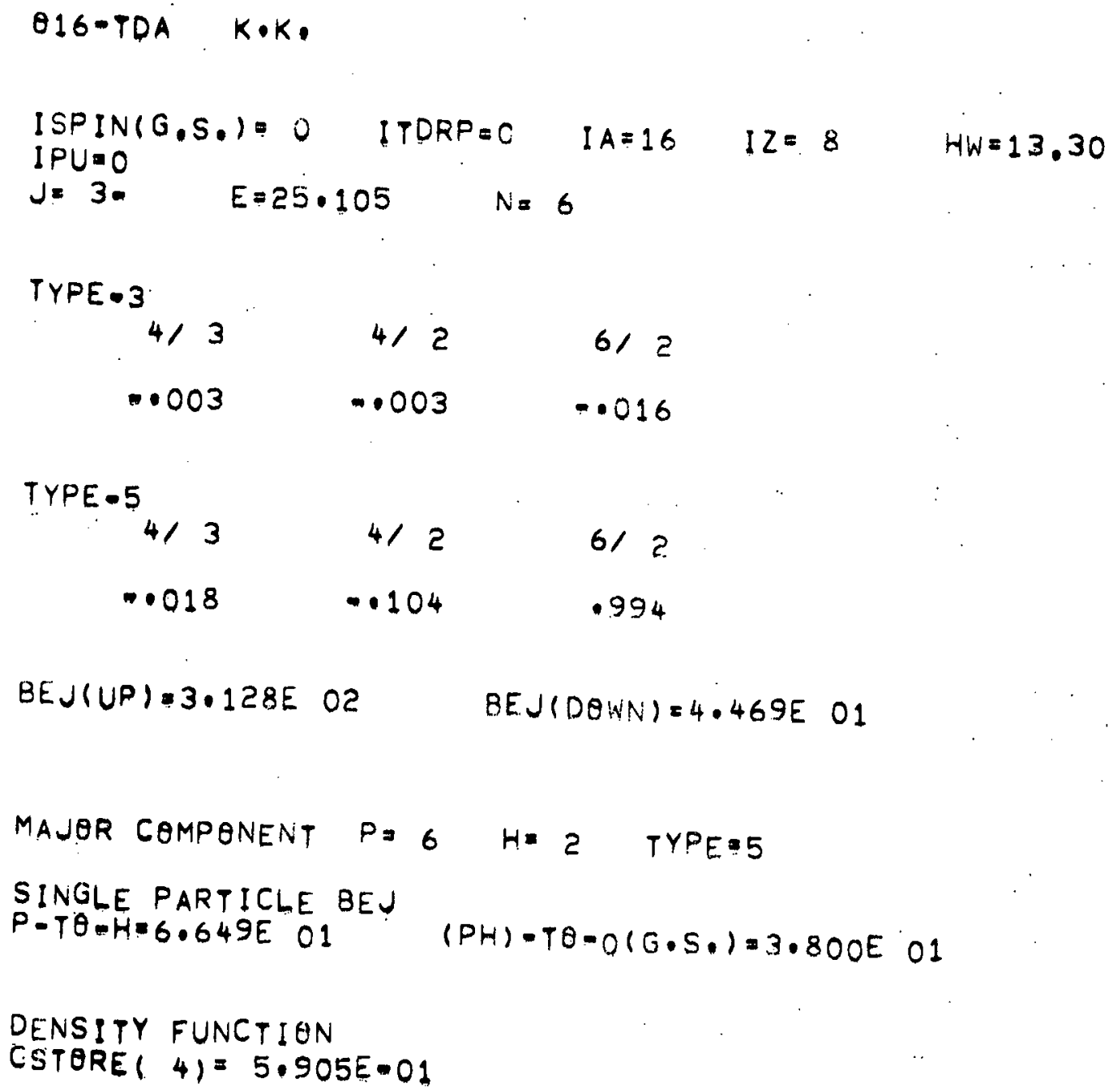




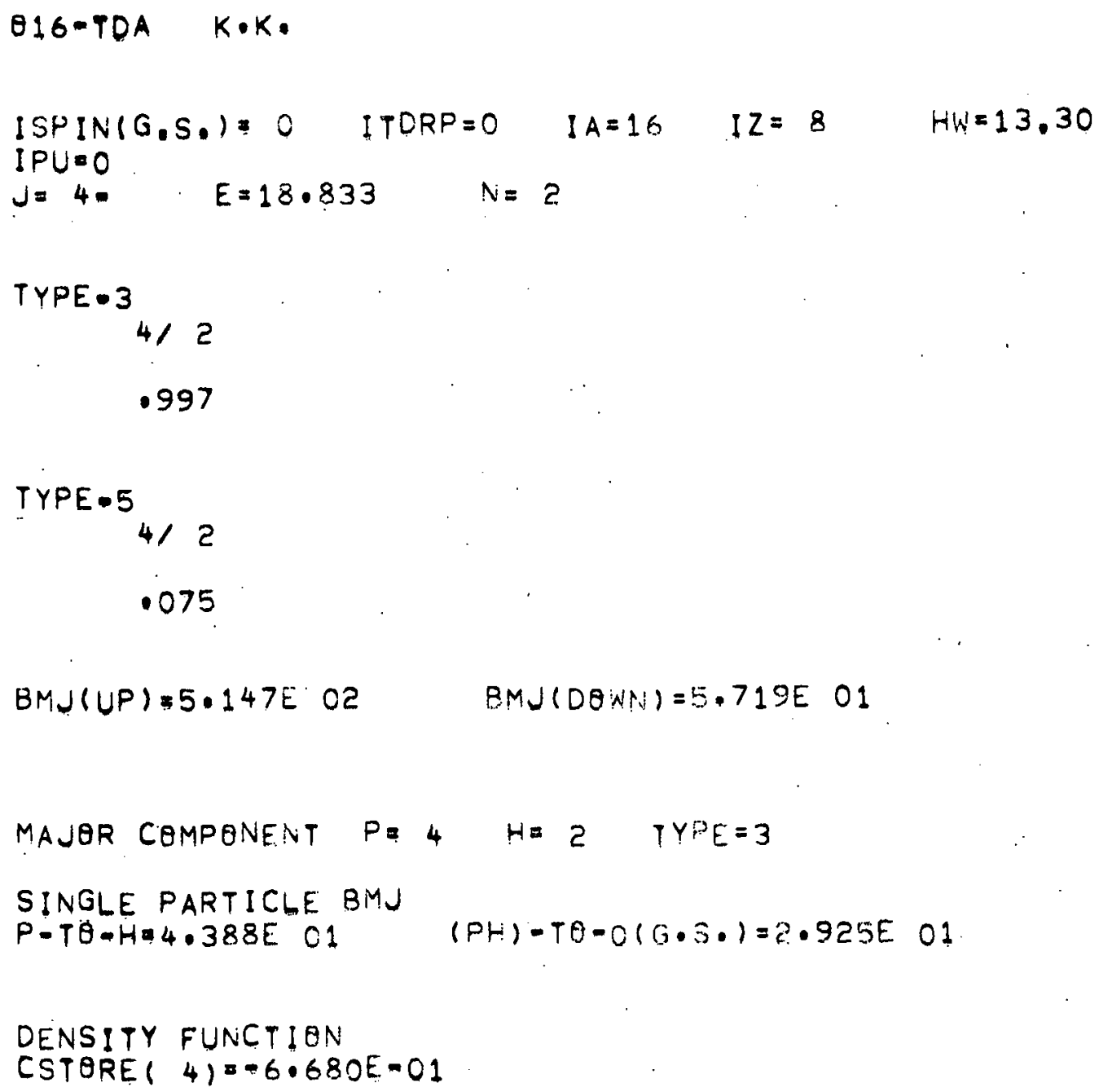




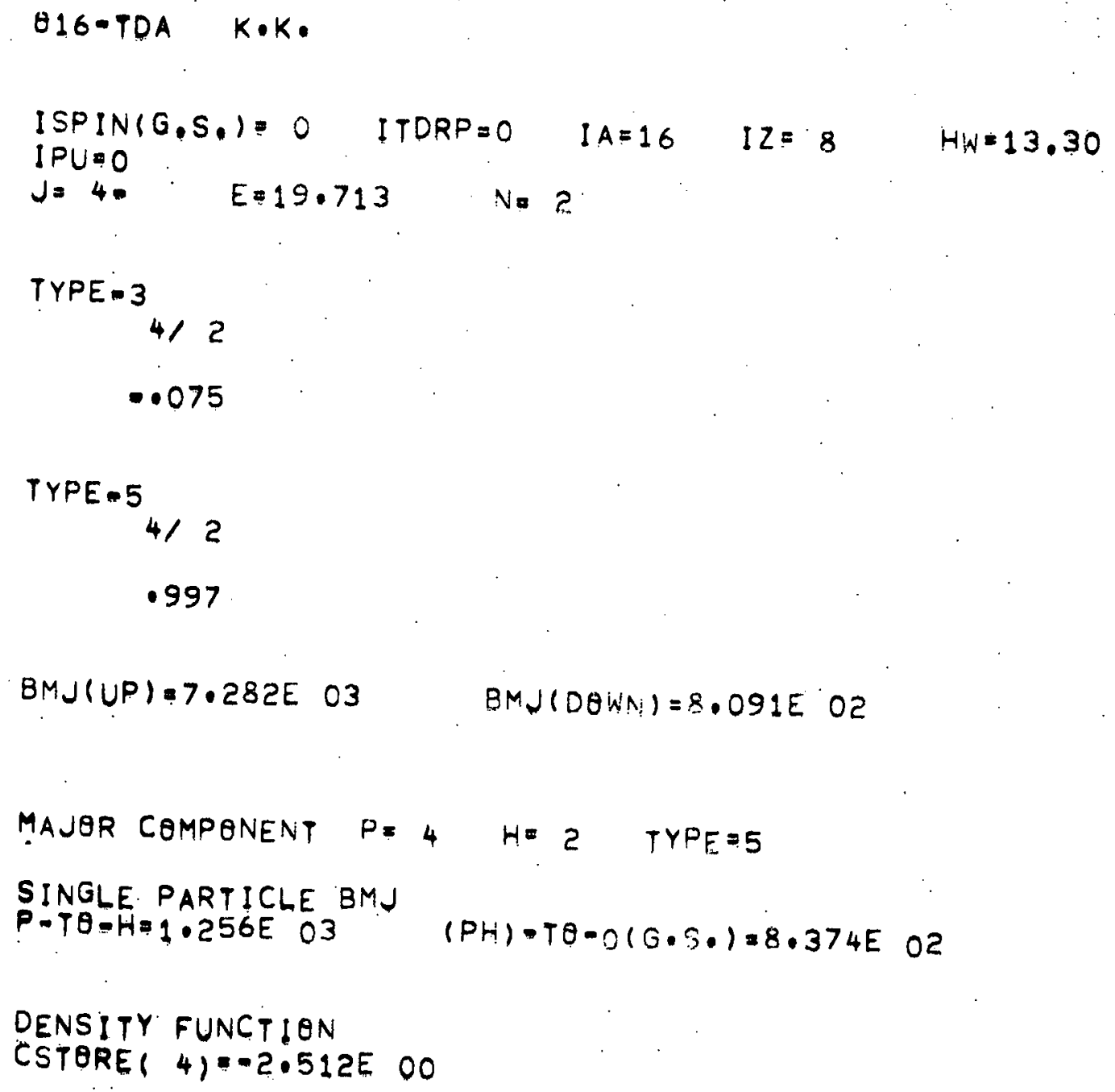


Q16-TDA K.K. MONOPOLE SHIFT

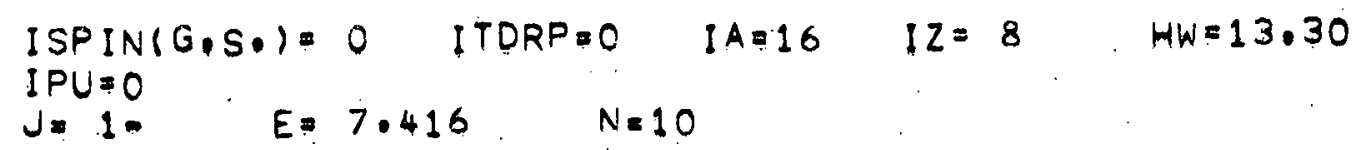

TYPE $=3$

$4 / 2$

$5 / 3$

$5 / 2$

$6 / 3$

$6 / 2$

$\cdot .308$

.858

$\cdot 332$

. .0231

.045

TYPE - 5

$\begin{array}{rrrrr}4 / 2 & 5 / 3 & 5 / 2 & 6 / 3 & 6 / 2 \\ .0005 & .049 & .006 & .003 & .0001\end{array}$

$B E J(U P)=3.356 E-04 \quad B E J(D O W N)=1.119 E-04$

MAJUR COMPONENT $P=5 \cdot H=3 \quad$ TYPE $=3$

SINGLE PARTICLE BEJ

$P-T \theta-H=1.241 E-01$

$(P H)-T \theta-O(G \cdot S \cdot)=8.271 E-02$

DENSITY FUNCTION

CSTORE ( 2) $=5.976 E-02$

CSTORE ( 4$)=3.410 E-02$ 
O16-TDA K.K. MONOPOLE SHIFT

$I S P I N(G \cdot S \cdot I=0 \quad I T D R P=0 \quad I A=16 \quad I Z=8 \quad H W=13.30$
$I P U=0$
$J=1=\quad E=13.169 \quad N=10$

TYPE -3

$\begin{array}{lllll}4 / 2 & 5 / 3 & 5 / 2 & 6 / 3 & 6 / 2 \\ .000 & .098 & .0330 & .087 & .011\end{array}$

IYPE -5

$\begin{array}{rrrrr}4 / 2 & 5 / 3 & 5 / 2 & 6 / 3 & 6 / 2 \\ . .115 & .926 & .051 & .015 & .028\end{array}$

BEJ $(U P)=8.074 E-02 \quad B E J(D Q W N)=2.691 E-02$

MAJOR COMPONENT. $P=5$. H: 3 TYPE=5

SINGLE PARTICLE BEJ

P.TO-H.1.241E-O1 $(P H)=T \theta-O(G \cdot S \cdot)=8 \cdot 271 E-02$

DENSITY FUNCT \ON

CSTORE ( 2) $=-8.877 E-01$

CSTORE ( 4$) \cdot 5.132 E-01$ 


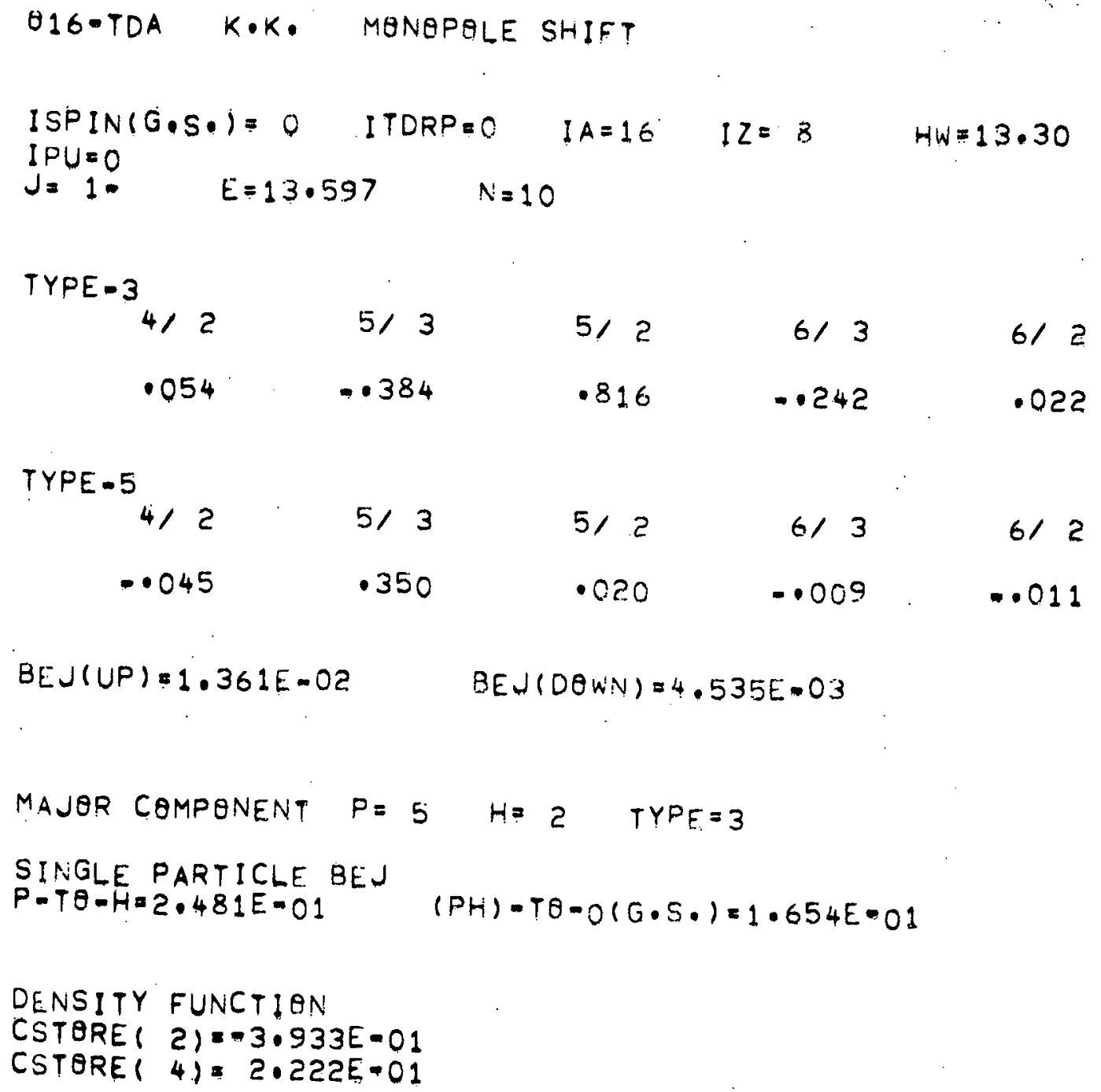


O:S-TDA. K.K. MONOPQLE SHIFT

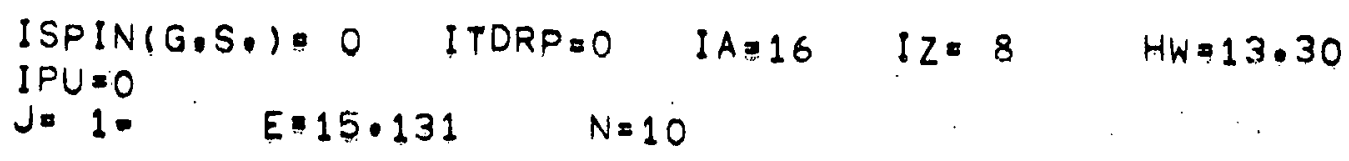

TYPE -3

$4 / 25 / 3 \quad 5 / 26 / 36 / 2$

$\begin{array}{lllll}.0576 & .0096 & .203 & .748 & .235\end{array}$

TYPE $=5$

$\begin{array}{rrrrr}4 / 2 & 5 / 3 & 5 / 2 & 6 / 3 & 6 / 2 \\ .0021 & .012 & .005 & .047 & .012\end{array}$

$B E J(U P)=5.998 E-04 \quad . \quad B E J(D \theta W N)=1.999 E-04$

MAJOR COMPONENT $P=6 \quad H=3 \quad$ TYPFE $=3$

SINGLE PARTICLE BEJ

P.TO-H=3.102E-01 (PH)-TO-O(G.S.) $=4 \cdot 135 E \cdot 01$

DENSITY FUNCTION

CSTORE( 2)=-1.983E-02

CSTORE ( 4$)=2.156 E-O_{2}$ 
194

$$
\begin{aligned}
& \text { Q16-TDA K.K. MONOPOLE SHIFT }
\end{aligned}
$$

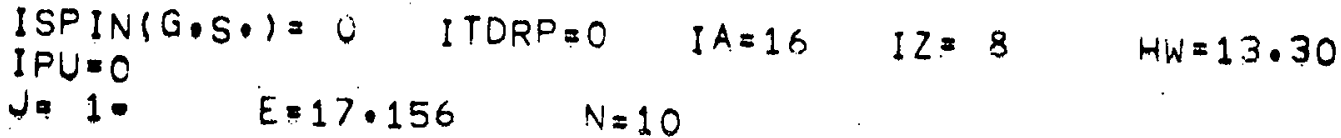

$$
\begin{aligned}
& \text { TYPE - } 3 \\
& 4 / 2 \\
& 5 / 3 \\
& 5 / 2 \\
& \text { 6/3 } \\
& 6 / 2 \\
& .027 \quad .002 \\
& \text { TYPE - } 5 \\
& 4 / 2 \quad 5 / 3 \\
& .005 \\
& .0045 \\
& 5 / ? \\
& 6 / 3 \\
& 612 \\
& .0319 \quad-.049 \quad-.160 \\
& .898 \\
& .248 \\
& B E J(U P)=6.910 E-02 \quad B E J(C \theta N)=2 \cdot 303 E-02 \\
& \text { MAJOR COMPQNENT P: } 6 \quad H=3 \quad T Y P E=5 \\
& \text { SINGLE PARTICLE BEJ } \\
& P=T \theta-H=3.102 E=01 \quad(P H) \cdot T \theta-O(G \cdot S \cdot)=4 \cdot 135 E \cdot 01 \\
& \text { DENS!TY FUNCTION } \\
& \text { CSTORE ( 2) = 2.862E-01 } \\
& \text { CSTORE }(4)=3.183 E-0_{2}
\end{aligned}
$$


Oj6-TOA K.K. MONEPQLE SHIFT

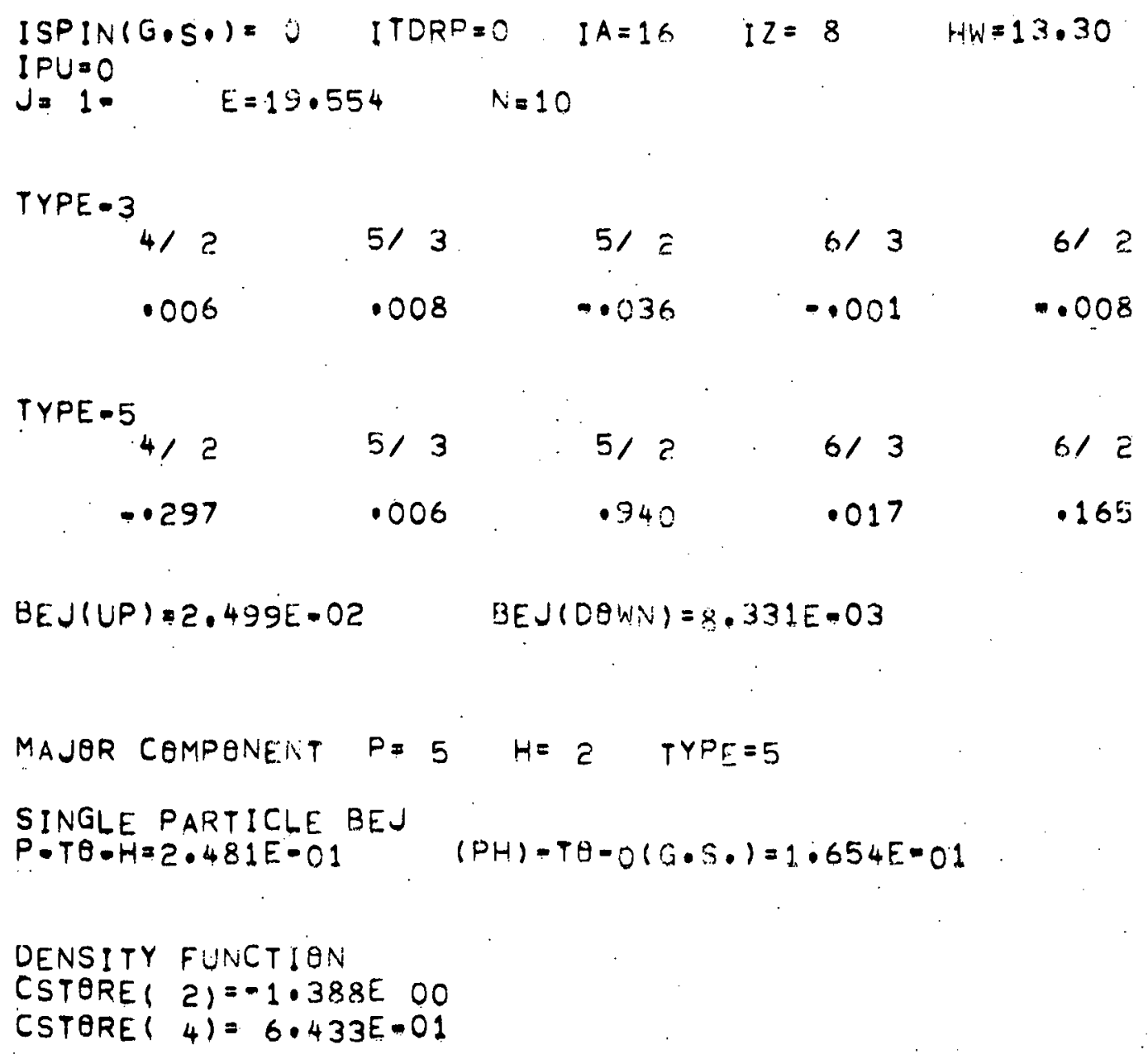




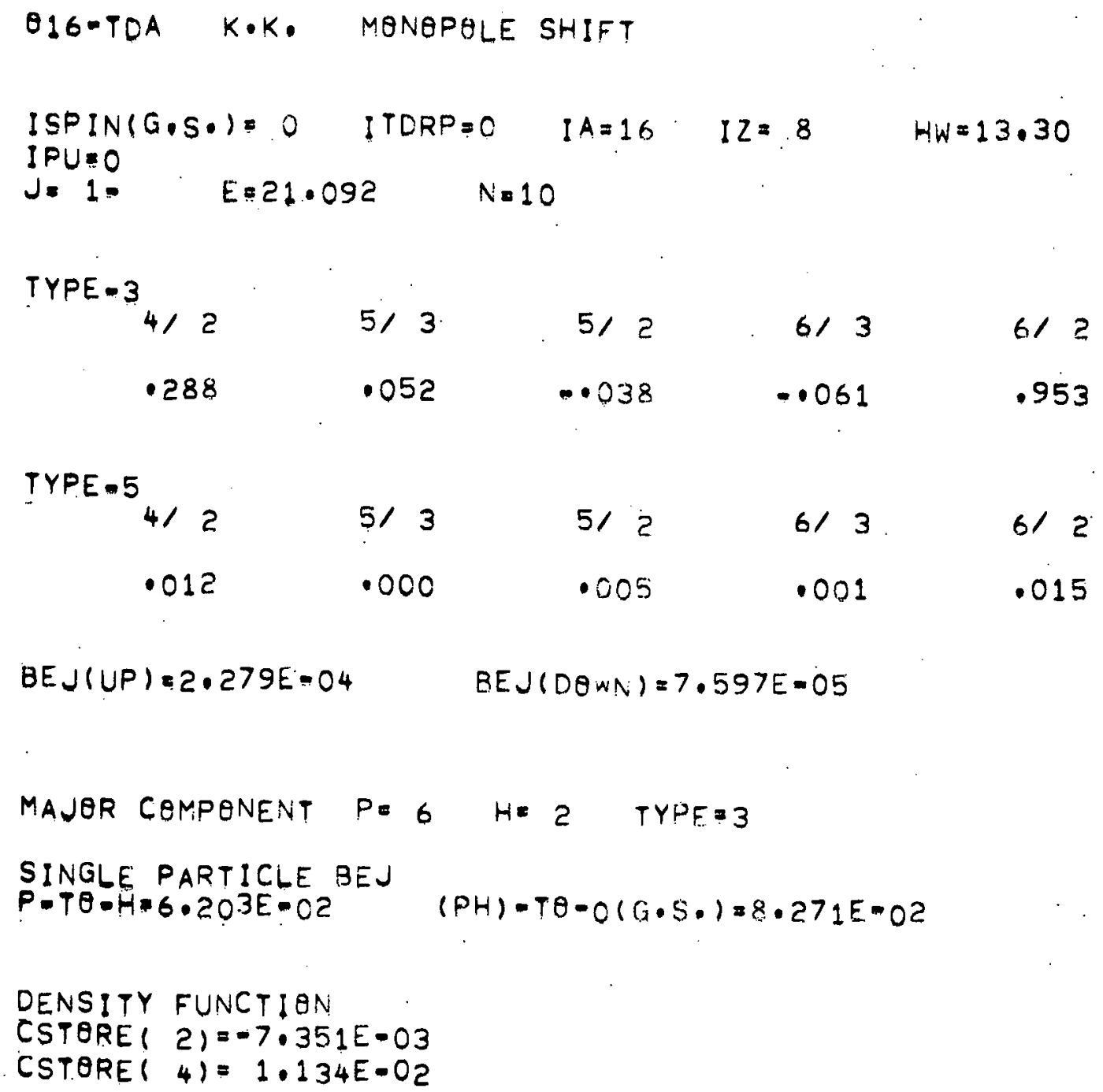


198

O16-TDA K.K. MONBPOLE SHIFT

$$
\begin{aligned}
& \text { ISPIN(G.S.) = } \quad \text { ITDRP=0 } \quad I A=16 \quad I Z=8 \quad H W=13.30 \\
& I P U=0 \\
& J=1 . \quad E=25.458 \quad N=10
\end{aligned}
$$

TYPE - 3

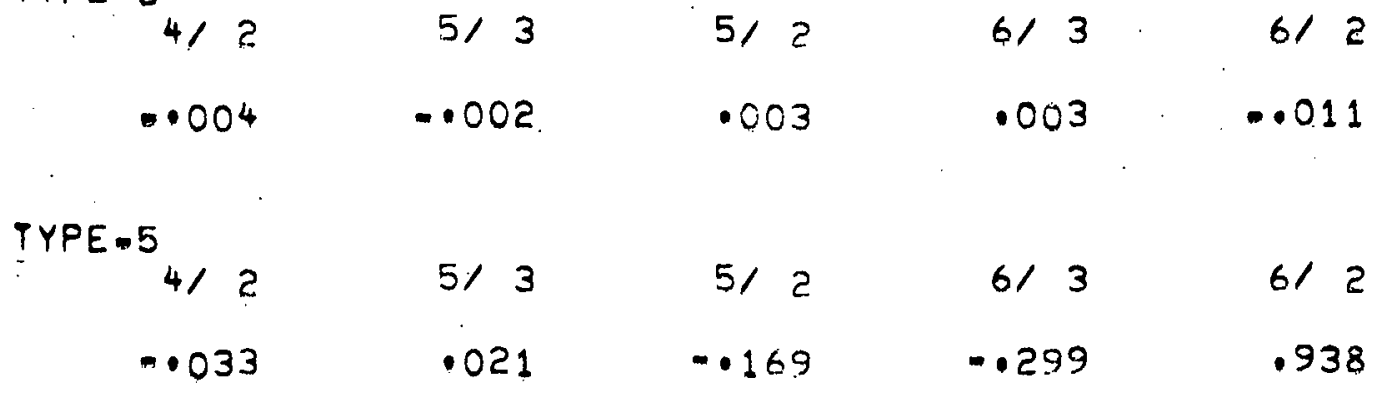

$B E J(U P)=9.181 E-01 \quad B E J(D \theta W N)=3.060 E-01$

MAJOR COMPONENT $P=6^{\circ} \quad H=2 \quad$ TYPE $=5$

SINGLE PARTICLE BEJ

$P-T \theta-H=6.203 E-02 \quad(P H)=T \theta-0(0.5)=.8.271 E=0$ ?

DENSITY FUNCTIEN

CSTORE ( 2)=2.266E-01

CSTORE $(4)=6 \cdot 239 E-01$ 
Q16-TDA K.K. MONOPOLE SHIFT

$$
\begin{aligned}
& \text { ISPIN(G.S.) }=0 \quad \text { ITDRP=0 } \quad I A=16 \quad I Z=8 \quad H \quad H W=13.30 \\
& I P U=0 . \quad E=8.869 \quad N=10 .
\end{aligned}
$$

TYPE - 3

$\begin{array}{lllll}4 / 3 & 4 / 2 & 5 / 2 & 6 / 3 & 6 / 2 \\ .971 & .222 & .050 & .060 & .006\end{array}$

TYPE $=5$

$\begin{array}{lllll}4 / 3 & 4 / 2 & 5 / 2 & 6 / 3 & 6 / 2 \\ .041 & .008 & .003 & .001 & .002\end{array}$

$B M J(U P)=1.089 E-01 \quad B M J(D Q W N)=2.179 E-02$

MAJOR COMPQNENT $P=4 \quad H=3$ TYPE:3

SINGLE PARTICLE BMJ

$P-T \theta-H=1.637 E-02 \quad(P H)-T \theta-O(G \cdot S)=.1.965 E-02$

DENSITY FUNCTION

CSTORE( 2) $=-1.248 E-02$

CSTORE $(4)=-1 \cdot 373 E-01$ 
OI6-TDA K.K. MONEPQLE SHIFT

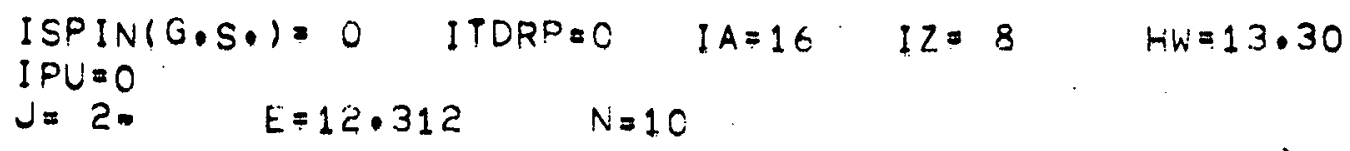

TYPE - 3

$4 / 3$

412

$5 / 2$

$6 / 3$

$6 / 2$

. .039

. .017

.002

. .010 .002

TYPE -5

$\begin{array}{lllll}4 / 3 & 4 / 2 & 5 / 2 & 6 / 3 & 6 / 2 \\ .965 & .236 & .071 & .005 & .070\end{array}$

$B M J(U P)=1.911 E 00$

$B M J(D Q N N)=3.821 E .01$

MAJOR COMPONENT $P=4 \quad H=3 \quad$ TYPE $=5$

SINGLE PARTICLE BMJ

$P=T \theta-H=1.049 E$ OO $\quad(P H)=T \theta-O(G .5)=.1.259 E 00$

DENSITY FUNCTION

CSTORE( 2):-2.338E-01

CSTORE $(4)=-5.023 E-0.1$ 


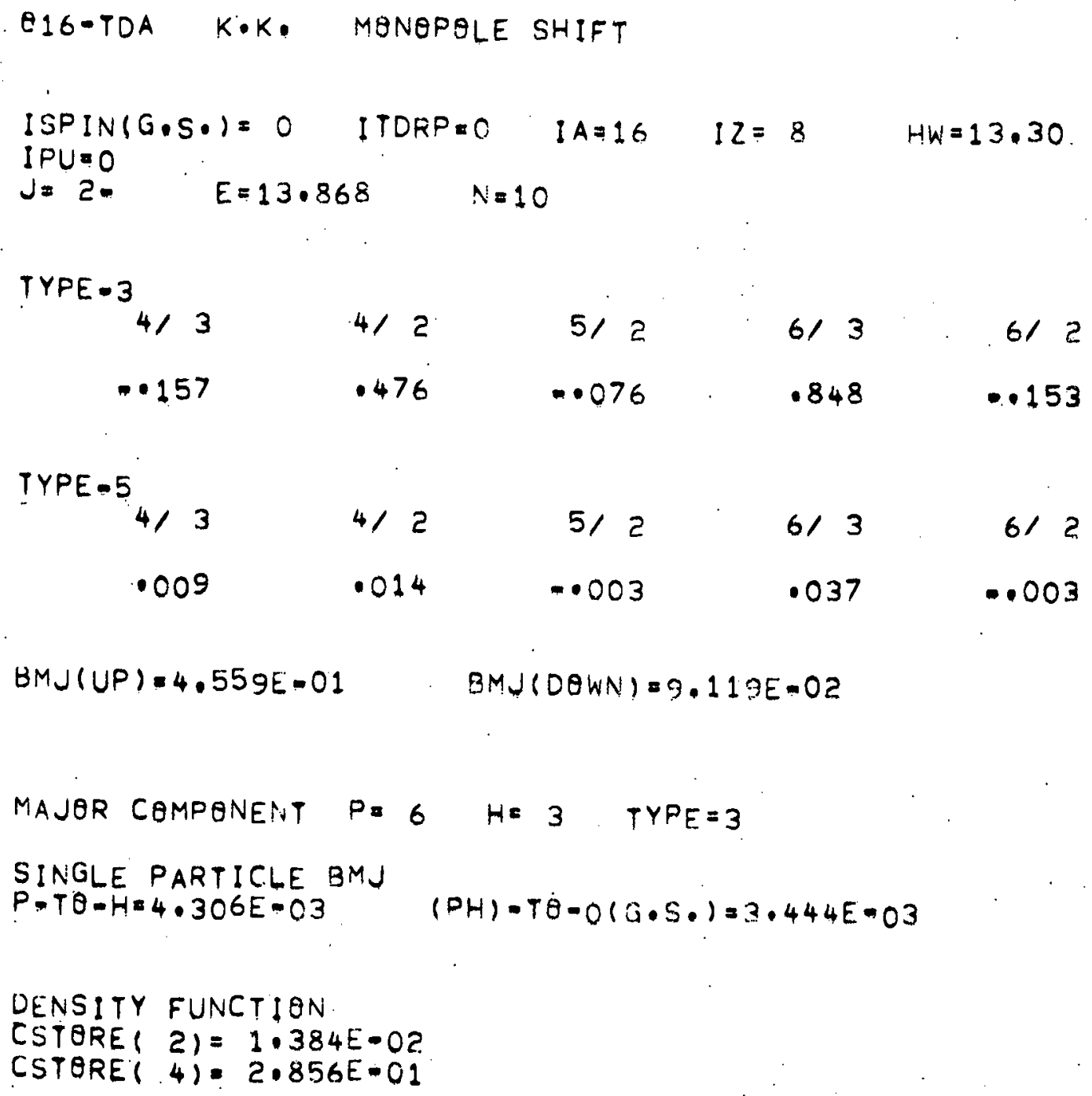


O16-TDA K.K. MONOPOLE SHIFT

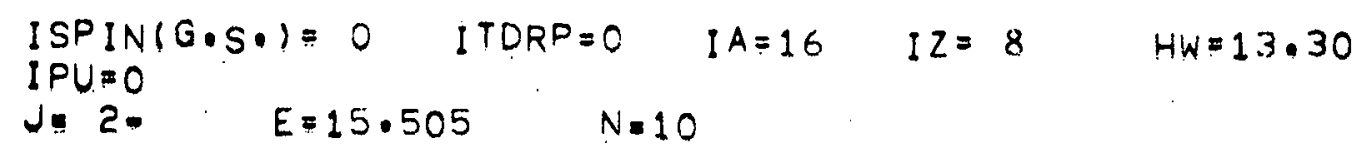

TYPE-3

$\begin{array}{rrrrr}4 / 3 & 4 / 2 & 5 / 2 & 6 / 3 & 6 / 2 \\ -.089 & .644 & -.615 & -.441 & .048\end{array}$

TYPE $=5$

$\begin{array}{lllll}4 / 3 & 4 / 2 & 5 / 2 & 6 / 3 & 6 / 2 \\ .003 & .016 & -.043 & .034 & .003\end{array}$

$B M J(U P)=3 \cdot 449 E \cdot 01$

$B M J\left(D O^{\prime} N N\right)=6.898 E-02$

MAJOR COMPONENT $P=4 \quad H=2 \quad$ TYPE $=3$

SINGLE PARTICLE $8 M J$

$P-T \theta-H=1 \cdot 148 E-01$.

$(P H)-T \theta-O(G \cdot S \cdot)=1 \cdot 377 E=01$

DENSITY FUNCTION

CSTORE ( 2)= 1.736E-01

CSTORE ( 4) =1.837E-01 


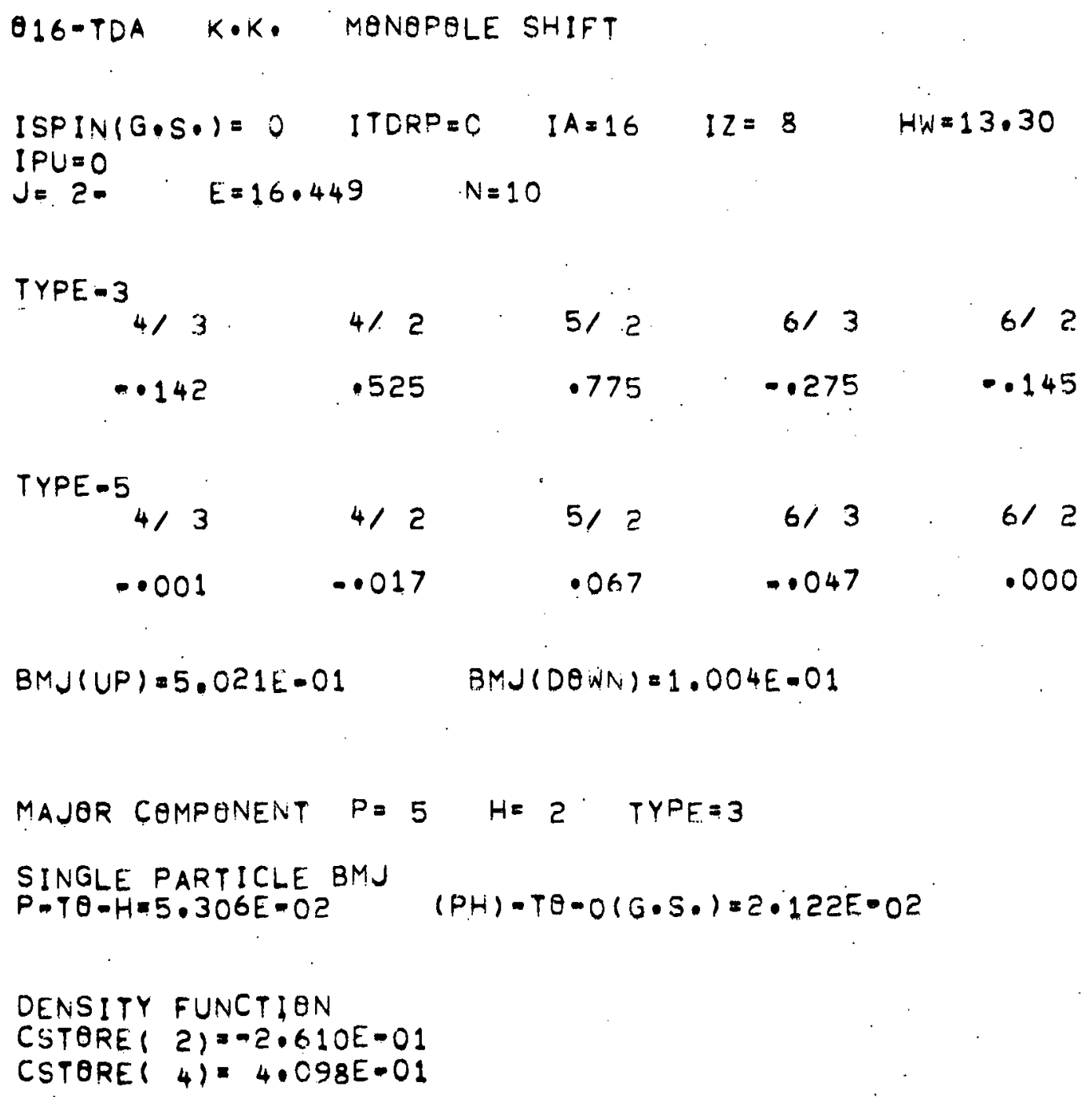


Q16-TDA K.K. MONOPOLE.SHIFT

ISPIN(G.S.) = $=\quad$ ITDRP=0 IA=16 IZ=8 $\quad H W=13.30$ $I P U=0$ $J=2 \cdot$ $E=17.033 \quad N=10$

TYPE - 3

$4 / 3$

$4 i 2$

$5 / 2$

$6 / 3$

$6 / 2$

.0004

.026

.027

. .059

.000

TYPE - 5

$4 / 3$

412

$5 / 2$

$6 / 3$

$6 / 2$

. .059

.301

.0028

.943

. .109

$B M J(U P)=2 \cdot 689 E-01$

$B M J(D \theta W N)=5.378 E-02$

MAJOR COMPONENT $P=6 \quad H=3 \quad$ TYPE $=5$

SINGLE PARTICLE BMJ

$P-T O-H=2.511 E=02$

$(P H)-T \theta-0(0.5)=.2.009 E-02$

DENSITY FUNCTION

CSTORE ( 2)=9.077E-02

CSTORE ( 4) $=1.872 E-01$ 


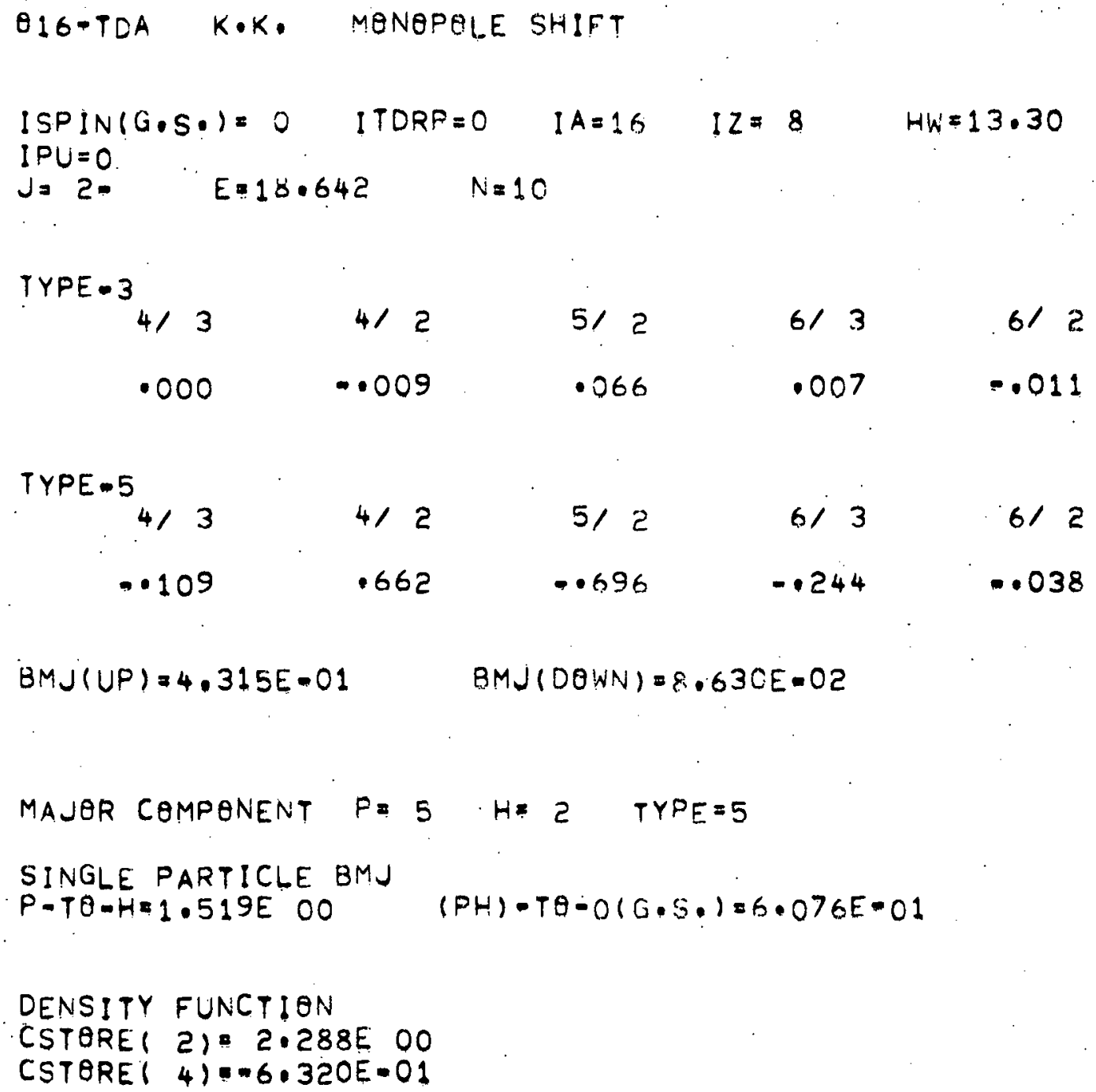


O16-TDA K.K. MONOPOLE SHIFT

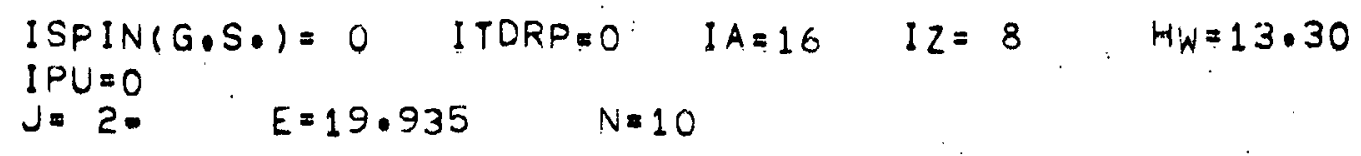

TYPE - 3

$\begin{array}{rrrrr}4 / 3 & 4 / 2 & 5 / 2 & 6 / 3 & 6 / 2 \\ . .055 & .181 & .072 & .070 & .976\end{array}$

\begin{tabular}{|c|c|c|c|c|}
\hline $4 / 3$ & $4 / 2$ & $5 / 2$ & $6 / 3$ & $6 / 2$ \\
\hline .010 & .030 & .024 & .011 & .009 \\
\hline
\end{tabular}

$B M J(U P)=1.301 E-01 \quad B M J(D Q W N)=2.602 E-0 ?$

MAJUR COMPONENT $P=6$ HE 2 TYPE $=3$

SINGLE PARTICLE BMJ

$P-T \theta-H=1.991 E-04 \quad(P H)=T \theta-O\left(G \cdot S_{A}\right)=1.593 E-04$

DENSITY FUNCT \ON

CSTORE ( 2) $=-8.277 E-02$

CSTORE $(4)=1.886 E-01$ 
O16-TDA K.K. MONBPALE SHIFT

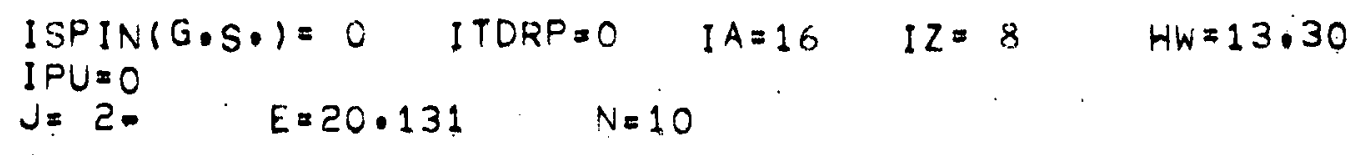

TYPE -3
4/3
$4 / 2$
$5 / 2$
$6 / 3$
$6 / 2$

.008

$-.021$

.048

.006

. .031

TYPE $=5$

$\begin{array}{rrrrr}4 / 3 & 4 / 2 & 5 / 2 & 6 / 3 & 6 / 2 \\ .0186 & .615 & .697 & -.211 & .229\end{array}$

$B M J(U P)=1.121 E$ O1 BMJ $(D Q$ NN $)=? .243 E 00$

MAJOR COMPONENT $P=5 \quad H=2 \quad$ TYPE $=5$

SINGLE PARTICLE. BMJ

$P-T \theta-H=1.519 E$ OO $\quad(P H)-T \theta-O(G . S)=.6.076 E-01$

DENSITY FUNCTION

CSTORE ( 2)=-2.292E.0O

CSTORE $(4) \cdot 2 \cdot 361 E$ OO 
Q16-TOA K.K. MONOPOLE SHIFT

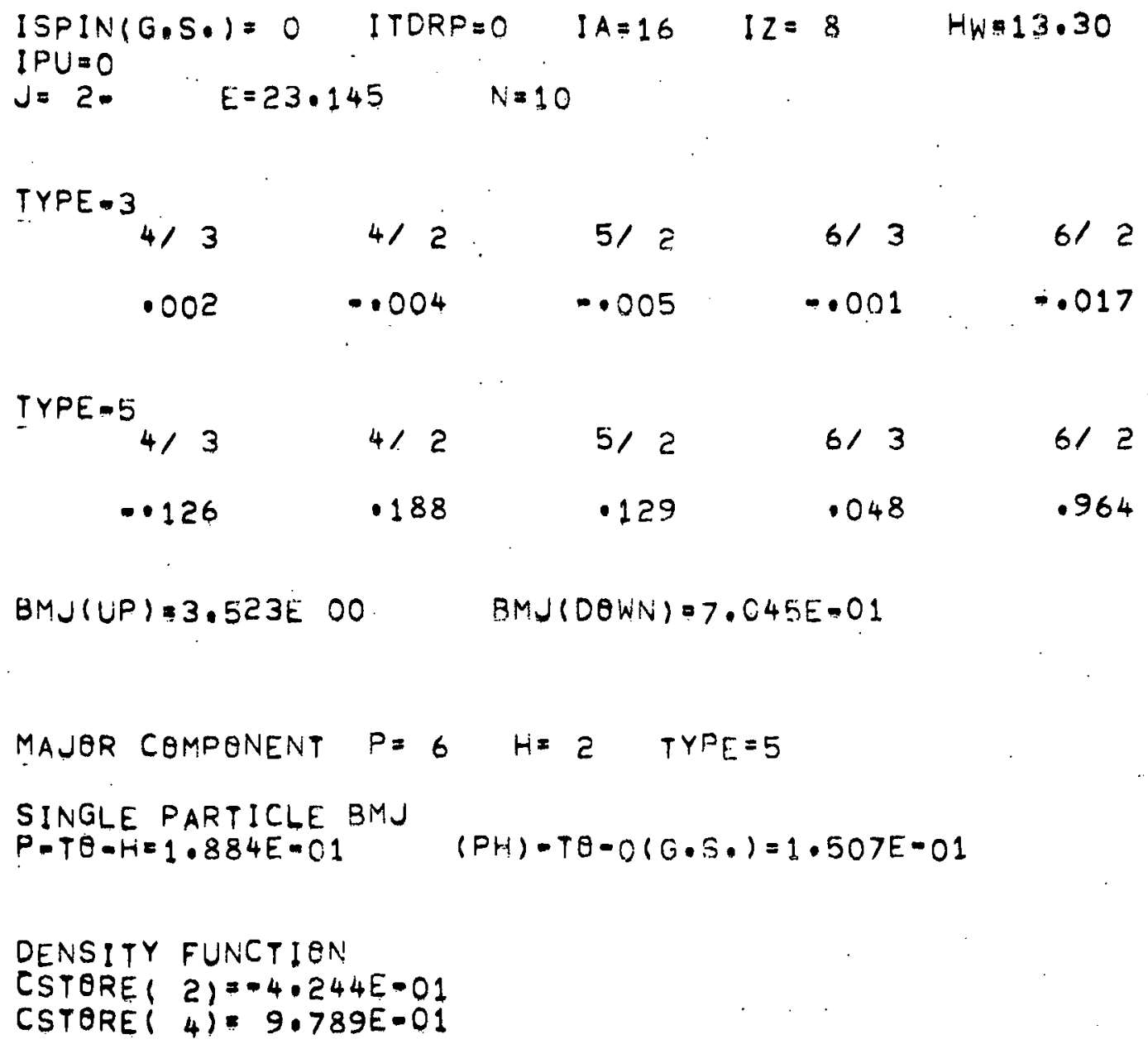




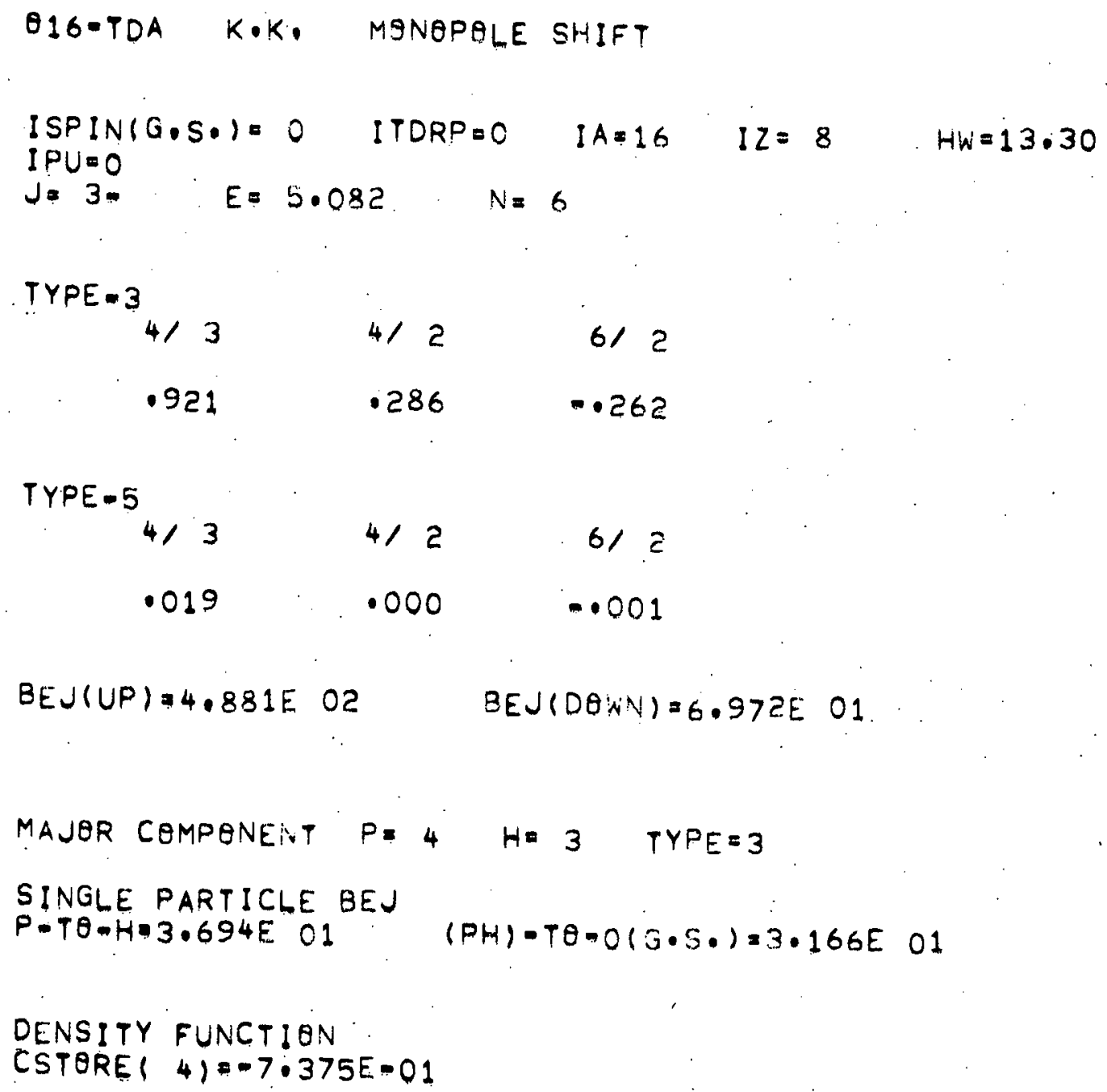




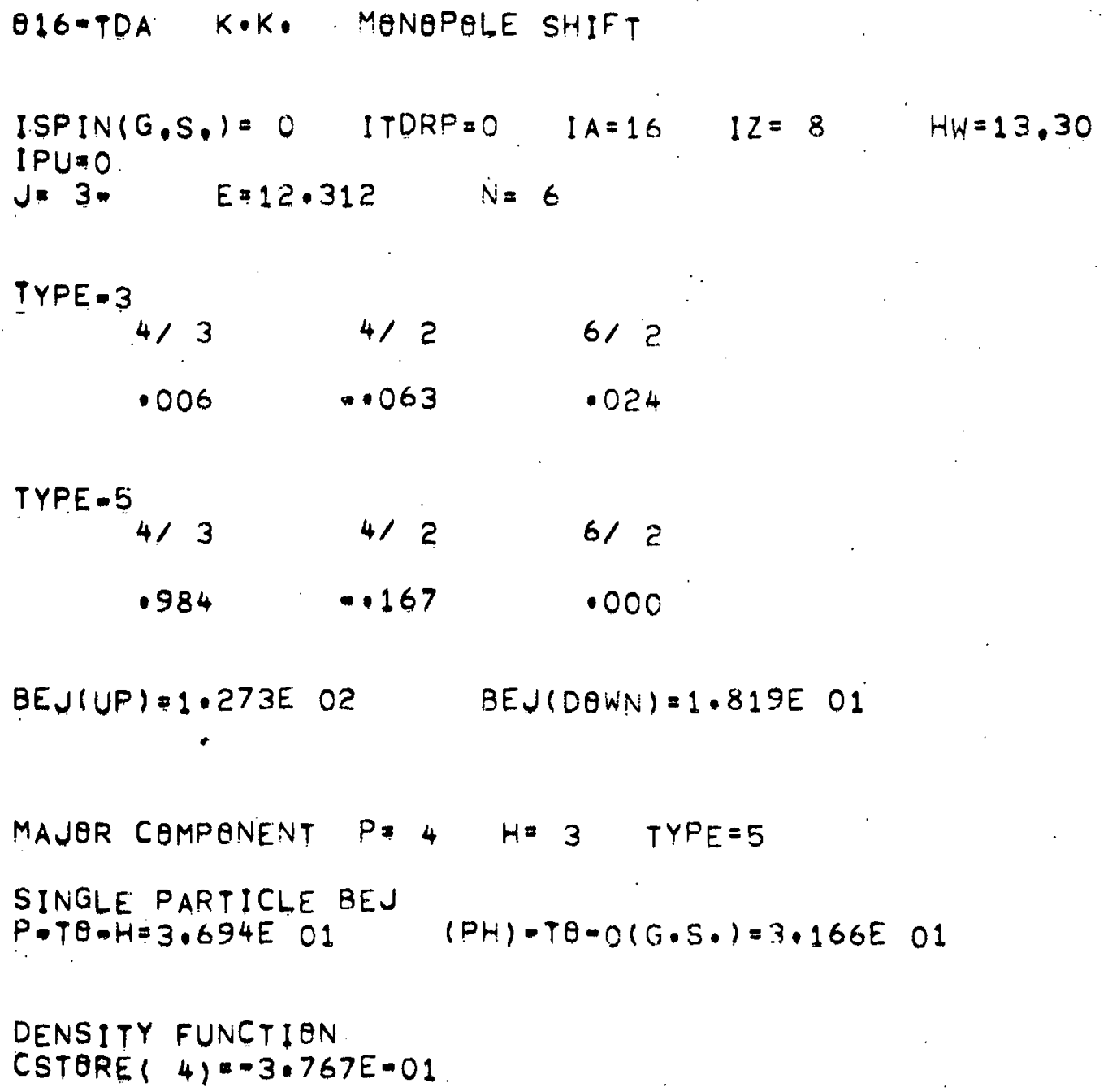




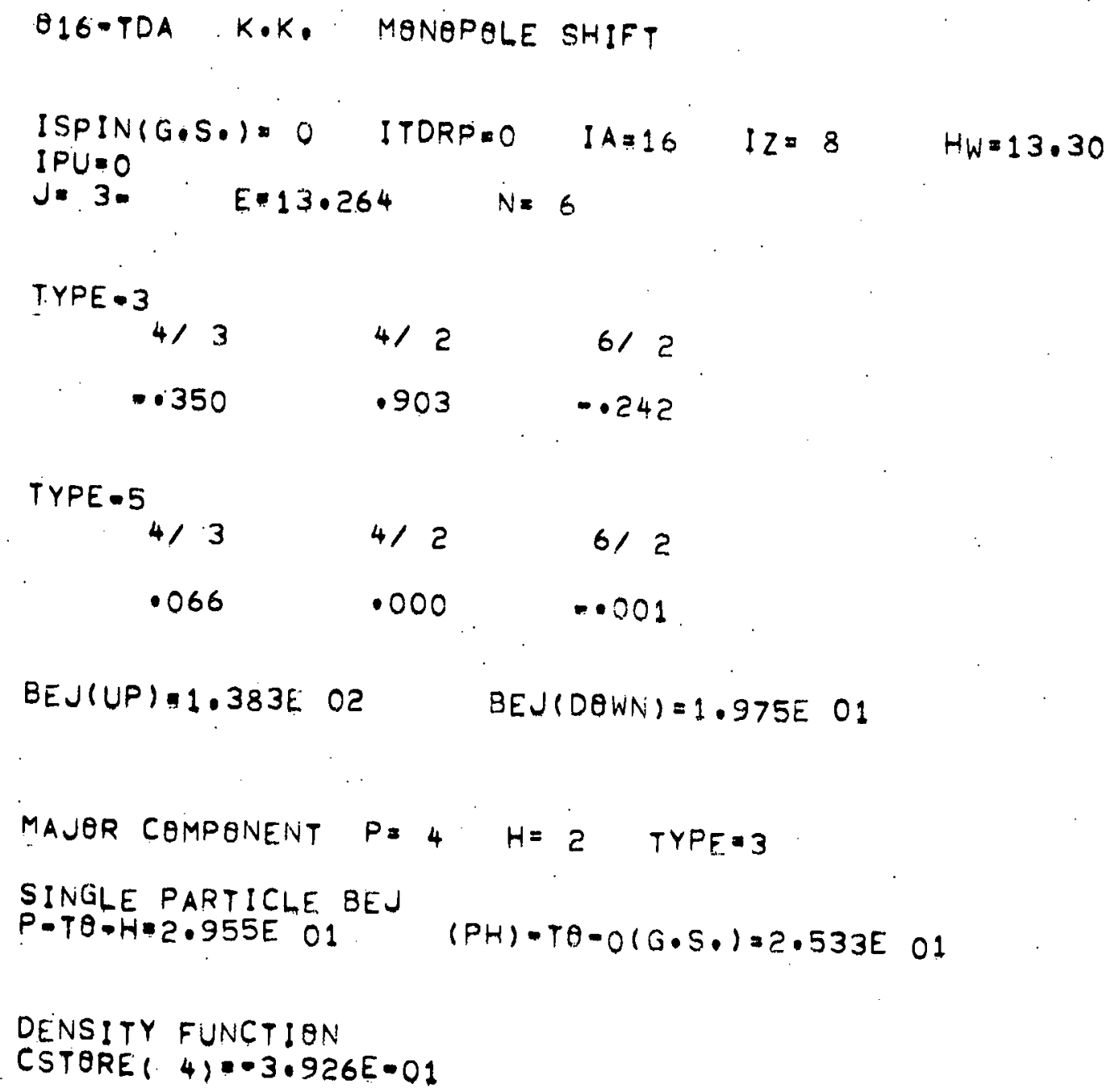




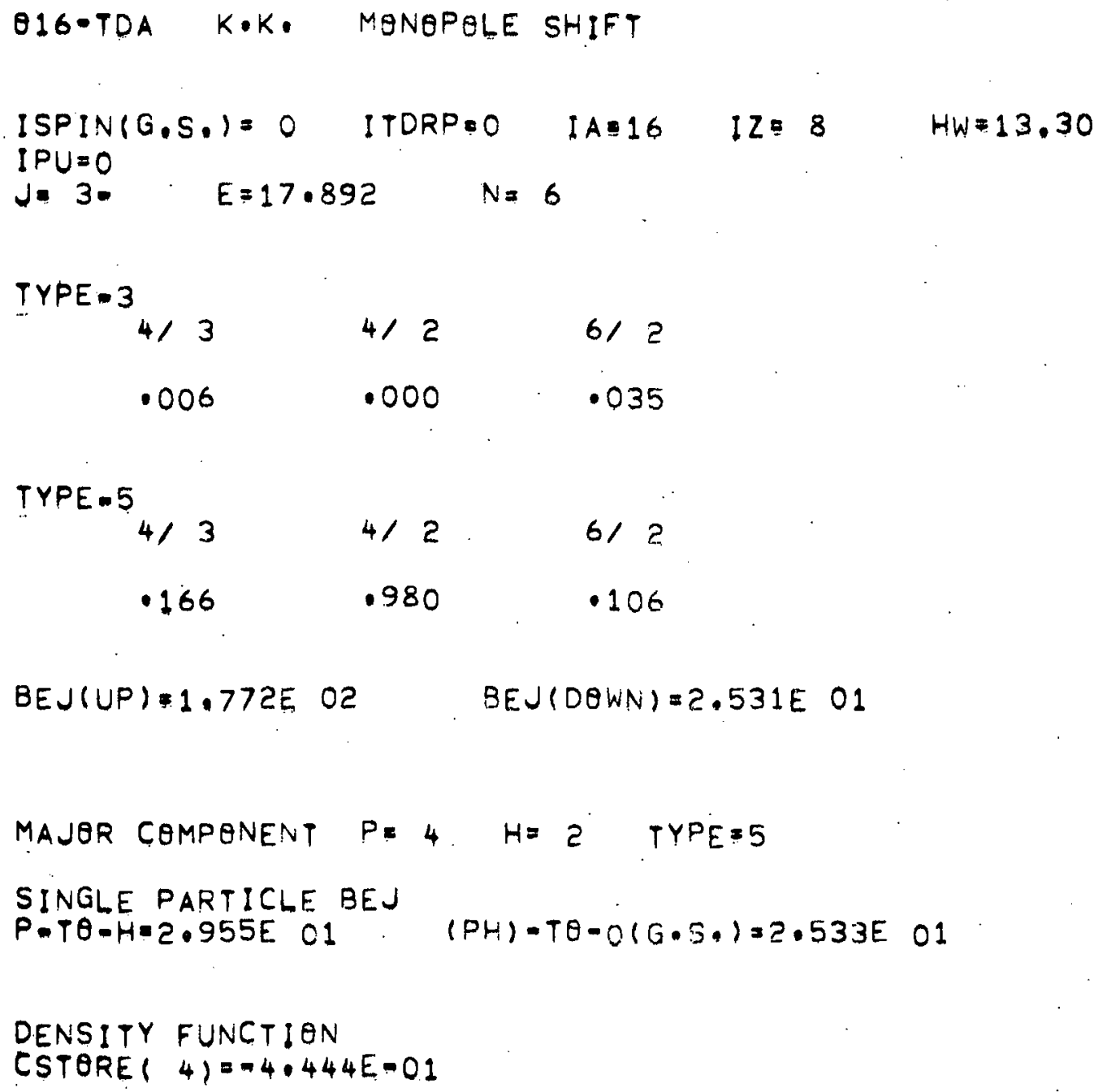


O16-TDA K.K. MONOPELE SHIFT

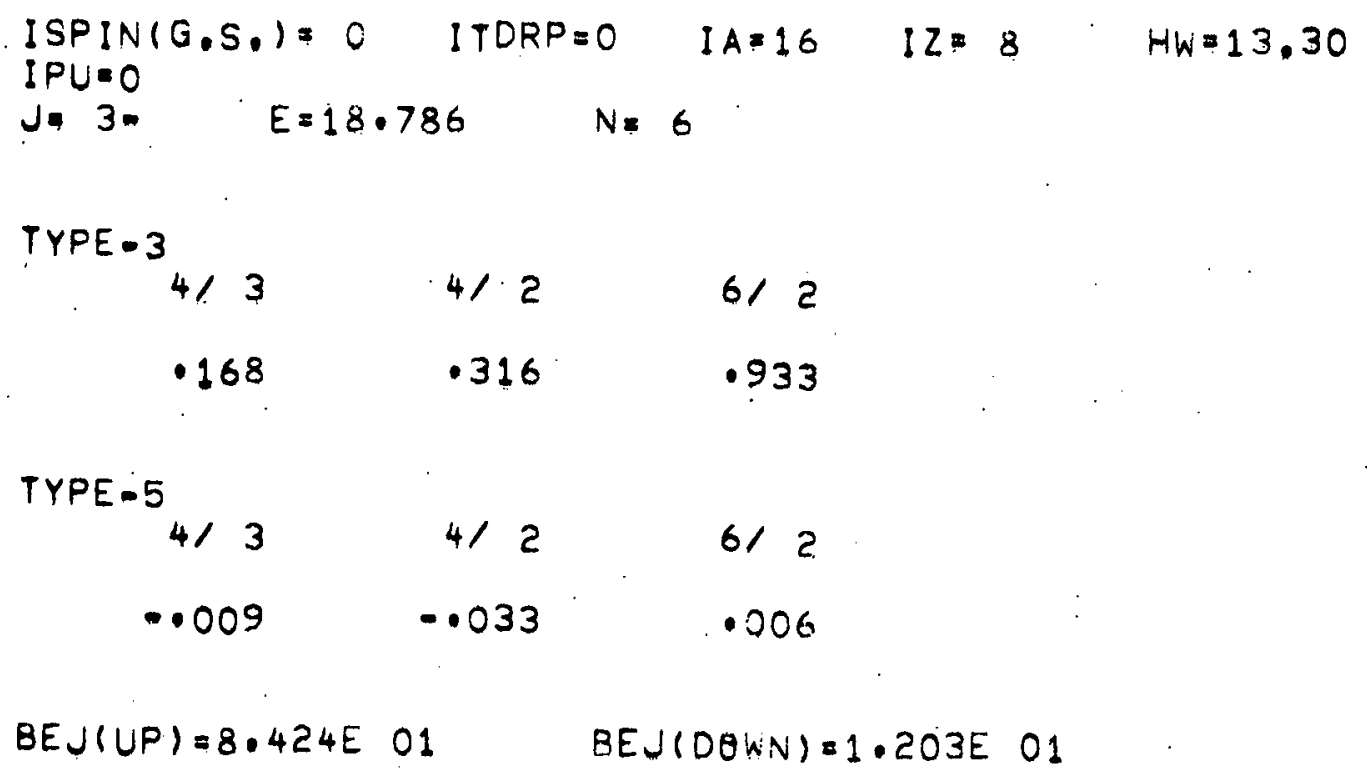




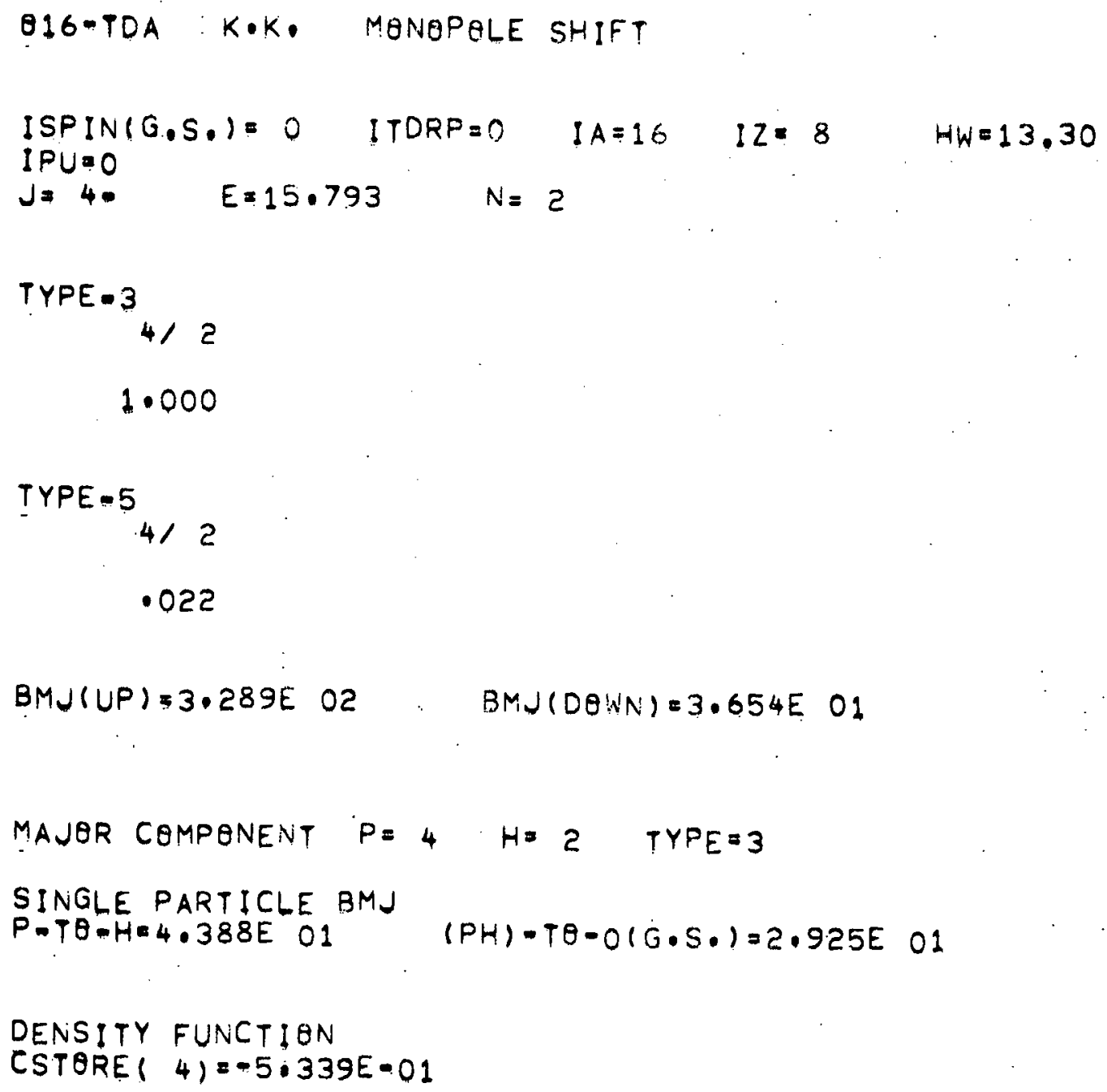


O16-TDA K.K. MONOPOLE SHIFT

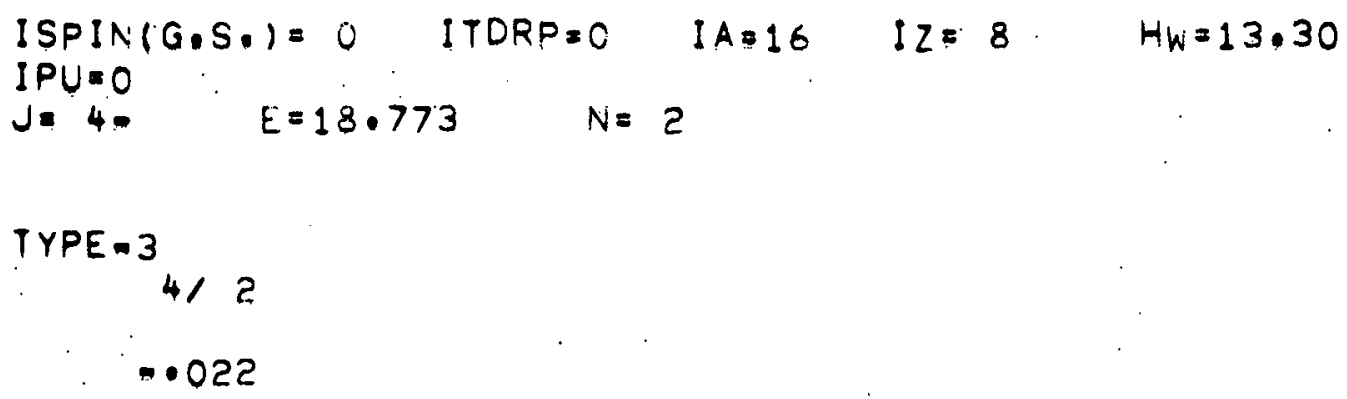




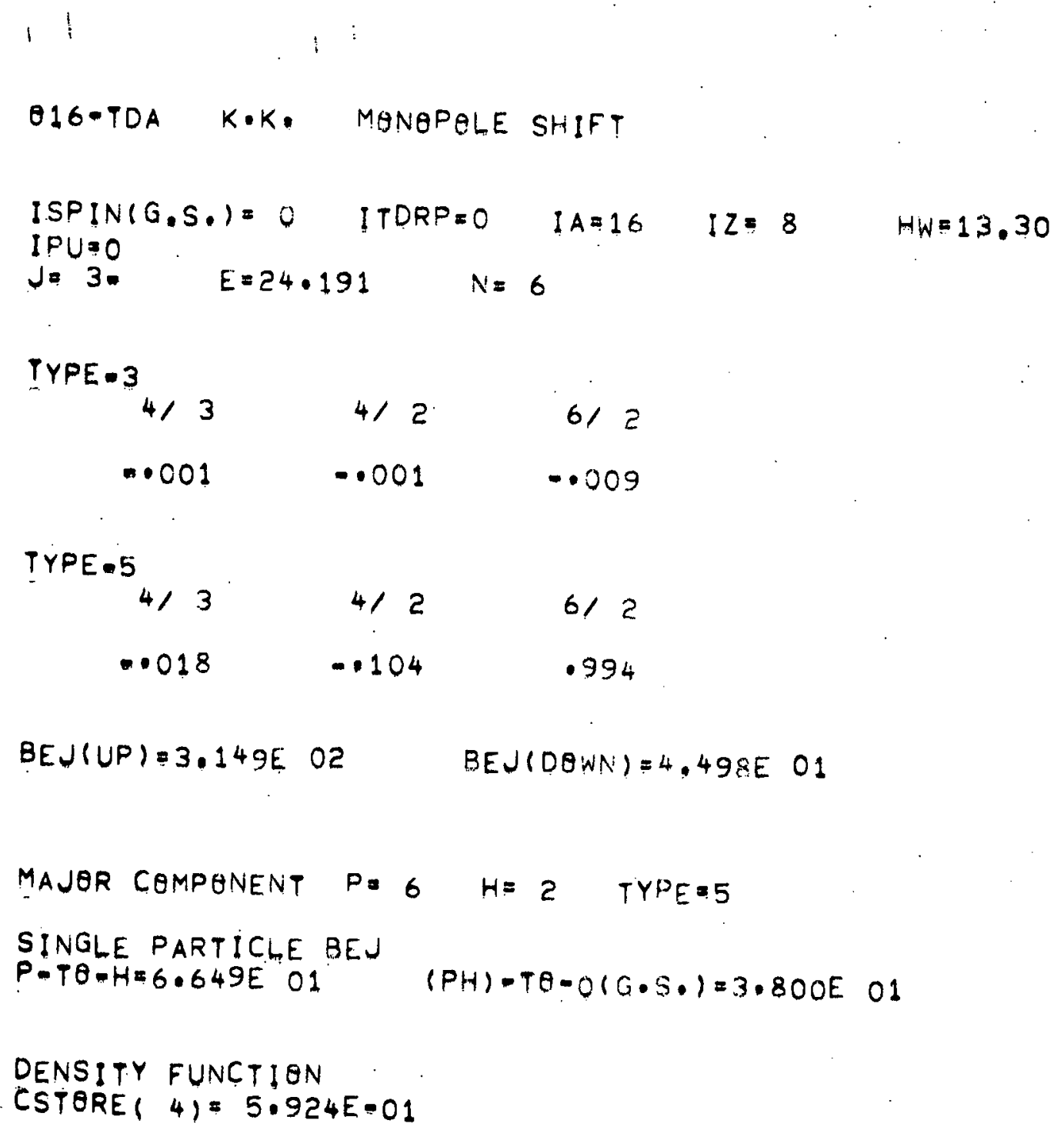


CA4O-TOA K.K. MENSPGLE SHIFT

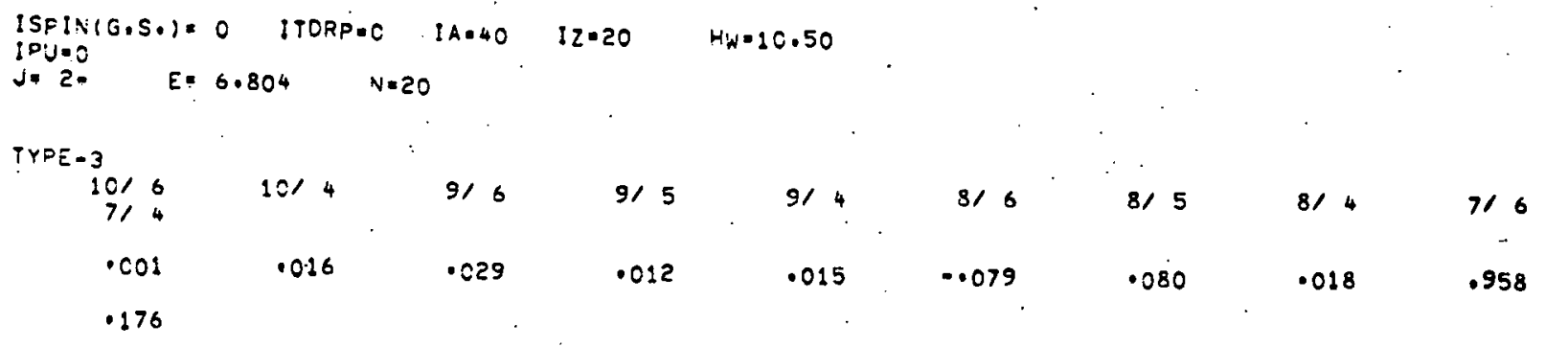

\begin{tabular}{|c|c|c|c|c|c|c|c|c|}
\hline $\begin{array}{cc}1 C^{\prime} & 6 \\
7 / & 4\end{array}$ & $10^{\prime} 4$ & $9 / 6$ & $9 / 5$ & $9 / 4$ & $8 / 6$ & $8 / 5$ & 814 & 716 \\
\hline - coc & .004 & $\because 006$ & .004 & .009 & $=020$ & .024 & .005 & .185 \\
\hline
\end{tabular}

BMJ(UP)=7.506E-01 . BMJ(DexU)=1.501E-01

MAJUR COMPONENT P. 7 H. 6 TYPE=3

SINGLE PARTICLE BMJ
O-TO-H. 3.733E-C2
(PH)-TO-C(O.S.) $=5.972 E=02$

DENSTTY FUNCT!ON

CSTPRE: $21=-4.578 E-02$

CSTORE ( 4). 2.822E-02

CSTORE( $61=-9.755 E=02$ 


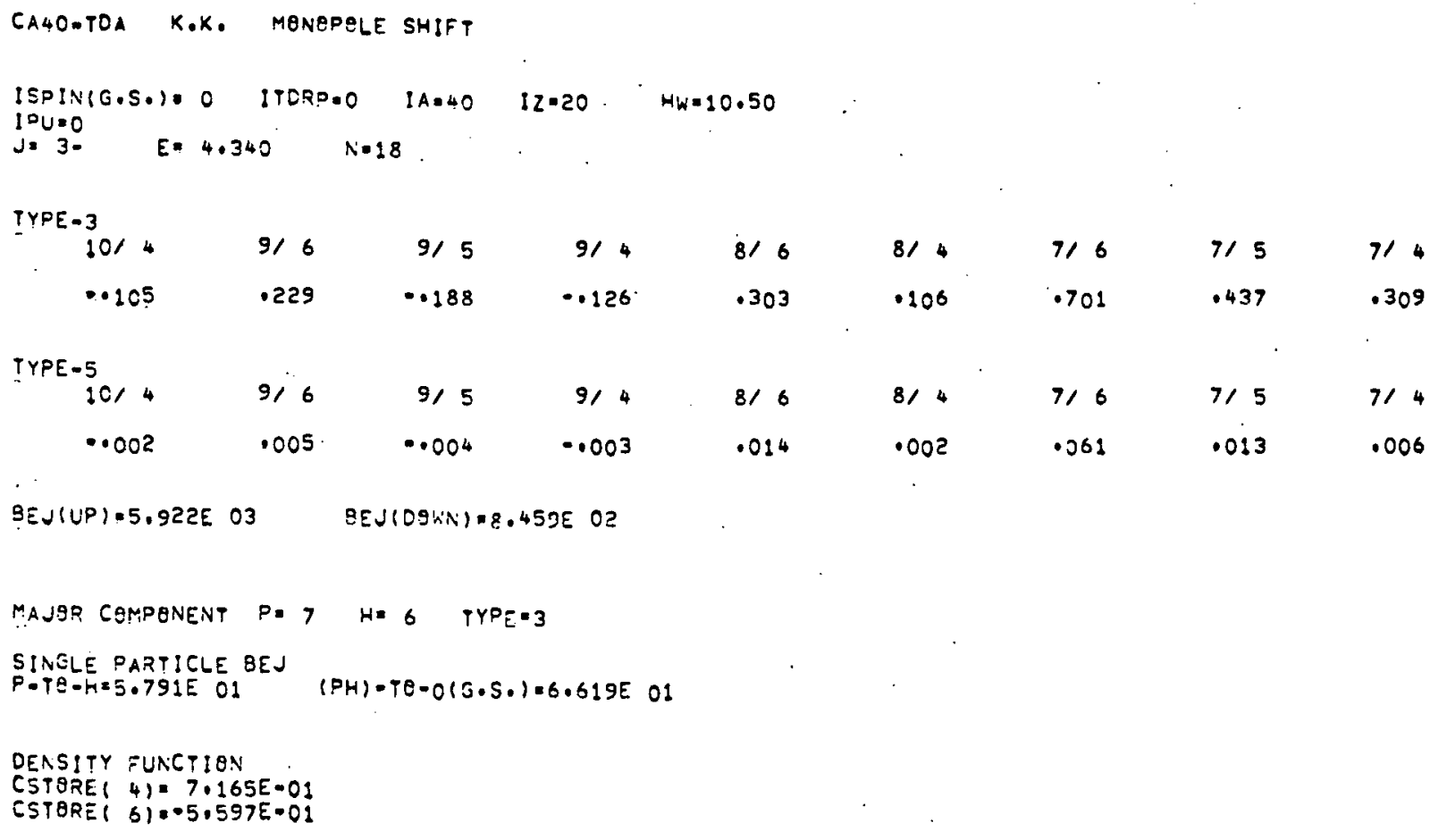




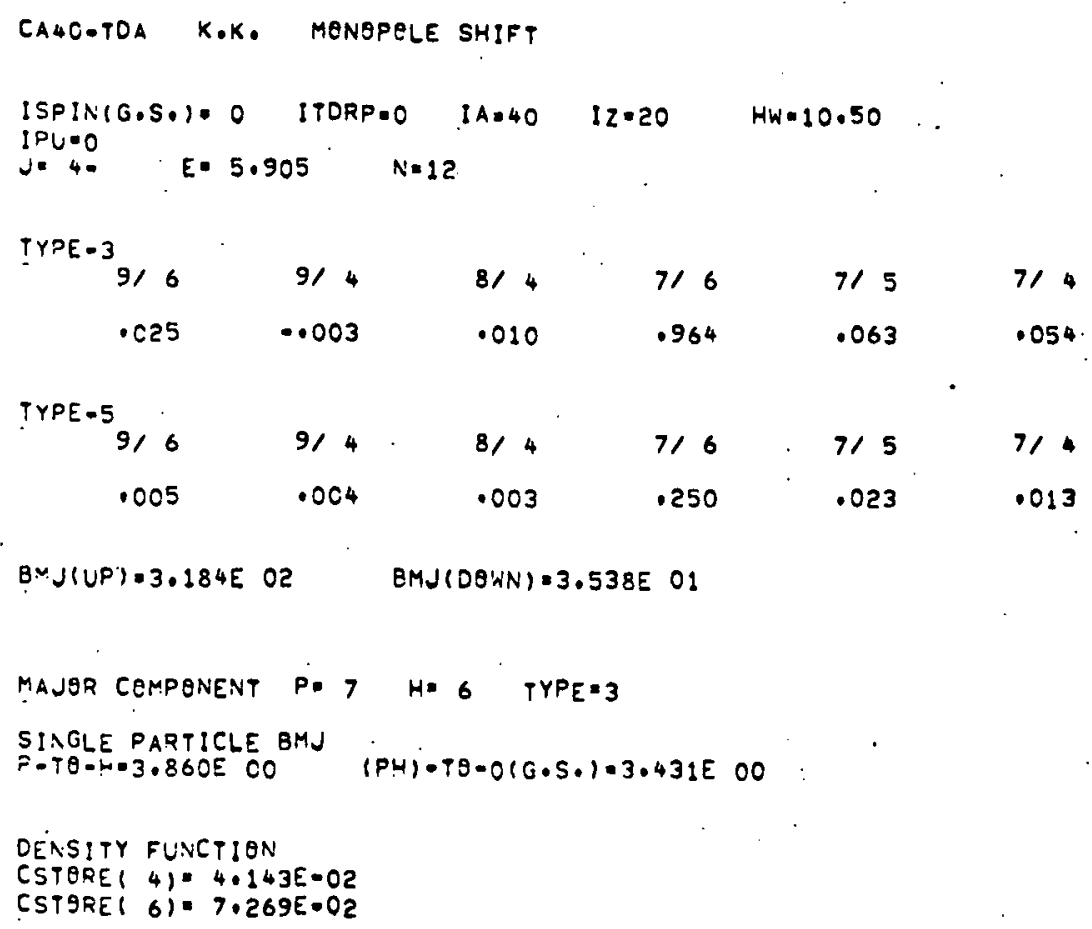




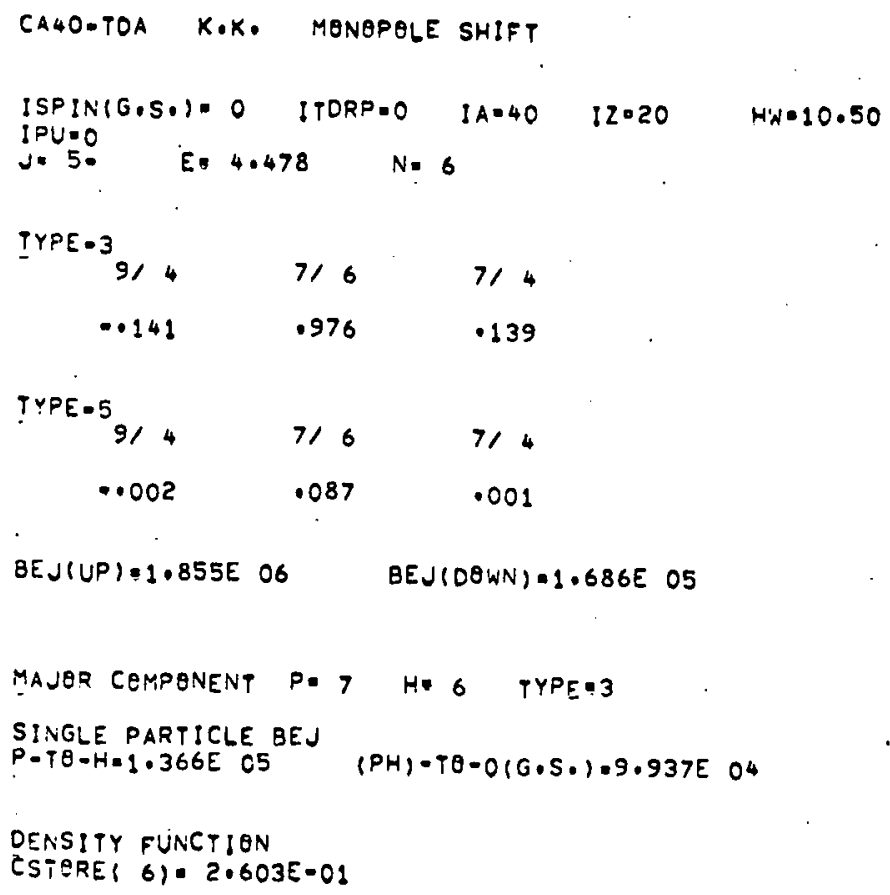




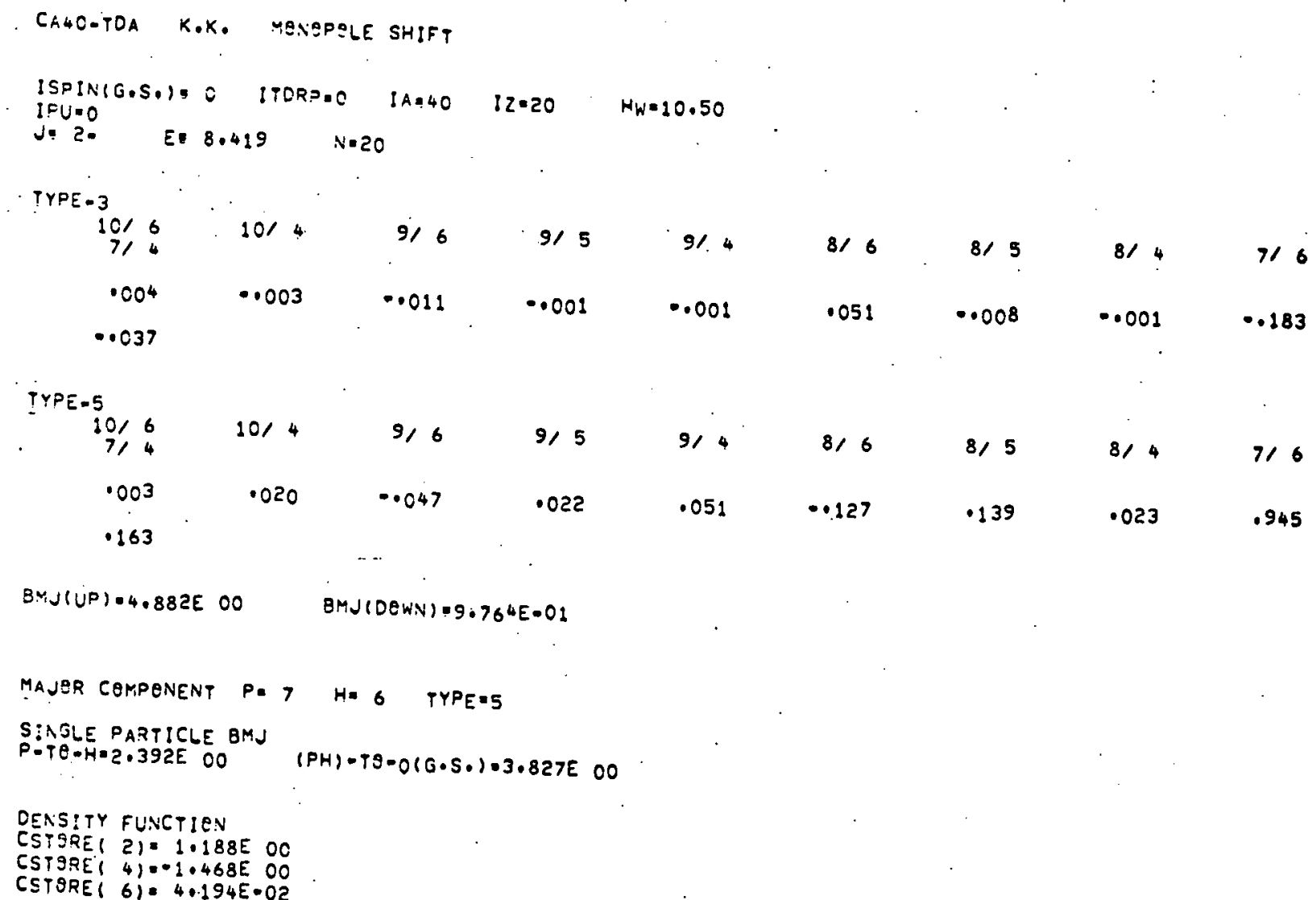




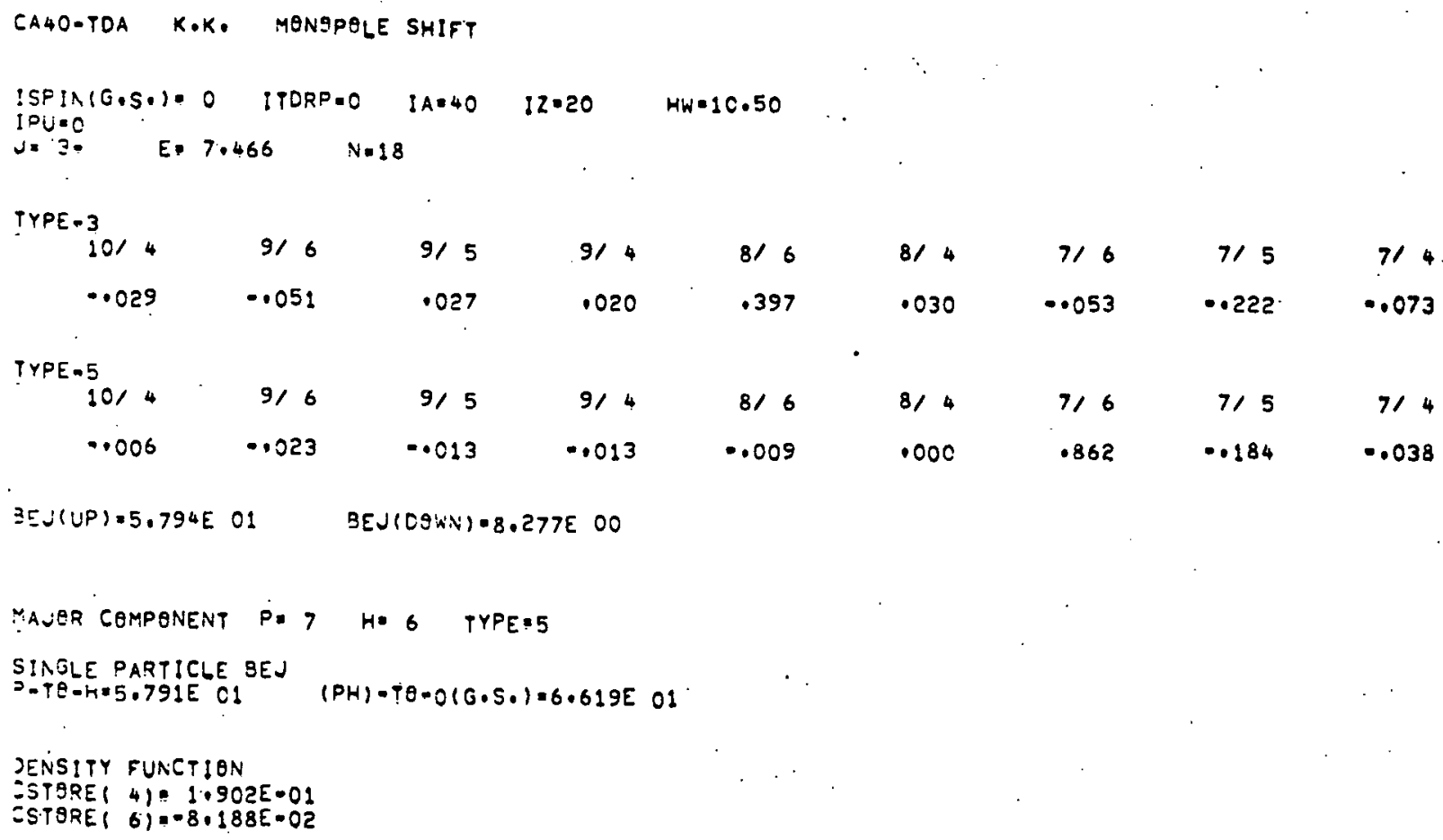




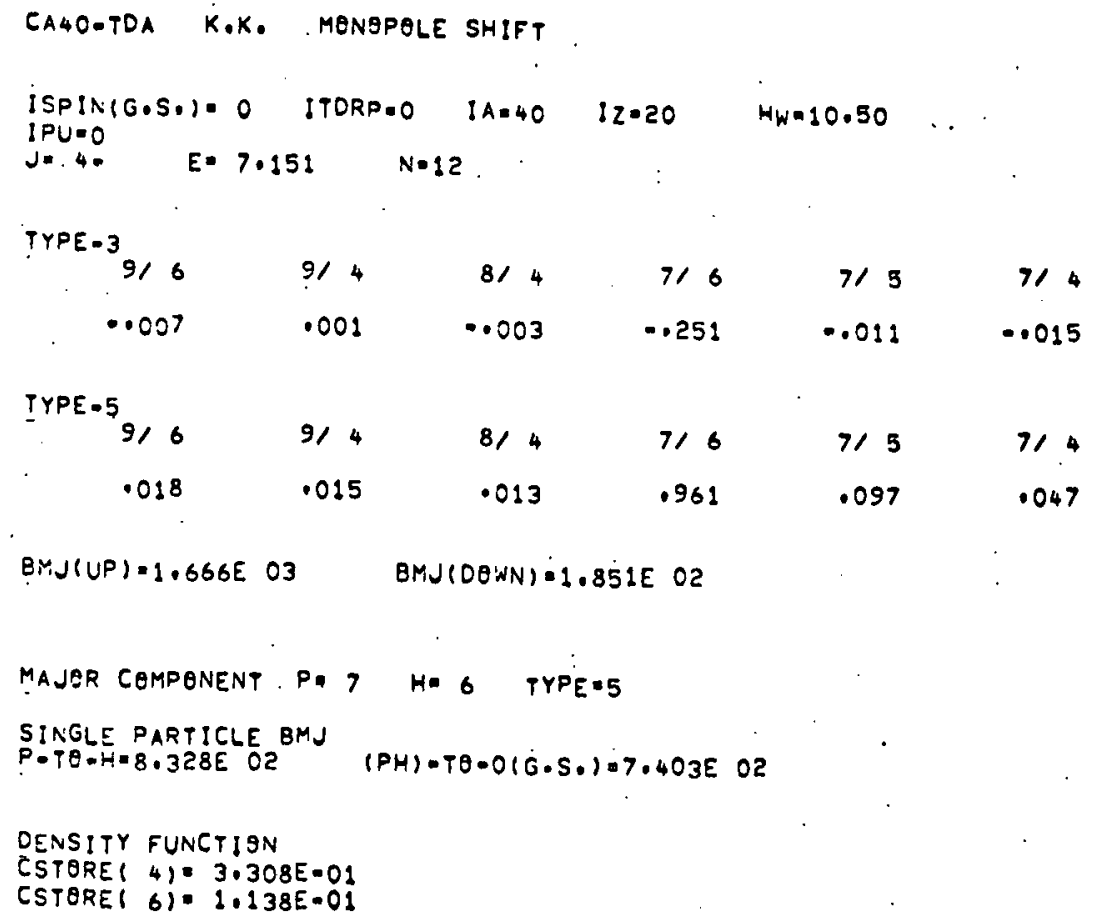




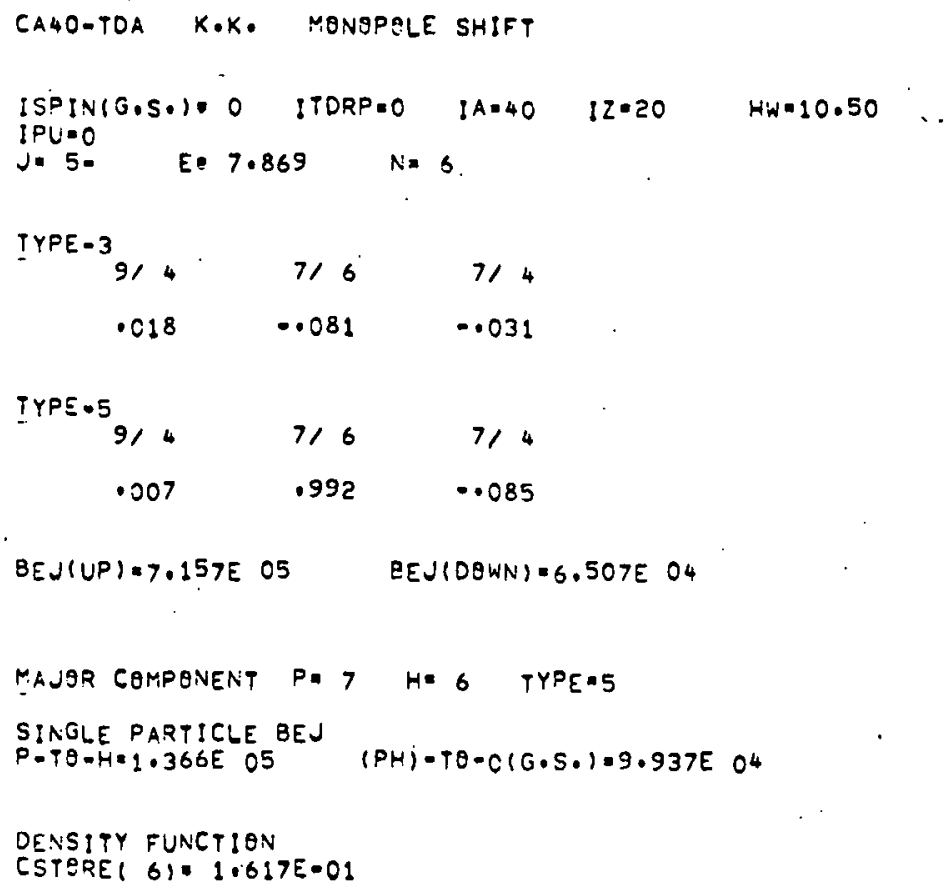




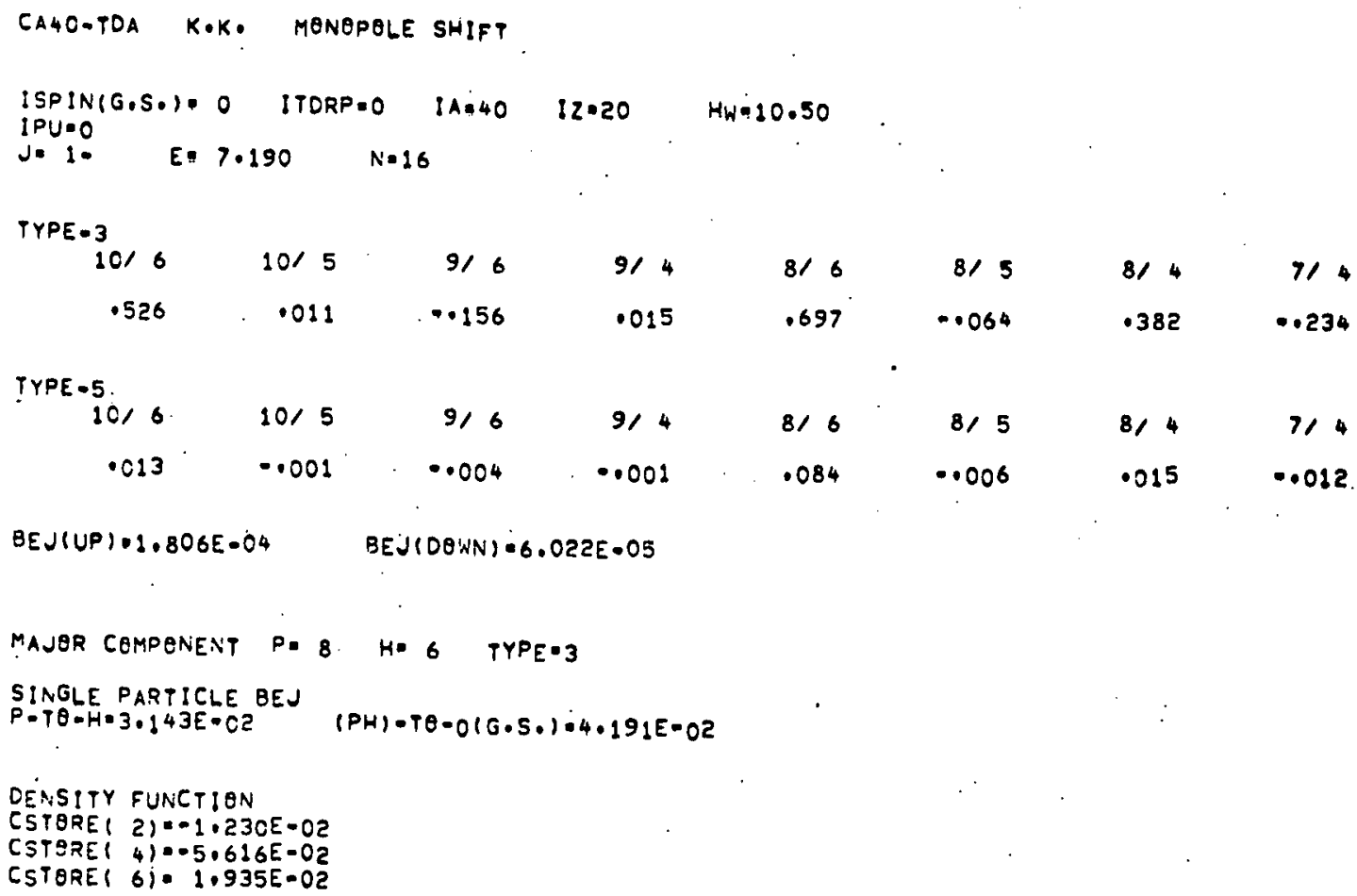




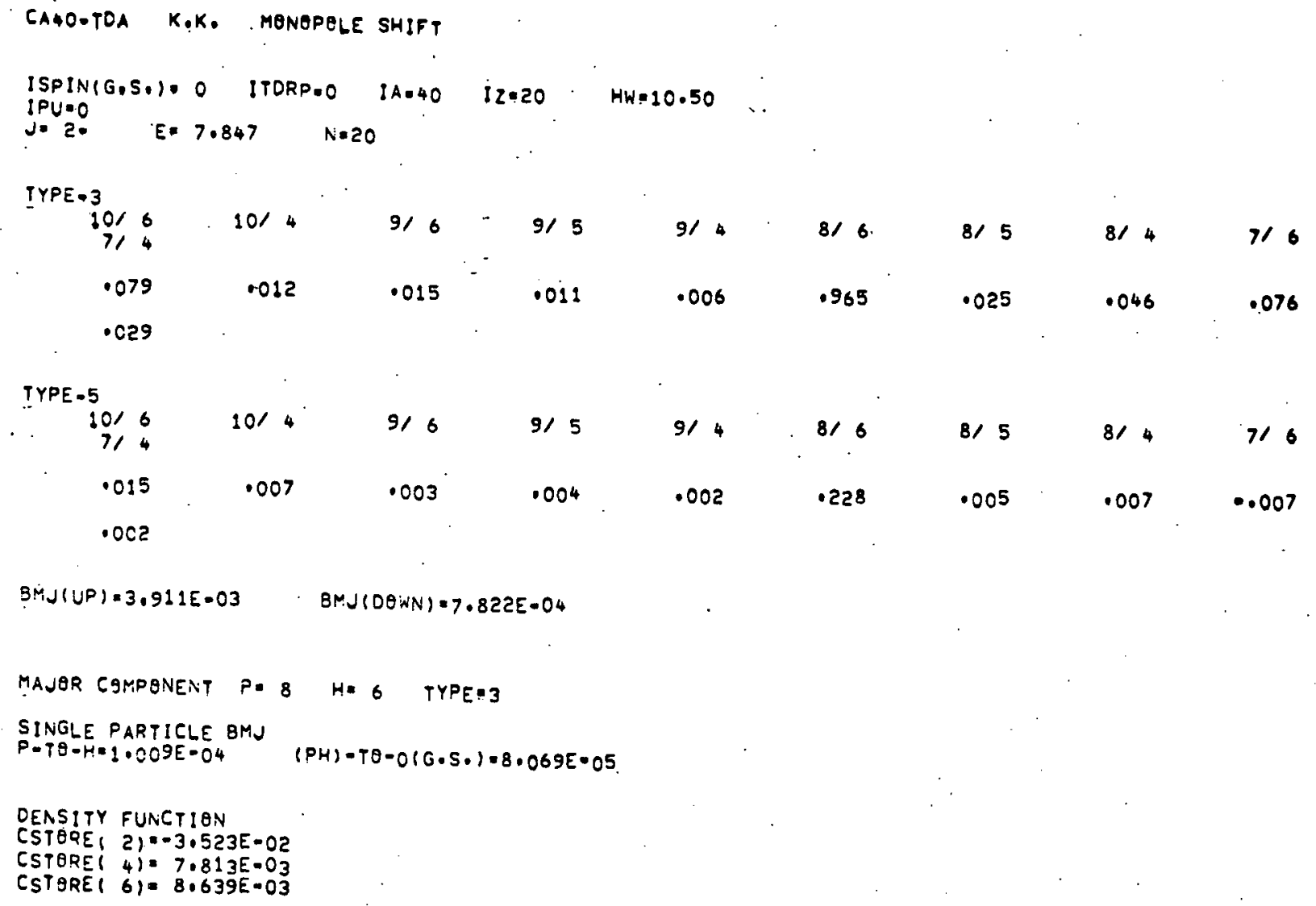




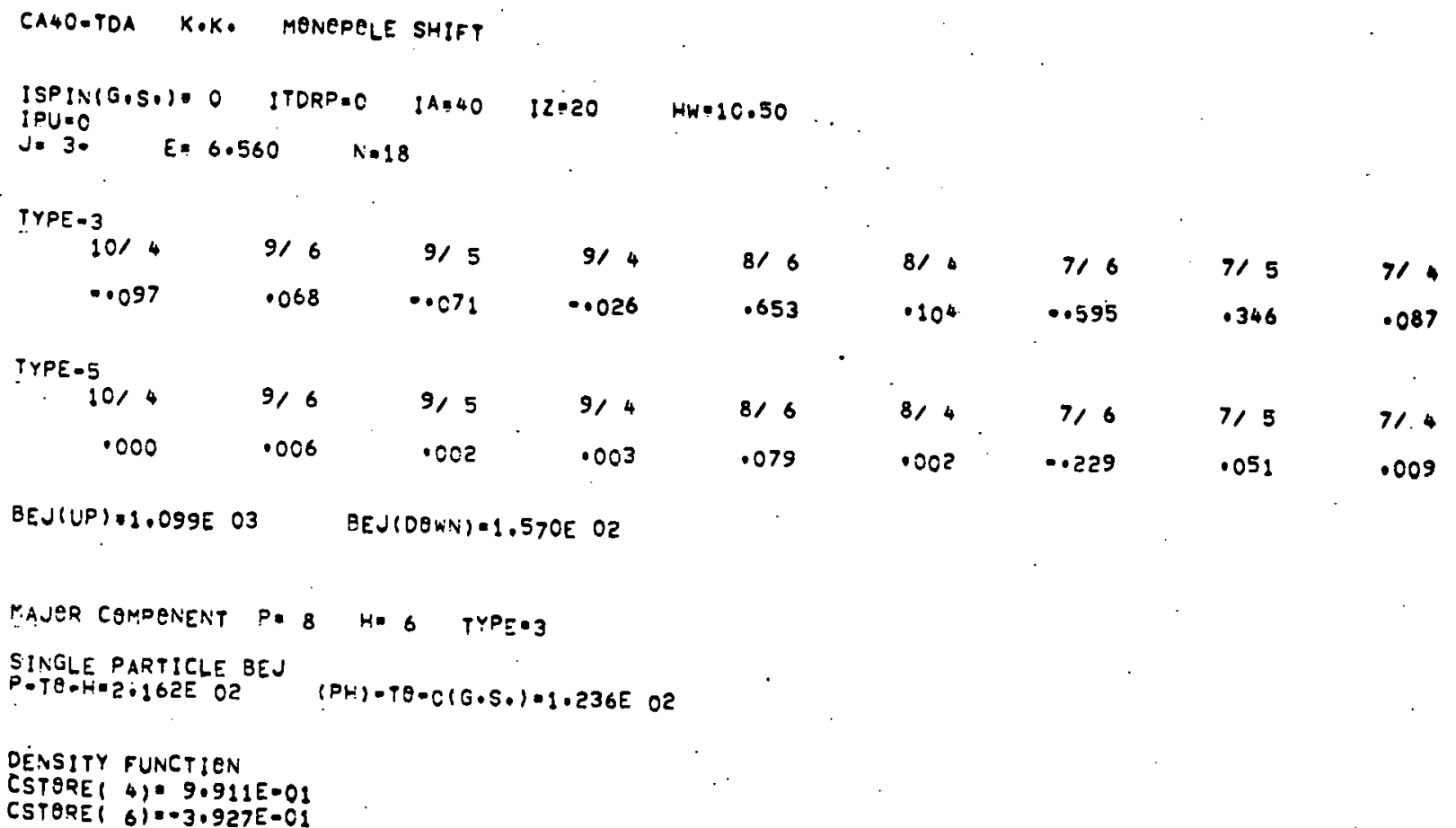




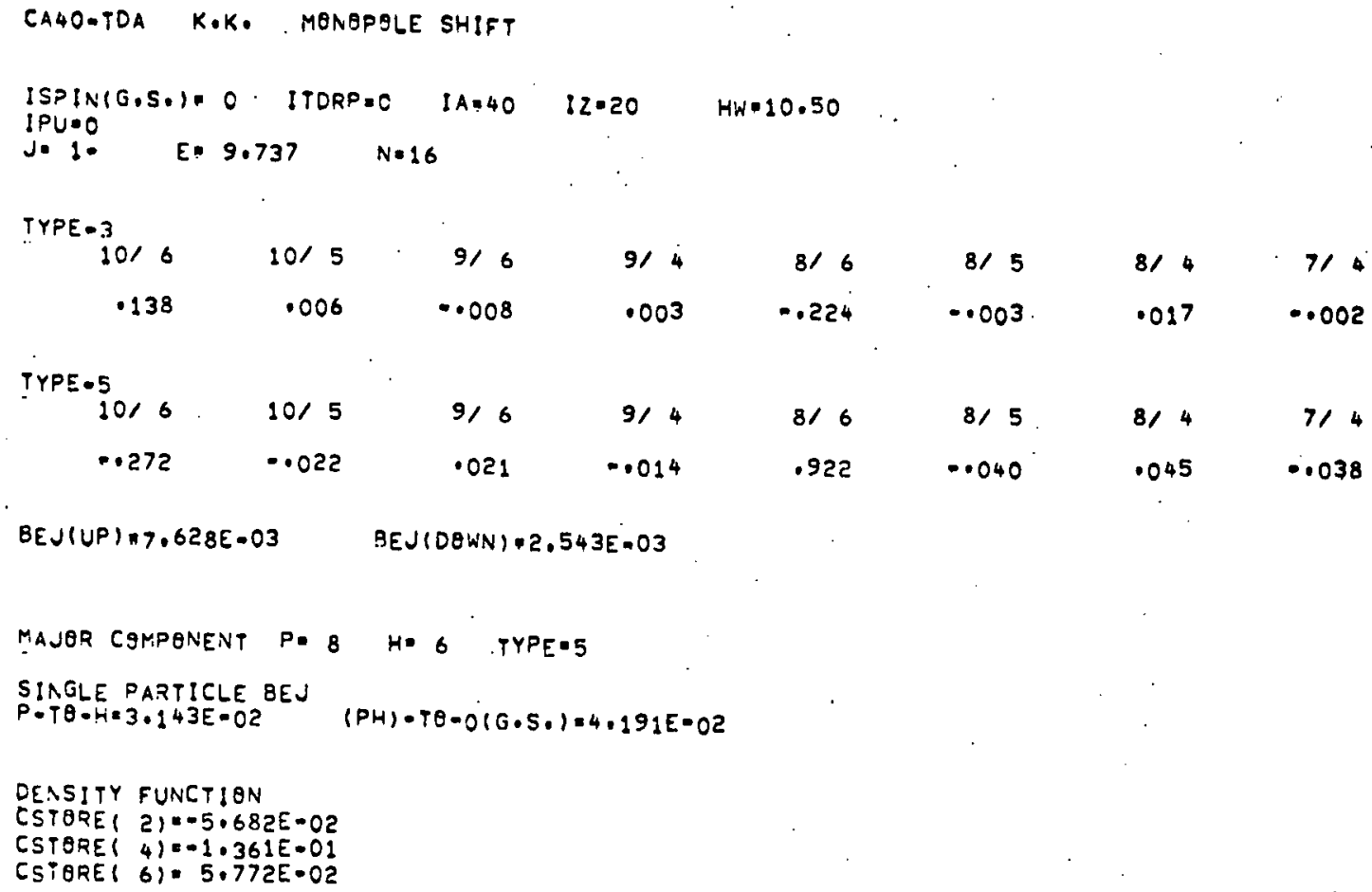




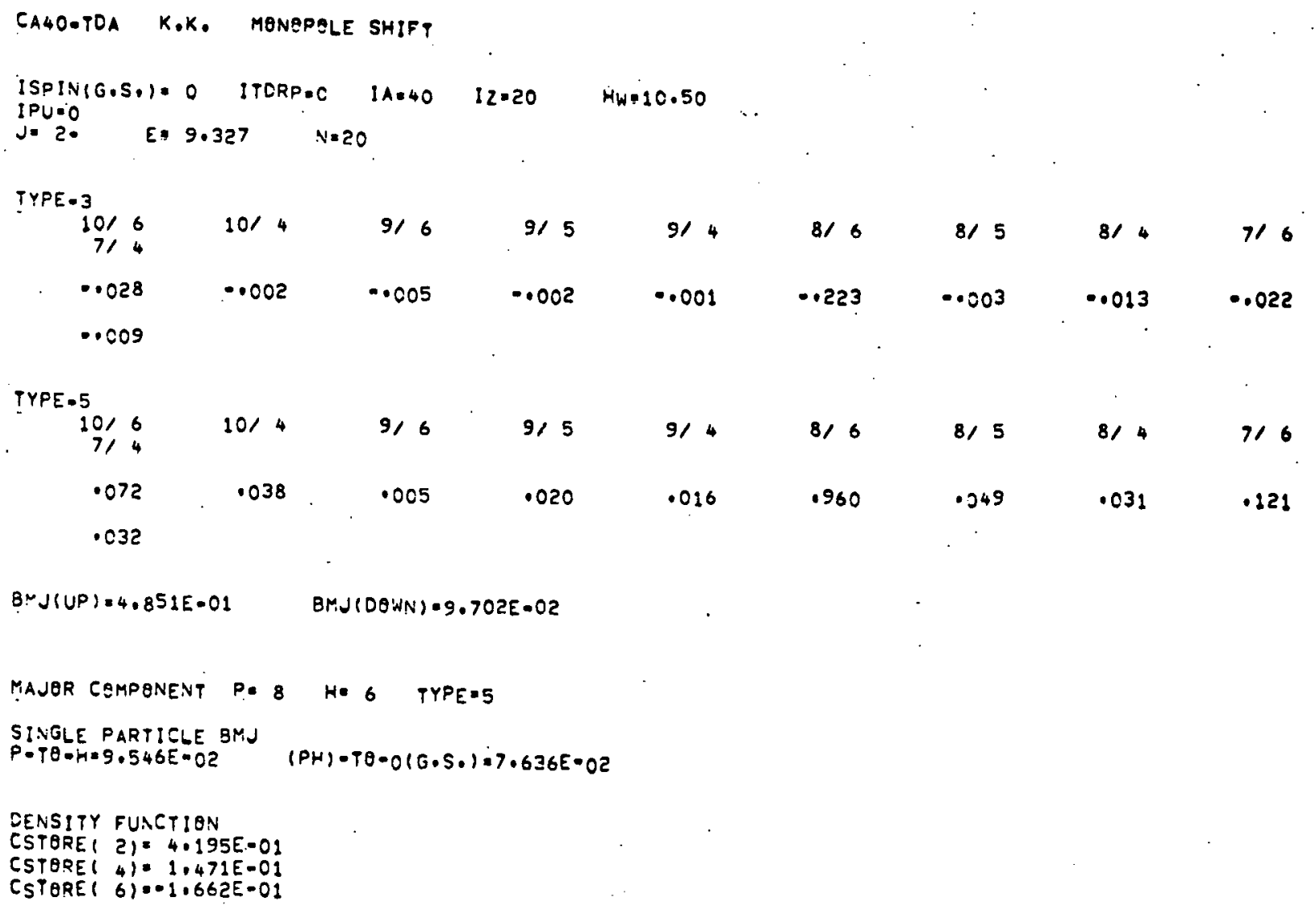




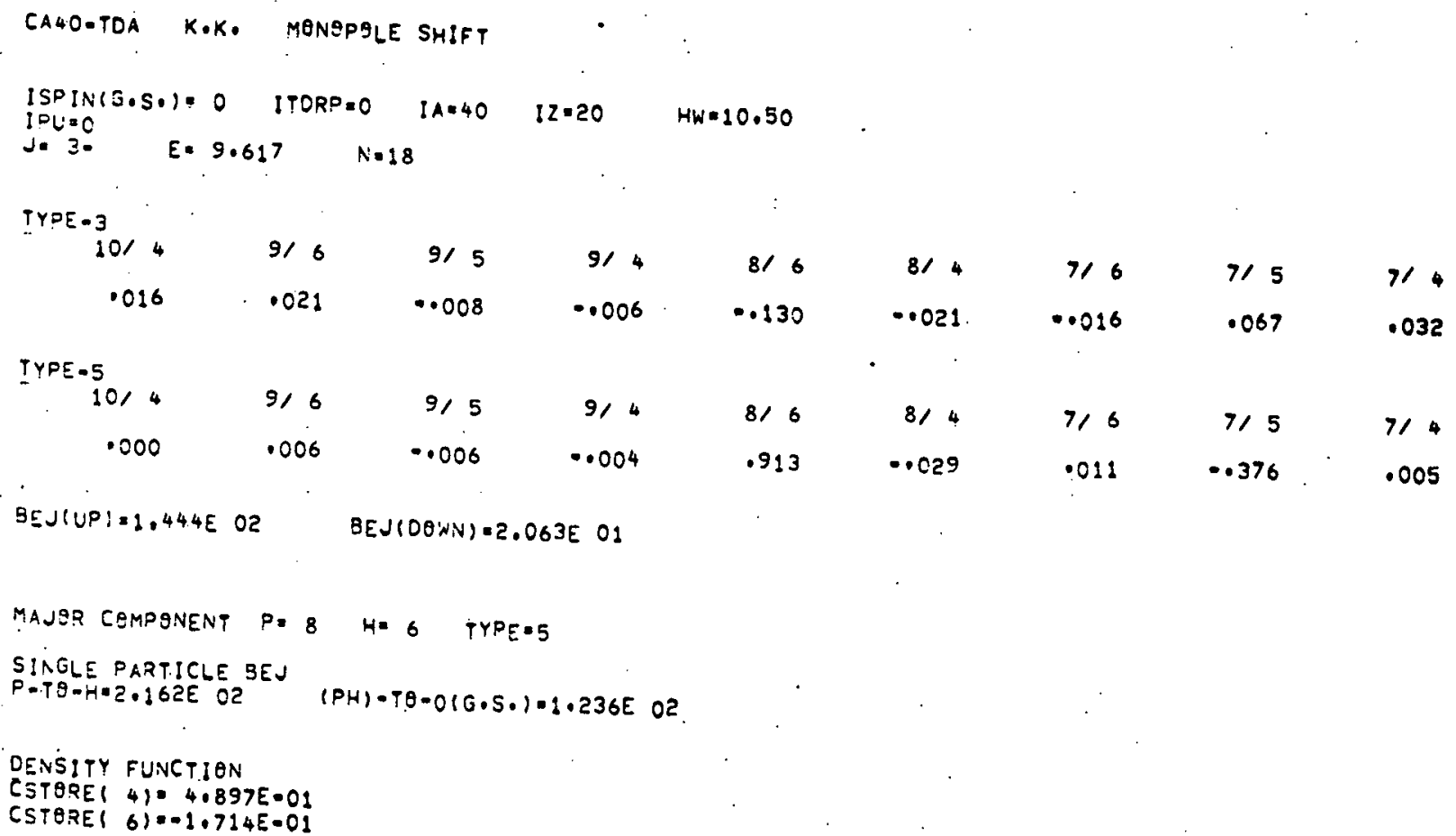

BEJ(UP: $1.444 E 02 \quad$ BEJ(DONN) $2.063 E 01$

MAJPR CEMPGNENT $P=8 \quad H=6$ TYPE 8

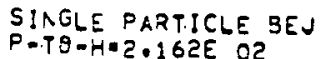

$(P H) \cdot T \theta=0(6 \cdot 5 \cdot 1 \cdot 1 \cdot 236 E$ O2

DENSITY FUNCTION

CSTORE ( 4): $4.897 E-01$

CSTERE( 6) $=-1.714 E=01$ 
CA40-TOA K.K. MENBPELE SHIFT

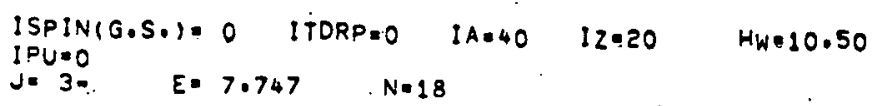

TYPE-3

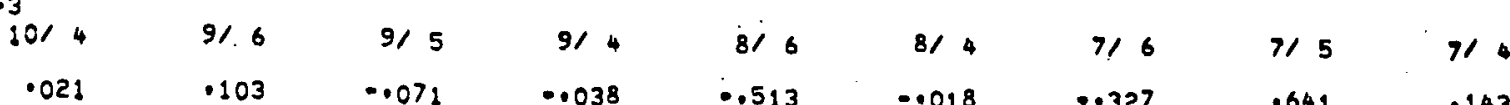

TYPE-5

$1014 \quad 9 / 6 \quad 9 / 5 \quad 9 / 4 \quad .8 / 6 \quad 8 / 4 \quad 716 \quad 7 / 5 \quad 714$

$\begin{array}{llllllllllll}0.002 & 0.008 & 0.008 & .000 & 0.138 & .001 & .408 & .003 & .014\end{array}$

BEJ(UP)=3.291E C2 BEJ(DOWN)=4.701E OI

MAJUR COMPONENT PH 7 H. 5 TYPE: 3

SINGLE PARTICLE BEJ

$(P H)-T \theta-O(G .5 \cdot)=2 \cdot 206 E$ O2

EENSTTY FUNCTION

CSTORE ( $11 \cdots \cdot-2.595 E-01$
CSTORE ( $61,-3.674 E-02$ 


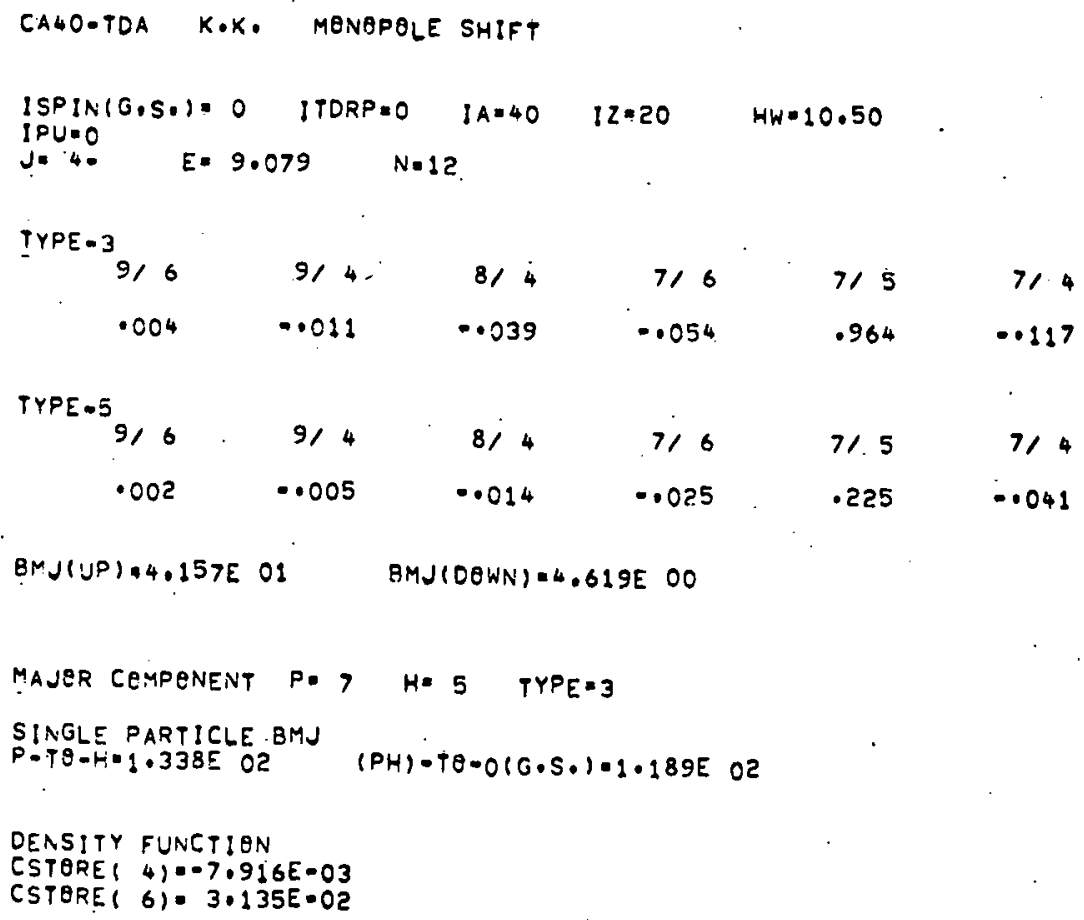




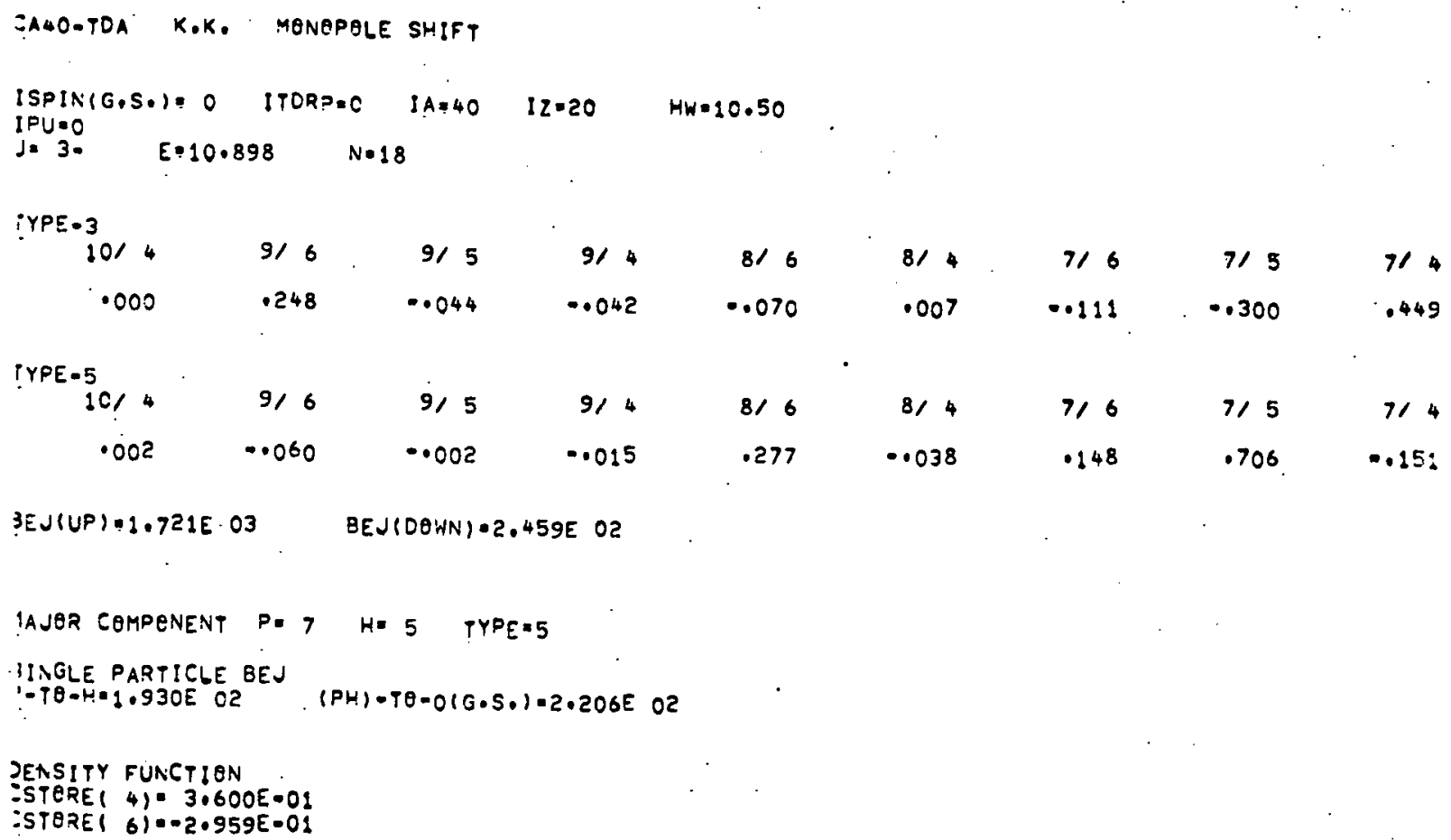




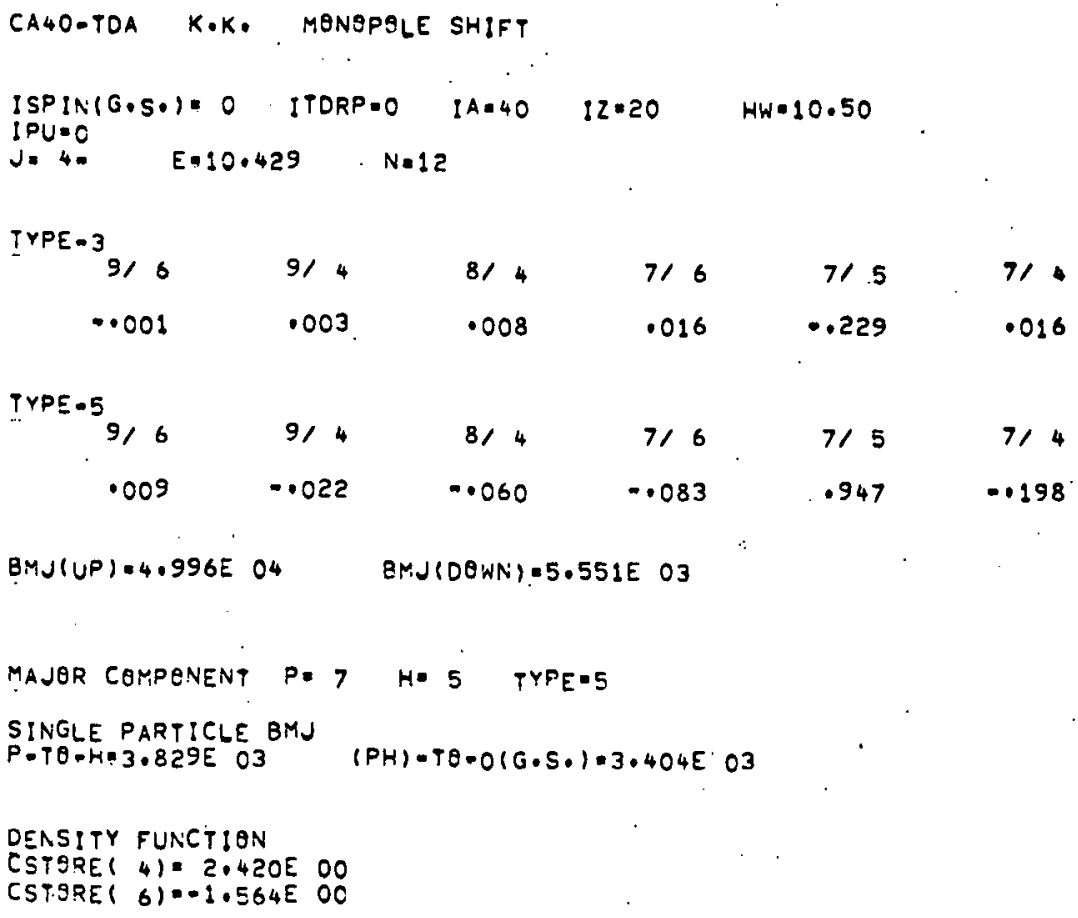




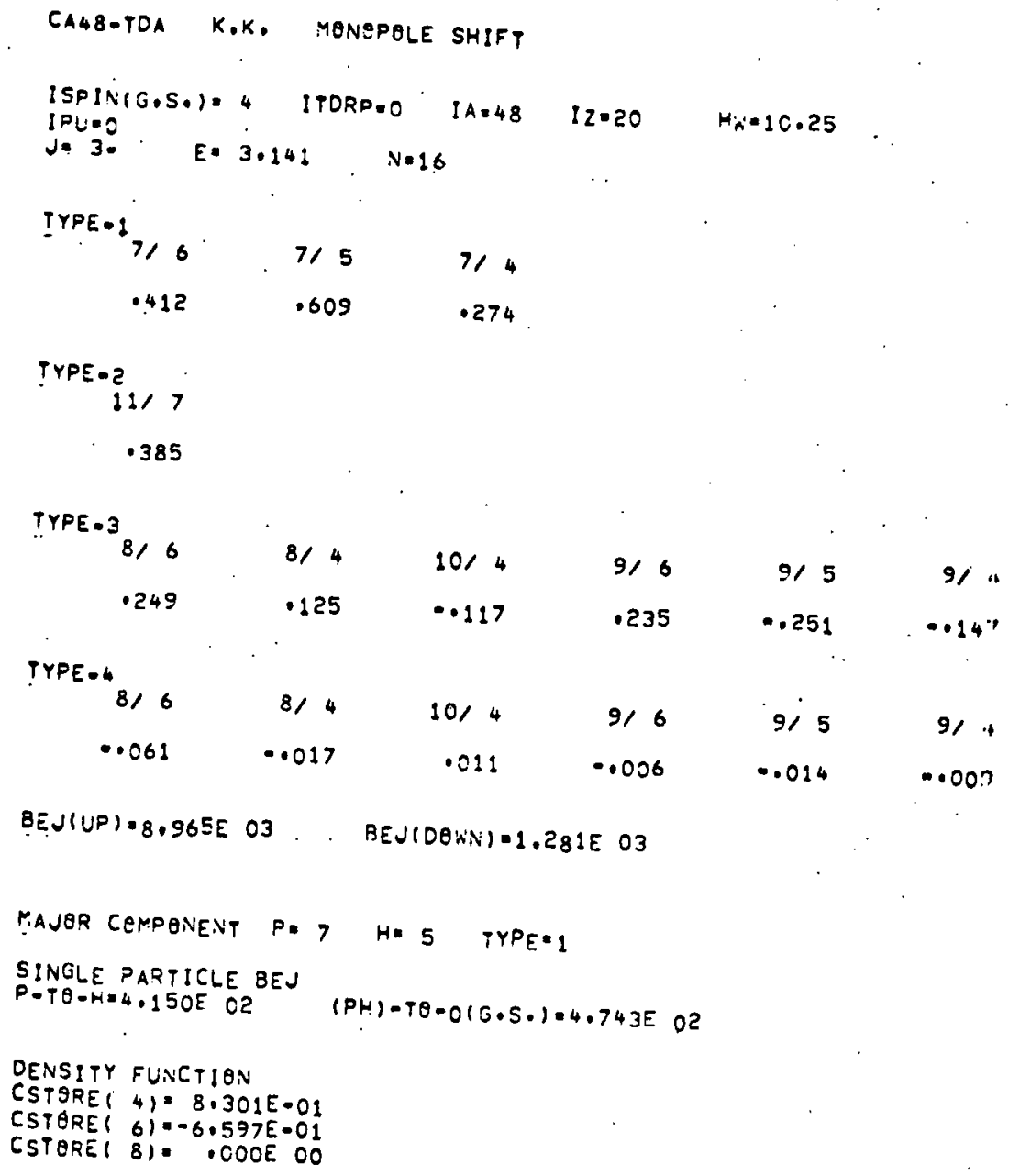




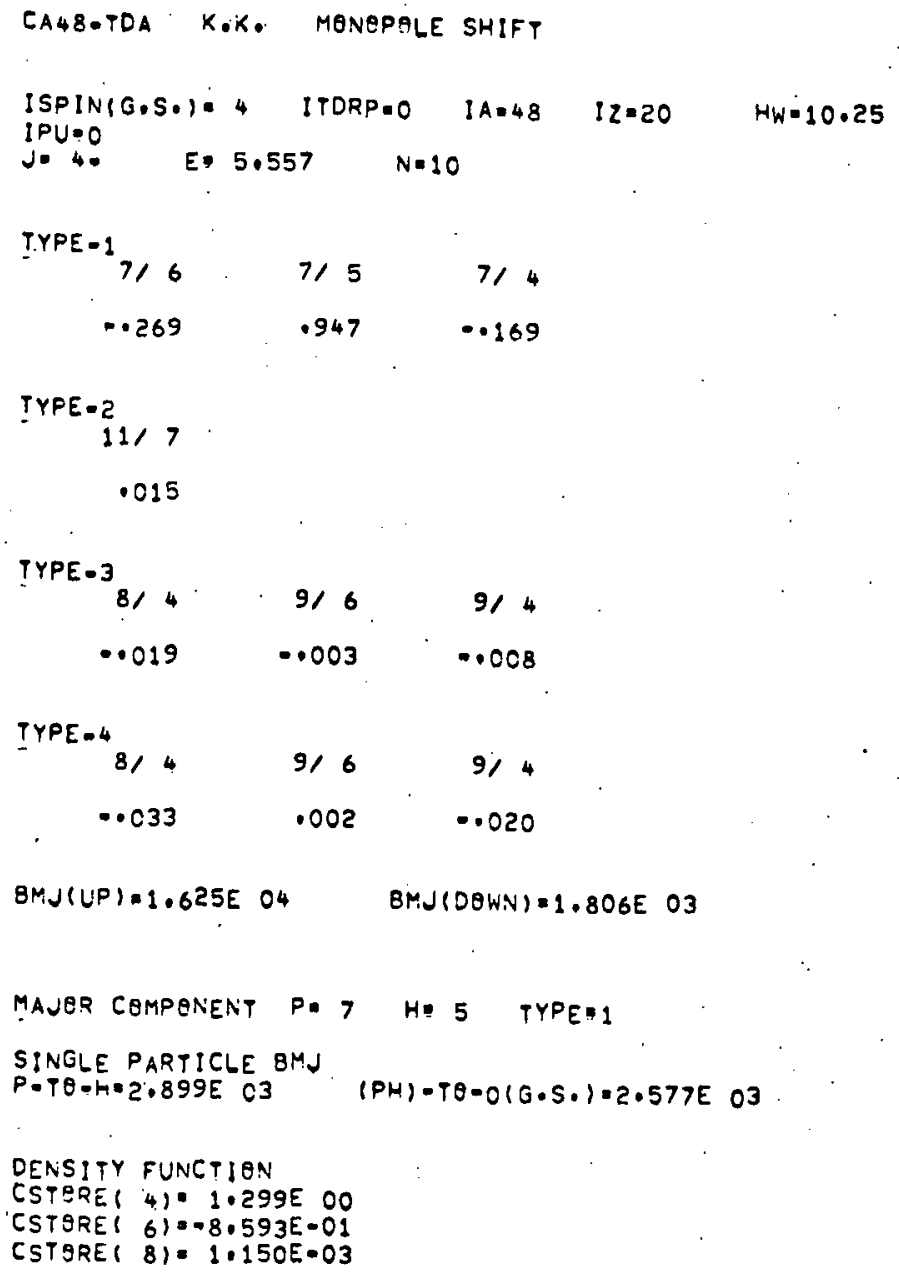




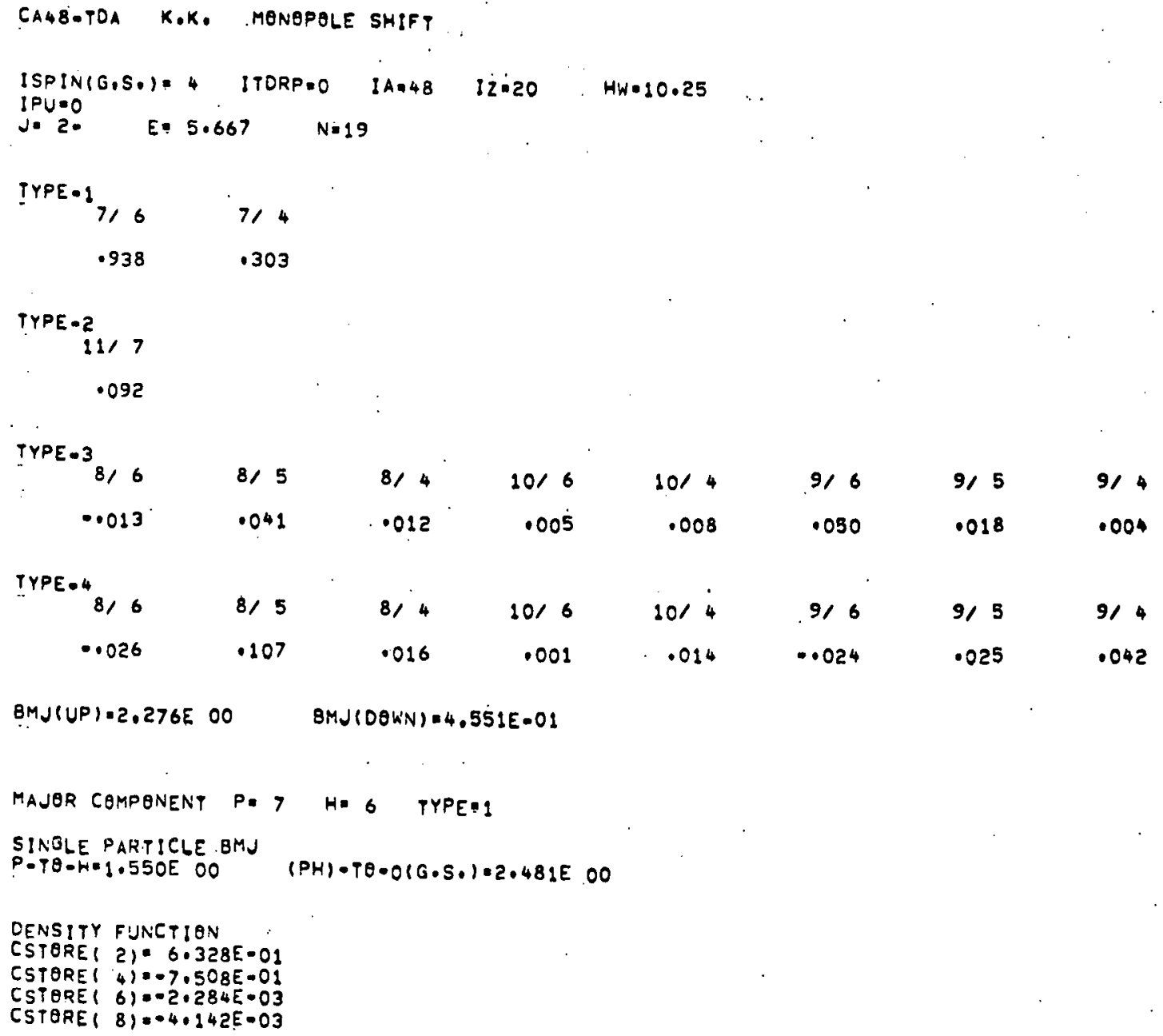




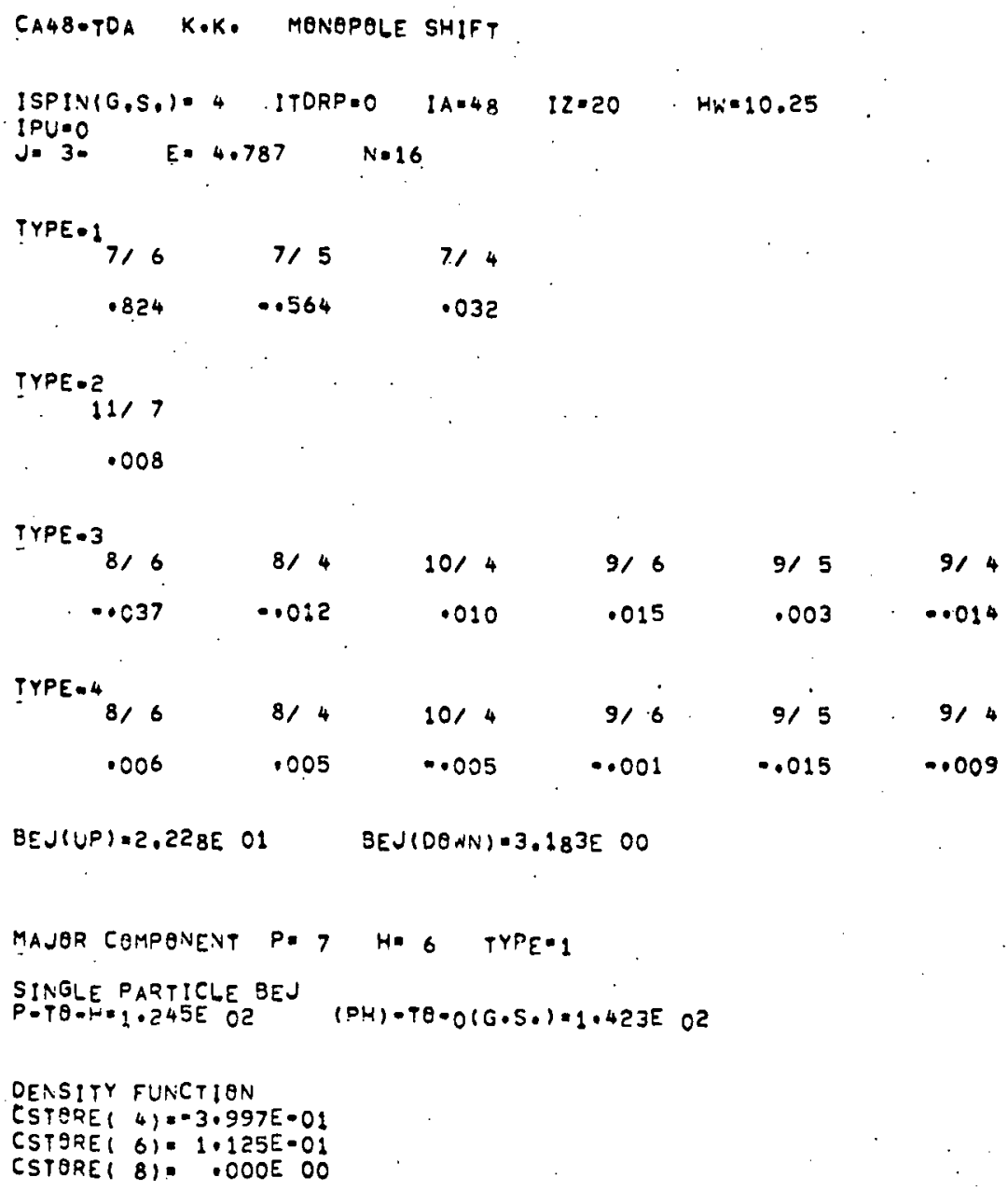




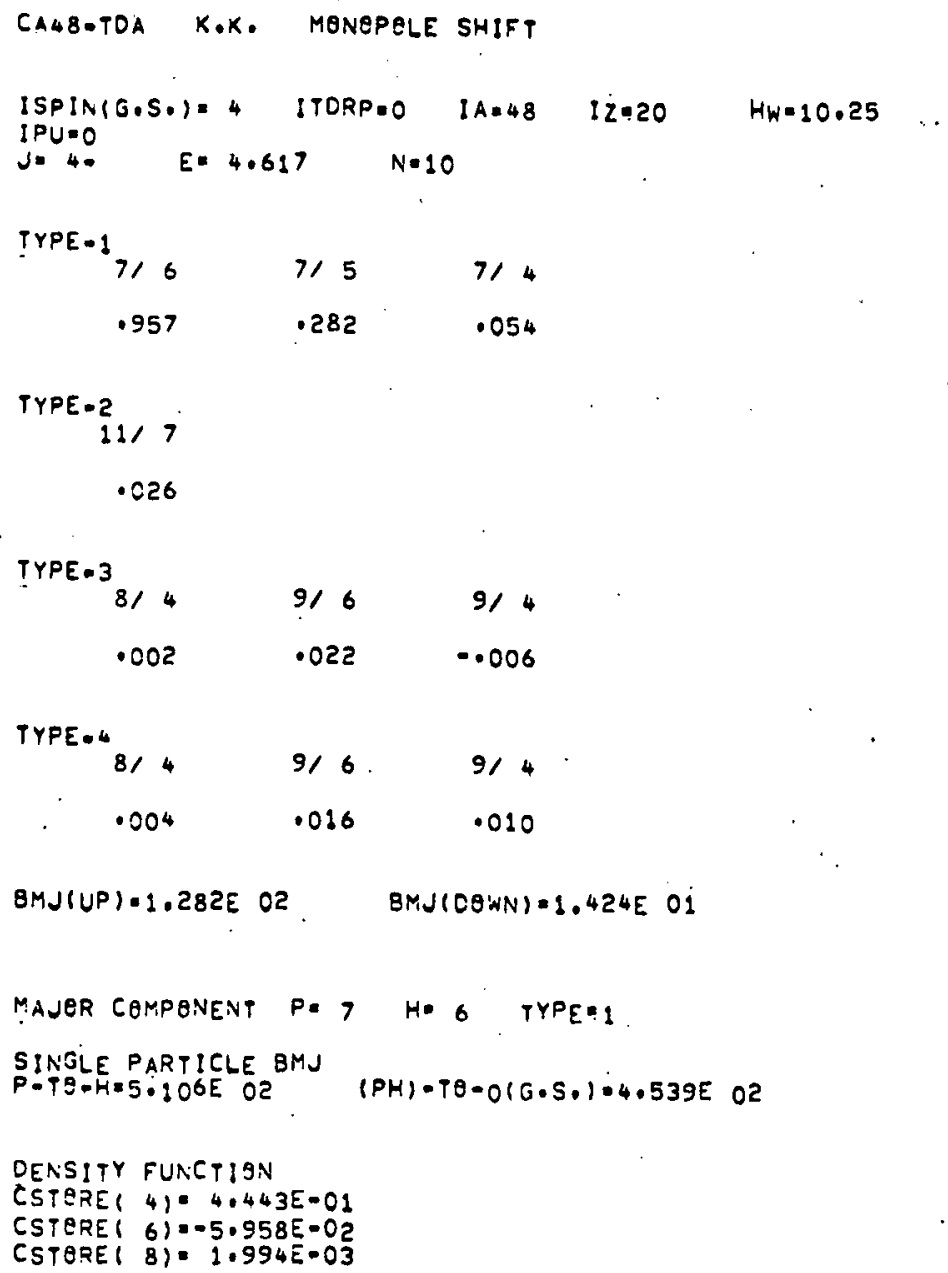




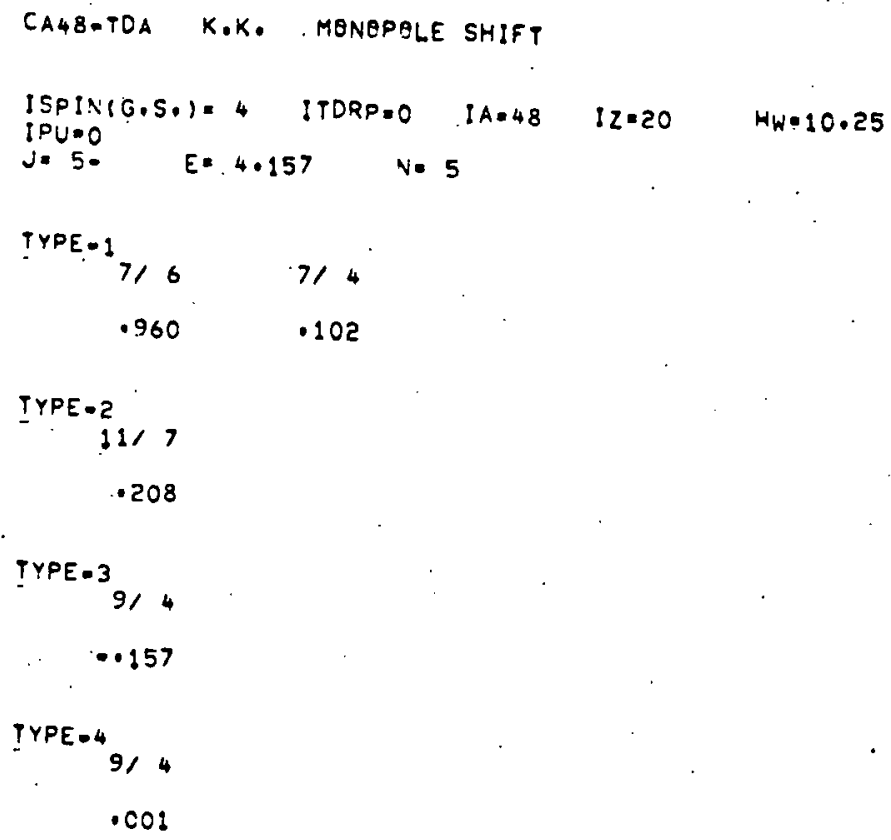

EEJ(UP) $=3.211 E$ O6 $\quad$ BEJ(OOWN)=2.919E OS

MAJQR CEMPONENT P. 7 H* 6 TYPE=1

SINGLE PARTICLE BEJ

$P=T \theta=H=3.083 E$ CS $\quad(P H)=T \theta-O(G . S .1=2.242 E O 5$

DENSITY FUNCTION .

CETPRE ( 6): 3.224E.01

CSTIRE 8 ) . .0OE 00 


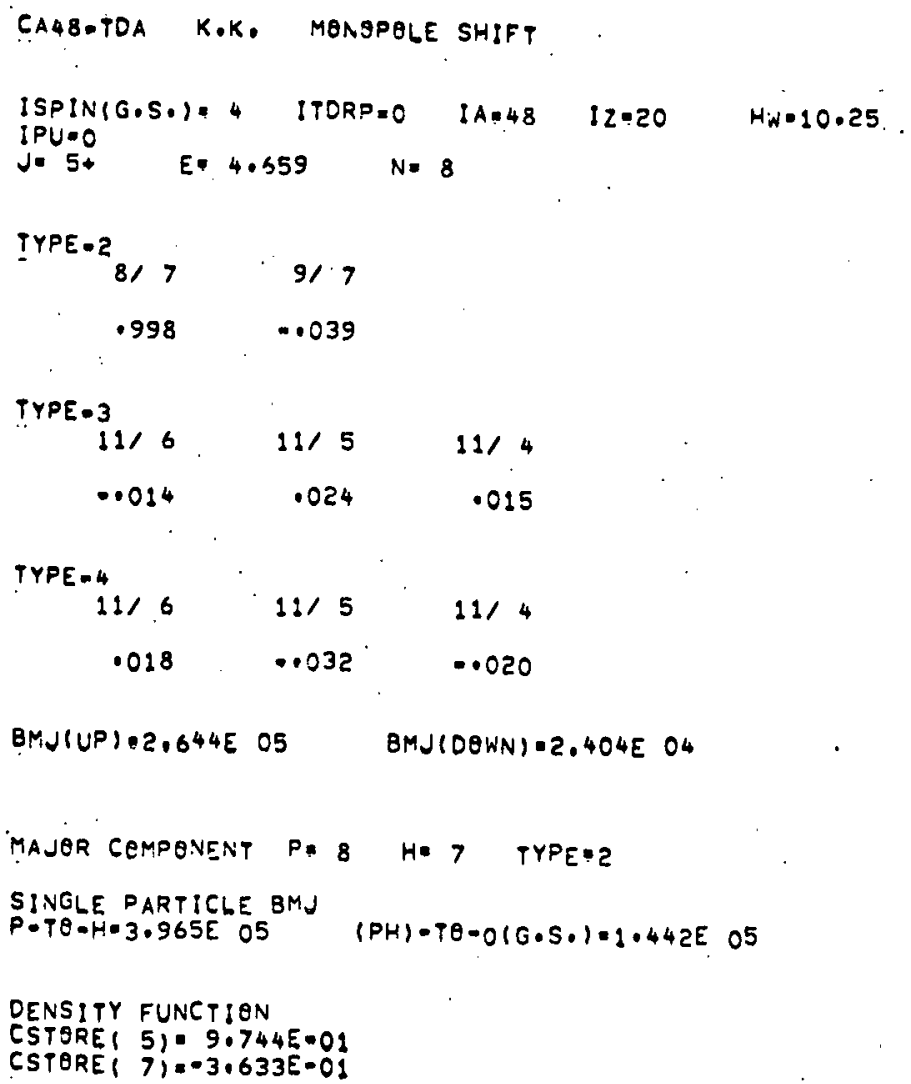


CAL8-TOA K.K. MONOPOLE SHIFT

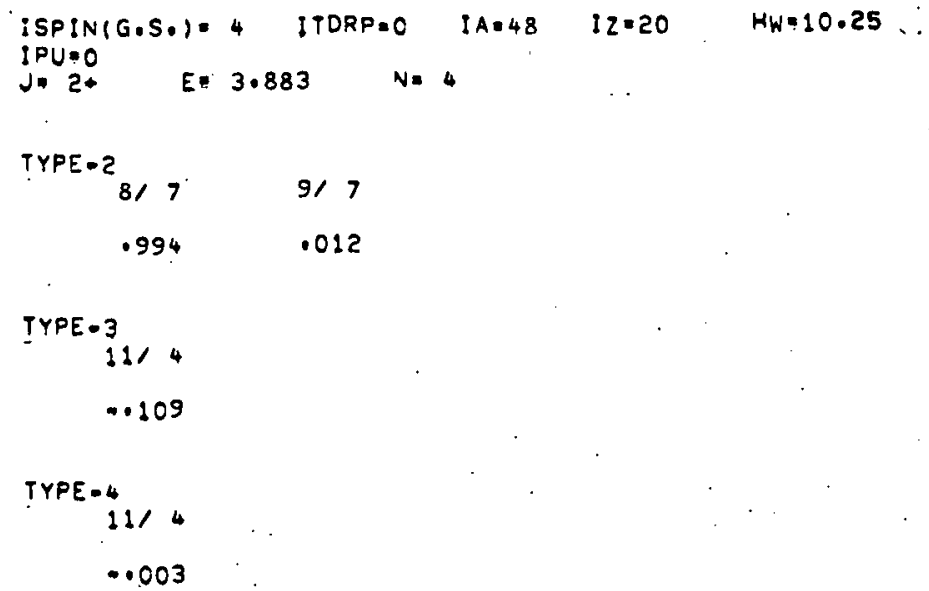




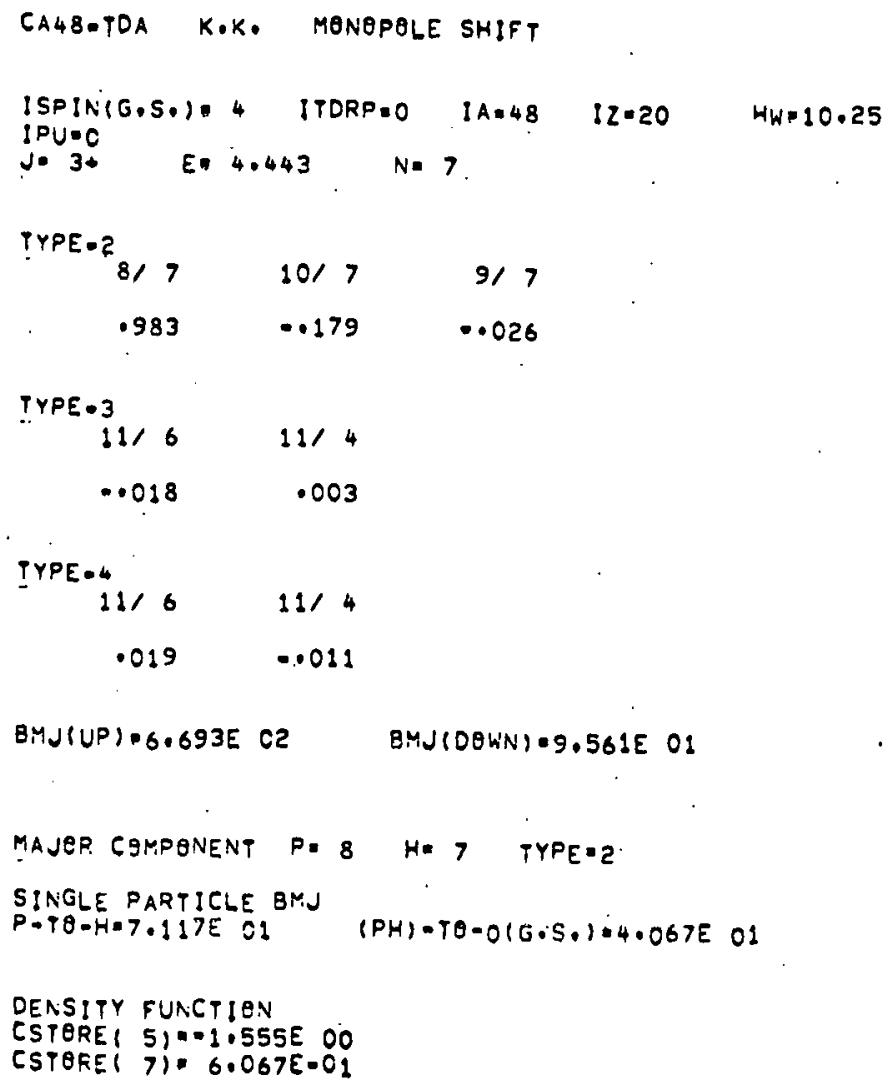




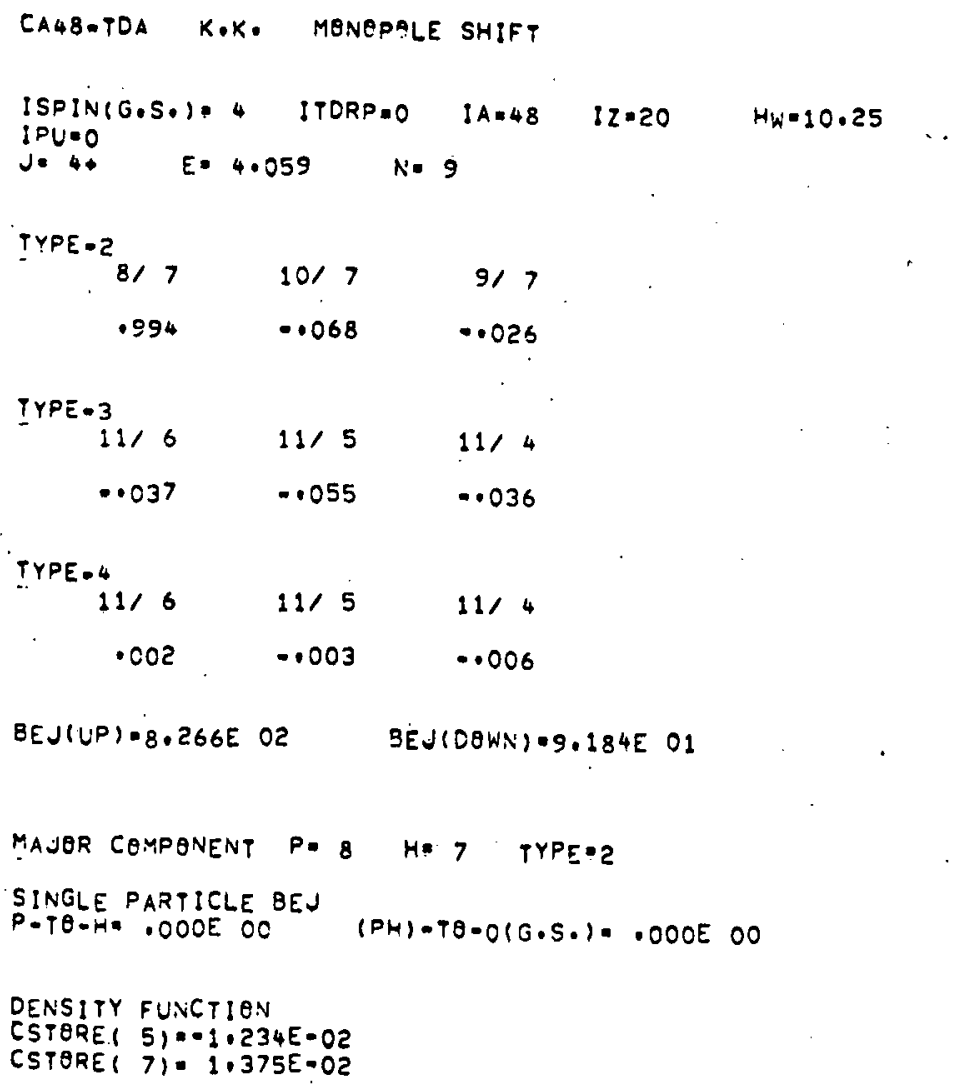




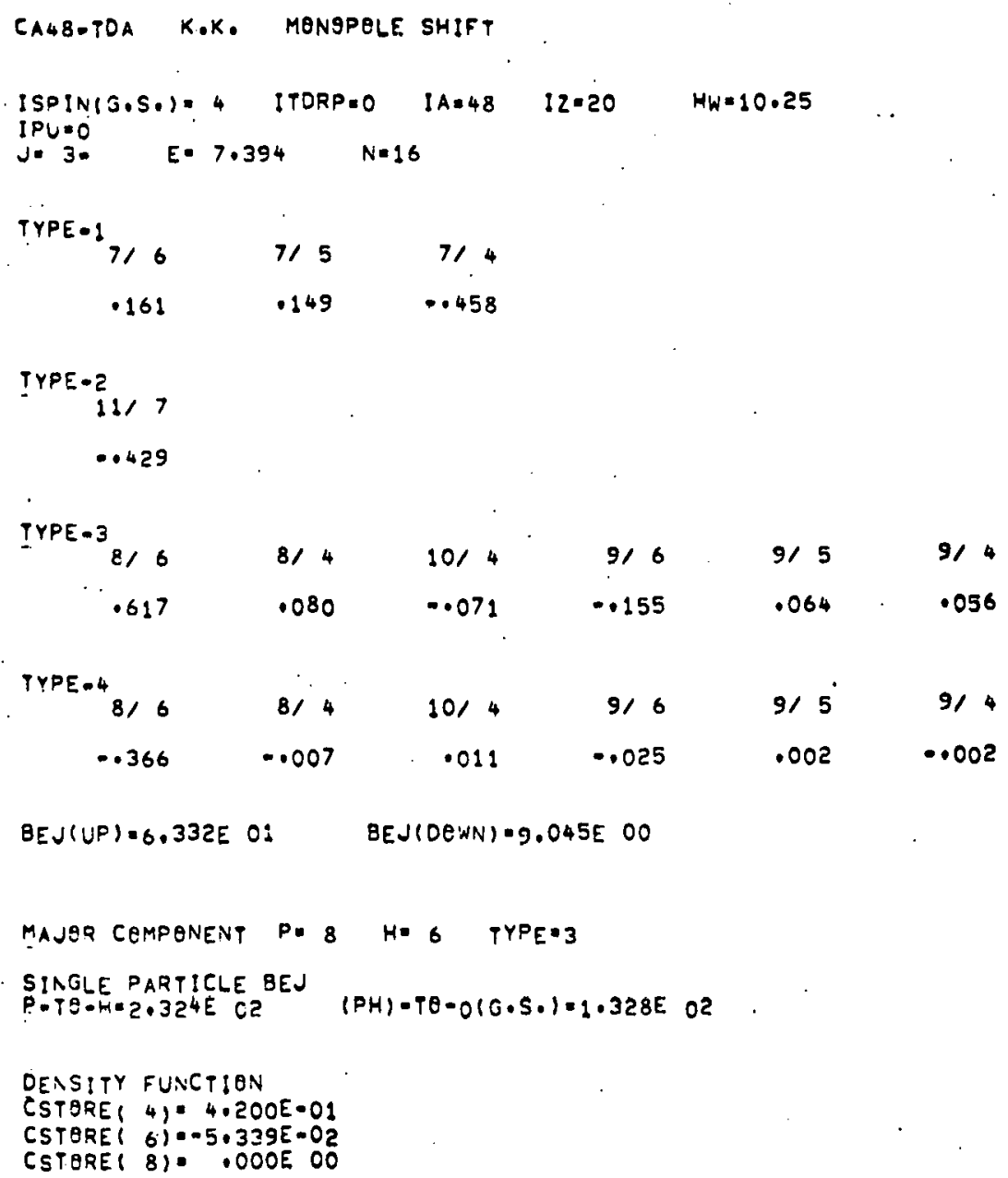


SR88-TOA K.K, MENGPELE SHIFT

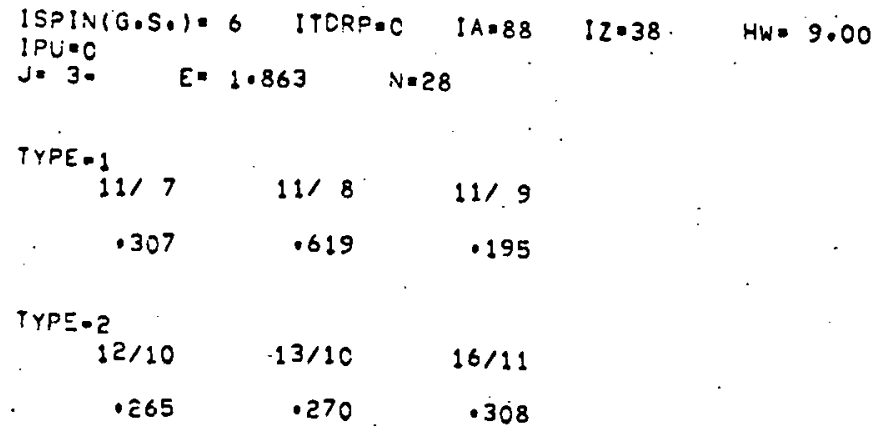

\begin{tabular}{|c|c|c|c|c|c|c|c|c|}
\hline $\begin{array}{l}12,7 \\
15,7\end{array}$ & $\begin{array}{l}12 / 8 \\
15 / 9\end{array}$ & $12 / 9$ & $13 / 7$ & $13 / 8$ & $13 / 9$ & $14 / 7$ & $14 / 9$ & 1587 \\
\hline$\because 007$ & .0016 & .024 & -.007 & -.005 &. .026 & .000 & -.008 & $\therefore .002$ \\
\hline .002 & ..009 & & & & & & & \\
\hline
\end{tabular}

SESJ(UP) $=3.408 E 04 \quad$ REJ 0 (ODAiN) $=4.868 E 03$

MAJER COMPENENT PEII H= 8 TYPE=1

SINGLE PARTICLE BEJ

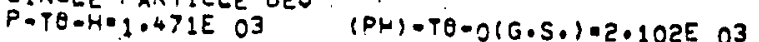

OENSITY FUN:CTION

CSTERE ( 4$)=-5.763 E-01$

CSTERE 6$)=8.162 E-01$

CSTARE ( 8) $=-2.637 E-01$ 


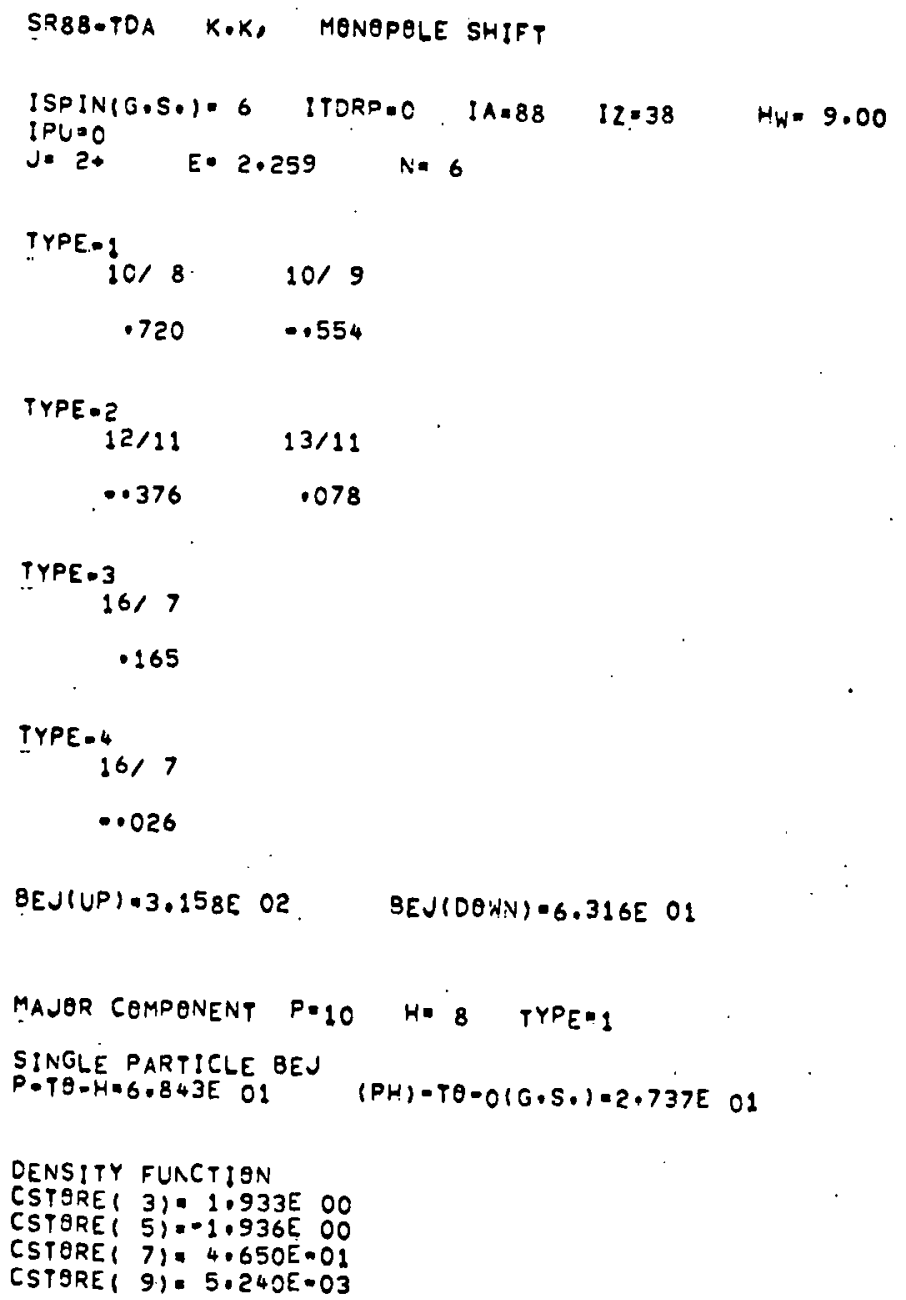




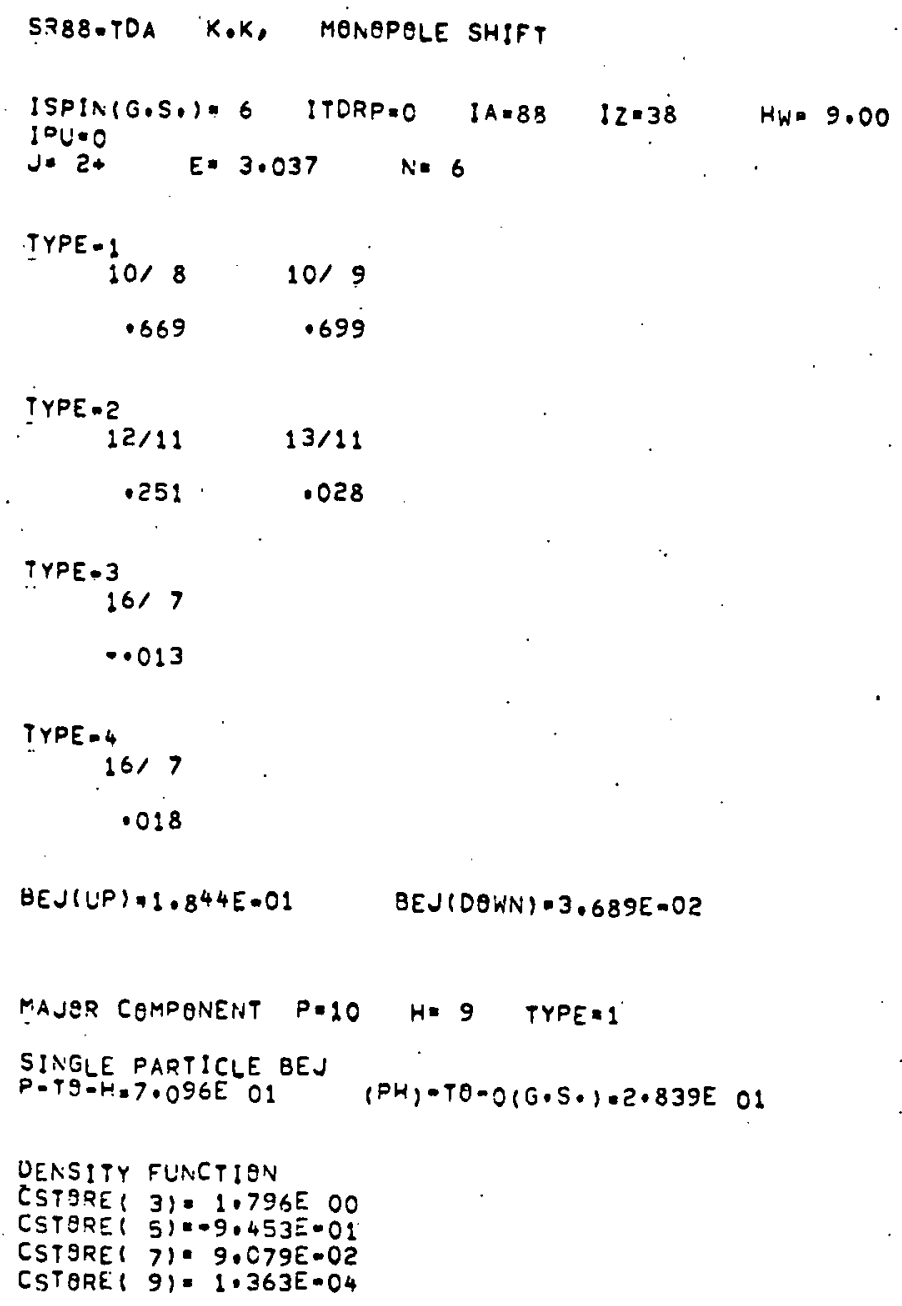




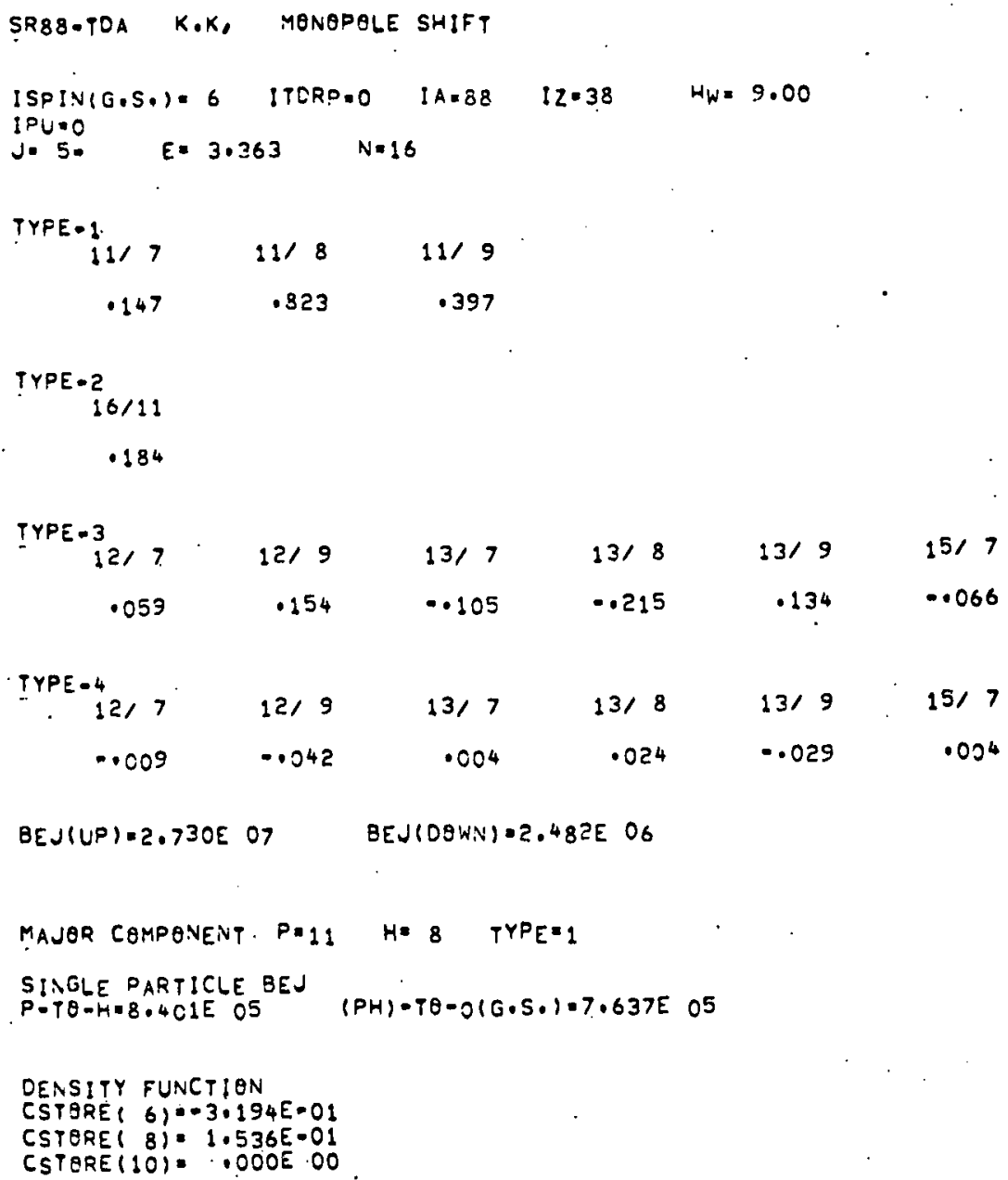




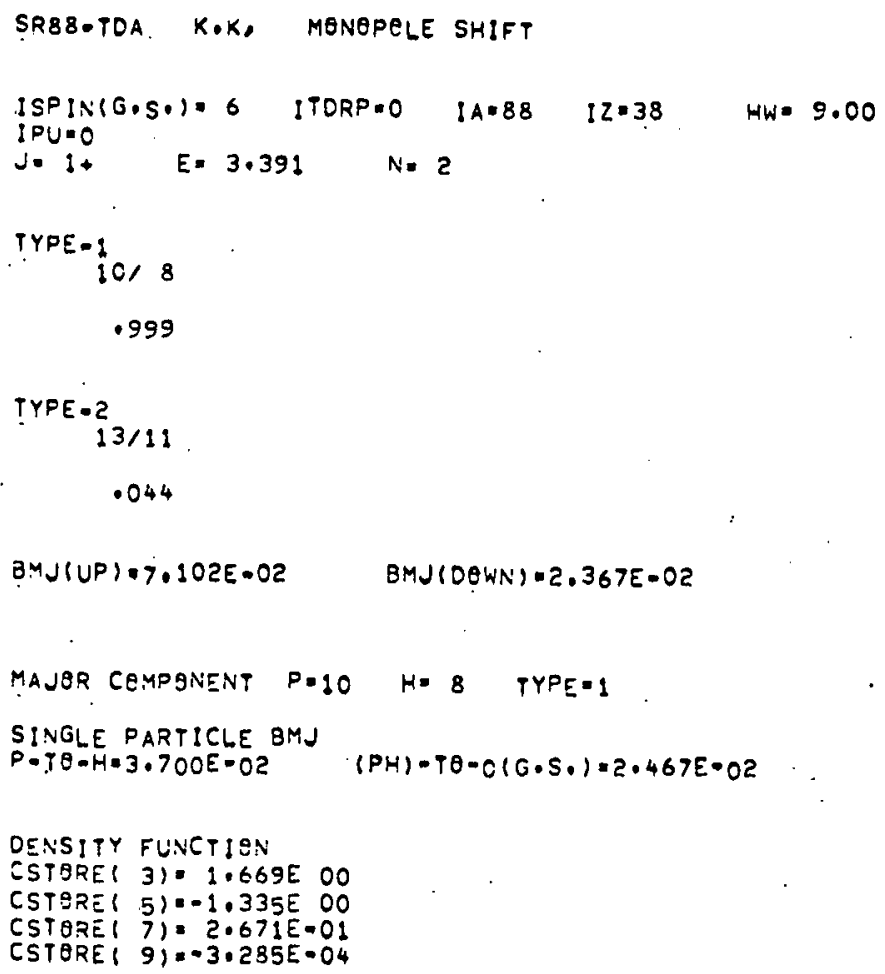




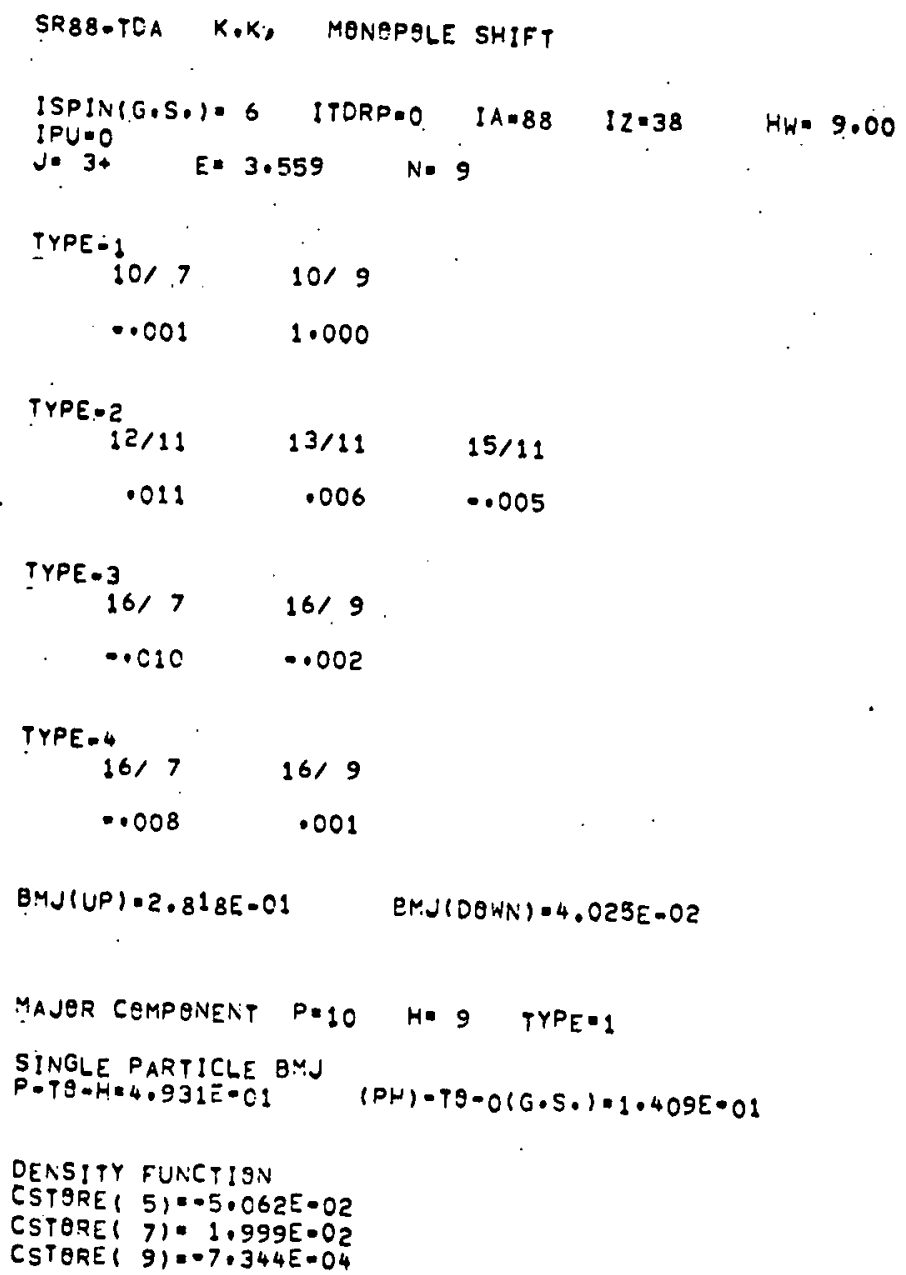




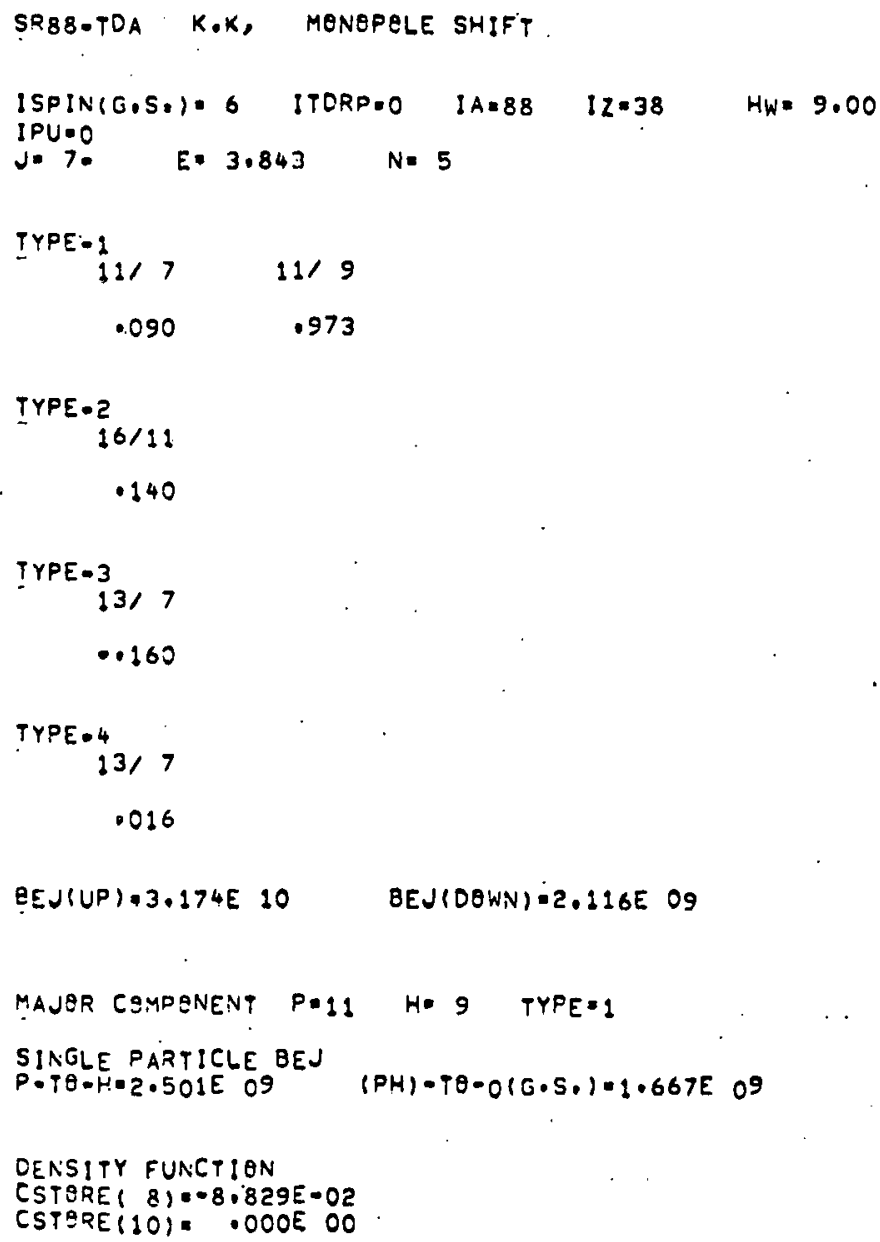




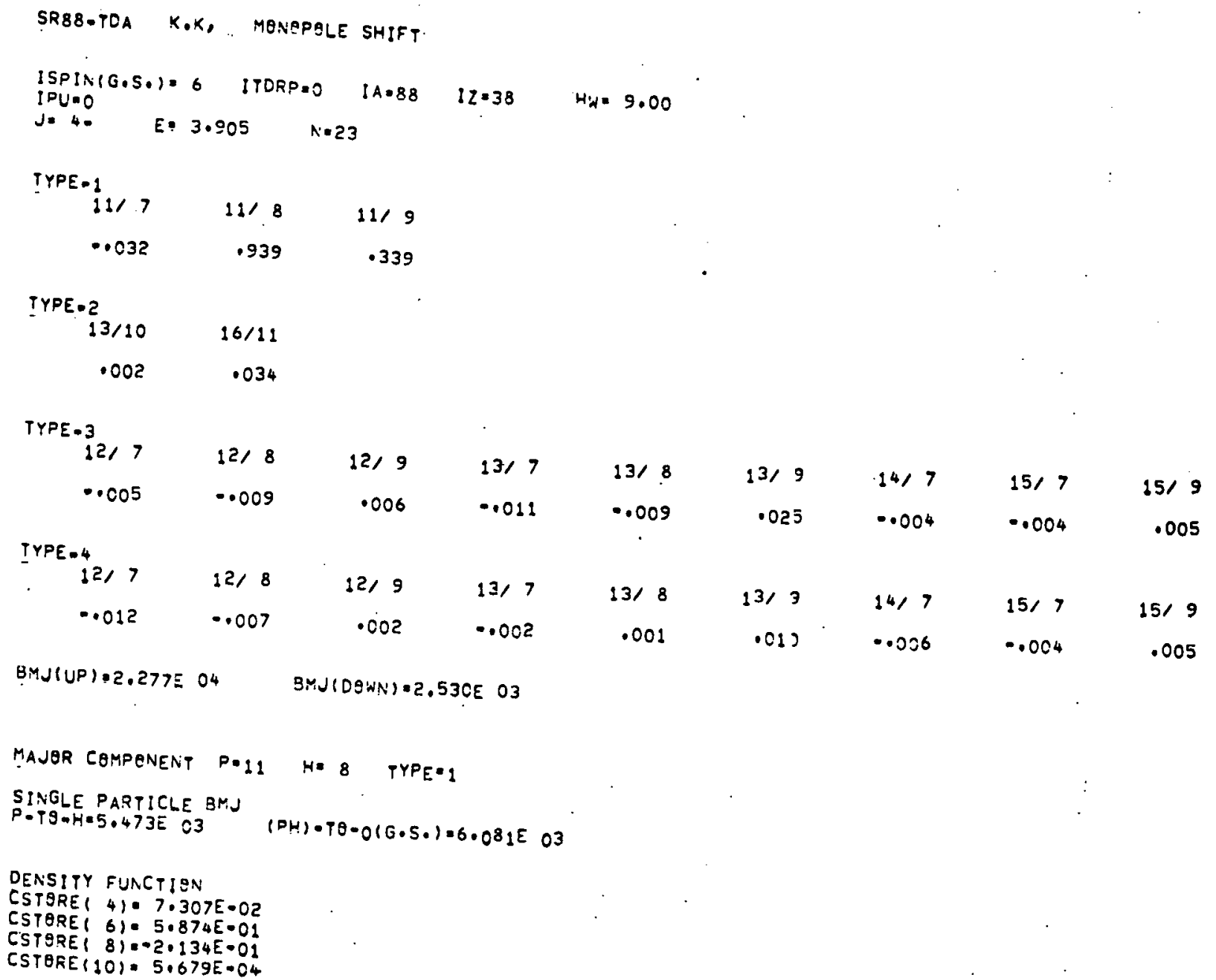




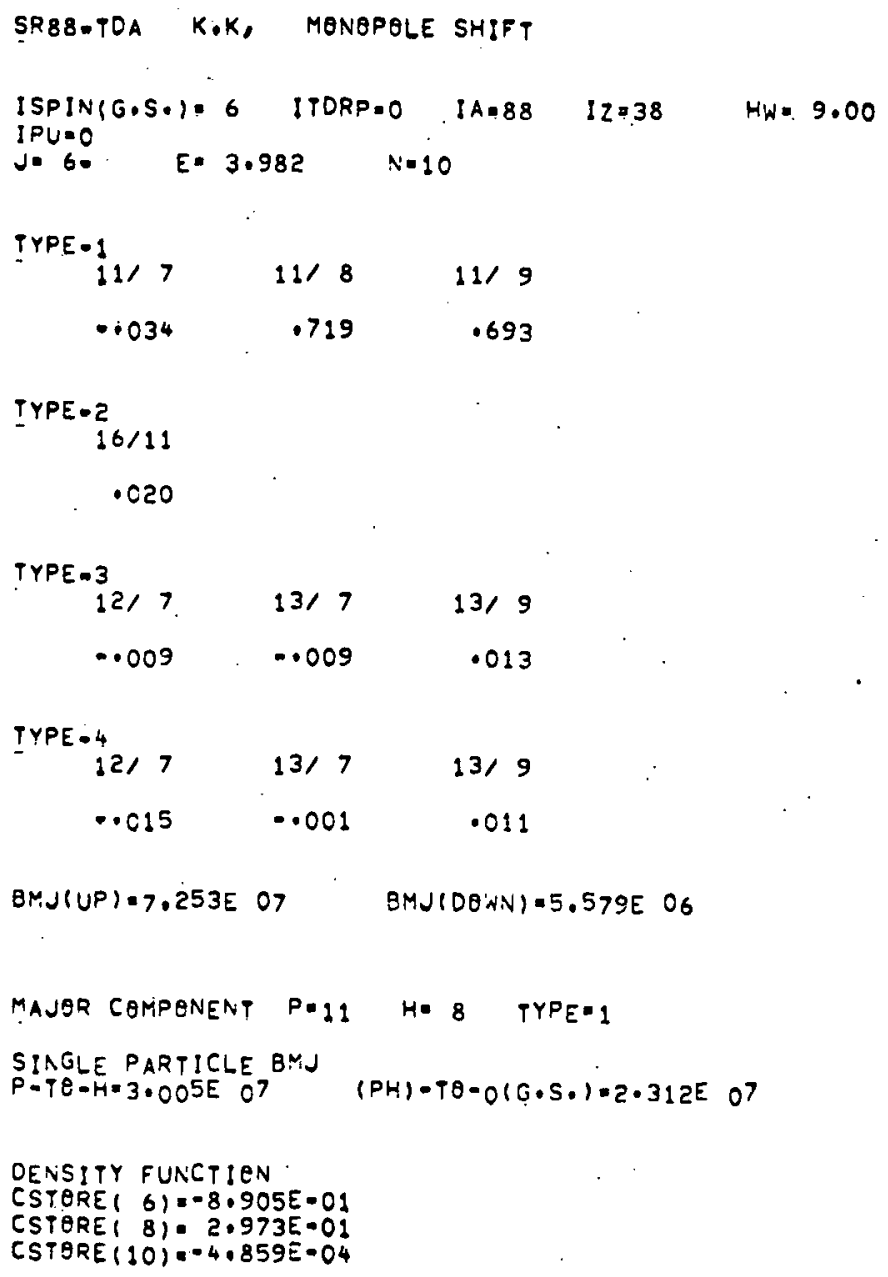




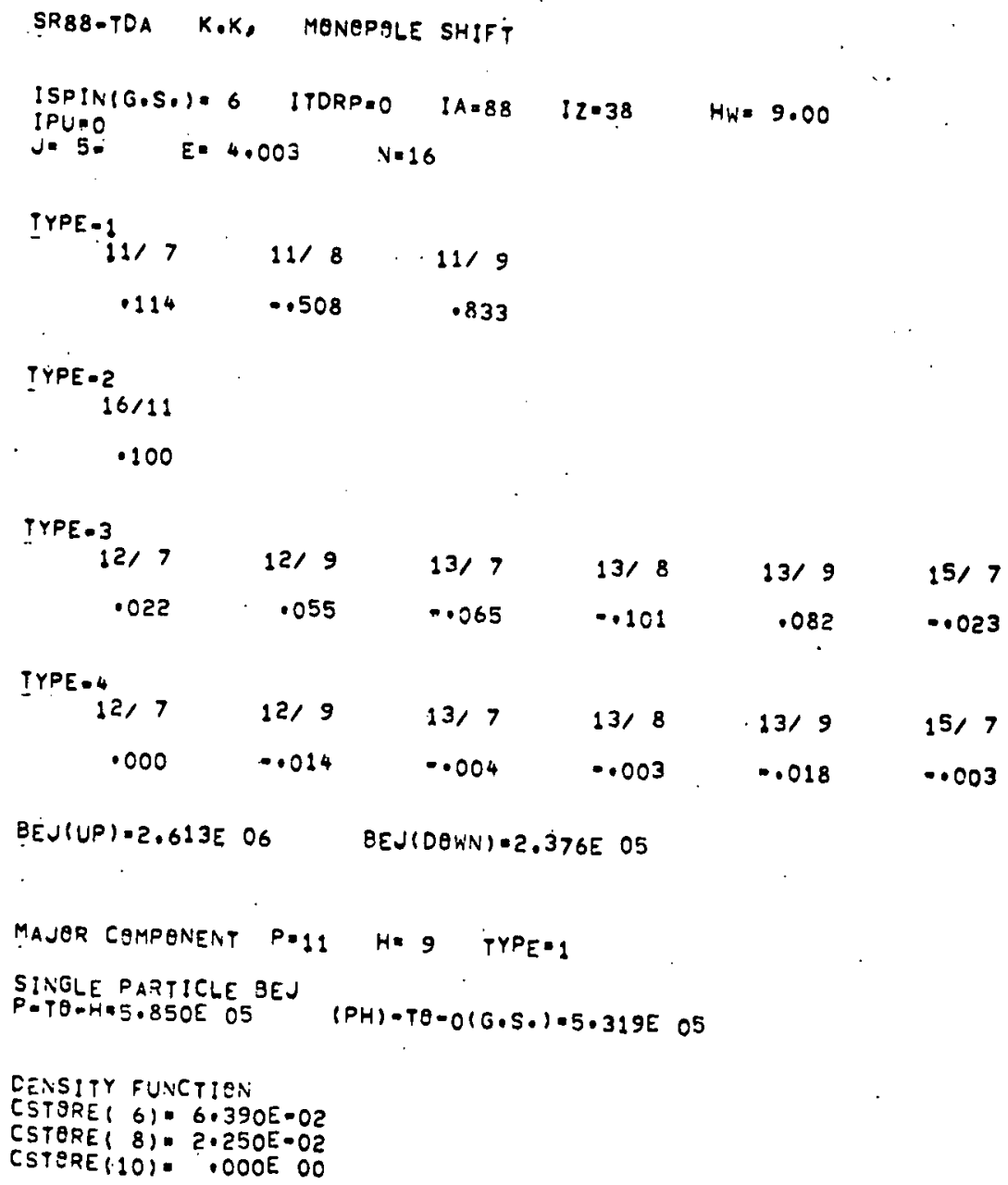




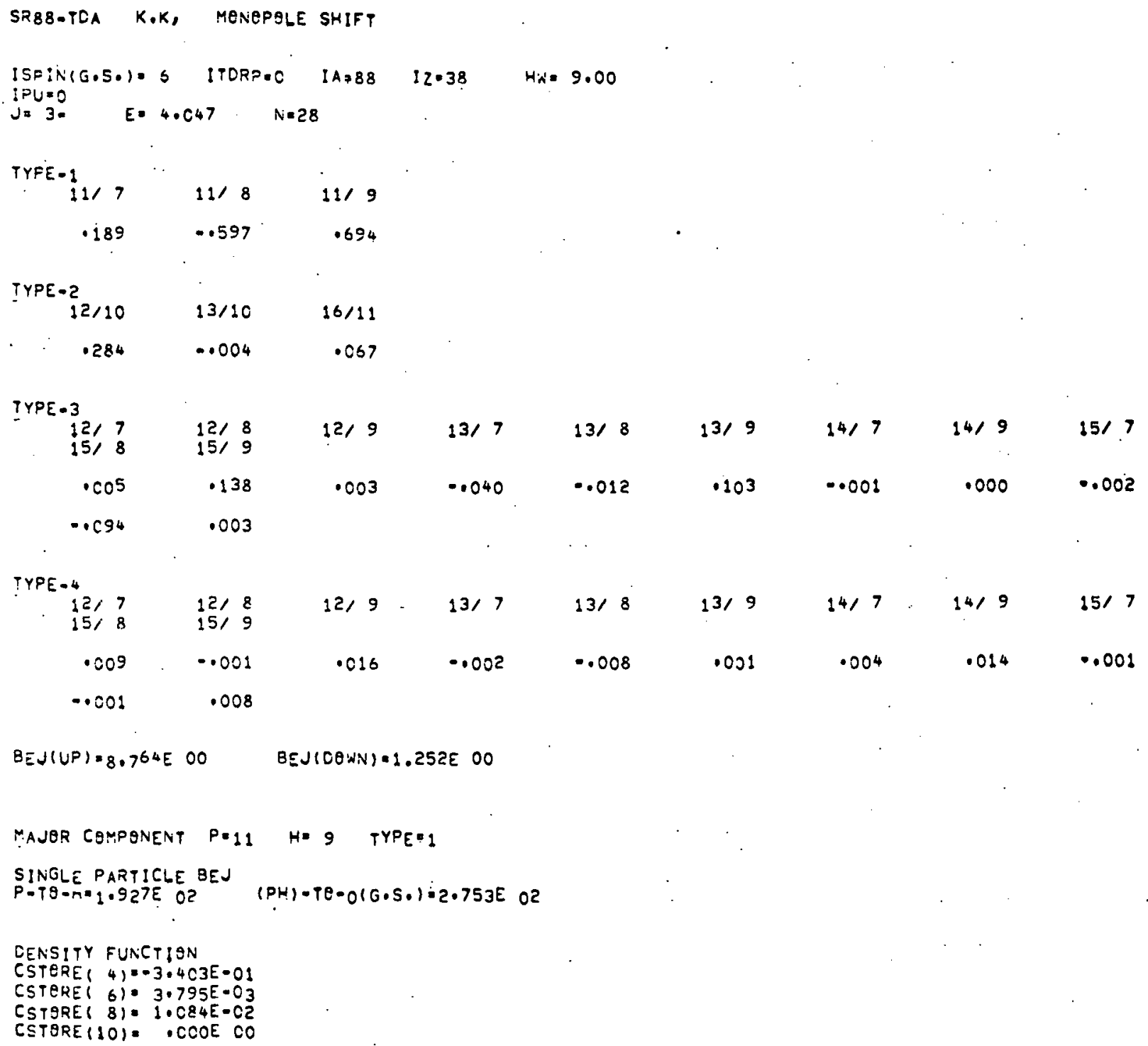




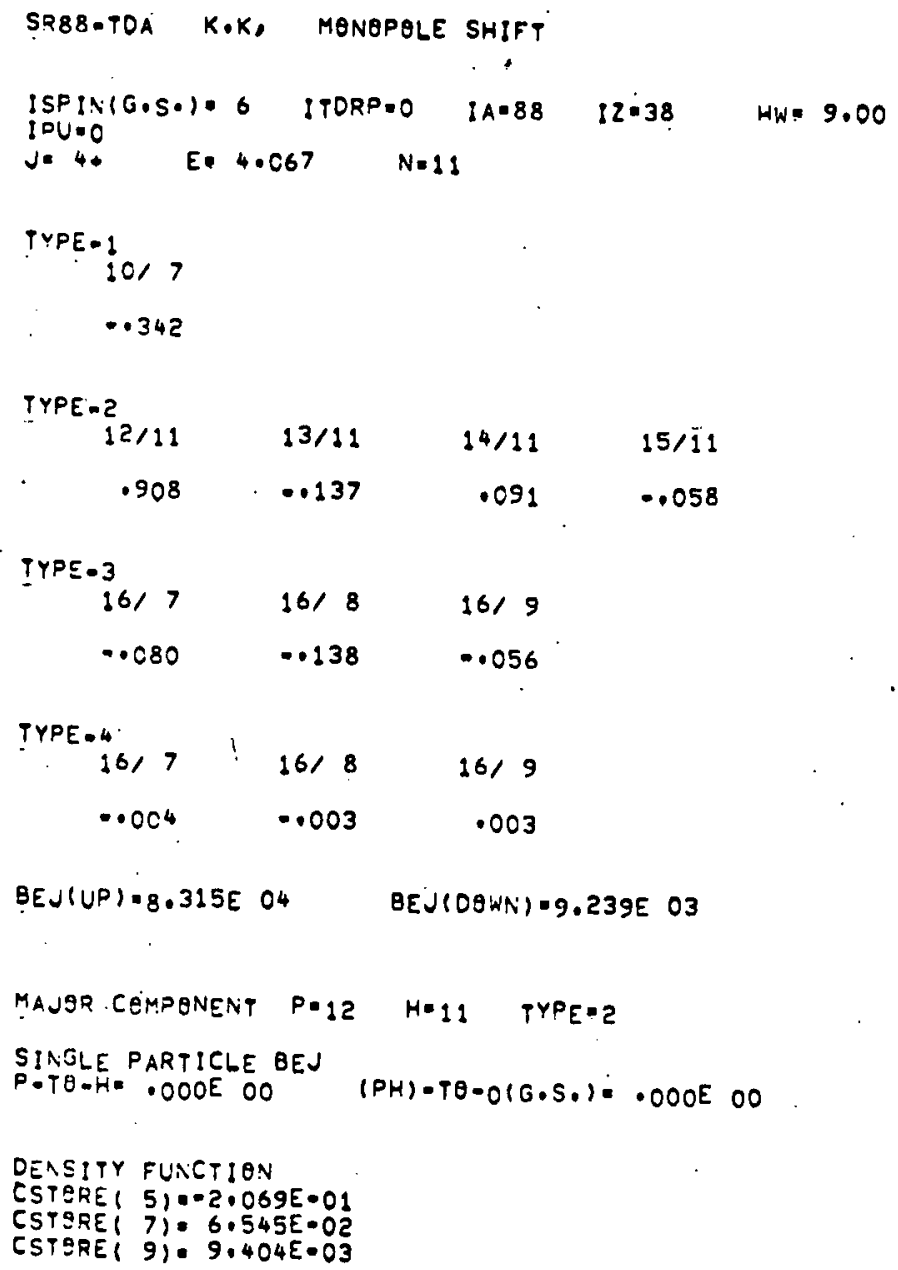




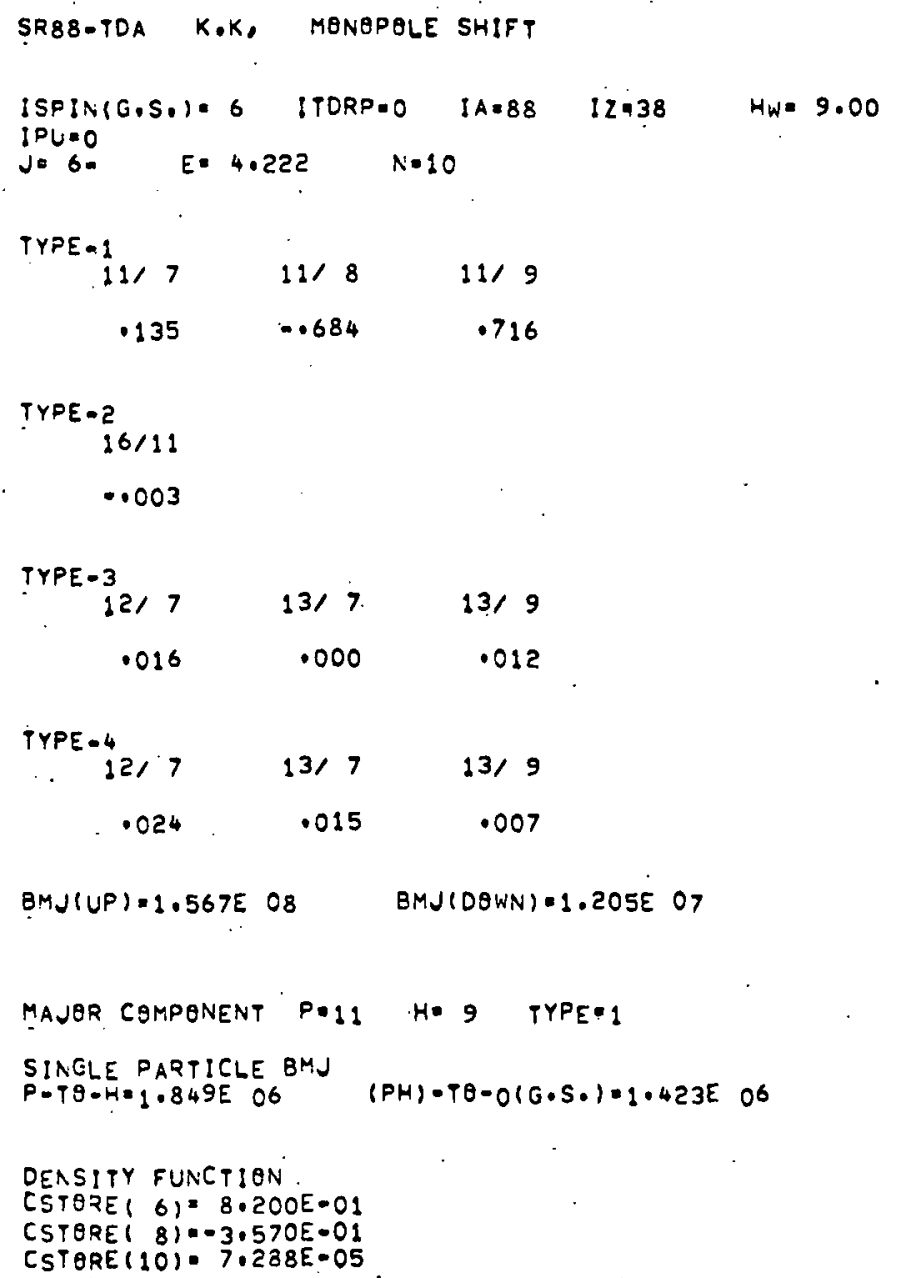




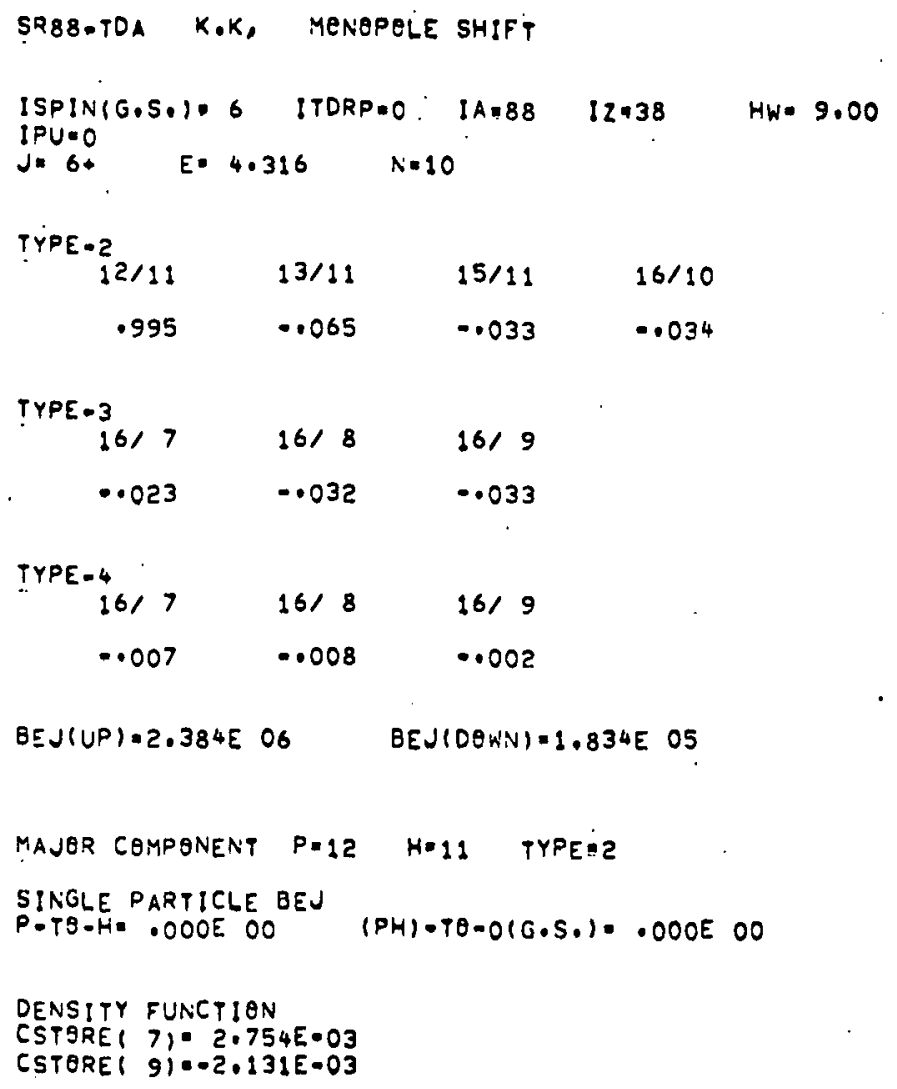




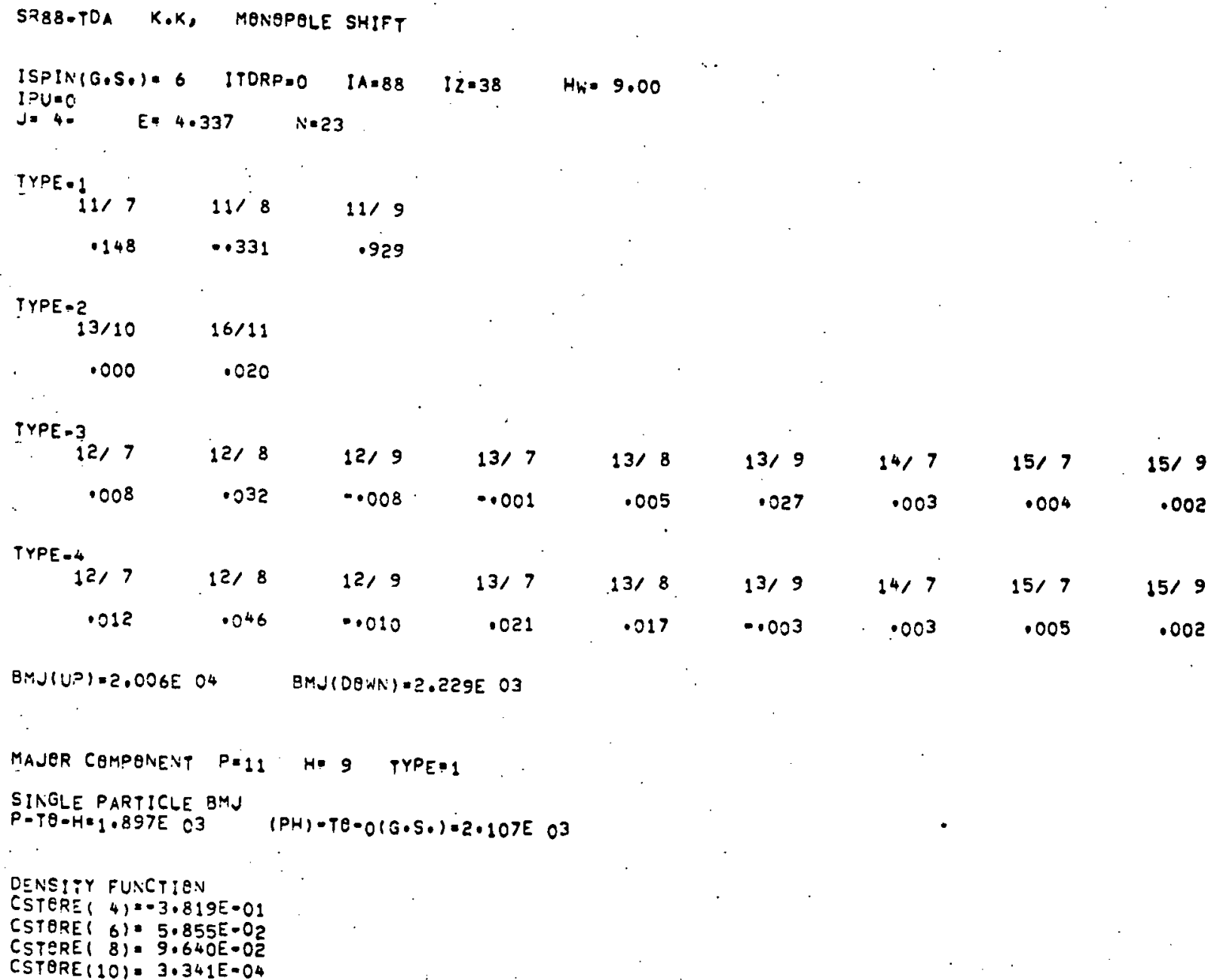




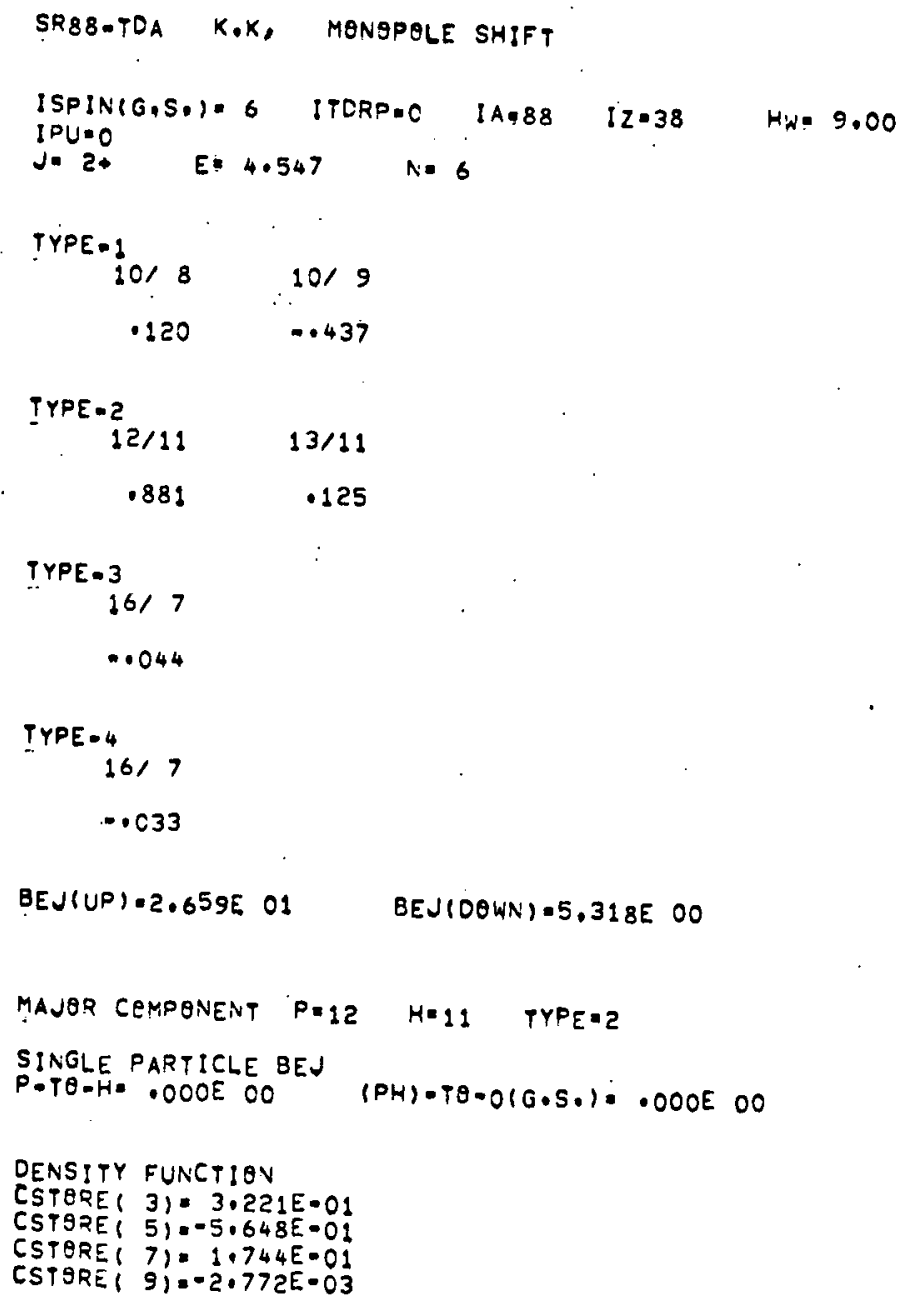

